\title{
OUR PLACE
}

A Cross Cultural Approach to Heritage Conservation

Tatiana Astrid Erményi 



\section{OUR PLACE}

A Cross Cultural Approach to Heritage Conservation

Tatiana Astrid Erményi

A 120 -point thesis

submitted to the Victoria University of Wellington

in partial fulfilment of the requirements for the

degree of Masters of Architecture (Professional)

Victoria University of Wellington

School of Architecture 



\section{ACKNOWLEDGMENTS}

irstly, I would like to thank my supervisors Philippe Campays and Regan Potangaroa. Philippe, thank you for your patience, guidance and for supporting me throughout the year. Regan, thank you for pushing me and giving me the opportunity to learn new technical skills.

To my friends, your support and encouragement helped me persevere through this experience more than you can imagine.

To my family, near and far. Thank you for your unconditional love and support

Los adoro...

And lastly, to all Cross Culture People, I hope this can help us start to form a sense of belonging. 



\section{ABSTRACT}

$\mathrm{T}$ he remarkable increase in migration across the world is one of the effects of globalization. Its byproduct is the materialization of Cross Culture People (Pollock \& Van Reken, 1999, p. 6). Research has revealed that in the process of migration, Cross Culture People may struggle to form a strong sense of identity and belonging as a result of experiencing a number of cultures throughout their lives.

Research has shown that, the heritage architecture of the host nation can act as a setting to help ground Cross Culture People in their new surroundings and form a collective identity. This thesis will explore such opportunity and as a result will ultimately propose a new building typology for heritage architecture.

The outcome of this thesis is a two-part design framework: The first part considers a careful site selection that helps select the right heritage building for the programme. The second, a design tactic framework which focuses on cultural wellbeing through cultural vitality and vibrancy. The design tactics emerging from this research develops solutions such as using unique public places that are adaptable, personal and evokes a transcultural narrative.

The framework is tested and developed to include theories such as Third Place and Biophilic Design and implemented towards a final design of a 'mixed used' public building. The final iteration reveals the need to consider the intangible aspects of heritage that help construct cross cultural identity and enhances a sense of belonging.

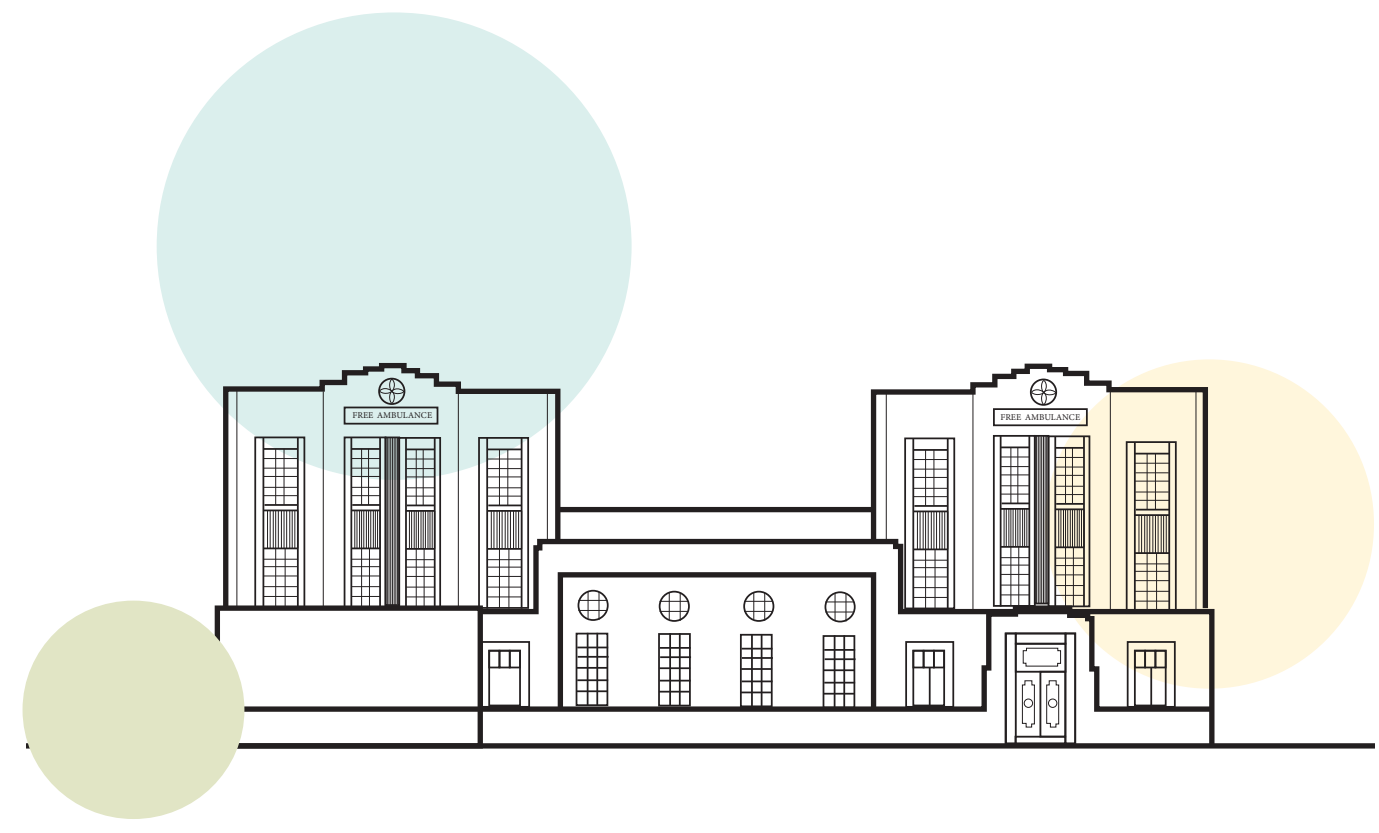




\section{CONTENTS}

1.0 - Introduction i

Introduction

Context

Aim

Methodology

2.0 - Cross Culture People 1

Introduction

Cross Culture People

Third Culture Kids

Perception of Heritage

Conclusion

3.0 - Culture, Heritage \& Identity

Introduction

Cultural Identity \& Wellbeing

Transcultural Heritage

Experiencing Heritage

Identity Through Cultural Heritage

Conclusion

4.0 - Culture \& Architecture

Introduction

Place

Traditions and Change

Precedents

Conclusion 
5.0 - Heritage Architecture

35

Introduction

Understanding Heritage

36

Heritage Categories

Conservation Approaches

The Intangible

Heritage Communities

Conclusion

6.0 - Framework

Introduction

Site Framework 46

Design Framework

7.0 - Iteration one

History

Precedents

Design Process

Reflection

8.0 - Iteration Two

History

Precedents

Design Process

Reflection 
9.0 - Iteration Three

123

History

Precedents

132

Design Process

Reflection

10.0 - Reflection

Introduction

Un-Commonalities

Commonalities

11.0 - Final Design

Site

Function

Biophilic Design

Third Place

Design Process

Circulation

Dome

Promenade

Reflection

12.0 - Conclusion

Conclusion

Future Works 292

Reference List 294

Figure List 




\section{Introduction}

Introduction

Context

Aim

Methodology 


\section{INTRODUCTION}

$\mathrm{T}$

here are various arguments whether $\mathrm{New}$ Zealand is still a bicultural or multicultural society, even though many lean towards the idea that New Zealand is fast becoming a multicultural society (Dalziel et al., 2019, p. 16). The reason for this circumstance is that there has been a significant increase in human migration in the last 100 years due to globalisation (Pollock \& Van Reken, 1999, p. 6). With this increase in movement there are now more numbers and varieties of Cross Culture People than ever before. There is little attention being given to help these people ground themselves and strengthen their identities and sense of belonging to a place.

Architectural heritage has a great impact on nations and communities, as they are vessels to build the identity of their citizens (Macdonald \& Tyler, 2013, p. 162).

This thesis draws from heritage studies on identity and creates a new approach to heritage that explores how to enhance a sense of belonging for a heritage community (a term explained further on). Utilising tangible forms of heritage to portray intangible aspects of this group's heritage. It will focus on the idea of place acting as a container, facilitating the idea of experience and using it as a Third Place to help build the identity of Cross Culture People who are torn between their home culture and their host culture. 


\section{CONTEXT}

$\mathrm{T}$ his thesis touches upon topics that are vast and extremely complex and does not aim to solve issues of discrimination, racial bias or sympathise with stereotypical 'Expats'. It does however aim to start a conversation about those who struggle to fit into a new environment or 'feel stuck' in between cultures. One of the aims through this research is to explore architecture as a safe haven for cross cultural expressions and to use tangible heritage to bridge the intangible aspects of culture.

This research seeks a way to celebrate diversity and inclusivity for people who feel they do not belong to any physical place. It explores the field of crosscultural understandings through design processes. This research can be applied to anywhere in the world. This particular project is set within the New Zealand context. It focuses on the third cultures arriving in the setting of a multi-cultural society within a bi-cultural framework (Māori and the Crown). This research will not address the socio-political complexity of postcolonial Aotearoa New Zealand. For this reason, this research also does not delve into the discussion of decolonisation. It does not have the capacity to address such an important issue, but the author remains aware of its presence.

The research will consider specific heritage buildings defined as such and considered historically significant by Heritage New Zealand

\section{$A \mid M$}

The aim of this thesis is to create a place for Cross Culture People to find a sense of place and identity through architecture. This architectural investigation will focus on how architectural heritage can create places of grounding for people that feel a sense of rootlessness.

This thesis will also contribute to heritage conservation practice by using heritage architecture as a tool to facilitate the discussion of identity and the balance between maintaining the original fabric and reviving historic spaces with modern functions. 


\section{METHODOLOGY}

his thesis follows a design-led process that can
be divided into three phases.
The first phase is research 'for' design process and the second and third phases follow a research 'through' design.

The first phase is an early investigation of interdisciplinary literature that has helped create the foundation for the design process.

This exploration included:

(i) understanding the needs and wants of Cross Culture People,

(ii) theories between culture, heritage and identity,

(iii) the connection between culture and the physical realm of architecture and

(iv) the discipline of heritage conservation.

This research was used to construct a two-part framework that informed key aspects to consider when designing the three iterations in the second phase.

The second phase is an iterative design process utilising three different buildings of varying degrees of heritage significance.

The third phase reflects on those iterations and builds upon those learnings to create a final design exploration. 

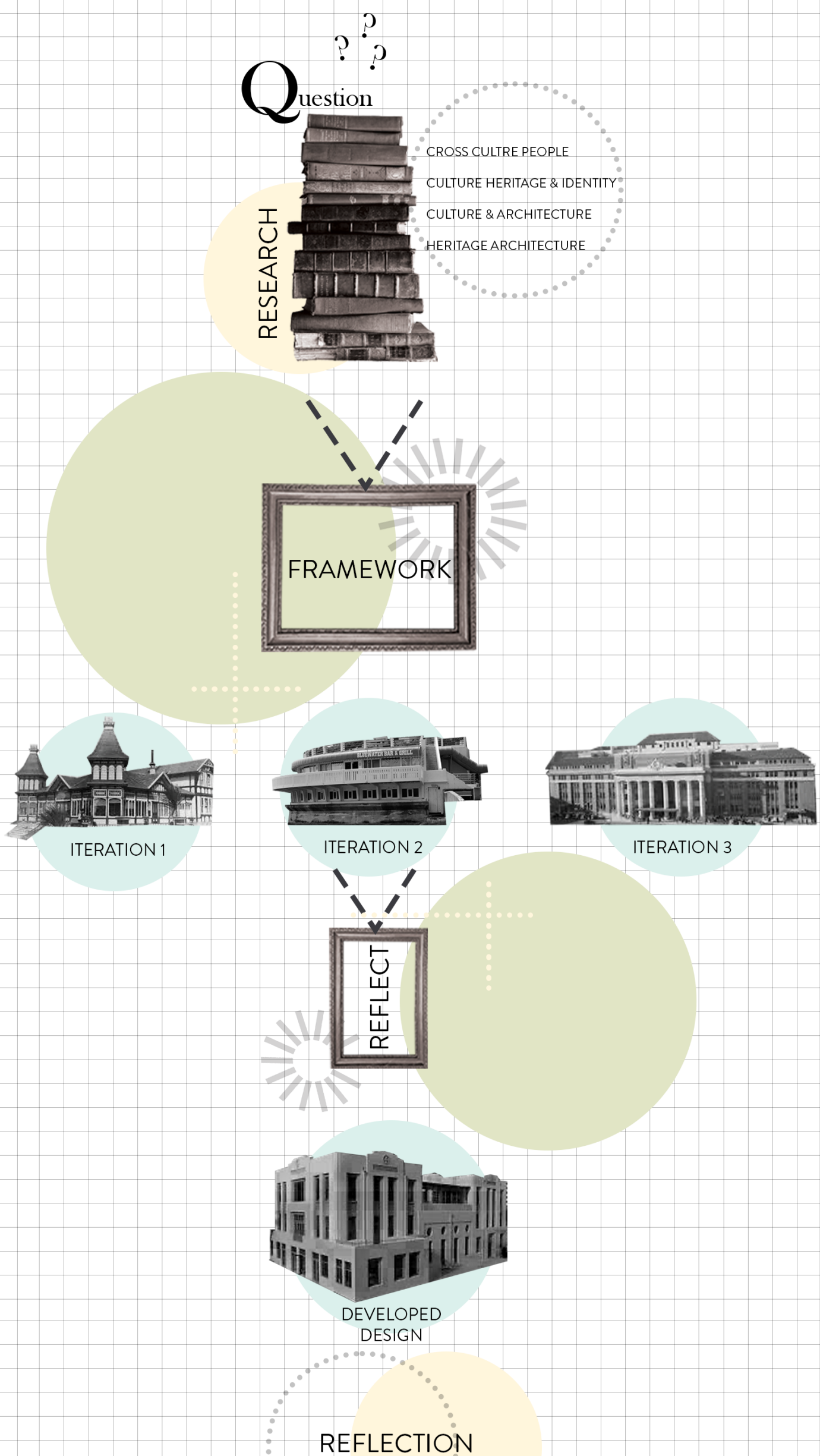



\section{Cross Culture People}

Introduction

Cross Culture Kids

Third Culture Kids

Perception of Heritage

Conclusion 
I am

a confusion of cultures.

Uniquely me.

I think this is good

because I can

understand

the traveller, sojourner, foreigner,

the home sickness

that comes.

I think this is also bad

because I cannot

be understood

by the person who has sown and grown in one place. They know not

the real meaning of homesickness

that hits me

now and then.

Sometimes I despair of

understanding them.

I am

an island

and

a United Nations.

Who can recognise either in me

but God?

- “Uniquely Me: by Alex Graham James

(Pollock \& Van Reken, 1999, p.38) 


\section{Introduction}

T

oday's modern world brings many opportunities to people; one of those opportunities is globalisation. Although it is sometimes seen as detrimental, globalisation creates a movement of people and allows them to live and work in places all around the world. As a result of such migrations, large groups of people have encountered new cultures and cultural settings. This thesis proposes the term of Cross Culture People (CCPs) to define people in cultural dis-location. This term is derived from Crossman and Van Reken's Cross Culture Kids who are defined as people that have lived or interacted with two or more cultures throughout their lives (Crossman, 2019).

It is important to note that the existence of Cross Culture People has been around for hundreds of years with expatriates that lived in specific communal systems such as military bases, missionary compounds, and business enclaves" (Pollock \& Van Reken, 1999, p. 21). There has been a significant increase in the last 100 years due to globalisation and there are now more numbers and varieties of Cross Culture People than ever before (Pollock \& Van Reken, 1999, p. 6). This group of people is increasing, however there is little attention being given to this group of characteristically lost identities.

\section{Cross Cultural Kids}

$\mathrm{V}$ an Reken and Pollock present the term CrossCultural Kids (CCKs). Cross-Cultural Kids are defined as people who live with or have interacted with two or more cultural environments for a significant period of their childhood (Crossman, 2019). Tanya Crossman is another author who looks at the impact of living as a Cross Cultural Kid. Crossman explains that CCKs also gravitate towards other people under the Cross-Cultural Umbrella as they share similar childhood experiences (Crossman, 2019). The Cross-Cultural Umbrella holds eleven different varieties of people which include Third Culture Kids (TCK), Children of Immigrants, Children of Refugees, and others (refer to Figure2.1). Crossman also explains there can be people that feel an intersectionality, where an individual can be two variables under the umbrella. This phenomenon also indicates why Cross Cultural Kids share similar experiences in their childhood, while also having distinct experiences. Because CCKs have so many experiences with culture, they often struggle with a sense of identity, as they neither identify with the culture they originated from nor the culture they live in. Therefore, CCKs must find within themselves their own cultural identities. This situation can be confusing and create problems in the sense of belonging as a CCKs may not feel part of their home culture nor their adoptive culture.

As mentioned earlier, this thesis proposes the use of the term Cross Culture People (CCP) instead of Kids. This is a more inclusive term which includes adult CCKs who have now grown up but have been through the same experiences that still shaped their identity. As TCKs are still under the Cross-Cultural Umbrella they are also included in the CCP definition, however it is also acknowledged that TCKs deal with the additional aspect of mobility. 


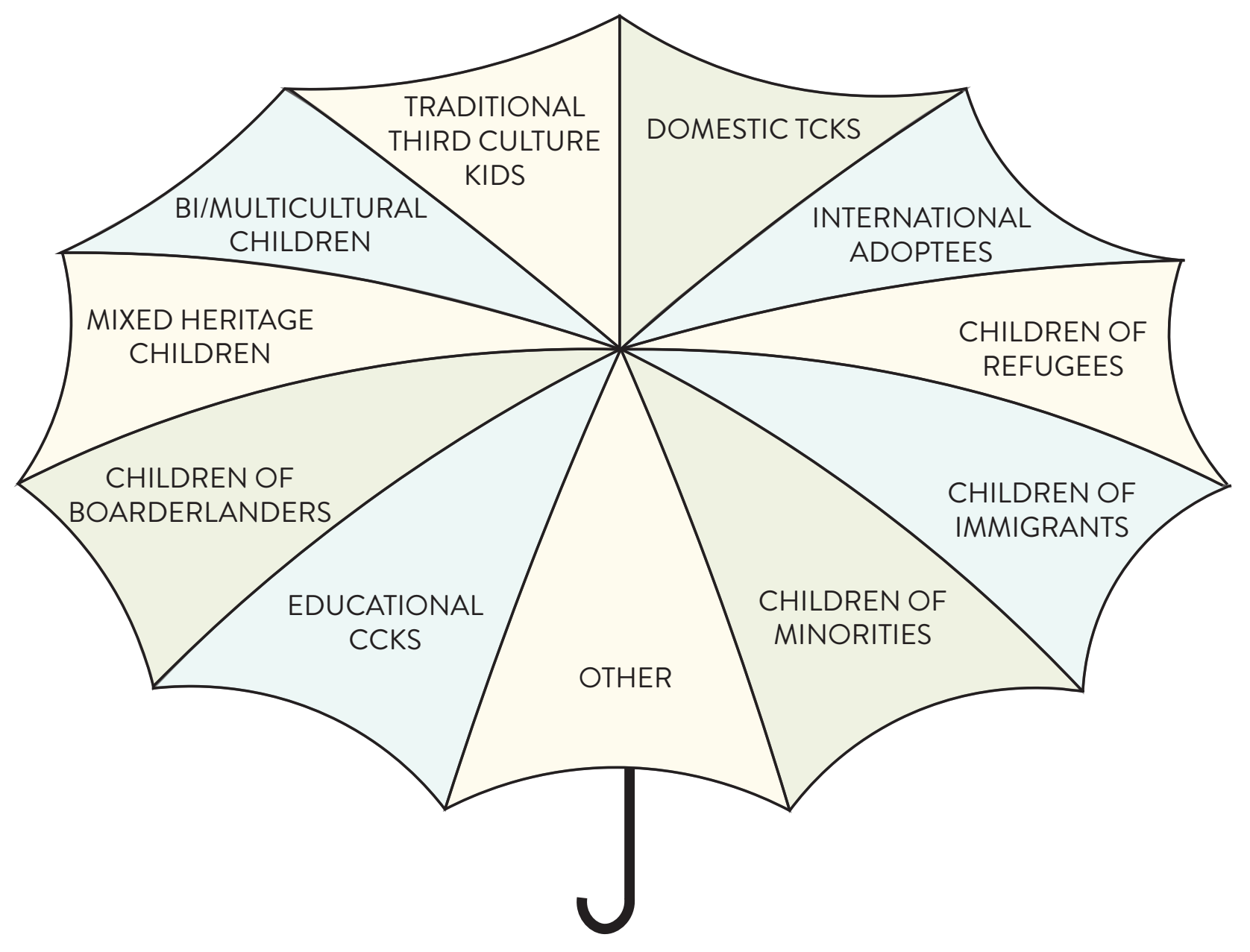

Figure.2.1: Cross Cultural Umbrella 


\section{Third Culture Kids}

$\mathrm{B}$ eneath the Cross-Cultural Umbrella lies a variety of terms, one being Third Culture Kids. Ruth Van Reken \& David Pollock are parents to the modern interpretation of the term Third Culture Kid (TCK). The original term was created by Ruth Hill Useem - a sociologist and anthropologist - and her husband during their research in the 1960s (Pollock \& Van Reken, 1999, p. 20). The term was used to refer to 'children who accompany their parents into another society'. To Van Reken and Pollock their definition specifies that a TCK is a person who has spent a significant part of his or her developmental years outside the parent's culture' (Pollock \& Van Reken, 1999, p. 19). This definition has a stronger focus on mobility, compared to CCKs, as they go in between cultures often and then back to their parents' home country. This is why many children of diplomats or military members are TCKs.

As Third Culture Kids do not identify fully with either their home culture or their host culture, they negotiate a third heritage within themselves (Pollock \& Van Reken, 1999, p. 20). Because of this Van Reken explains that TCKs live in an intangible world, not tied to one visible place" (1999, p. 72). Culture by definition means a group of people who share something in common generally being a geographical location, but TCKs are tied by shared experiences and the idea of third culture. These experiences give them a three-dimensional view of the world and an opportunity for cross cultural enrichment. As they live in various cultures, it allows them to not only learn about cultural differences, but also to experience the world in a tangible way that is impossible to do through television or reading books (Pollock \& Van Reken, 1999, p. 83). This experience explains why Third Culture Kids usually have a sense of ownership and interest in cultures other than just their original citizenship (Pollock \& Van Reken, 1999, p. 86). This diverse upbringing gives TCKs additional skills such as intercultural communication, linguistic ability, mediation, diplomacy and the management of diversity' setting them apart from others giving them the ability to be cultural chameleons (Pollock \& Van Reken, 1999, p. 91).

Laia Colomer suggests that TCKs experiences might help us to foresee what belonging and identity could mean in a globalised world, and consequently, the meanings and uses of heritage for Cross Cultural People in the future.' (2017, p. 923). Because of the globalised labour market and 'independent families that simply look to improve their quality of life' there will continue to be an increasing number of people moving overseas (Colomer, 2017, p. 917). Migration studies refers to this as hybridity, biculturalism, or creolisation to stress how identity is negotiated between the culture of origin and the culture of the arrival. Social psychology and neuroscience state "that high mobility during people's formative years affects the behavioural parts of their brain that develop their adult personalities, culturally and socially, to the point of developing other ways to perceive, imagine and behave in the world" (Colomer, 2017, p. 918).

\section{THIRD CULTURE}
FAMILY
CULTURE
$\mathrm{HOST}$
CULTURE 


\section{TCK/CCP Perception of Heritage}

C olomer also discusses TCKs and their links to cultural identity and heritage. Through a survey, she gathered 146 responses from adult TCKs who had spent at least one year of their childhood in two or more countries (2017, p. 918). The average responder was female between the ages 36 and 65 who spoke three languages usually English, Spanish and French and held a passport from either the USA or UK and had lived in three countries in their childhood.

The respondents showed a strong linking to nomadic life, considering global mobility and multiculturalism more important for the construction of identity than 'religion, sexual orientation, gender, birthplace, passport, school, socioeconomic condition, and current place of residency' (2017, p. 918).

The first section of the survey examined whether participants acknowledged local and national heritage as significant to their multicultural identity. The results indicated that participants 'accepted that local/national cultural heritages helped them establish their cultural identity as global nomads' (2017, p. 919). However, just over half of the responders agreed that only national heritages are relevant for the reason stated above. As TCKs have lived in several countries and understand the relevance of borders and passports in a globalised world (Colomer, 2017, p. 919), heritage acts as a contributing factor. TCKs 'have the ability to shift between different cultural identities or blend identities without necessarily feeling a sense of belonging to any of them' (Colomer, 2017, p. 919). Half of responders also did not consider their multicultural life is represented in any type of local/ national cultural heritage. Participants in this survey believe that '... the mix of different cultural heritages', '... the cultural heritage around the world', and '... the natural landscape' are the best scenarios in which to build their identity. Both of the first scenarios are obvious choices for global citizens; however, natural landscapes stand out. Responders of the survey related to natural landscapes, as places that did not require a negotiation between identities and were considered less altered by human cultural interaction.

Most of the responders considered multiculturalism, multiple moves, mobility, and globalism to be the most relevant, followed by international schooling, restlessness, rootlessness, and cosmopolitanism to assemble a shared collective memory of people experiencing cross-cultural lives. This helps them identify themselves when managing doubt around feeling like an outsider or the 'us and them' culture. They also believed that the cultural heritage of Cross Culture people must address or represent either '... the experience of being nomad', '... multiculturalism' or '... globalism' (Colomer, 2017, p. 919). When asked to name places or objects that represent this group of people all answers seemed to be related to mobility. Particularly airports, passports, suitcases, time zones charts, transportation tickets, and all kind of places of transportation - such as buses, trains and roads, depending on each person's personal experience (Colomer, 2017, p. 919). Colomer also comments numerous times throughout TCK literature of the significance of the airport as a comfortable homelike environment (Colomer, 2017, p. 919). The survey concluded that it is important to have a more open process of creating meanings of heritage for the community.

Colomer also explored TCKs perception of UNESCO World Heritage Sites as places of significance to people of multicultural backgrounds. The results showed that participants did not recognise UNESCO World Heritage Sites as significant and did not mention any UNESCO intangible cultural heritage in 
the countries they had lived in. This shows that there seems to be a detachment from present expressions of cultural heritage. No common expressions of defining local, national or global heritage, either tangible or intangible are significant to TCK participants (Colomer \& Holtorf, 2019, pp. 154-155).

The cultural heritage of TCKs, is the idea of taking comfort in global human experience rather than trying to constraint it to a group of people or a place. TCKs lack connection to national identities meaning that national cultural heritage is not the best place to organize diversity within a global community. However, TCKs still describe detachment from the
UNESCO World Heritage sites, even though these sites are known as places of universal value for the purpose of preserving world heritage of humankind as a collective. A theory for this may be because UNESCO's values are Western in character and have little understanding of non-western or indigenous culture (Colomer \& Holtorf, 2019, p. 159).

TCKs struggle fitting into the Authorised Heritage Discourse, while still struggling to imagine their own alternative manifestations of heritage. When asked to talk about cultural heritage, TCKs used traditional forms of culture and heritage as they were taught during their formative years.
Transculture

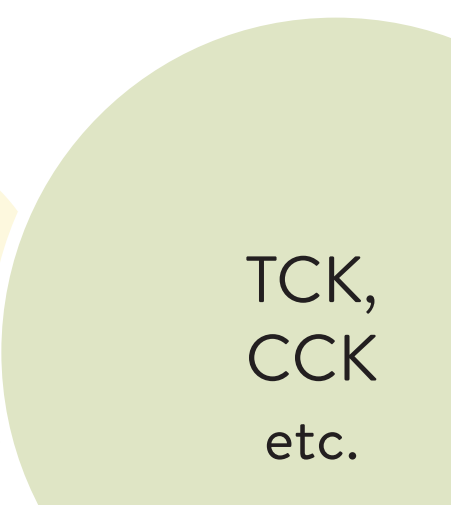

Figure.2.3: Mixing of cultures within a group of $\mathrm{CCPs}$ 
Identity construction

Global Mobility

Multiculturalism

$74 \%$

$69 \%$

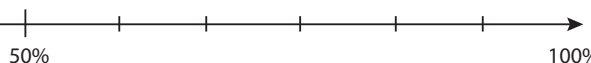

$>$ religion, sexul orientation, gender, birthplace, passport, school, socioeconomic condition and current place of residency

Multicultural Identity

Local/National Heritage

National Heritage

Not Considered

$46.6 \%$

$55 \%$

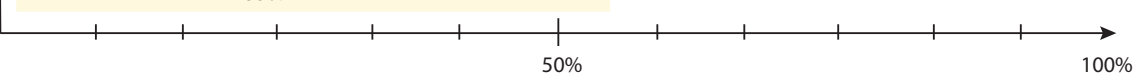

Build Identity

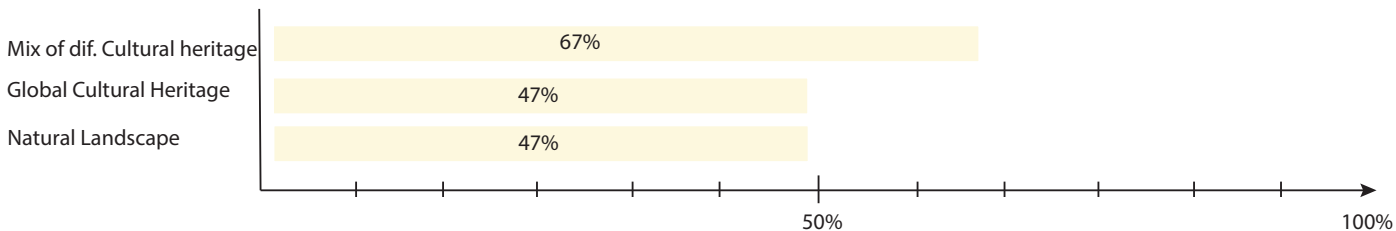

Assembledge of collective memory

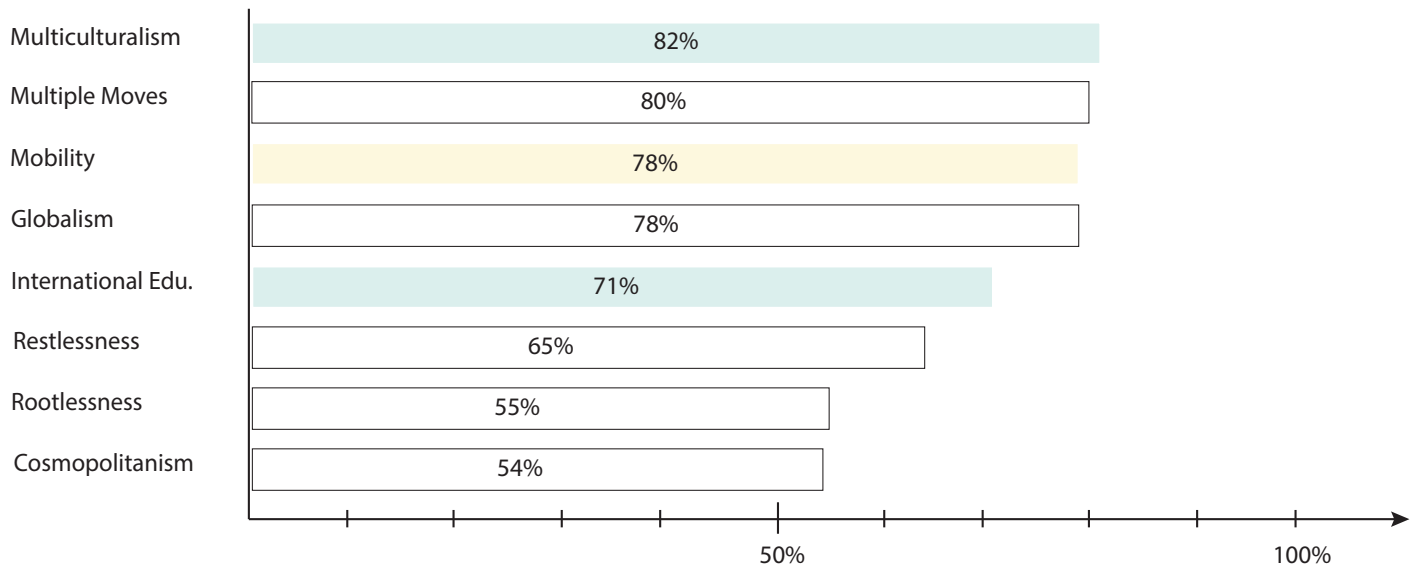

Representation of Cross Cultural Heritage

Nomad Experience

Multiculturalism

Globalism

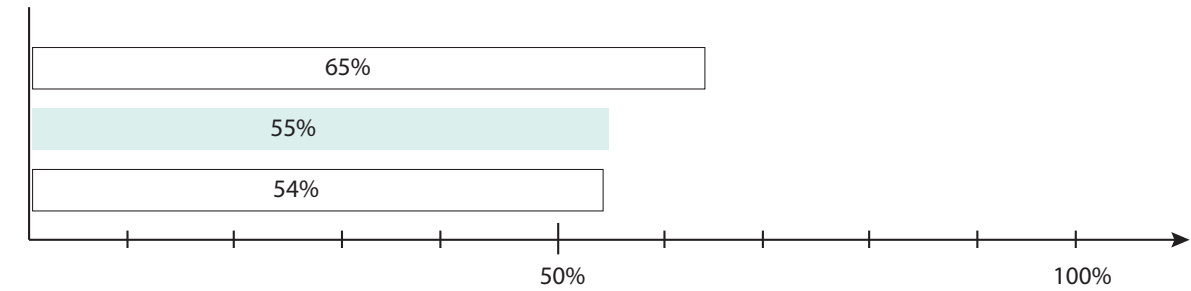




\section{Conclusion}

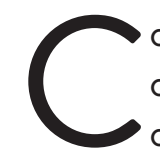

olomer acknowledges an increase in the study of TCKs, focusing on their lack of cultural ownership and the constant transitioning between cultures'. She also suggests that in order to understand heritage outside the profession, we need to design other forms of engagement and become open to give significance to other forms of heritage perception. These could include other research practices designed to give a voice to people's perception (Colomer \& Holtorf, 2019, p. 160). This thesis proposes an architectural approach to the topic and how it can aid the public engagement.

This research suggests that CCPs experience a form of "Third Culture" proving it is an important part of cross culture living. This can be used to describe and acknowledge how Cross Culture People also have a third culture - a culture they negotiate within themselves. Although CCPs do not have a physical location that ties them together, they are tied by shared experiences and the idea of third culture. Through additional research, this thesis will determine how to create a physical location to express and nurture their shared experiences.

All the authors cited within this chapter address the struggle of cross culture people and their feelings of belonging and identity. Therefore, it is important that the proposed design facilitates and celebrates their identities as a collective. These design interventions will also help promote the connections of a group of people that already gravitates towards each other because of their shared life experiences and differences. Creating a united public space will help create a sense of support and a space of belonging. Using the idea of Heritage communities to encourage unity will be discussed in chapter four.

As CCPs live in an intangible world, research suggests that creating a tangible place for them to express that
"Third Culture" could help ground them into their surroundings. From the survey it is apparent that there is little connection between Cross Culture People and UNESCO World Heritage sites or national heritage. Therefore, this thesis will focus on utilising local heritage architecture as a place for CCPs to use and create a shared experience. The TCK survey also will help outline the main criteria for the development of the "Third Culture Place" and what they deem as important for building their identities.

The following chapter will look at the connection between culture, identity and heritage. It will also explore the tight knit relationship between these topics and how it could benefit the practice of architecture.

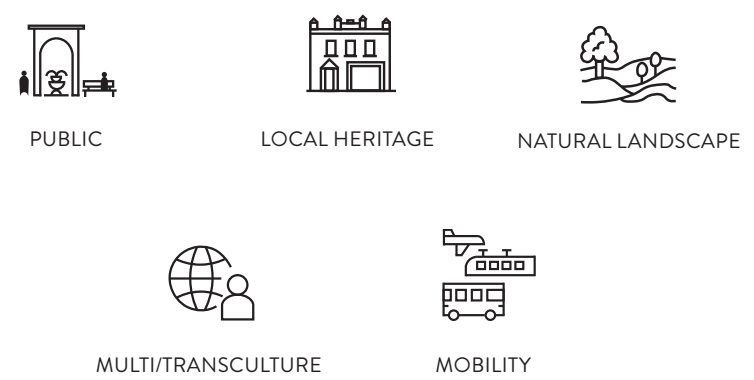

Figure.2.5: Framework consideration 


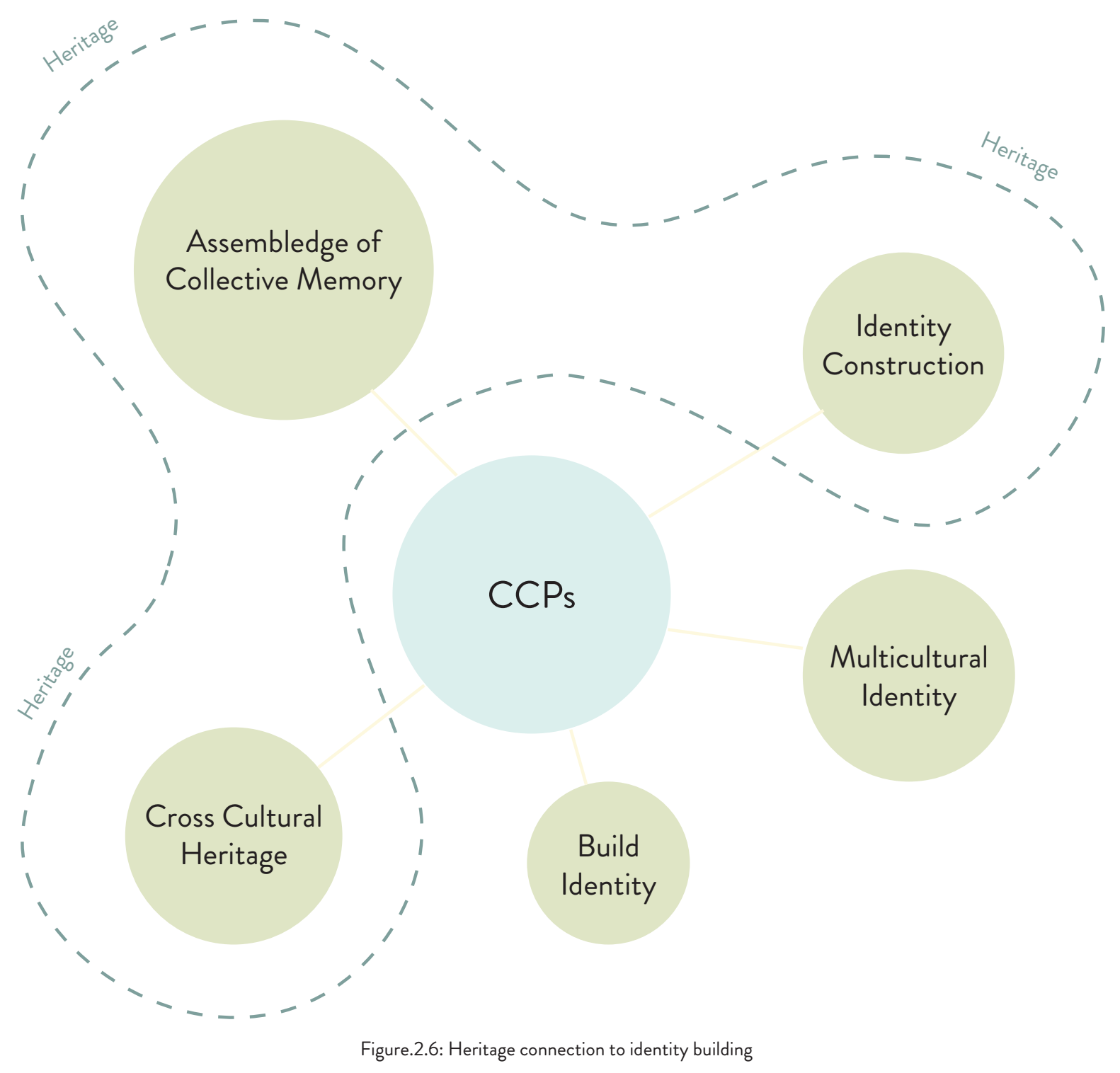





\section{Culture, Heritage \& Identity}

Introduction

Cultural Identity \& Wellbeing

Transcultural Heritage

Experiencing Heritage

Identity Through Cultural Heritage Conclusion 


\section{Introduction}

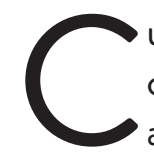

ulture, Heritage and Identity are three concepts that are tightly intertwined with one another. So much so, that one cannot speak about one concept without at least mentioning one of the others. These three concepts are the pillars to an enriched society that makes the world such an interesting and diverse place. The connection between heritage and identity is well defined in heritage literature; material culture as heritage represents the 'slippery' concept of identity (Smith, 2006, p. 48). Like history, identity evokes feelings of belonging and continuity, while the physicality gives an added sense of materiality (Smith, 2006, p. 48). This chapter will look to explain aspects of each concept and illustrate how tightly knit they are to one another and why it is important that Cross Culture People should have tangible heritage to strengthen their sense of identity.

\section{Cultural Identity \& Wellbeing}

$\mathrm{T}$ he New Zealand Ministry of Culture and Heritage highlights the importance of understanding that a young person's cultural development is as important as their overall personal wellbeing. A strong cultural identity is important as it can increase people's sense of belonging and therefore self-worth (Dalziel et al., 2019, p. 4). Cultural identity is defined as 'having a strong sense of identity, belonging and the ability to be one's self' (Dalziel et al., 2019, p. 13). As cultural identity is important to wellbeing, it gives people a sense of security and belonging, showing positive outcomes in health and education (Dalziel et al., 2019, p. 13).

Some cultures, such as Asian cultures are described as collectivistic in comparison to some European cultures, which are usually described as more individualistic (Dalziel et al., 2019, p. 5). New Zealand falls under the latter category; therefore, this could be a contributing factor as to why Cross Culture people from either culture categories struggle with the transition from one to the other.

To highlight the importance of culture, the Ministry created a Cultural Wellbeing Framework.

This Framework mentions the importance of the following concepts:

Cultural Vitality, which specifically refers to the ability to give people the opportunity to express their culture and engage in their respective cultural practices - like the festival of Diwali or Lunar New Year. It also mentions Cultural Vibrancy which refers to the dynamism and richness of the culture itself (Dalziel et al., 2019, p. 4).

Cultural Vitality allows communities to participate in creative and cultural activities, which gives them the 
opportunity to extend their cultural values from one generation to another and pass the evolved culture to the following generations (Dalziel et al., 2019, p. 15). Cultural Vitality is nationally significant and crucial to acknowledge that a nation is not made up of a single cultural identity, especially a country like New Zealand which is fast becoming a multicultural society (Dalziel et al., 2019, p. 16). This process is known as nationbuilding and is helping strengthen New Zealand's collective identity (Dalziel et al., 2019, p. 16).

Cultural Vibrancy is another term for Cultural Identity but includes a better sense of diversity and dynamism which is an essential part to cultural wellbeing. An essential ingredient to a vibrant culture is the support for great art development, creating pathways for artists, engaging with audiences, connecting with communities and contributing to vibrant societies and cultures (Dalziel et al., 2019, p. 14). Cultural Competence is another term used to define the space that enables people to connect and maintain their culture and allow them to pass on their cultural knowledge for future generations (Dalziel et al., 2019 , p. 15). Culture also refers to how we see and represent ourselves to other people to create a sense of commonality and difference (Dalziel et al., 2019, p. 15).

Embodied culture is the concept of knowledge and skills that a child learns throughout their lifetime. This is taught by their families, at their schools and throughout life in general (Dalziel et al., 2019, p. 13).

Tangible culture exists in physical objects such as buildings, structure, artefacts and artworks and is commonly known as cultural heritage. It is also important that cultural heritage maintains a connection to nature and a sense of place (Dalziel et al., 2019 , p. 13). A survey conducted by the Department of Conservation (DOC) in 2016 stated that $85 \%$ of New Zealander's connection to nature improved their lives in general (Dalziel et al., 2019, p. 13).

The Ministry also created a list of indicators to measure cultural wellbeing in the scope of cultural identity.

The indicators are as follows.

- Cultural development of children - The transference of knowledge, understanding who they are, where they belong and their connection to culture and community.

- Cultural efficacy and competence - language development and retention

- Cultural safety and respect - ability to be one's self, a sense of belonging and cultural respect

- Cultural assets and taonga - preservation of heritage, number of these places, speakers of native languages

- Cultural engagement and vitality attendance and participation in cultural events, local media content and an inclusive national identity (Dalziel et al., 2019, p. 12) . 


\section{Transcultural \\ Heritage}

S haron Macdonald introduces the concept of transcultural heritage. Transcultural, meaning a 'crossing and mixing' of cultures, which involves bringing elements from different cultures and fusing them together to create something new while keeping identifiable features from their previous state (Macdonald \& Tyler, 2013, p. 163). An example of transculture is the colonisation of the Americas when the Europeans brought with them their own values and traditions. It is generally perceived that the world is split into separate 'cultures', however while anthropology played a role in creating this concept it also criticises this view of seeing the world of 'islands of difference' (Macdonald \& Tyler, 2013, p. 163).

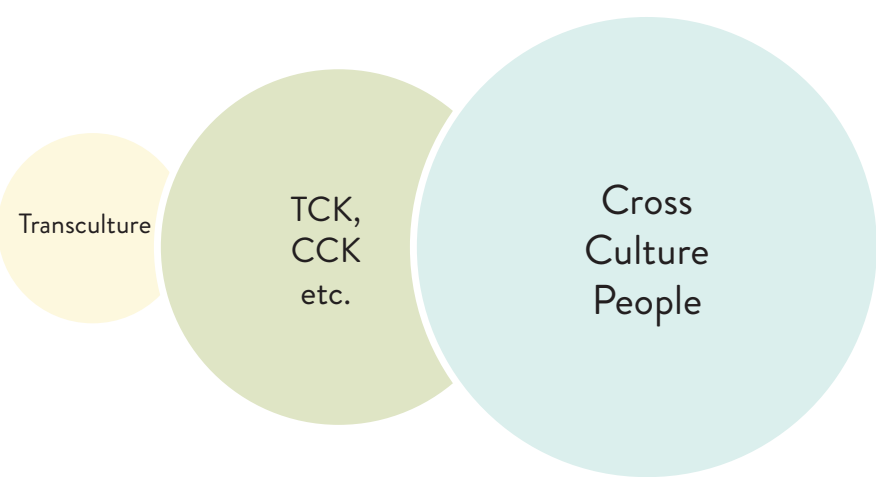

Figure.3.1: Transculturalism within CCPs

It is also acknowledged that the term 'Culture' is also used to describe those of a nationality or an ethnicity (Macdonald \& Tyler, 2013, p. 163). The term Transcultural is also used to describe the process of cultural mixing to create new cultural forms like "syncretic", 'creole' (Macdonald \& Tyler, 2013, p. 164). These previous terms have also been criticised, as it suggests that they were pre-existing, 'pure' or 'non-creolised' cultures or identities.

The term multicultural is another term that has been adopted to recognise that many cities, especially larger European cities that are home to generations of people who have migrated from all over the world and each have different cultural practices (Macdonald \& Tyler, 2013, p. 164).

She also mentions Charles Taylor's observation, where the idea that cultures and individuals are 'distinct and in need of expressing their distinctiveness' (Macdonald \& Tyler, 2013, p. 165). This idea has been the thinking since the eighteenth century and the footprint of a modern society, showing that multiculturalism aims to allow all 'self-identifying' cultural groups instead of a single national identity (Macdonald \& Tyler, 2013, p. 165).

Macdonald questions whether heritage can accommodate multiple identities, including identities that are transcultural (Macdonald \& Tyler, 2013, p. 162). Due to immigration, we are beginning to recognise that there is a collection of identities within a nation (Macdonald \& Tyler, 2013, p. 162). Macdonald also questions whether it is possible to use memories and heritage to create new identity stories that aim to include a mix of cultures and create cultural diversity. Jonas Frykman explains that 'Monuments are a strange kind of material culture with lives of their own' (Macdonald \& Tyler, 2013, p. 166). This thinking can also be applied to museums. Both museums and monuments aim to gather the public, which is argued to be essential, to form a sense of belonging and congregation for a nation (Macdonald \& Tyler, 2013, p. 166).

In social and cultural theory, it is thought that existing cultures or identity models may become in current times 'obsolete or inadequate'. This forms part of the social and cultural transformation argument often 
referred to as 'globalisation'. This theory suggests that increased global movement - of people, goods, symbols and imagery - challenges the idea of identity. This is manifested via modern information and communication technology and the movement of people, be it temporary such as tourism or permanent migration. Some theories suggest that this process enhances identity fluidity, as people are able to disassociate themselves from their birthplace creating fusion identities constructed out of the material and virtual worlds they encounter (Macdonald \& Tyler, 2013, p. 167).

It is generally understood that culture can be learnt over generations. However, heritage holds fast and shows where one comes from (Macdonald \& Tyler,
2013, p. 168). It is sometimes argued that multicultural policies only acknowledge some forms of culture, such as food and clothing which are seen as safe cultural markers instead of disruptive differences in practical heritage (Macdonald \& Tyler, 2013, p. 169).

Macdonald also introduces the use of Transcultural Galleries. These galleries aim to exhibit cultural diversity and provide a new way of displaying a nation, which proves that museums and exhibitions are agencies of social change and have an effect on communication between cultures. These places allow self-identifying communities to request their culture to be represented in museums, who then begin to include more transcultural forms or identities (Macdonald \& Tyler, 2013, pp. 182-183).

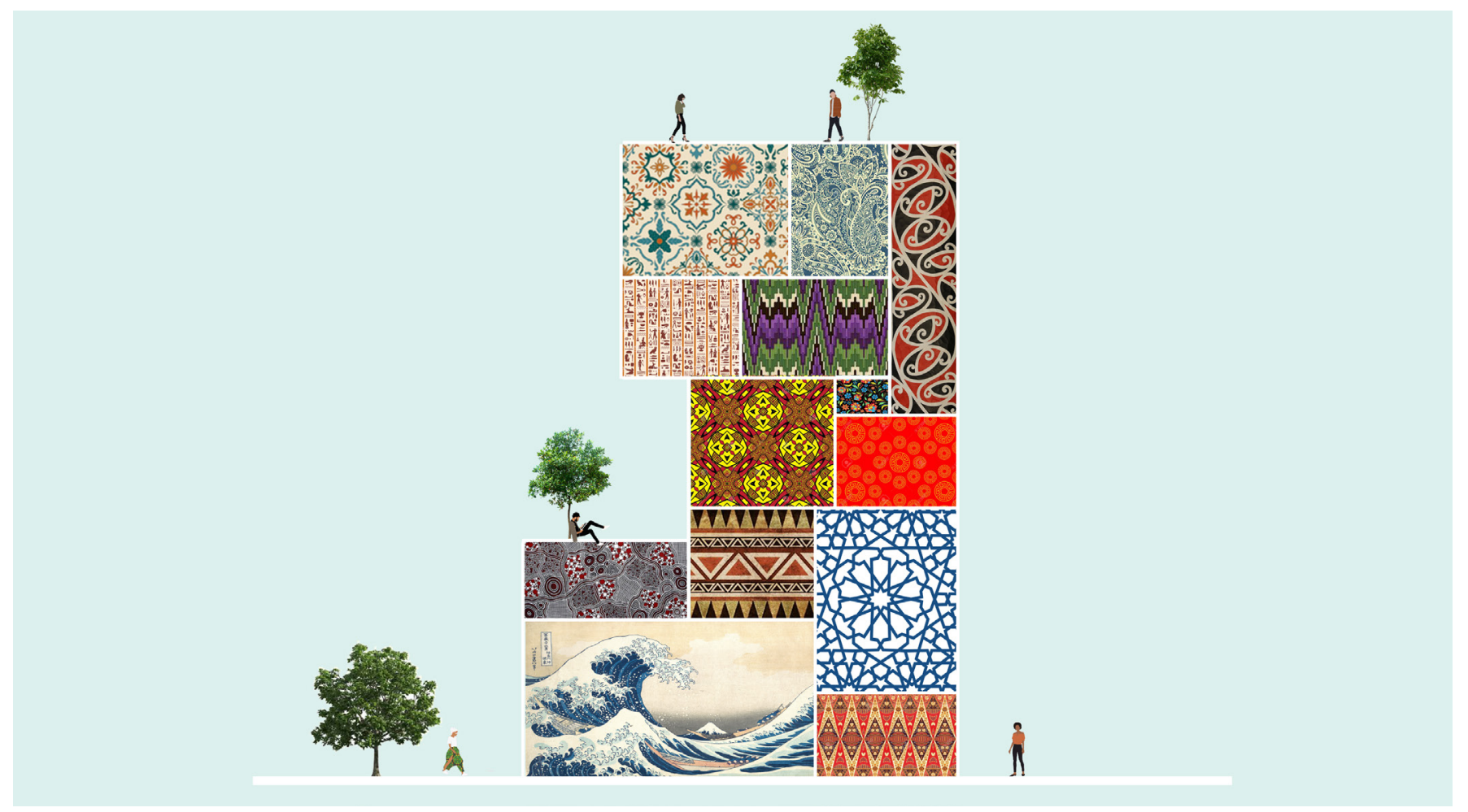

Figure.3.2: Transcultural galleries diagram 


\section{Heritage as an Experience}

aurajane Smith describes heritage as a 'cultural process about meaning making' and as a movement that individuals, communities and nations use to create and define identity, social and cultural meaning (2006, p. 87). Literature describes heritage as a cultural process, some see it used as legitimisation of the power of a nation's identity, as a communicative practice defined by culture and as a way to engage with history (Smith, 2006, p. 45).

However, Smith argues that heritage must be experienced and ultimately is the experience (Smith, 2006, p. 47). It is also important that there is a sense of memory, remembrance and performance that comes with that experience (Smith, 2006, p. 47).

Remembrance not only includes recounting oral histories, but also embodying that remembering through acts of performance is a form of heritage. Generally, in heritage studies it is the grand, the rare, or monumental that is acknowledged as a national identity, even though it is argued that everyday activities, habits and common-place symbols continually remind people of their identity or heritage (Smith, 2006, p. 49). This process may also help at the sub-national level, for members of certain social, ethnic, cultural or geographic groups to define their sense of identity (Smith, 2006, p. 49).

The idea of habitus can be used to develop this link between identity and heritage. Habitus is the abstract environment that reflects values and dispositions that define individual and group conduct, taste and expectations and aims to ensure regularity in new situations. Individuals and communities are forced to renegotiate and recover a sense of the past and to assert a sense of habitus due to the erosion of customs and expectations from modernisation (Smith, 2006, p. 49). Literature on Globalisation states that more critical attention has begun to focus more carefully on expressions of sub-national, and in particular 'local' constructions of identity and how heritage may play a role (Smith, 2006, p. 50). 


\section{Identity through Cultural Heritage}

A ntoine Lahoud refers to heritage in the tangible and intangible sense (2008, p. 389). Looking specifically at a nation's heritage through an architectural perspective that includes objects and structures of the past (Lahoud, 2008, p. 389). Tangible cultural heritage of humanity comes from the long development and transfer of traditions within a society. Culture is also prone to outside influences and 'cross fertilisation' (Lahoud, 2008, p. 389). The concept of nationality acts as a collective identity that symbolizes continuity of history (Lahoud, 2008, p. 389).

Architecture presents itself as a unique response to a specific location (Lahoud, 2008, p. 390). It presents itself as physical evidence of 'ancestral cultures and lifestyles' connecting people and communities to a place (Lahoud, 2008, p. 390). Having historical reminders such as those that help citizens have a stronger sense of identity, enforcing who they are, where they came from and a sense of what's to come (Lahoud, 2008, p. 390). This is why the identification with a place implies that a place has 'character' or attributes that distinguishes a place from another, that gives a place a unique presence or distinctive atmosphere (Lahoud, 2008, p. 390). This distinction explains why people are inclined to protect architectural heritage as it exposes and reflects the identity of a group of people (Lahoud, 2008, p. 390). To reach psychological security, everyone has an instinctive drive to embody the behaviours and attitude of significant figures in their environment (Lahoud, 2008, p. 390). Individuals also aim to enhance and protect their identity and because of this, identity has a serious impact on social inclusion (Lahoud, 2008, p. 390). This process helps communities feel more socially integrated. Countries can use old architectural structures to create a tight bond between citizens and their nation (Lahoud, 2008, p. 390). This enforces that heritage buildings are traces of a nation's ancestral past. Therefore, it is the duty of the citizens to conserve that tangible form of history for its intangible benefits. Choosing a select few of the best expressions of the past and improving and elaborating it for the future generations in order to better the sense of belonging for the nation (Lahoud, 2008, p. 392). Lahoud uses the example of the Lebanese house, which has gone through a number of stages before reaching its current form. With each stage and each iteration of civilization the Lebanese house has transformed to mirror the culture of its society at the time. Reflecting the attitudes, beliefs and vision of its society (Lahoud, 2008, p. 392). 


\section{Conclusion}

$\mathrm{T}$

his chapter has looked at various terms relating to the connections of cultural heritage and identity in order to create this thesis' design framework. It is apparent from this research that in order to enhance the sense of identity of Cross Culture People, there needs to be a better level of Cultural wellbeing brought through vitality, vibrancy and embodied culture. This can be done by giving CCPs the opportunities to express their unique culture through art and events and through learning new knowledge and skills. The topic of nature also adds to a person's cultural wellbeing, explaining why CCPs rated nature as one of the ingredients for building their identity.

This chapter also brought forward the idea of cultural mixing known as transculture. The idea that heritage allows for multiple identities could help Cross Cultural People negotiate between their cultures and form their own identities. Using heritage architecture could therefore create new identities and be more inclusive and diverse aiding in the creation of a collective memory. This idea is strengthened by Colomer's survey that has already determined that local heritage would help express their multicultural identity. The use of transcultural galleries would also give the opportunities to this group of people to express those identities beyond the confines of a museum.

Heritage embodies a plethora of meaning. Such architectural spaces can bring up a creative expression of collective identity. Heritage is also seen as an experience and should have a sense of memory, where remembrance can be evoked through acts of performance.

Having a form of tangible heritage ensures a transfer of traditions, which would help create a sense of stability. A physical reminder that has character and a distinct atmosphere would also strengthen the people's connection with the place. Cross culture can then be seen as a form of nationality of its own and would help them create a collective identity.

Architecture is one of the larger forms of cultural expression and acts as a tangible reminder of the past. The following chapter will look further into how culture and architecture coexist together.

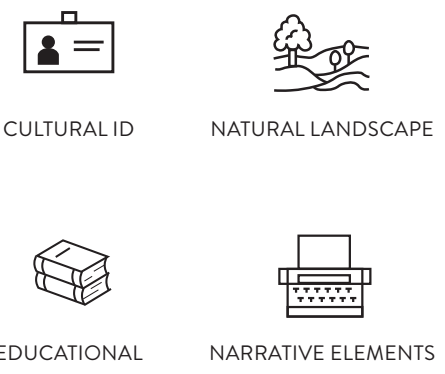

Figure.3.3: Framework consideration 



\title{
4. Culture and Architecture
}

\author{
Introduction \\ Place \\ Traditions and Change \\ Precedents \\ Conclusion
}




\section{Introduction}

$\mathrm{H}$ aving spoken of the research based on sociological and anthropological views of culture, heritage and identity it is now important to bring this thesis back into the physical realms of architecture. This chapter will look at how culture plays a role within place and architecture and the different approaches to do so.

\section{Place}

A Itman and Low define place as the 'environmental settings to which people are emotionally and culturally attached' (Low \& Altman, 1992, p. 5). Place-identity is part of the main foundations of self-identity of a person. It consists of a broadly conceived notion about the physical world the individual lives in (Proshansky et al., 1983, p. 59). These notions take form of 'memories, ideals, feelings, attitudes, values, preferences, meanings, and conceptions of behaviour and experience' which creates the detailed environment that sets the scene for life of every person (Proshansky et al., 1983, p. 59). For this reason, a sense of belonging to a new location is difficult to recreate (Proshansky et al., 1983, p. 66).

Memory is place orientated or place supported (Hayden, 1997, p. 46). Place memory can be used to trigger social memory through urban landscapes (Hayden, 1997, p. 46). Philosopher Edwards Casey explains the concept that sees "place as a container of experiences to contribute to memorability". Place triggers the ability to connect to the built and natural environments within the cultural landscape. Historical places help define citizens public past for this reason (Hayden, 1997, p. 46).

There have been attempts to embed public memory in elements within a building. There has been a lack of ordinary buildings being used to evoke public memory. However, much like monumental architecture, common urban spaces like halls and schools can be used to visually express social memory. Any strategies to promote public history should use place memory as well as social memory (Hayden, 1997, p. 47). 


\section{Traditions and Change}

$\mathrm{P}$ aul Memmott Anthropological literature has two competing definitions of what 'tradition' is as a scientific term. The first one, sees tradition as a naturalistic entity made up of old and new parts to create this abstract concept of a 'tradition' or a 'culture' (Memmott, 2011, p. 39). The second one, and favoured definition accepts that traditions change, often between generations making it an interpreted process (Memmott, 2011, p. 40). Memmott reiterates that there is no such thing as an unchanged society and that all cultures change regularly (Memmott, 2011, p. 40).

Memmott also mentions that globalisation escalates the process of de-linking identity and place and therefore, further deterritorialization of traditions. This process challenges the idea that tradition is an expression of a specific geographical location and similar cultured group. This process has been seen before in colonialism which also brought moments of deterritorialization of tradition (Memmott, 2011, p. 40). The deterritorialization of tradition is the result of de-linking traditions from its contextual location and 're-spatialising' it into new surroundings that expresses customs differently. In cultural change literature this process is referred to as 'diffusion' of cultural traits. People have diffused cultural elements and practices such as buildings, artefacts and recipes through migration (Memmott, 2011, p. 42).

Deterritorialization of tradition can develop in a variety of ways. It can be done by inserting the tradition into a museum, foreign fair or exhibition to transport it into an area of public display. For architectural tradition, it can be the transportation of artefacts or building materials to be reconstructed into a setting as was done for World Fairs. During the late nineteenth and early twentieth century, villages were re constructed for exotic displays and as an easy way to view the world through a tourist attraction (Memmott, 2011, p. 41). Another form of deterritorialization is for people within a culture to migrate and reconstruct their traditions from the materials and artefacts locally available. This process also helps create culturally referenced places of inward reflection of self (Memmott, 2011, p. 41).

Tradition is highly interpretive through forms, words and in particularly, images. A new form of deterritorialization through simulated realities which can be duplicated and distributed up to a global level and throughout numerous sites (Memmott, 2011, p. 42). 'Hyper-traditions' is another term to describe the transformation of tradition including technologies of communication, transportation and electronic media (Memmott, 2011, p. 42).

Memmott also talks about bicultural architecture. Bicultural architecture appears to be a label for the exchange of two groups, where both groups accept and 'acculturate' each other's cultural traditions. But Memmott explains that the process is much more complex than that (Memmott, 2011, p. 44). 'Integration' or 'assimilation' of one cultural group into a dominant culture with no reciprocal shift to recognise the other cultural stance (Memmott, 2011, p. 44).

Wojciech Bonenberg looks at how cross-cultural design is applied in architecture while focusing on spatial and social harmony. His definition looks at more of a multicultural context of architecture rather than this thesis' definition of cross culture - a negotiation between cultures.

Bonenberg examines how cultural capital - both tangible and intangible - has turned into economic capital (Bonenberg, 2016, p. 105). Traditionally, culture was seen as a cost factor that requires upkeep. 
However, now it is seen as an opportunity to generate profit for investors (Bonenberg, 2016, p. 106) through tourism and other means.

Cultural theory of urban development states that every space developed by humans is understood to be an expression of their culture (Bonenberg, 2016, p. 107). Cultural differences are being blurred, and patterns are becoming 'homogenised and standardised' (Bonenberg, 2016, p. 107). An example of this is the architecture towards the end of the 20th century which saw the growth of the international style favouring cubistic variation of modernism (Bonenberg, 2016, p. 107). The author talks about the idea of "glocalisation" as a way of adapting global strategies to local areas. This idea highlights the uniqueness of local cultures, treating cultural differences as a positive which in comparison to globalisation, aims to unify consumption patterns (Bonenberg, 2016, p. 108). Urban composition favours uniqueness and an urban environment that has been developed over centuries, highlighted by greenery and water begins to gain additional significance (Bonenberg, 2016, p. 109).

Culture will include several characteristics from a wide range, to be expressed through architecture. This then makes up a cultural pattern which is adopted by a community worthy of expressing their identity (Bonenberg, 2016, p. 109)
Culture generating attributes that are used when designing architectural forms include:

- aesthetics

- cognitive

- utilitarian

- identification

- integrative and adaptive

- religious and magical

- emotional

- educational

- ludic

- symbolic

- expressive

- ideological

These attributes form "patterns of culture" (Bonenberg, 2016, p. 109) where each culture will select a small number of attributes to construct architectural form. These patterns also support the shaping of a collective memory of a group (Bonenberg, 2016, p. 109). Architecture can communicate these pattens of culture. 


\section{Precedents}

The key criteria for assessing Bonenberg's definition of cross-cultural design include:

Uniqueness - features that differentiate local architecture

Familiarity - allows people to take preference over certain architectural forms

Personalisation - reflects inhabitants' own expression Local Symbolism - symbols of pride and prestige Cultural Identification - architectural features that correlate with local traditions

Expression of traditions - architectural features worth protecting and preserving (Bonenberg, 2016, p. 111).

These features enhance social ties, raise a sense of security and caring for the unique heritage of a place therefore allowing architecture to better suit a local community (2016, p. 114).

Bonenberg also mentions the theory of Urban Empathy. This theory stresses the importance of local communities' preferences for cross-cultural design. Emphasising that architects should research how the design solutions will be accepted by the local community before proposing any design ideas (Bonenberg, 2016, p. 113).
A rchitecture can take inspiration from tangible and intangible cultural heritage.

The following passage will look at two precedents that sees architecture acknowledge both tangible and intangible aspects of their respective cultures. Both approaches to the projects share a common goal of creating a community-based place that aims to create a better sense of identity to a group of people. 


\section{NEW ANDEAN ARCHITECTURE}

$\mathrm{B}$ olivian architect Freddy Mamani's mission is to bring back culture, colour and personality into the city of El Alto (Howarth, 2019). El Alto is one of the youngest cities in the country, but it quickly grew into the second biggest population as migrants from rural areas choose to settle there. These rural migrants come from a variety of different Bolivian cultural backgrounds and $75 \%$ identify as Aymara (Howarth, 2019).

The fast-growing city uses its traditional adobe and mud brick building method to keep up with influx. This gives the cold alpine and high-altitude city an increased monochromatic feel. His architectural style is derived from the ancient local architecture, specifically from the ancient city of Tiwanaku. This ancient city is 60 kilometres away from El Alto and thrived between 500-1000 AD, controlling most of the Southern Andes. The palace of the UNESCO World Heritage site is still used for events.

The style aims to incorporate the lines and motifs from the ancient architecture of the imperial capital of Tiwanaku in a contemporary way. Taking inspiration from the geometric shapes found amongst the ruins including natural and animal forms. Mamani then transforms it into a more figurative design language. The result takes the Tiwanaku elements and translates them into symmetrical forms in contemporary architecture.

"This architecture has its own language, its own culture, its own identity and translates these ancient ideas into the contemporary city" Freddy Mamani (Howarth, 2019)

The colours used for his buildings are derived from the local tradition of woven textiles worn by the women of the Aymara culture. These colours give the buildings façades their striking presence and is used to transmit joy to its occupants. The bold patterns from the façade continue inside with floral shaped ceiling plates for large chandeliers and capitals as columns. The builders learn artisanal architectural moulding techniques from a young age and craftsmen hand paint the intricate interior spaces.

These buildings serve multiple purposes. The first floor serves as a store or commercial space while the second and third floors are large activity halls for bringing families and the community together. The fourth and fifth floors accommodate apartments or sports facilities while the top floor is left for a 'Cholet' (a term combining the words chalet and slang chola referring to a women of indigenous ancestry) (Howarth, 2019).

There are seventy of Mamani's buildings in El Alto and one hundred in Bolivia. These buildings are seen as a status symbol as people want to express their culture and identity. Other contractors have begun to incorporate more colour into their buildings as well, following in his footsteps. This movement has begun to change their plain city into an artistic expression of their culture and identity and has made the city into a tourist destination.

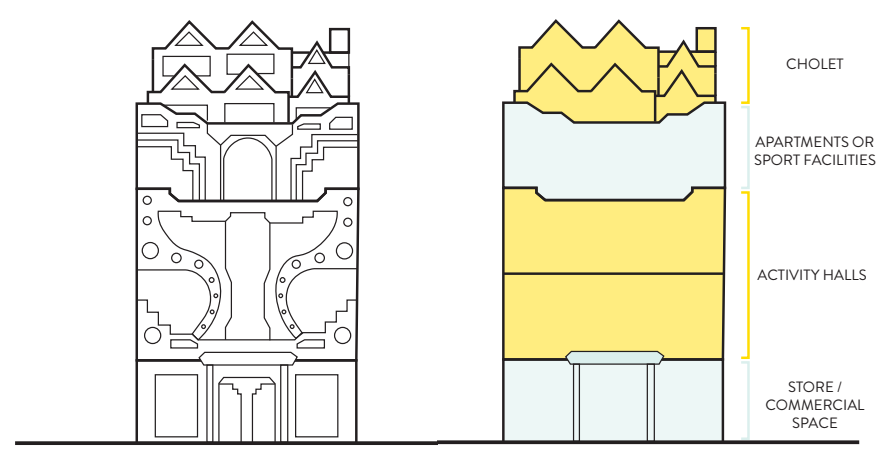

Figure.4.1: Building Function 
This content is unavailable.

Please consult the figure

list for further details.

This content is unavailable.

Please consult the figure

list for further details.
This content is unavailable.

Please consult the figure

list for further details.

Figure.4.2: Examples of Mamani's designs 


\section{WALUMBA ELDERS CENTRE}

A ustralian firm Iredale Pedersen Hook's Walumba Elders Centre is an award-winning facility.

Located in Warrmarn (Warmun) in Western Australia this building was designed for an aboriginal community affected by severe flooding. The 2011 flood destroyed most of the housing in the area as well as the previous facilities. 350 people from the Gija community were forced to temporarily leave their homes during the rebuild period which took approximately two years (Howarth, 2017).

The new retirement facility was built next to the community school. The project intent was to aid in the conveyance of aboriginal lore, the Gija language and the cultural knowledge to the younger generation. It is centring it into the heart of the community in order to help it heal its people (Howarth, 2017).

The layout of the building is made up of two parallel wings connected by its large ' $U$ ' shaped roof. The large concrete piles raise the building 2.4 meters above ground to avoid future floods. It has been cladded in corrugated iron and has multiple staircases leading to a minimalistic landscaped courtyard (Howarth, 2017).
The facility includes accommodation for self and high care occupants. The design of the building also includes factors essential to the Aboriginal culture. These include gender separation, access to public and private outdoor spaces and areas for ceremonies involving fire and smoke. The many staircases allow for the occupants to continue the avoidance of certain group members - a tradition very important to aboriginal culture (Howarth, 2017).

The concept of the bridge was used physically and metaphorically in this design to convey the idea of a passage of knowledge between the generations and passing from this life to the next (Howarth, 2017).

While both the examples cater to one single culture, they are both perfect examples of how to express them through architecture, in both tangible and intangible ways. While the Andean Architecture creates a new architectural language to reiterate an ancient tradition and art form, the second example uses contemporary architecture to facilitate ancient traditions and rituals. 
This content is unavailable.

Please consult the figure

list for further details.

This content is unavailable.

Please consult the figure

list for further details.
This content is unavailable.

Please consult the figure

list for further details.

Figure.4.3: Walumba Elders Centre 


\section{Conclusion}

$\mathrm{B}$ onenberg's principles for creating cross cultural architecture creates an interesting foundation for the topic of this thesis as his research has used a multicultural approach to designing spaces and analysed a variety of successful tactics. Cross referencing this research with the survey data provided by Laia Colomer will help structure the framework for the upcoming experimentation.

This thesis does not aim to create a new architectural style like Mamani but rather a collection of steps to create places to aid in the creation of their own identity. Much like the 'Wallumba Elders centre' in Australia, which is a place to nurture their intangible heritage through the expression of their rituals and traditions.

Much like the precedent mentioned, the building should take form of a community driven space that is adaptive and educational. The theory of Urban Empathy also reiterates the process of this thesis, by taking specific identity building components given by TCKs from Colomer's survey as direct data to influence the design framework.

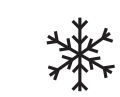

UNIQUENESS

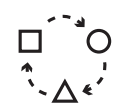

ADAPTABILITY

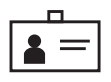

CULTURAL ID

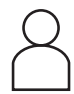

PERSONALISATION

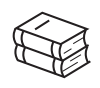

EDUCATIONAL

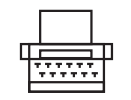

NARRATIVE ELEMENTS

Figure.4.4: Framework consideration 



\title{
5. Heritage Conservation
}

\author{
Introduction \\ Understanding Heritage \\ Heritage Categories \\ Conservation Approaches \\ The Intangible \\ Heritage Communities \\ Conclusion
}




\section{Introduction}

$\mathrm{T}$ he previous chapters have looked at what cross cultural people need in order to build a better sense of identity. It also looked at what type of place and what it would include. This chapter will briefly outline the development of heritage conservation, the battle between the tangible and intangible heritage, what is regarded as heritage in New Zealand and the different approaches to the conservation of heritage architecture.

\section{Understanding Heritage}

M iles Glendinning writes on the extensive history and development of heritage conservation, which started on the fifteenth century Europe. The modern architectural movement of the conservation of heritage however, had not fully developed until the eighteenth century during the 'Enlightenment period' (2013, p. 48). Conservation was heavily impacted during the First World War, and after the excessive destruction it helped in the development of preservation standards. This created a revived movement to define protection criteria through professional organisations responsible for the protection of historic buildings, such as the International Committee on Intellectual Cooperation $(\mathrm{ICIC})$ in 1922, followed by the creation of the International Museum Office (IMO) in 1926 (Glendinning, 2013, p. 198). The Charter of Athens, which was founded in 1932 would become the framework for heritage conservation in the twentieth century (Glendinning, 2013, p. 199). These organisations also saw the development of many other international legislations, the first being the Venice Charter in 1964. Other non-government organisation like ICOMOS (International Council on Monuments and Sites) established charters around the world. New Zealand established its own ICOMOS chapter in 1992, to encourage the practice of heritage conservation.

Recently non-government organisations such as DOCOMOMO (DOcumentation and COnservation of buildings, sites and neighbourhoods of the MOdern MOvement) have acknowledged significance in architectural heritage such as the modernist movement, recognising buildings built as late as the 1980 s. Forty parties around the world compiled a register of modern buildings, sites and neighbourhoods to document and preserve. This thesis will focus on buildings registered within Heritage New Zealand's classifications. 


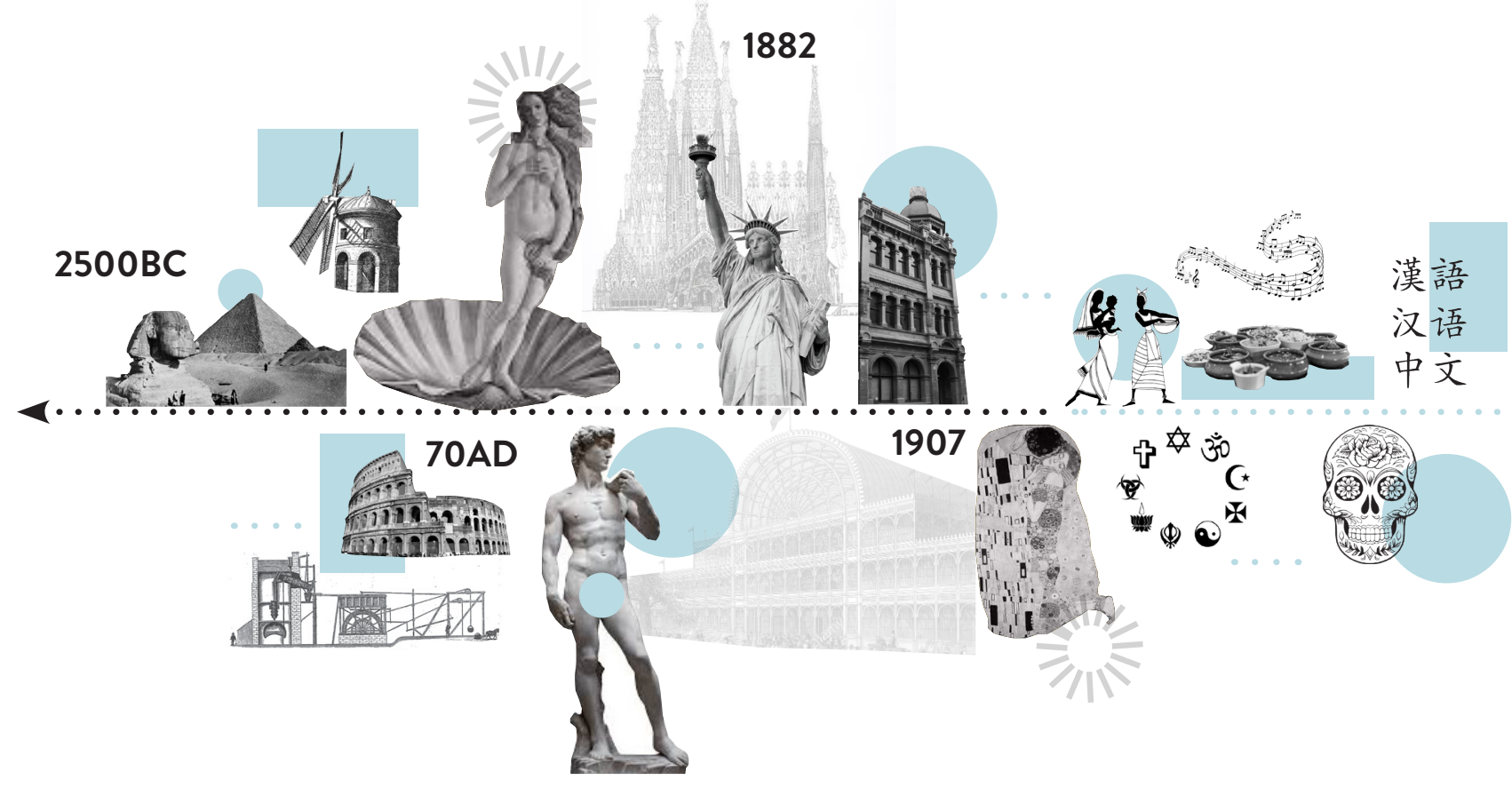

Figure.5.1: Heritage development time line 


\section{Heritage Categories Conservation Approaches}

$\mathrm{H}$ eritage New Zealand has catalogued a large number of heritage buildings in order to document and protect these places. Their List is divided into five parts:

Historic Places - historical archaeological site (pre 1900s), building or memorial.

Category One - a historic place with special or outstanding historic or cultural significance

- $\quad$ Category Two - a historic place with historic or cultural significance

Historic Areas - groups of historic places related to one another like a geographic area with numerous sites, a heritage precinct or a historical or cultural area.

Wāhi Tūpuna - places important to Māori for ancestral significance

Wāhi Tapu - places sacred to Māori in the traditional, ritual, religious or mythological sense

Wāhi Tapu Areas - areas that have numerous Wāhi Tapu (About the List, n.d.)

From these classifications it can be seen that attempts have been made to also include aspects of the intangible such as mythological, ritual and religious significance. $\mathrm{n}$ order to protect these heritage places there are three different processes that can be undertaken: (i) preservation, (ii) conservation and (iii) restoration. Although they appear very similar, it is their definitions that reveal quite different approaches.

Preservation - requires little to no intervention to ensure its continued survival. Nothing should obscure or remove signs of age to hide its authenticity and integrity (ICOMOS New Zealand, 2010, p. 6)

Conservation - established by understanding and appreciating all aspects of its cultural heritage value both tangible and intangible. To respect original fabric, meanings and use of a place. Require cautious approach to do as much work as necessary and balance with minimum intervention to retain its authenticity and integrity (ICOMOS New Zealand, 2010, p. 2).

Restoration - involves reassembly, reinstatement and occasionally removal of additions that take away from the cultural heritage value. It is important to respect the original fabric ensuring the cultural heritage value of a place is recovered (ICOMOS New Zealand, 2010, p. 7).

Selecting which approach to take depends on the level of protection that the heritage building has. However, working with heritage buildings also requires the right balance between protecting the heritage fabric and future proofing. 


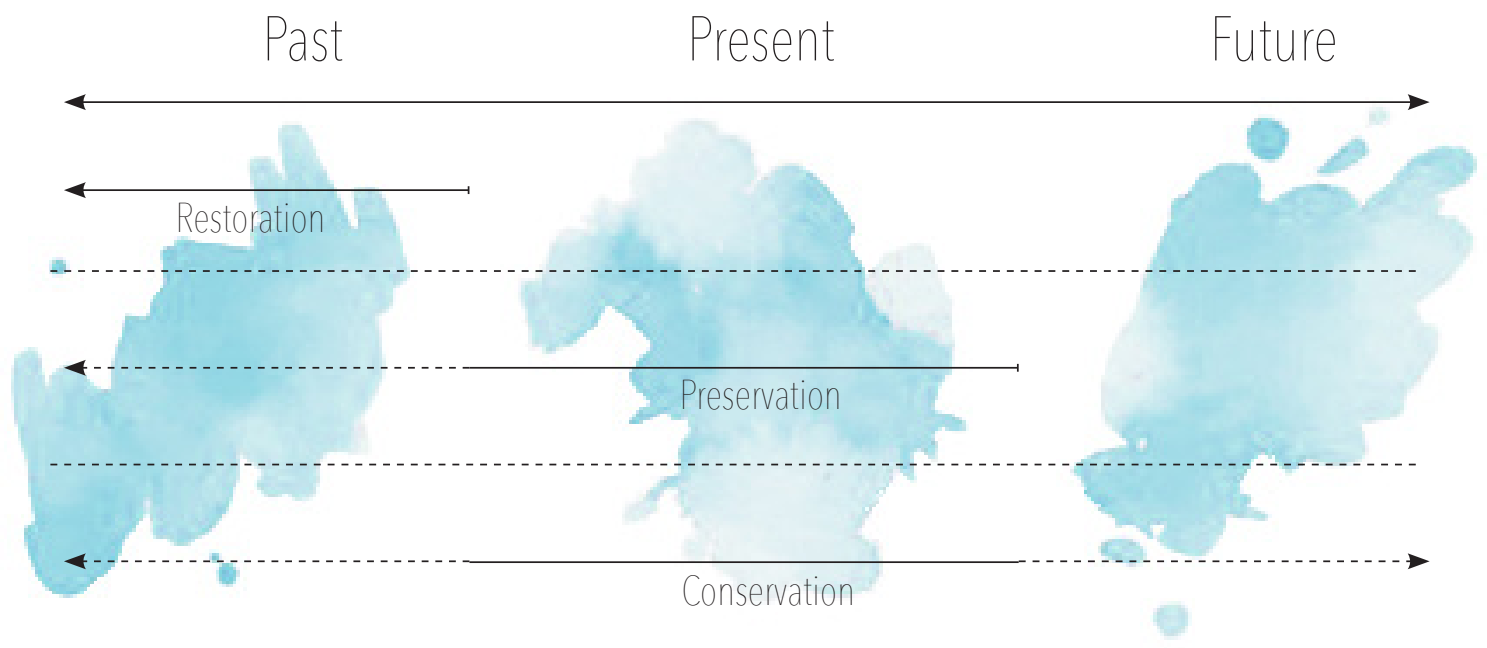

Figure.5.2: Heritage position 


\section{The Intangible}

ecturer of Museum and Heritage studies Rodney Harrison argues that there has been a significant growth in efforts to preserve traces of history during the late 20th and early 21st century. He also notes the current change of interpretations of heritage from the physical to immaterial, stating that 'This modern period has seen heritage increasingly shift away from a concern with 'things' to a concern with cultures and traditions and the intangible' (2012, p. 115).

Heritage can be split into two groupings known as tangible and intangible heritage. Tangible being physical objects such as historical monuments, archaeological sites and national parks. Intangible heritage refers to living traditions, skills, languages and expressions. There is extensive research around the interdisciplinary field of Heritage Studies however, less tangible approaches seem to be unnoticed within conventional practice. In 2003, UNESCO adopted however the convention for the safeguarding of Intangible Culture Heritage in an attempt to shift the focus from historical monuments to intangible characteristics like living traditions, skills and oral expressions (Harrison, 2012, p. 115).

Laurajane Smith also examines the topic of intangible heritage and argues that the discipline of heritage conservation privileges the tangible, as it is simpler to apply cultural meaning (Smith, 2006, p. 12). Smith explains that conservation practices are more concerned with the "negotiation and regulation of a range of cultural and social values and meanings' (Smith, 2006, p. 12). Visiting heritage sites in the tourism industry as well as the management of these sites, acts as a form of maintenance or conservation and preservation of social and cultural meanings. This creates a form of meaning and identity making through different practices such as economic, leisure and social/cultural. The act of legitimately recognising heritage through management and conservation practices gives heritage a material authority to construct identities while capturing the attention of experts like historians, archaeologists and conservation architects (Smith, 2006, p. 50). She also explains that heritage practices can be defined by several techniques, management, protocols and procedures that a number of professionals such as 'heritage managers, archaeologists, architects, museum curators and other experts undertake' (Smith, 2006, p. 13). 


\section{Heritage Communities}

C ultural heritage is an essential part of culture and it includes everything from ethnicity, collective identity and territory to common and shared past (Colomer \& Holtorf, 2019, p. 147). Cultural heritage is a manifestation of shared cultural history and common collective identity that people give themselves. The world has been transformed by globalisation and even when people move around, their cultural identity stays alive. Often cultural identity is seen as an 'us and them' situation which can lead to exclusion, or worse, conflict (Colomer \& Holtorf, 2019, p. 147).

With a higher degree of cultural diversity, cultural heritage does not have the ability to define nations with distinct identities and narratives to feel unity. Multicultural society act like they are united, but they are actually divided as they have a lack of cohesion and integration (Colomer \& Holtorf, 2019, p. 148). The question is, can we draw 'memory and heritage - form new identity stories' that include cultural diversity and mixed culture? (Macdonald \& Tyler, 2013, p. 162).

A way to return to cultural heritage is to identify and promote the use of heritage through "heritage communities" that are not connected to certain aspects of culture. Following Faro's Convention from 2005 to adopt a people-centred perspective and create a view that heritage must be valued throughout daily life. "Heritage communities" are made up of people who value certain expressions of cultural heritage which they want to sustain for future generations. This allows people to benefit from cultural heritage and enrich their communities while respecting other cultural heritages as much as their own. These communities also need their social identity to be given a sense of historical continuity that does not need to be linked to a national past. (Colomer \& Holtorf, 2019, p. 149).
Third Cultural Kids cultural identity is a mix of memories, images, skills and cultures.

Is there an ability to create new heritage? TCKs are the embodiment of globalism and multiculturalism which results in feelings of restlessness and rootlessness. It is also due to marginal feelings because of the dominating relationship of their residential culture (Colomer \& Holtorf, 2019, p. 151). Colomer refers to it as "cultural homelessness" as TCKs belong "everywhere and nowhere 'they lack full cultural ownership (2019, p. 152).

The process of cross-cultural heritage could be the key case exemplifying the emergence of a $\mathrm{New}$ Heritage. New Heritage is not about what is left of the past and how to manage it, but about people's values, interpretations, uses and benefits of heritage in society. New Heritage is less about objects and their worth and more about their meaning. Seeing heritage as an interaction between people and their world. Our understanding of TCK cross cultural heritage is an understanding of one particular group and their place in the world. (Colomer \& Holtorf, 2019, p. 160). Cross cultural heritage exemplifies possibilities and challenges of community participation in heritage management. This challenges ethics of decision making about what heritage is and why it matters. Cross cultural heritage therefore requests new ways of imagining and thinking about heritage that are meaningful to global and multicultural citizens in our time (Colomer \& Holtorf, 2019, p. 160). 


\section{Conclusion}

$\mathrm{T}$

his chapter has introduced the evolving interpretations of heritage throughout time as well as an outline of the development of the field of heritage conservation and how it is documented here in New Zealand. This was followed by the three general approaches to see these places live on for future generations. While this thesis does not focus on the movement's development or these approaches in detail it is important to understand the concepts of heritage conservation. This thesis will also take an architectural approach to incorporate not just the tangible but the intangible for the coming iterations. Having Cross Cultural People as part of the Heritage Community would also create an interesting opportunity to further experiment within the physical realm of architectural heritage management.

These explorative iterations will each look at a building from different categories of Heritage New Zealand's heritage list. The first being a historic area, the second a historic place Category Two and finally a historic place Category One. They will also state where on the spectrum of Preservation, Restoration or Conservation they stand. Each iteration will assess its heritage approach.

The following chapter will take the learnings form these research chapters and create a framework to be able to create places to nurture Cross Cultural People.
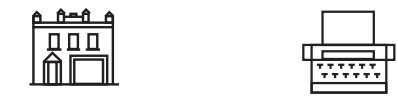

LOCAL HERITAGE NARRATIVE ELEMENTS

Figure.5.3: Framework consideration 

6. Framework

Introduction

Site Framework

Design Framework 


\section{Introduction}

$\mathrm{t}$ is apparent from the previous research that cross cultural people lack a sense of inclusion, identity and general sense of belonging.

Researching the appropriate topic fields has brought forward several different possible tactics to achieve the desired outcome. These tactics are represented by architectural, design and atmospheric criteria.

They have also been curated into a design framework which is made up of several criteria that will inform design decisions for the experimental design iterations throughout this thesis.

The framework below was created to describe a new building typology for cross cultural people.

This framework is organised into two parts. The first part describes the process to be used to select an appropriate site. The second one, is a series of design tactics for the applied design. A successful crosscultural place should incorporate all aspects of this framework.

\section{Site selection}

Public - Easily accessible and gives them an increased feeling of inclusion as well as a sense of safety

Uniqueness - Help differentiate local architecture from other buildings

Local Heritage Significance - Cross culture people are more connected to these buildings and will help generate a sense of identity

Cultural Identification - Features that represent the local tradition, history and collective memory of the location.

Natural landscape - Build a sense of identity and increase cultural well-being

Essence of Mobility/Transportation - Accessibility and acknowledging restlessness and rootlessness for a number of cross-cultural people

\section{SITE SELECTION}

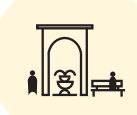

PUBLIC

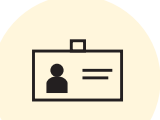

CULTURAL ID

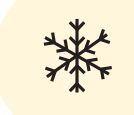

UNIQUENESS

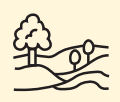

NATURAL LANDSCAPE

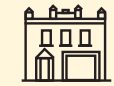

LOCAL HERITAGE
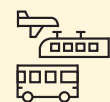

MOBILITY 


\section{Design Tactics}

Multiculturalism or Transcultural - Create a space for a number of cultures to co-exist together harmoniously.

Educational - Enhance a collective memory through facilitating the learning of different cultures

Nature - Enhances cultural well-being and helps build cross cultural identity.

Adaptability - Flexibility of use, changeability, multifunctional

Personalisation - To reflect inhabitants' preferences regarding their cultural habits and values. Further expressing their identity

Narrative Elements - Symbolic decorative elements to evoke the cross-cultural experience.
A new building typology is required to create a sense of inclusion and grounding for people that each have their own unique backgrounds. These new spaces will need to follow the criteria to ensure that these key design points are met for the intended users. The iterations will also indicate where it sits within the conservation front.

\section{DESIGN TACTICS}

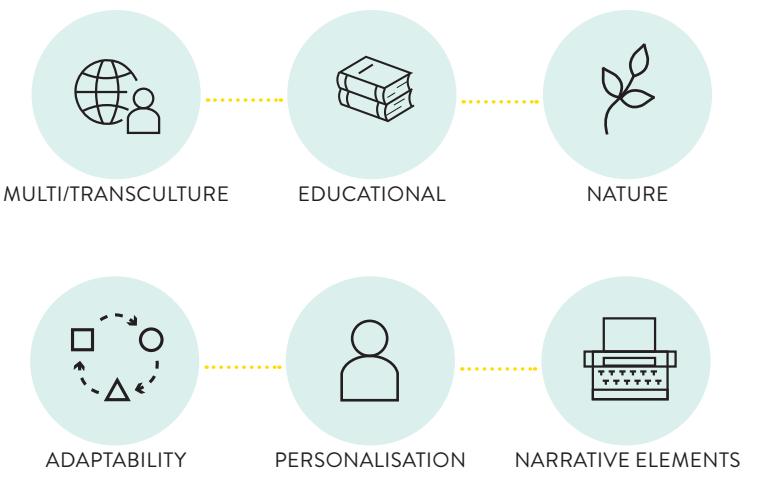

Figure.6.2: Design framework icons 

7. Iteration one

History

Precedents

Design Process

Reflection 


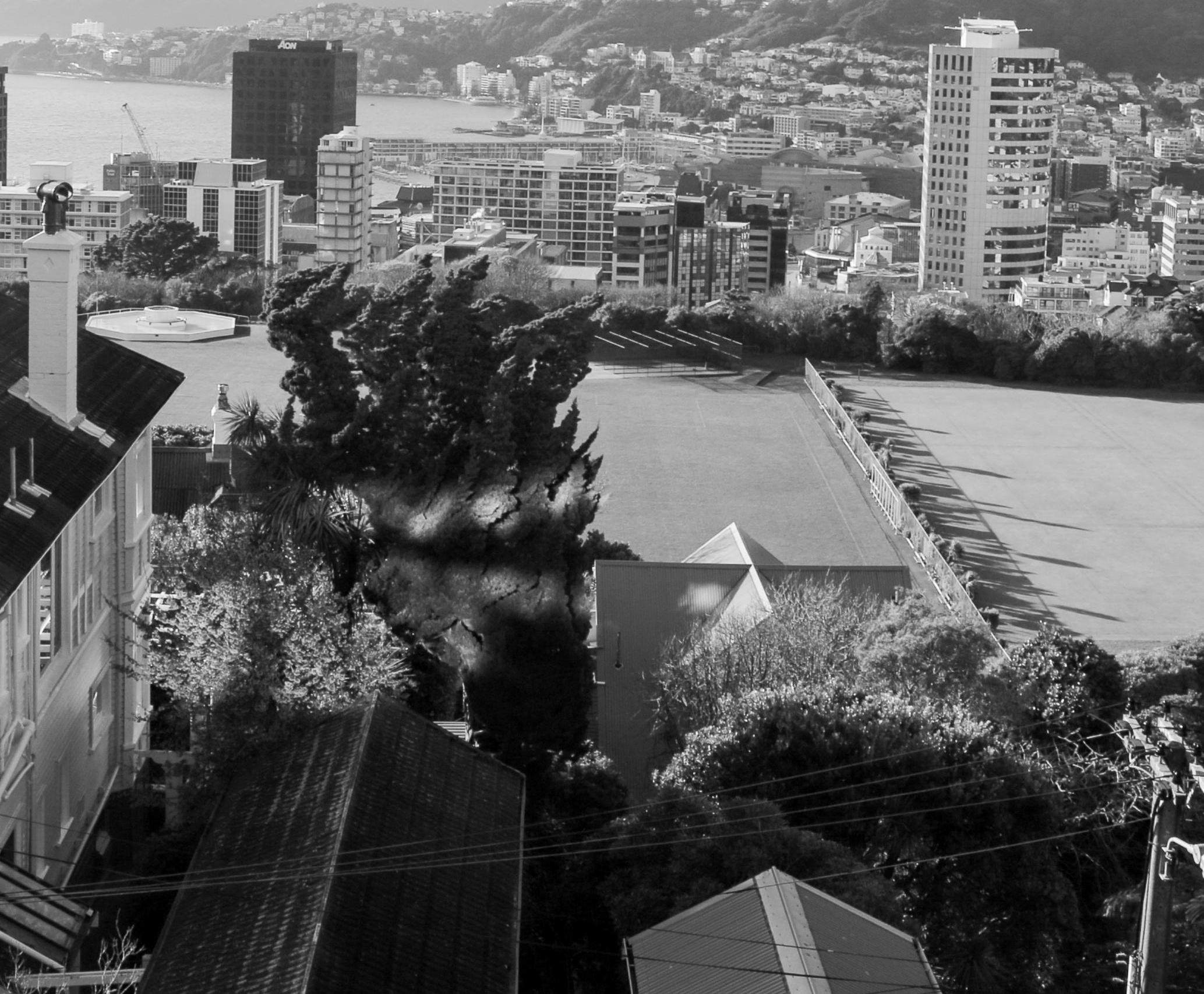




\section{TEA KIOSK}

101 Glenmore Street, Thorndon, Wellington 1 Upland Road, Kelburn, Wellington

Historic Area 


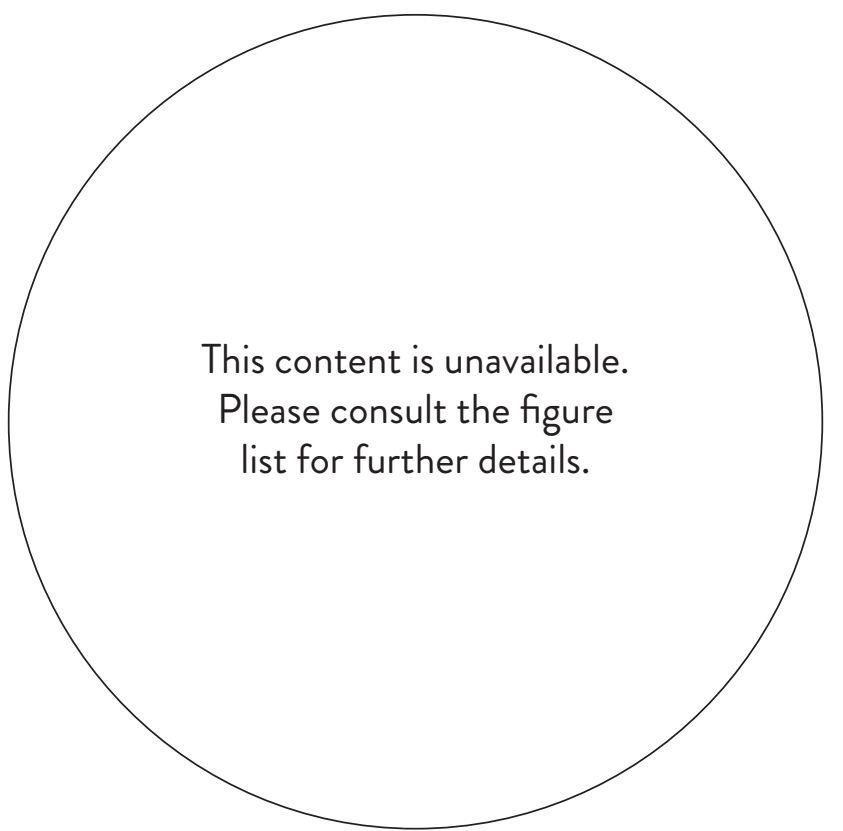

Figure.7.1: Site 1902

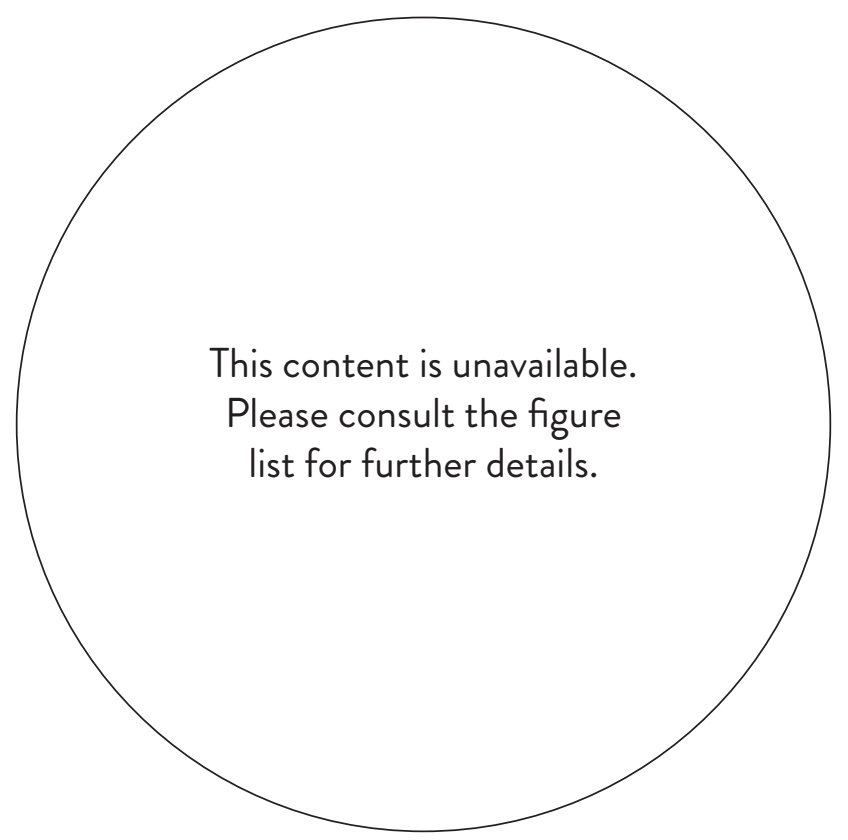

Figure.7.2: The Kiosk

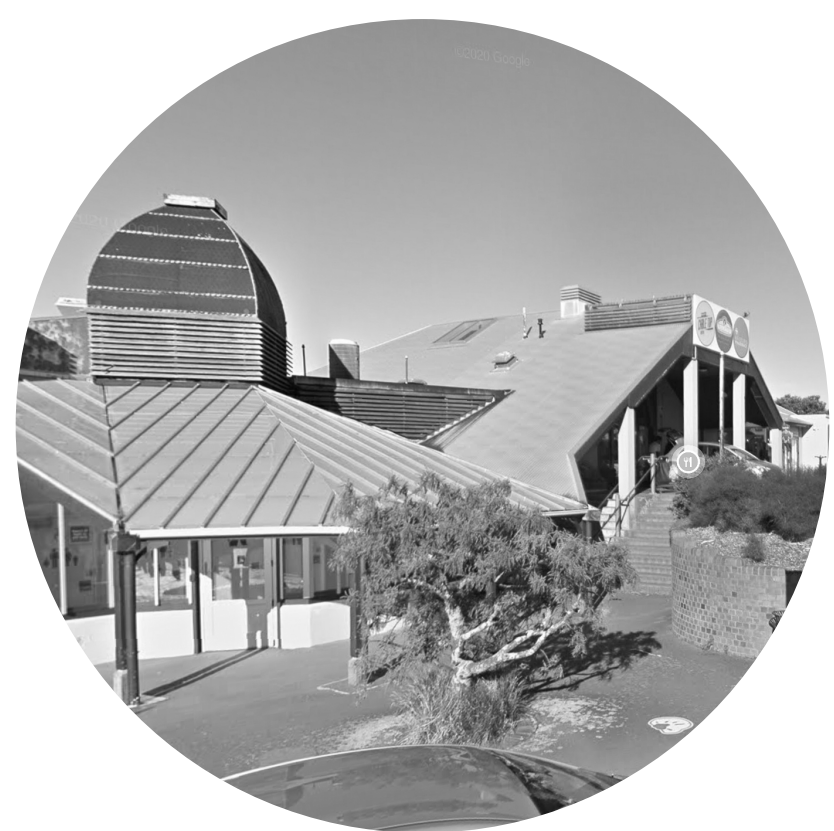

Figure.7.3: Current Building on Site 
This content is unavailable.

Please consult the figure

list for further details.

Figure.7.5: Original Plans

This content is unavailable.

Please consult the figure

list for further details.

Figure.7.6: Original Plans 
This content is unavailable.

Please consult the figure

list for further details.

Figure.7.7: Original Plans

This content is unavailable.

Please consult the figure

list for further details.

Figure.7.8: Renovation Plans 


\section{HISTORY}

$\mathrm{T}$ he Wellington Botanical Garden is one of the earliest and most significant public gardens in New Zealand, occupying an area of 25 hectares in the suburb of Kelburn (Hemi, 2015). The land was original occupied by the Kumutoto Pà until European settlers took over the land in 1840 which formed the Wellington Town Belt. A map from the 'McCleverty Award deed' (Wellington City Council, 2002, p. 13) shows a settlement in the upper cable car area around Upland road. In 1847 part of the taken land was given back to the Kumutoto settlement as compensation. The 52 acres were later purchased back in 1851 which later became part of the Botanic Gardens in 1871 (Wellington City Council, 2002, p. 13).

James Hector stated that the land would be suitable for a 'public park and a garden for botanical, horticultural and acclimatisation purposes' (Hemi, 2015). Then in 1869 Parliament passed the Botanic Garden Act and established the gardens, where many exotic species of plants and animals were introduced. The animals included pheasants, fowls, emus and a monkey which regularly escaped. Most of the animals were then transferred to Newtown Zoo (Hemi, 2015). The main role of the gardens, however, was to trial the planting of foreign plants which could have been suitable for New Zealand. These trials would then inform future domestic and plantation development. During 1870 and 1871 the gardens were used to trial different conifer species from around the world and still to this day holds the oldest Pinus radiata in the country (Hemi, 2015). The gardens have a diverse terrain of hills and valleys which holds remnants of preEuropean bush, a variety of plants and gardens and architectural significant buildings (Hemi, 2015). Some of these buildings, like the Cable Car Winding House are heritage protected. The building is now used as a cable car Museum and sits atop the Botanical Garden next to the site that held the infamous Tea Kiosk. Built in 1905, the Edwardian styled building was used as a tea kiosk, accommodation during a world war, pub and restaurant. Then in 1982 the building burnt down under suspicious circumstances, after years of debate over the appropriate use of the building. A new building was designed by Wellington Architect lan Athfield to sit on the site and house a ticket desk and restaurant. 


\section{REASONING}

$\mathrm{T}$

his site was selected for its historical significance and its layering of culture. The site occupation layering of the Kumutoto $\mathrm{P} \bar{a}$, an Edwardian Tea kiosk and a modern Athfield building evokes its evolving cultural nature. The new proposed structure will create a space for Cross Cultural discussion to further celebrate that idea.

The Gardens have a variety of buildings, some heritage protected and some not. This provides the opportunity to experiment designing around a historic area, while not directly altering a heritage protected building. The site is on the edge of the Botanical Gardens, to allow for a close connection to the natural landscape and views over the harbour, to enhance the sense of place for its users. A closeness to nature is described by cross cultural people as important for identity construction and is also important for cultural wellbeing. The site is accessible and well connected to the city by foot, car, bus and cable car. It is also an existing tourist attraction bringing in a variety of people from different cultures and giving the opportunity to further showcase the cultural vibrancy of Wellington. 
This content is unavailable.

Please consult the figure

list for further details.

This content is unavailable.

Please consult the figure

list for further details.
This content is unavailable.

Please consult the figure

list for further details. 


\section{CRYSTAL HOUSES}

$\mathrm{T}$

his project was designed by MVRDV and Gietermans \& Van Dijk in 2016. Located in Amsterdam, this project celebrates both Dutch heritage and international architecture.

The brief for the project was to create a representation of the original building to stay in keeping with the streetscape and update to the new zoning laws. The glass brick facade mimics the original design from the layering of the bricks and the window frame details but is stretched vertically to increase the interior space. The glass brick facade dissolves up into traditional terracotta bricks to stick with the traditional aesthetics. This design is an attempt to create a solution to the loss of character in the area. The designers aimed to bring back what had to be demolished and took it one step further. The solid glass bricks bonded with transparent adhesive as a substitute mortar to create a structure as strong as concrete (Crystal Houses / MVRDV, 2016).
Although the building is a new structure, the design takes into consideration its historical surroundings. Utilising new materials to express the original composition of the facade shows great respect to its architectural heritage.

The tea kiosk can take lessons from this project by implementing a similar reconstruction approach while utilising new and improved materials. Using glass can add a modernity while still respecting the original style of the Edwardian design. The glass also gives it a 'ghost' like effect perhaps bringing a transparency to the idea of transculture and an homage to its suspicious demise. 
This content is unavailable.

Please consult the figure

list for further details.

This content is unavailable.

Please consult the figure

list for further details.
This content is unavailable.

Please consult the figure

list for further details. 


\section{BASILICA DI SANTA MARIA DI SIPONTO}

$\mathrm{D}$ esigned by artist Edoardo Tresoldi the wire mesh structure replicates the church that was on the site centuries before. Tresoldi specialises in large scale wire sculptures both architectural and figurative pieces. The archaeological site is in Siponto, southern Italy.

The installation sits on the site of a church of an ancient Roman settlement. The church was then deserted in the thirteenth century following a series of earthquakes. The sculpture will stay indefinitely on site as a reminder of what once stood there.

The brief for the installation was to reconstruct the basilica, but as it was unsure of the exact elements and size of the structure Tresoldi had some creative freedom.

The Romanesque domes, architectural windows and columns are illuminated at night by spotlights (Mairs, 2016).
This project is a unique example of the relationship between the past and present

This precedent perfectly showcases how to memorialise a building that no longer exists. The choice of materiality and transparency gives it a ghost like appearance. Its impermanence to the site means it does not alter the archaeological importance or its historical significance. 


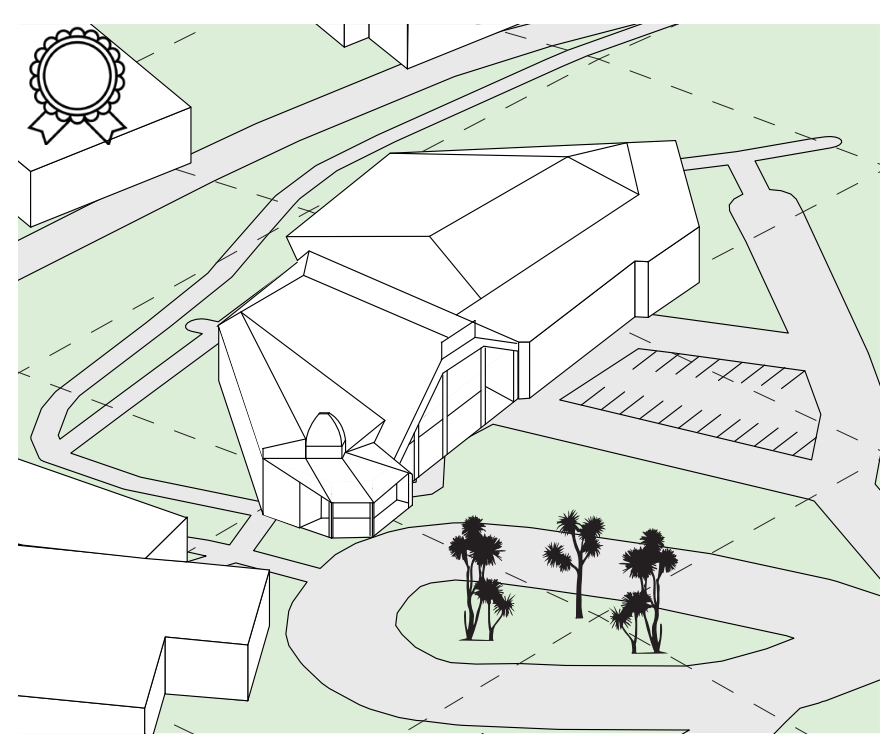

Current building

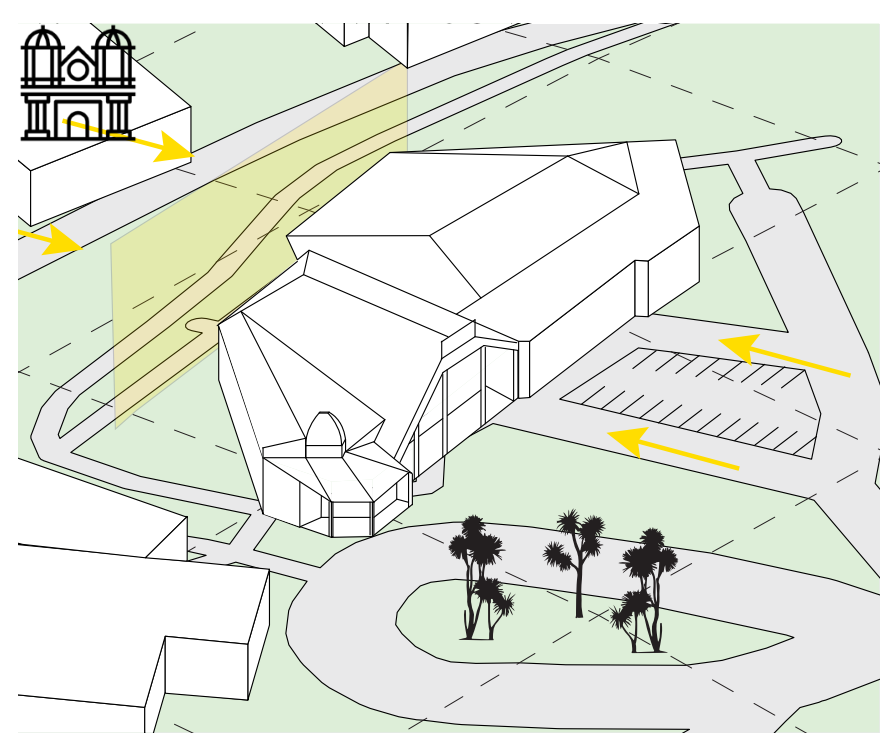

Area of interest

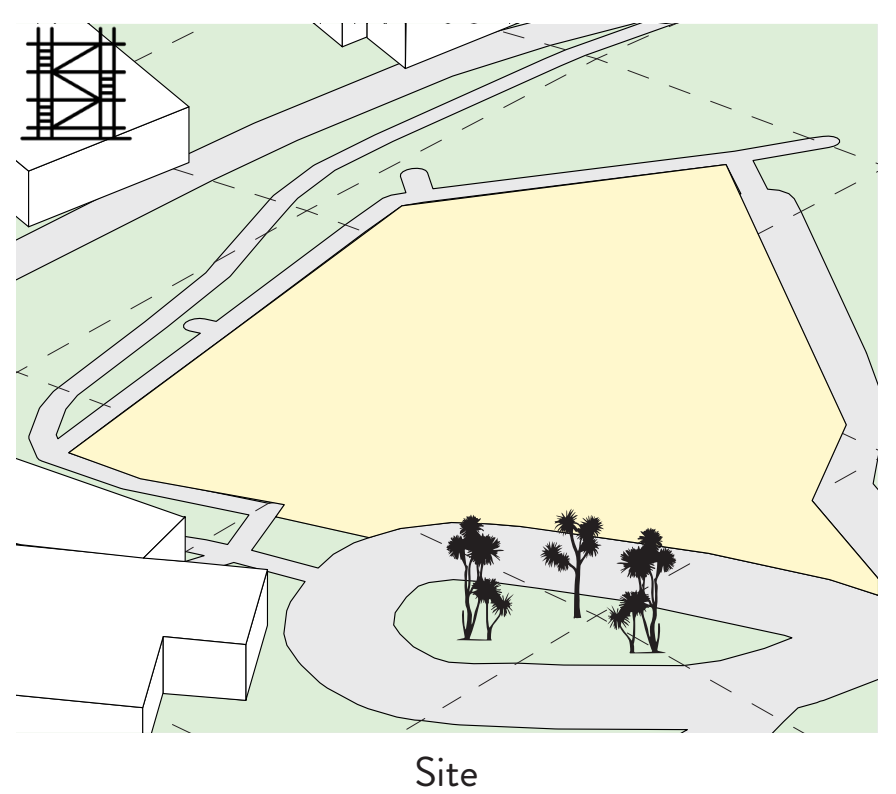

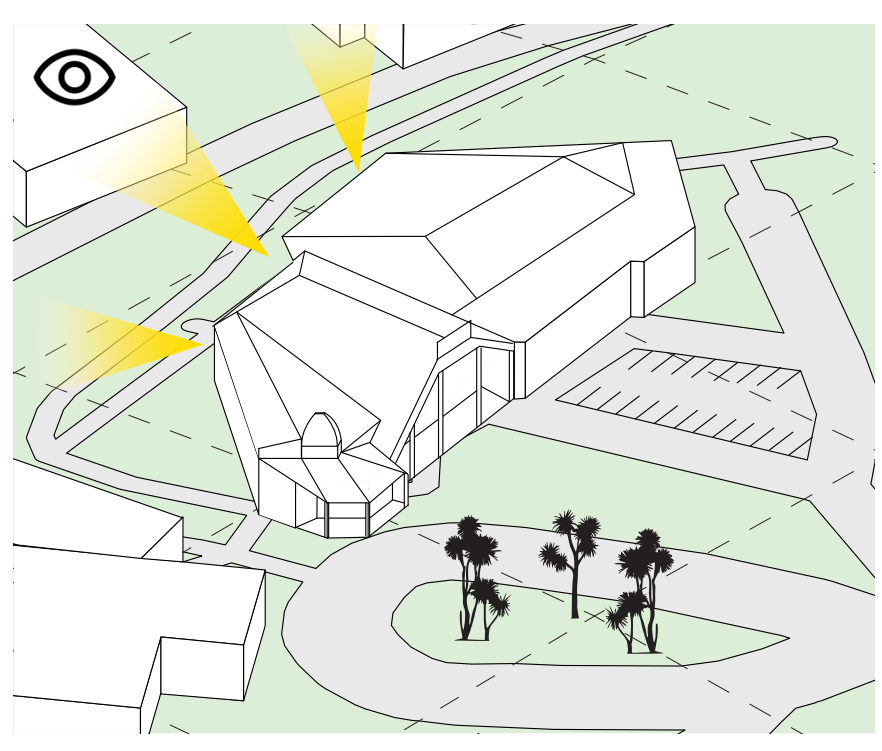

View

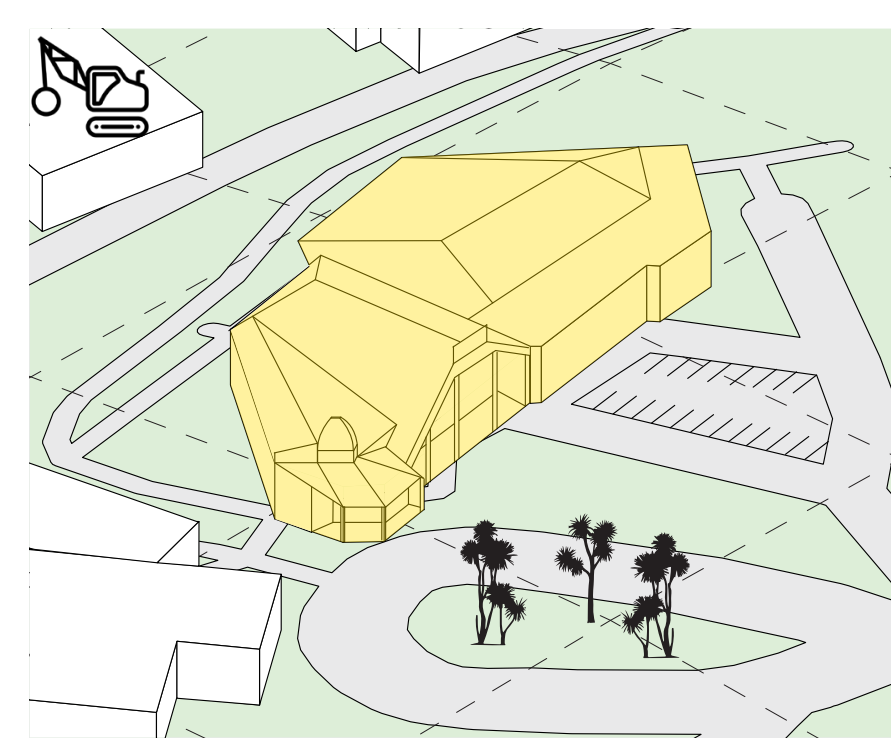

Demolition

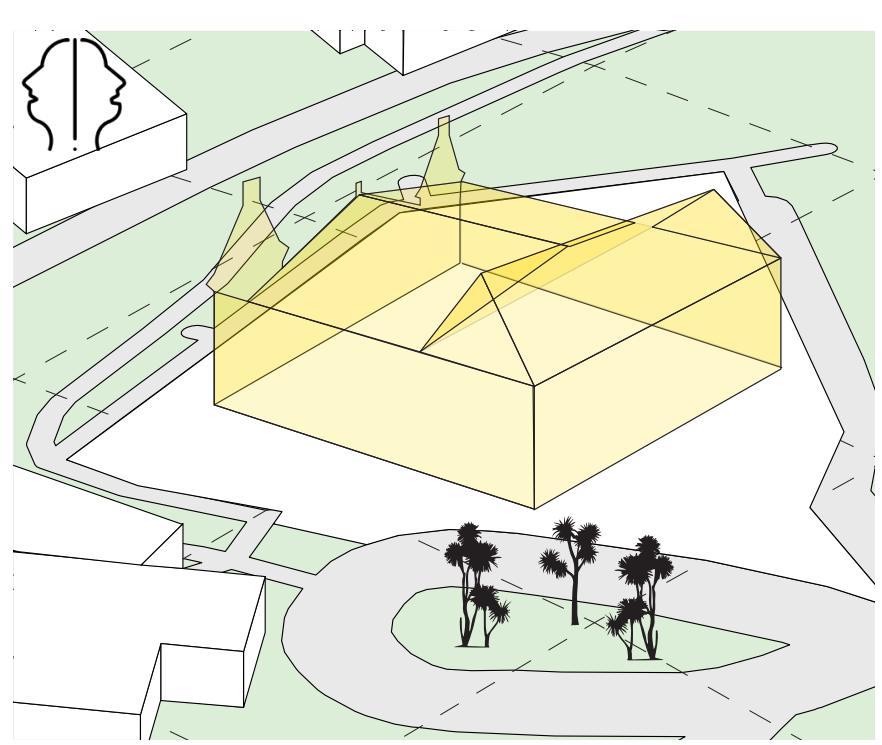

Proposed intervention 


\section{DESIGN DECISIONS}

$\mathrm{T}$

his iteration will take on a slightly different approach to conservation as it will delve into the ideas of replication. The new design will not fully replicate the old tea kiosk but will represent the essence of the old Edwardian building while also acknowledging the original occupiers of the site, the Māori Pā. This iteration will also take form of an experiential installation, to allow visitors walk through and immerse themselves within the layering of cultures. 

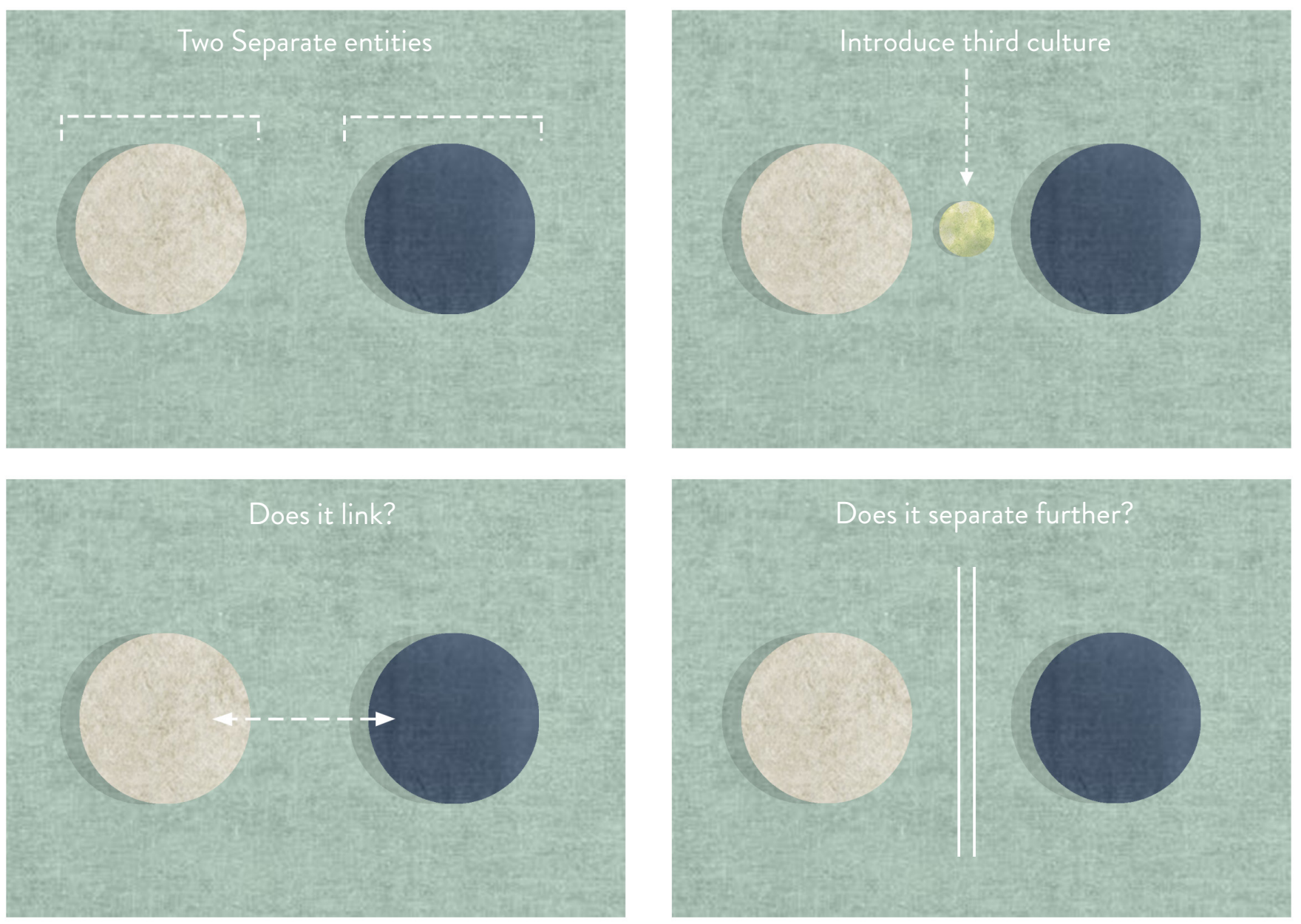

How will the relationship between the sites past present and future interact with each other? 

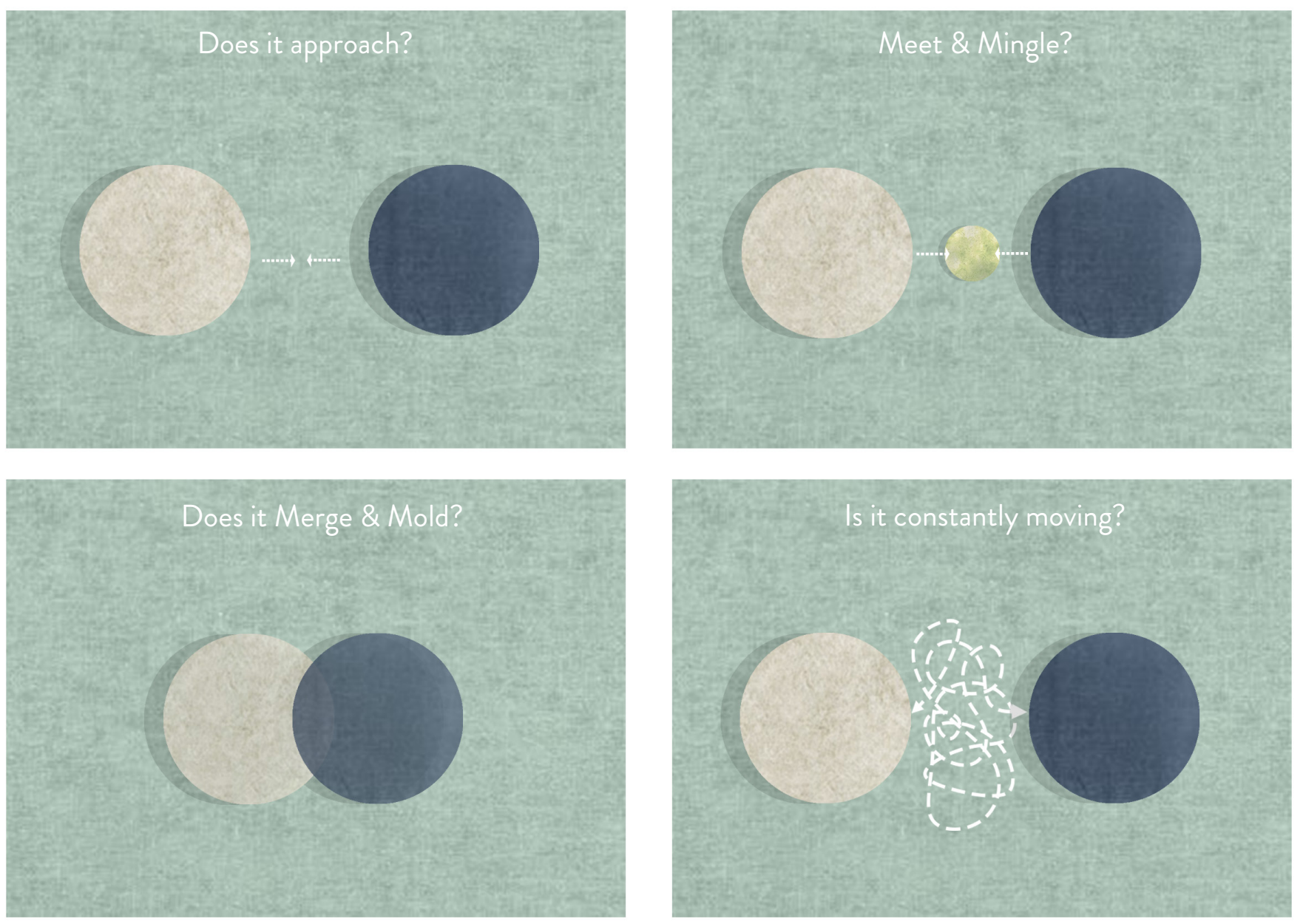

Figure.7.12: Relationship between cultures diagram 


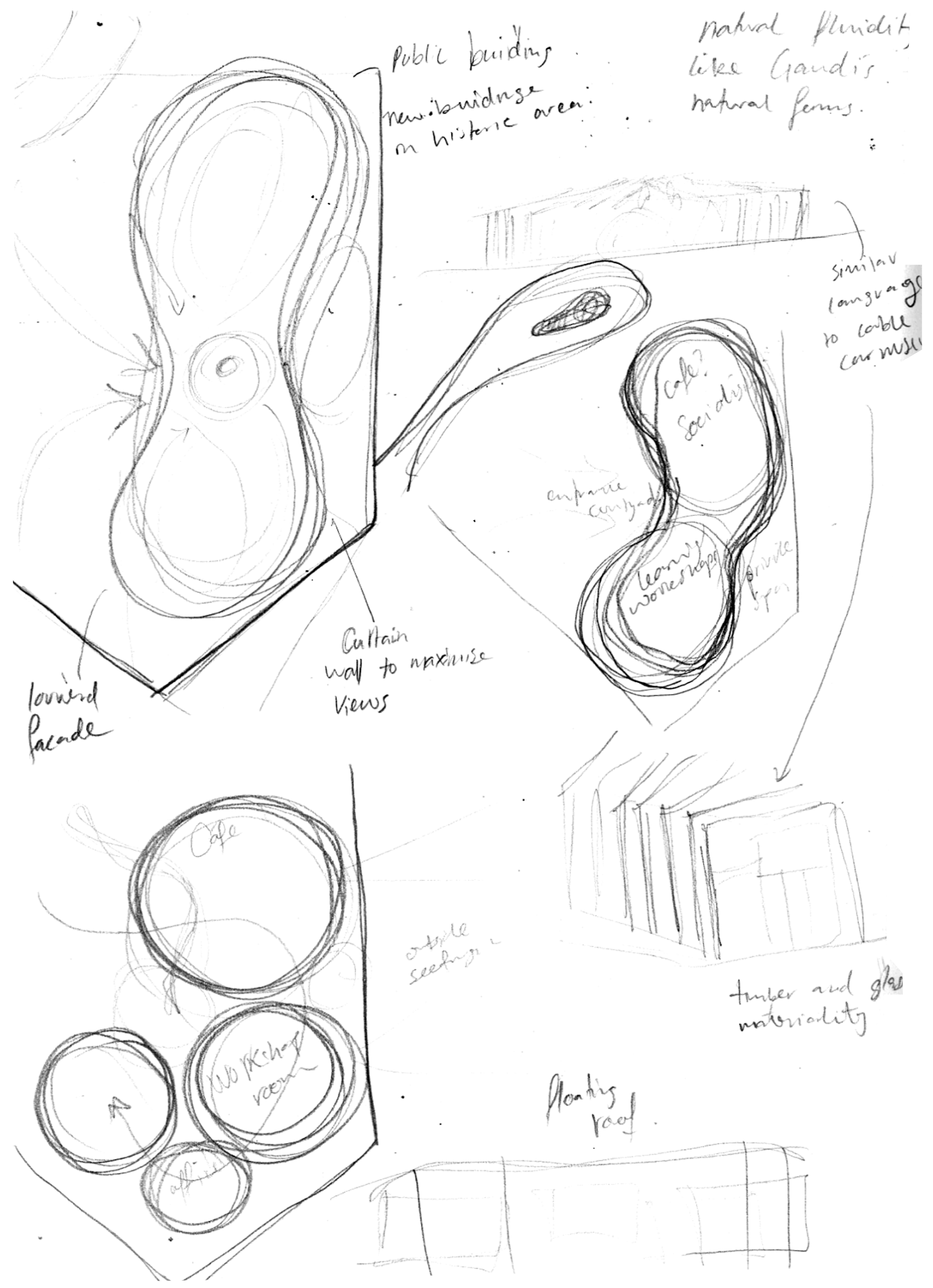

Figure.7.13: Sketch development 

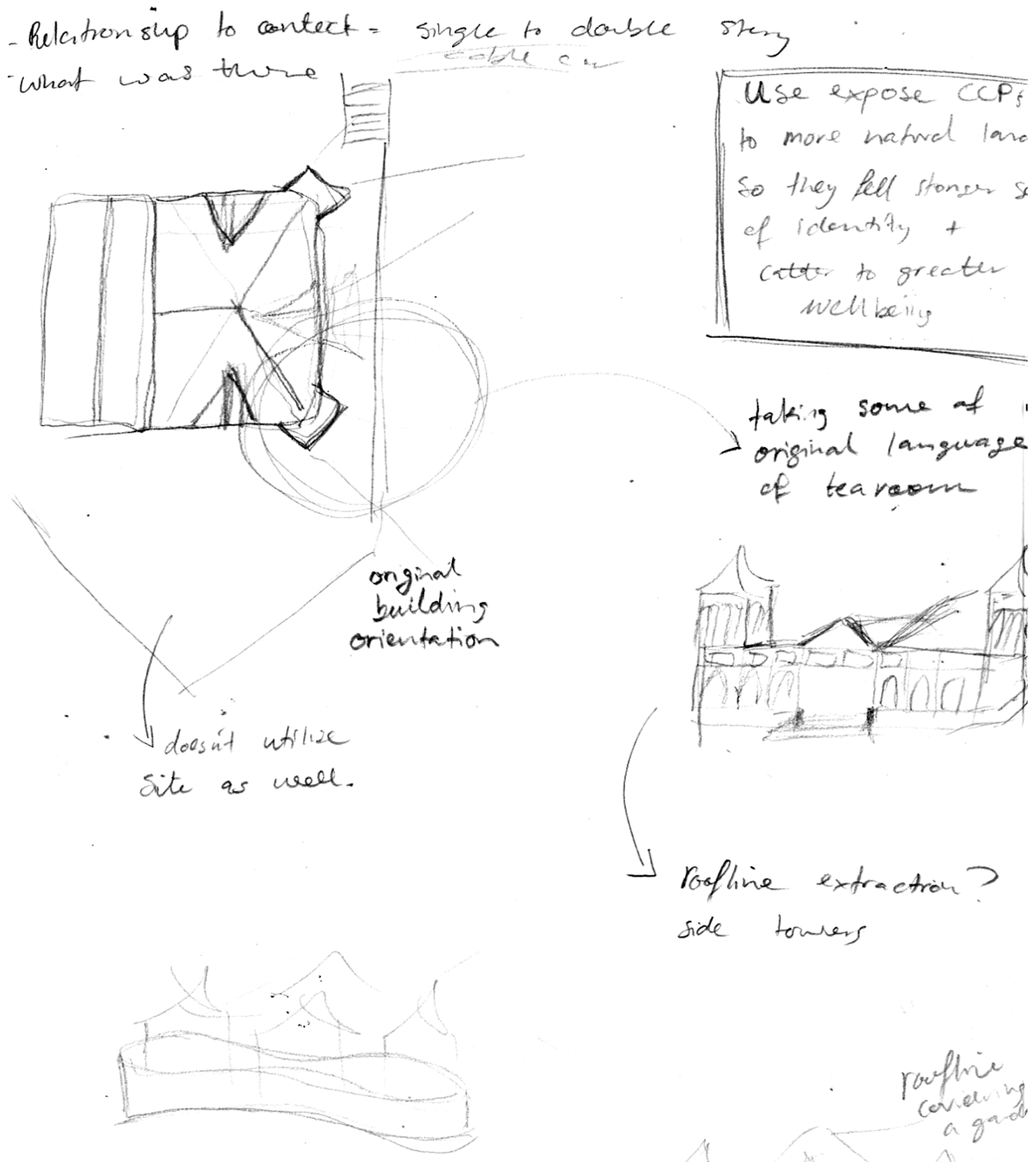

side towners
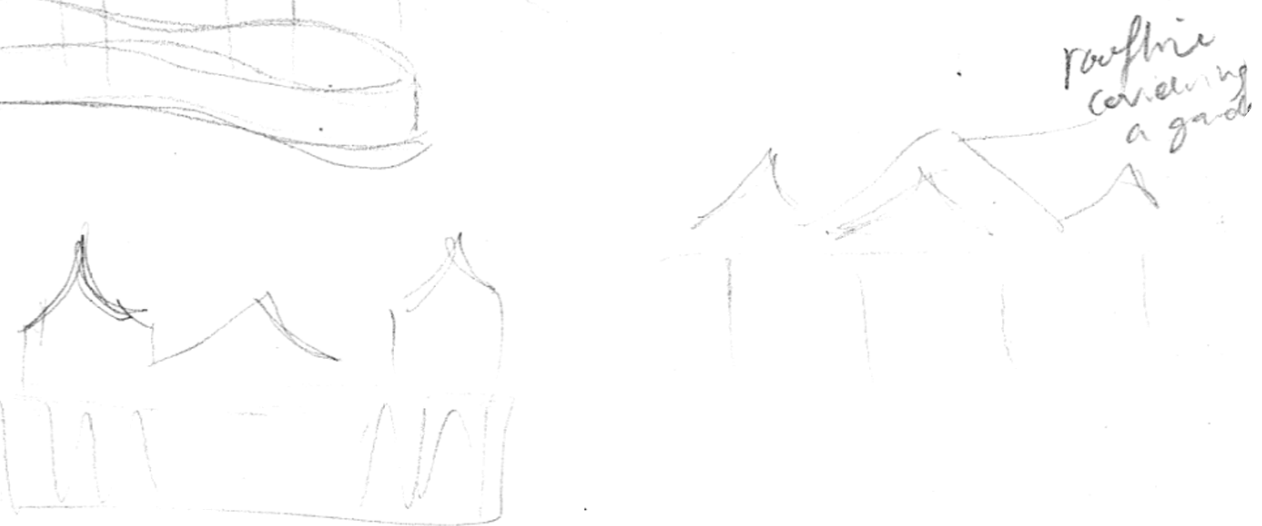

Figure.7.14: Sketch development continued 
maori Mare

inference : $\psi^{e d w a r d i a n}$ influence.

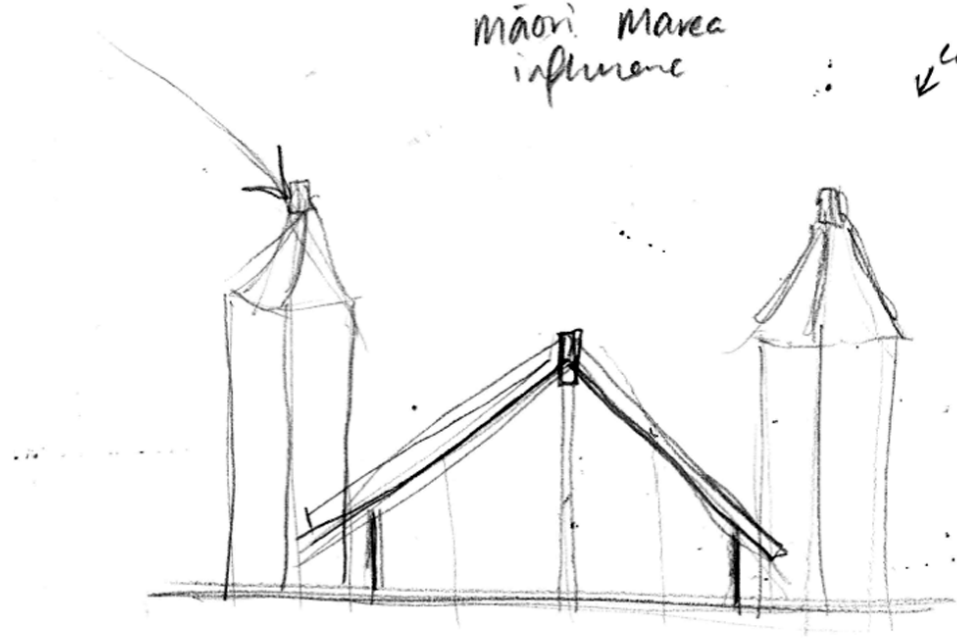

facade? facing Upland or Hab our?

maybe flow plans the same.
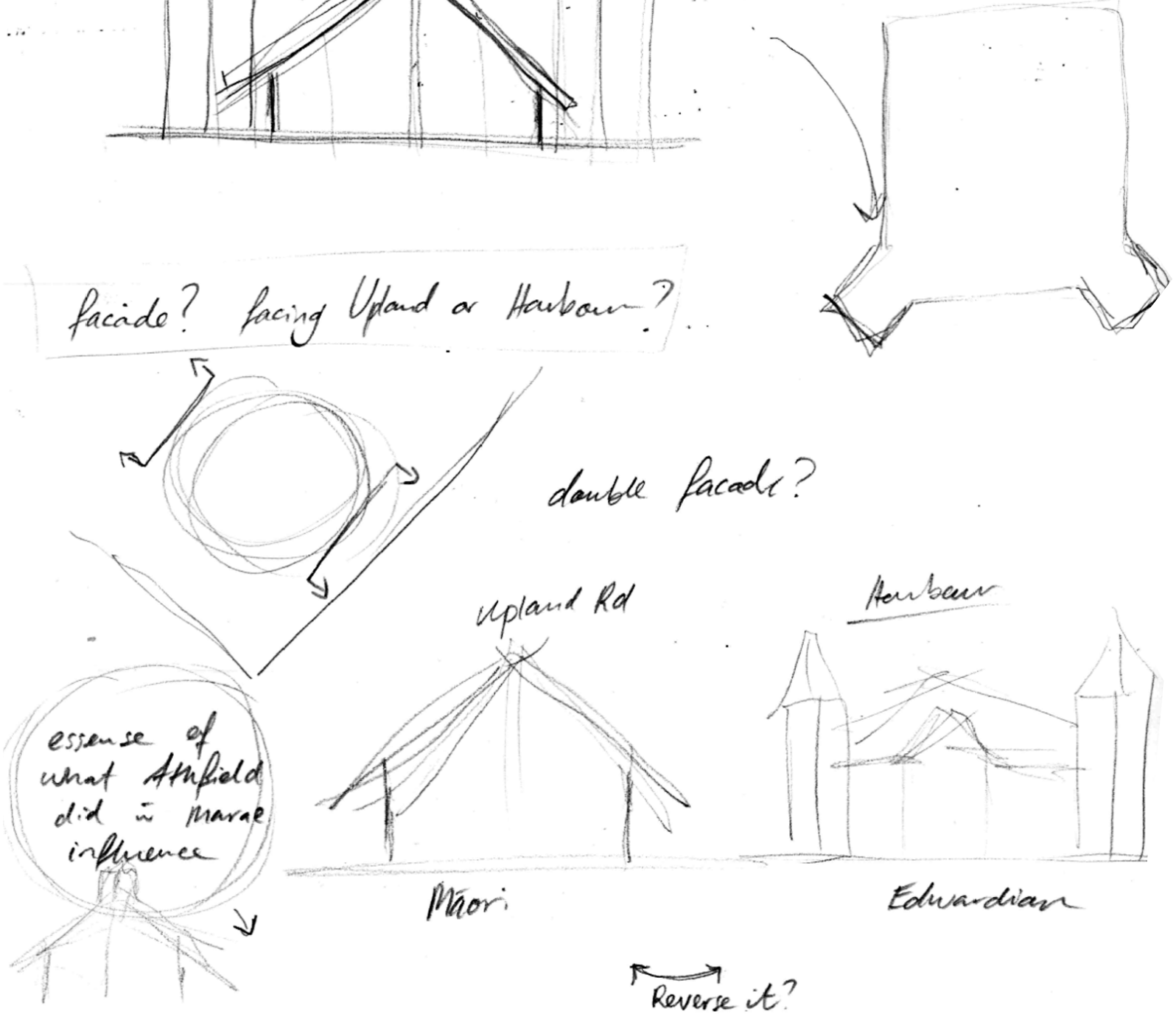

double facade?

4. upland Rd Hen bar

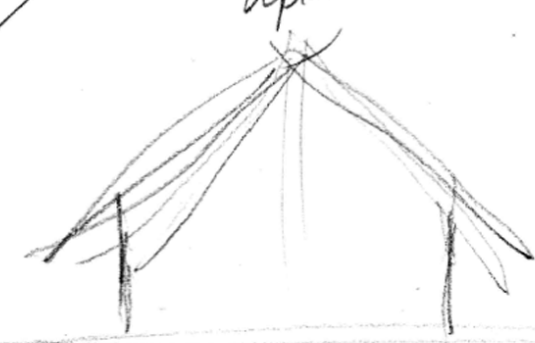

Manor:

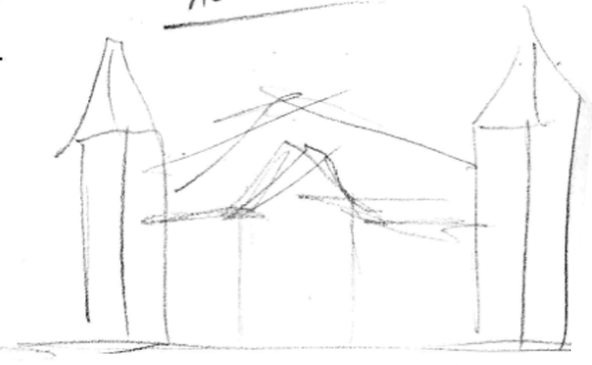

Edwardian

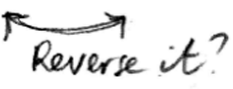

a layering + transition of cultural expression

Figure.7.15: Sketch development

68 
Materiality? timber + glass (precedents glass constructive)

original

modern + allows for mere views while literally expressing transparency between cultures.

Replicate original Edwardian building?

Replica's?

Not related to cos cutlery to fir

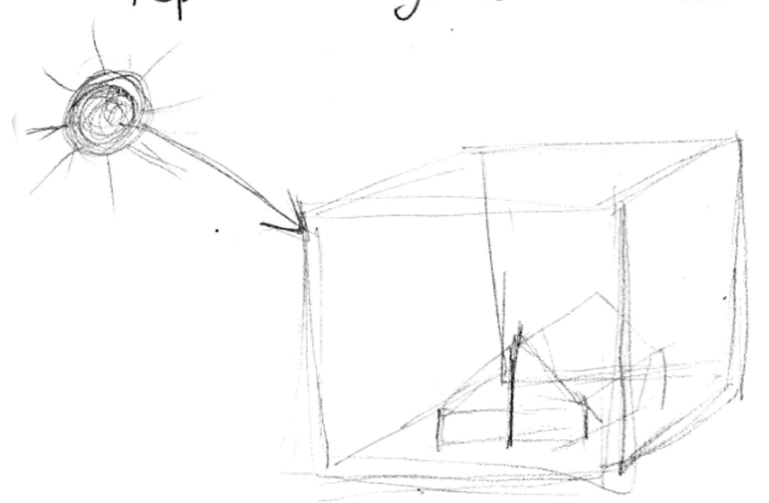

glass box for expression glass keri.

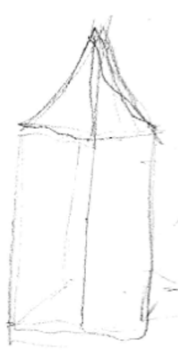

son w er wing ?

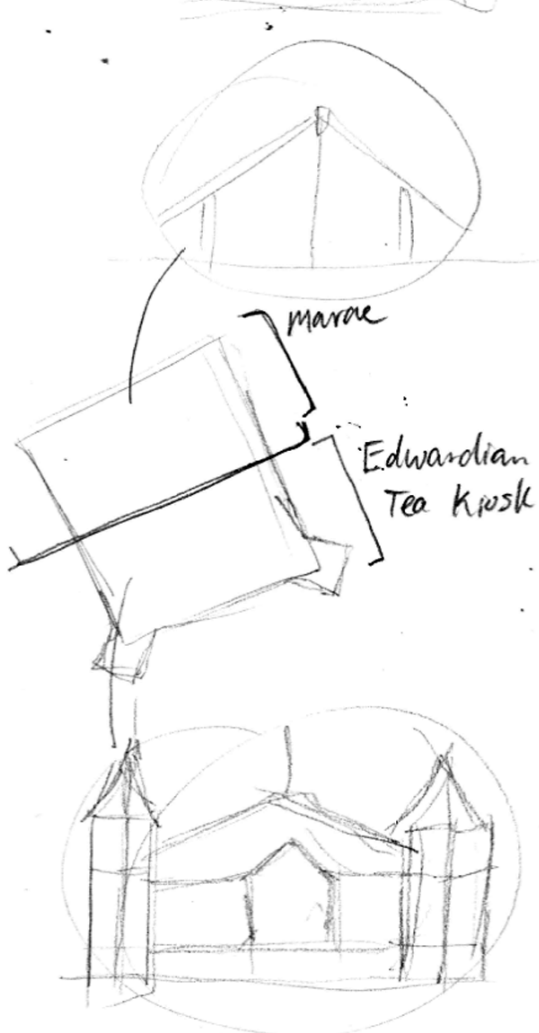

Mari + European influenced structure to hanse discussion an cross - culture

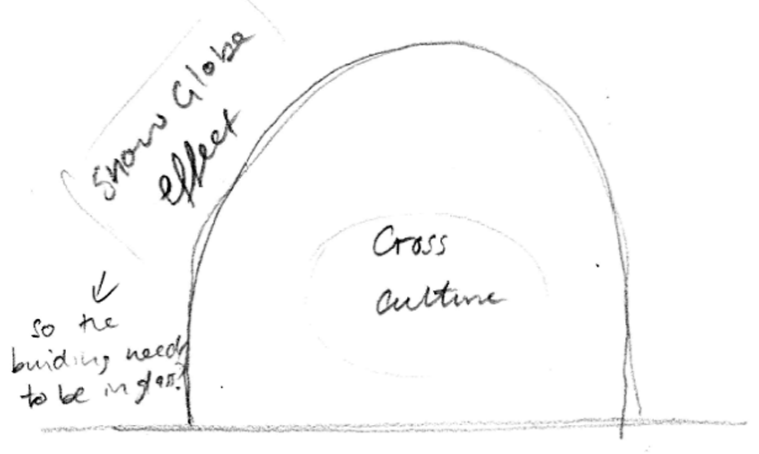

Figure.7.16: Further sketch development

69 


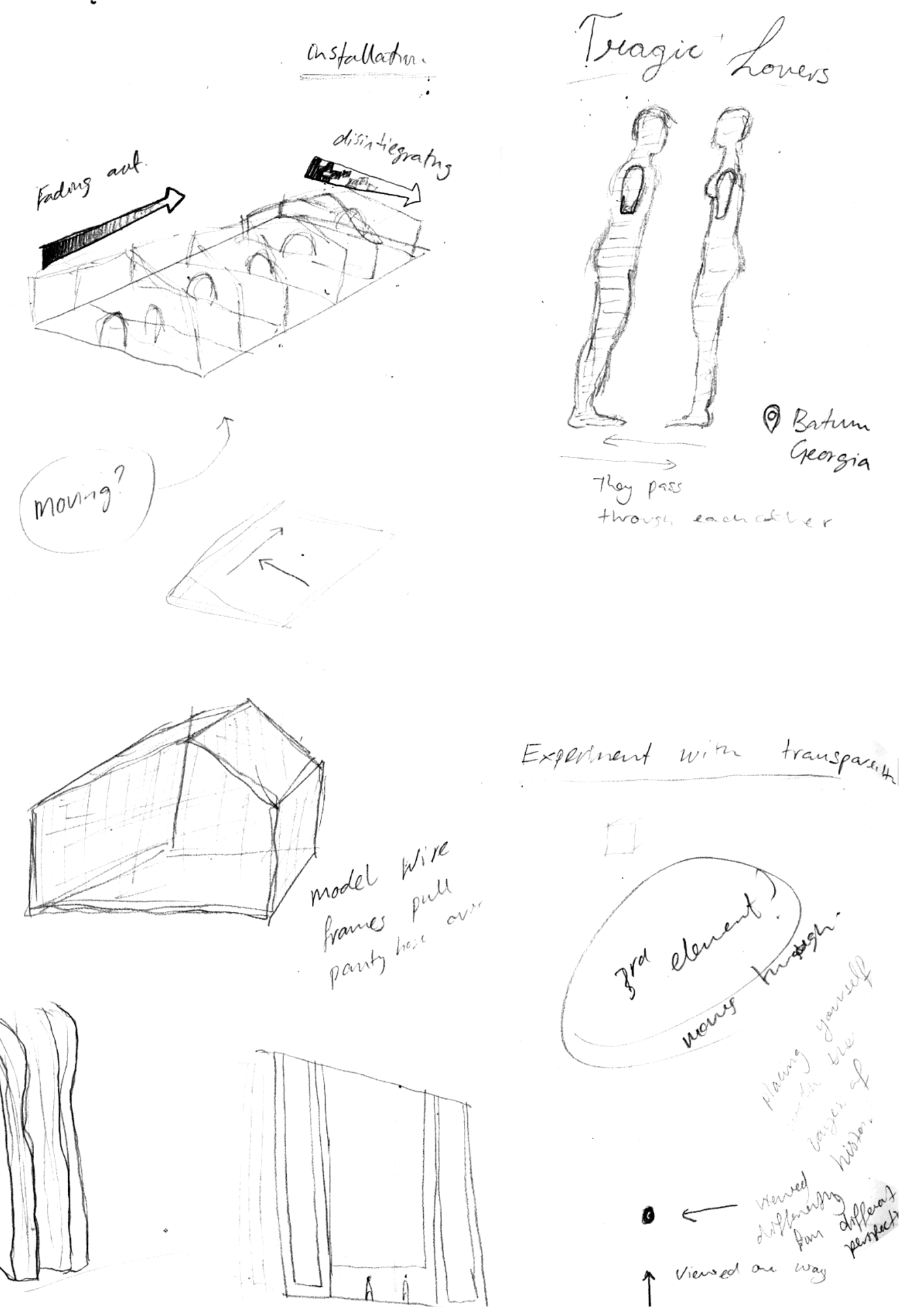

Figure.7.17: Sketch development 
no righ
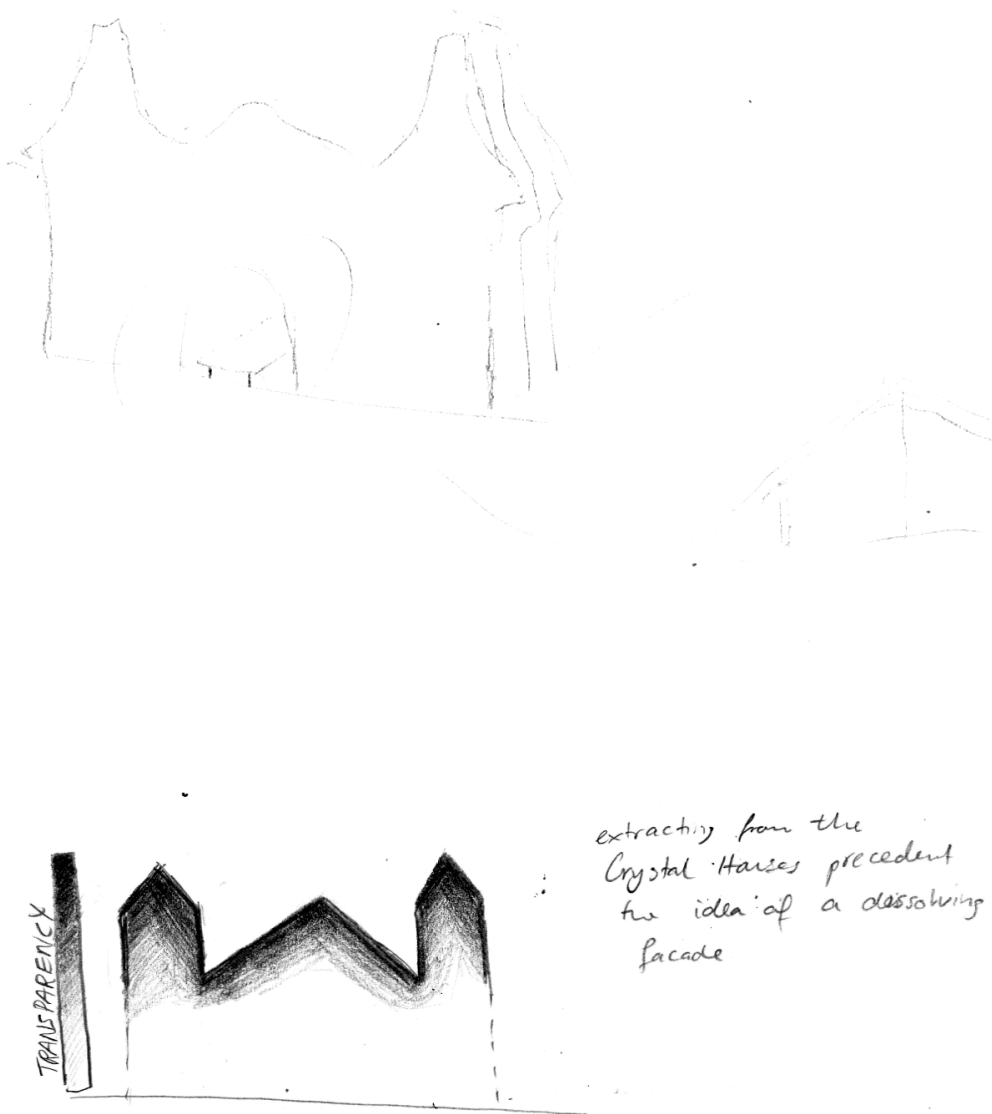

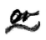

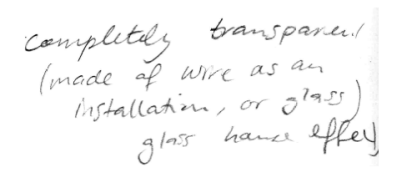

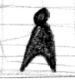

Figure.7.18: Sketch development continued 


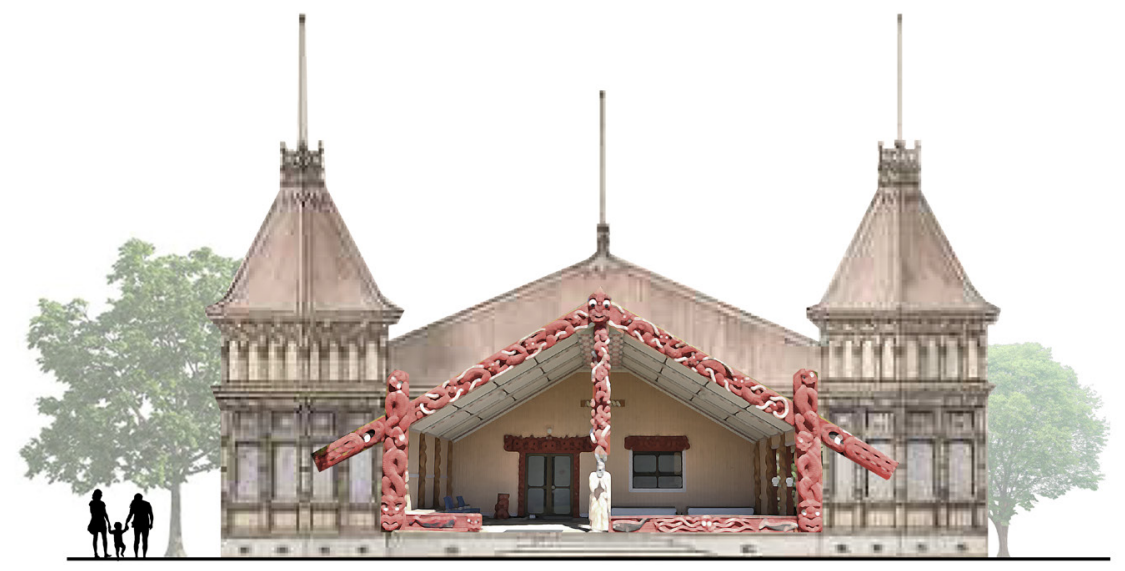

Layering of past structures
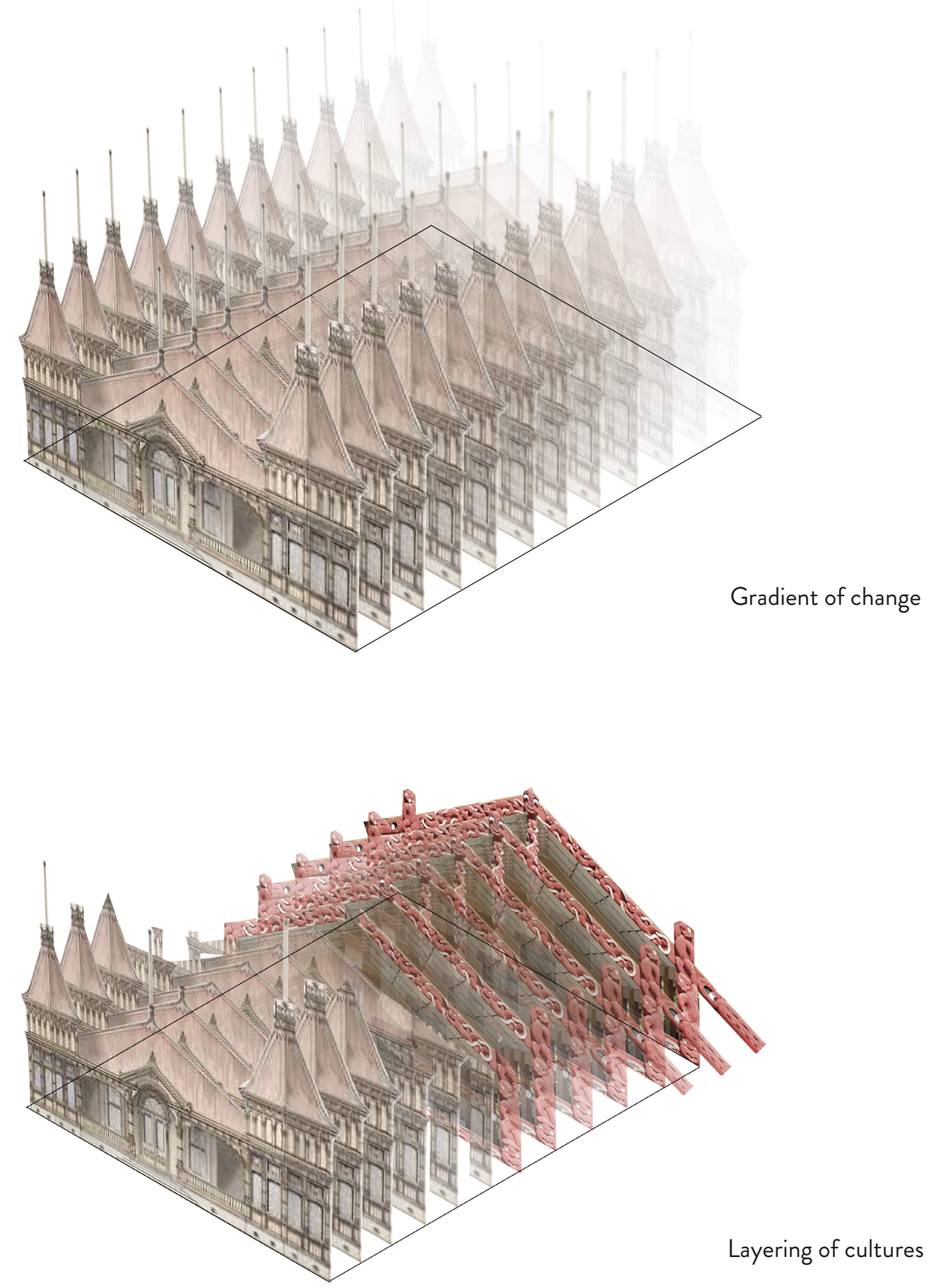

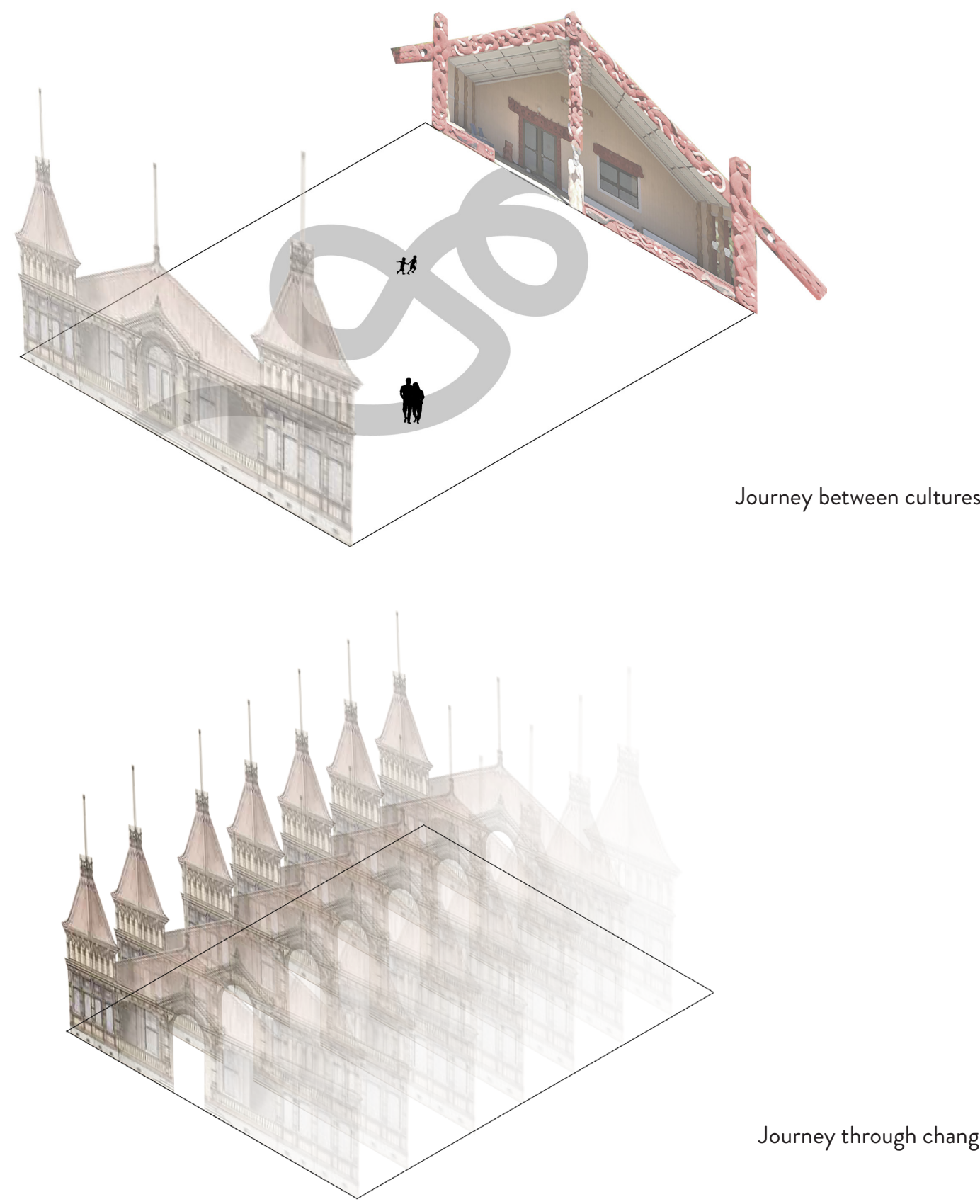

Journey through change

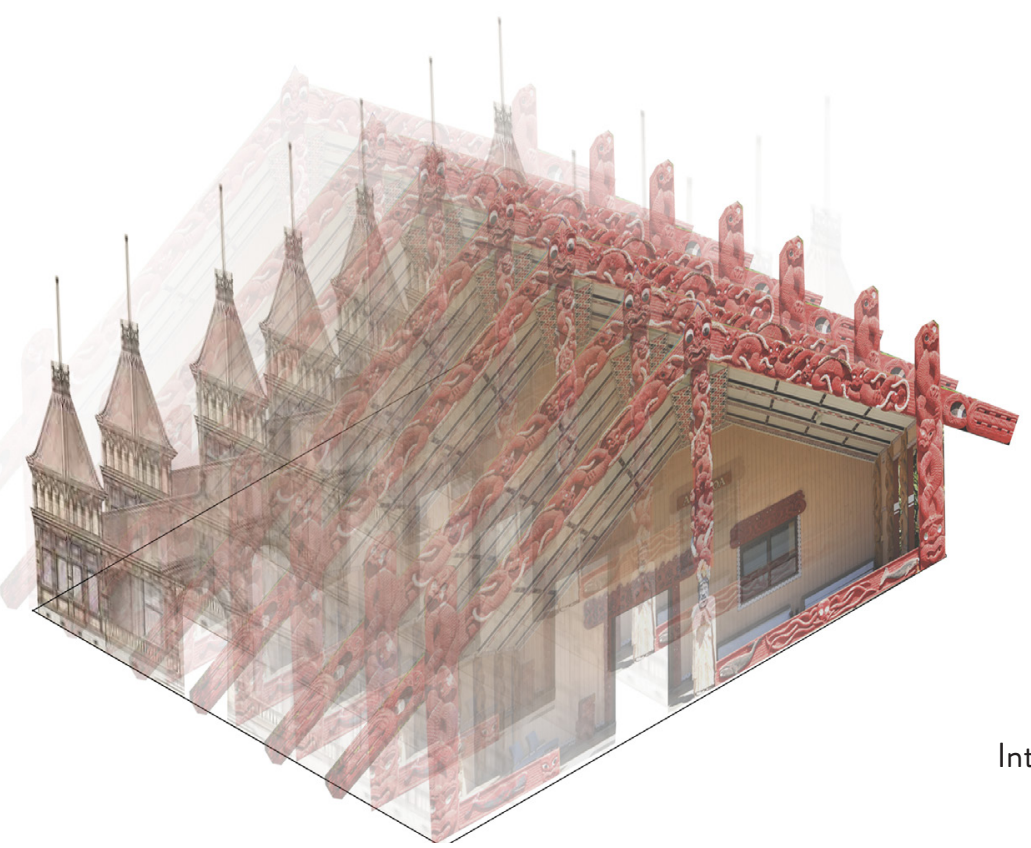

Interlocking of change

Figure.7.19: Collage iterative development 

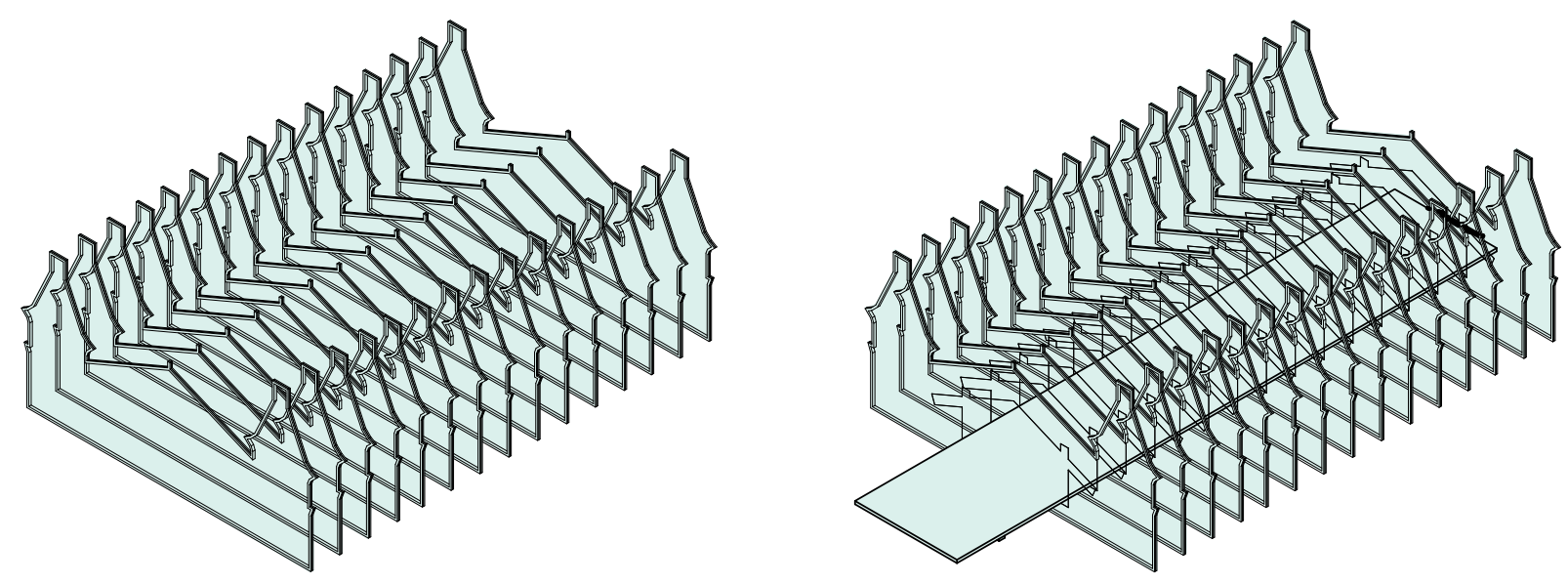

2

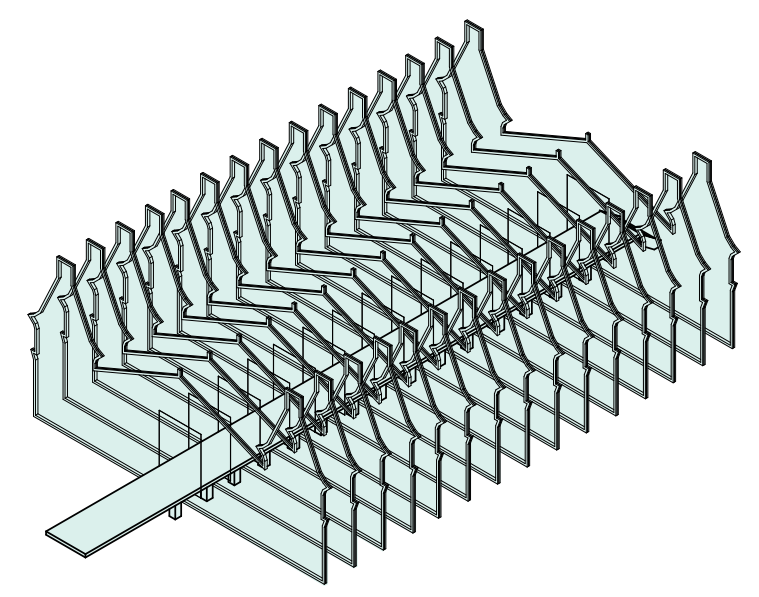

5

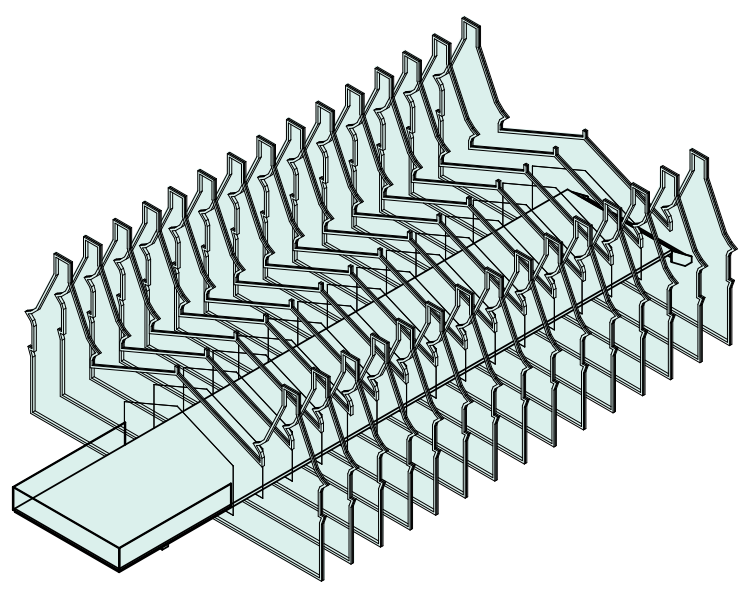

3

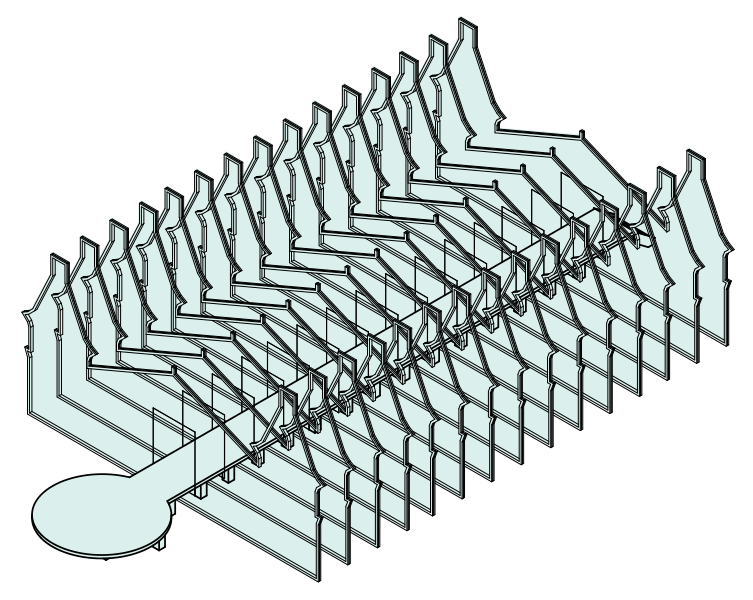

Each iteration plays with the idea of merging past structures of the site. The literal form of the Marae to the simplistic gable form used to inspire the opening of the installation 


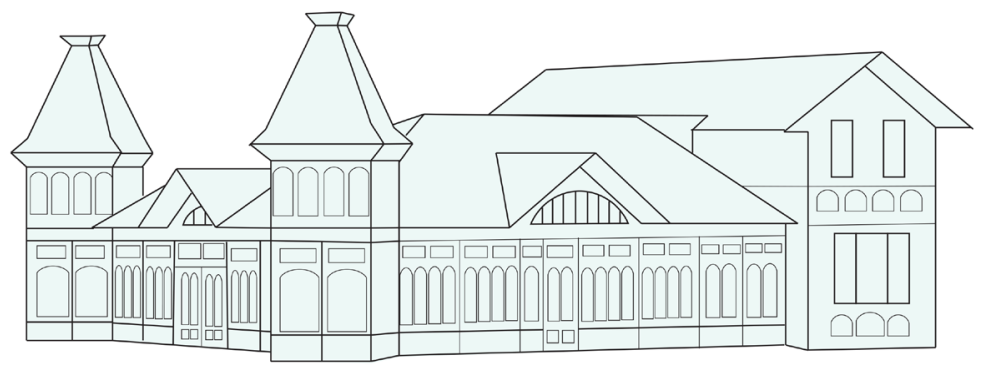

Using transparency on the form

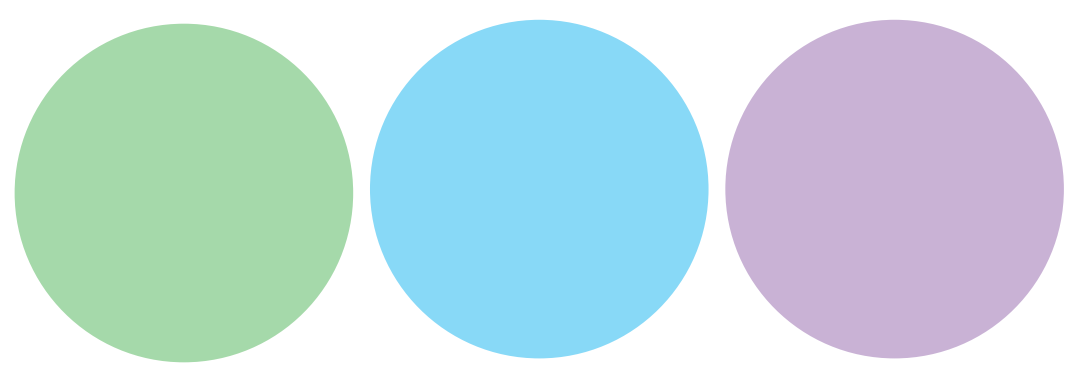

Applying colour for diversity

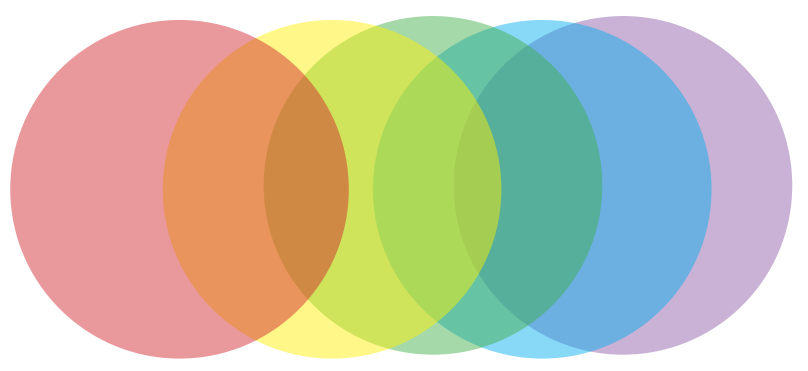

Overlapping the colours

Figure.7.21: Colour exploration 


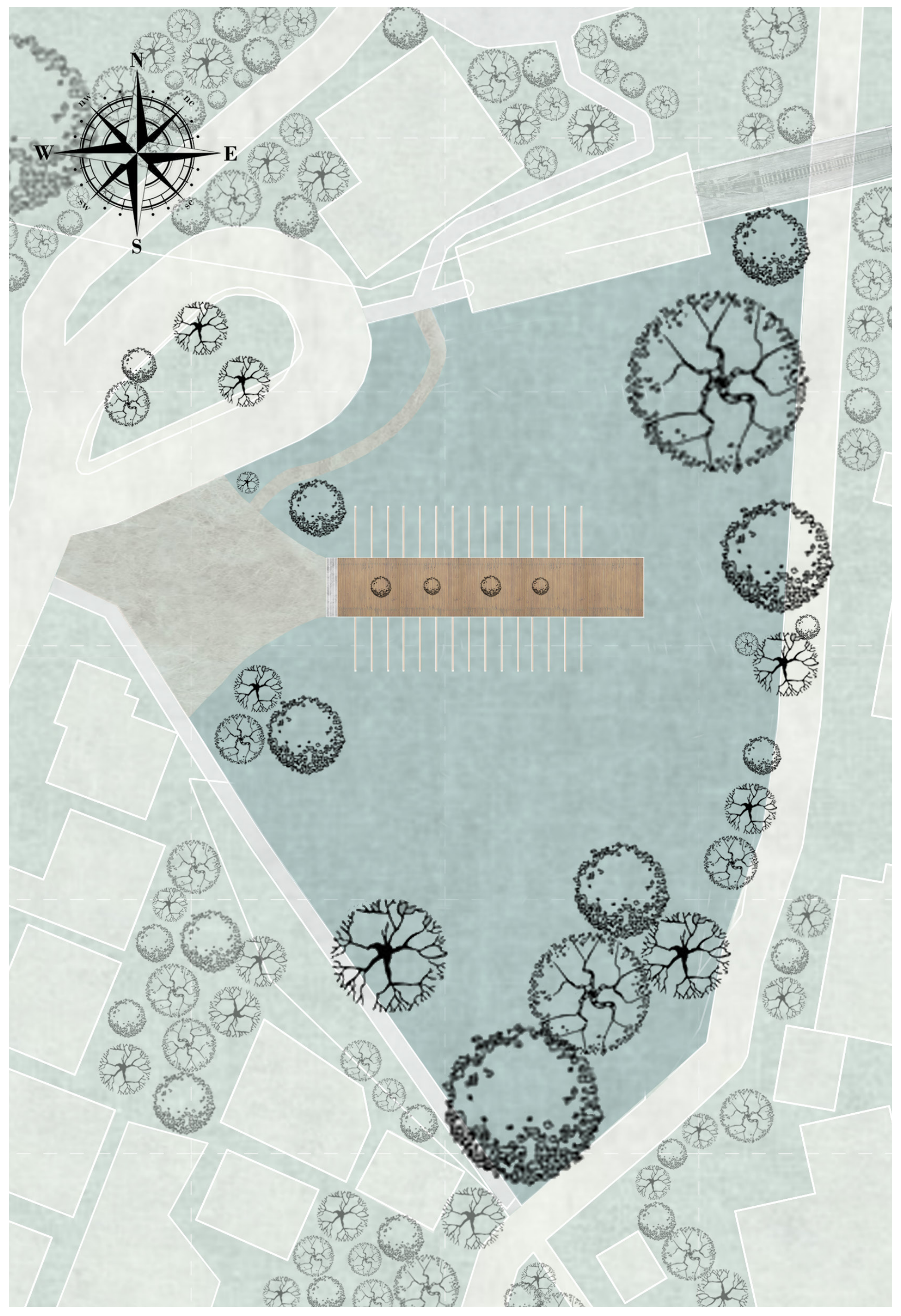


A Cross Cultural Installation 


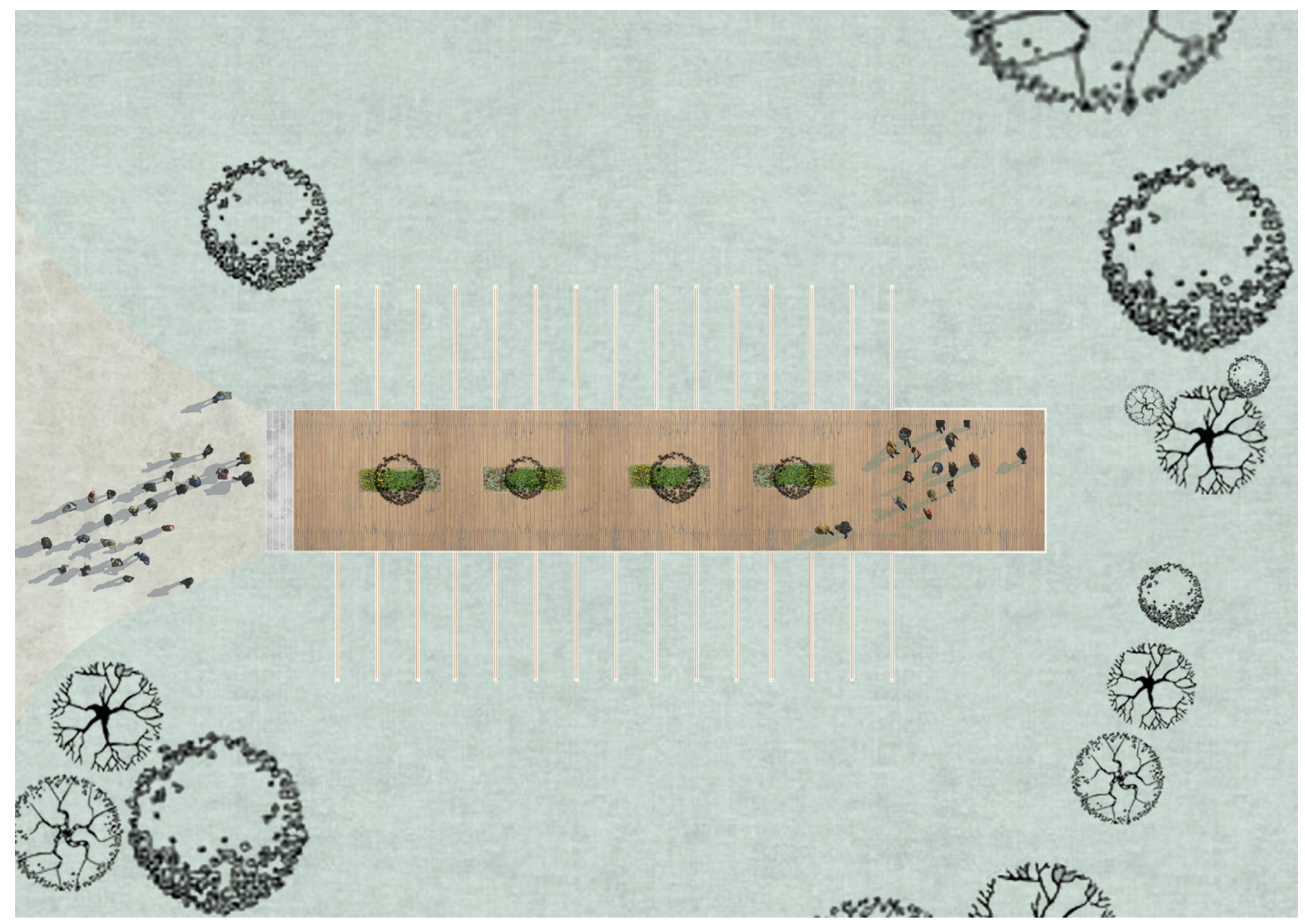

Figure.7.23: Floor plan 


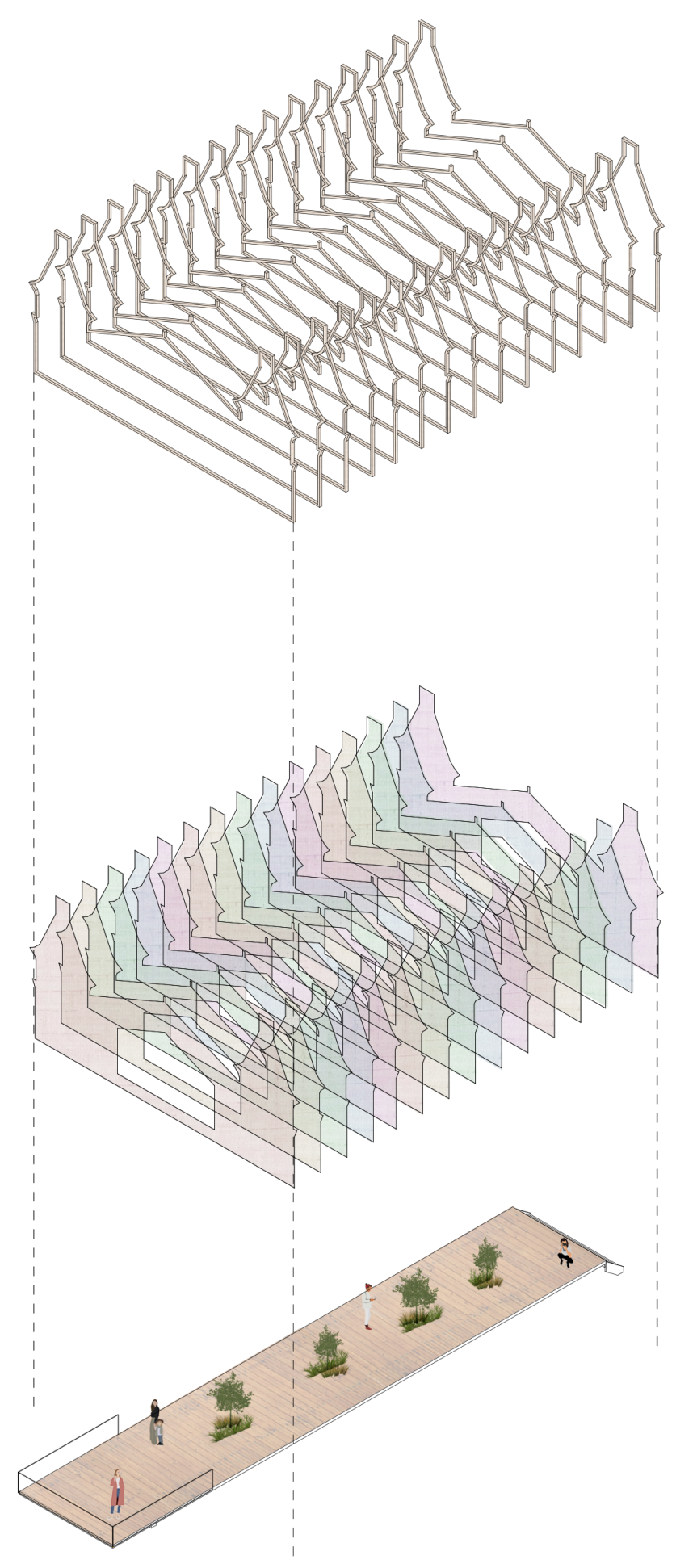

Figure.7.24: Exploded axo 


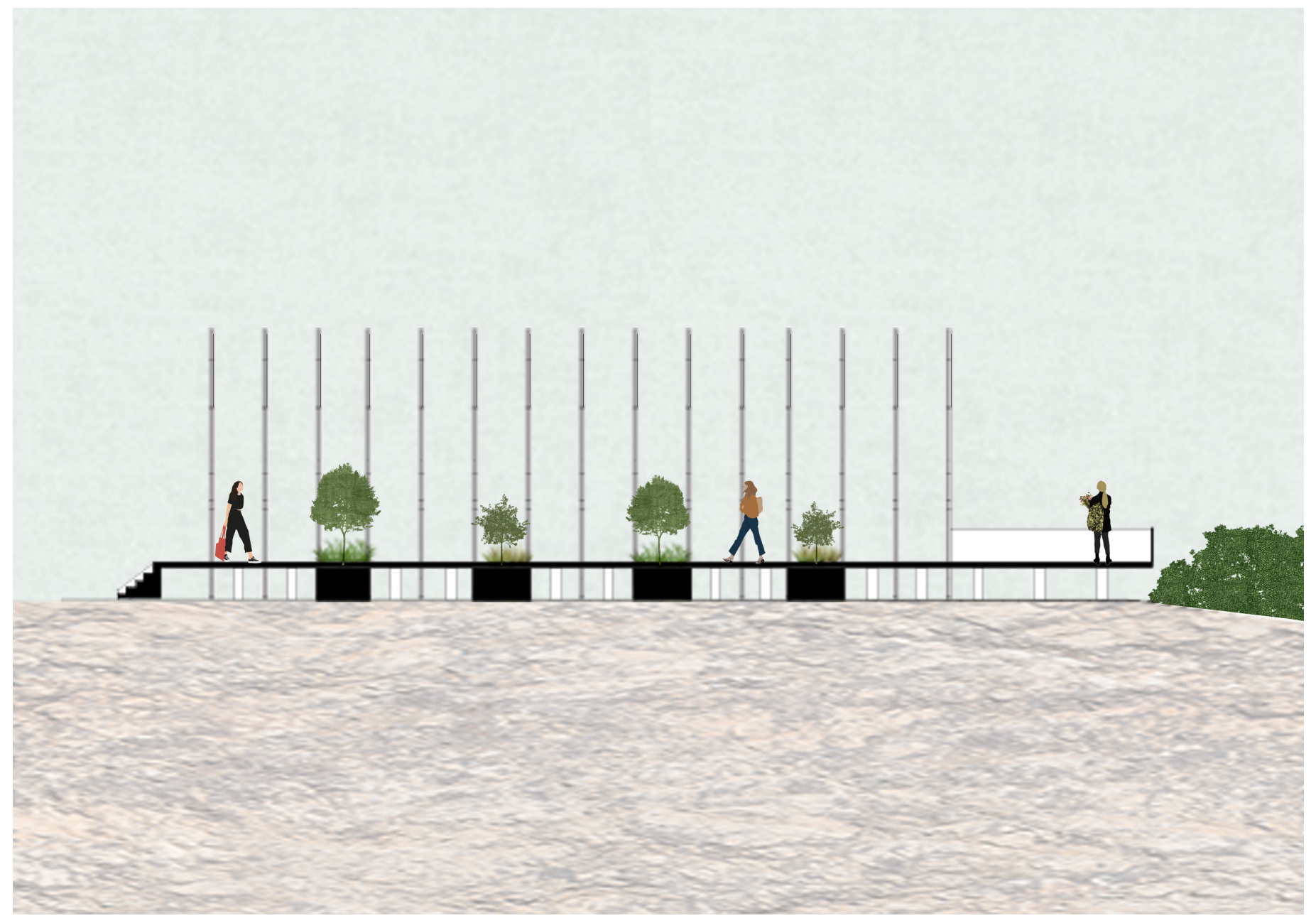

Figure.7.25: Section 


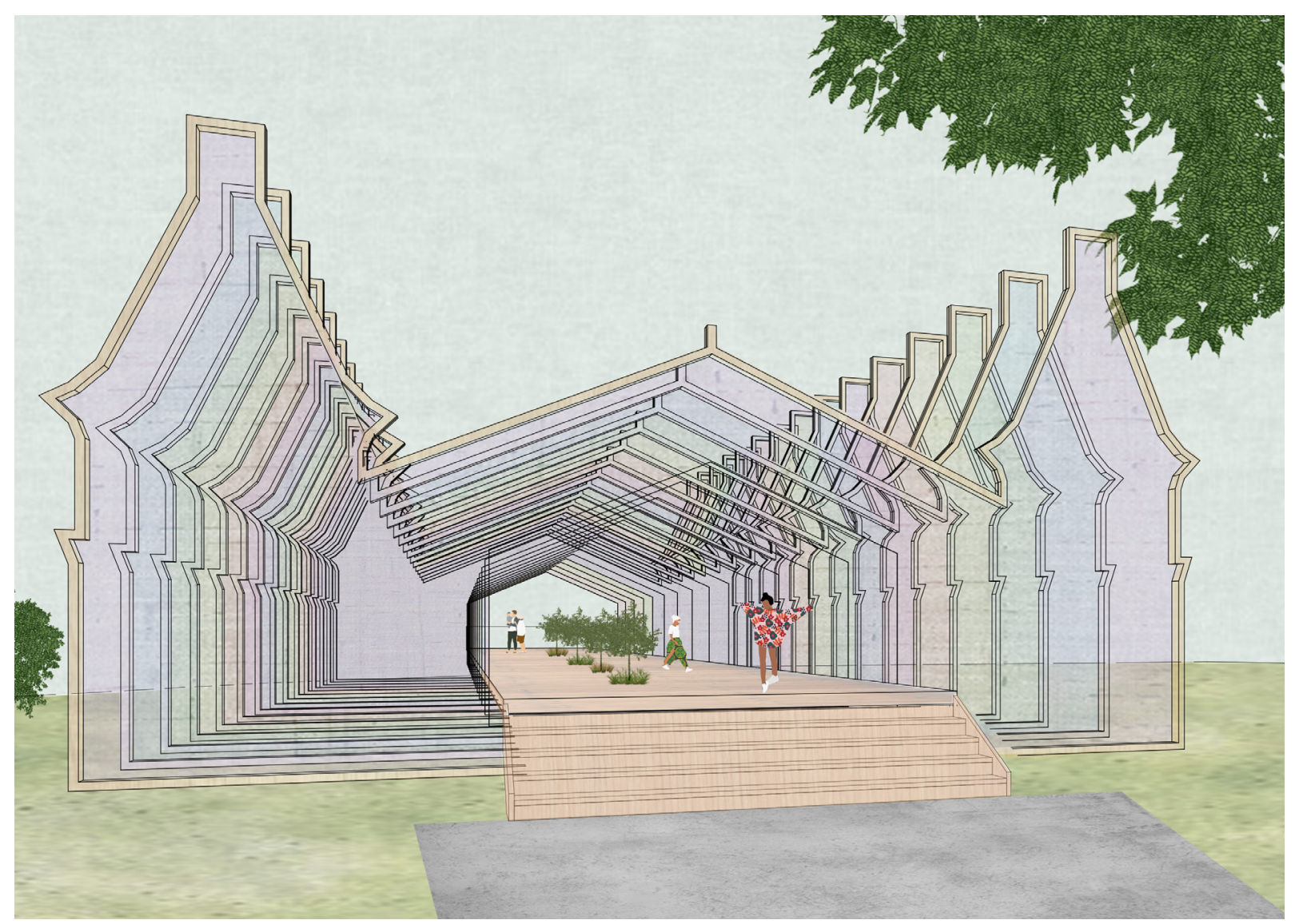

Figure.7.26: Entrance to the installation

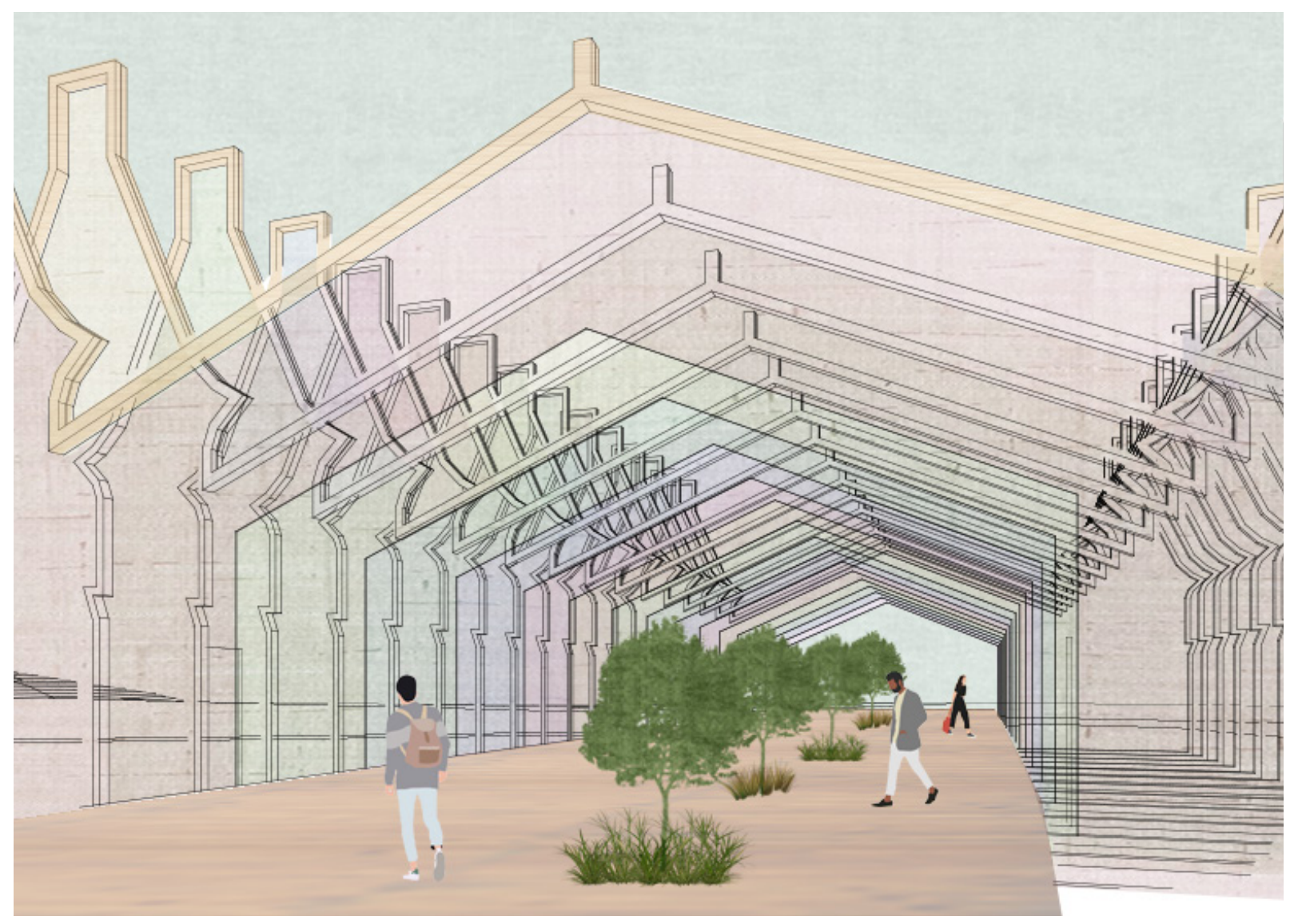

Figure.7.27: End of Installation 


\section{FRAMEWORK CRITIQUE}

$\mathrm{T}$ he site and tea kiosk referenced for this iteration was able to complete all criteria for site selection. The site is already a busy tourist destination as it is closely located to the cable car and the botanical gardens. The building also has a strong connection to the local heritage of the area and was regarded as unique.

The site also has a tie to the cultural identity of Wellington, being the site of a previous $P \bar{a}$ site and an iconic public building. Its proximity to the Wellington botanical gardens and striking view of the harbour sufficiently meets the natural landscape criteria. Lastly, the essence of mobility is brought by the cable car neighbouring the site.

Moving on to the design tactics, this iteration completes only half of the frameworks criteria.
It covers the multicultural aspect from an awareness point of view as it acknowledges that both Māori and early Pākehā occupied the site. The iteration also uses education as a way to show respect and to communicate the multicultural society that New Zealand is.

Although it does not accommodate any natural elements into the design, it can be argued that the openness into its surroundings and its use of the view is its inclusion of nature. The design also plays with the narrative of change. Change of cultures, change of structure and change of occupants.

\section{SITE SELECTION}

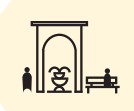

PUBLIC

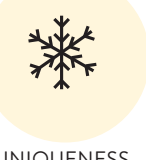

UNIQUENESS

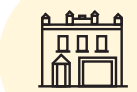

LOCAL HERITAGE

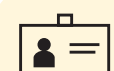

CULTURAL ID

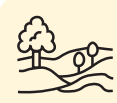

NATURAL LANDSCAPE

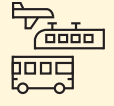

MOBILITY

\section{DESIGN TACTICS}

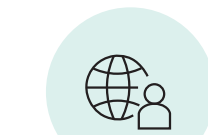

MULTI/TRANSCULTURE

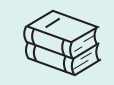

EDUCATIONAL

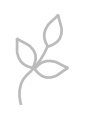

NATURE

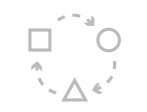

ADAPTABILITY

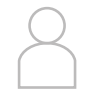

PERSONALISATION

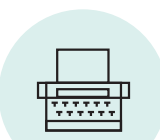

NARRATIVE ELEMENTS 


\section{REFLECTION}

$\mathrm{T}$

his iteration also stands on a subcategory of the spectrum of heritage conservation. It follows a loose replication stance; all be it an abstract one at that. Although the building is no longer there it still is a part of the site's history, much like the previous Māori Pā.

The inclusion of Māori elements is weak but deliberate. It was done this way as not to mimic or disrespect the culture. The design also uses transparent materials as a language to speak of the acknowledgment of all previous occupants of the site.

Overall, the design is simplistic with a basic structural arrangement and could be regarded as a safe intervention.

It is a good first step into exploring this cross-cultural approach to heritage conservation. However, moving forward the next iterations should aim to implement more design criteria.
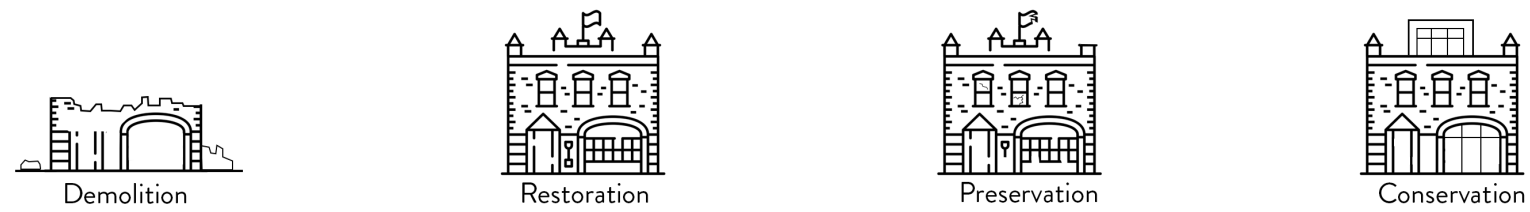

8. Iteration Two

\author{
History \\ Precedents \\ Design Process \\ Reflection
}




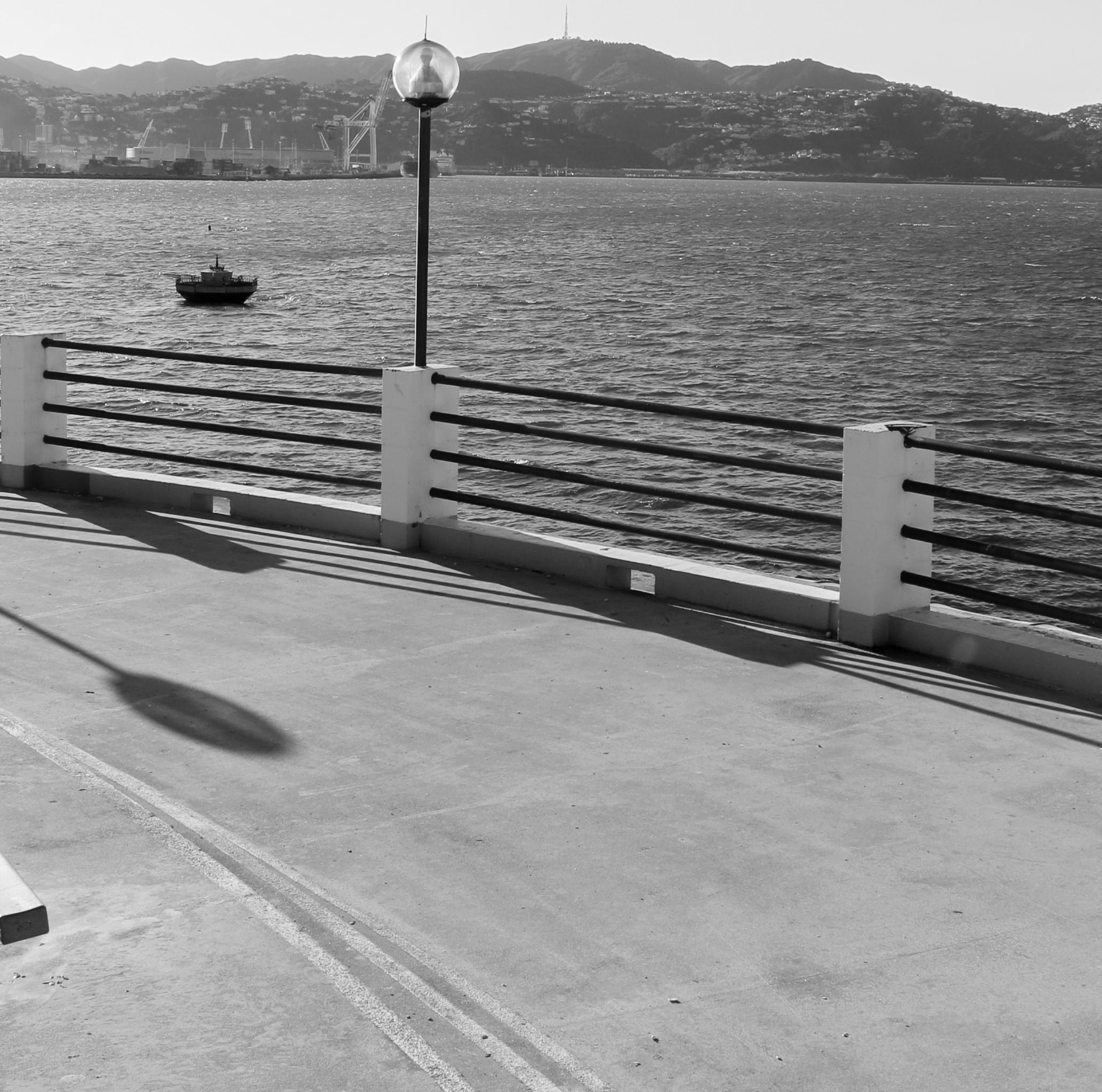




\section{BAND ROTUNDA}

245 Oriental Parade, Oriental Bay

Historic Place Category 2 


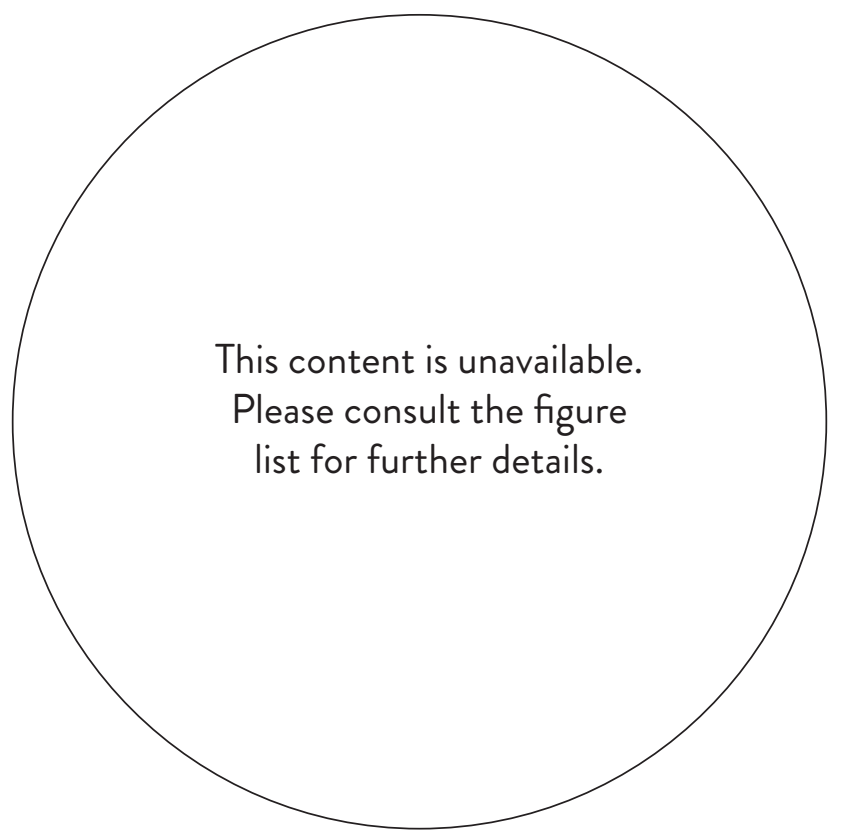

Figure.8.1: Wooden Band Rotunda 1930
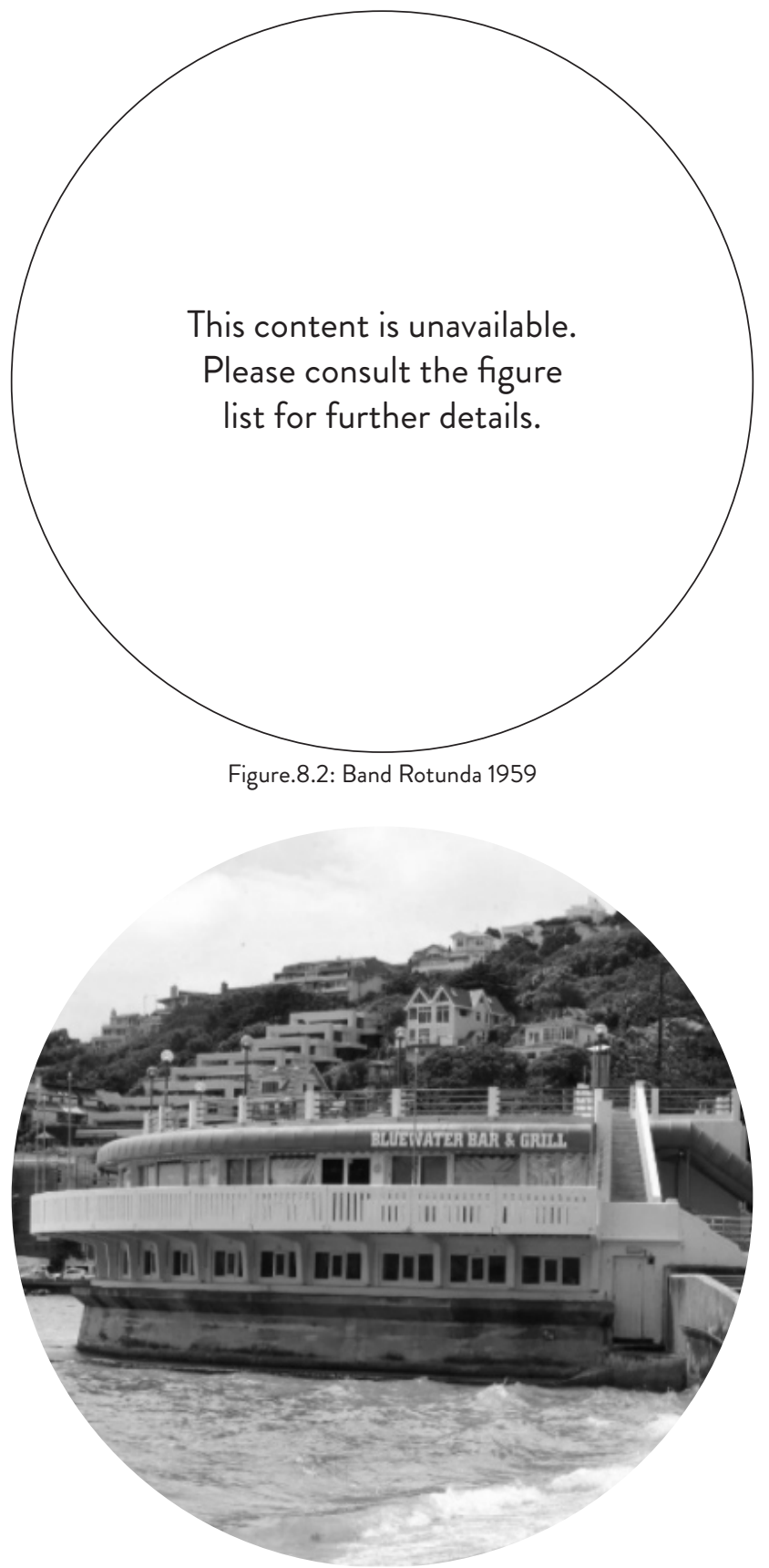

Figure.8.3: Current Building on Site 


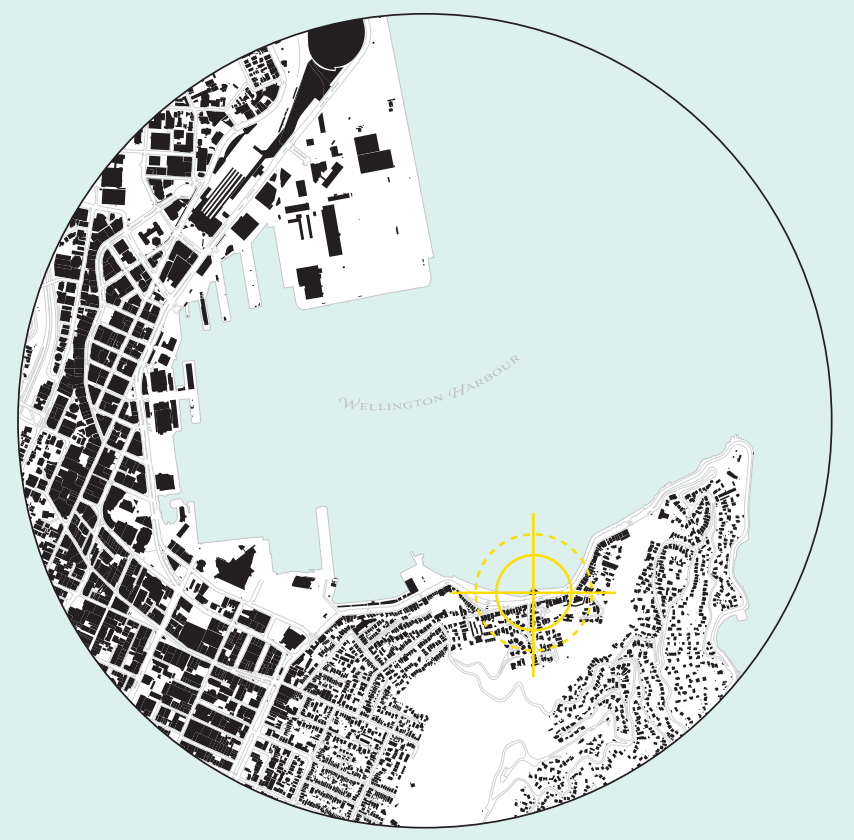


This content is unavailable.

Please consult the figure

list for further details.

Figure.8.5: 1921 Band Rotunda Renovations

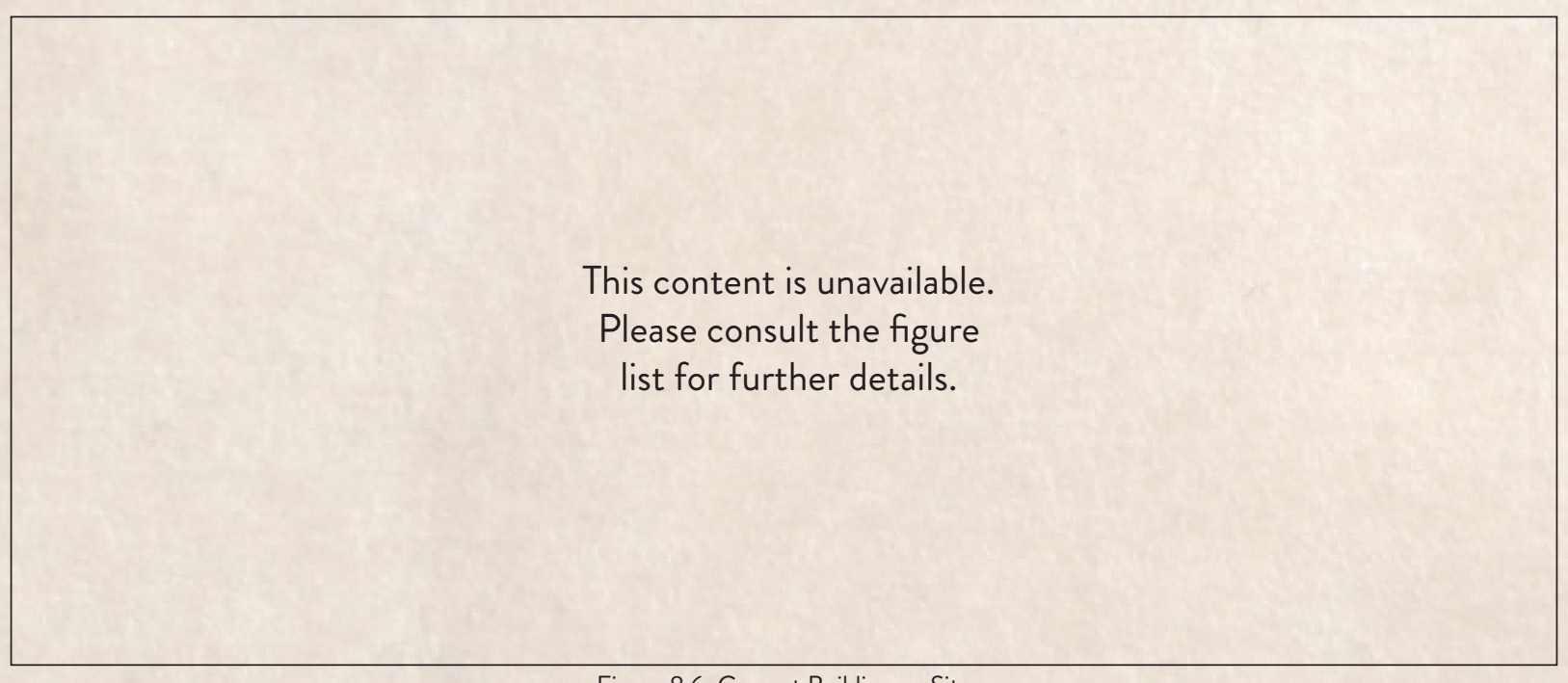

Figure.8.6: Current Building on Site 
This content is unavailable.

Please consult the figure

list for further details.

Figure.8.7: Band Rotunda Elevations 1936

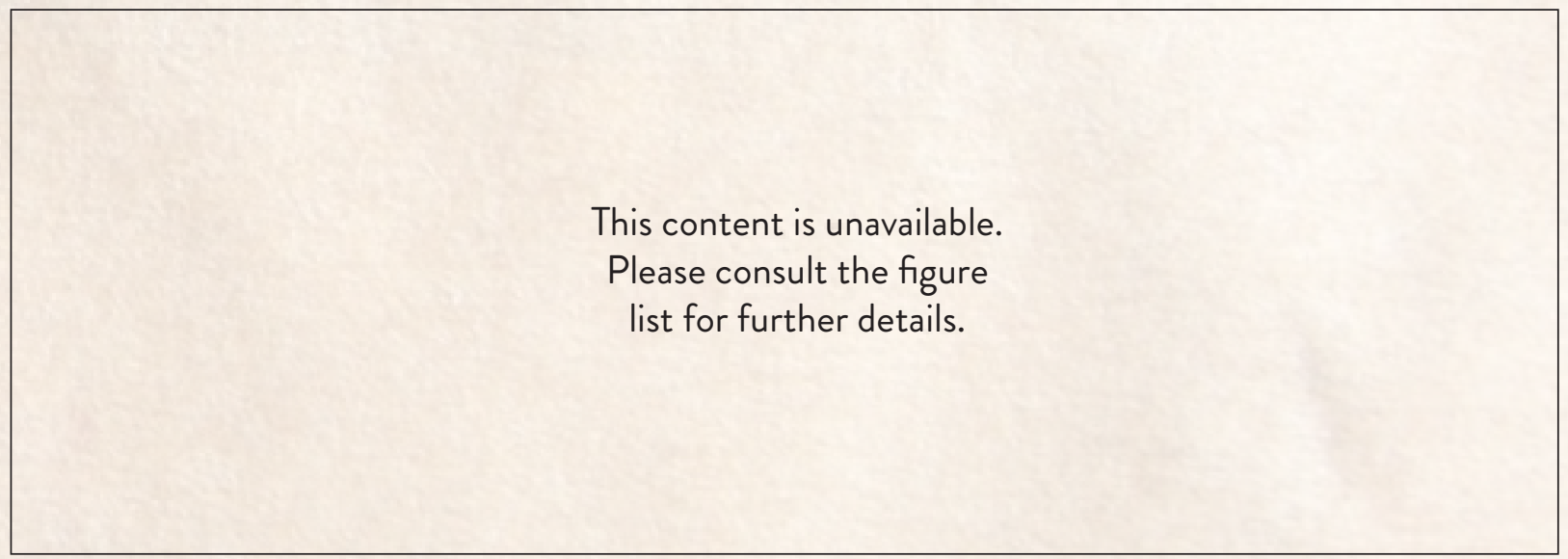

Figure.8.8: Band Rotunda Sections 1936 


\section{HISTORY}

$\mathrm{D}$ uring the development of Oriental parade in 1916, a sea wall was built along the bay and around a rocky outcrop. In 1918 a band rotunda relocated from Jervois Quay, was placed on the outfacing platform to give the public a comfortable place to sit, rest and listen to music. A decade later, the timber rotunda fell into disrepair with little maintenance and little use as bands moved their performances to theatres since cars driving along the parade ruined the band performances. The Band rotunda was moved to its third and final location in 1936 to settle in Brooklyn's Central Park (Oriental Parade Band Rotunda (Former), n.d.).

The Art Deco and Modern style building was built in 1937 from reinforced concrete to accommodate changing rooms and toilets for the beach goers. The building was built within the sea wall following the same semi-circular shape. Sand was brought to the beach every decade as it continued to be swept away by the sea (Oriental Parade Band Rotunda (Former), n.d.).
In the 1970s, discussions began to find alternative uses for the building. A second level was added to the building in 1985, to house a restaurant with a new rooftop look out area. The lower level was converted into a community meeting room and exhibition space. Several years later, in 2003, self-contained toilets were brought back and added to the building (Oriental Parade Band Rotunda (Former), n.d.).

Ultimately, in 2012 the building fell back into disrepair as structural issues started to surface in the heavy flooring after an earthquake.

This building continues to be historically significant as it has a strong connection to the early twentieth century development of the parade, a space for beach goers, as a restaurant and art centre. The rotunda also holds social value as an area for the public and as a space for shared recreational experiences (Oriental Parade Band Rotunda (Former), n.d.). 


\section{REASONING}

n Colomer's survey, cross cultural participants indicated what they considered important for building a sense of identity. The three aspects were 'Mixing of Different Cultural Heritages', 'Global Cultural Heritage' and 'Natural Landscape'.

The Rotunda represents the local heritage of Oriental parade and acts as a vessel to express multicultural identity giving people, especially Cross Culture People a place to gather as a group to enhance feelings of belonging and identity. The new Rotunda will act as a hub for CCPs, creating a place to facilitate the mixing of different cultures and celebrate the concept of global cultural heritage through the sharing of experiences and performance.

Natural landscape was one of the three most important aspects to building identity for Cross Cultural People. The Former Band Rotunda sits on the edge of oriental parade and over the sea. This creates a third space resembling how CCPs live in a third culture where they constantly have to negotiate their identity. 
This content is unavailable.

Please consult the figure

list for further details.

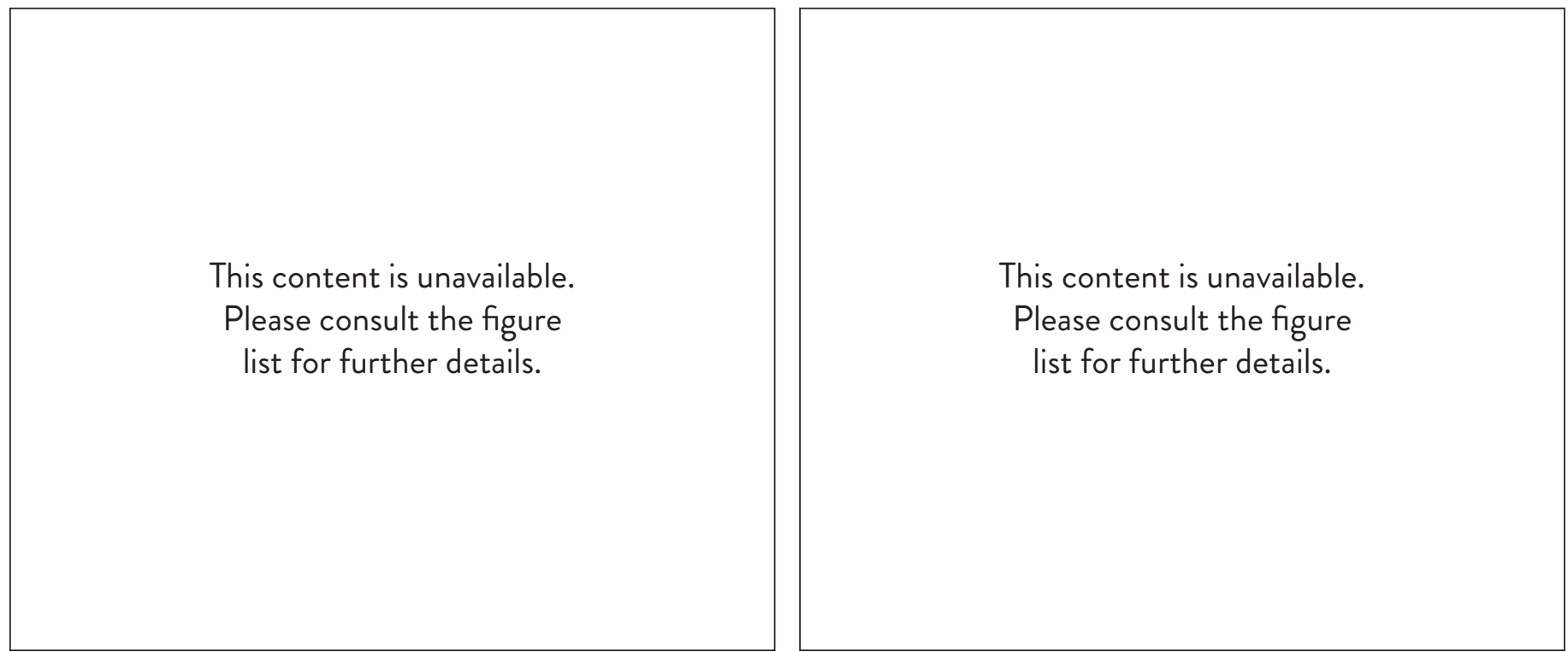

Figure.8.9: Palace of Culture 


\section{PALACE OF CULTURE}

$\mathrm{T}$ his "Palace of Culture" was designed by Archiproba and is located in Zheleznovodsk, Russia. This luxurious example of a cultural centre was commissioned by the Tourism Council and was built in 1982. This twelve-thousand-meter building is a fine example of Brezhnev's era architecture. The rectangular shape of the building is inspired by the modernist style with a recessed glass volume sitting within. The form of the structure creates a central atrium topped with pyramid skylights to penetrate the building with light. Monumental, embossed copper panels sit above the main entrances (Pintos, 2019).

The buildings restoration takes great care of the historical object paying special attention to the material heritage.

The building accommodates a cinema, concert and lecture hall, dance halls recreational areas, educational and exhibition spaces, chess club and library (Pintos, 2019).
This project uses an existing heritage building and uses it to house a conversation of culture. Taking specific care of the interior material details to create a luxurious space to house such an important topic in today's world.

This precedent expresses the importance of open flexible spaces. The centre has a wide variety of programs that all facilitate the learning and communication of cultures. This gives an idea of the types of rooms that could be included in the band rotunda. 
This content is unavailable.

Please consult the figure

list for further details.

This content is unavailable.

Please consult the figure

list for further details.
This content is unavailable.

Please consult the figure

list for further details. 


\section{DAOÍZ Y VELARDE CULTURAL CENTRE}

The Daoiz y Velarde Cultural Centre in Venturada, Spain was re-imagined in 2013. The former barracks were preserved to represent Madrid's industrial and military heritage.

The restoration respected the original layout of the building, the saw-tooth metal structure and brick facade. The building's interior was stripped out leaving and empty container to house the new cultural centre (Ott, 2019).

The new interior spaces are split into two areas with individual entry points and circulation. The spaces are visually connected and are able to be adapted for different events.

The large open spaces within the building allow for meeting spaces, exhibitions and informative areas (Ott, 2019).
This cultural centre uses the skin of the original building to house its new function, as two separate objects that never touch.

The rugged metal and brick original structure is a stark contrast to the white boxes housing the new program, making it obvious what is new and old.

The programming of this building is similar to the previous precedent, as it allows for wide open spaces that facilitate exhibitions, meetings and performances. This tactic could benefit the proposed design of the Oriental Parade Rotunda, as a way to preserve the exterior shell of the structure and to alter the interior as wide-open spaces for the needed programs. 


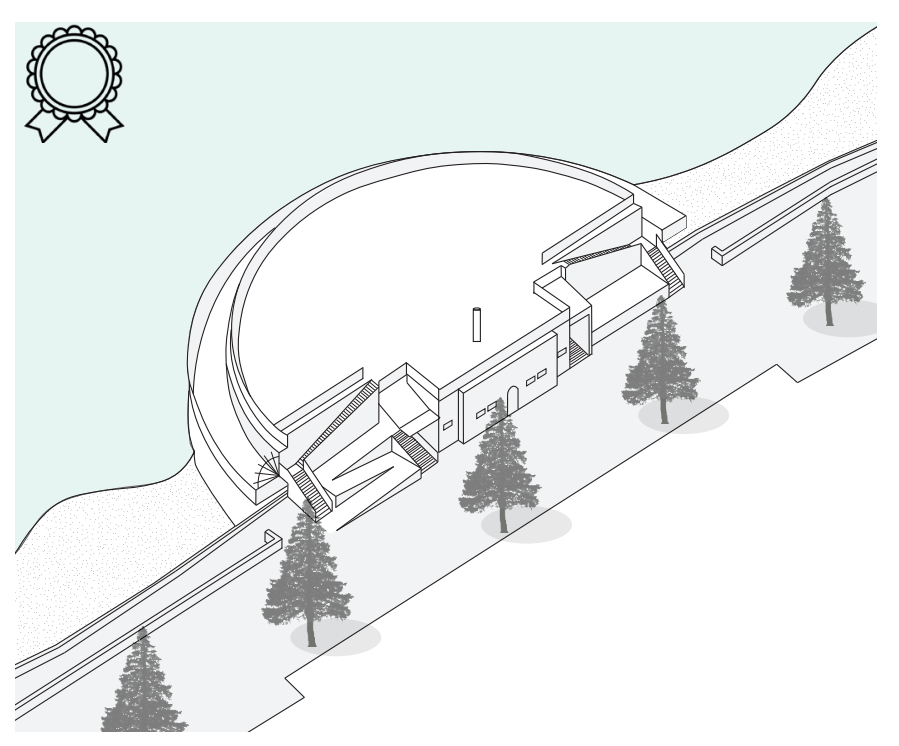

Original building

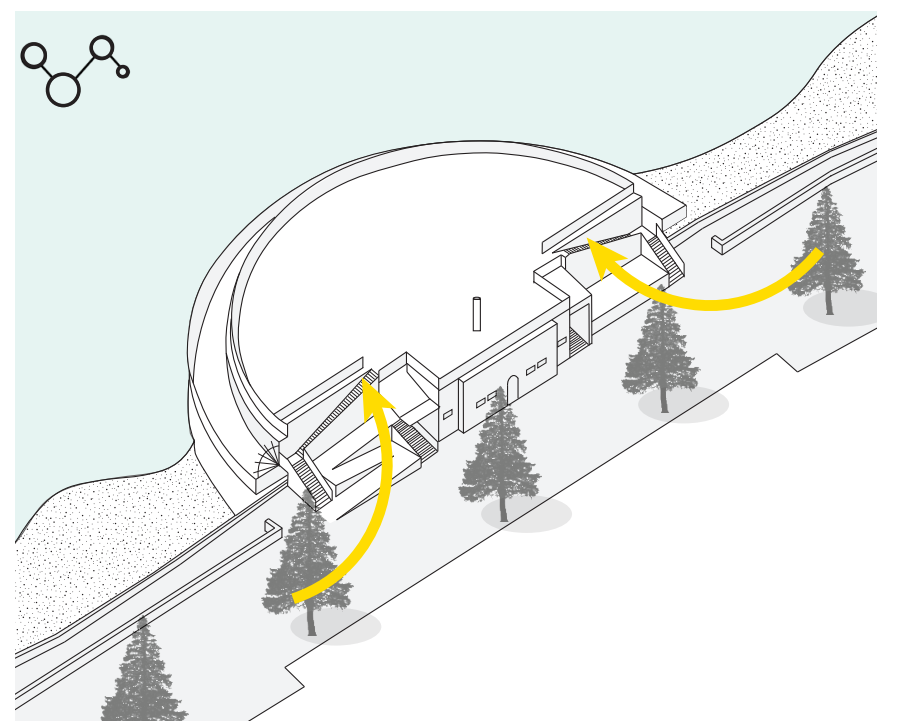

Area of interest

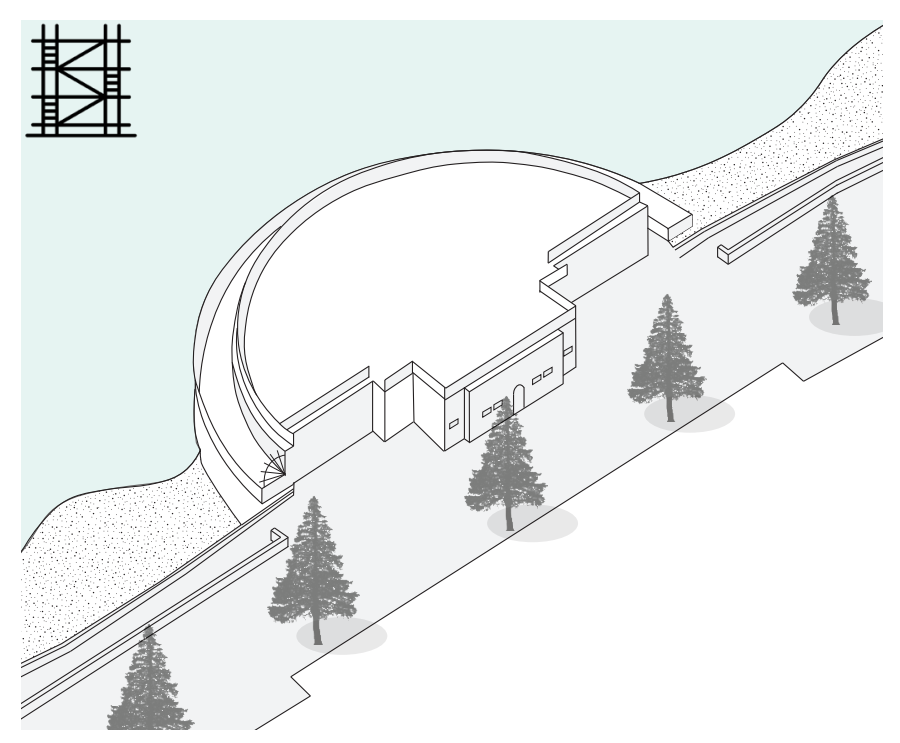

Unchanged
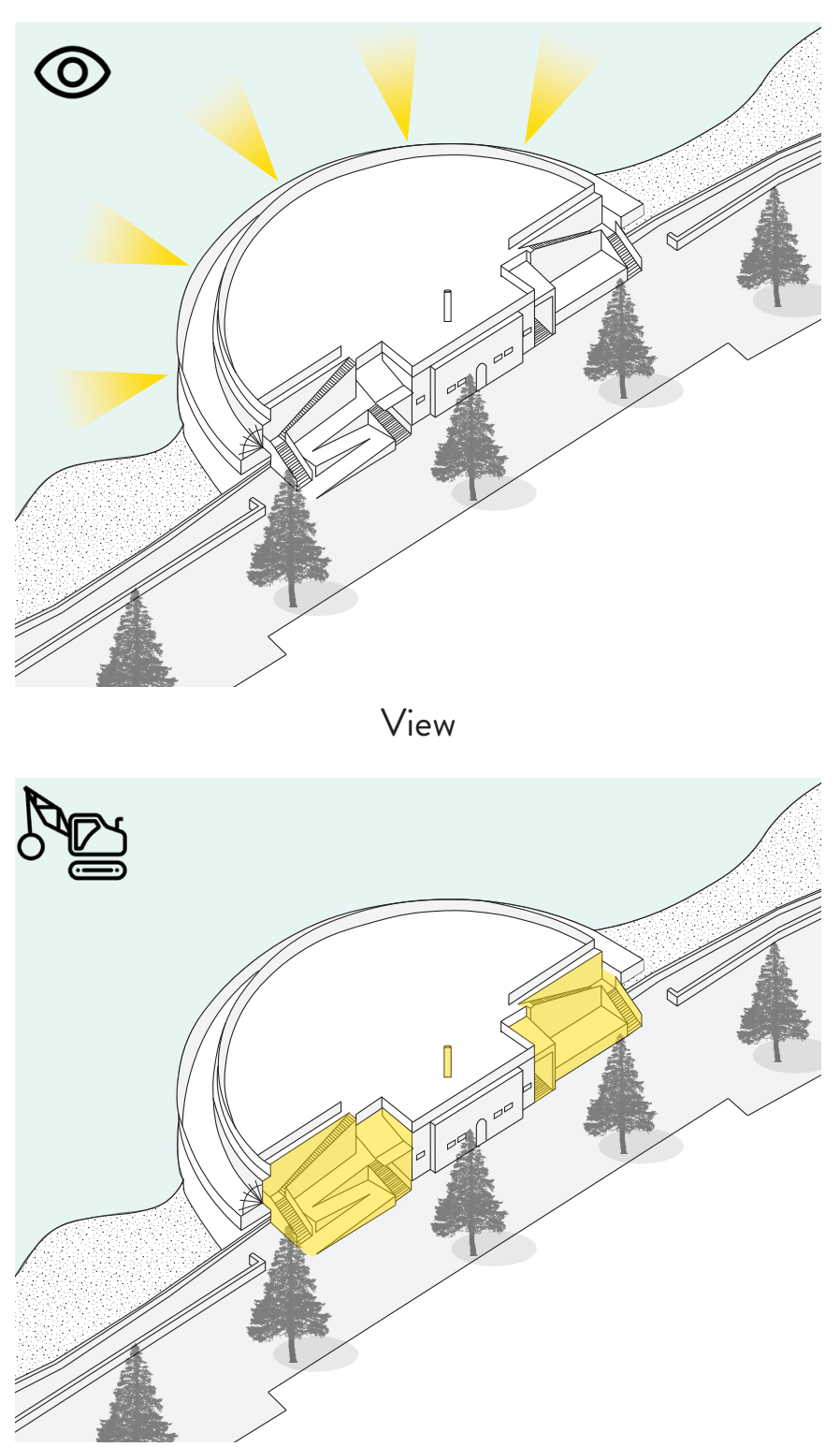

Demolition

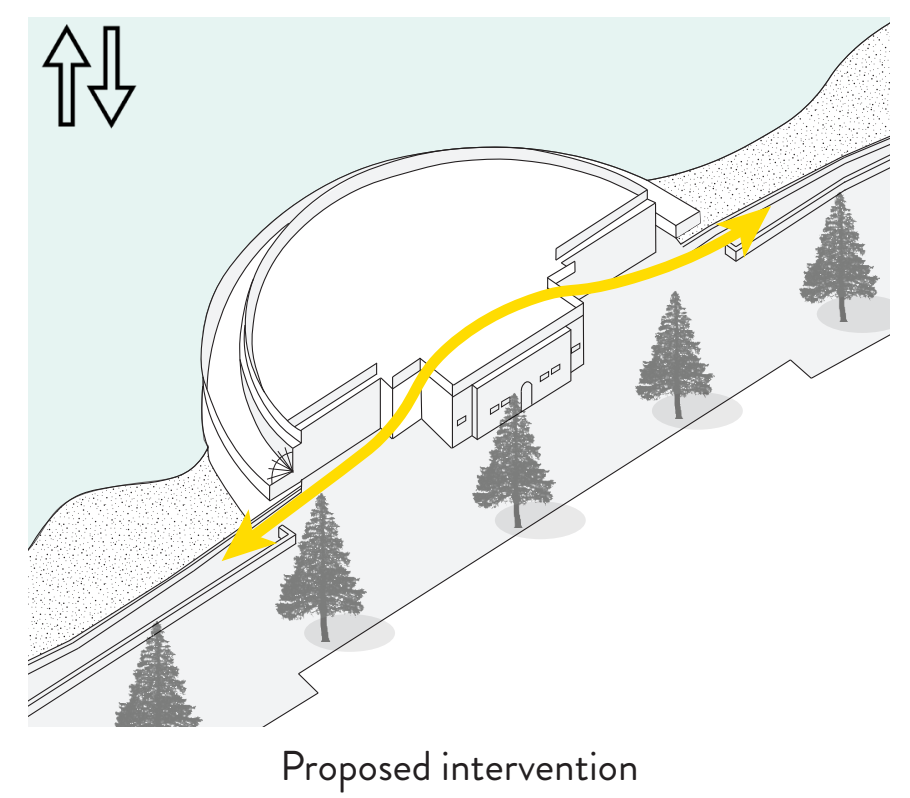

Figure.8.11: Design considerations 


\section{DESIGN DECISIONS}

The site sits between land and sea, representing a third space neither on land nor on sea, this represents the third culture of CCPs. As Colomer found in her survey, Airports are an important building typology for CCPs, (especially TCKs as it represents mobility and change). This building will be reinvigorated to be a "Cross Cultural Port" with layout flows similar to airports. With a central 'check in desk' and waiting lounge arrangement in the exhibition space. The curved ramps lead onto the next stage of the journey up into the workshop/ meeting space. This then transition on the next part of the journey, the rooftop performance space that allows for open engagement to the public for a sense of inclusiveness. The chosen precedents informed the types of spaces that were relevant for a cultural centre and how they interacted with a heritage building and its materials.

The new design will respect all its layers of change from the 1930 s pavilion to the 1980 s changing rooms. 


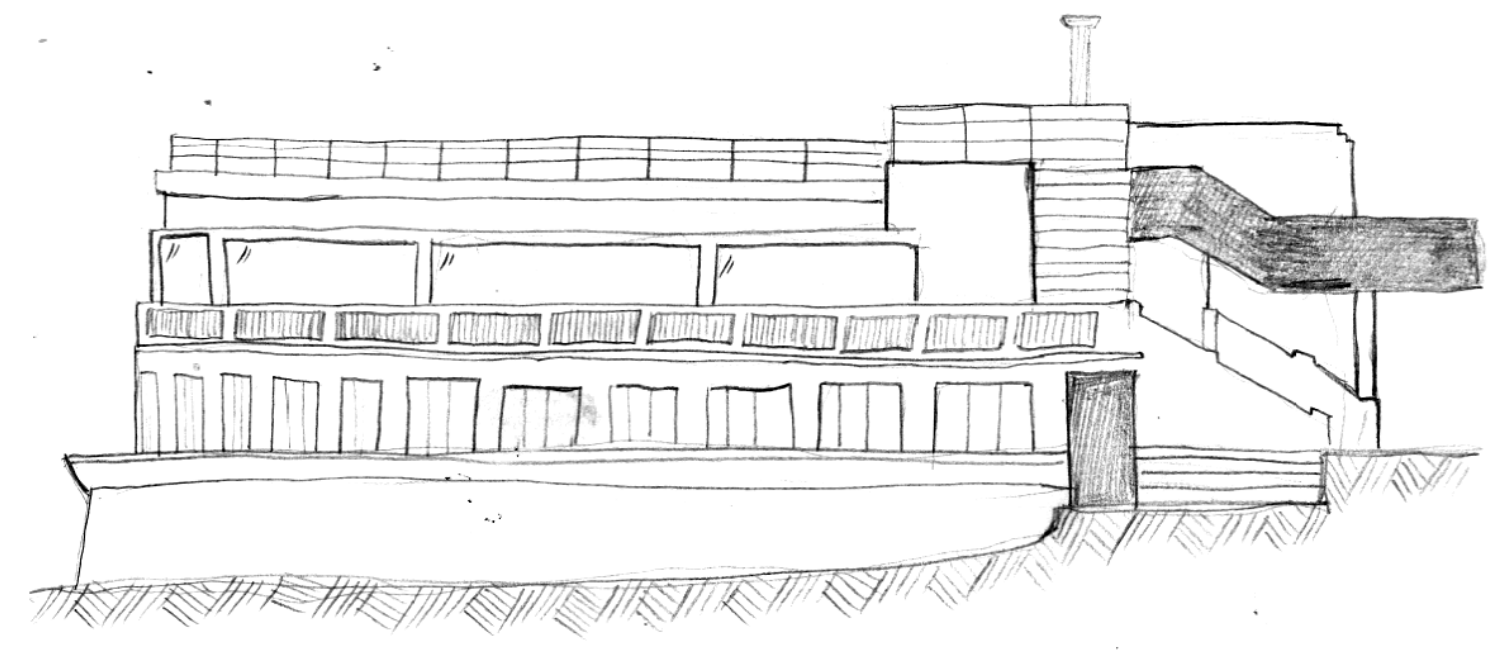

Briented Pade

Figure.8.12: Side elevation sketch 

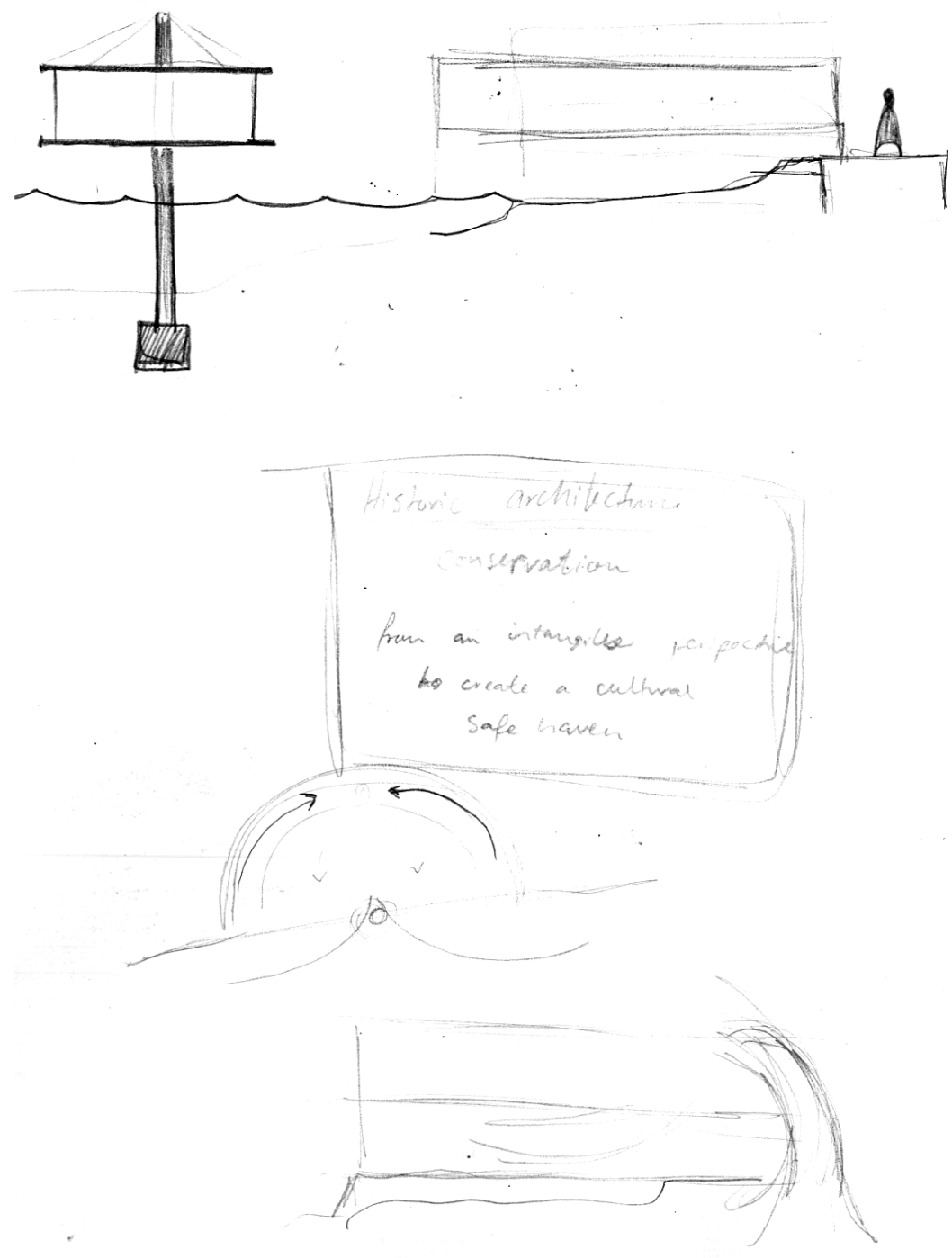

Figure.8.13: Sketch development 
Flexible space for meetings/ workshops/ cafes or socializing

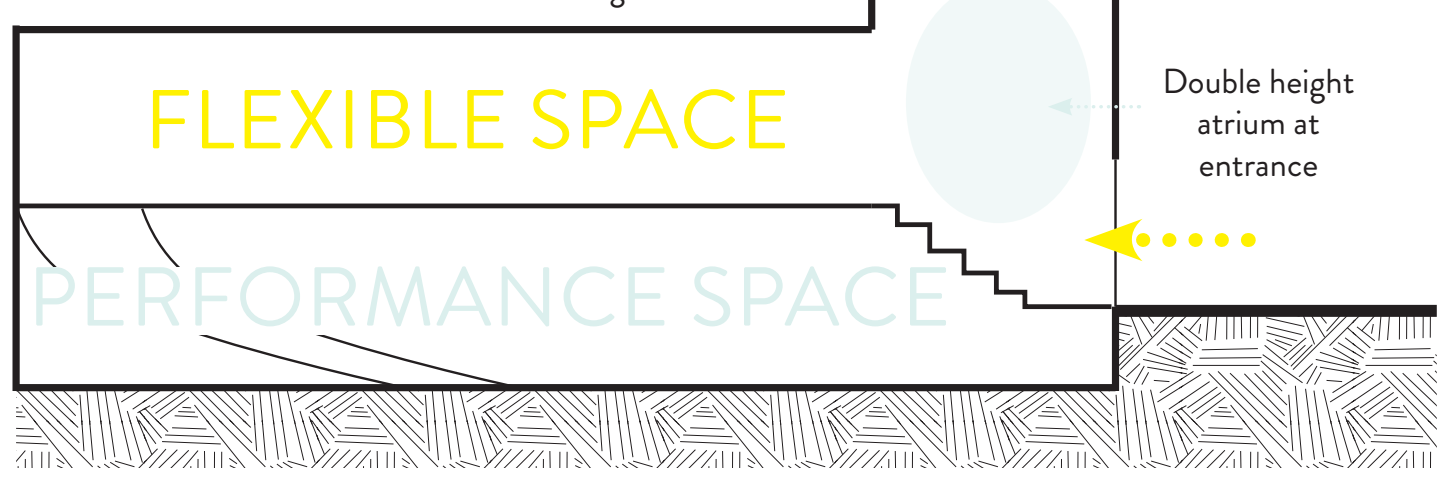

Curved ramps connect to first floor

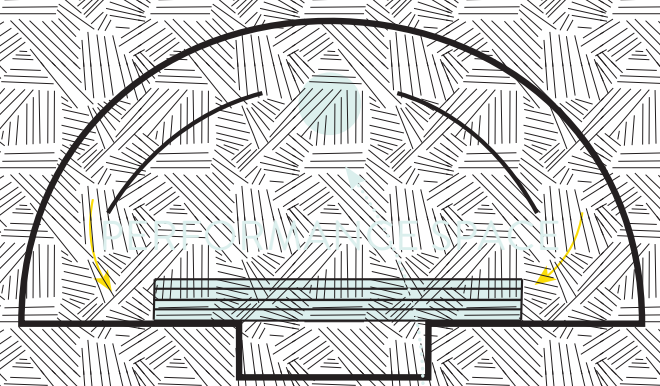

Ground Floor Plan Diagram
Curved ramps connect to ground floor

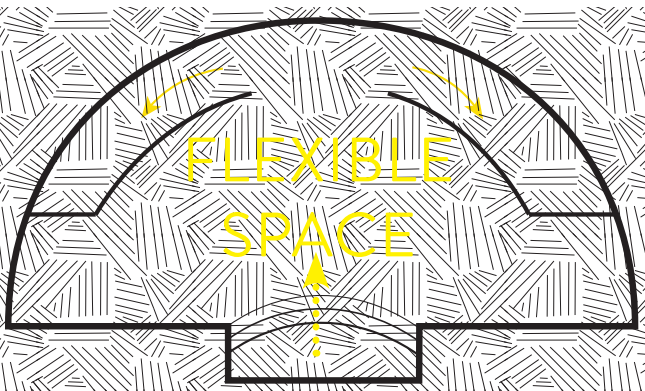

First Floor Plan Diagram

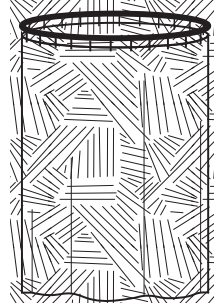

Circular curtain rail as a movable backstage space for performances

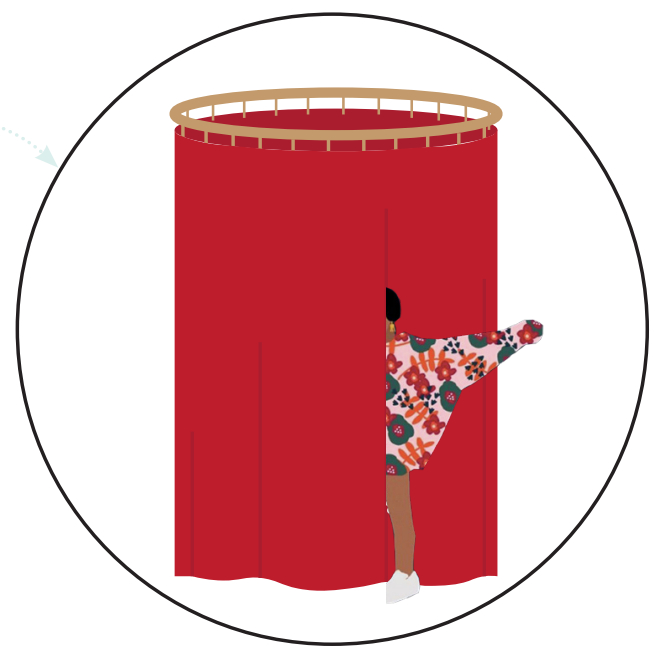

Figure.8.14: Diagrammatic development 


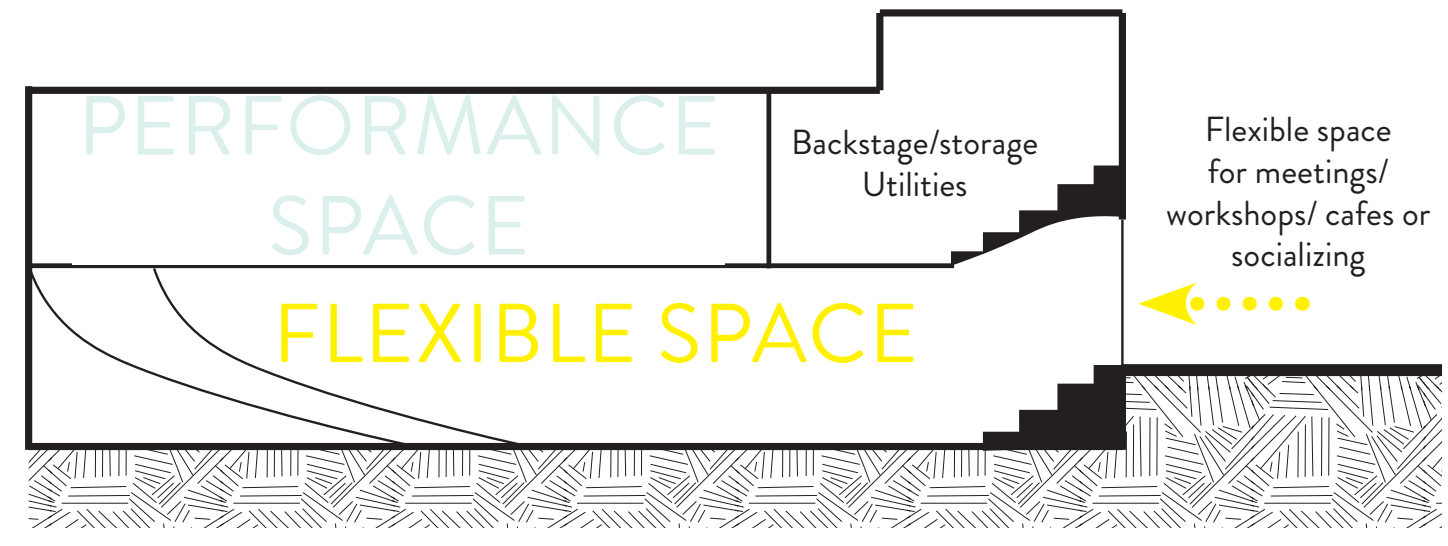

Curved ramps connect to first floor

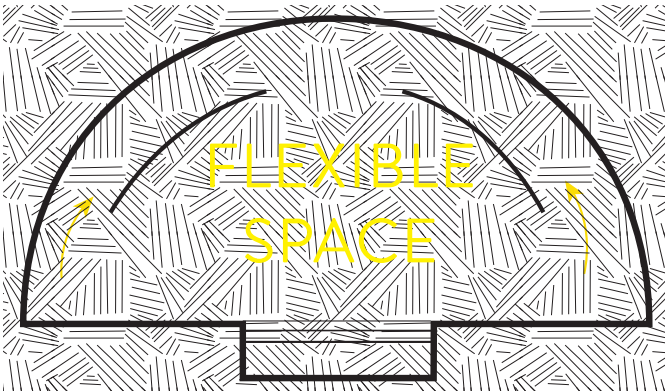

Ground Floor Plan Diagram
Curved ramps connect to ground floor

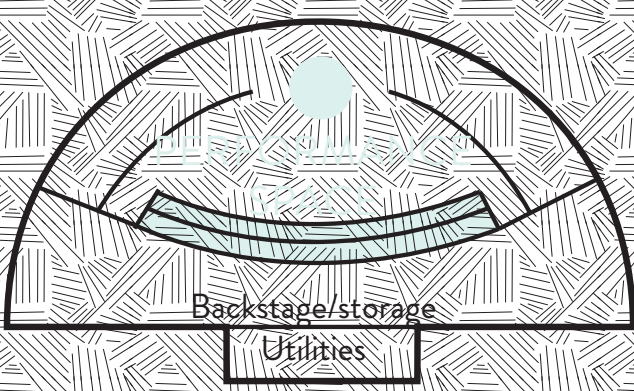

First Floor Plan Diagram
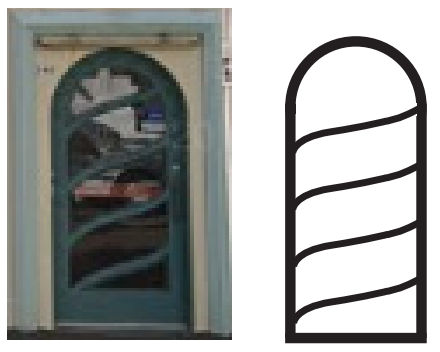

Arched door referencing

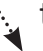
the arch ramp facade.

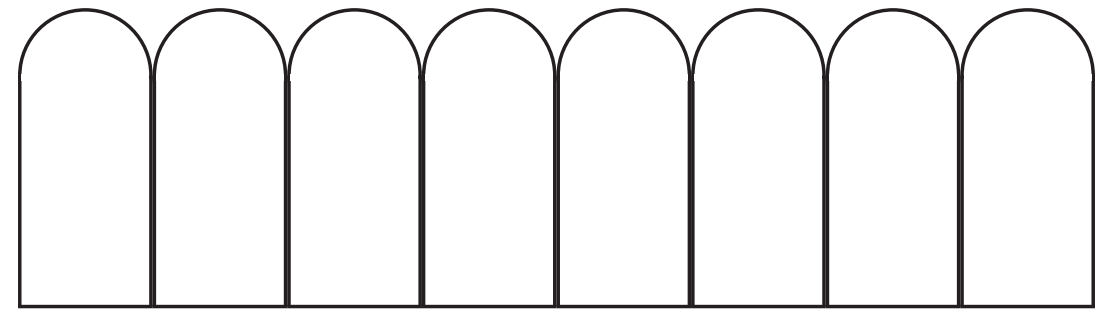

Figure.8.15: Development diagrams 

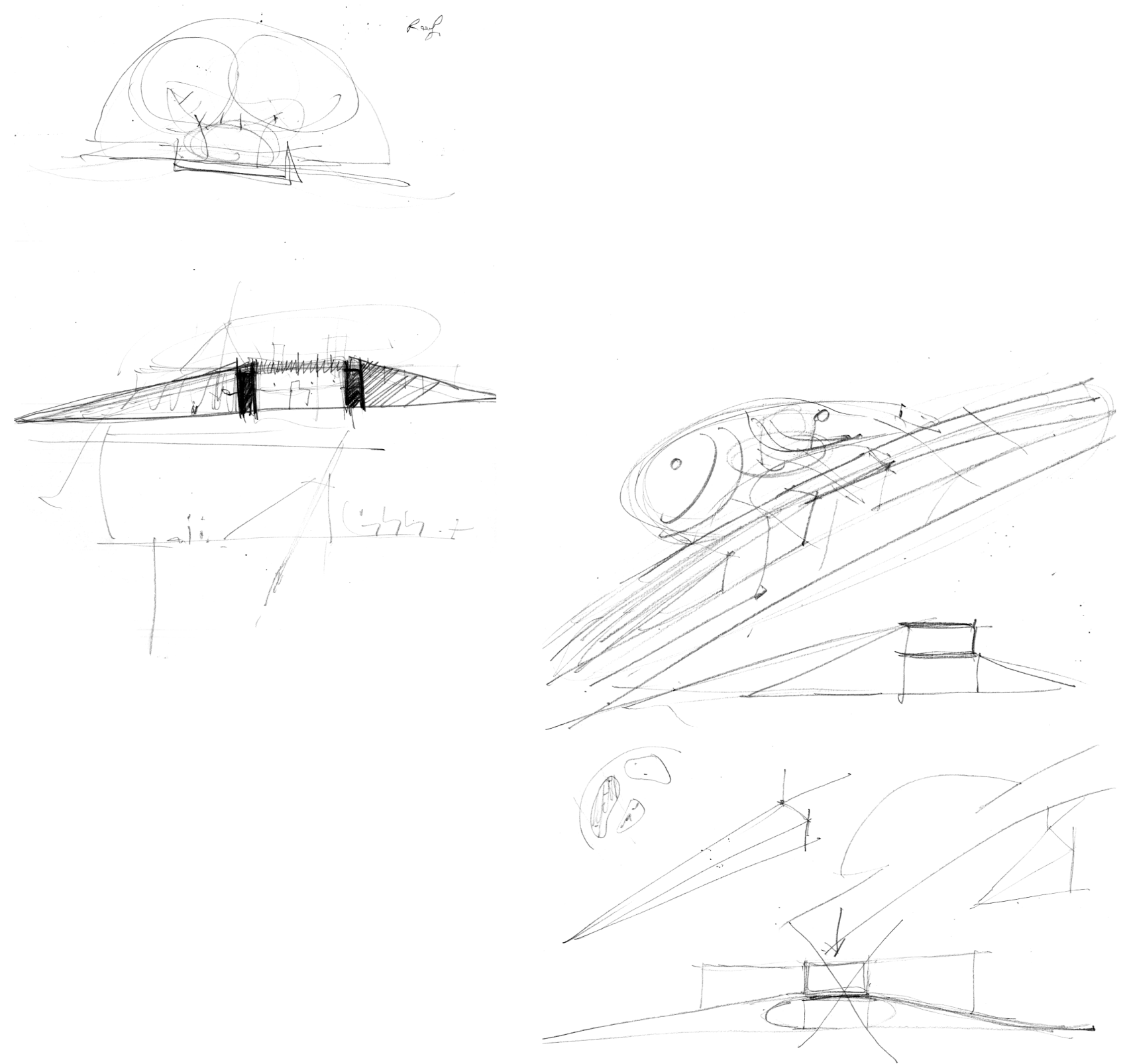

Figure.8.16: Ramp sketch development 


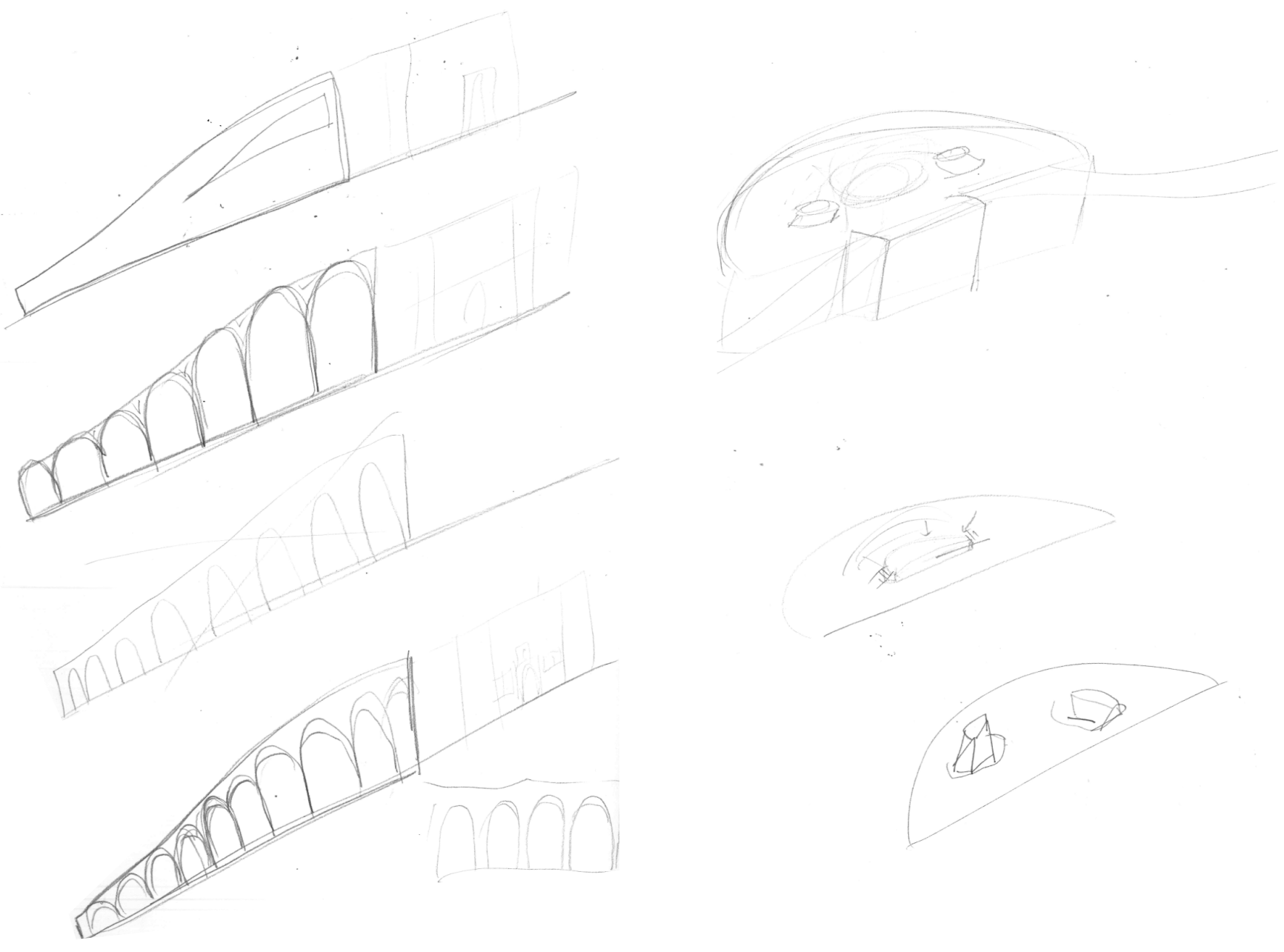

Figure.8.17: Ramp facade development 


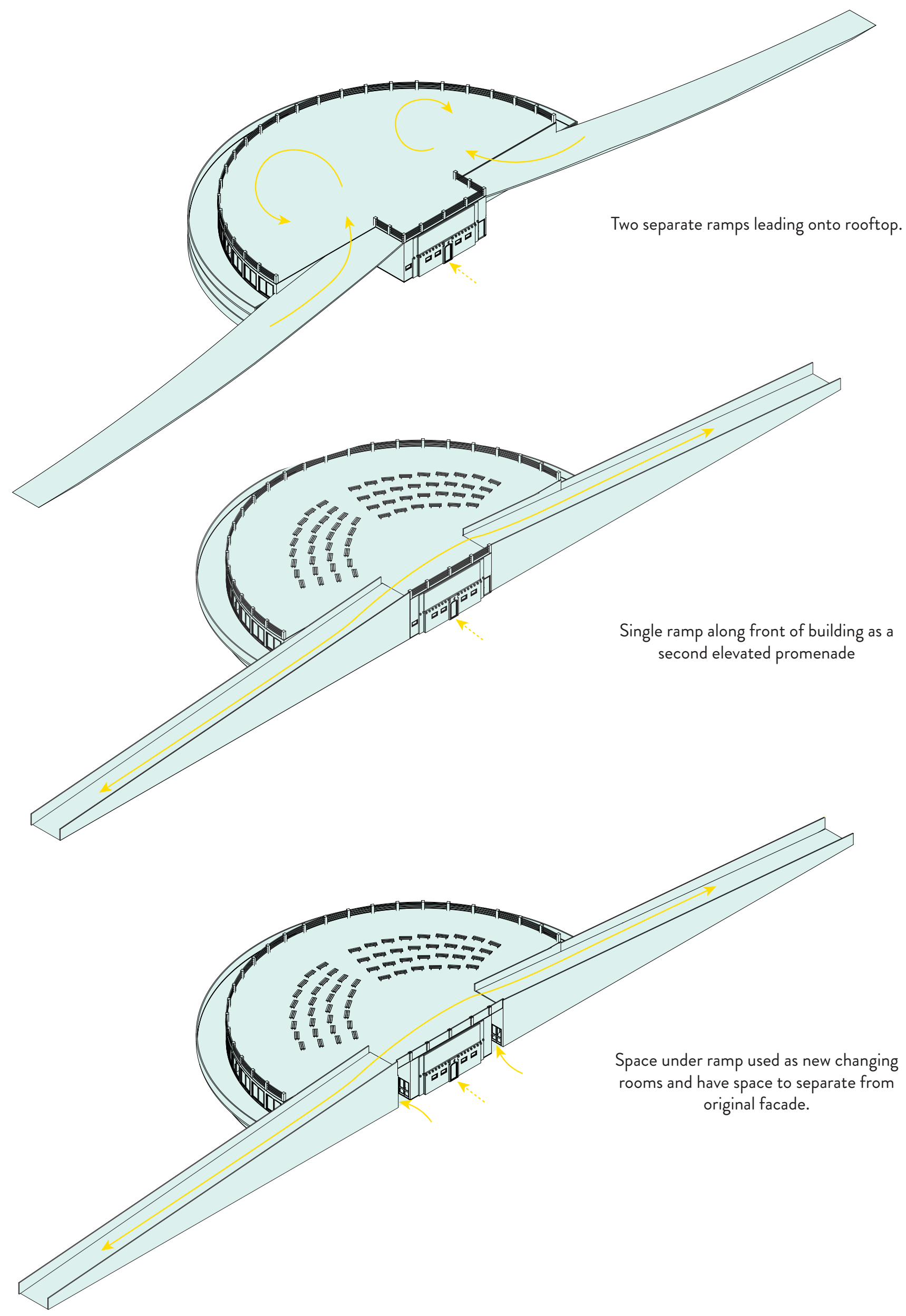




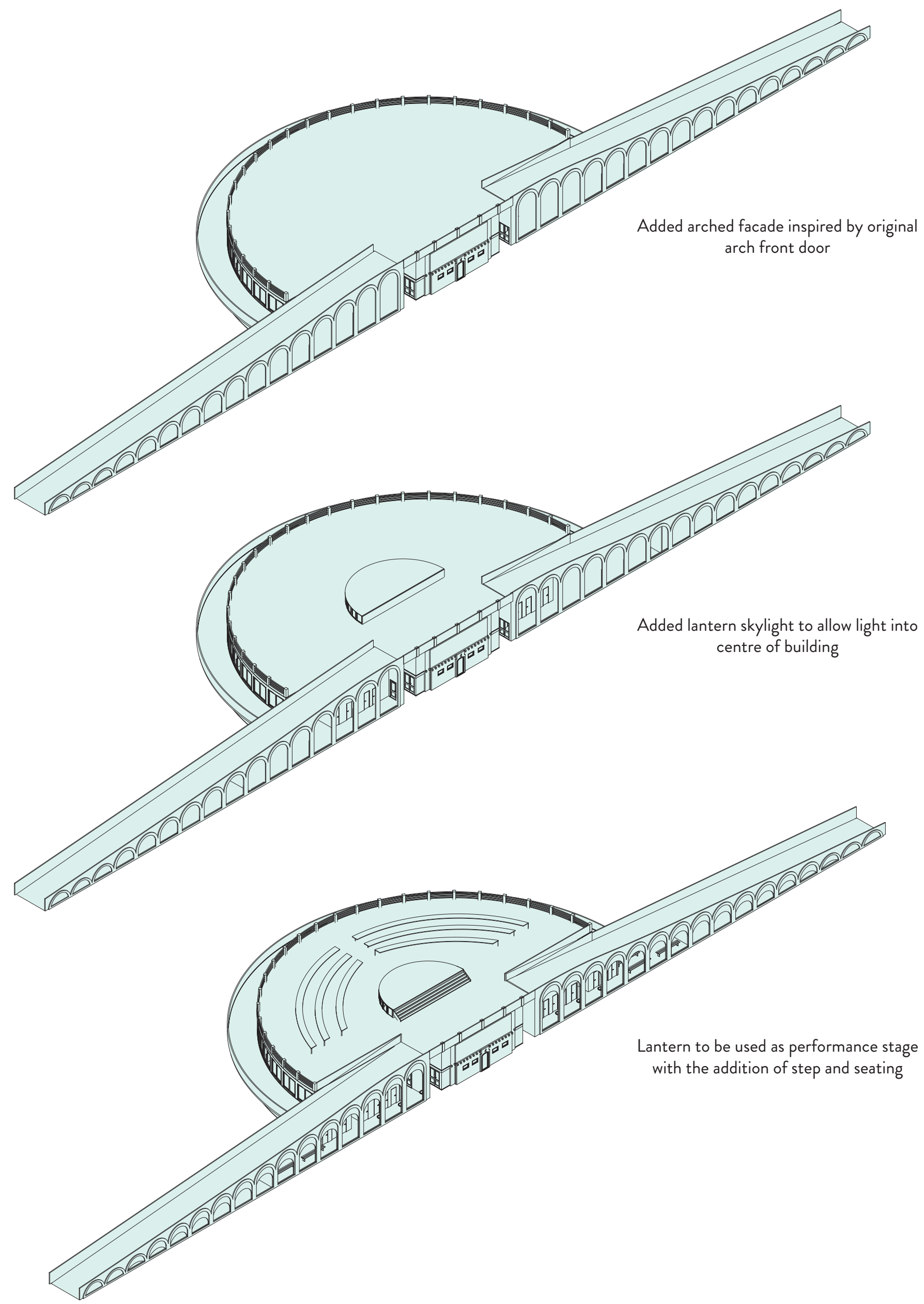



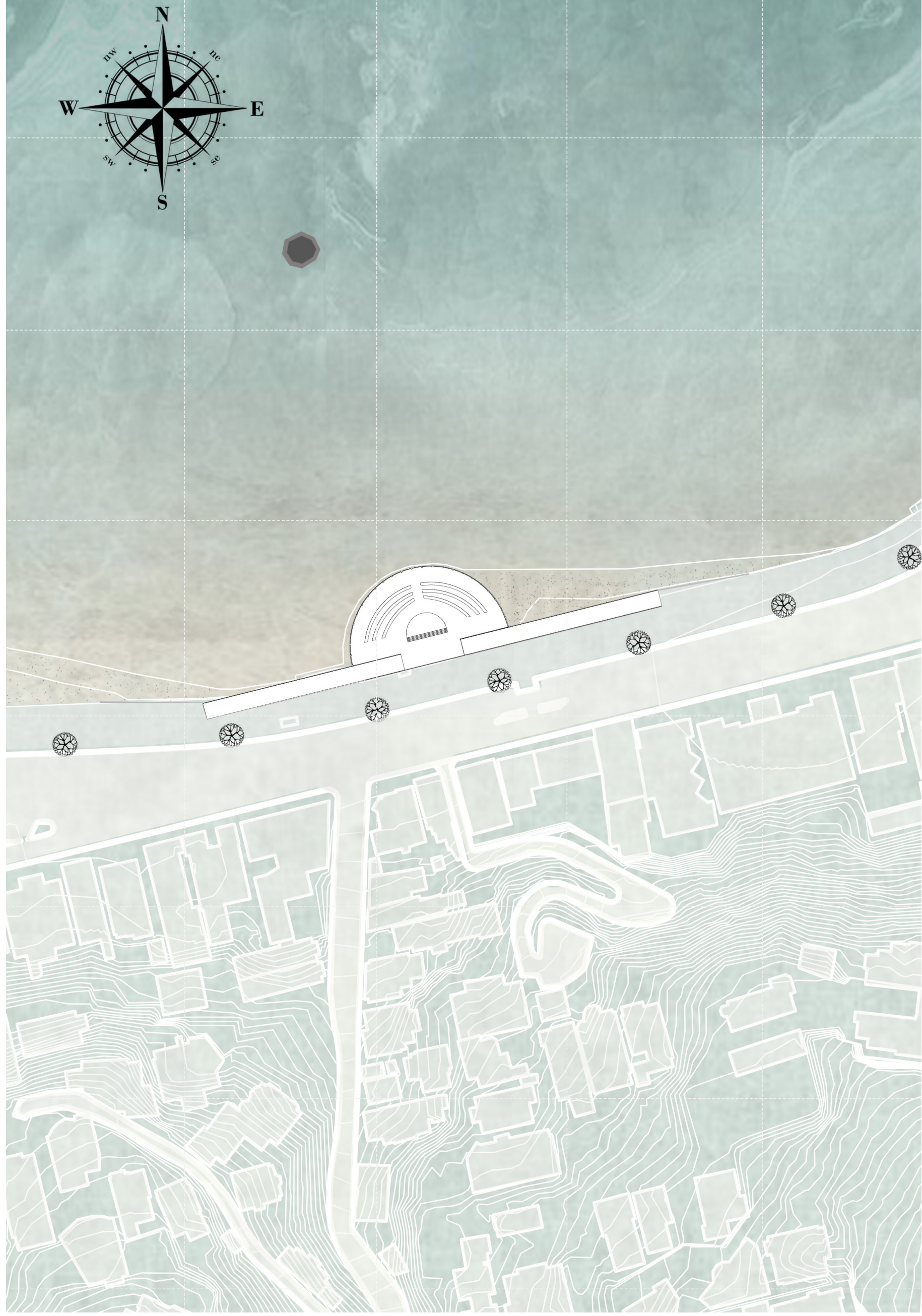
A Cross Cultural Centre 


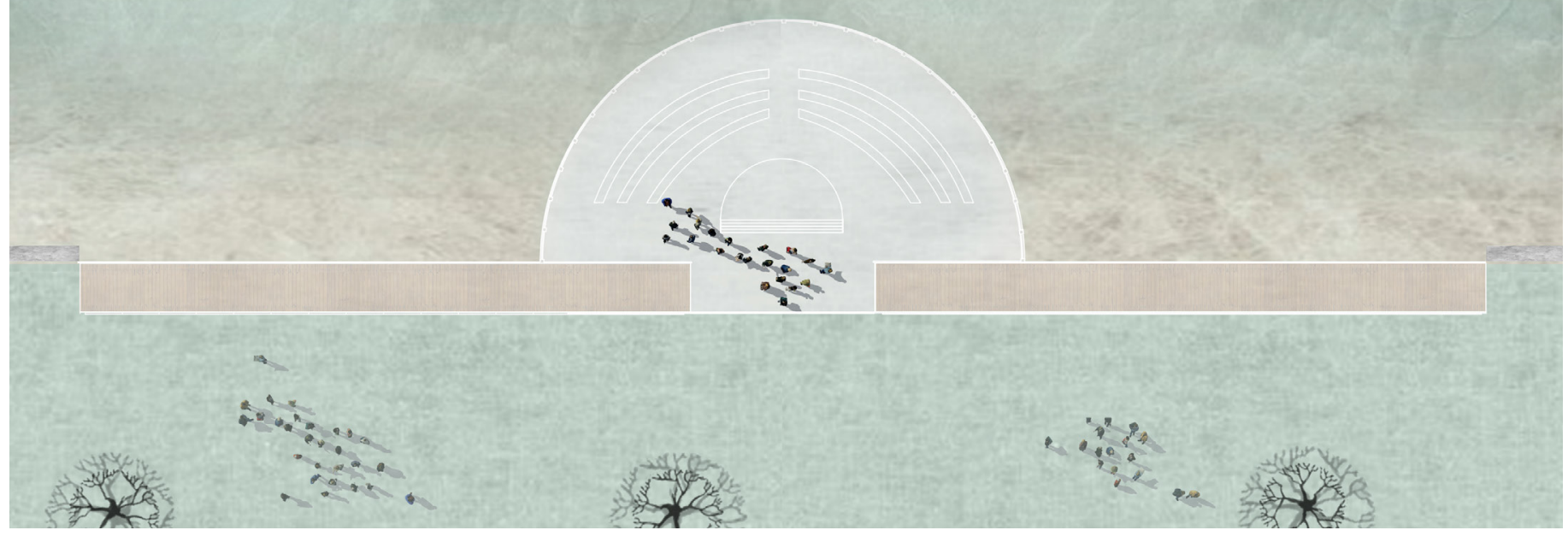

Figure.8.20: Roof plan

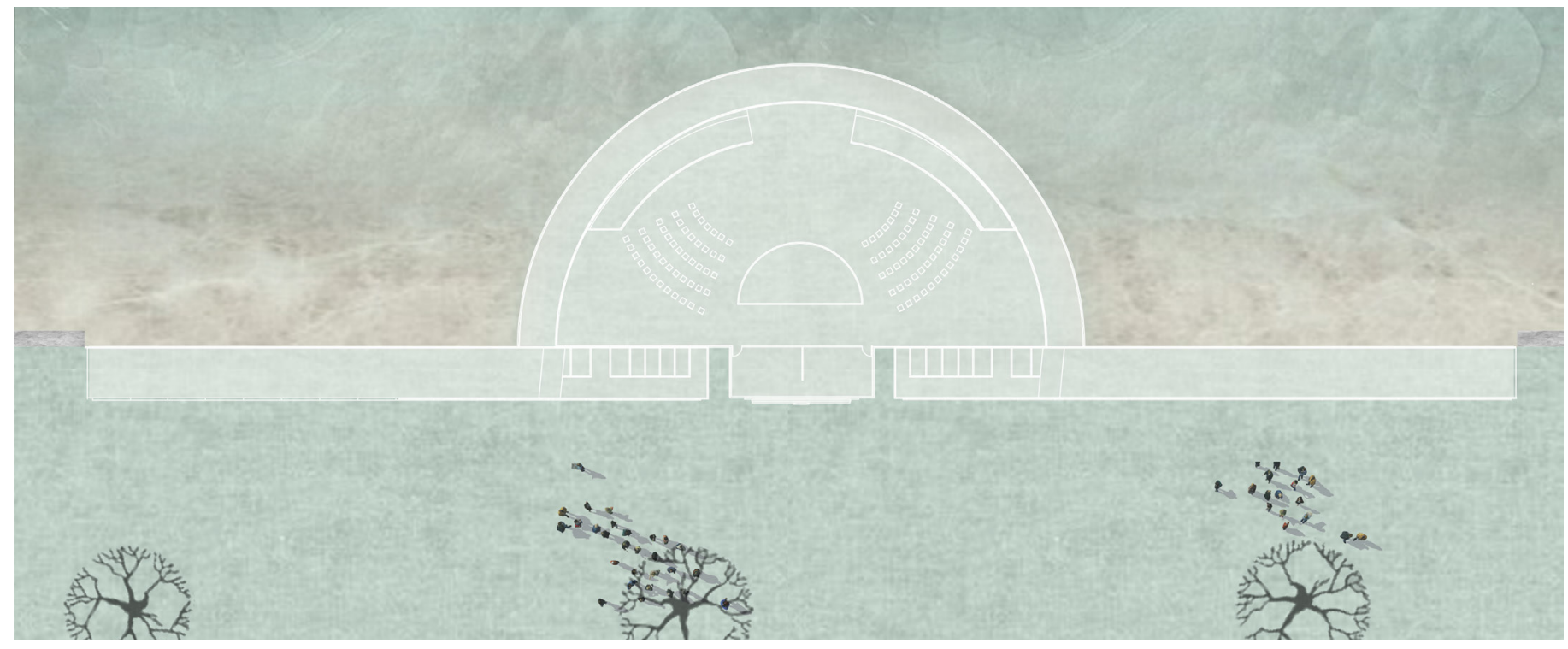

Figure.8.21: First floor plan

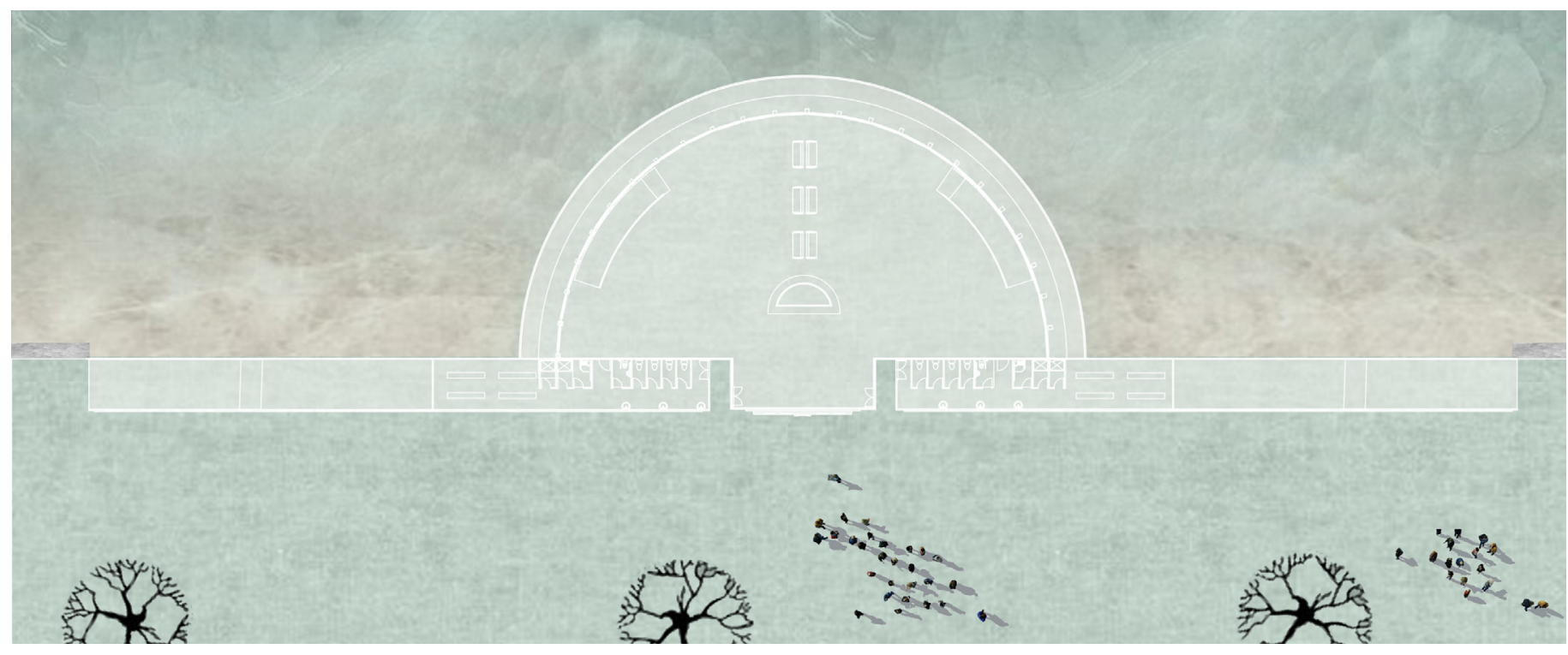

Figure.8.22: Ground floor plan 


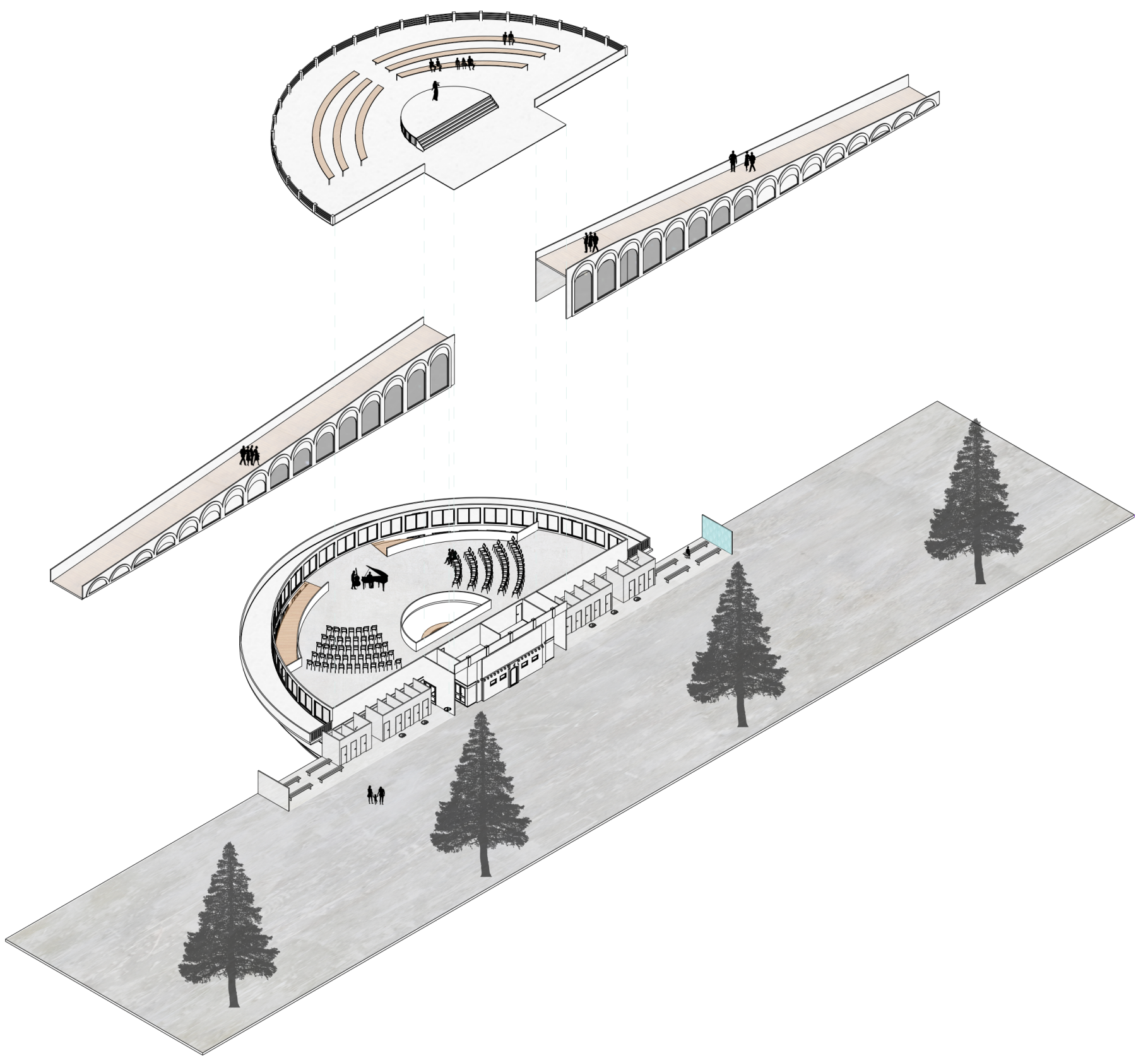

Figure.8.23: Rotunda exploded axo 


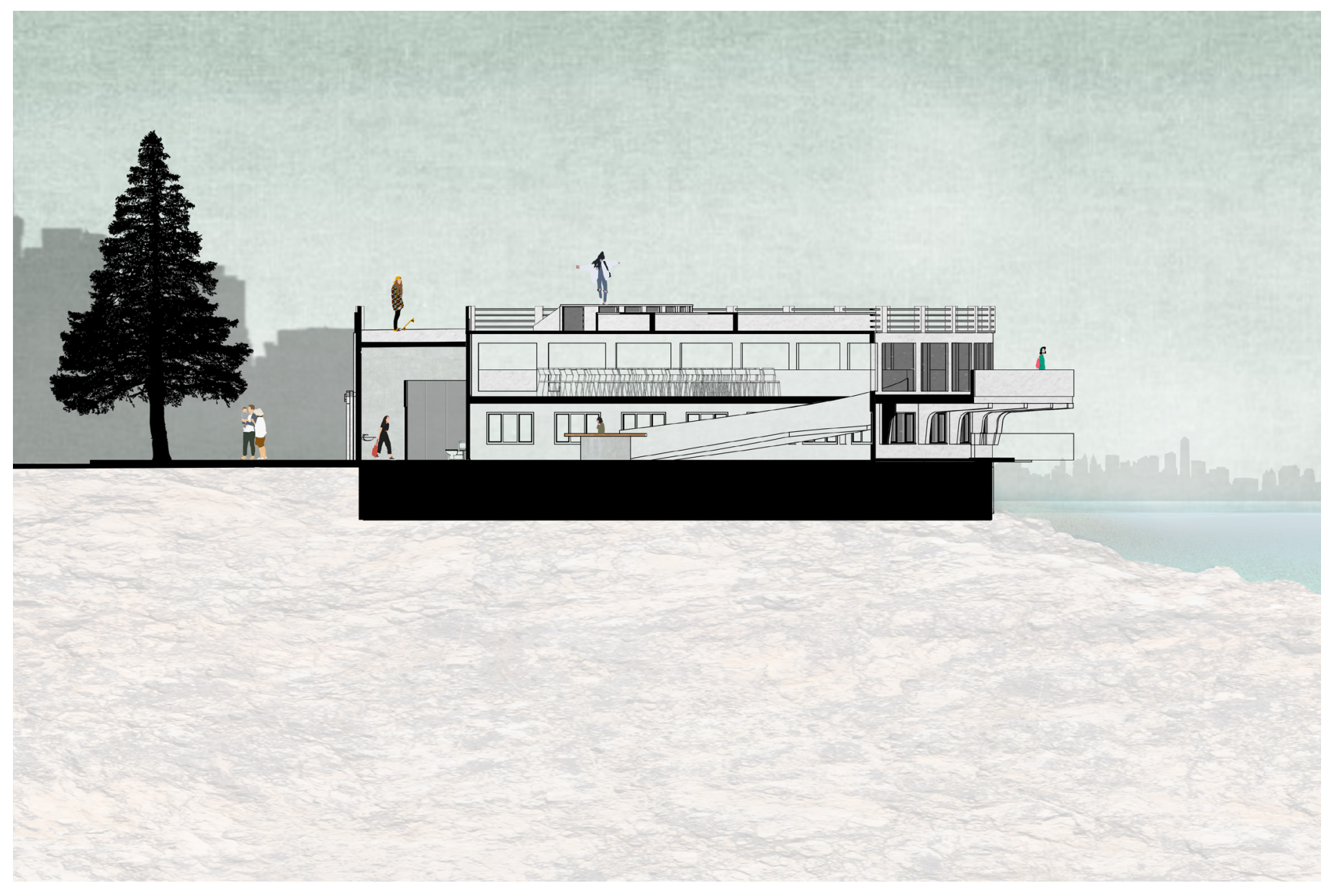

Figure.8.24: Cross section 


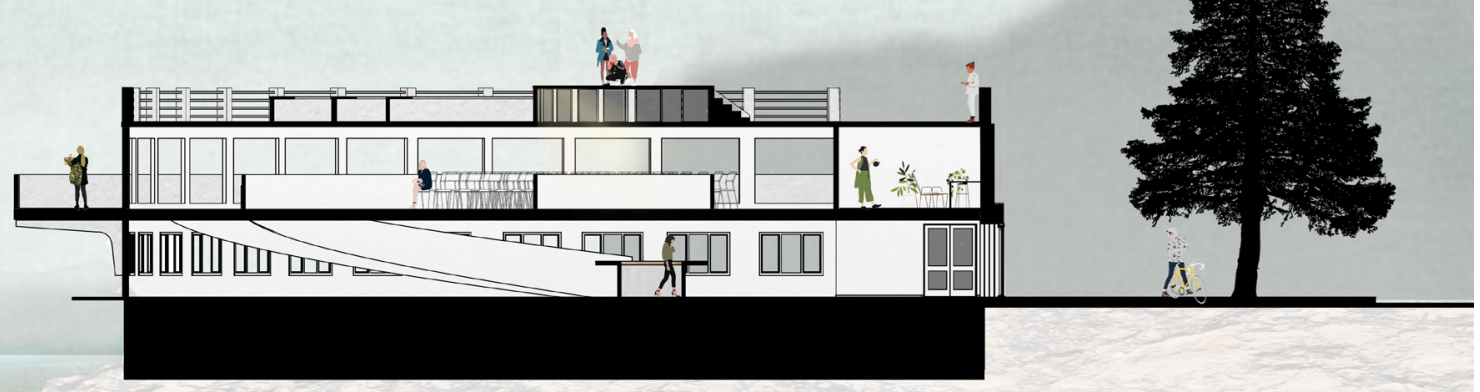

Figure.8.25: Cross section 


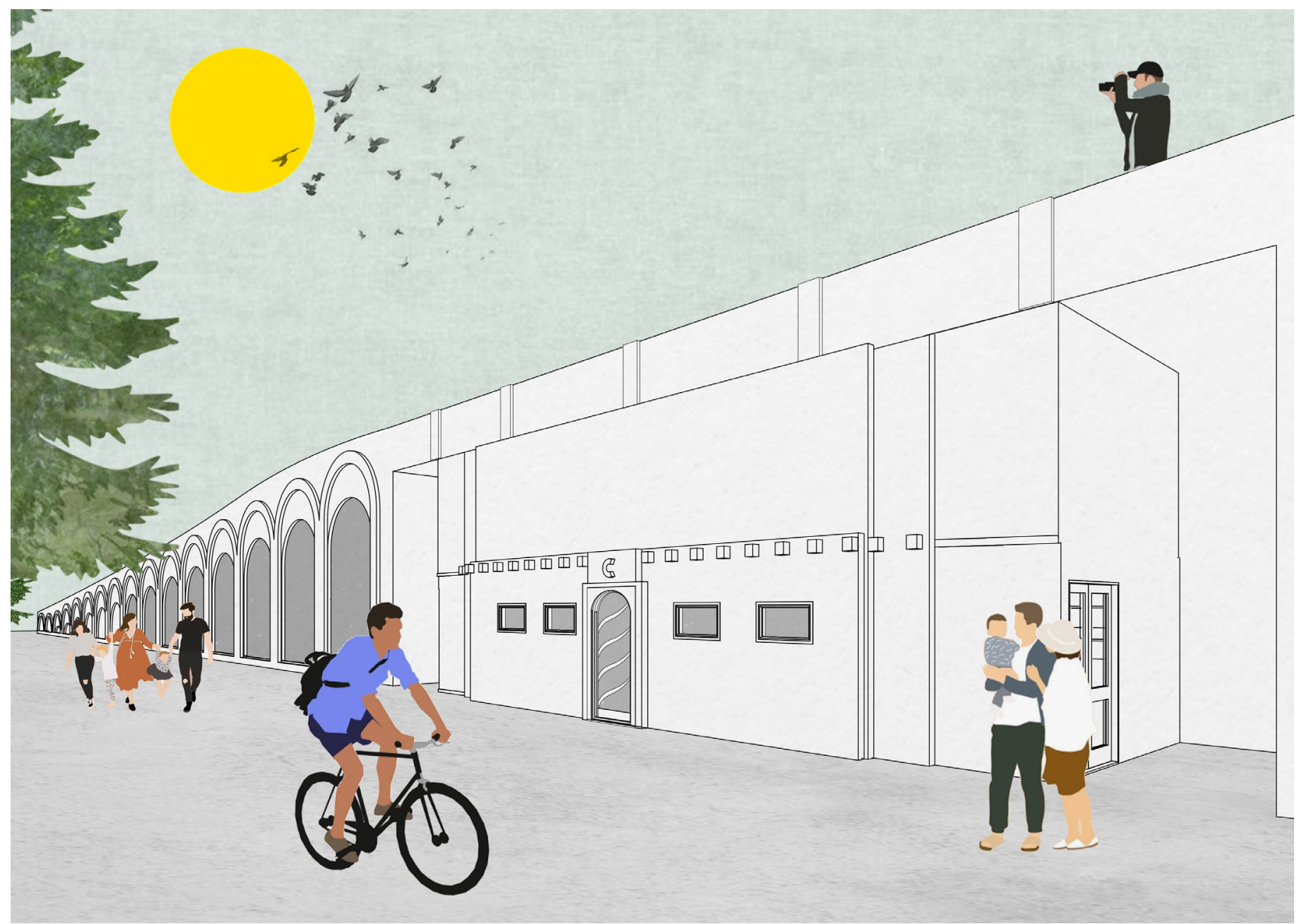

Figure.8.26: Entrance to the building 


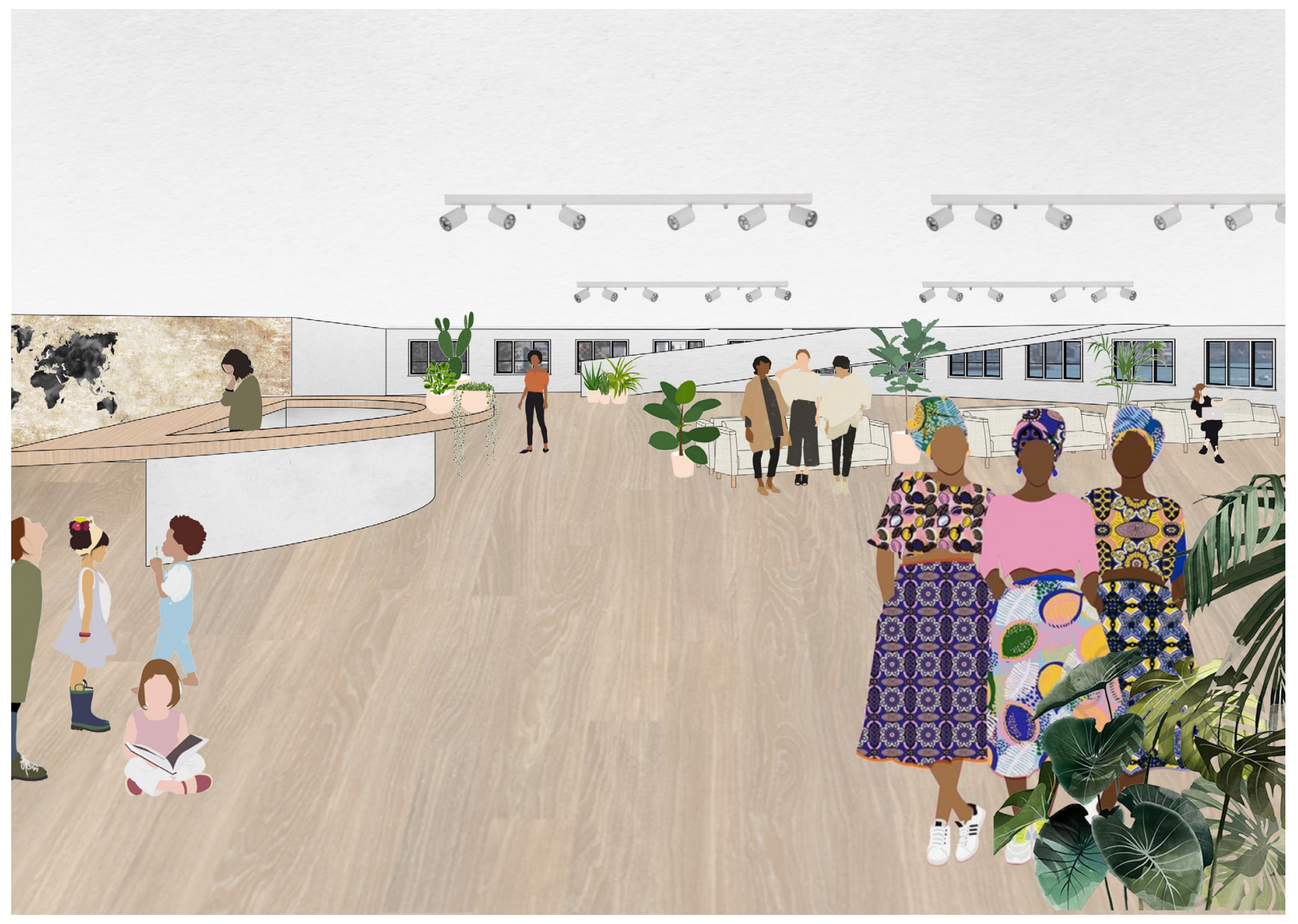

Figure.8.27: Exhibition space 


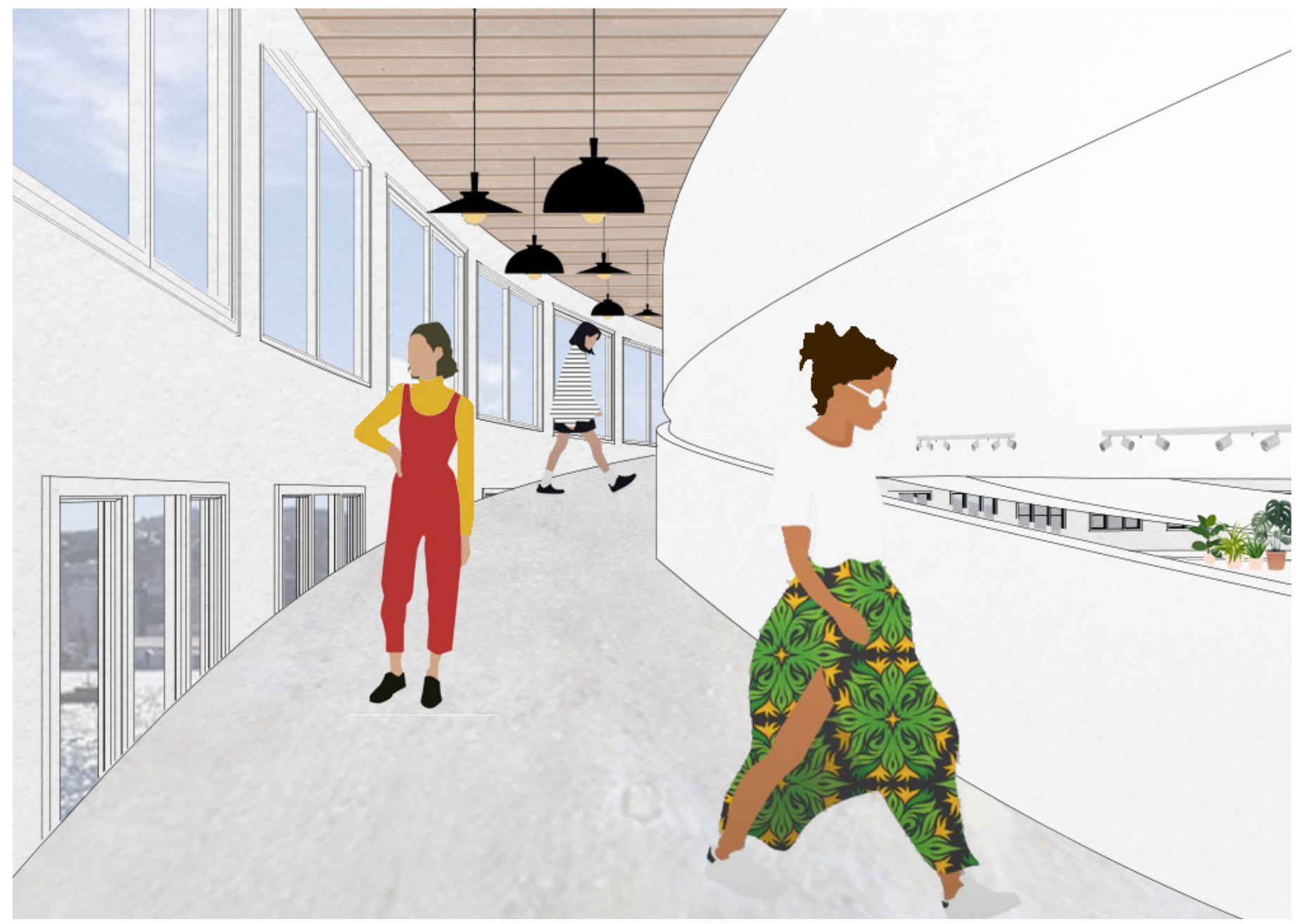

Figure.8.28: Ascending left ramp 


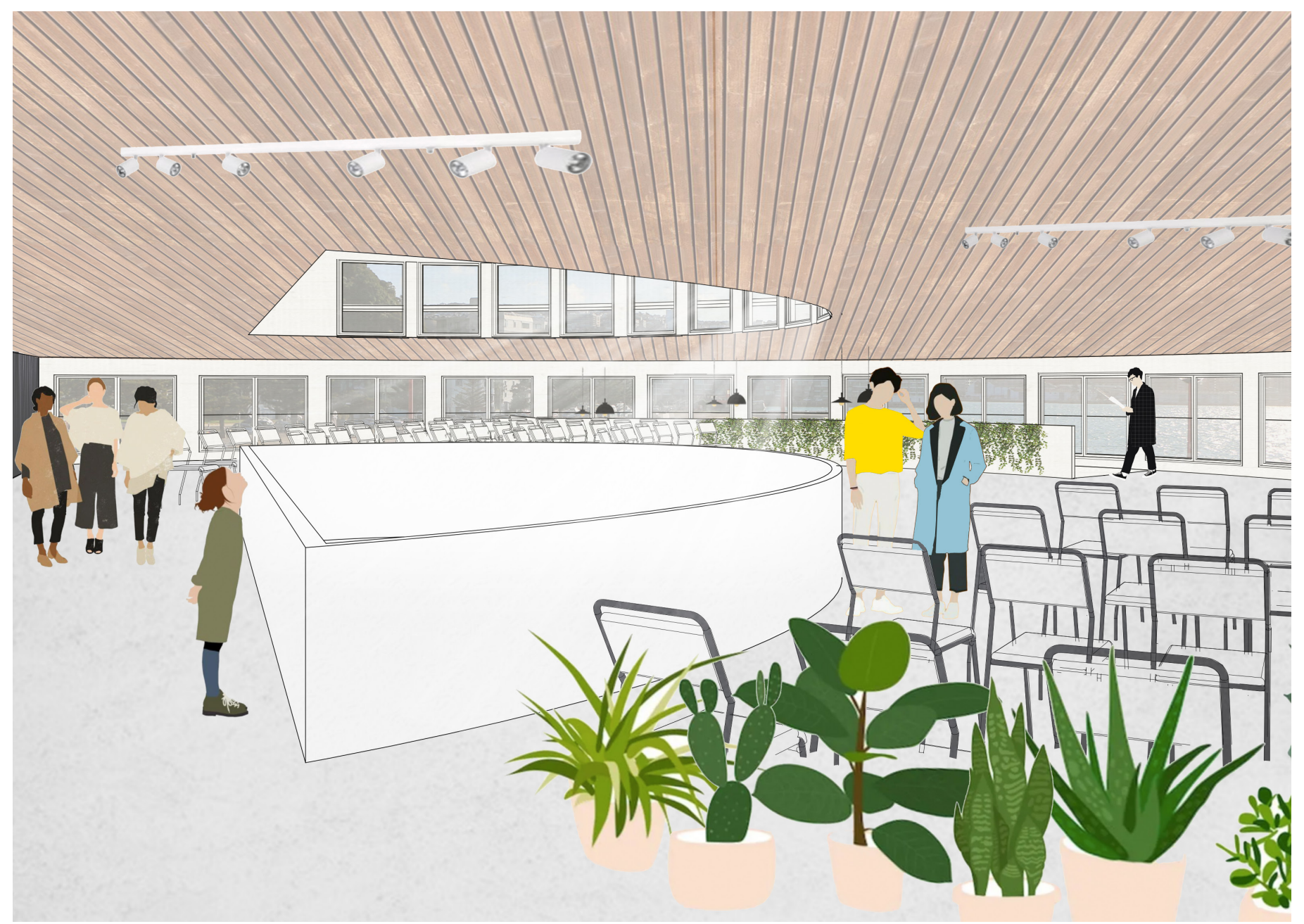

Figure.8.29: Performance space

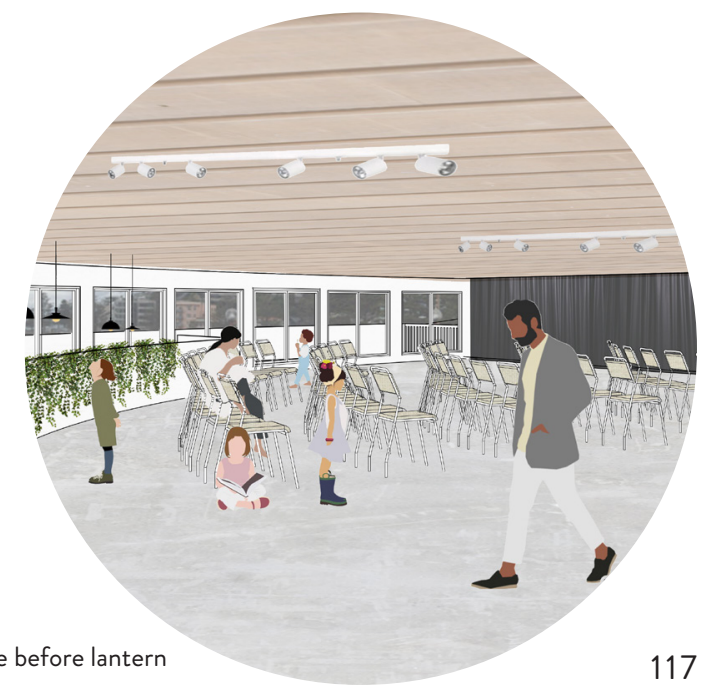




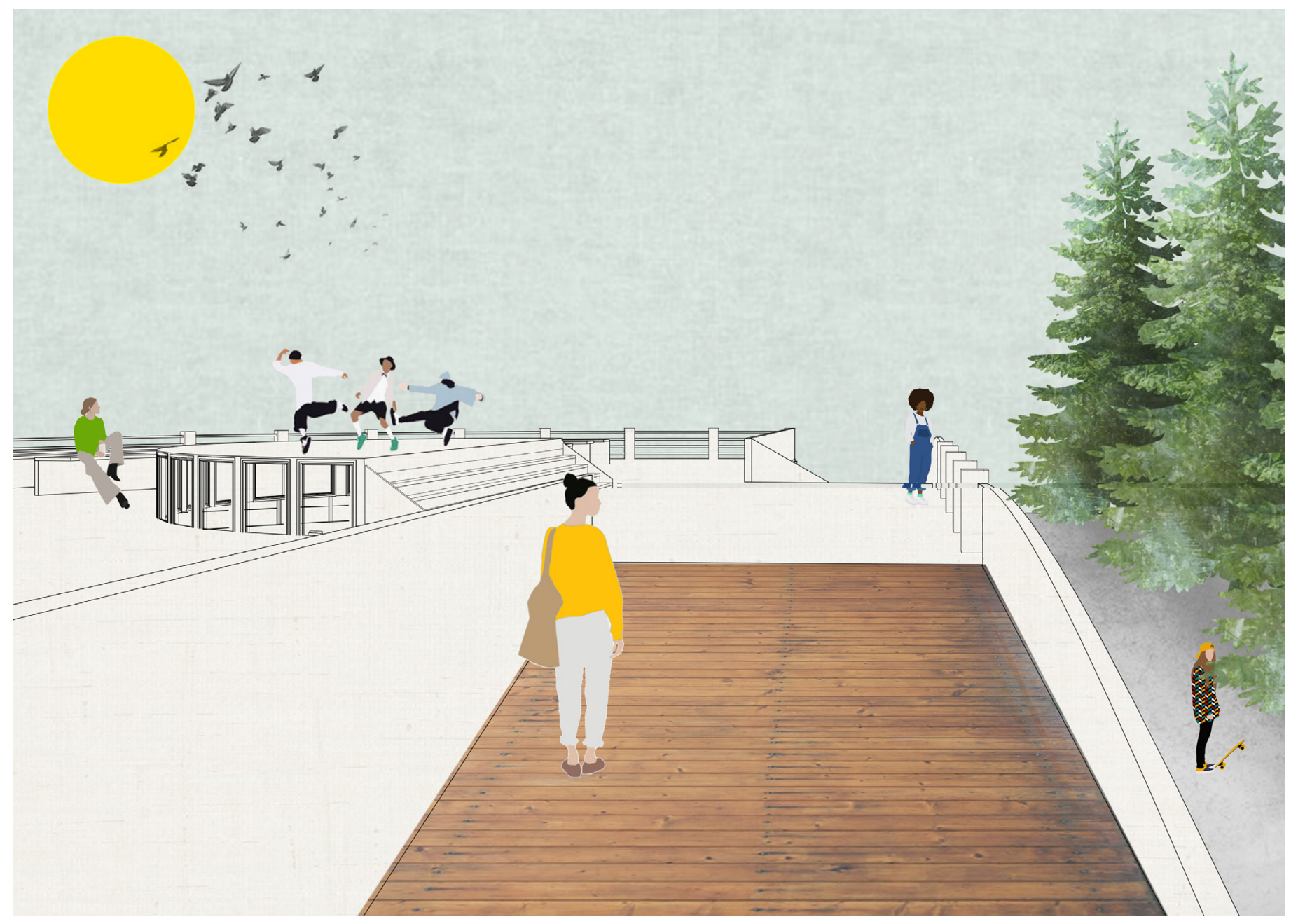

Figure.8.31: Walking up elevated promenade 


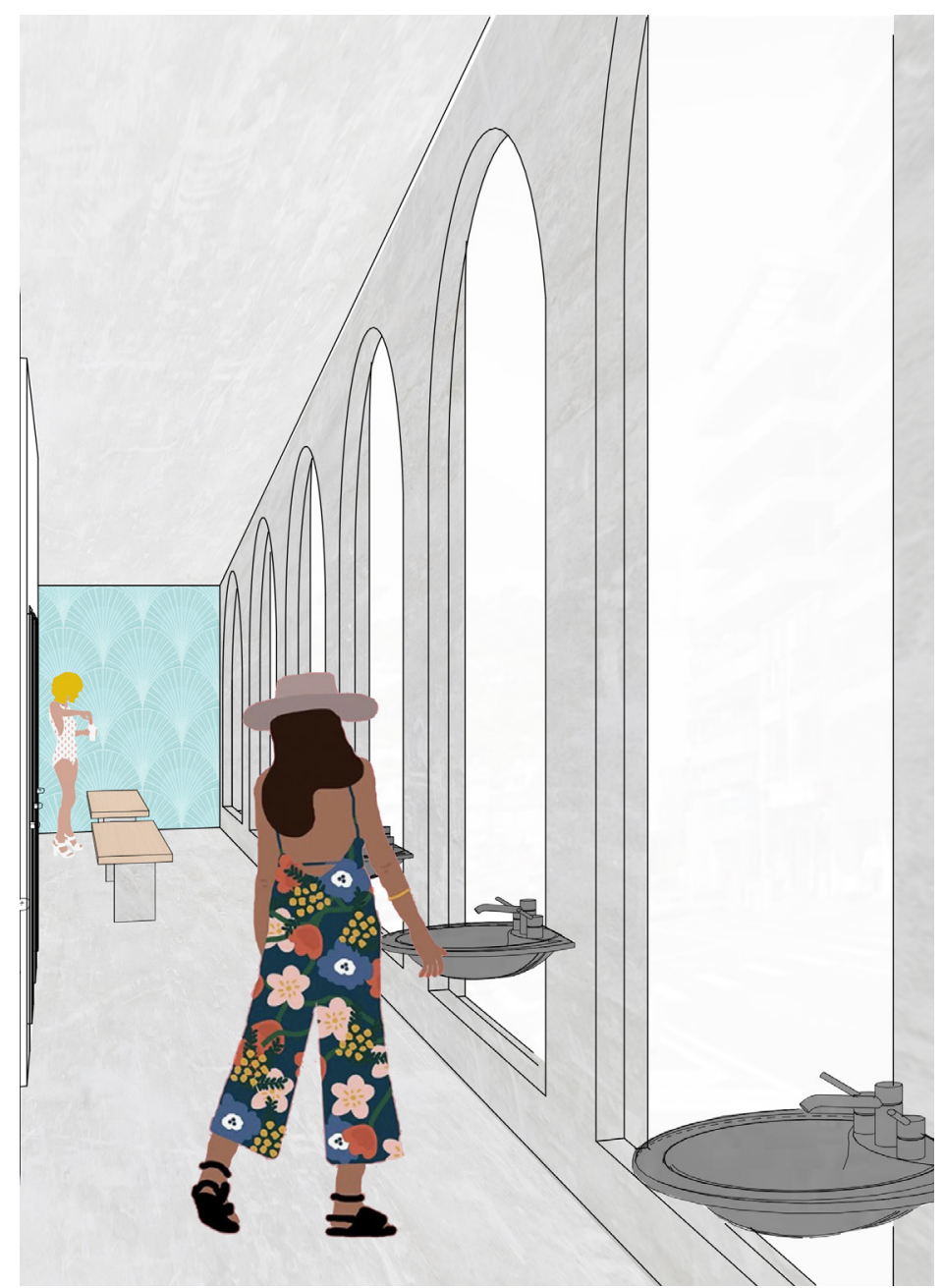

Figure.8.32: Changing rooms 


\section{FRAMEWORK CRITIQUE}

$\mathrm{T}$ he heritage building for this second iteration met most aspects of the site selection criteria. It is in a very public setting along one of Wellington's most prominent street and responds to the first requirement of being a public setting. The building is unique, being the only building along that section of the sea wall and with a semi-circular shape. The building also represents the local heritage and its transition of a public performance space into practical facilities and restaurant. The building represents the cultural identity of the area, by using that coastal feel that kiwis love and cherish. The Rotunda has a strong connection to the natural landscape, as it grasps onto the edge of the bay looking out into the harbour. This also plays with the strong sense of in between that creates its own sense of third place.

However, one element of the criteria is lacking. The iteration does not actively reference mobility, although it could be argued that it is brought by the high amount of pedestrian foot traffic around the building.
In reflection, this iteration ensures the celebration of cross culture instead of actively referencing it. This iteration does not directly educate people, but does facilitate opportunities, by being public and create a space to make others aware of this topic.

The design ensures that the preserved large windows maintain a connection to the water. The interior also uses indoor plants to reiterate that connection to nature. The open interior spaces allow it to be both, adaptable for any use, and easy to personalize for its ever changing and different users. This iteration creates an in between space without relying on any narrative elements but by physical sitting in between the sea and land.

\section{SITE SELECTION}
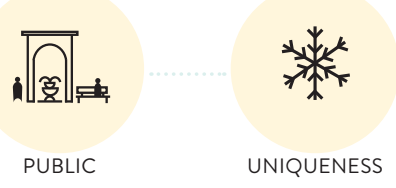

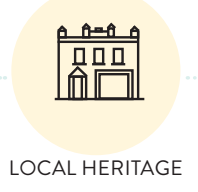

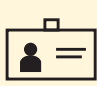

CULTURAL ID

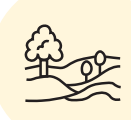

NATURAL LANDSCAPE

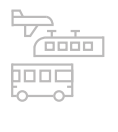

MOBILITY

\section{DESIGN TACTICS}

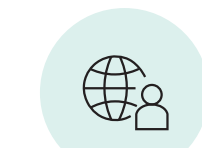

MULTI/TRANSCULTURE

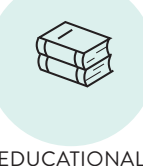

EDUCATIONAL

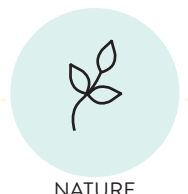

NATURE

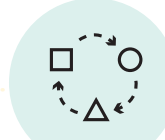

ADAPTABILITY
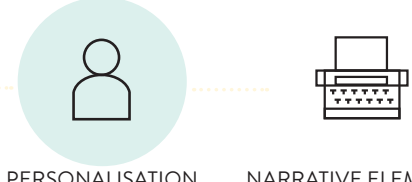

PERSONALISATION 


\section{REFLECTION}

$\mathrm{T}$

he final design for this iteration sits within the realm of conservation. While the shell of the Band Rotunda stays relatively the same, the complex access ramp and staircases at the front of the building have been removed. Access to the first floor is internal through a pair of sweeping ramps.

The overall composition aims to facilitate the concept of place being a container for experience. This is to allow for new memories to be created and to connect to a place.

The interior material reads as default and permanent. The interior is meant to feel flexible, so materiality could echo the impermanence its cross-cultural users feel in a place that is neither home nor new. The interior materiality needs a stronger contrast against the original building.
The temporary and flexible design inhabits the heritage building, while the exterior promenade ramp anchors it as a permanent expression, solidifying cross cultural people into society.

Instead of the ramp being two separate elements arriving onto the roof top, the ramp continues all the way through as one element up and over the front of the building as a second elevated promenade. Under the ramps are the new bathroom and changing rooms to continue to be used by beach goers.

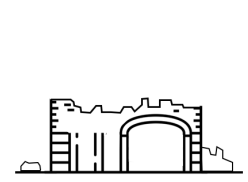

Demolition

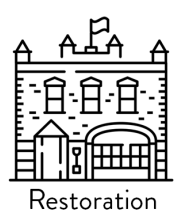

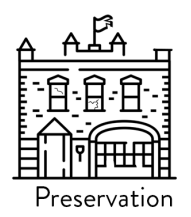

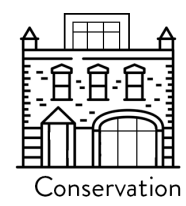



9. Iteration Three

\author{
History \\ Precedents \\ Design Process \\ Reflection
}




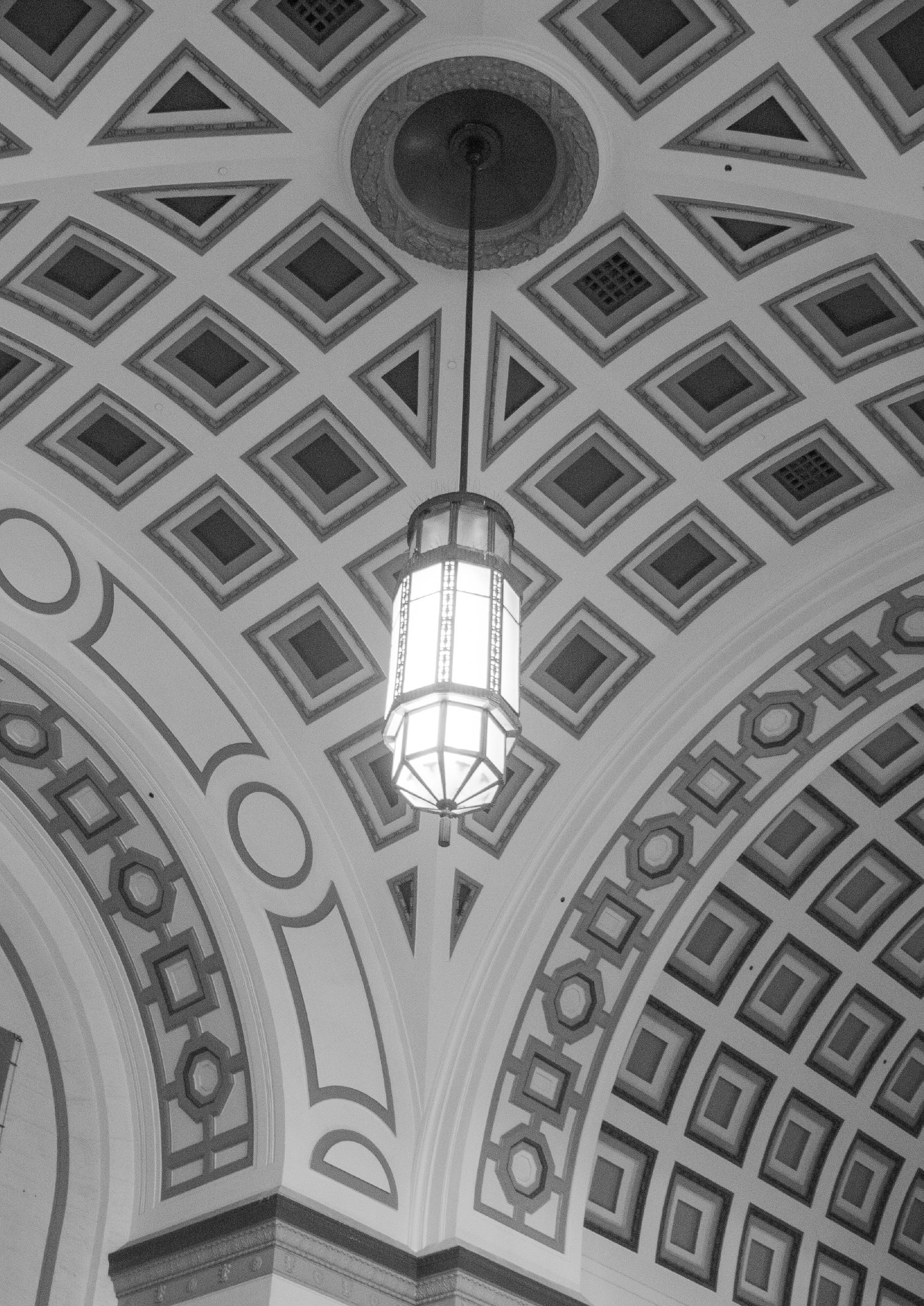


RAILWAY STATION

Bunny Street, Waterloo Quay And Featherston Street, Wellington

Category 1 


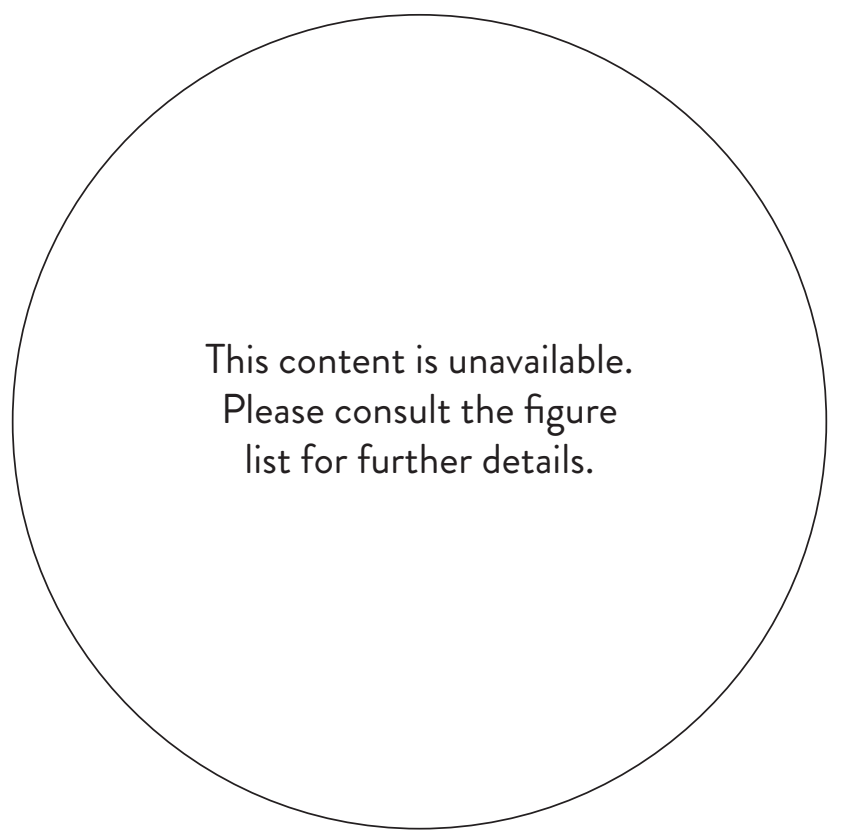

Figure.9.1: Lambton Railway station on Thorndon Quay 1924

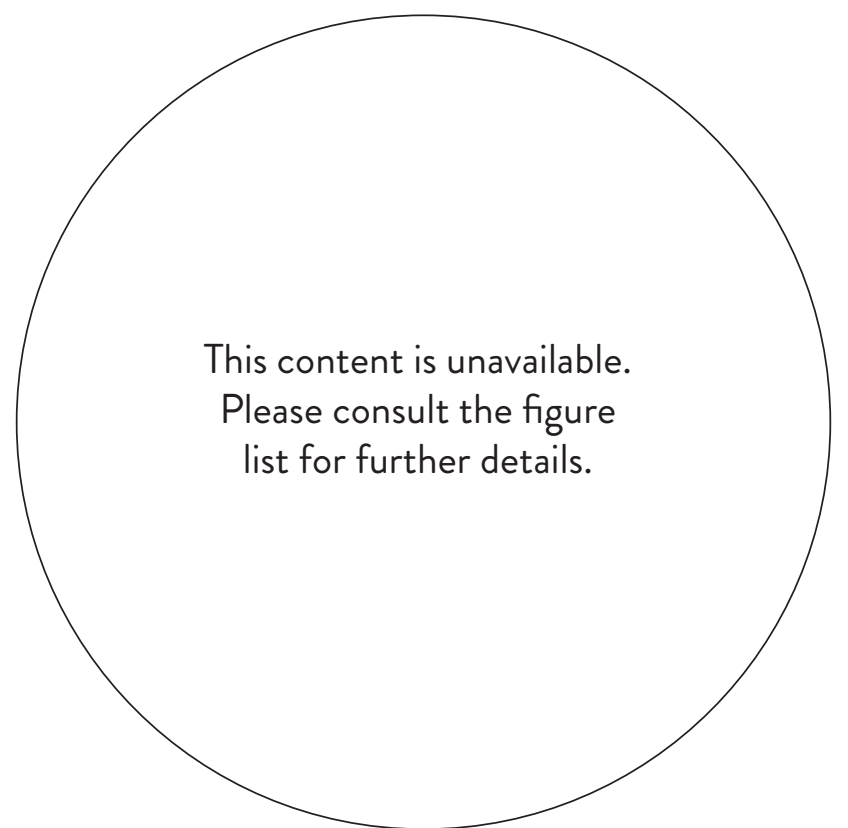

Figure.9.2: Wellington Railway Station 1937

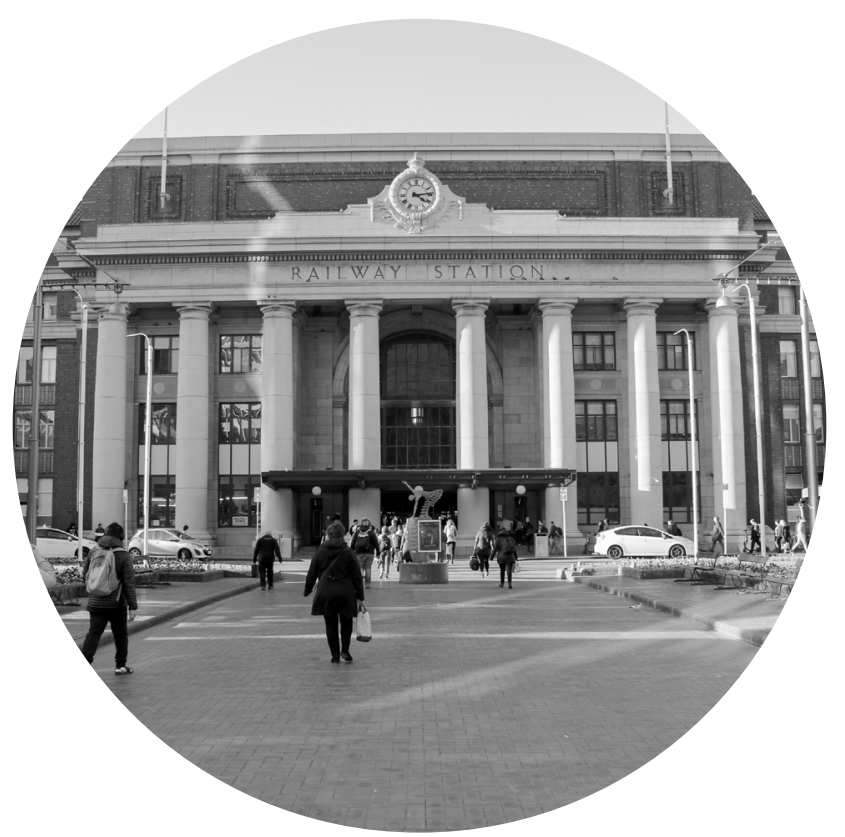




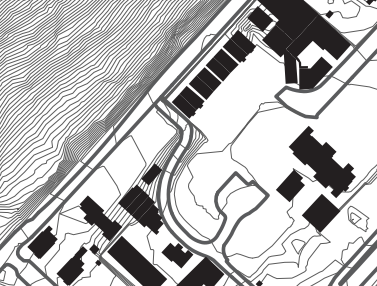

$+1$

(1) $\frac{1}{0^{2}-7^{2}}$

Actar
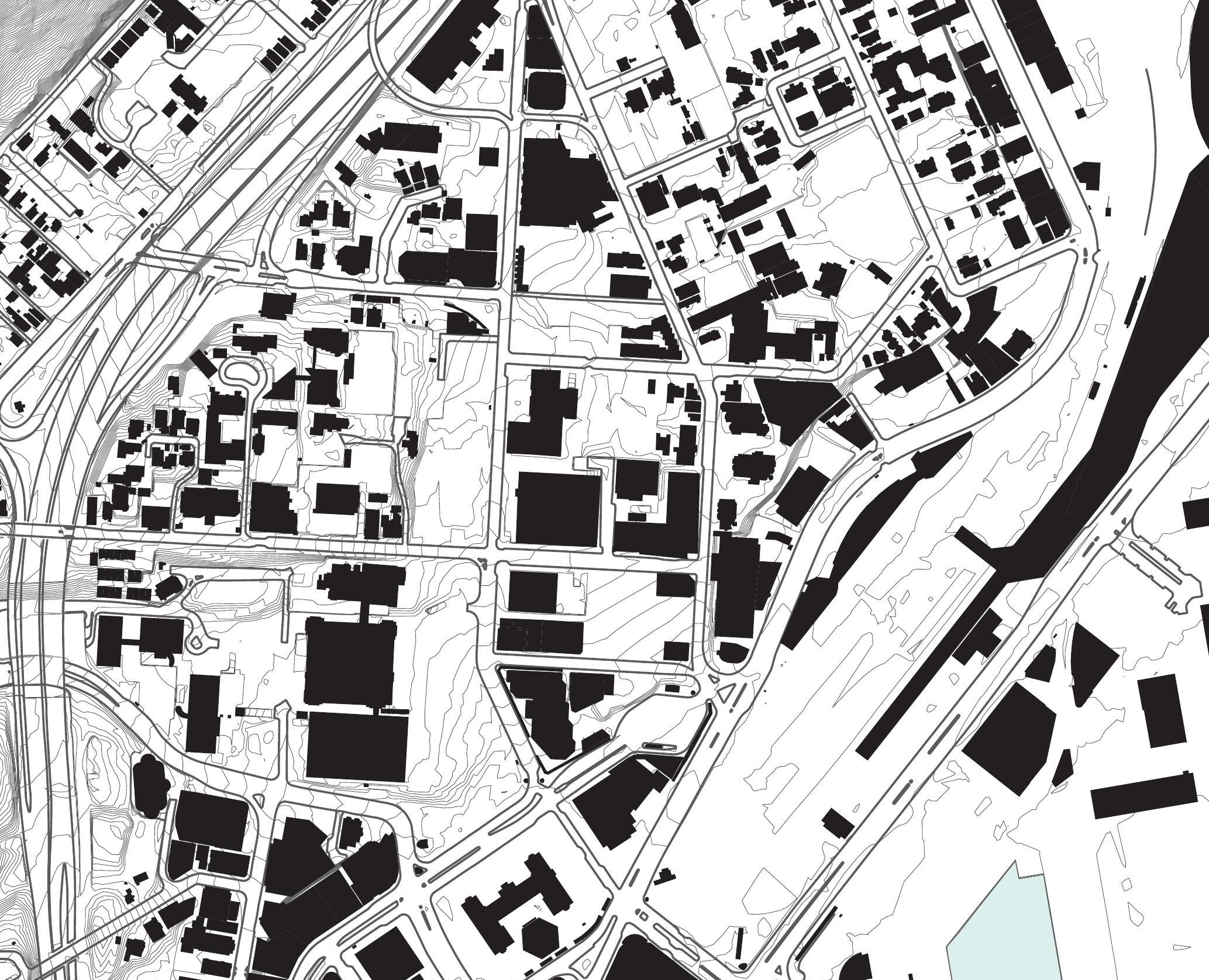

3)

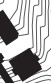

4

II 1

3 10 : $\rightarrow$ is?

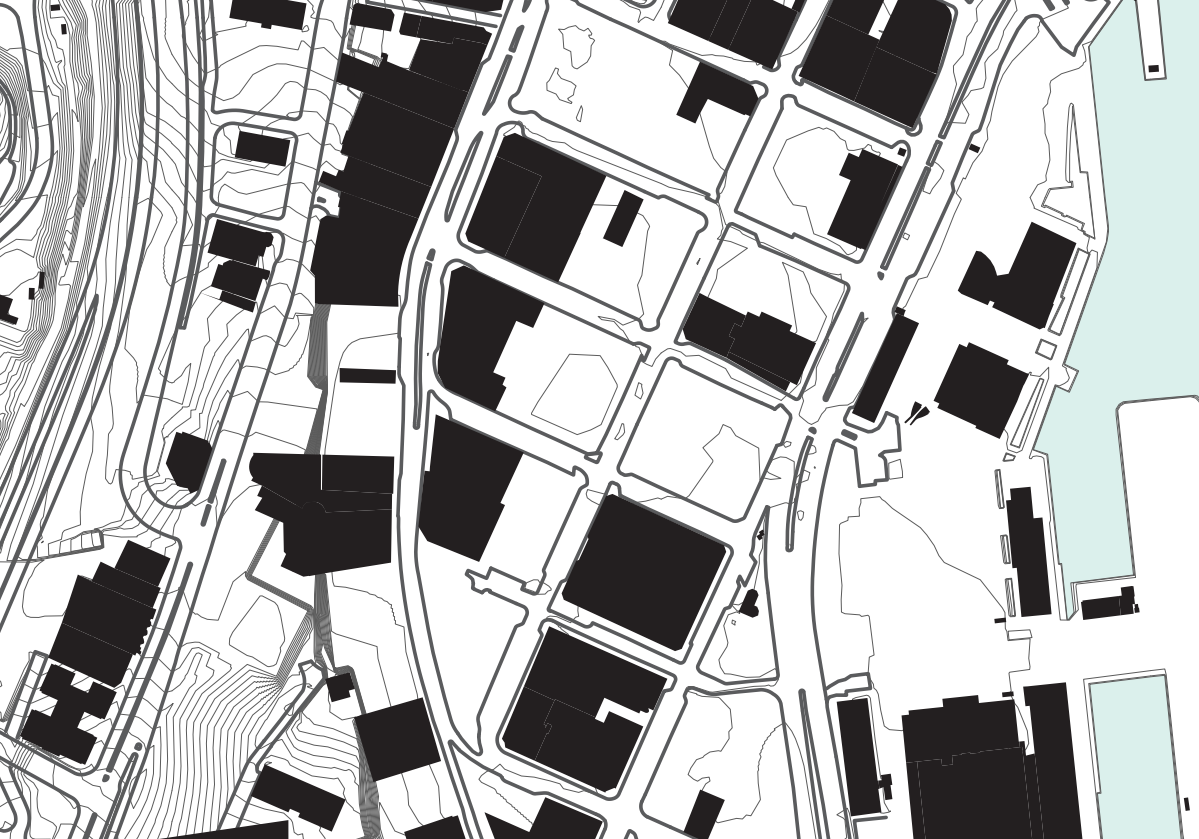


This content is unavailable.

Please consult the figure

list for further details.

Figure.9.5: Railway Station Elevation 1933

This content is unavailable.

Please consult the figure

list for further details.

Figure.9.6: Railway Station Side Elevations 1933 
This content is unavailable.

Please consult the figure

list for further details.

Figure.9.7: Railway Station Plan 1933

This content is unavailable.

Please consult the figure

list for further details.

Figure.9.8: Railway Station Plan 1933 


\section{HISTORY}

$\mathrm{T}$ he large Neo-Classical building and Beaux-Arts landscaping create a regal entrance to the North Islands Railway system.

This building is the third railway station in the area. The first was built in 1874 to create a link to the Hutt Valley, but unfortunately burnt down in 1878. It was replaced in 1880 to service the Wairarapa Line and then six years later a second station was built to accommodate the privately owned Manawatu Line (Wellington Railway Station, 2017). In 1908 the government bought the Wellington and Manawatu Line as their region began to outgrow its single platform station. This prompted a development coordinated by the government to undertake 28 hectares of land reclamation and developing a new main station (Wellington Railway Station, n.d.). Land reclamation started in 1924 and finished in 1932. The Fletcher Construction company began construction in July 1933 on the building designed by architects Gray Young, Morton and Young on a budget of $£ 339,137$ - a generous amount during the Depression. The station was opened in 1937, its design reflecting the importance of the development of the railway network, representing Wellington's central position in the railway network, it remains New Zealand's busiest terminal (Wellington Railway Station, n.d.).

The U-shaped building stretches 23.5 metres tall and 105.5 metre long. It sits on the reinforced concrete piles grounded down into the original harbour bed. Built out of Coromandel granite and a superstructure made up of a steel frame which is encased in concrete (Wellington Railway Station, n.d.). Inspired by modern structural Japanese Design, the outer walls are clad in red brick speared through with steel reinforcing (Wellington Railway Station, 2017). The buildings elevations use a tinted cement render and coloured tiles under each window and eight, thirteen metre Doric columns dominate its front façade. Five of the six floors were used as offices for the Railway department.

The ticketing large hall uses Whangarei and Hanmer marble with a compass pattern in its centre (Wellington Railway Station, n.d.).

Behind the main building is the smaller social hall building that sits above the head offices garage. The hall was built for the rail workers to socialise and was used for a variety of social events (Wellington Railway Station, n.d.).

In 1982 the Rail Department cut staff numbers and its spare offices were leased out. Six years later the ground floor of the station was re-arranged with the barber shop and men's lavatories were converted into a café and bar and the women's waiting rooms were changed into toilet blocks. The original dining room and kitchen was also converted into more offices (Wellington Railway Station, n.d.). In 2000 Tranz Rail transferred the head offices to Auckland and three years later 3 floors in the west wing were given a new layout to be able to lease it to Victoria University. The old booking hall was also converted into a supermarket in 2007. 


\title{
REASONING
}

\begin{abstract}
This site was chosen for its strong significance to the local heritage. Hailed as one of the finest public buildings in New Zealand, it sets the perfect scene for a group of people that struggle to feel a part of something bigger. The setting of a busy railway station creates a familiar environment for Cross Cultural people and in particular TCKs who have strong attachments with mobility.

The building exudes cultural identity as it symbolises the early development of the country's railway, showcasing Wellington's Engineering Heritage.

This building creates a unique opportunity as one of the most used heritage listed buildings in the city. As the station is a Category One listed building, it has a different level of protection. With little able to be altered this creates a design challenge, adding another level of experimentation for this iteration.
\end{abstract}


This content is unavailable.

Please consult the figure

list for further details.

This content is unavailable.

Please consult the figure

list for further details.
This content is unavailable.

Please consult the figure

list for further details. 


\section{LE DIAMANT THEATRE}

ocated in Quebec Canada is the Le Diamant

Theatre. The Second Empire styled building was built in 1879, the building was designed by Joseph-Ferdinand Peachy, an associate of Charles Baillairgé. The building was occupied by the YMCA until the 1940s, afterwards only the ground floor shop was used while its upper stories fell into disrepair (Le Diamant - The Building, n.d.).

In 2018 the building was remodelled to join with its neighbouring theatre, with only its front facades remaining. The new development holds offices, a multipurpose performance hall with $600+$ seats and large entrance foyer (Le Diamant - The Building, n.d.). The tessellated glass structure intersects between the old facade and theatre hall acting as a place of light and allows the public to disperse. The diagonal cut through the site was inspired by urban analysis as the old city met with the new grid layout with the original building meeting in its way (Coarchitecture, 2018).
While this precedent only utilizes the heritage building's facade, it shows an interesting process of developing and future proofing its existence.

The removal of that much of the station's fabric would not be acceptable, but this precedent explores interesting connections between the old and new characteristics.

The juxtaposition of materiality and composition creates a stunning form and would be an interesting experiment to apply to this iteration. The idea of cutting through the building and experimenting with the concept of third place within the building. 
This content is unavailable.

Please consult the figure

list for further details.

This content is unavailable.

Please consult the figure

list for further details.
This content is unavailable.

Please consult the figure

list for further details. 


\section{AUCKLAND ART GALLERY}

$\mathrm{N}$ ew Zealand's very own Auckland Art Gallery - Toi o Tāmaki recently went through a major development in 2018. The French Château styled gallery is recognized by Heritage New Zealand as a Category One listed building. The building was designed by Melbourne architect John Grainger and Charles D'Ebro as Auckland's first civic building (Building -A Place for Art, n.d.). Opened in 1887, the building was used as a library, municipal offices and gallery spaces. 100 years on and the gallery occupied the whole building having extended it on three separate occasions (Barrett, n.d.). These extensions added considerable character to the building, including the Mackelvie gallery and the research library. The new addition took six years to complete, finally opening to the public in 2011. The new design by Australian firm FJMT and New Zealand firm Archimedia aims to retain the original Château and Mackelvie gallery features while sensitively combining the 21 st century addition. The new elements aim to enhance the relationship with the old Māori Pā in Albert park, reflecting a 'commitment' to biculturalism (Barrett, n.d.). Overall, this building aims to connect its audience with art, heritage and place (Barrett, n.d.).
The Category One listed building exemplifies the stunning balance of the heritage conservation of the original building and its new addition. The new building neither overpowers nor shies away from its heritage counterpart. The original facade still stands tall and unavoidable in its corner location, while its addition slots into it with a sympathetic but grand facade of its own. Playing with a juxtaposition of materiality and scale, with its multi-story spaces.

This iteration will aim to connect its users to art, heritage and place from a cross cultural perspective. Extending the railway station to create large gallery spaces will facilitate a public location able to enhance the 'entrance' of Wellington's CBD. 


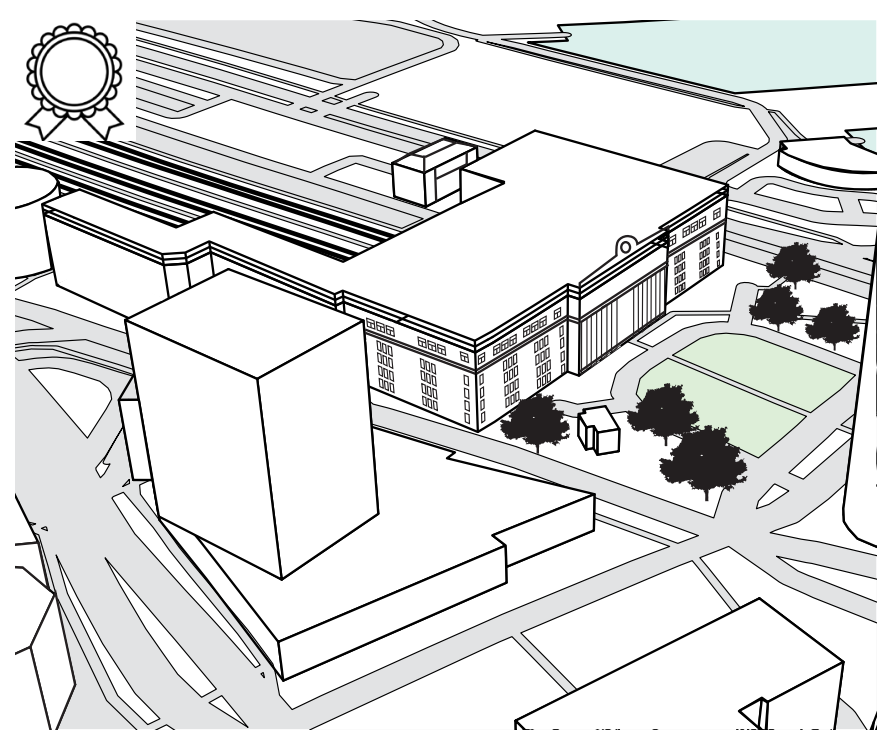

Original building

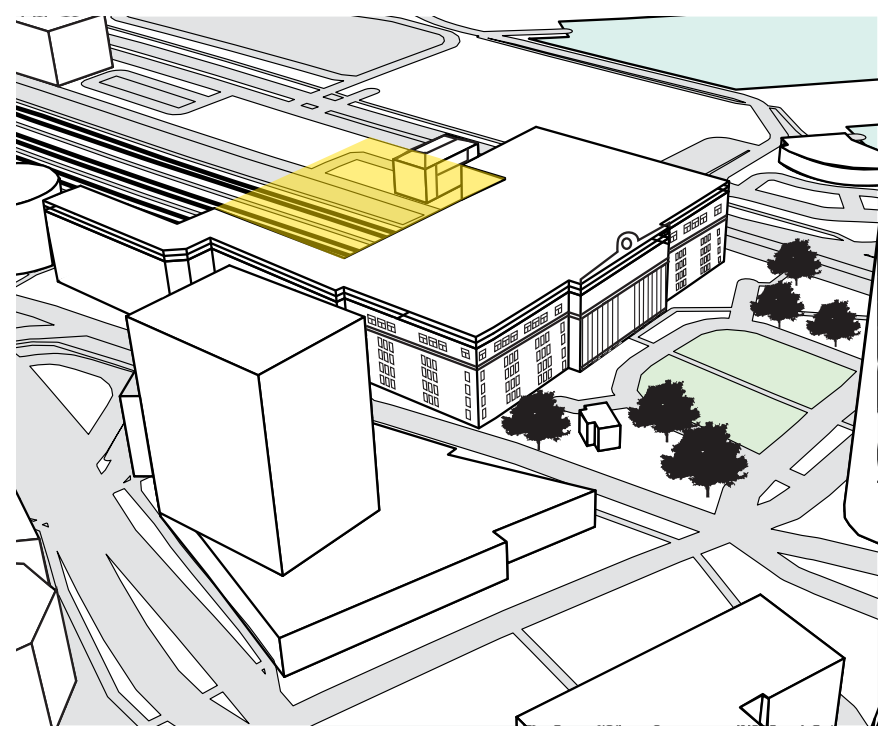

Area of interest

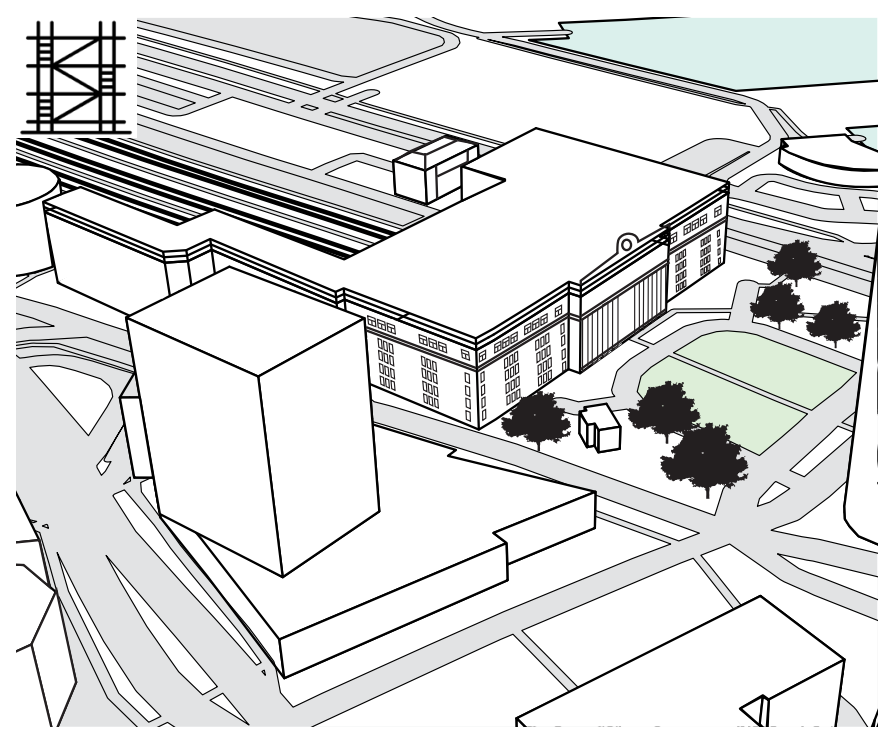

Unchanged

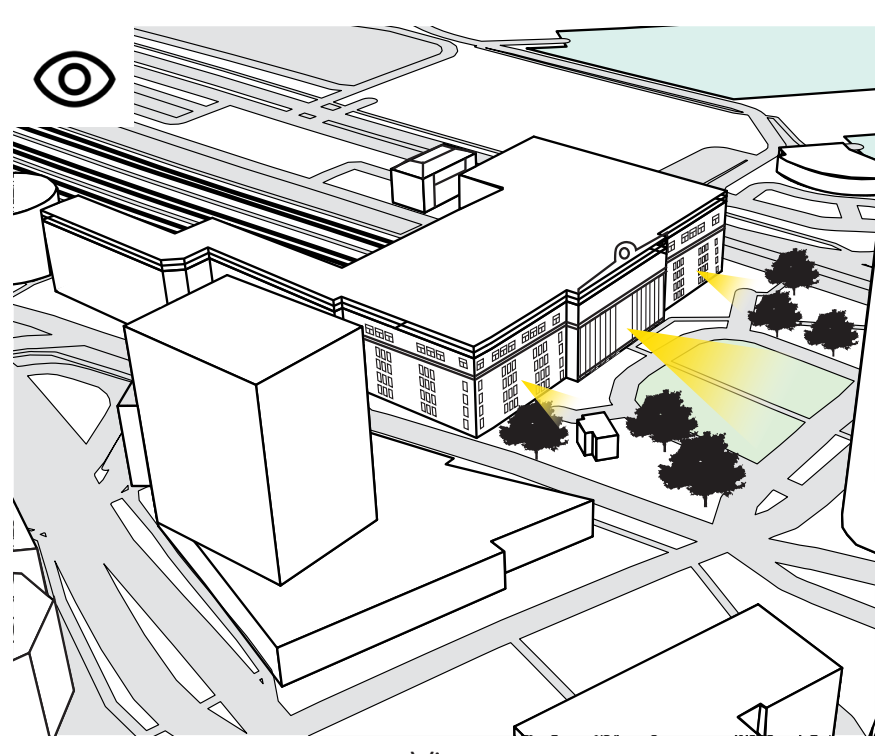

View

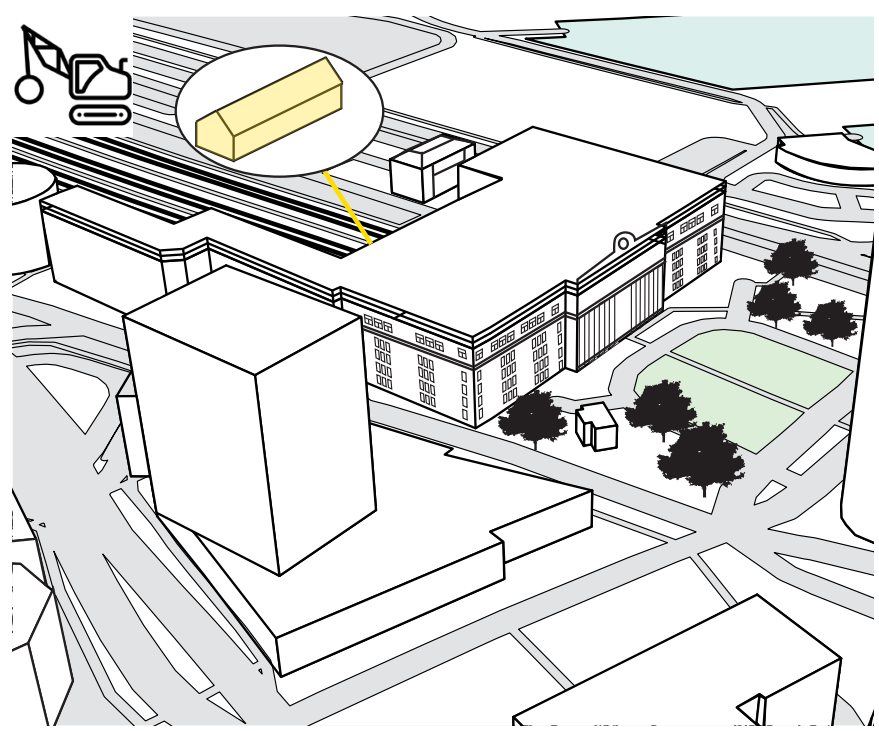

Demolition

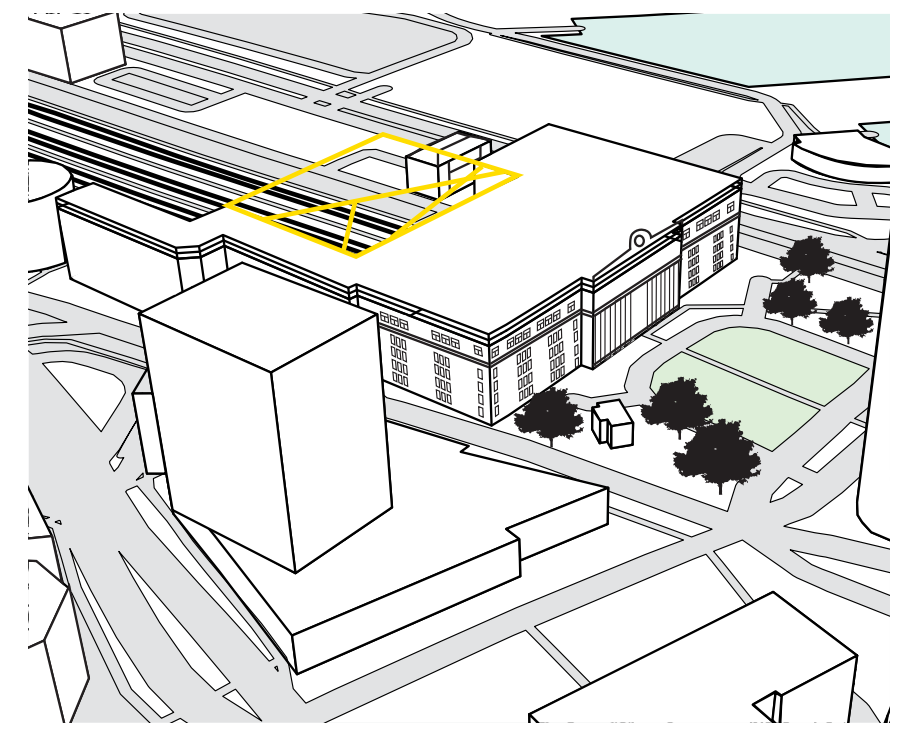

Proposed intervention 


\section{DESIGN DECISIONS}

Taking note from the Auckland gallery project, this iteration will aim to slot into the existing Category One building, not taking centre stage, but significantly adding to the experience of the building. This iteration will continue to facilitate the primary original use as a main train station but will reuse the old office spaces as a new transcultural gallery in an attempt to unite and educate the public on the mixing of cultures which is definitely relevant for the New Zealand context as a large percentage of citizens were not born here. As the gate to Wellington, this site will be a perfect place to discuss the topic of transcultural people. 
Wellington Railway Station
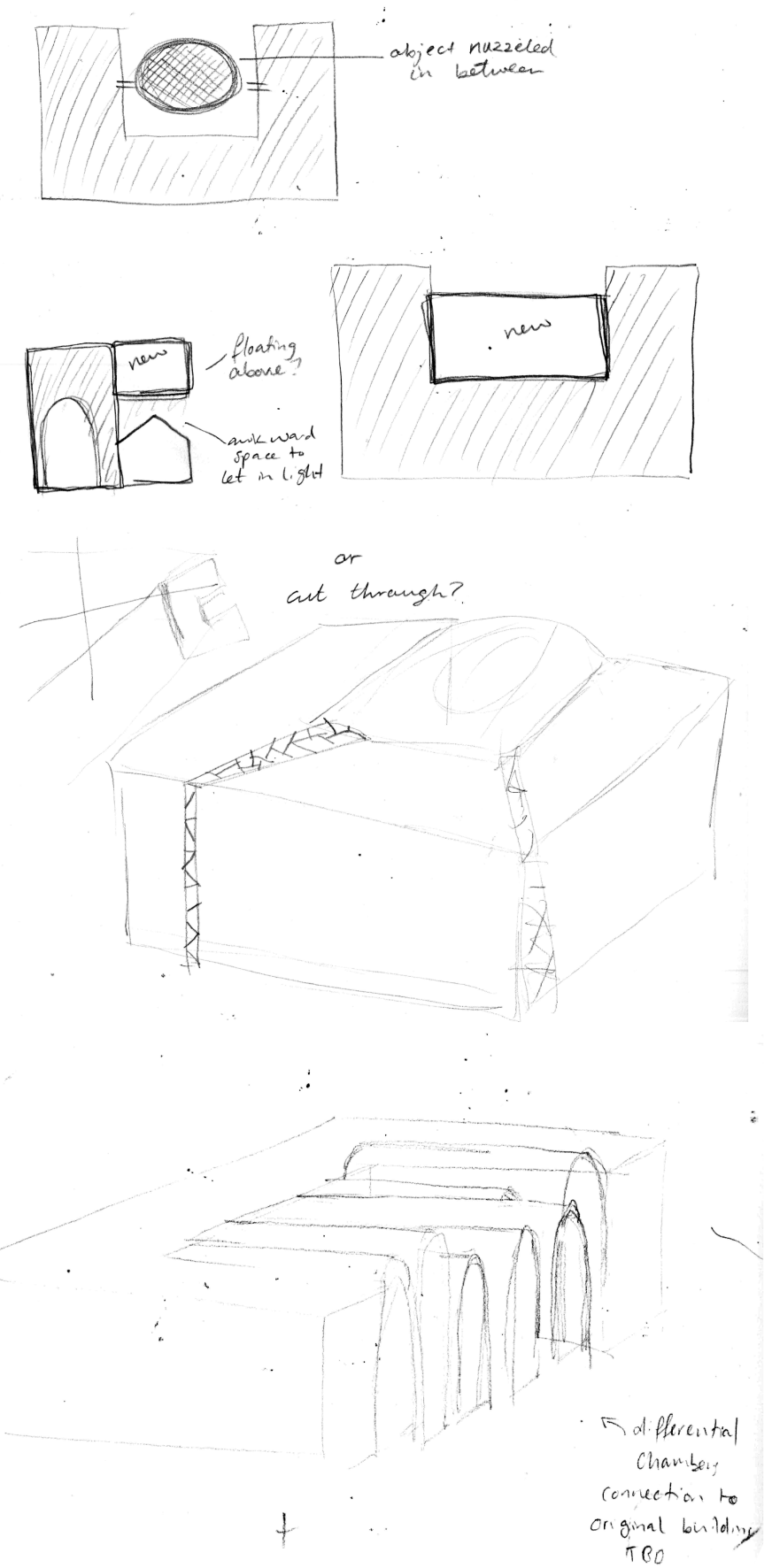
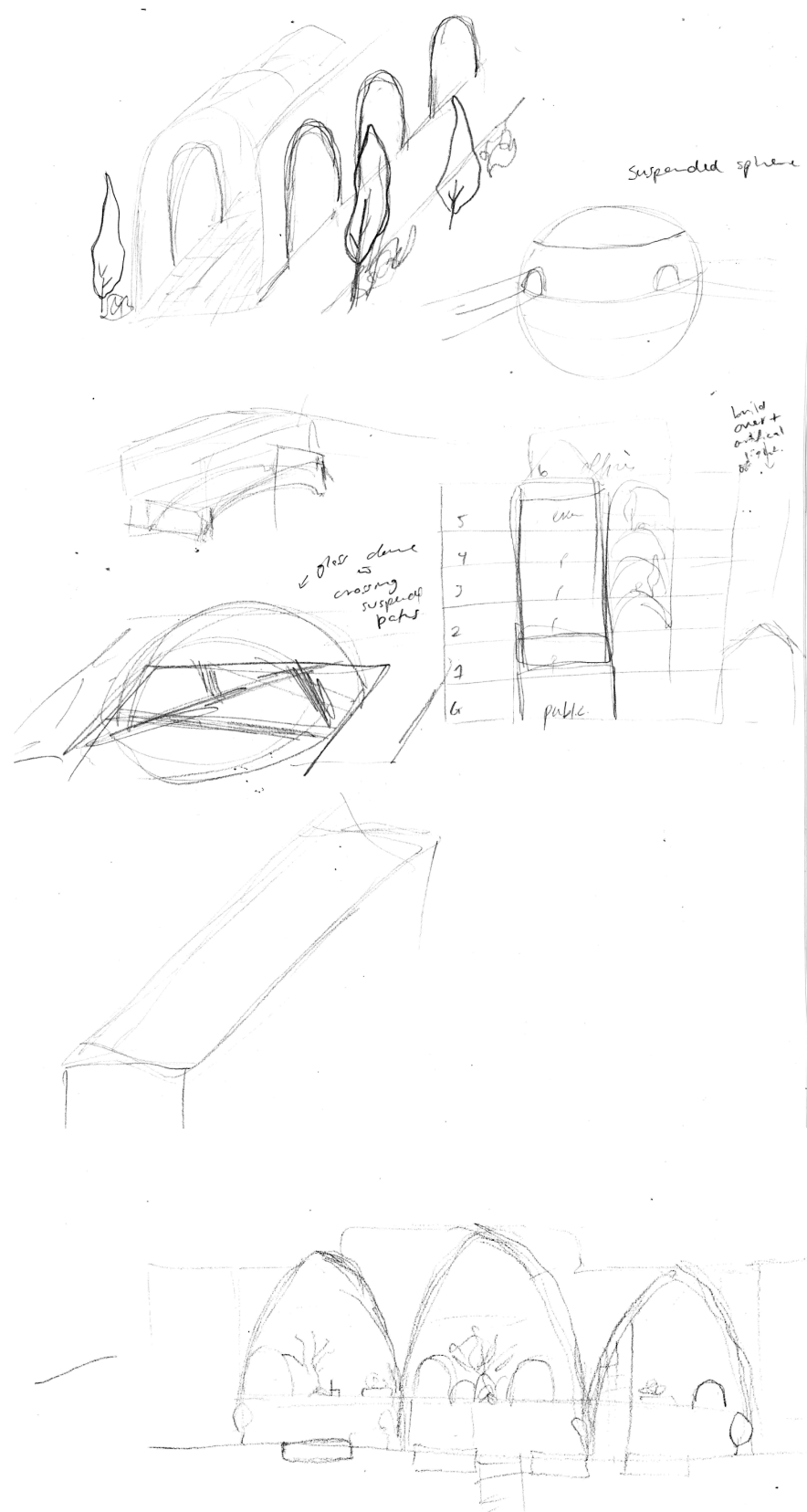

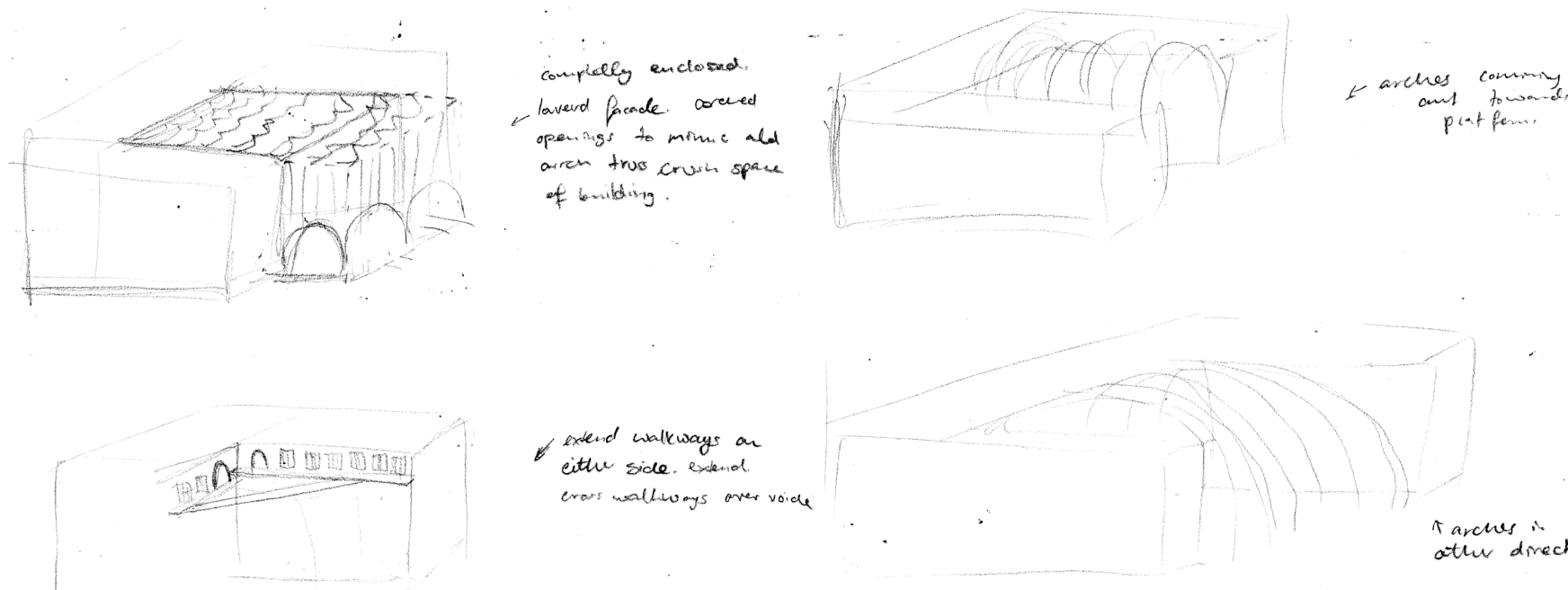
6 extend walkways an
erours walliwarys over voide

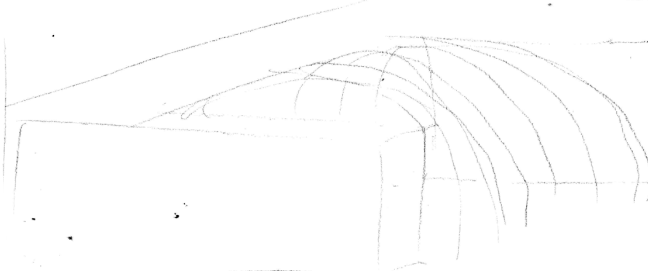

rarches irection

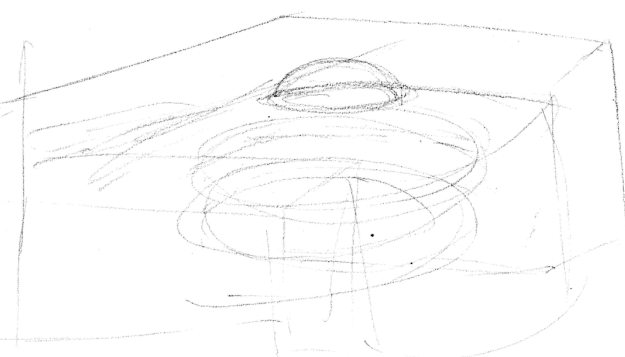

- sporaling

+ void space

incivades a olome

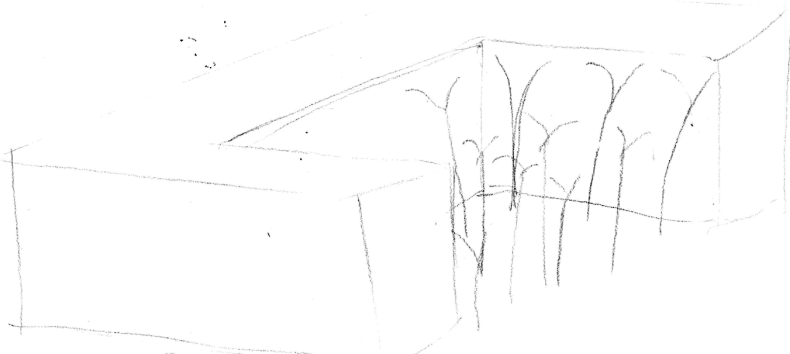

Figure.9.13: Sketch development continued 


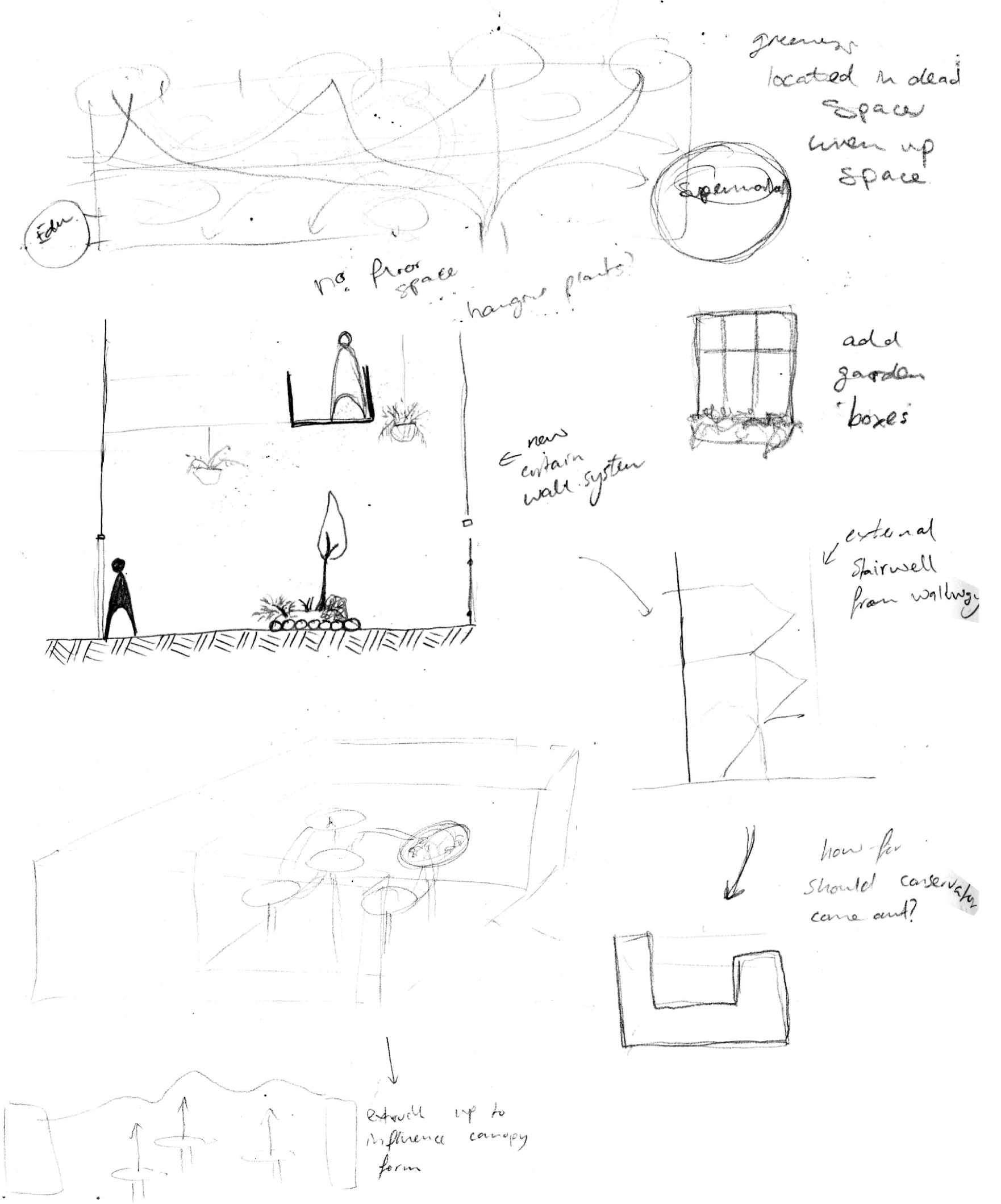

Figure.9.14: Sketch development continued 


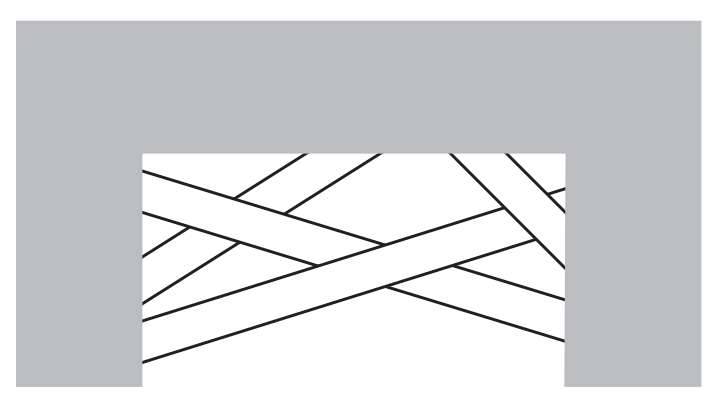

Non-connection walkways

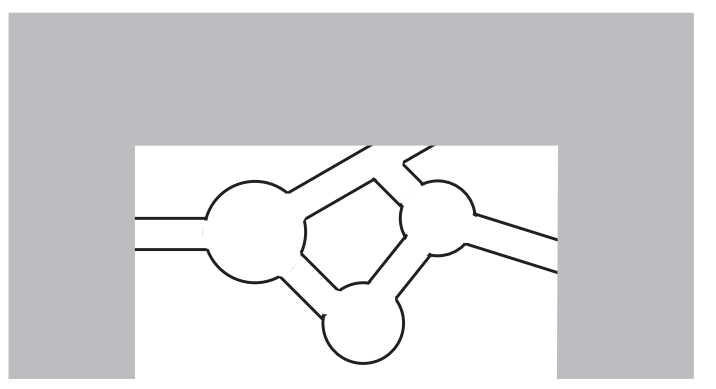

Exaggerating connecting points

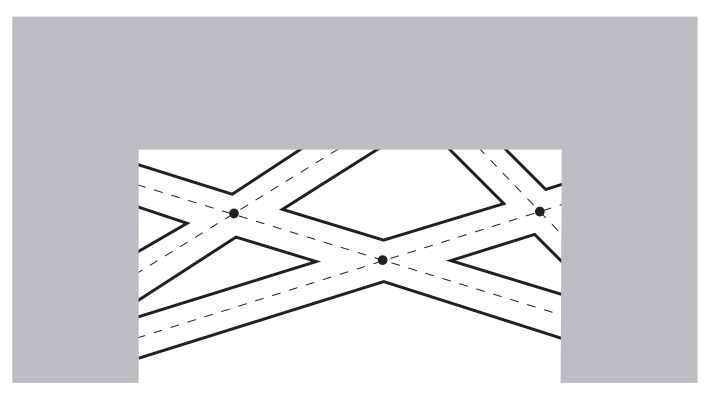

Conjoint walkways

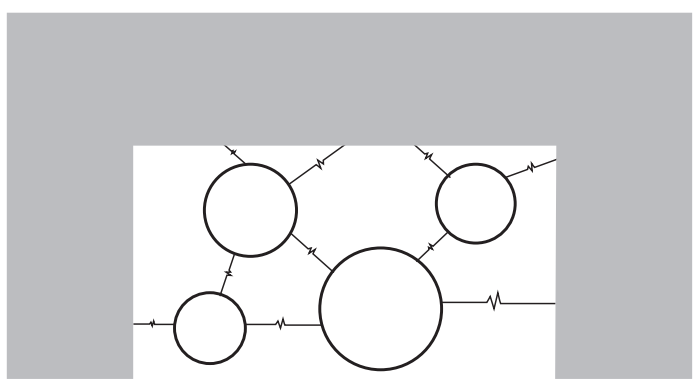

Points with connections

Platform arrangements influencing contours of the canopy above 
田囘田田田田田田田田田

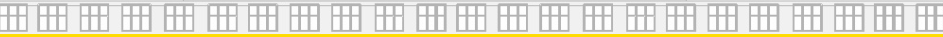

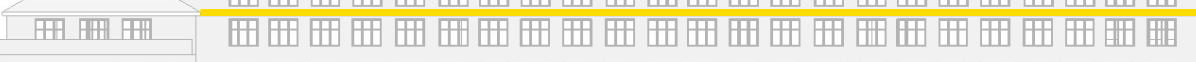

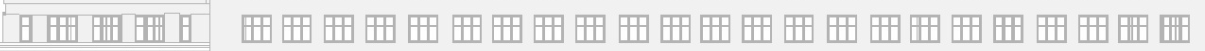

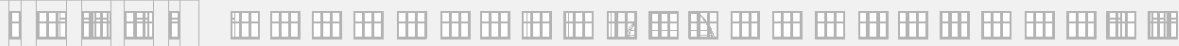

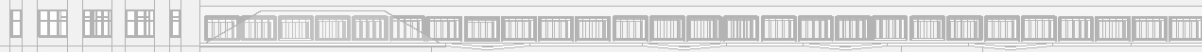

日曲囘囘 日

$\mathbb{P} \mathbb{A}$ 昍

畍 昍

畍 昍

明

North Elevation

田田田田田田田田田田田

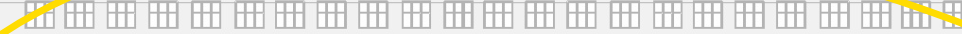

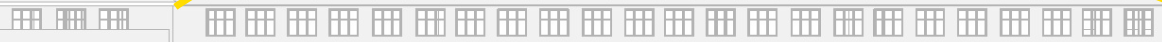

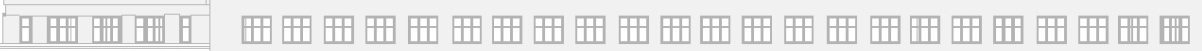

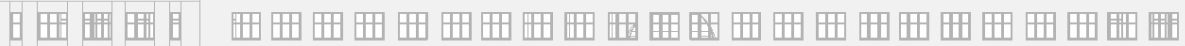

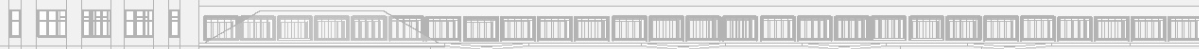

日田田田日

畞

㽢 昍

畔 昍

明 昍

North Elevation

田田田罡田田田田击思田

\begin{tabular}{|c|c|c|}
\hline & 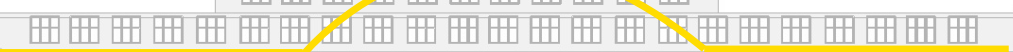 & \\
\hline 囘 刪冊冊 & 田田田田田田田田田田田田田田田四田田田田田四四 & \\
\hline 日曲曲曲旦 & 田田田田田田田田田田田田田田田田田田田田田四回 & 田田 昍 \\
\hline 日曲曲囲目 & 四田田田田田田四田四田田田田田田田田田田田四粗 & 畔 昍 \\
\hline 日田朋囲目 & 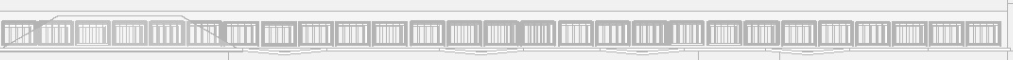 & 畾 昍 \\
\hline 日曲田理日 & & 明 明 \\
\hline
\end{tabular}

North Elevation

田田田田田田田田田田田

\begin{tabular}{|c|c|c|}
\hline & 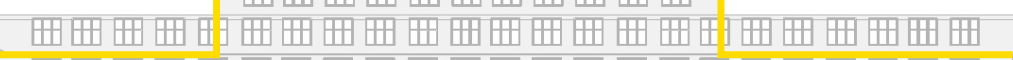 & \\
\hline 曲 姗冊 & 田田田田田田田田田田田田田田田田田田田田田四四 & \\
\hline 日曲曲曲日 & 田田田田田田田田田田田田田田田田田田田田田四四 & 田田 昍 \\
\hline 日曲脨冊目 & 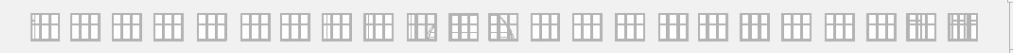 & 畔 昍 \\
\hline 日田佣囲目 & 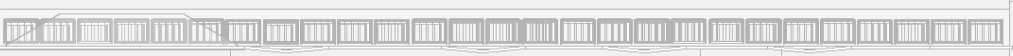 & 㽘 昍 \\
\hline 日田田田日 & & 明 明 \\
\hline
\end{tabular}

North Elevation 
田囘囘囘田田囘囘囘田田

田田田田田田田田田田田田田田田田田田田田田田两

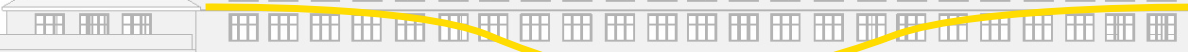

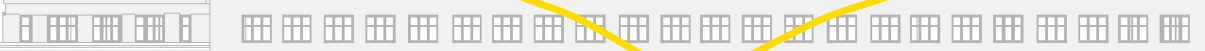

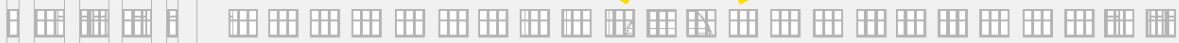

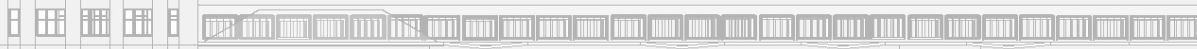

日曲田囘旦

$\mathbb{B A B} \quad$ 明

畔 昍

畉 昍

明 明

North Elevation

田田田田田田田田田田田

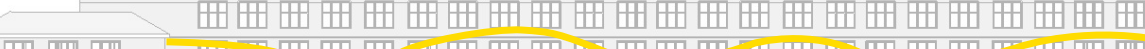

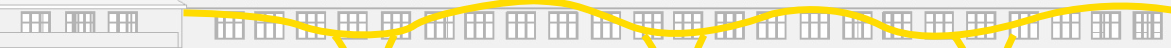

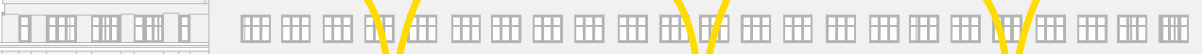

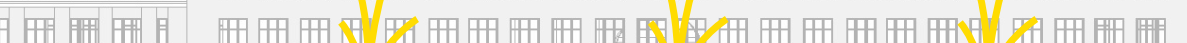

c

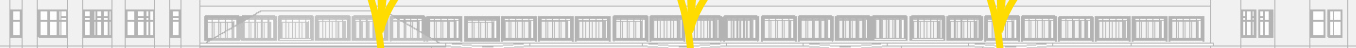

日田田田日

明昍

North Elevation

田田田田田田田田田田田

\begin{tabular}{|c|c|c|}
\hline 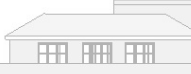 & 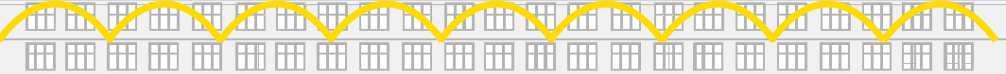 & \\
\hline 日曲冊曲日 & 田田田田田田田田田田田田田田田田田田田田四四 & $\mathbb{A P A}$ 昍 \\
\hline 日曲脨囲目 & 四田田田田田田四田四四田田田田田田田田田田四明 & 㽗 昍 \\
\hline 日曲佣囲目 & (1) & 㽖 昍 \\
\hline 日田田四 日 & & 明 时 \\
\hline
\end{tabular}

North Elevation

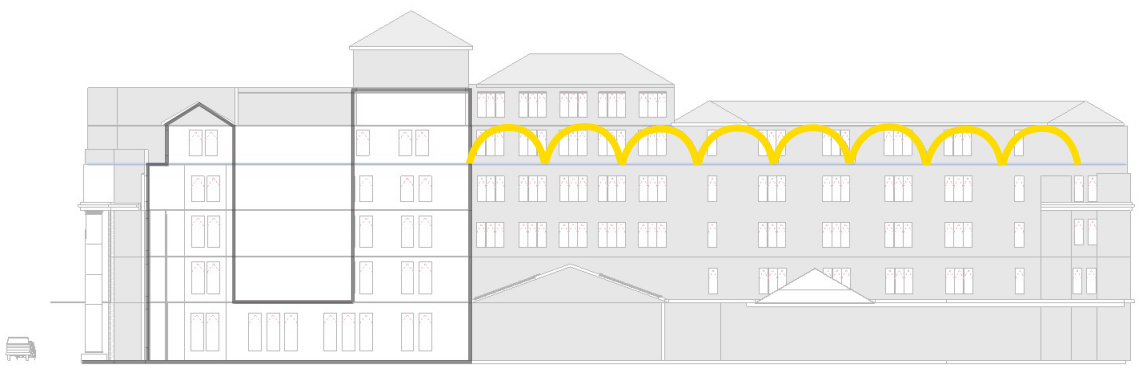

East Elevation

Figure.9.16: Canopy iterations 


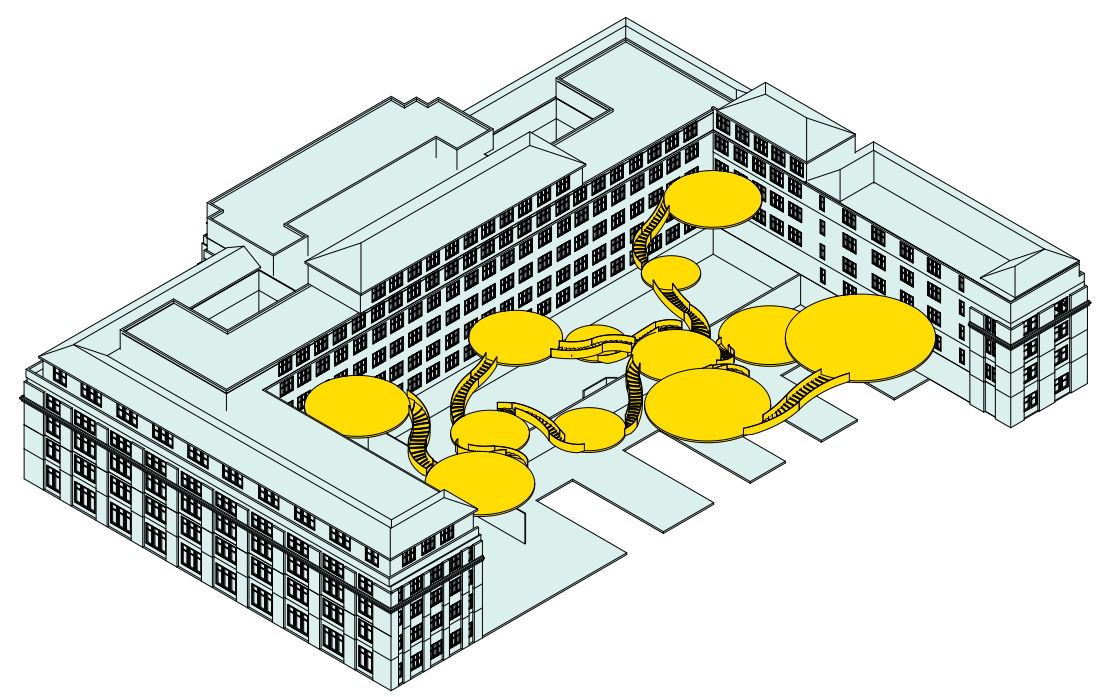

Arrangement of platforms

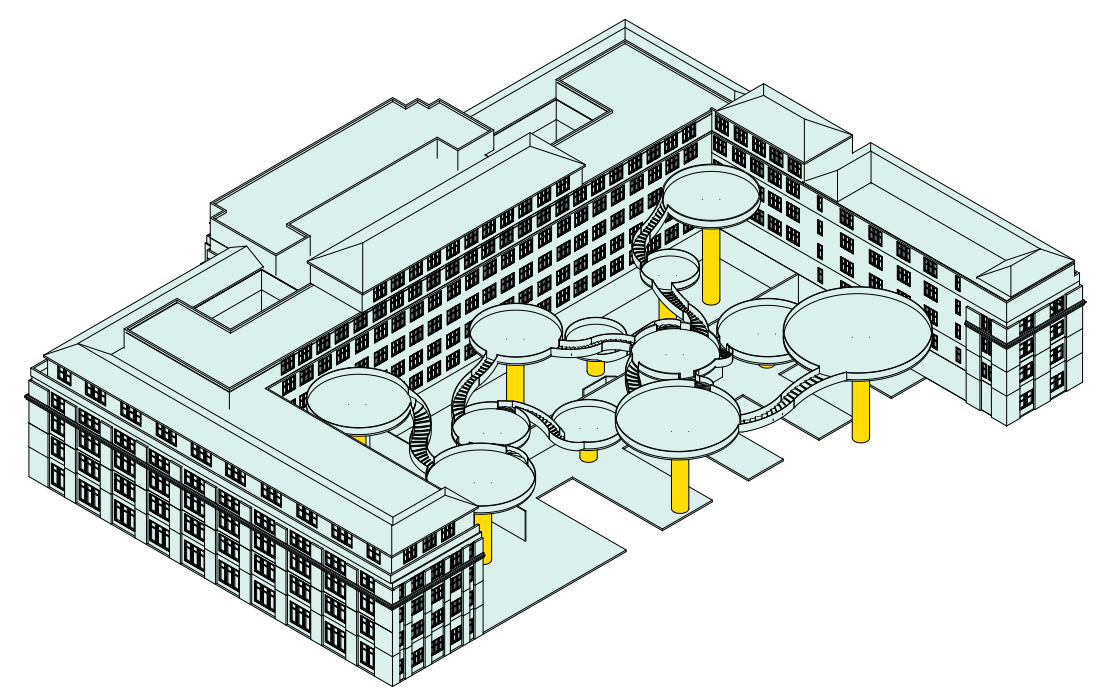

Trunk Supports

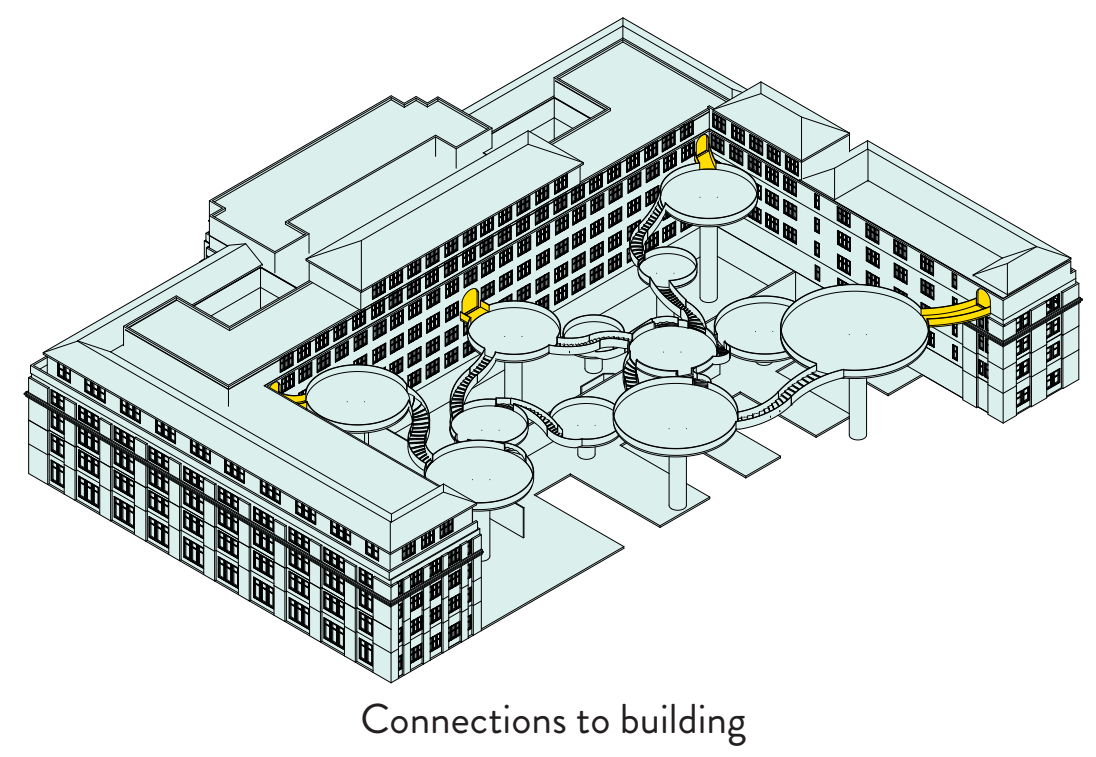




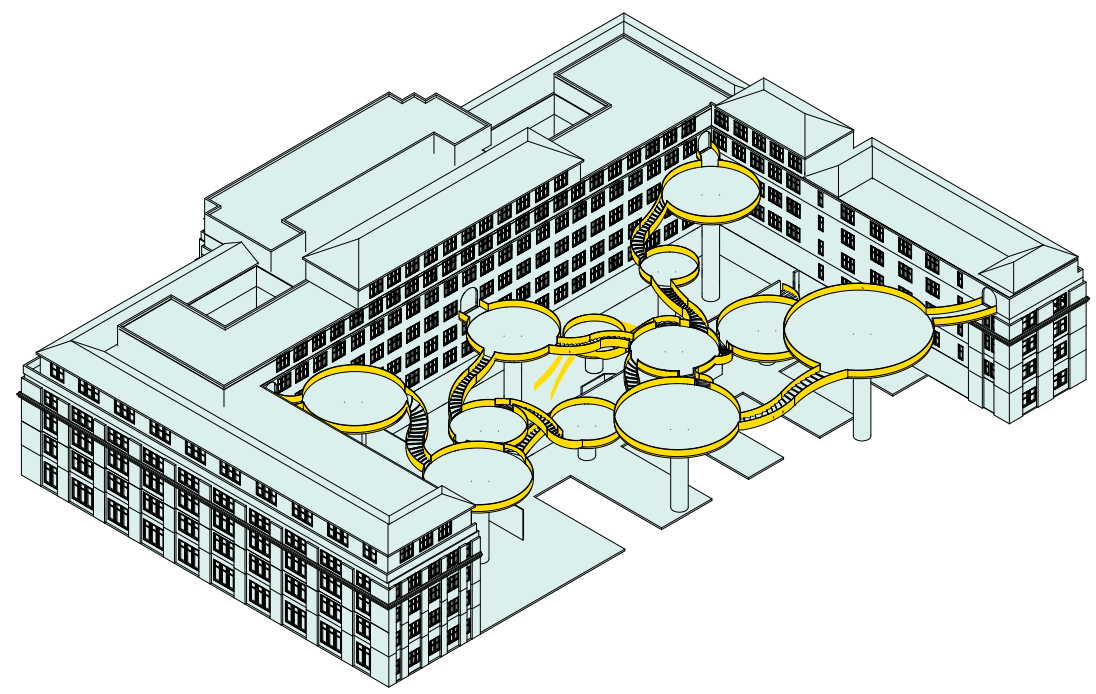

Solid balustrade

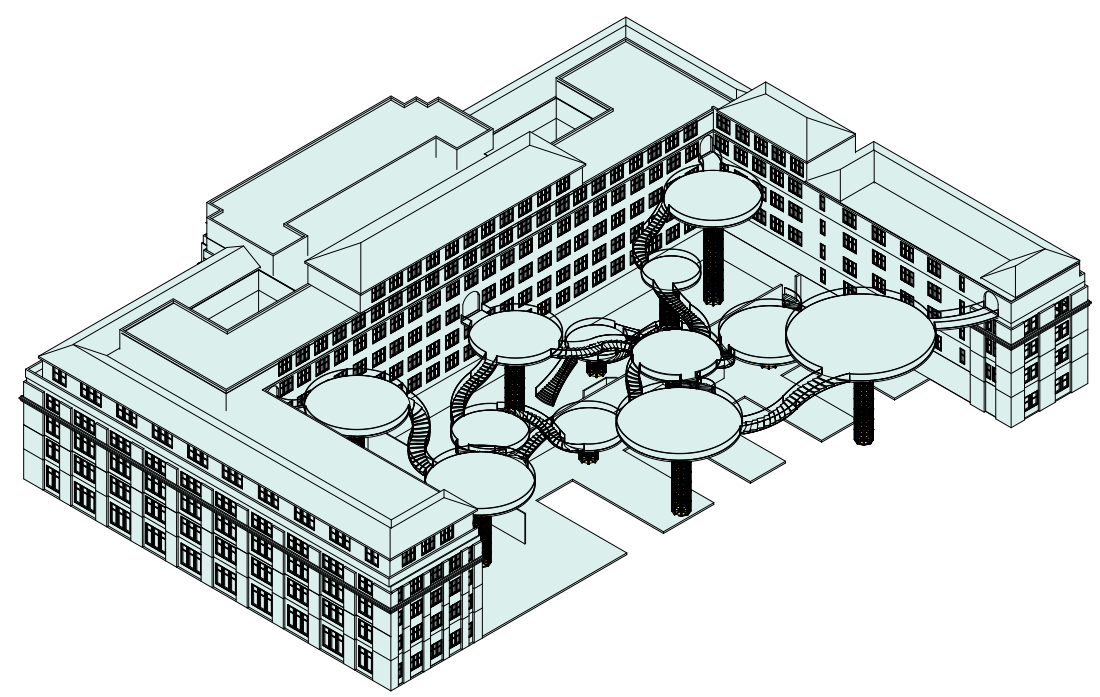

Structured Supports

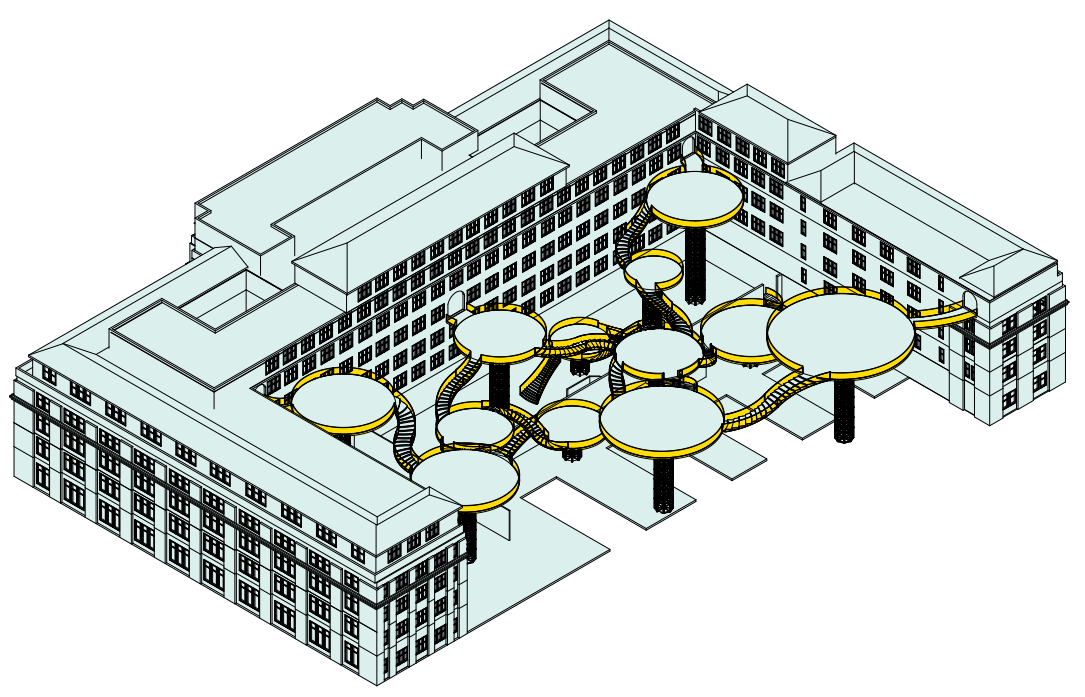

Transparent balustrade 


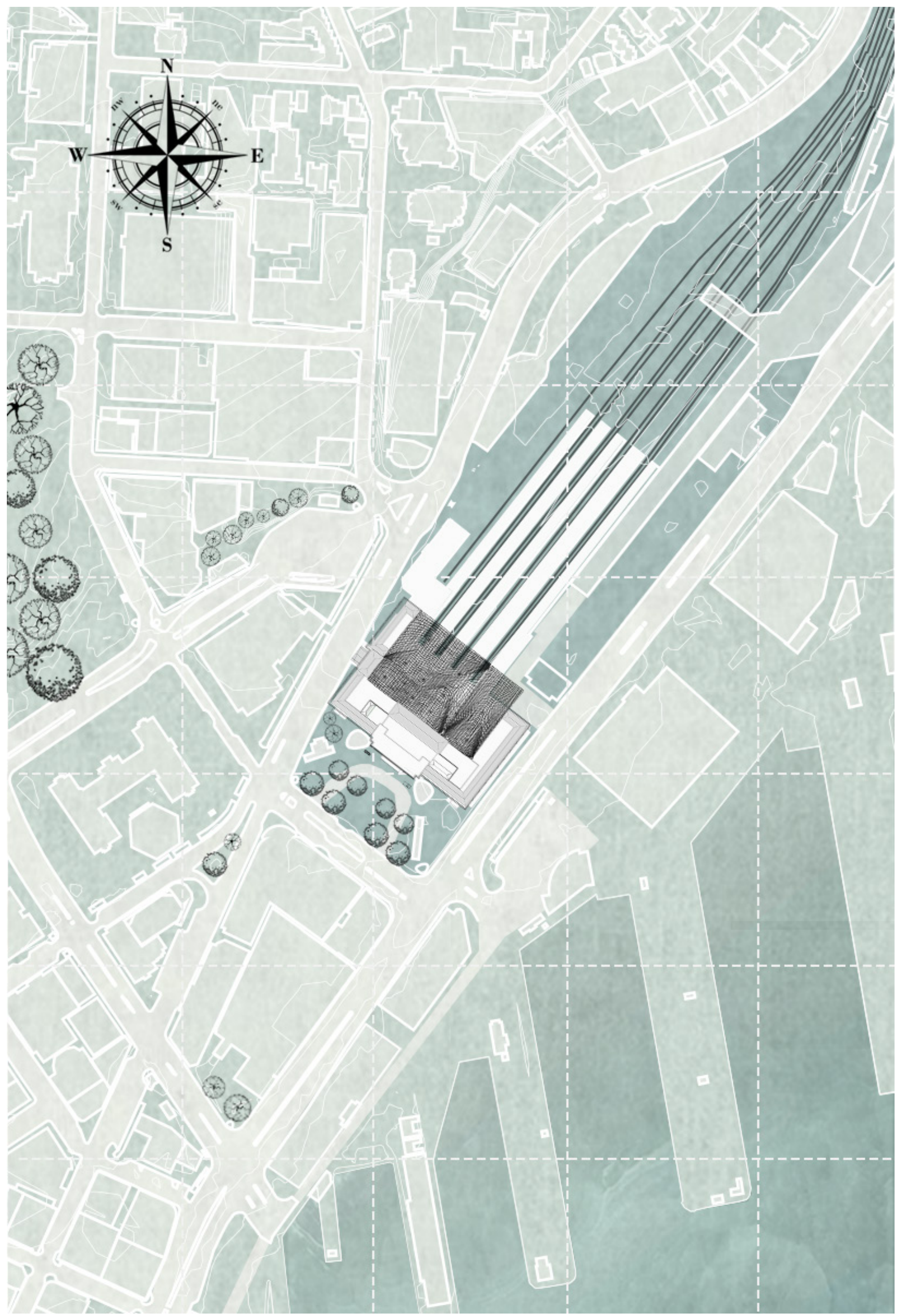


A Transcultural Gallery 


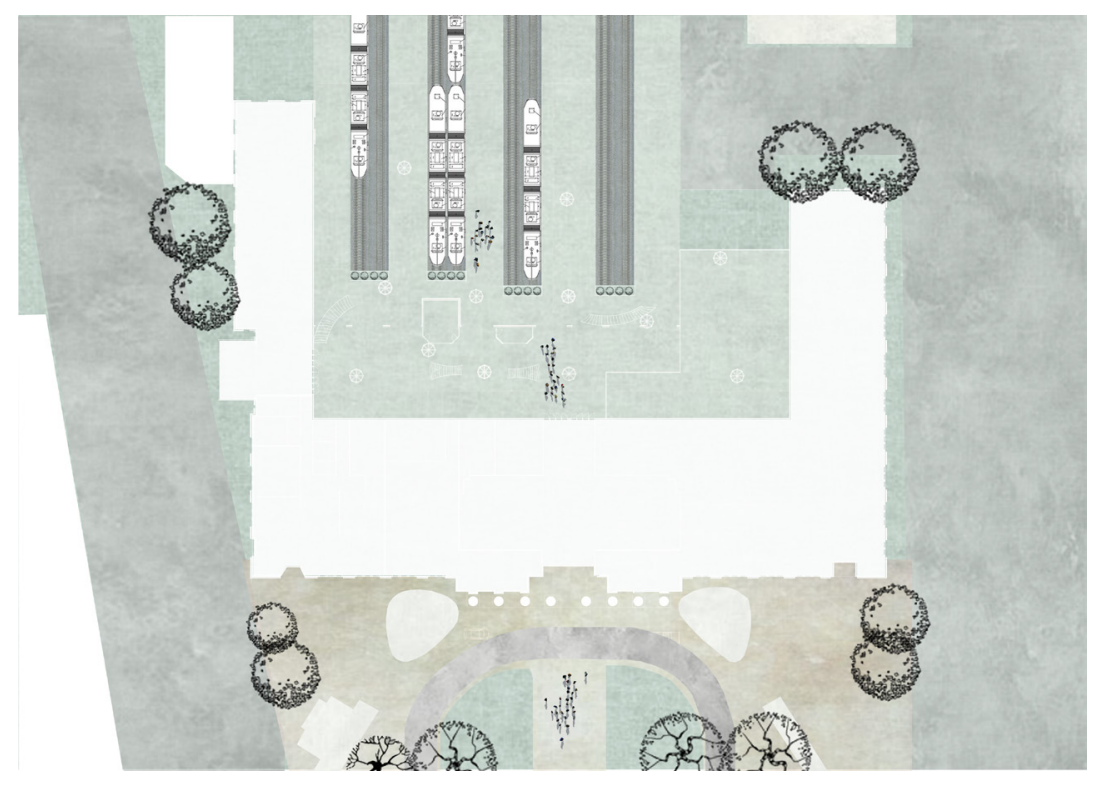

Figure.9.19: Ground floor plan

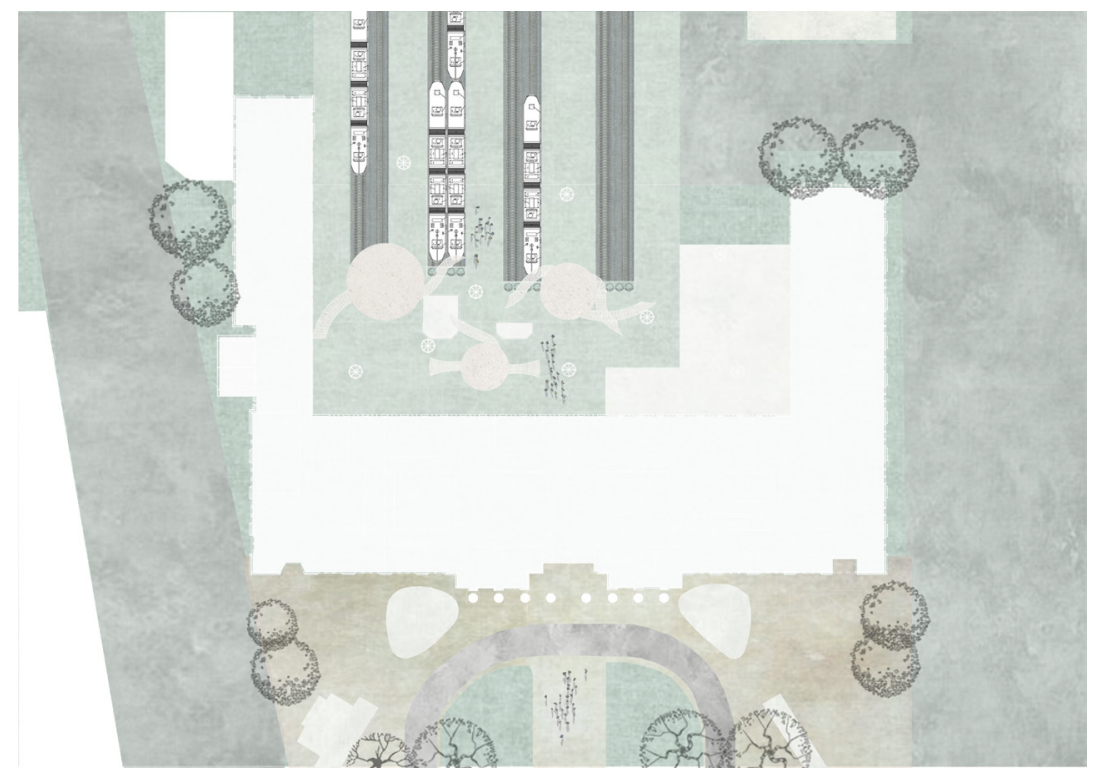

Figure.9.20: First floor plan

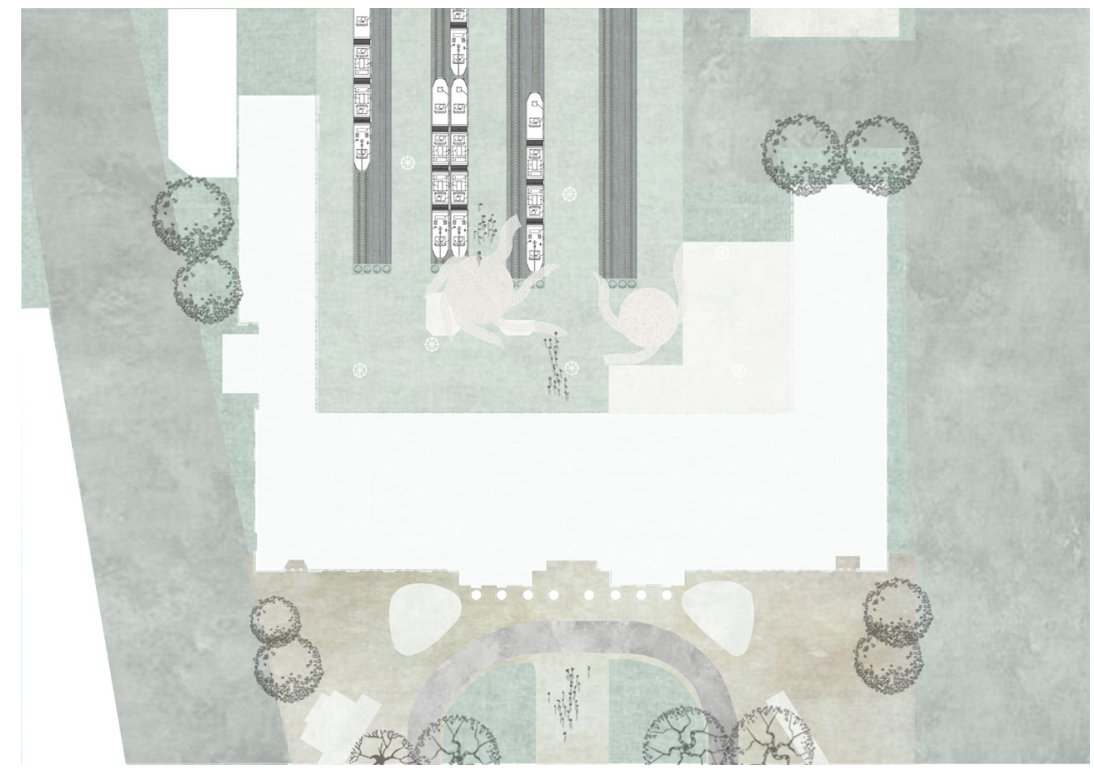

Figure.9.21: Second floor plan 


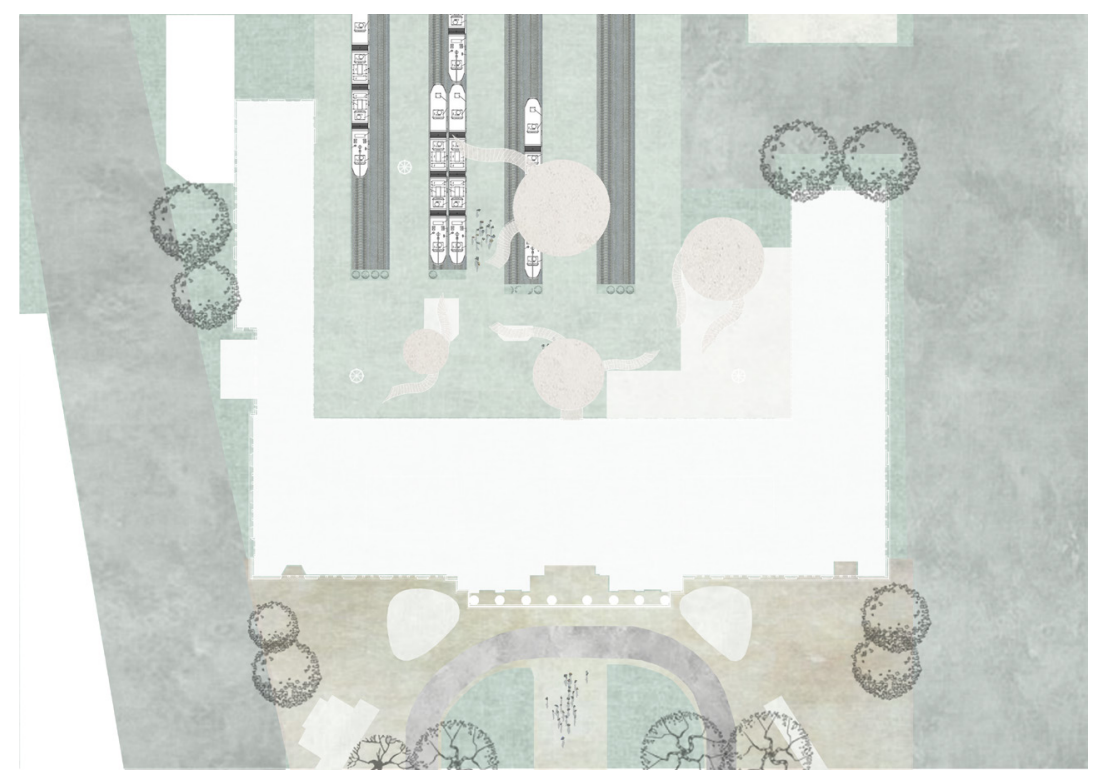

Figure.9.22: Third floor plan

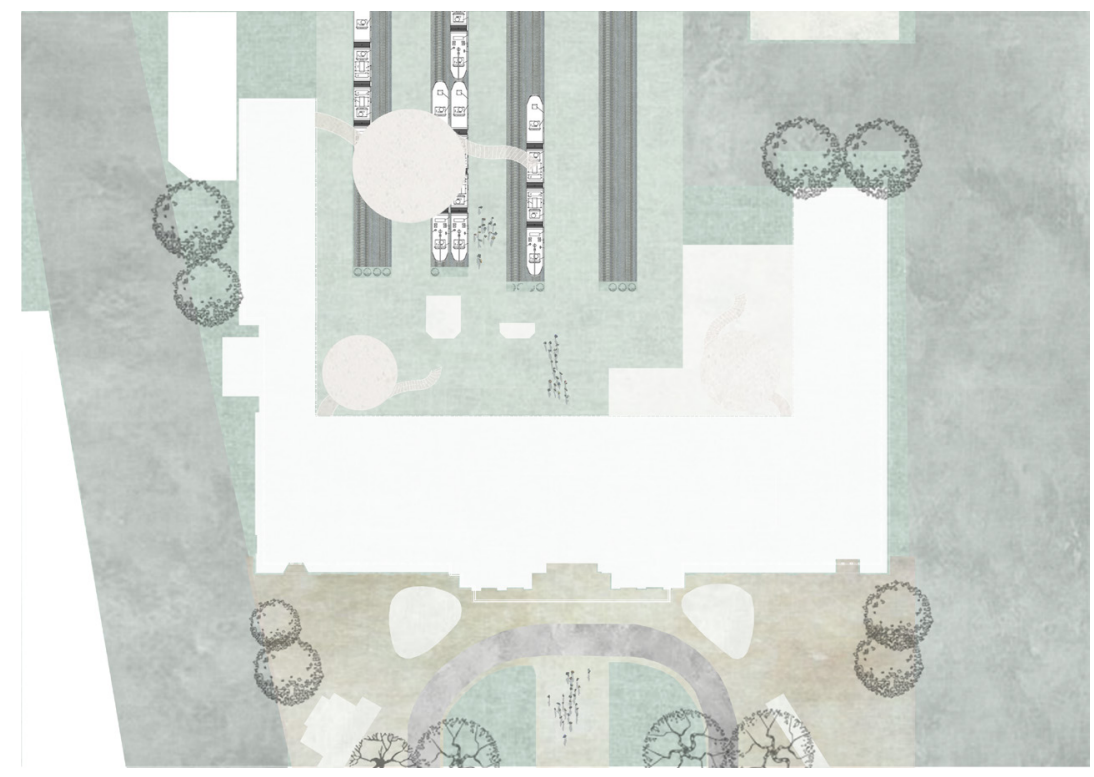

Figure.9.23: Forth floor plan

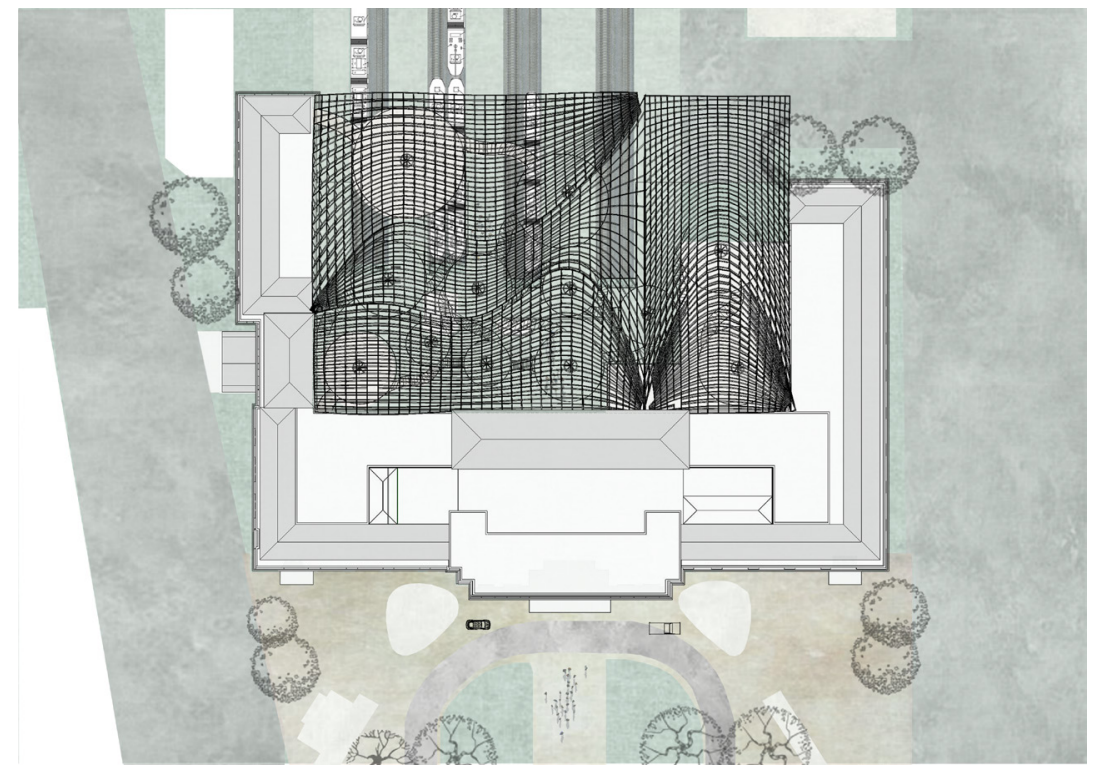

Figure.9.24: Fifth floor plan 


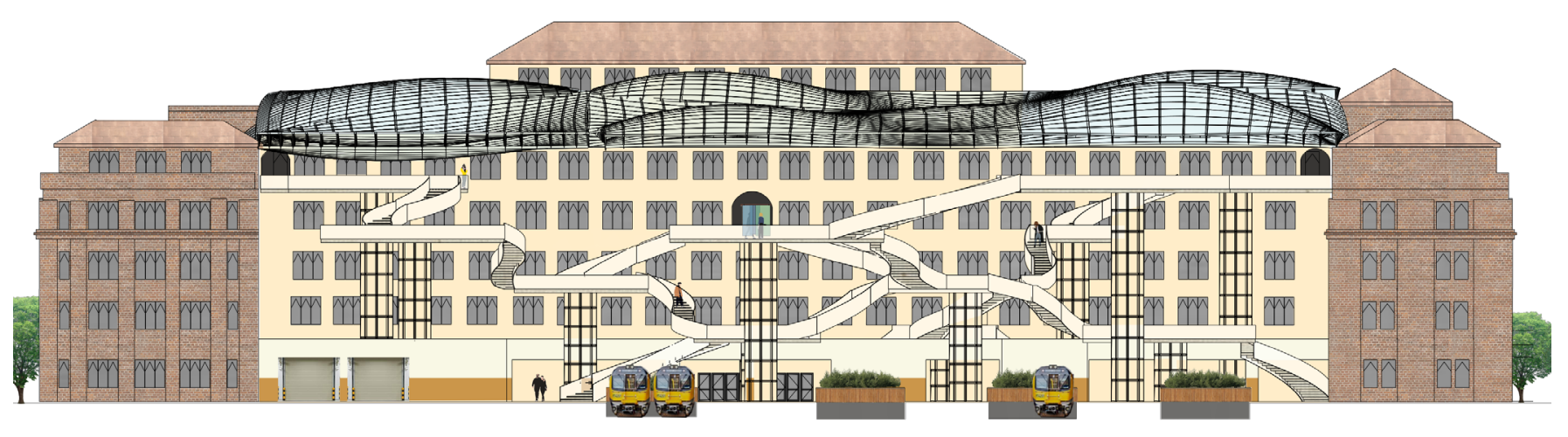

Figure.9.25: Longitudinal section 


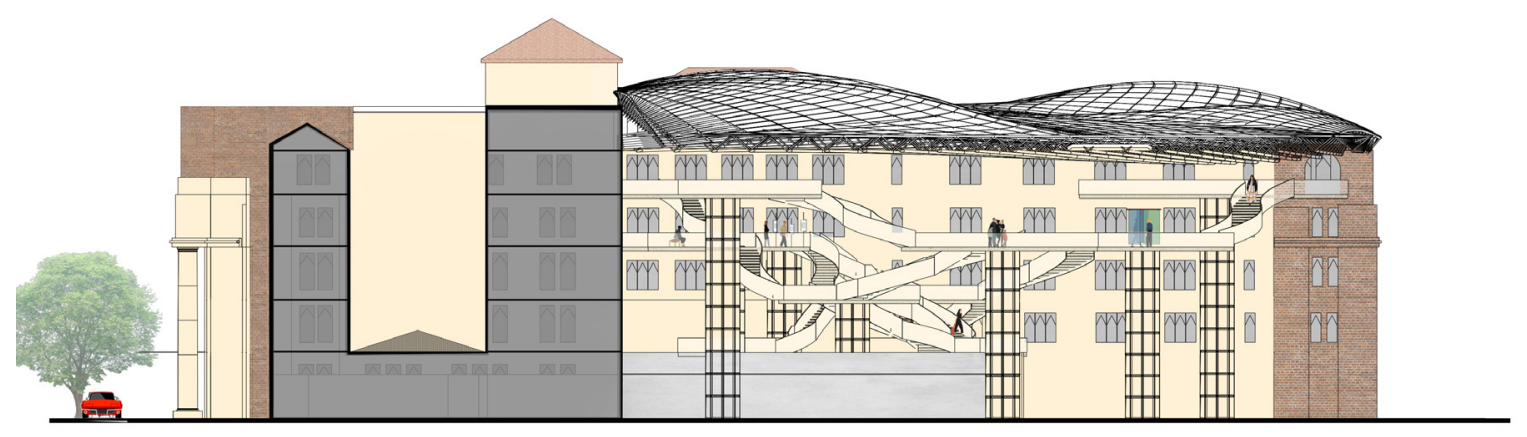

Figure.9.26: Cross section 


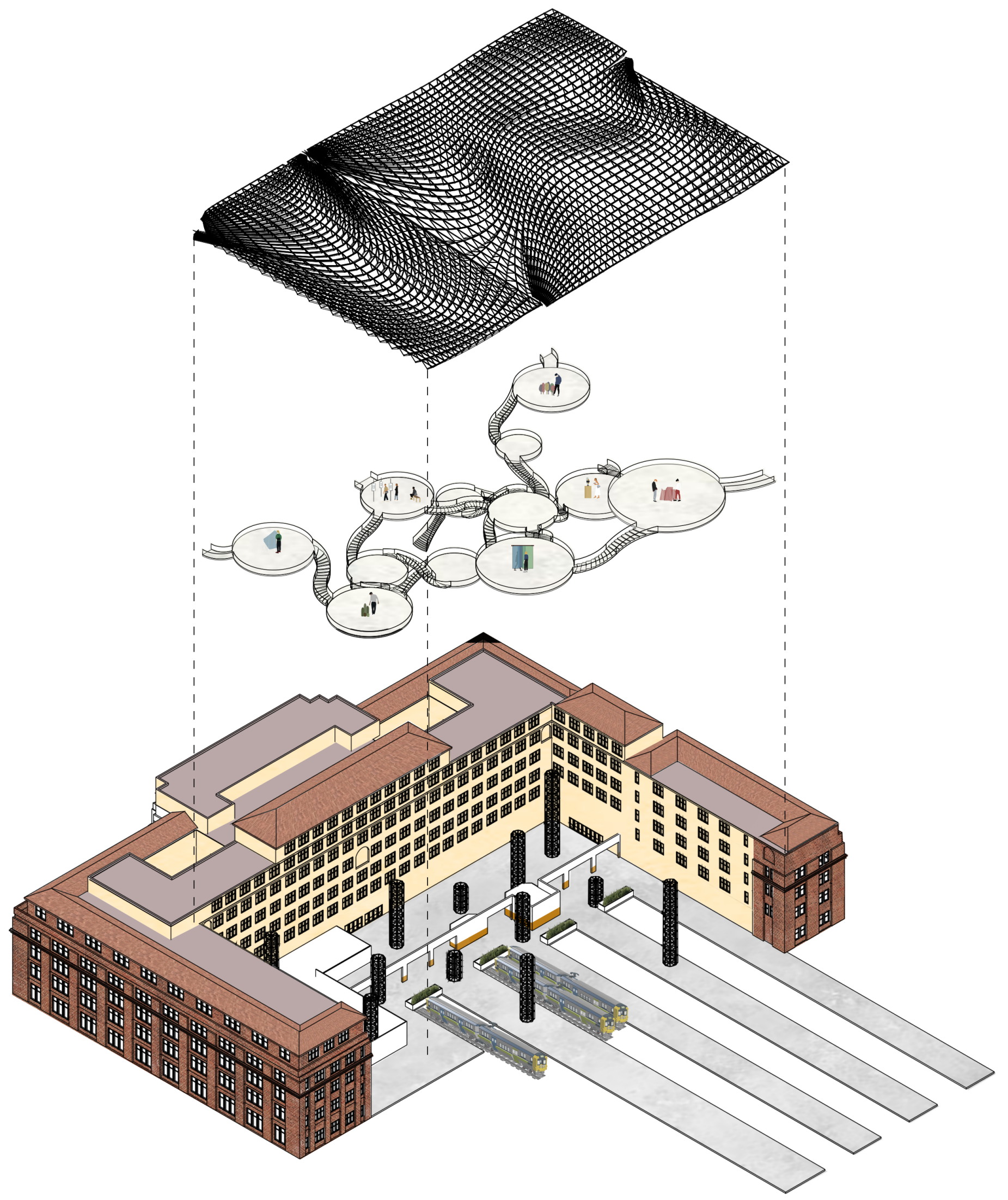

Figure.9.27: Station Axo 


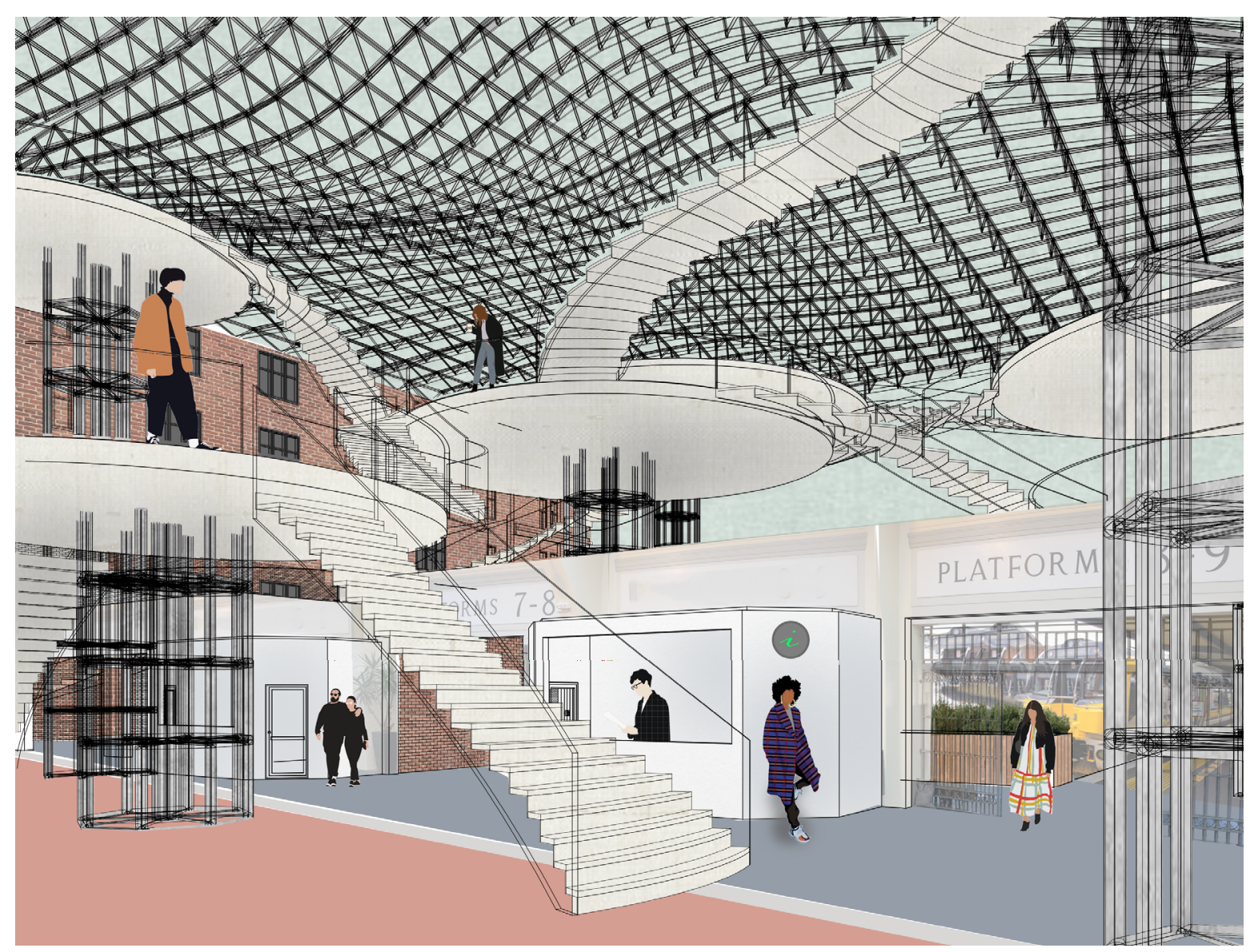

Figure.9.28: View from under platforms 


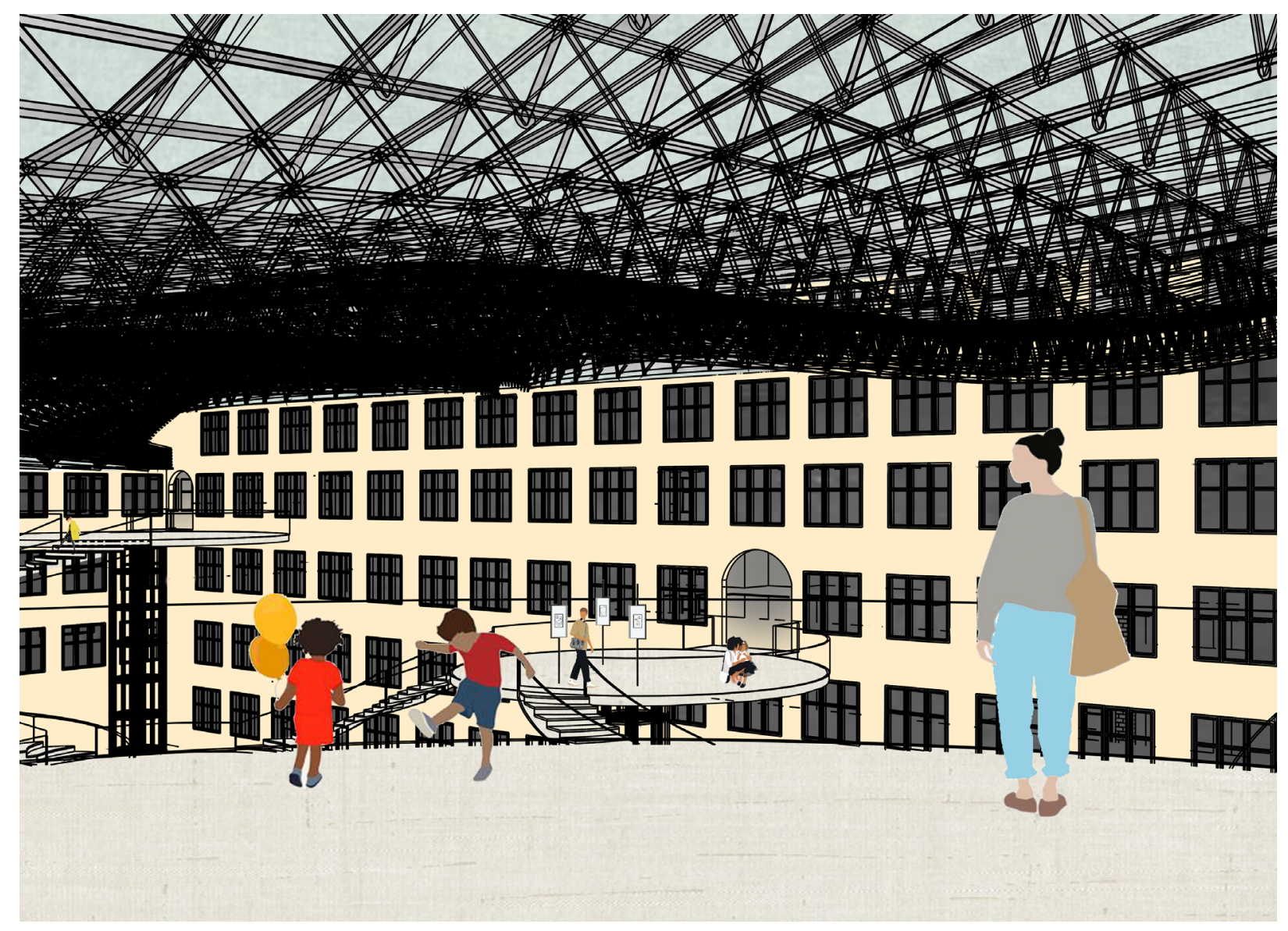

Figure.9.29: Above the trains 


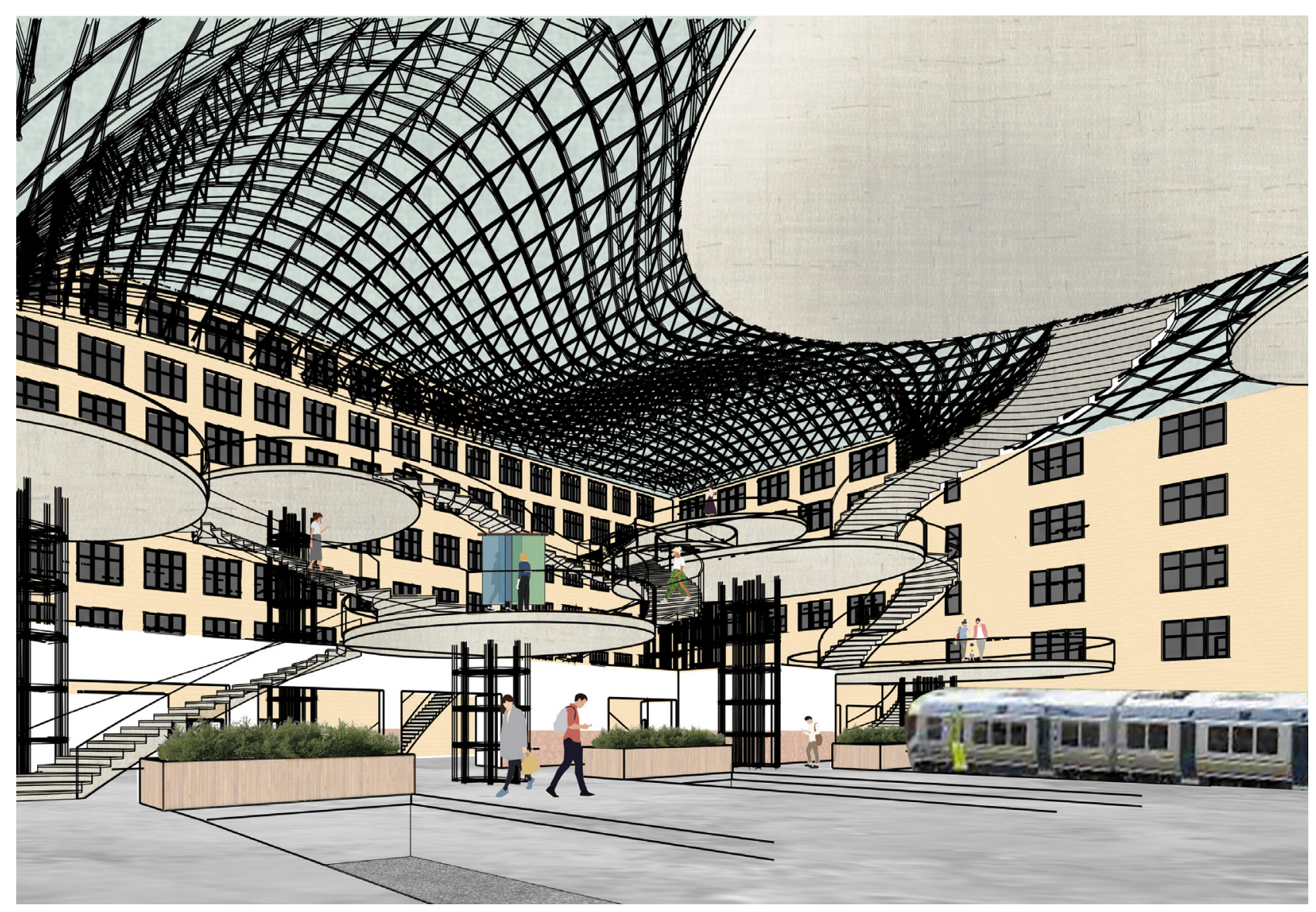

Figure.9.30: View below the platforms 


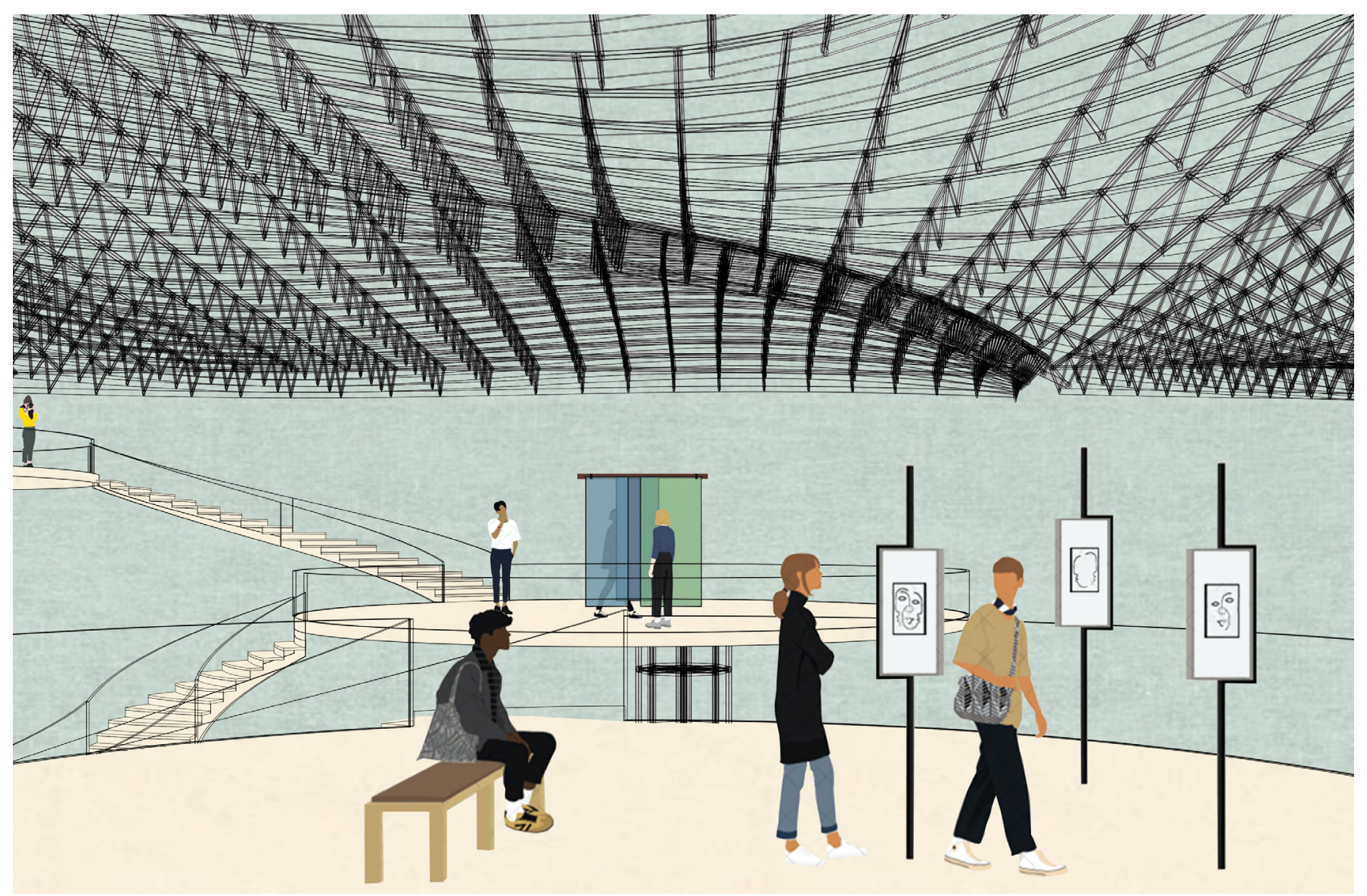

Figure.9.31: Exhibitions on the platforms 


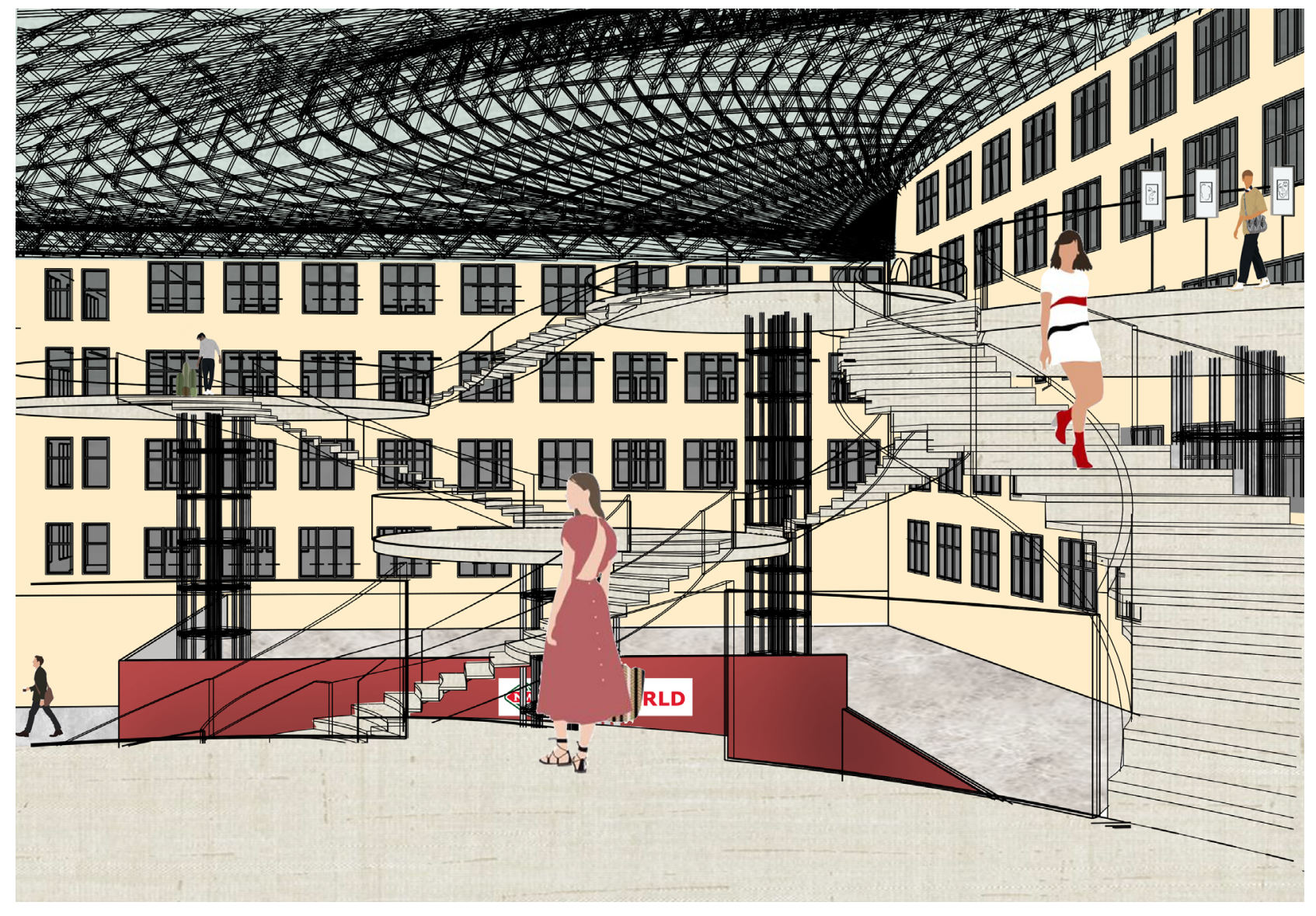

Figure.9.32: Amongst the platforms 


\section{FRAMEWORK CRITIQUE}

$\mathrm{T}$ his iteration met all but one criterion for the site selection.

It is one of the most prominent public buildings in Wellington as thousands commute through the station every day and with some more private areas in the floors above. The building is also considered unique as one of the grandest buildings in the area. It has also a strong sense of not only national but local heritage as a reminder of New Zealand's Engineering heritage. The building also serves as a reminder of New Zealand's cultural identity by showcasing their Railway development.

Although it had little connection to its natural landscape, the design intervention attempts to create a sense of a built-natural environment. Being a busy train station, it is obvious as to how the essence of mobility is strong in this building.

The intervention was able to meet all criteria for the design tactics. The many large platform spaces give the opportunity for several people to meet and mingle while also allowing for space for transcultural gallery exhibitions. The exhibition spaces also contribute to the educational criteria as an opportunity to spread awareness of the topic. Although there is not actual nature in this space, the design appears to mimic a canopy of trees in built form. The glass canopy structure adding to that greenhouse feel. The platforms were left as open spaces to allow for adaptability and personalisation. This allows people to use them as sitting spaces while one waits for their train or as meeting spaces with friends. They can also be used as exhibition spaces not only for the transcultural community but for artists and the railway station as well.

With the number of access points and connecting walkways, each person can experience their own unique journey through the space.

The narrative of the space explores the idea that although cross cultural people feel a disconnect from their surroundings, they are all united through their collective memory.
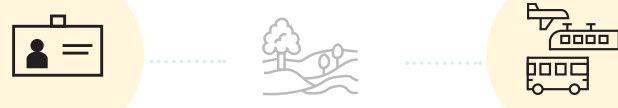

एव:

CULTURALID NATURAL LANDSCAPE MOBILITY

\section{DESIGN TACTICS}

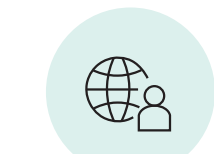

MULTI/TRANSCULTURE

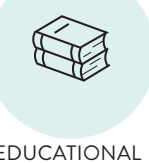

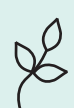

NATURE

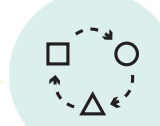

ADAPTABILITY

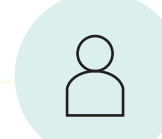

PERSONALISATION

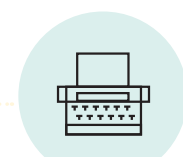

NARRATIVE ELEMENTS 


\section{REFLECTION}

This iteration also stands on a subcategory of the spectrum of heritage conservation. This category one building is already well looked after, with minimal changes except for some of the ground floor layout. This iteration focuses on the detached area of the concourse and platforms.

Although the intervention acts as its own separate entity, it allows the building itself to be more open and inviting. This creates a more playful space that invites people to explore in rather than just walk through.

Taking on feedback from the previous review, this iteration aimed to utilise the criteria of the framework in a way that would not hold back the design potential. Previous iterations were labelled as safe possibly due to the constriction of the framework. However, upon further reflection it is suspected that the safe approach to those iterations were from a conservation perspective.
Ironically, the building with the highest protection order has the most playful intervention.

Therefore, it will be important to find a balance between following the design criteria and heritage conservation principles.

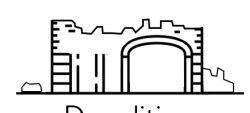

Demolition

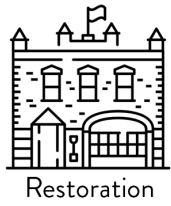

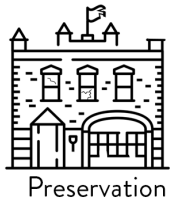

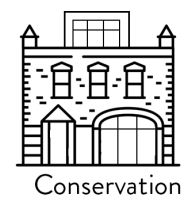





\title{
10. Iteration Reflection
}

\author{
Introduction
}

Un-Commonalities

Commonalities 


\section{Introduction}

$\mathrm{T}$

his iterative design phase proved to be an important part of the research process. Upon reflection, it revealed that the primary framework is in need of further refining. Although none of the iterations fulfilled all performance criteria, it was obvious that there is another layer of design intent required.

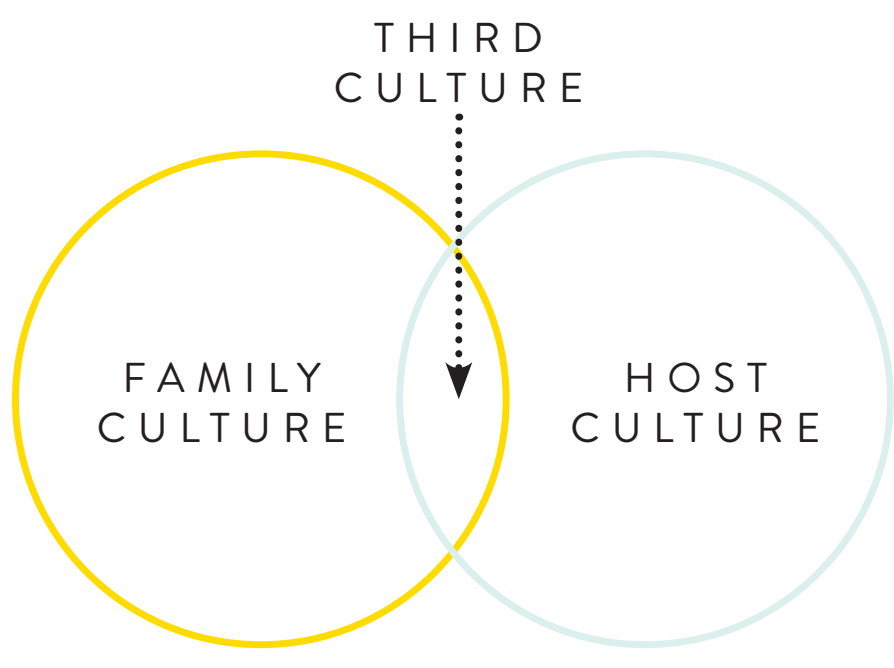

Figure.10.1: Third culture venn diagram

\section{Un-Commonalities}

E ach iteration dealt with a different scale. The first an installation, the second a building and the third an urban scale intervention. Due to their scale, each iteration was resolved to a different level of detail. From this experiment it is apparent that the second iteration gives enough scale to express the intent clearly while also delving into enough detail for a resolved design.

All of the iterations play with different levels of public engagement. While the first iteration forces you through a certain path, the second iteration invites you above the promenade onto the Rotunda platform. The third iteration is more hidden, creating a sense of almost avoidance. For the next phase it will be important to find the right balance of engagement, as the primary framework calls for a public space. Public spaces that are hidden are not as successful as spaces that are obvious and inviting.

The iterations also experimented with different uses. The first being an installation, the second a Cross Cultural centre and the third a Transcultural Gallery. While these uses were derived from the preliminary research and applied to the iterations with the appropriate scale, there was no strong reasoning behind the choice. 


\section{Commonalities}

W hile they have their differences the iterations also have several commonalities besides the criteria defined by the framework. The primary framework formed the three iterations into spaces that aimed to invite CCPs into the space, however upon reflection, a number of recurring phenomena occur when expressing this architecturally. The iteration exploration was able to uncover a few tactics which encompass the sense of CCPs.

All of the iterations aim to create an experiential journey. The first with an experiential installation and the second with the elevated promenade. The third iteration experiments with a combination of the two through a multi-levelled promenade experience with the intention of creating spaces for transcultural experiences. Therefore, it could be worth developing this idea of the promenade as a Third Place. The primary framework called for public spaces and the iterations delivered that. The iterations aimed to create connections for its users and creates safe spaces to meet. However, to strengthen the type of space, it may be worth examining Oldenburg's theory of Third Place for further development.

All the iterations played with the narrative idea of the in between and layering. The "In Between" encapsulates the sentiment of Cross Culture People and how they feel when they are "in between culture" and the idea of the layering of histories which directly connects with using heritage buildings for these spaces.
The iterations also use sites with strong connections to the natural landscape while integrating it further into its interior. The final iteration could also benefit from further research into Biophilic design to strengthen its intention in the intervention.

In the previous reviews it was mentioned that the first two iterations were quite safe designs and lack a playful feel. Indicating that it was possible that the framework was holding back the idea of design. To counteract that and experiment further, the third iteration took on a more "playful" approach by creating an abstract or whimsical intervention. Therefore, moving forward, it will be important to use the framework and use it in a such a way as to not hinder the design process. The final design should include more experimentation and freedom.

There was also some uncertainty as to how the functions for the precedents relate to the overall scheme of the project. While working with heritage buildings it will also be important to find the right balance between intervention and the existing fabric. This can be done by using the conceptual stage to explore more creative solutions and pairing them back to adhere to heritage conservation standards while also following the cross-cultural framework. The concept of the promenade was encouraged but required further refinement. Suggestions included, defining the term and including a sense of performance. This leads to the potential discussion on the role of 'the promenade' as a third place. 
Through this reflection it has been determined that the primary framework has delivered a diverse selection of spaces but requires further refinement. They have exposed gaps in the framework and will help create a series of strategies that must always be included when designing for CCPs spaces.

Moving forward the final design will take forward these findings and create a new building typology to aid in the conservation of heritage buildings. This final design will incorporate these strategies while fully committing to heritage conservation and crosscultural design.

The outcome will combine a number of strategies extracted from research and from tested implementation in the iterative design phase.

Iteration Phase Lessons:

Evoke a sense of Journey or Experience

Create a Third Place

Express the In between

Demonstrate Layering

Apply Biophilic Design Principles

\section{ADDITIONAL CONSIDERATIONS}

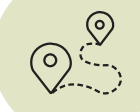

JOURNEY/ EXPERIENCE

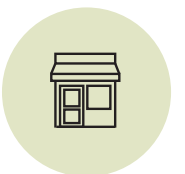

THIRD PLACE

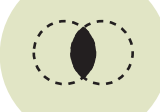

IN BETWEEN

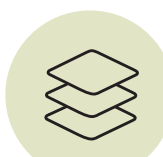

LAYERING

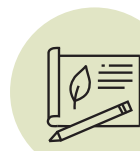

BIOPHILIC DESIGN

Figure.10.2: Additional consideration for amended framework 
CCP Design

Experimentation

Using Primary Tactics

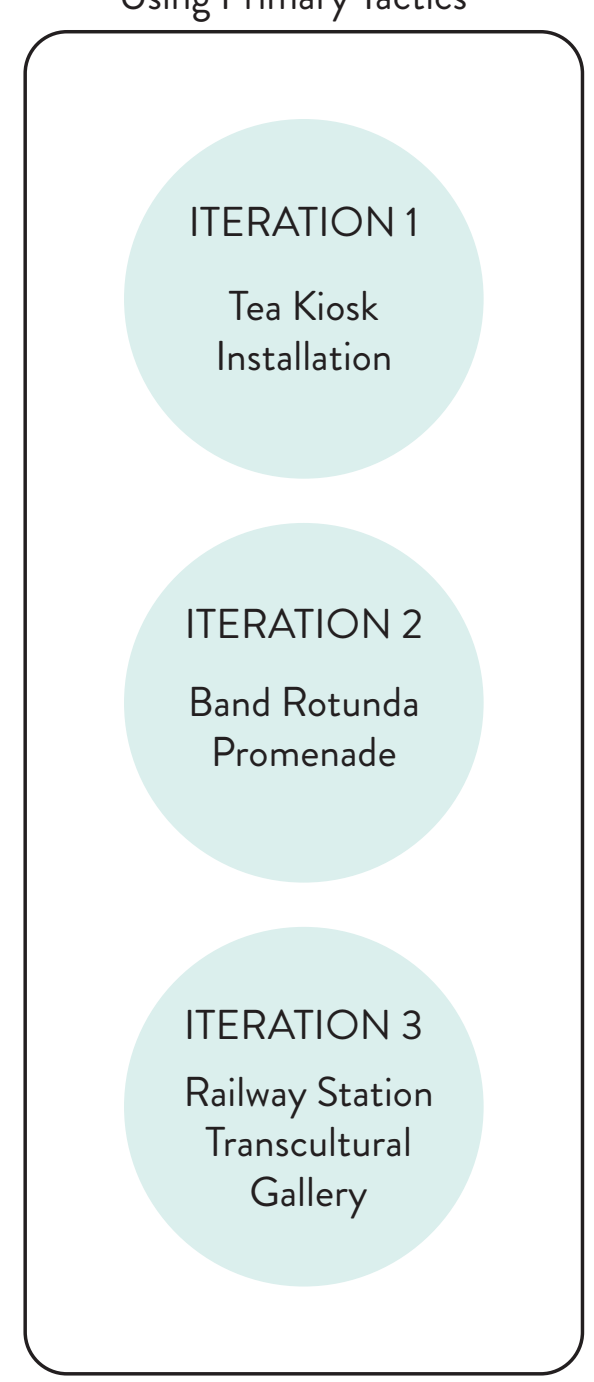

From Implementation to Heritage Conservation

Using Developed Tactics

Figure.10.3: Creating additional framework

Journey/

Experience

Third Space

In between

Layering

Biophilic 



\section{Final Design}

Site

Function

Biophilic Design

Third Place

Design Process

Circulation

Dome

Promenade

Reflection 


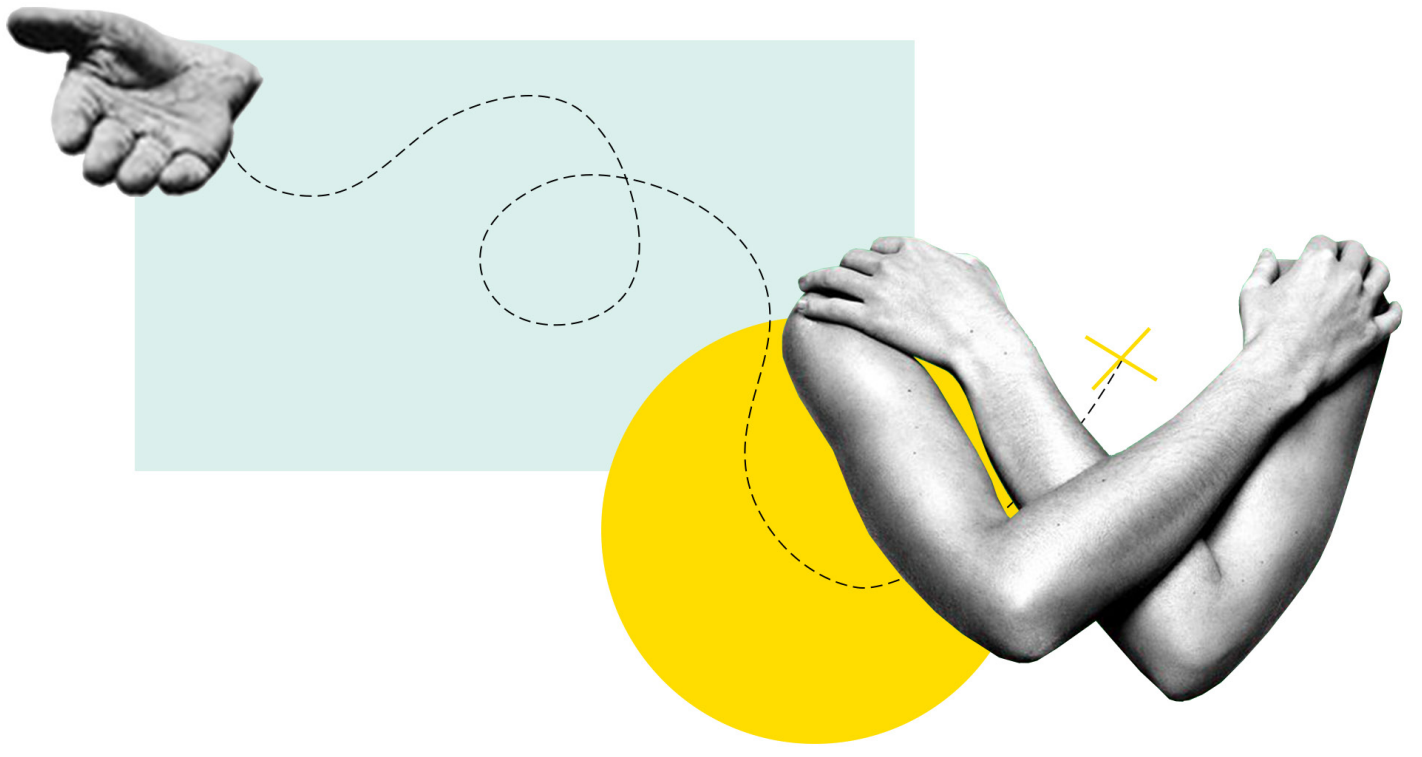

Figure.11.1: Experiential collage

Extend your hand, reach out, join us on our collective individual journey, welcoming embrace 


\section{SITE SELECTION}

he site for this thesis takes place in Wellington, New Zealand. Wellington was chosen for its increasing population and strong presence of diverse cultures. 


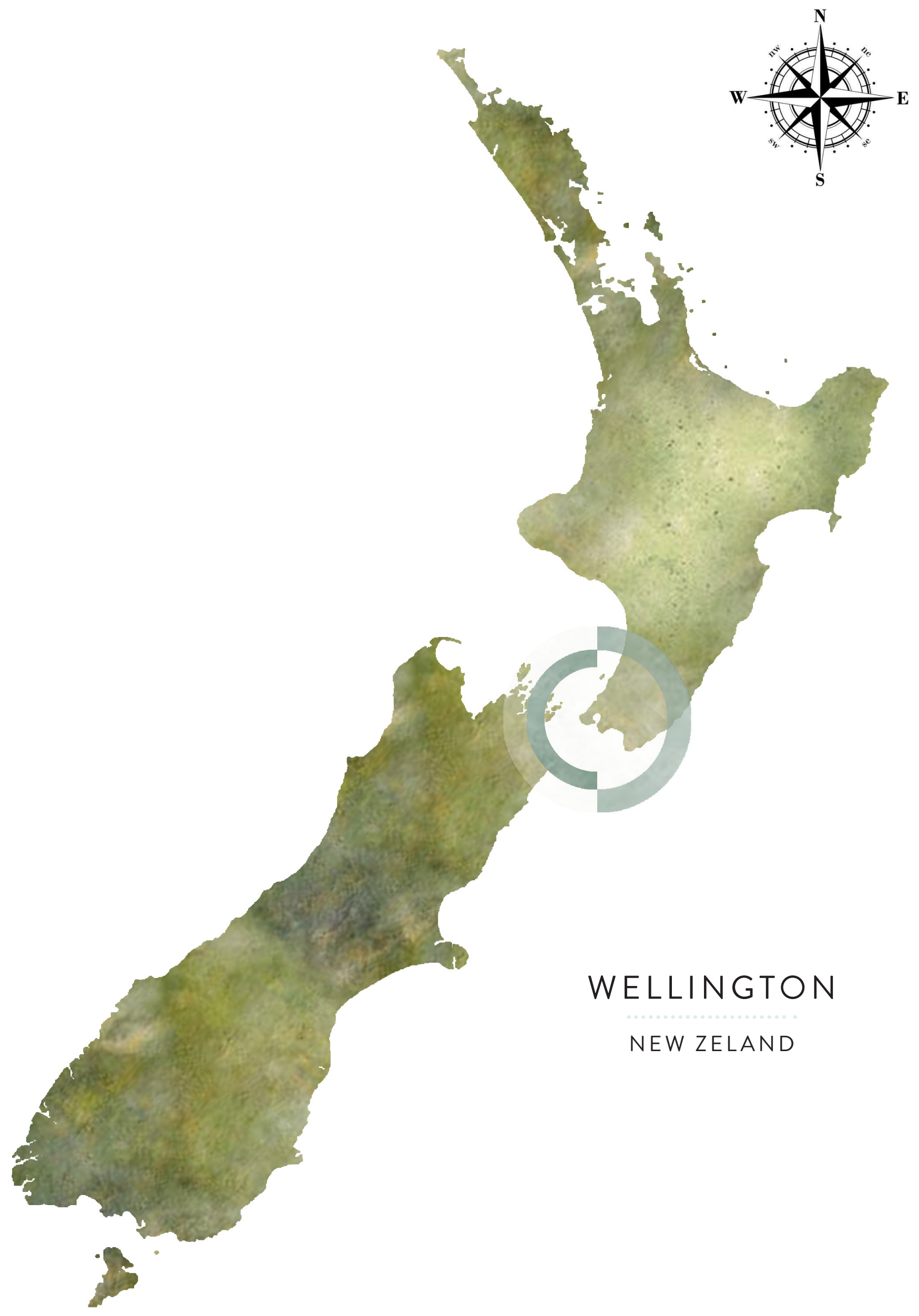

Figure.11.2: Map of NZ 


\section{HERITAGE IN WELLINGTON}

W

ellington's architectural heritage is distributed throughout its CBD. The area of interest for this thesis is around the waterfront in order to maintain a strong connection with the natural landscape especially between land and sea. 

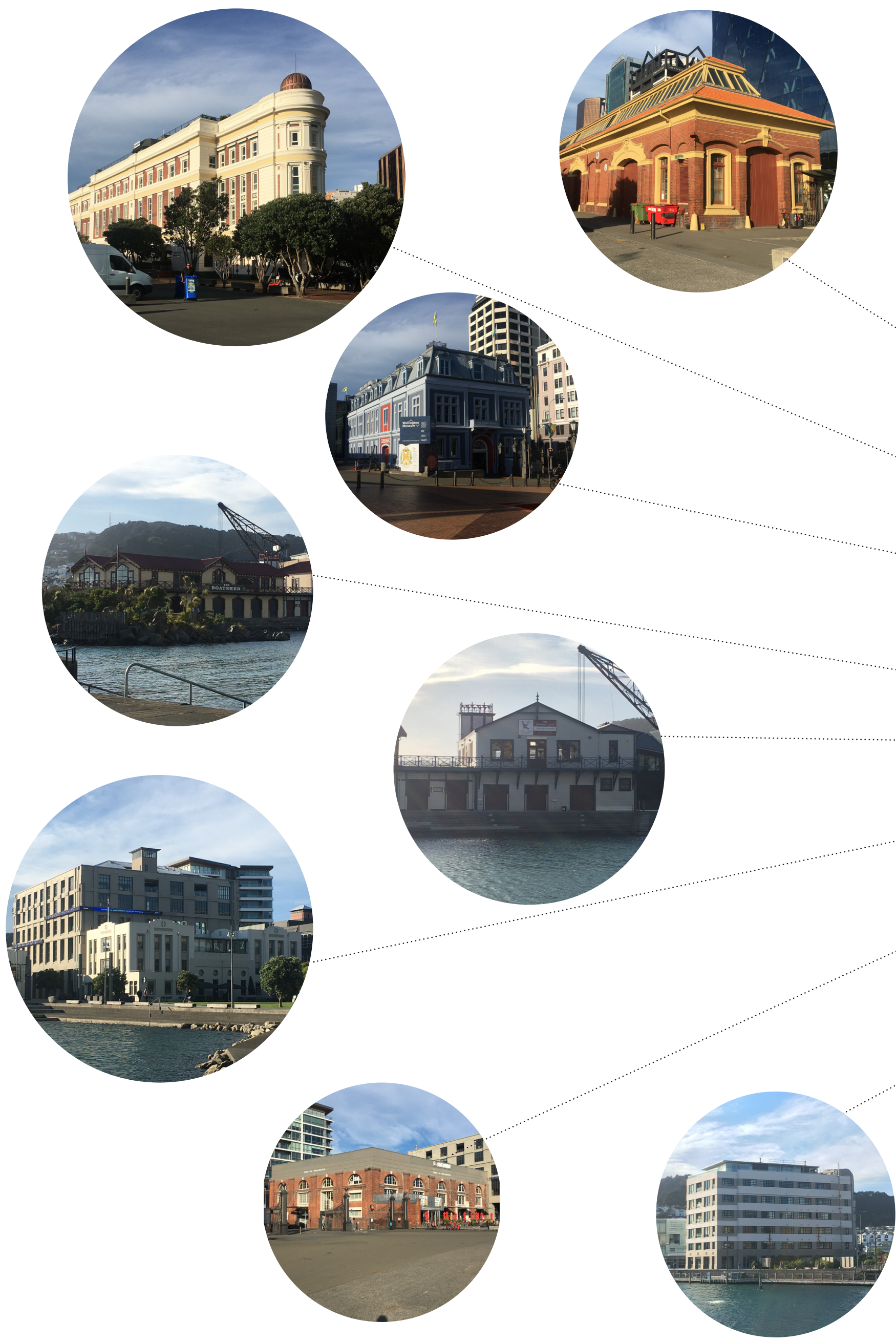


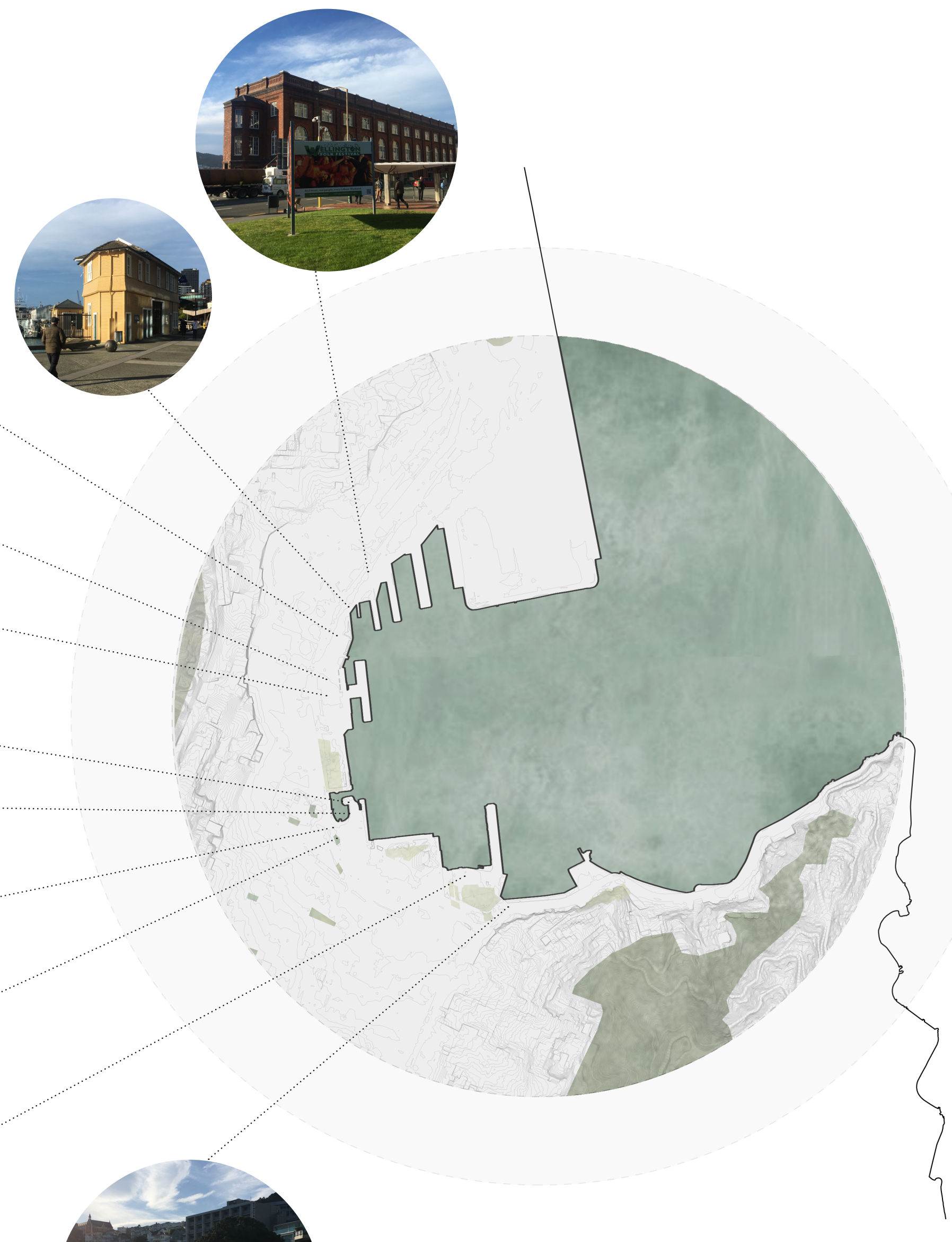

Figure.11.4: Heritage Buildings along Waterfront 


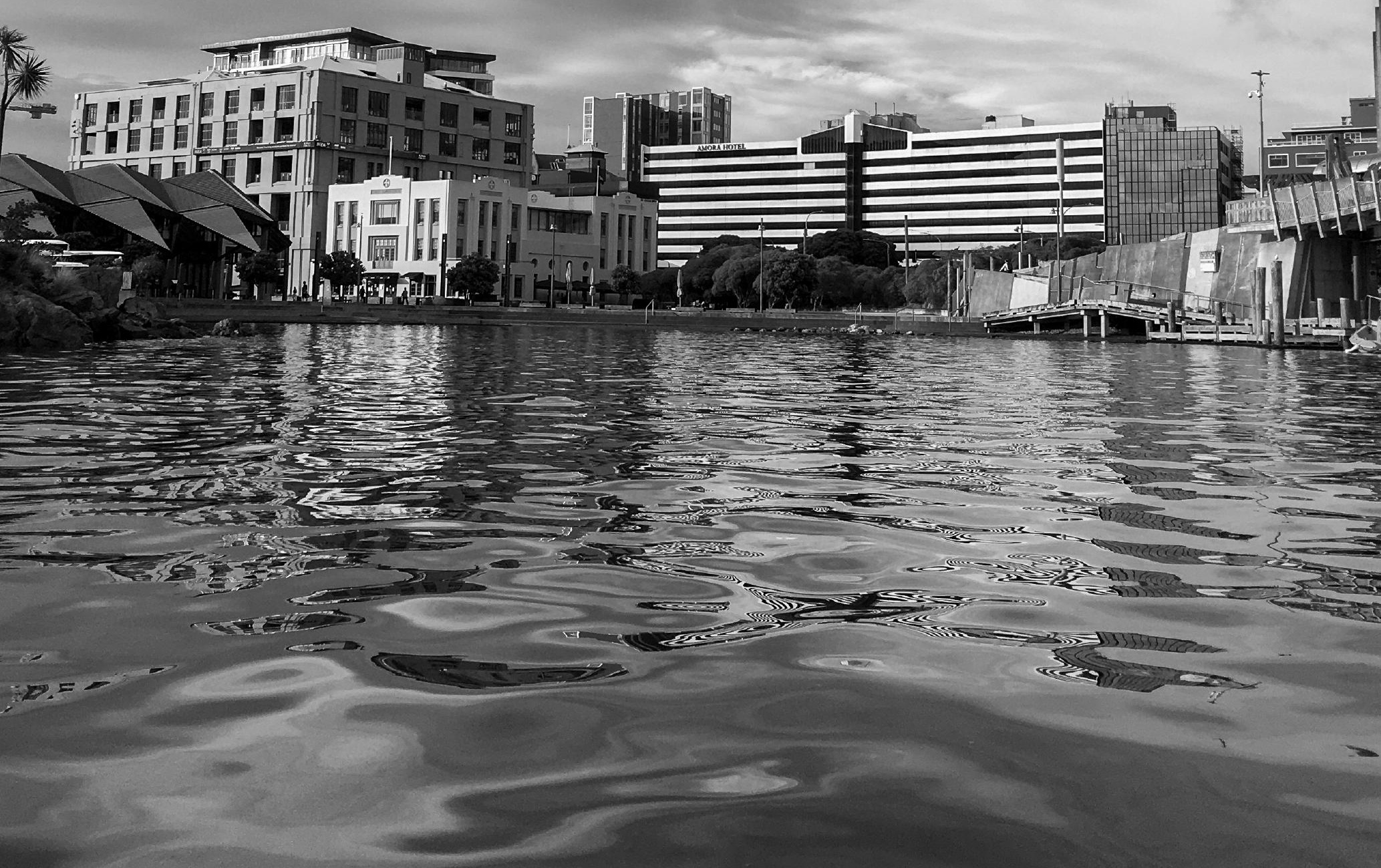




\title{
WELLINGTON FREE AMBULANCE BUILDING (FORMER)
}

\author{
5-9 Cable Street And Jervois Quay, Wellington \\ Category 1
}




\section{HISTORY}

A $t$ the eclipse of the twentieth century, Wellington had only recently purchased Ashford Litters which were hand wheeled wooden stretchers, based in the fire department (Free Ambulance Building, 2017). Three horse drawn ambulances replaced them and were housed at Queen's wharf and Wellington Hospital (Free Ambulance Building, n.d.). Motor vehicles then replaced the horse drawn ambulances, but the vehicles were privately owned and required payment prior to the patient's transportation to hospital.

Wellington's Mayor Charles Norwood saw a flaw in the system and established the Free Ambulance service which was based on the Australian system. This new service began in November 1927, with six employees and four ambulances set up in the Naval Artillery Boat Shed (the current Rowing Club). However, the space was not well suited for the service and the City Council arranged to move the Rowing Club into the old Naval Artillery Boat shed to free up land for the Free Ambulance building (Free Ambulance Building, 2017).

The mayor employed prominent Wellington architect William Turnbull, who was asked to design a 'highly distinctive, modern and functional' building for the ambulance service (Free Ambulance Building, n.d.). Turnbull began designing a brick building in the Classical style for the site. However, after the Napier earthquake he altered the plans to follow the inexpensive Art Deco style which was used for the Napier rebuild. The building was built by Alfred Lemmon for $£ 16,369$, which was funded by public donations (Free Ambulance Building, n.d.). Construction took place between 1932 and 1933. The buildings foundations are constructed of reinforced concrete with cast in situ concrete walls, floors and roofs with steel framing (Free Ambulance
Building, 2017).

The building focuses on vertical expression which is seen in the elongated windows and decorative mouldings on the façades. The overall massing and stepped parapets are restrained references to the Art Deco style. The interior of the building emphasises the use of natural light and ventilation with its large skylight and use of open spaces (Free Ambulance Building, 2017).

Fundraising and local support from Charles Odlin, the original owner of the adjoining Odlin's building, allowed the service to expand to cover the wider Wellington region while remaining free (Free Ambulance Building, n.d.). The service used the building for 60 years, until the service sought to relocate to Thorndon due to redevelopment in the area and an increase of traffic flow. Harbour management threatened to demolish the building for a casino hotel, but public outcry stopped the plans and heritage protection (in the form of a Heritage Order) was secured (Free Ambulance Building, 2017).

The former Free Ambulance Building is considered both nationally and locally historically significant. It was the first building purposely built ambulance station in New Zealand and its location on one of Wellington's main roads gives it significant townscape value. Its local significance continues with its association with former Mayor Charles Norwood and Wellington architect William Turnbull as well as its significance to Wellington's health services (Free Ambulance Building, n.d.). 


\title{
REASONING
}

\author{
This site was selected as a result of a number of \\ contributing factors.
}

(i) Its unique in scale and architectural style within its waterfront context.

(ii) It is a distinctive landmark on Wellington's waterfront and creates a visual contrast against its surrounding buildings.

(iii) Its location in terms of cultural significance is also a contributing factor. It is located close to the Museum of New Zealand Te Papa Tongarewa, a main street and other cultural buildings and theatres.

(iv) This building is also a registered heritage building (Category One with Heritage New Zealand. Its historical significance is not only on a national level as the first purpose-built ambulance building in $\mathrm{New}$ Zealand but on a local level as well.

(v) Its location in terms of nature makes it a strong site for the intended use as a CCP hub. Its prominent site on Wellington's waterfront gives it a strong connection to the sea, and its neighbouring green space allows for endless opportunities to engage its users with nature 


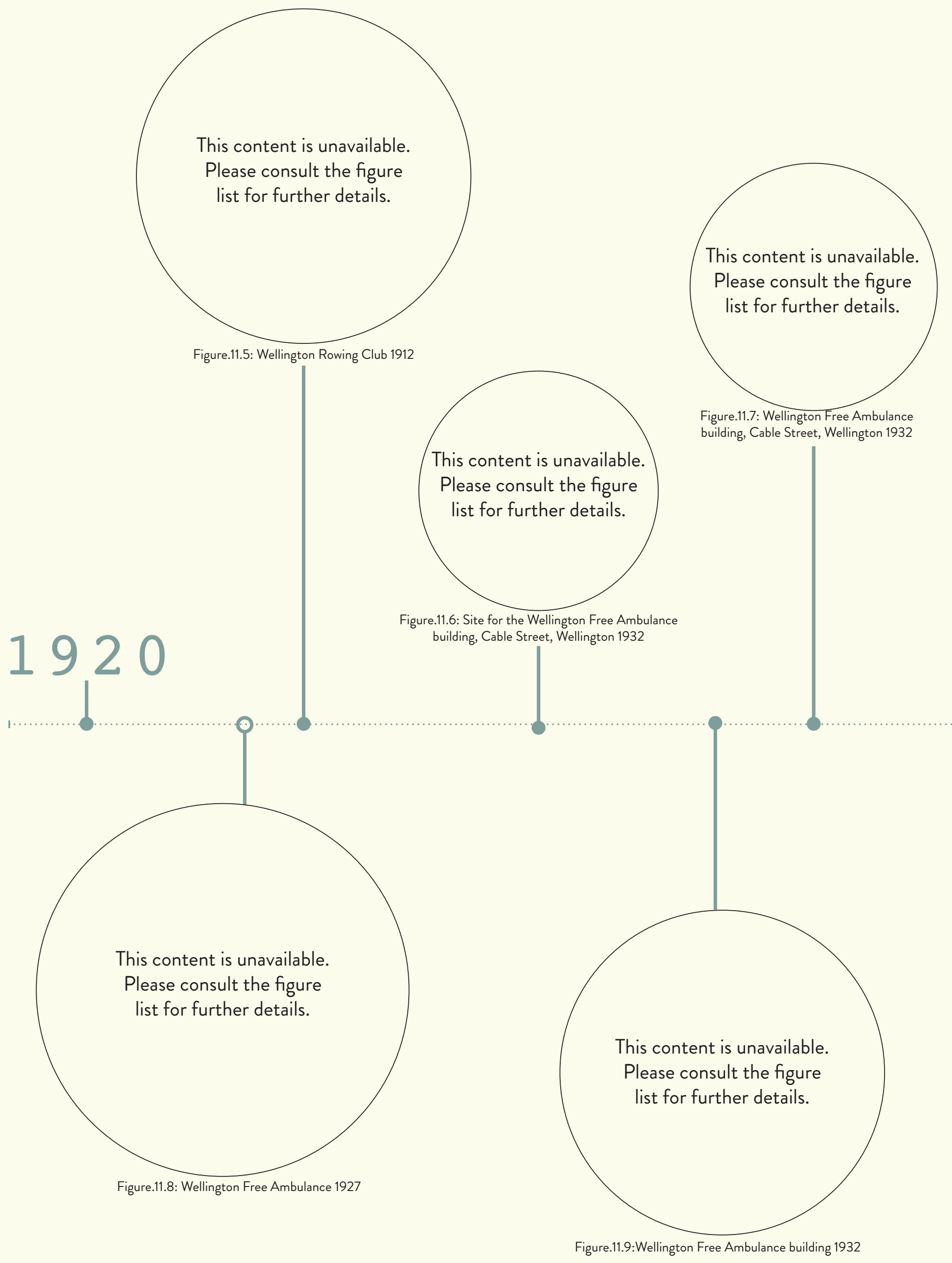



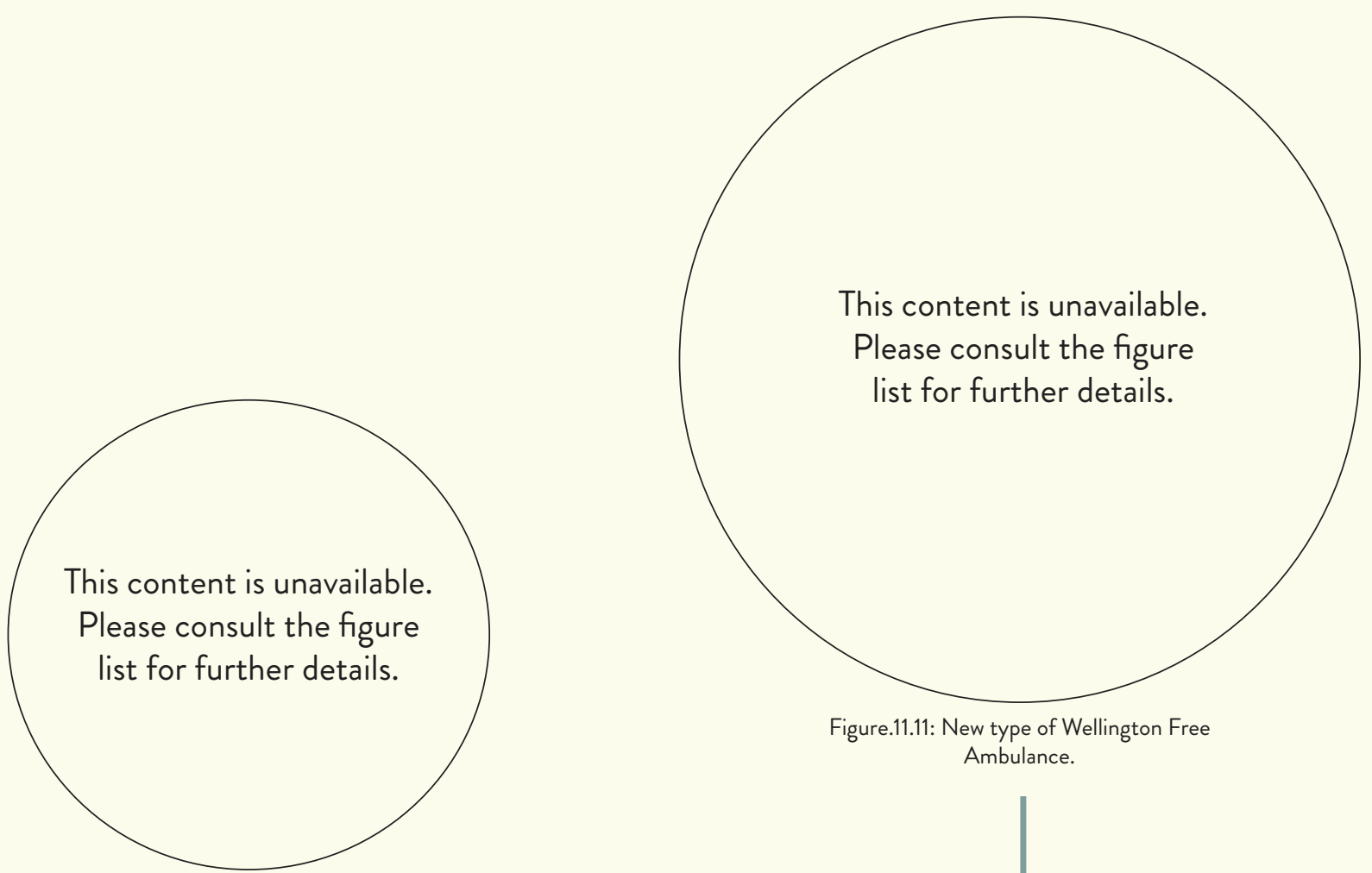

Figure.11.11: New type of Wellington Free Ambulance.

Figure.11.10: Cable Street, Wellington 1939

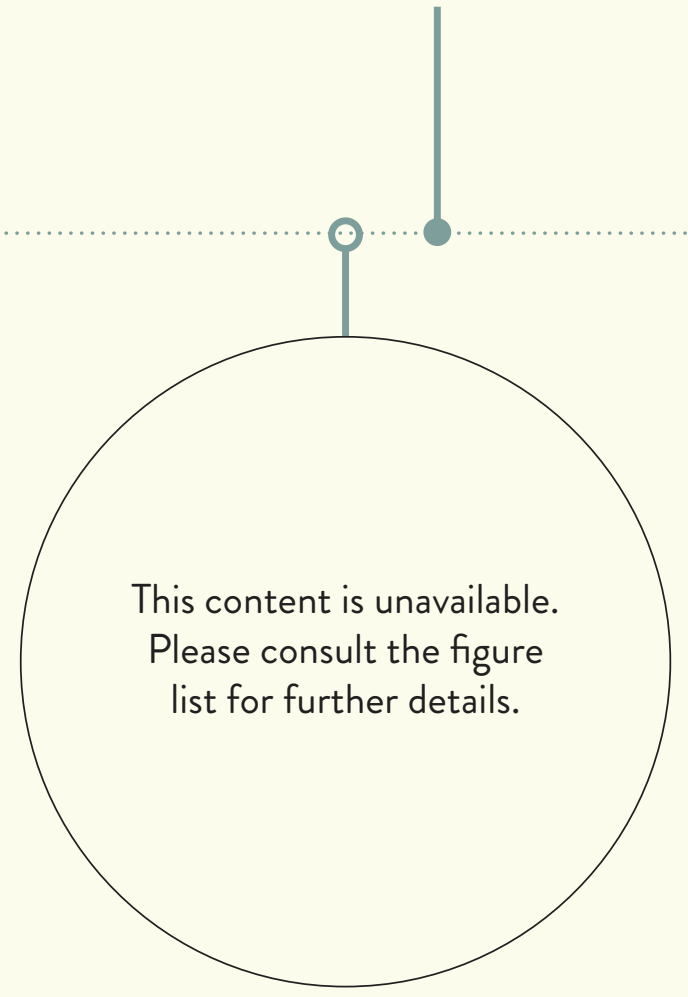

Figure.11.12: Wellington Free Ambulance building at night 1933

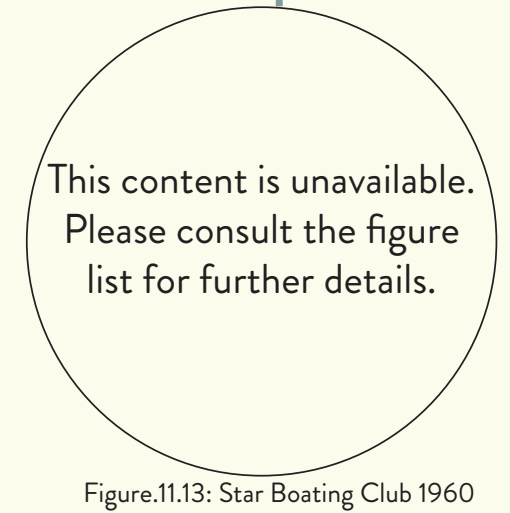

This content is unavailable.

Please consult the figure list for further details.

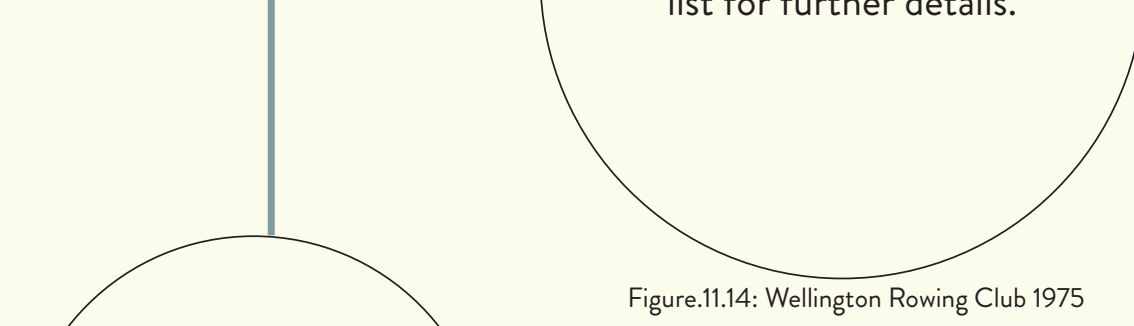

Figure.11.13: Star Boating Club 1960 


\section{SITE ANALYSIS}

\section{Sun Path}

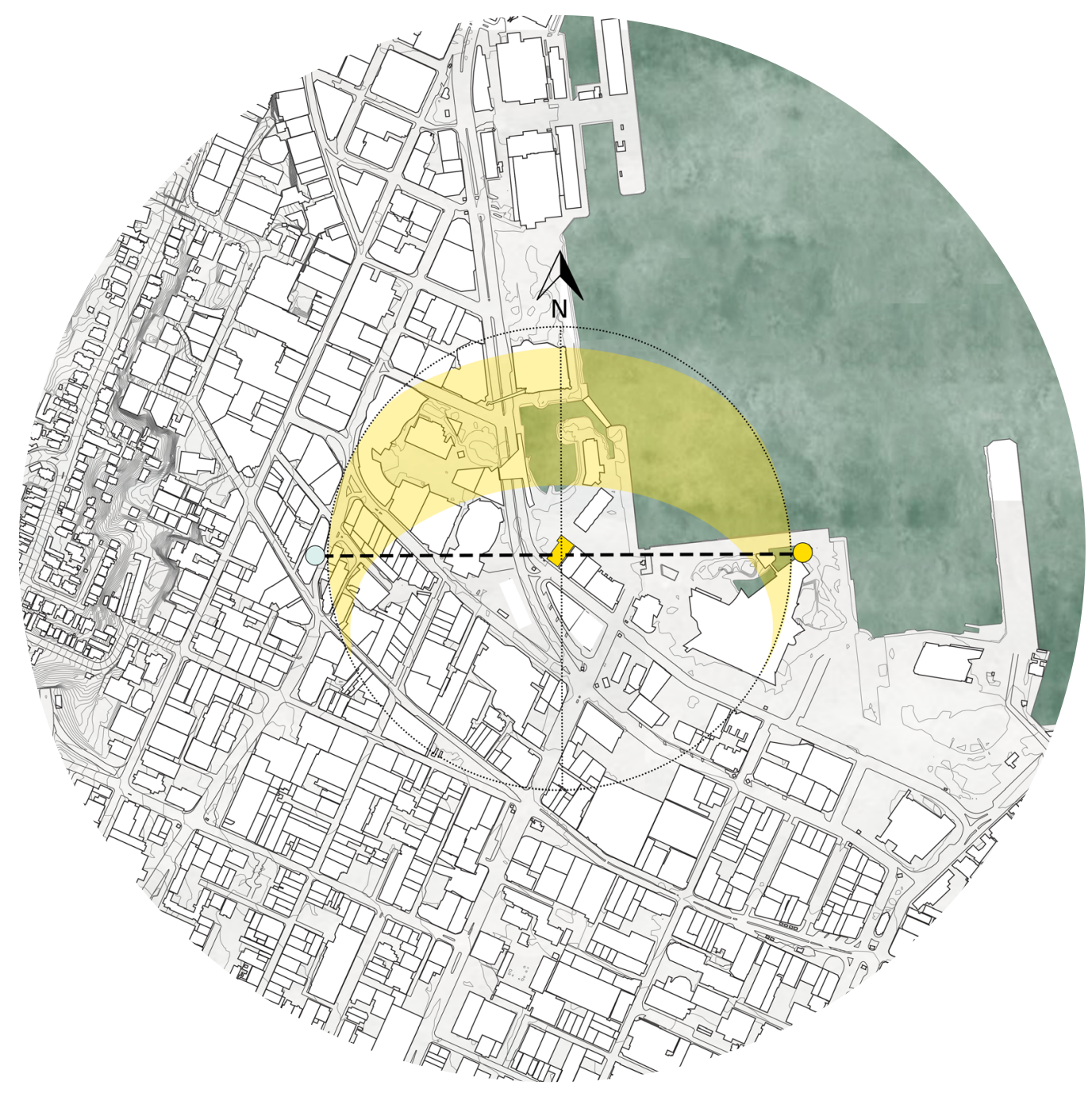

at Spring Equinox
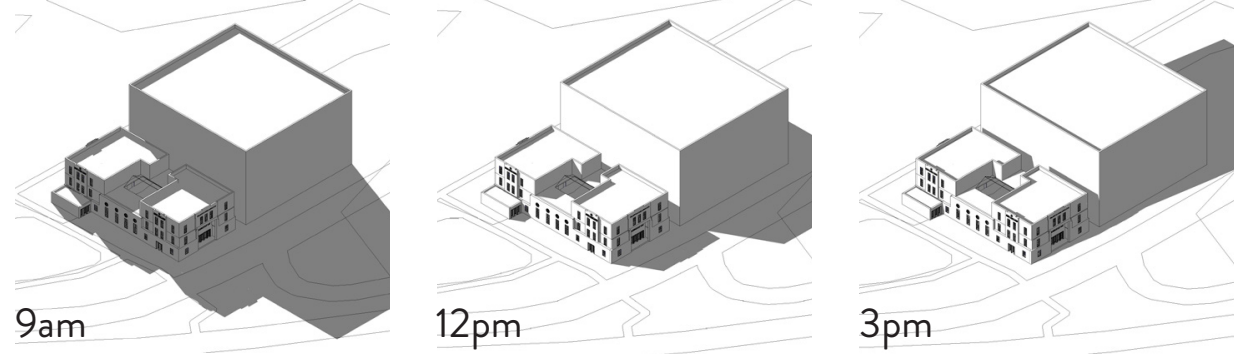

$3 p m$

Figure.11.15: Sun Path Diagram

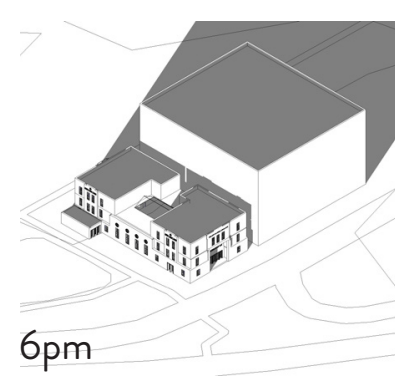

$6 p m$ 


\section{Reclaimed Land}

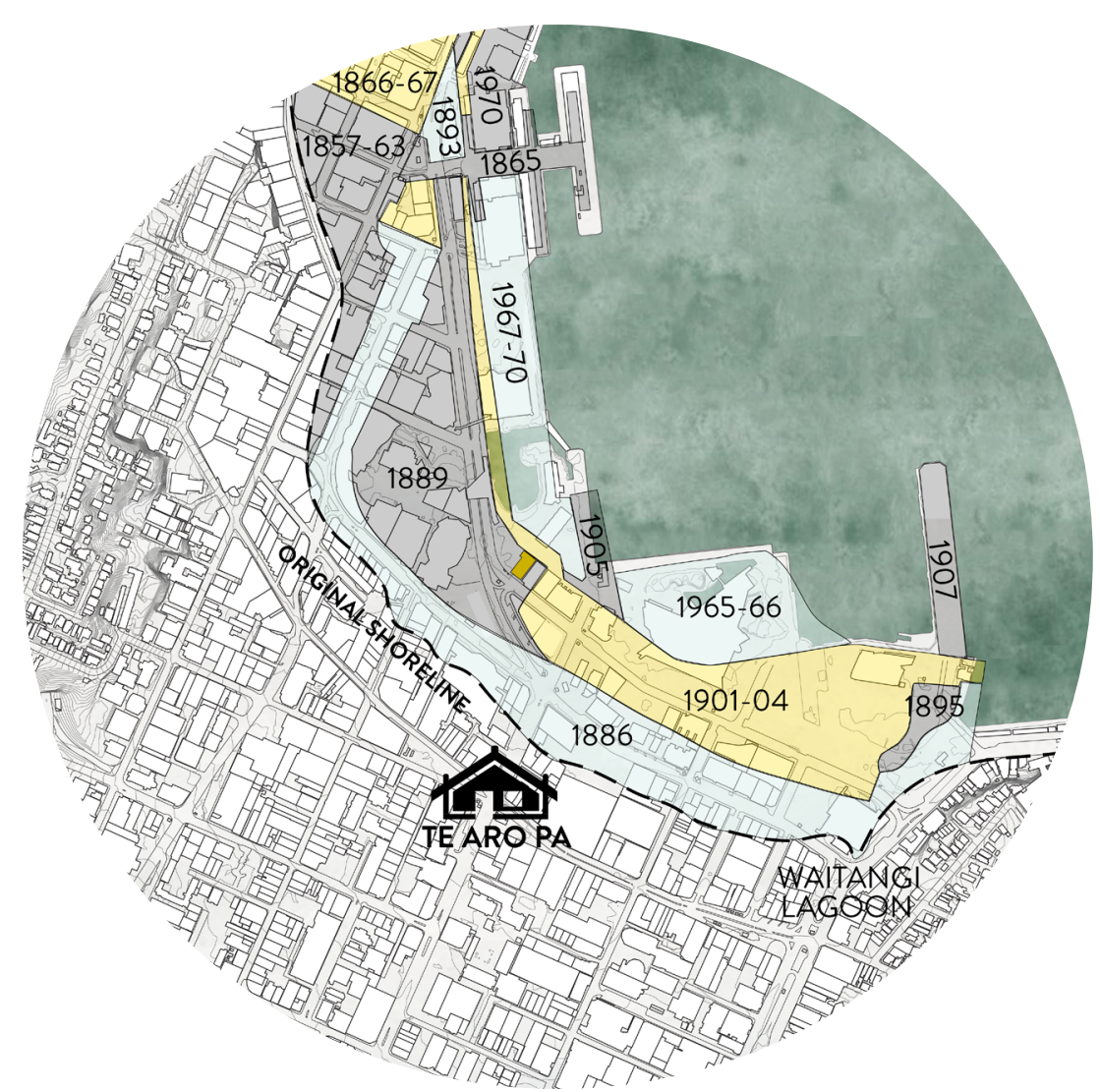

Figure.11.16: Reclaimed Land Diagram

\section{Wind Zone}

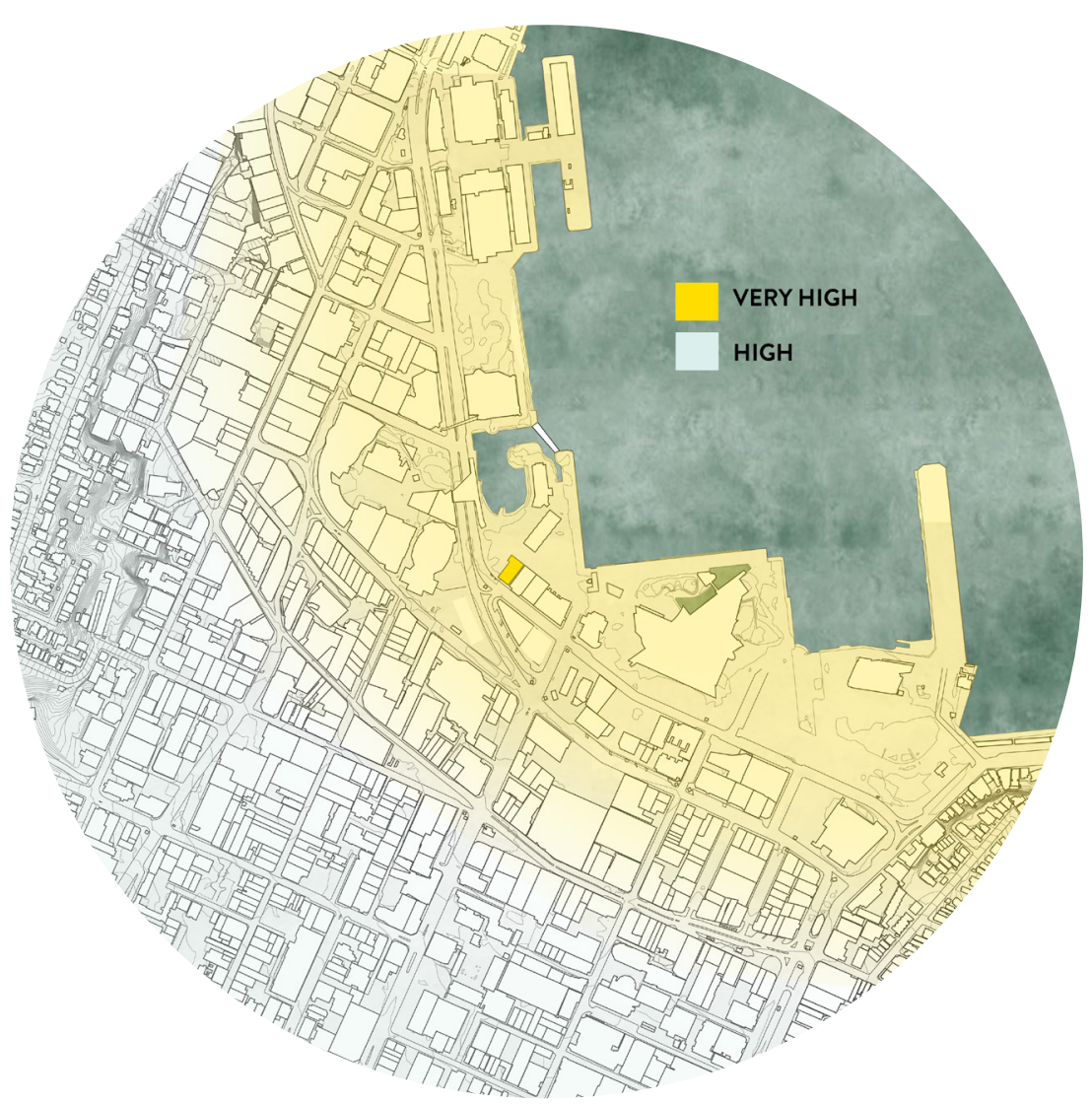

Figure.11.17: Wind Zone Diagram 


\section{Acces s}

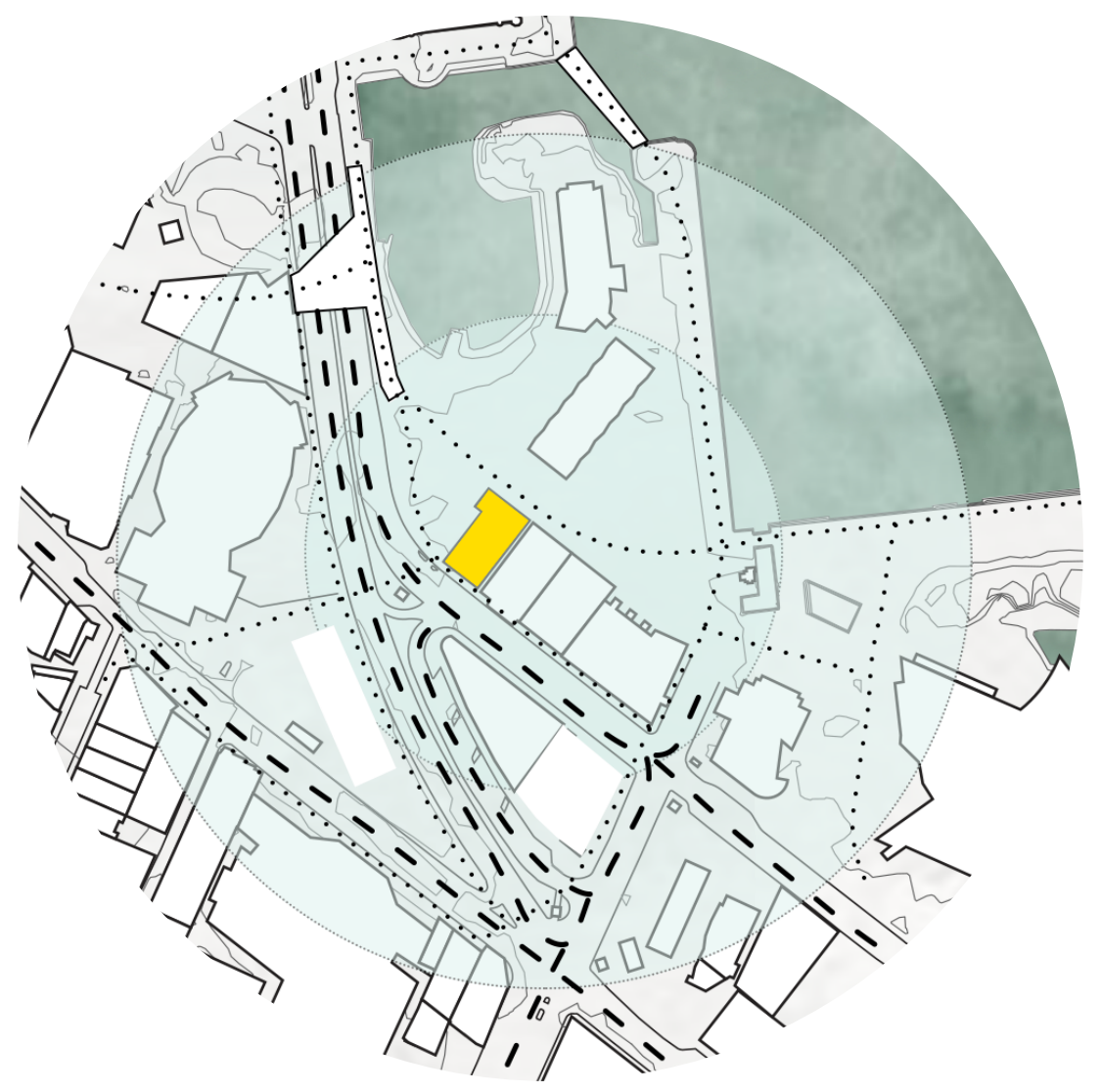

Figure.11.18: Access Diagram

\section{Transport Routes}

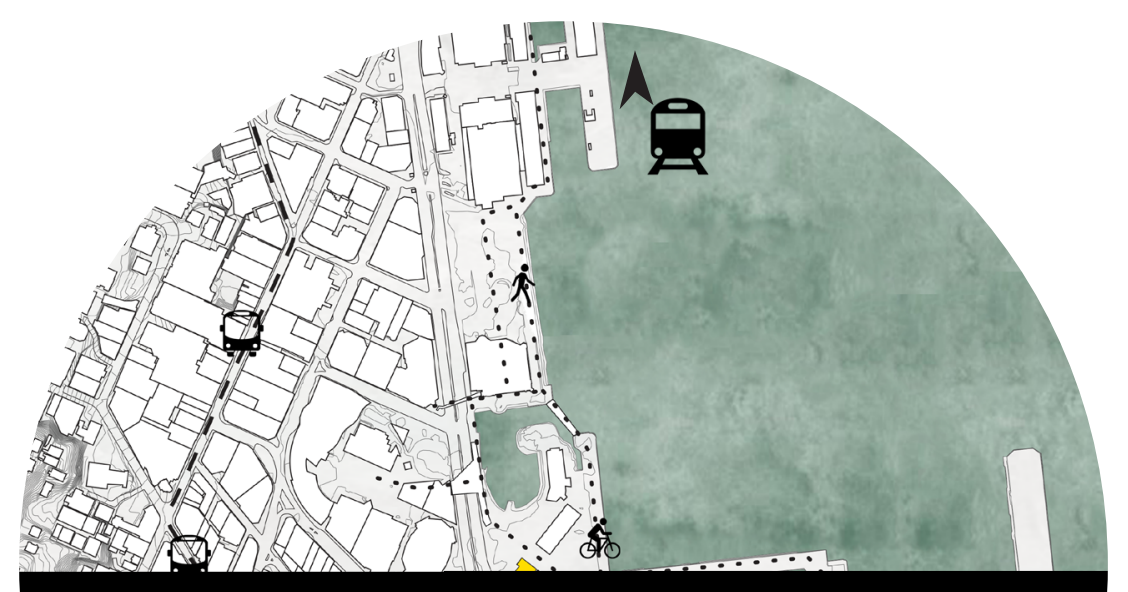




\section{Museums \& Theaters}

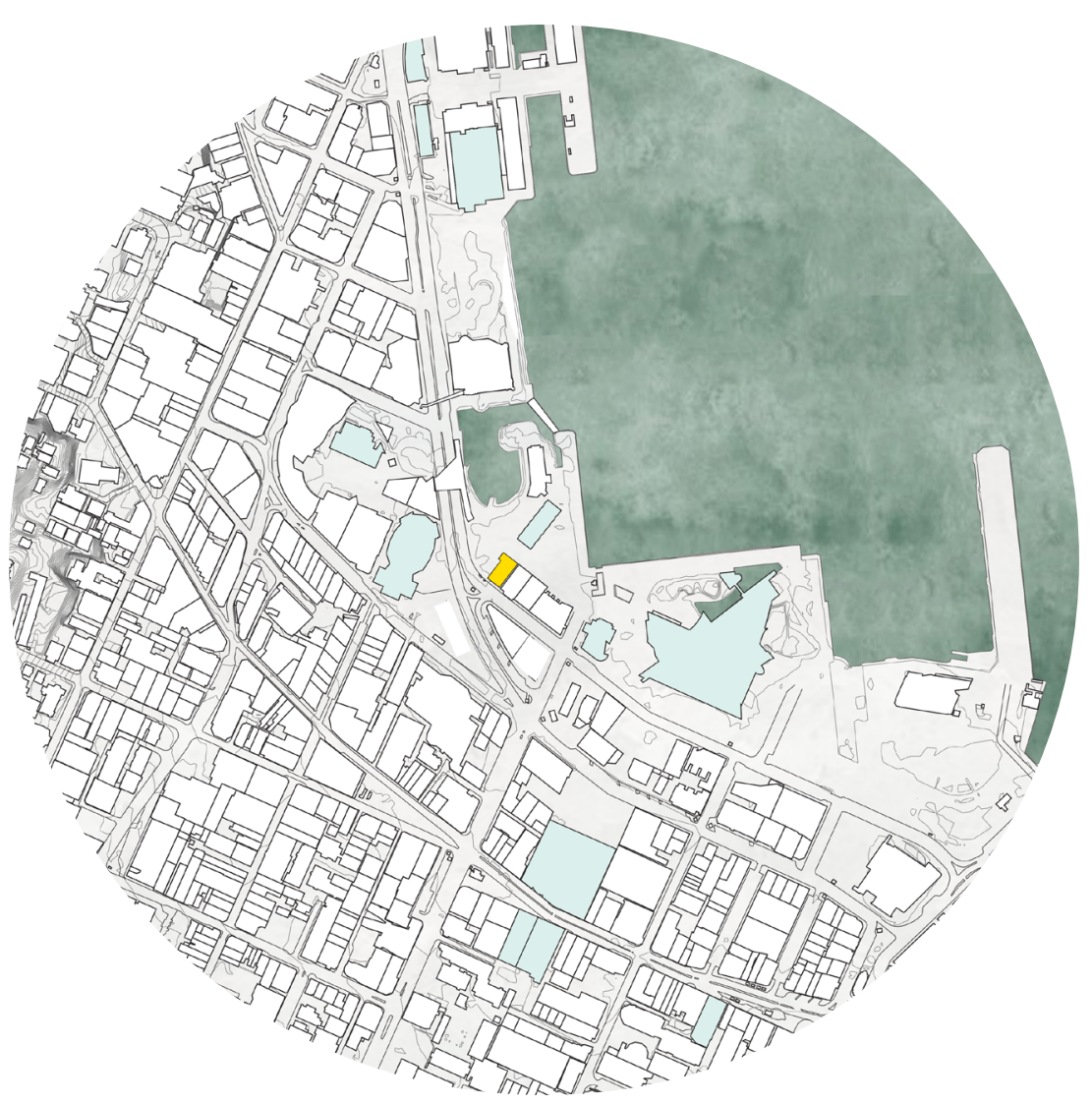

Figure.11.20: Public Buildings Diagram

\section{Green Space}

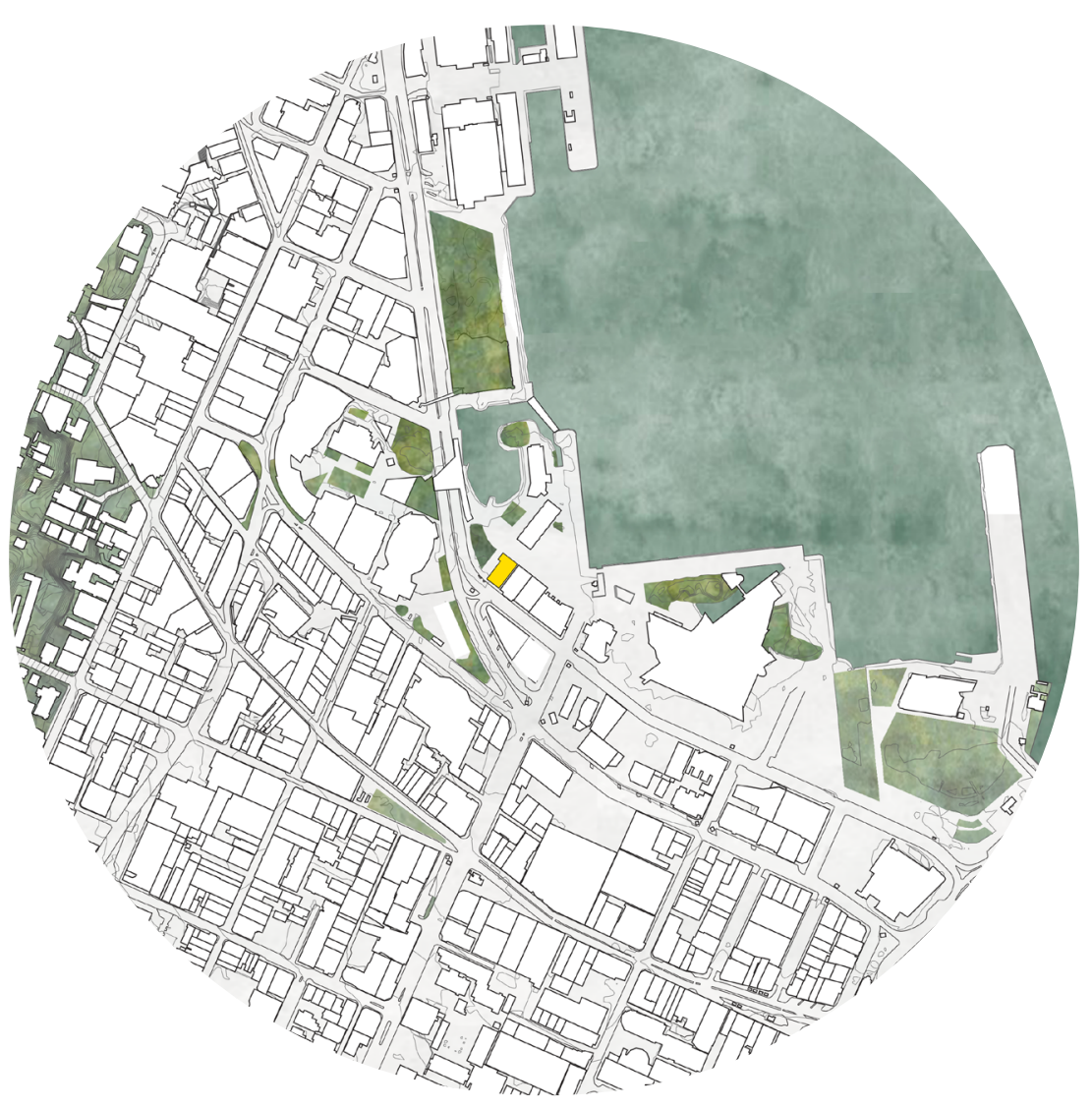

Figure.11.21: Green Space Diagram 


\section{BUILDING FUNCTION}

The function for this building will be based off of the previous Bolivian Cholet precedent from

Chapter Four. These Cholets house a number of uses both residential and commercial. This project does not call for residential spaces and will therefore focus on more of a balance between commercial and community spaces.

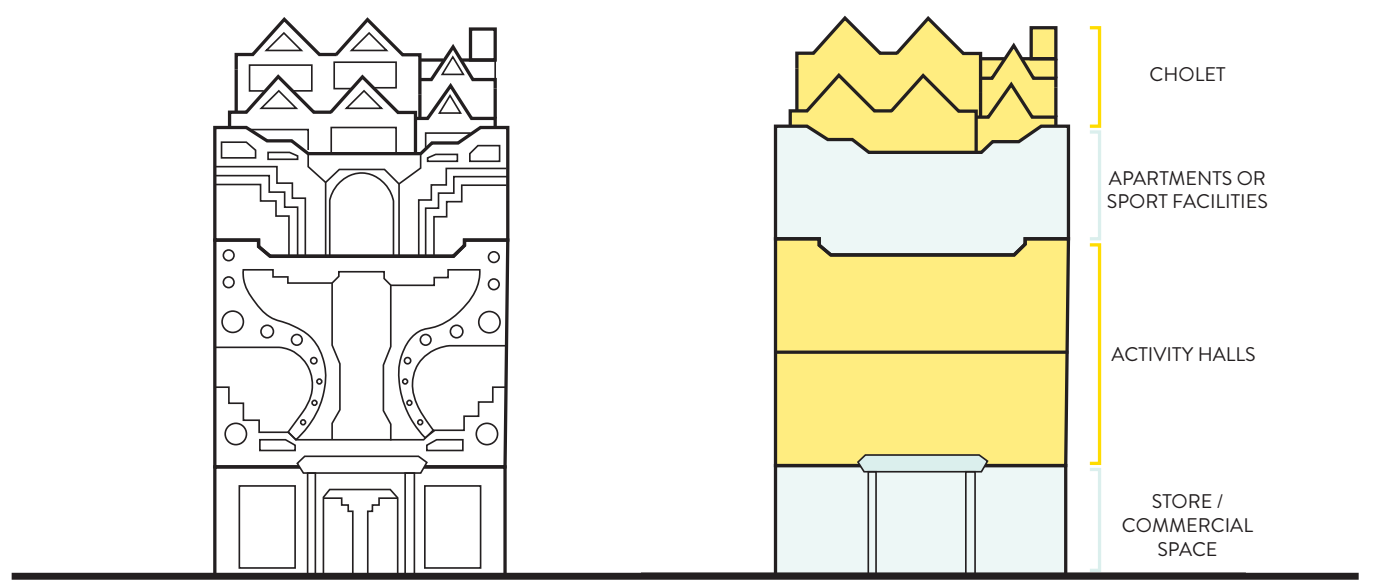

Figure.11.22: Cholet Function break-down

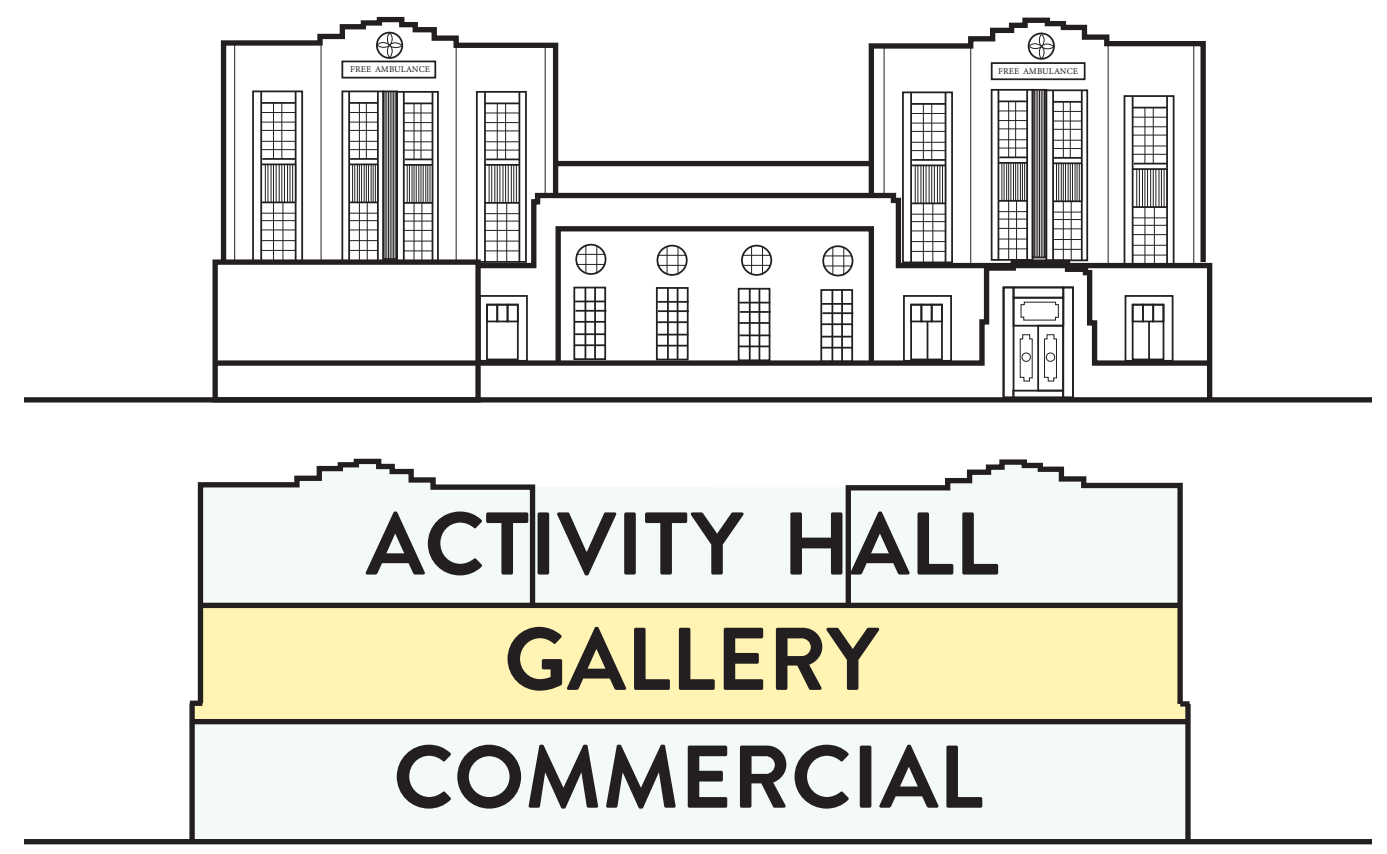


Commercial

$$
\begin{gathered}
\text { Cafe } \\
\text { Shop } \\
\text { Workshop }
\end{gathered}
$$

Activity Hall

$$
\text { Gallery } \begin{gathered}
\text { Large Hall } \\
\text { Smaller Spaces } \\
\text { (for education) }
\end{gathered}
$$

\begin{tabular}{|c|c|c|c|}
\hline & PUBLIC ACCESS AND USE & FUNCTIONING & STAFF WORKINGS \\
\hline 崖 & $\begin{array}{l}\text { Access - open } \\
\text { - easy access to the store \& gallery } \\
\text { Main public use floor } \\
\text { Creating a public connection }\end{array}$ & $\begin{array}{l}\text { Cafe } \\
\text { - indoor \& outdoor seating } \\
\text { - counter, kitchen \& storage } \\
\text { - access to gallery space and } \\
\text { store }\end{array}$ & $\begin{array}{l}\text { Office } \\
\text { - space for admin work } \\
\text { Storage } \\
\text { - for back stock } \\
\text { Toilets } \\
\text { - usable for the staff \& patrons } \\
\end{array}$ \\
\hline $\begin{array}{l}\text { r } \\
\\
\\
\\
\end{array}$ & $\begin{array}{l}\text { Access - open/controlled } \\
\text { - areas to sit } \\
\text { - balance between spaces of } \\
\text { art and empty spaces to } \\
\text { reflect } \\
\text { Connection to cafe through } \\
\text { central circulation } \\
\text { Workshop more private }\end{array}$ & $\begin{array}{l}\text { Exhibition Spaces } \\
\text { - both wall and plinth display } \\
\text { spaces } \\
\text { Store } \\
\text { - open versetile space with } \\
\text { counter } \\
\text { Workshop } \\
\text { - work benches and equipment }\end{array}$ & $\begin{array}{l}\text { Office } \\
\text { - for admin on gallery sales } \\
\text { Storage } \\
\text { - for items in transit to } \\
\text { purchasers } \\
\text { Toilets }\end{array}$ \\
\hline 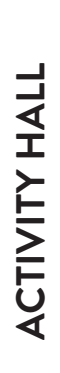 & $\begin{array}{l}\text { Access - controlled } \\
\text { - via the central circulation } \\
\text { and connection with the } \\
\text { outdoor promenade } \\
\text { - connectivity of an "in } \\
\text { beteen" community }\end{array}$ & $\begin{array}{l}\text { Activity Spaces } \\
\text { - a large function spaces as } \\
\text { well as smaller function spaces } \\
\text { with an outdoor element } \\
\text { (connection to promenade), } \\
\text { kitchen } \\
\text { Class spaces } \\
\text { - flexible seating, board space }\end{array}$ & $\begin{array}{l}\text { Office } \\
\text { - admin \& organization work- } \\
\text { space } \\
\text { Storage } \\
\text { - equipment \& supplies closet } \\
\text { Toilets }\end{array}$ \\
\hline 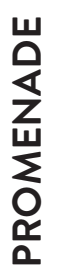 & $\begin{array}{l}\text { Access - open } \\
\text { - connects building to the } \\
\text { surrounding landscape } \\
\text { - useable and protected } \\
\text { outdoor space }\end{array}$ & $\begin{array}{l}\text { - Shade and wind shelter } \\
\text { - Connection to the natural } \\
\text { landscape } \\
\text { - Recreational space }\end{array}$ & N/A \\
\hline
\end{tabular}

Figure.11.24: Gradient of Access

\section{SPATIAL REQUIREMENTS}




\section{BIOPHILIC DESIGN}

B iophilic design is an architectural and design response to Biophilia. Biophilia is described as the need to connect with living things (Biophilic Design, 2018). Being in sterile built environments hinders our connection to nature. The effects of being in these spaces have the developmental consequences and affects people physical and mental health (Biophilic Design, 2018). Biophilic design is also more than simply adding plants to a space, it acts as a "green band aid" (Biophilic Design, 2018).

Scale plays an important part in biophilic design. It is a non-linear process as the further away our spaces are from nature, the more necessary it becomes (see figure below). Scale could also help quantify the need of intervention for a typology in relation to other projects. This could help designers grasp the need of their projects more accurately (Biophilic Design, 2018).

There is a weakened connection to nature the further from the ground people are, as well as the separation from human interaction. This especially affects children and their development again linking to the Ministry's' Well-being Framework. A more thoughtful approach to biophilic design would be to analyse the site and look at the demographics of the users (Biophilic Design, 2018).

The objective of Biophilic design is to deliberately refashion nature to satisfy human needs in a way that

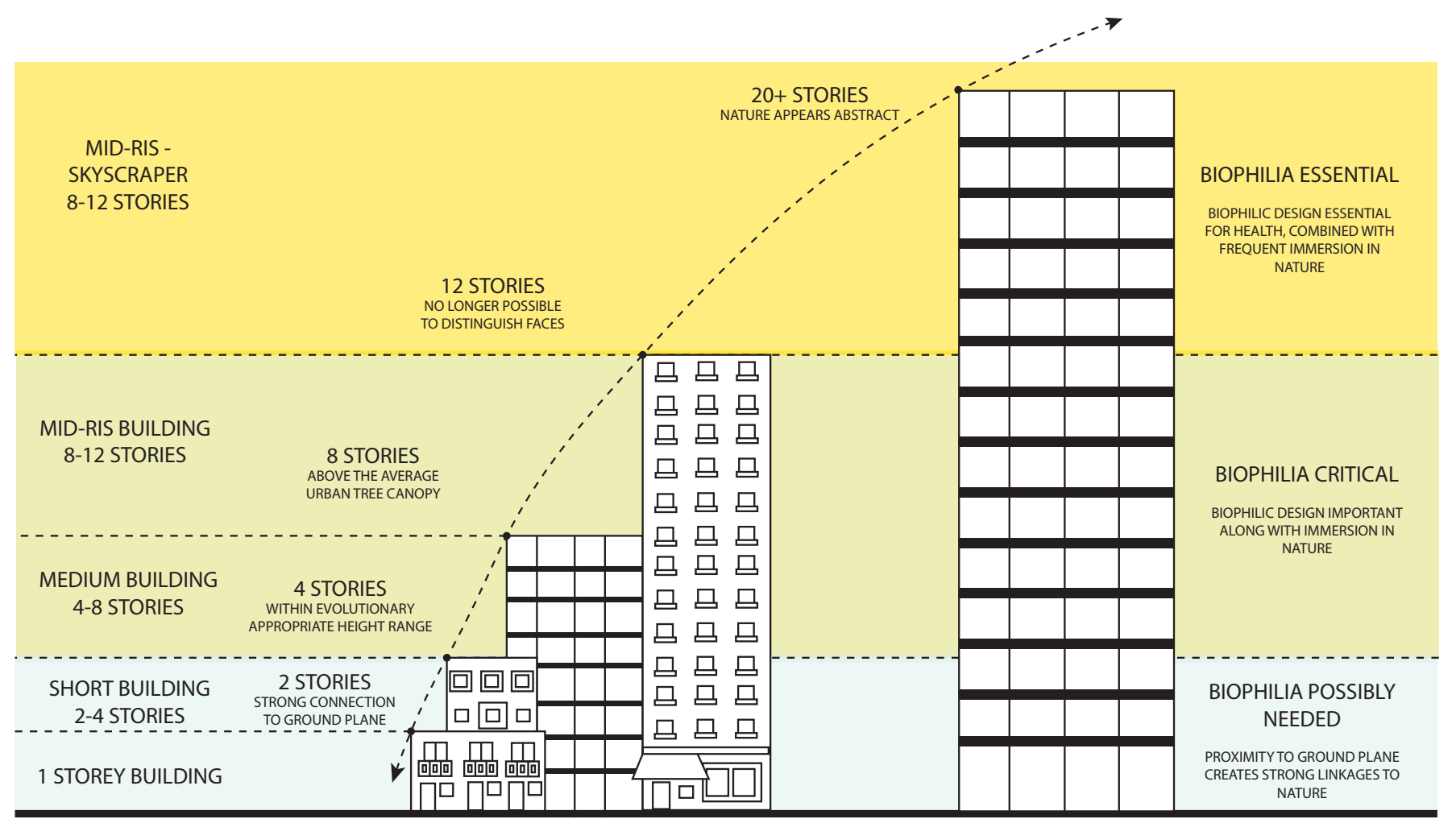

Figure.11.26: Biophilic requirement to building size diagram inspired by Trim Tab 
celebrates the natural world. This form of design can enrich both nature and human well-being as described in the Ministry of Culture and Heritages' Well-being Framework. The increasing amount of space taken up by the built environment continues to separate humans from the natural world. Biophilic design could help bring back that sense of nature. It is seen as the 'missing link' to sustainable design as it is seen as the most successful way to achieving long lasting sustainability (Kellert et al., 2013, p. 5).

Biophilic Design requires the completion of several outlined specifications aimed to help designers apply it to the built environment. Kellert explains the two basic dimensions of biophilic design followed by six design elements achieved by almost 70 attributes. These specifications aim to assist designers achieve biophilic design in the built environment (Kellert et al., 2013, p. 5). Note that not all attributes need to be used, but the more it is used the more effective the outcome becomes.

The first basic dimension described by Kellert is the Organic or Naturalistic dimension. He defines them as shapes and forms used in the built environment that are derived from nature (Kellert et al., 2013, p. $5)$. This is achieved by directly referencing nature through daylighting, plants animals, natural habitats and ecosystems (Kellert et al., 2013, p. 5). It can also be indirectly referenced with tactics that require continual human involvement such as potted plants, water fountains and aquariums (Kellert et al., 2013, p. 6). Lastly this basic dimension can be achieved symbolically, as the natural world is represented through images, metaphor and other tactics (Kellert et al., 2013, p. 6).
The second dimension of biophilic design described by Kellert is, Place-based or Vernacular. This is defined as buildings or landscapes that connect to the ecology and culture of the area (Kellert et al., 2013, p. 6). This includes the 'spirit of place' which emphasising the idea that buildings and landscapes of importance to people become essential to creating their individual and collective identities (Kellert et al., 2013, p. 6).

These basic dimensions directly correlate to six biophilic design elements.

The elements are:

$$
\begin{aligned}
& \text { Environmental Features } \\
& \text { Natural Shapes and forms } \\
& \text { Natural patterns and processes } \\
& \text { Light and space } \\
& \text { Place-based relationships } \\
& \text { Evolved human-nature relationships }
\end{aligned}
$$

These six elements lead on to close to 70 biophilic design attributes that aid in the construction of successful biophilic buildings (See Figure11.27). Although there is an in depth and layered process to designing these spaces, Kellert notes that these elements and attributes are a work in progress and are subject to change over time (2013, p. 14). 


\section{Basic Design Dimensions \\ Organic or Naturalistic}

Place-Based or Vernacular

\section{Design Elements}

- Environmental Features

- Natural Shapes \& Forms

- Natural Patterns \& Processes
- Light \& Space

- Place-Based Relationships

- Evolved Human-Nature

Realtionships

\section{Element Attributes}

\section{Environmental Features}

Colour

Water

Air

Sunlight

Plants

Animals

Natura Materials

Views \& Vistas

Facade Greening

Geology \& Landscape

Habitats \& Ecostsyems

Fire

\section{Natural Shapes \& Forms}

Botanical Motifs

Tree \& Columnar Supports

Animal Motifs

Shell \& Spirals

Egg, Oval and Tube Forms

Arches, Vaults, Domes

No Straight Lines \& Right Angles

Simulation of Natural Features

Biomorphy

Geomorphology

Biomimicry

\section{Place-Based Relationships}

Geographic Connection to Place Historic Connection to Place Ecological Connection to Place Cultural Connection to Place Indigenous Materials Landscape Orientation Landscape Features that Define Building Form Landscape Ecology Intergration of Culture and Ecology Spirit of Place

Avoiding Placelessness
Natural Patterns \& Processes

Sensory variability Information Richness Age, Change \& Patina of Time

Growth \& Efflorescence

Central Focal Point

Patterned Wholes

Bounded Spaces

Linked series \& Chains Integration of Parts to Wholes Complementary Contrasts Dynamic Balance \& Tension Fractals

Hierarchically Organzied Ratios \& Scales

\section{Evolved Human-Nature Realtionships}

Prospect \& Refuge Order and Complexity

Curiosity \& Enticement

Change \& Metamorphosis Security \& Protection Mastery \& Control

Affection \& Attachment Attraction \& Beauty Exploration \& Discovery Information \& Cognition Fear \& Awe

Reverence \& Spirituality 


\section{Conclusion}

$\mathrm{R}$ esearch has shown that it is important to implement Biophilic design principles with heritage conservation values. It will be important for this final design phase to find a balance between respecting the original fabric and history of the building and by giving it new life for its new users. The New York Highline project is an example of combining Heritage Architecture and Biophilic Design. This 1930s rail line was abandoned after only 30 years of use. This piece of engineering history was then transformed into High Line Park, a 1.5-mile-long walkway creating an elevated promenade for the city centre (Lopate \& The Common, 2011). This project creates an interesting precedent for this final design project as its heritage value is still intact, while elevating the wellbeing of its users through the implementation of natural fabric.

The scale of this intervention will need only a small amount of biophilic design intervention as it is already close to the ground and has little separation to its surroundings. Although the scale of this intervention does not require a high biophilic input, it will still be important to have a strong presence of nature. It will need to include more biophilic attributes on the higher levels of the building as well as a connection to the surrounding landscape.

Including Biophilic Design in this project will also create complimentary combination of architectural styles. The Art Deco building displays a style that references elements from nature in a linear and geometrical language. This modern take of the implementation of nature to the built environment, could elevate this previous attempt at a natural influence on the built environment. Characteristics of Art Deco style are evoking a machine-made aesthetic with relative simplicity symmetry and repetition. It also uses simple and clean shapes and geometric ornamentation

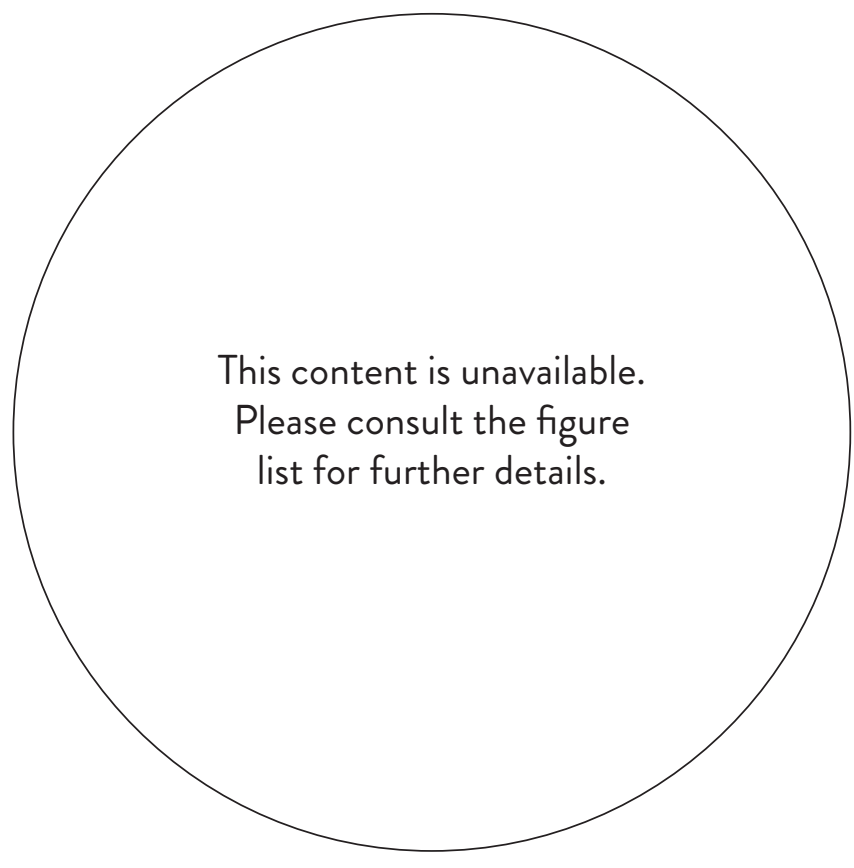

Figure.11.28: The New York Highline

depicting forms of florals, animals and sun-rays. Art Deco also favours a number of materials such as, chrome, ivory, jade, plastics, reinforced concrete, silver and vita glass (Art Deco - Art Movement, n.d.). The style also favours a tropical colour pallet and pastel shades and utilises mouldings and neon lights for added flare (Art Deco - Art Movement, n.d.). 


\section{THIRD PLACE THEORY}

$\mathrm{T}$ he theory of Third Place looks at creating a balanced lifestyle for its users. This balanced life occurs in three different places. The first being the domestic place (home), the second a place of productivity or gain (work) and lastly a place of social inclusivity and celebration of community (Oldenburg, 1999, p. 15). Most cultures have a form of third place, some are more successful than others. The Arabian coffee house, German bierstube, English pub and the less successful American coffee shop. Oldenburg describes the eight characters to creating a successful Third Place as seen bellow.

\section{On Neutral Ground}

Oldenburg explains that the first step to creating a third place is to assure it is on Neutral Ground (1999,

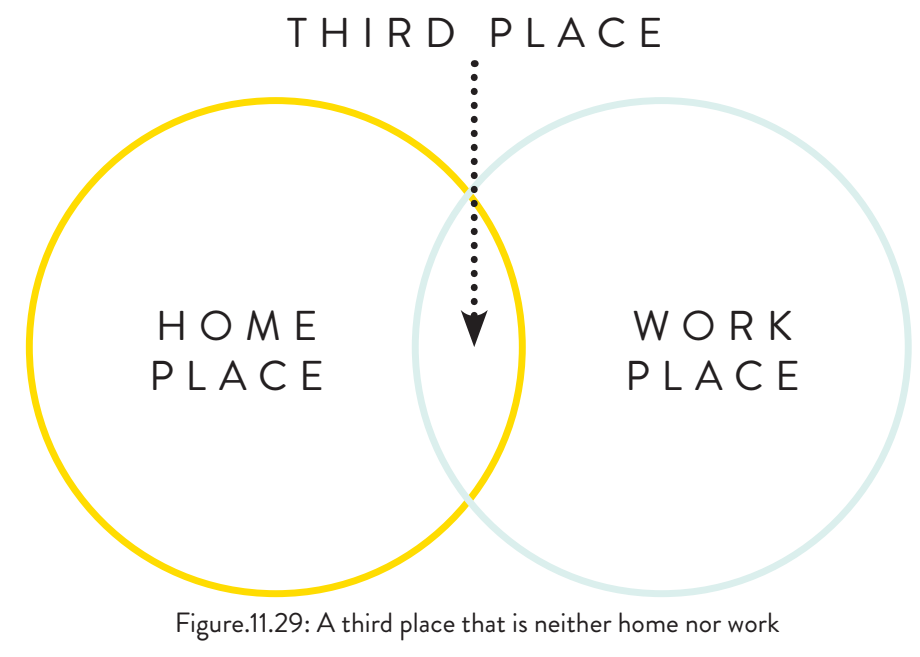
p. 22). He refers to Neutral Ground as a place where people are not obligated to be and are able to come and go as they please (Oldenburg, 1999, p. 22). This gives people the opportunity to have more informal relationships than they could have out of their homes (Oldenburg, 1999, p. 23). In the past, Urban Planners assumed that if people's private spaces were well designed there would be no need for public spaces (Oldenburg, 1999, p. 23). However, Jane Jacobs argues that much like visiting a restaurant when one has a kitchen at home these spaces create a public and neutral setting for a sense of unity (Oldenburg, 1999, p. 23).

\section{Acts as a Leveller}

During the seventeenth century, England began to establish the idea of the coffeehouse in order to 'level' its citizens (Oldenburg, 1999, p. 23). This was a

direct attempt to rid any difference of status between its people. These early coffeehouses also had a wide variety of items available to choose from so as to widen the variety of company (Oldenburg, 1999, p. 24).

The main idea for these levelling places is to be inclusive (Oldenburg, 1999, p. 24). They have to be accessible to the public and have no formal criteria or membership, allowing people to expand their possibilities. Oldenburg refers to Georg Simmel's term of 'pure sociability' meaning the occasion of people gatherings to feel a sense of joy and relief away from purpose and role (1999, pp. 24 \& 25).

These places give people the opportunity to be their true self in a positive environment with status and negativity being left at the door (Oldenburg, 1999, p. 25). 
Conversation is the Main

Activity

So far Oldenburg has described Neutral Ground as the place, levelling as the stage and now for the performance of Third Place. The performance of Third Place is conversation (Oldenburg, 1999, p. 26). Third place conversation also compliments the levelling process (Oldenburg, 1999, p. 28). Cultures that treasure the art of conversation frequent Third Places more than cultures that do not (Oldenburg, 1999, p. 26). Oldenburg mentions Tibor Scitovsky statistical data proving that the rate that the English visit their local pub and the French visit their local café shows their love for social conversation (Oldenburg, 1999, p. 27). However, other more individualistic cultures such as America seem to be shocked at the leisurely activity and admit to envying it (Oldenburg, 1999, p. 27). Incorporating music and activities into these places can also encourage conversation (Oldenburg, 1999, p. 30).

\section{Accessibility and}

\section{Accommodation}

Third Places act as a remedy for loneliness and create the opportunity for good company, which in turn creates a greater sense of community (Oldenburg, 1999 , p. 32). Therefore, it is important that these spaces are easy to access in the sense of time and location (Oldenburg, 1999, p. 32). They must stay open long hours so users can visit before, between and after their daily obligations which will most likely be unplanned, infrequent or brief but knowing it's an option to visit is important.

\section{The Regulars}

Regular patrons play an important part in creating, inviting and accepting environment for newcomers as its essential for the vitality of Third Places (Oldenburg, 1999, p. 34).

\section{A Low Profile}

The physical appearance of Third Places usually appears to be quite plain. Although these places have a plain appearance it's their homeliness that is appealing to its users. Oldenburg mentions a variety of factors that gives these spaces their home-like characteristic (Oldenburg, 1999, p. 36). The first one of these characteristics is an older building that was built for another purpose, as a newer place is more tailored for its intended purpose (Oldenburg, 1999, p. 36). Having a plain appearance also acts as a form of protection. Being plain inside and out so as not to upstage its occupants and continue a sense of levelling in a modest environment (Oldenburg, 1999, p. 37).

\section{The Mood Is Playful}

It is also important for Third Places to have a playful mood (Oldenburg, 1999, p. 37).

The essence of playfulness can be subtle as long as there is a feeling of joy and acceptance (Oldenburg, 1999 , p. 38). This will ensure that people within the space feels part of something bigger and is helped by the inclusion of one another in the forms of play.

It is a place where one loses track of time and hates to leave, creating an urge to return is what keeps Third Places going (Oldenburg, 1999, p. 38). 


\section{Conclusion}

\section{A Home away from Home}

Third places feel like a second home to its users, due to its sense of comfort. These good-natured environments often feel more like home than peoples own private homes (Oldenburg, 1999, p. 39). While someone's home is a private setting, third places are more of a public venue (Oldenburg, 1999, p. 39). Oldenburg mentions David Seamon's trait of home as a place to feel centred, sense of possession over their setting, where one may feel restored, free to feel at peace and a sense of warmth (Oldenburg, 1999, pp. 38-41). Although Seamon's traits are based on the private home they translate well into third place characteristics.
The environment that Third Places create will not just nurture but express the personality and individuality of its cross-cultured users.

This design will need to be on neutral ground and act as a leveller to ensure an inclusive environment. It should also aim to be a place for cross cultural people to feel welcome and allow them to visit whenever they need a safe and comfortable place to converse with others. The place can be of a low profile, but the atmosphere should still be playful to not only for the regular clientele but to entice newcomers.

This theory also strengthens the decision to use a heritage building as Oldenburg mentions 'the added sense of homeliness' from an older building with a previous use. This demonstrates that a heritage building is both appropriate as a Third Place and as the expression of the multicultural identity of CCPs. All these traits will be taken into consideration for the final experimentation. 


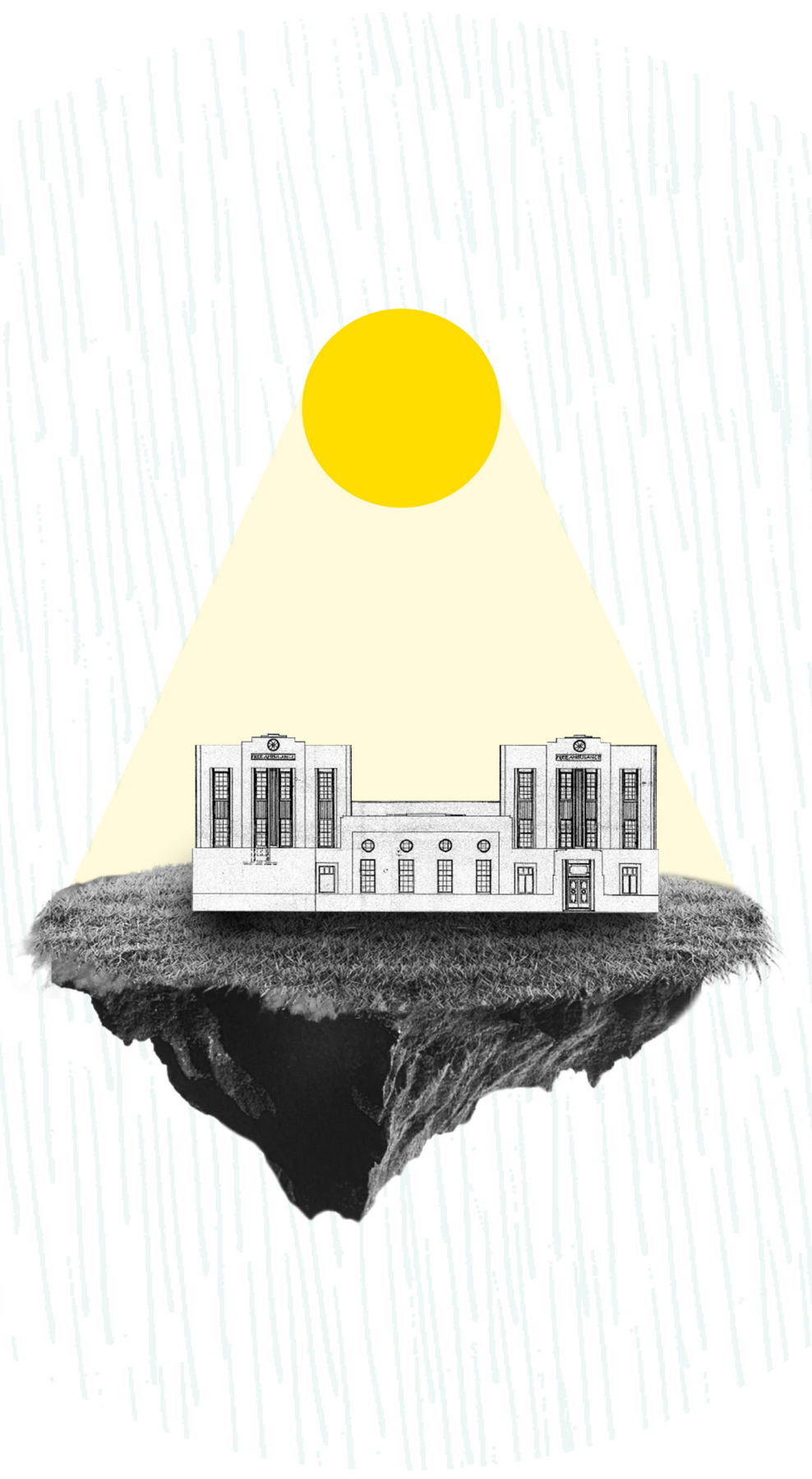

Figure.11.30: Collage Representation of the Free Ambulance Building as a Third Place 


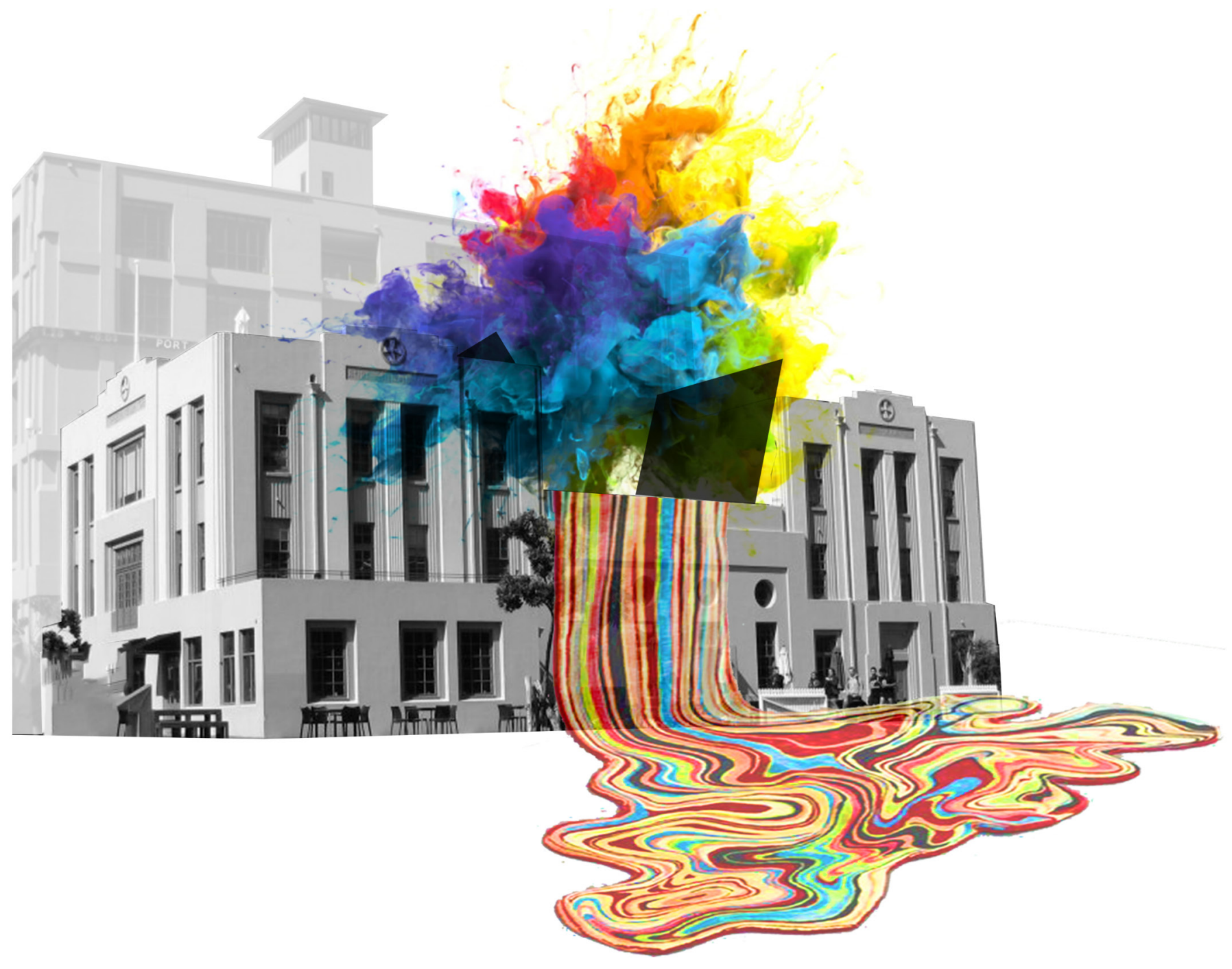

Figure.11.31: Collage of Design Intent 


\section{DESIGN DECISIONS}

The final design will look into creating a multifunctional space within the Free Ambulance building while respecting its original fabric. The design will look at creating a central circulation form to connect the ground floor to the first floor. The design will also look at creating a new skylight structure to follow Biophilic design principles and maintain an original feature of the building. Finally, the design will look at forming a promenade to further connect the building to the natural landscape.

Overall the intervention will aim to connect all aspects of the design into a harmonious space for the CCP users. 
Design Language

\footnotetext{
The buildings Art Deco Style utilises strong angular and geometric language with accents of curves in some of its detailing for contrast.
} 

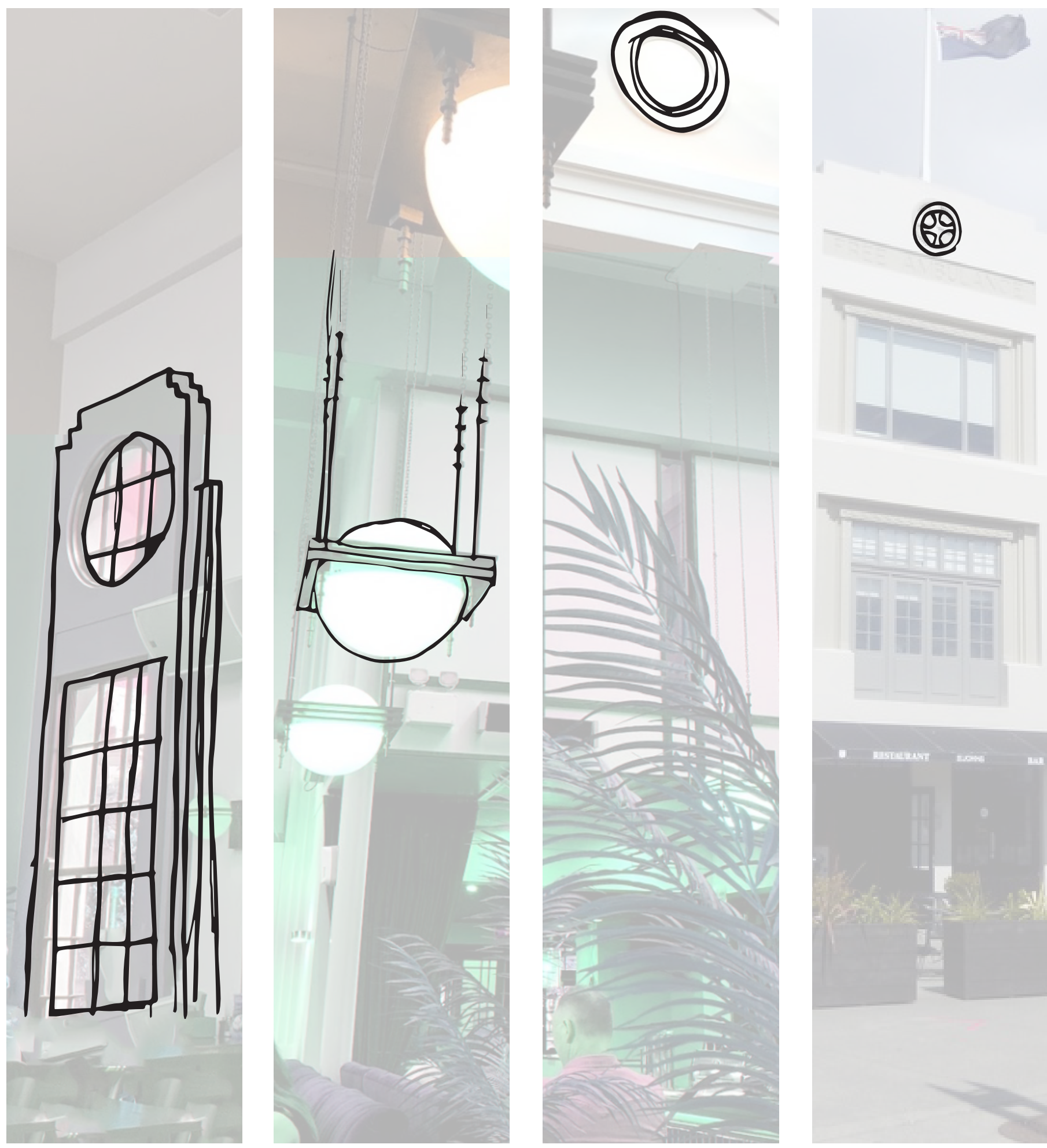

Figure.11.32: Circular References within and Linear Building 


\section{GROUND FLOOR}

1

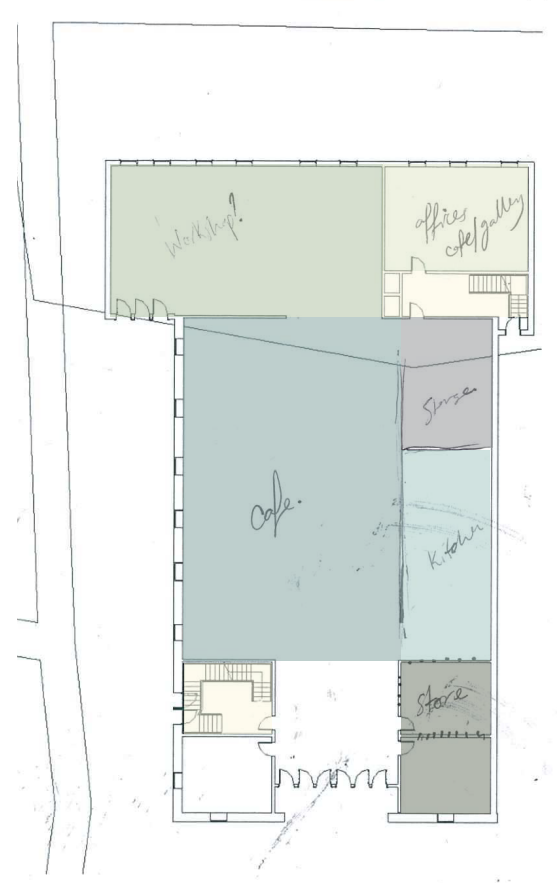

3

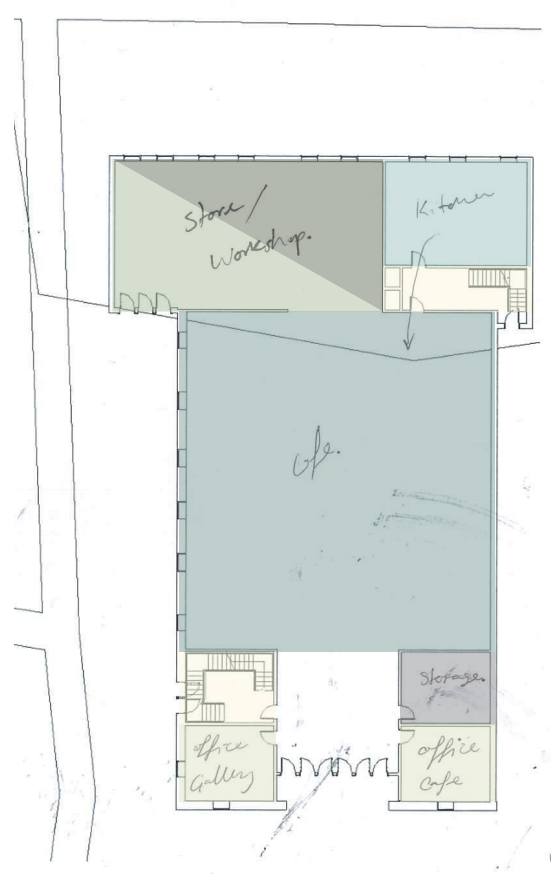

2

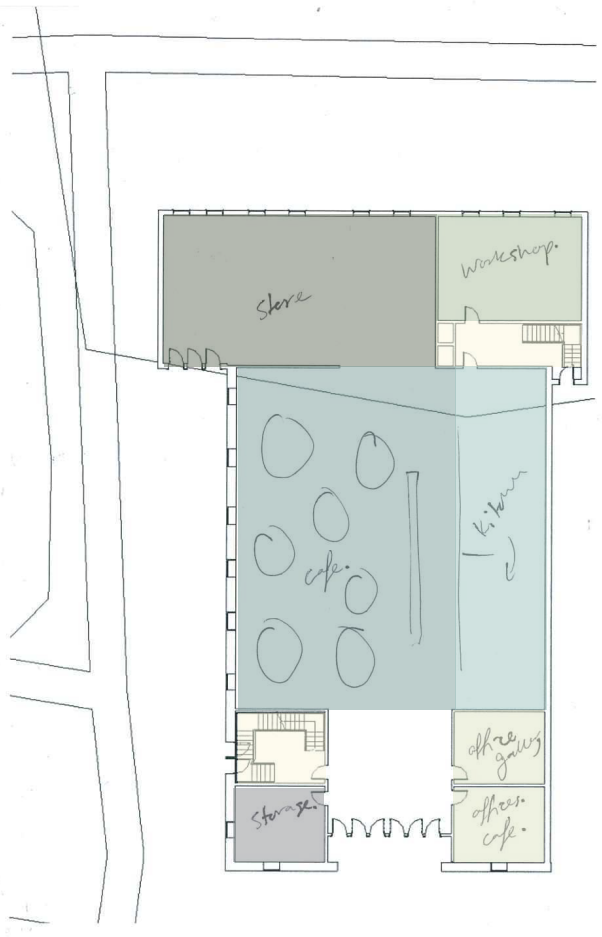

4

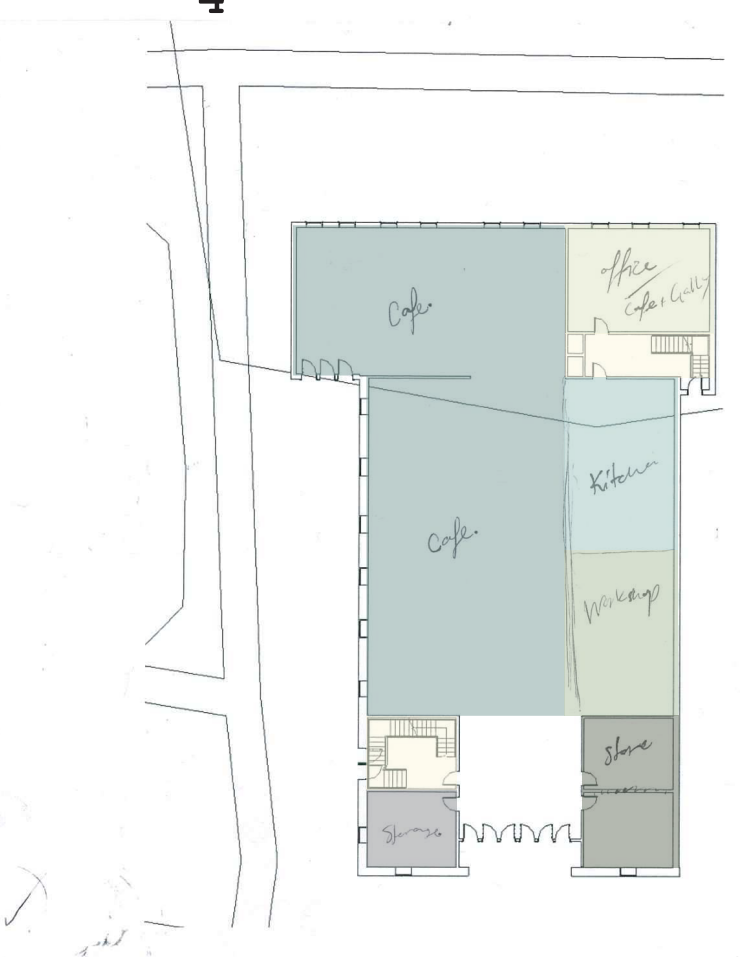

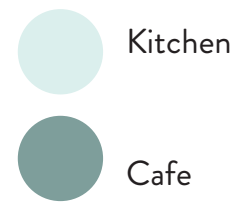

Access

Workshop

Office

Store 


\section{FIRST FLOOR}

1

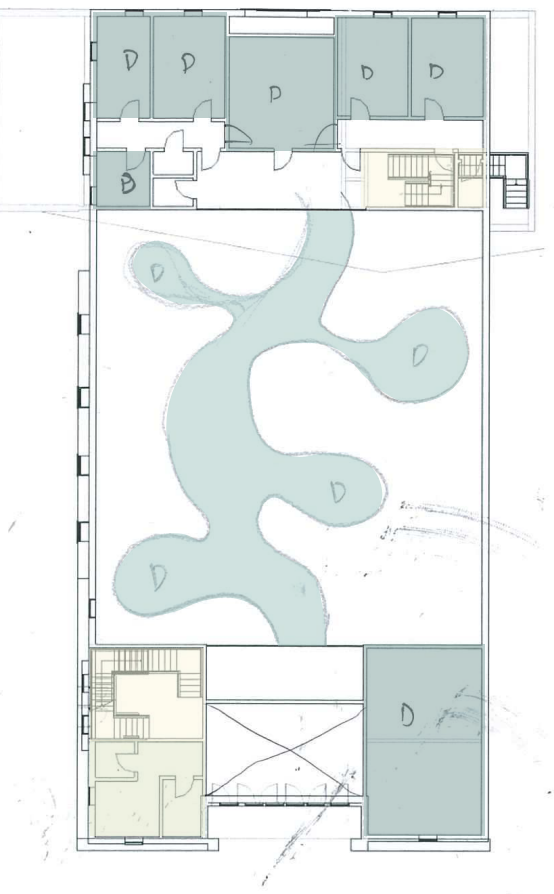

3

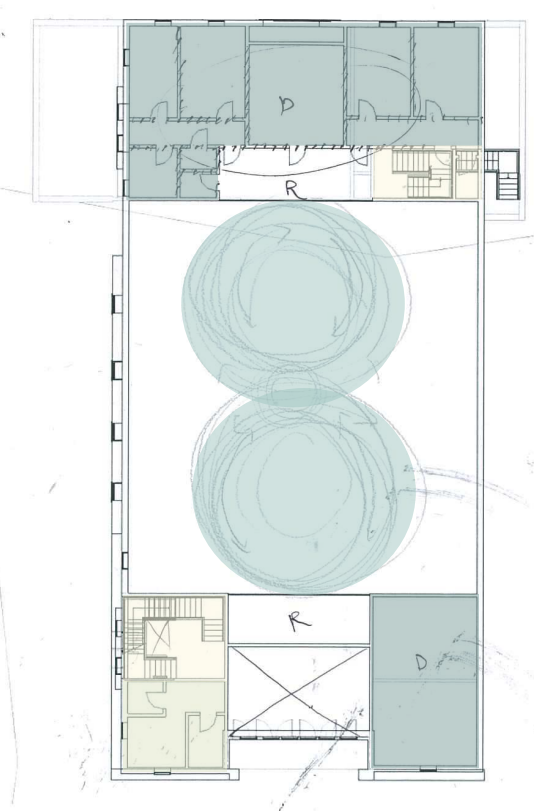

2

use skelctal
similar to

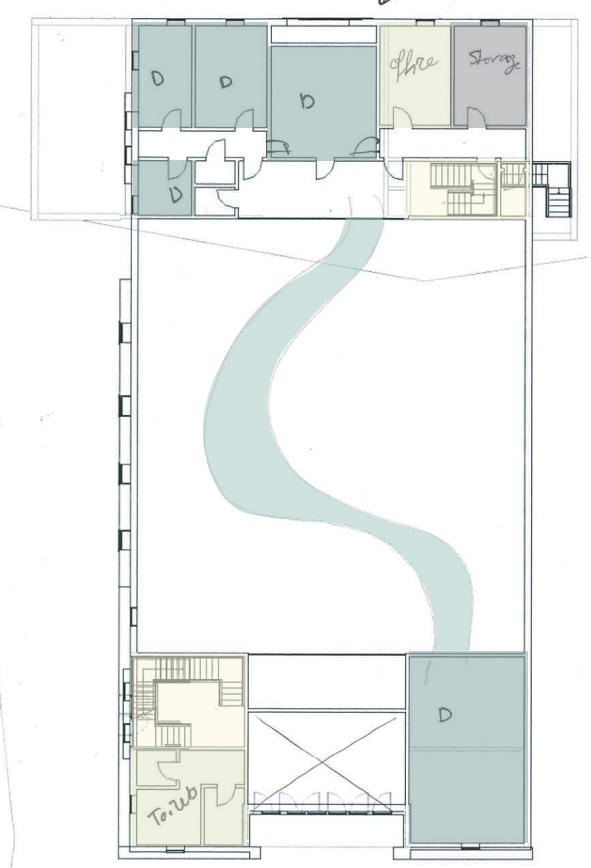

4

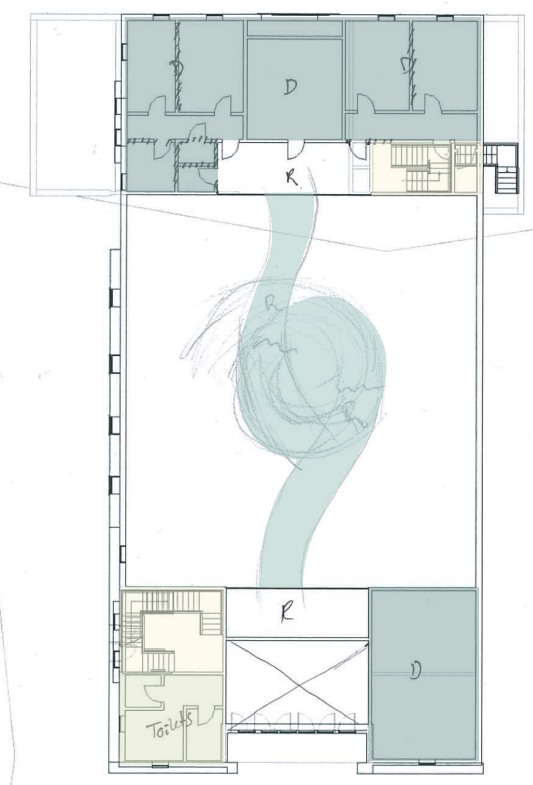

Central

Circulation

Display Space

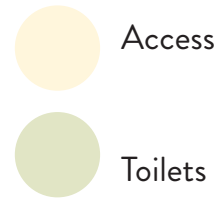

Toilets
Kitchen

Storage 


\section{SECOND FLOOR}

1

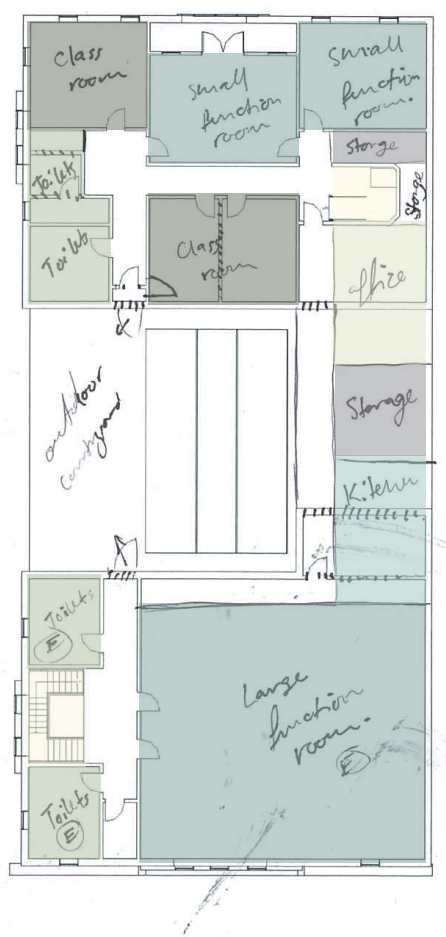

3

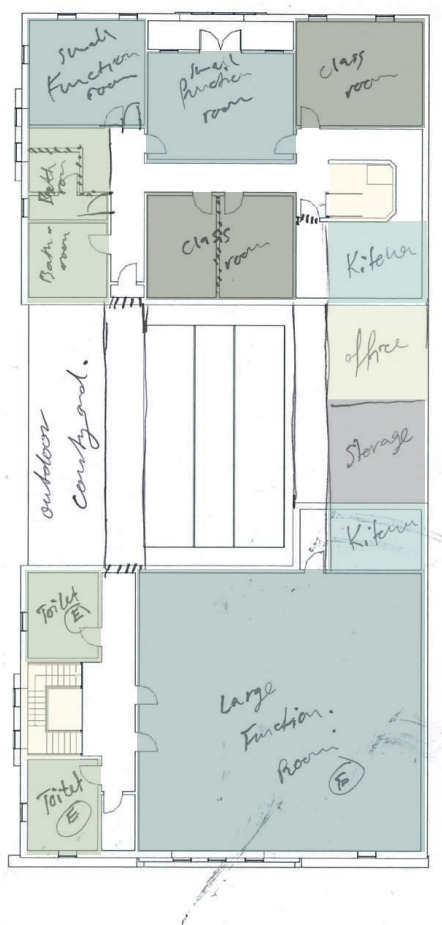

Kitchen

Function Room
2

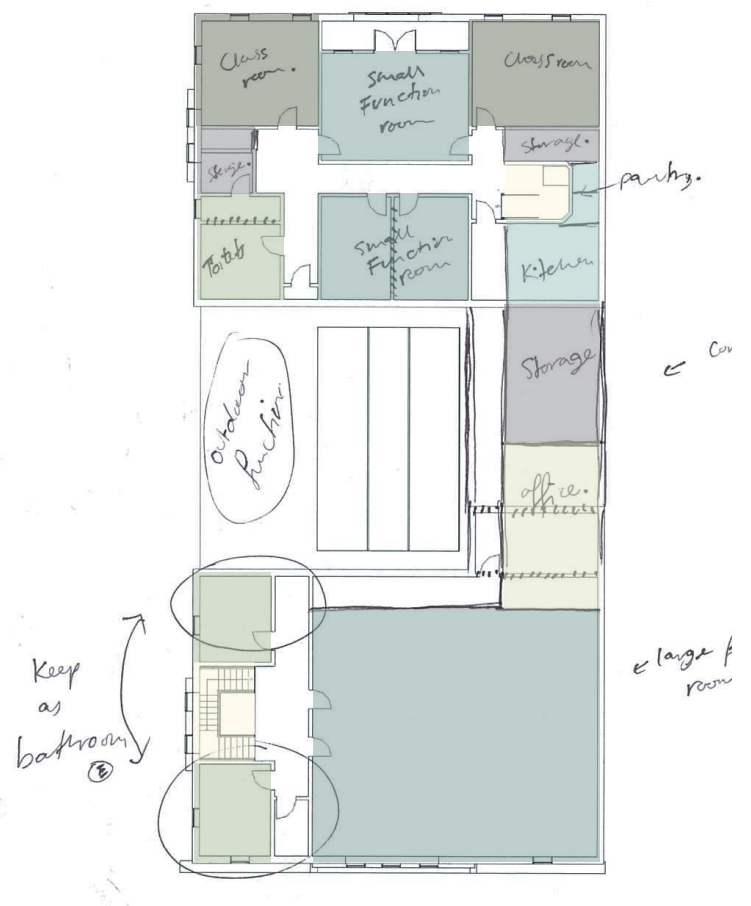

4

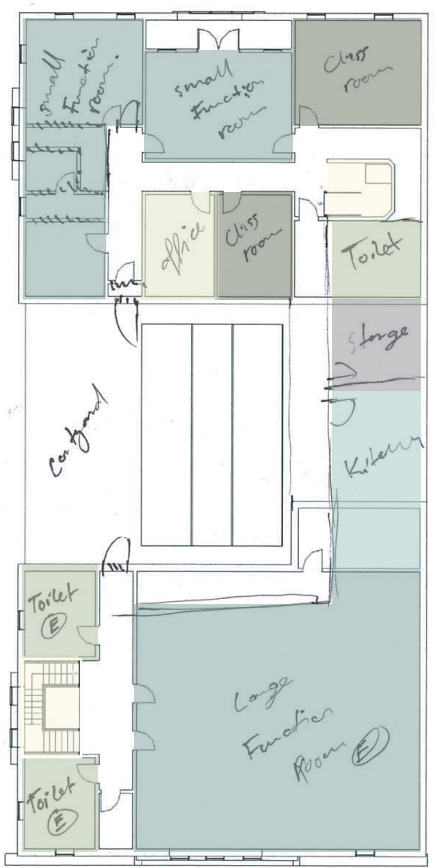

Toilet

Classroom 


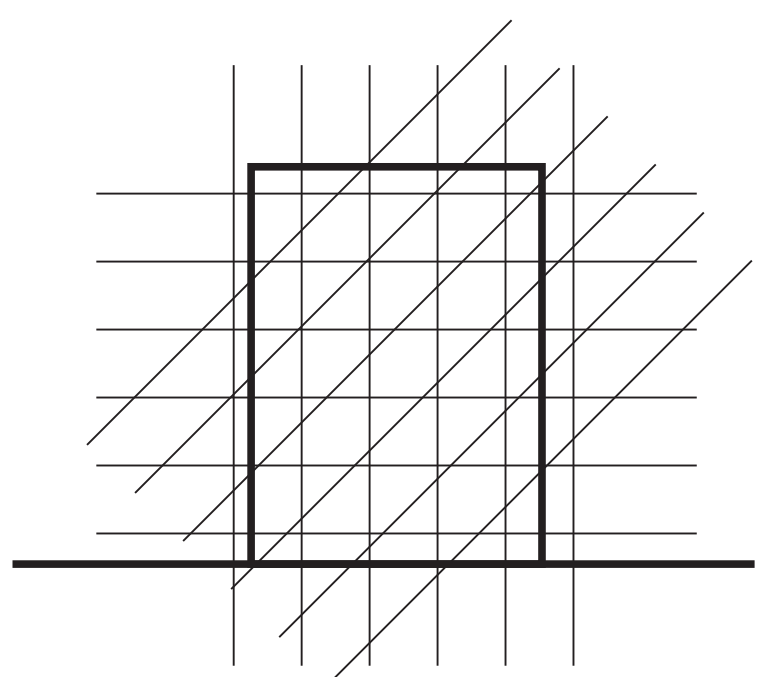

Figure.11.36: Experimental separation of space in section

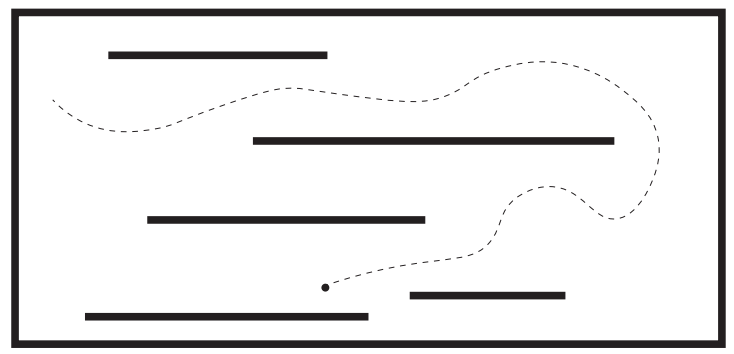

Figure.11.37: Experimental separation of space in plan

Connecting both sides of the second floor while maintaining space for the skylight.

Figure.11.38: Diagram of Main Exterior Alteration 


\section{CENTRAL CIRCULATION}
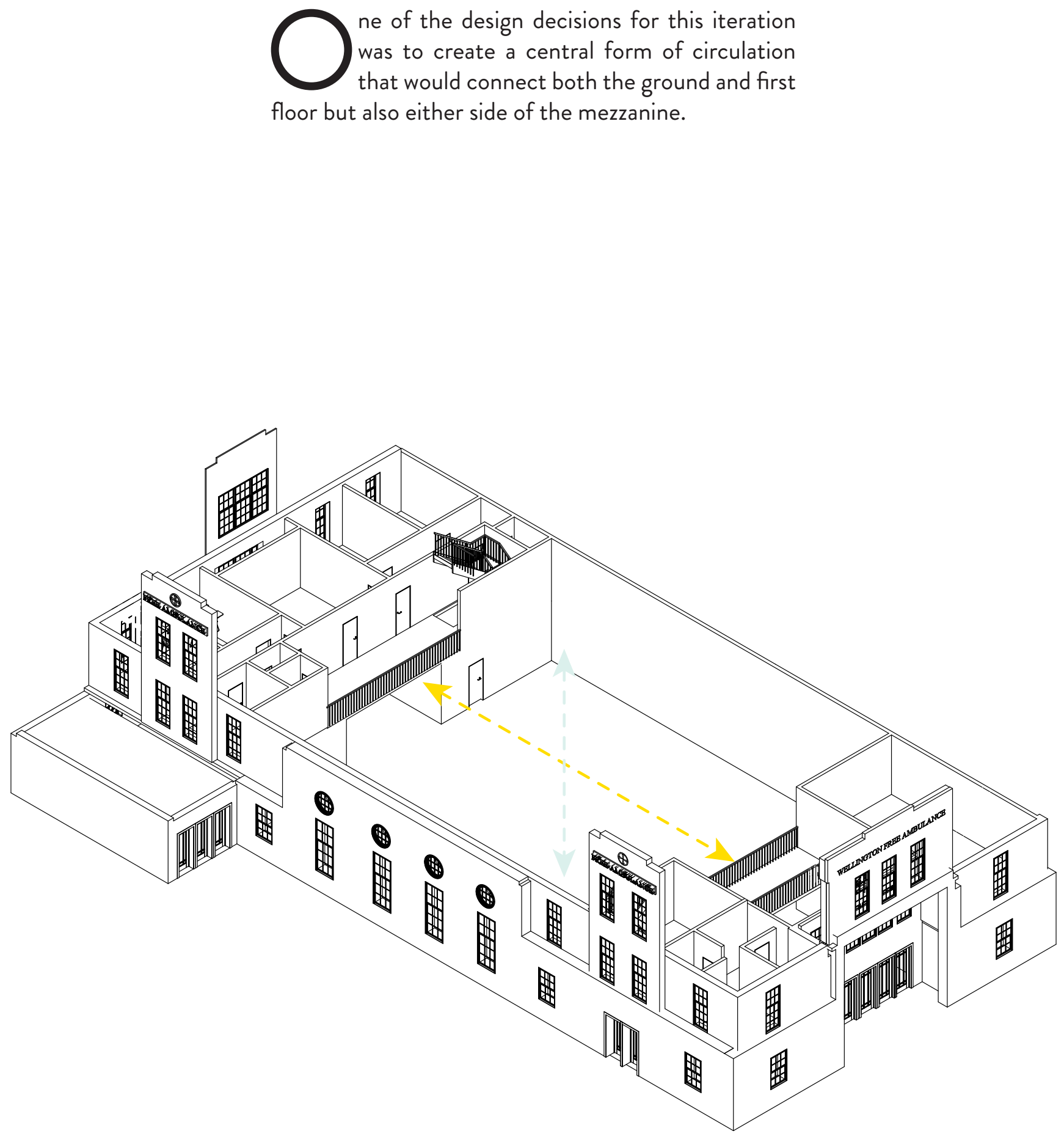

Figure.11.39: Points of connection intended for the circulation 


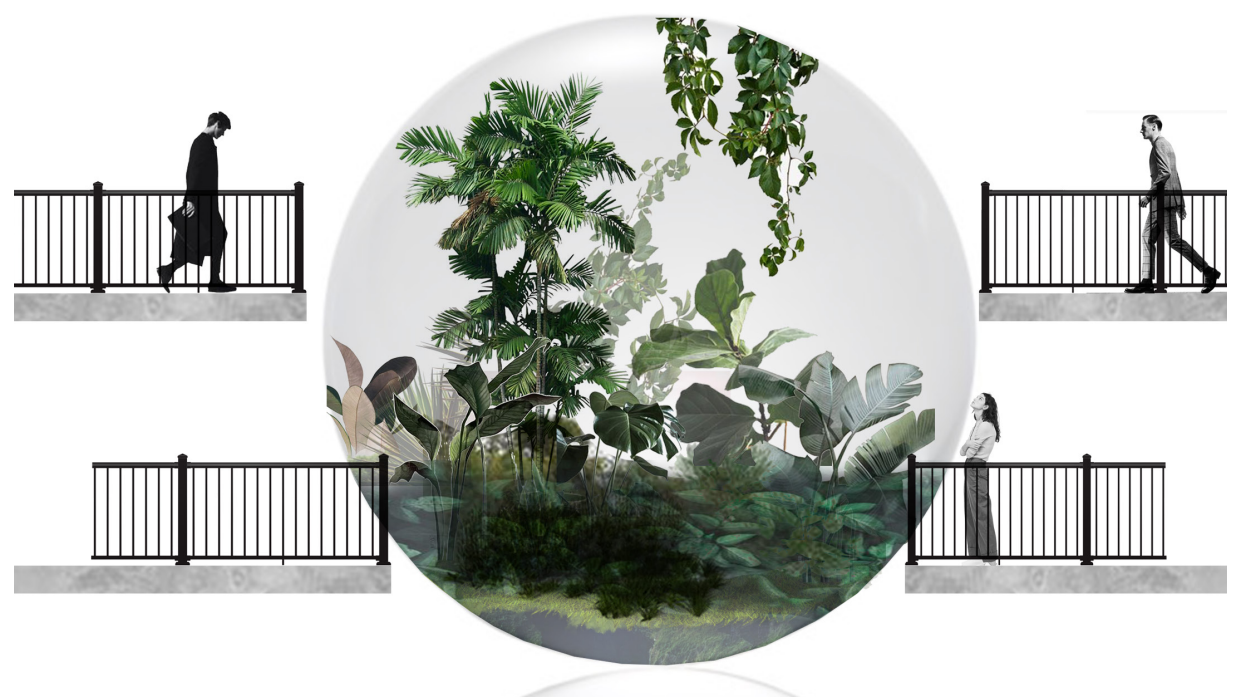

Figure.11.40: Experimental collage of circulation space
A world within a world

a new third place

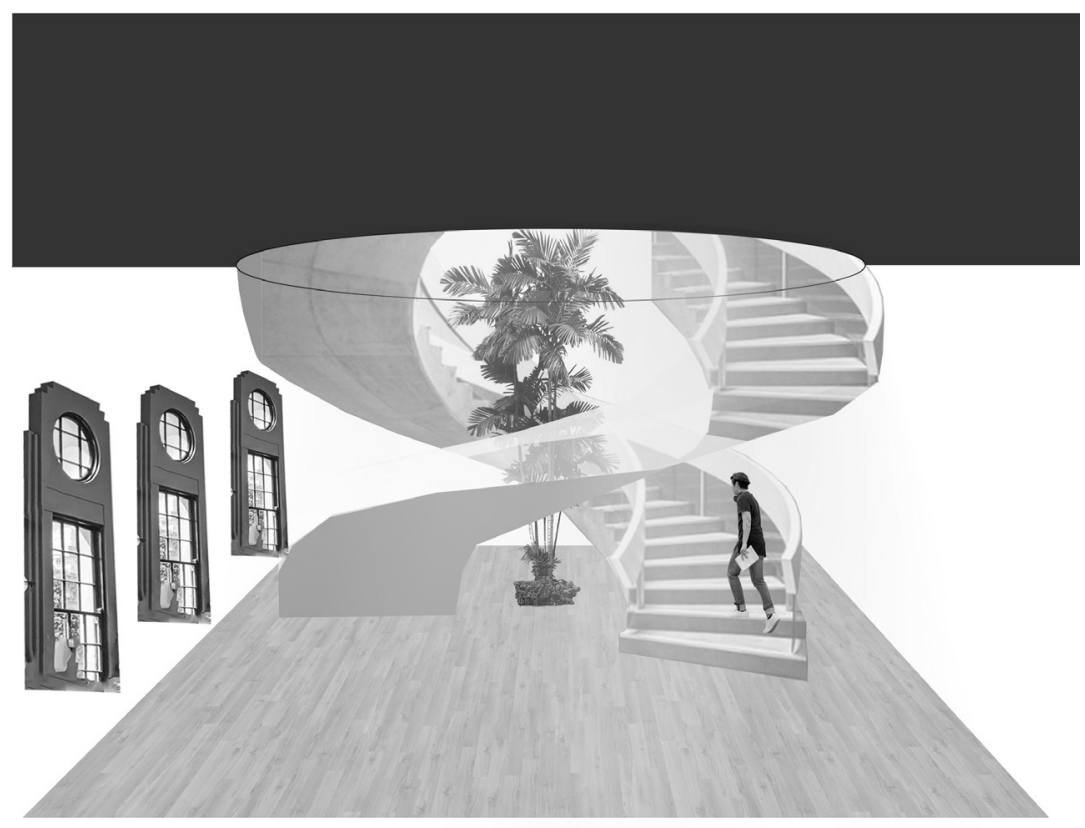

Figure.11.41: Experimental collage of circulation space 


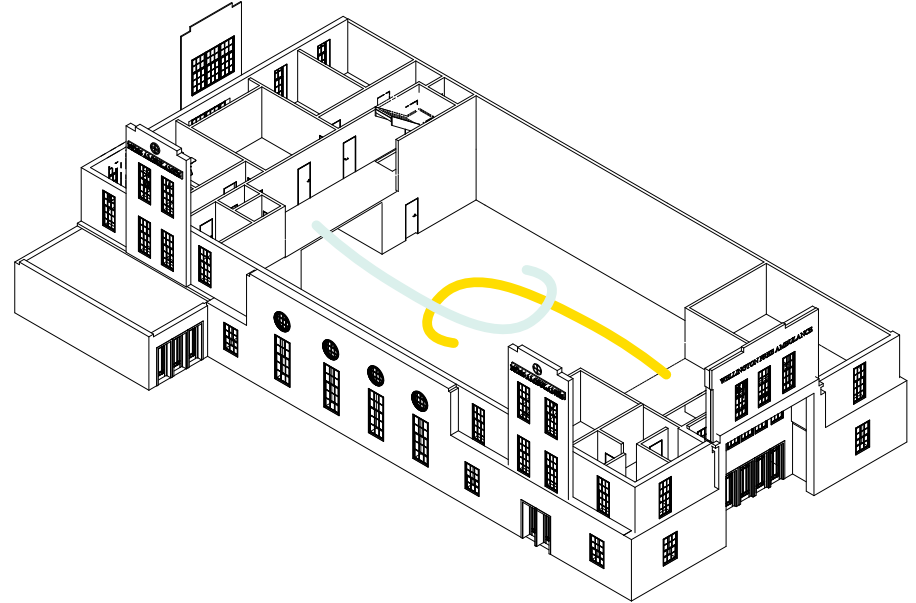

a

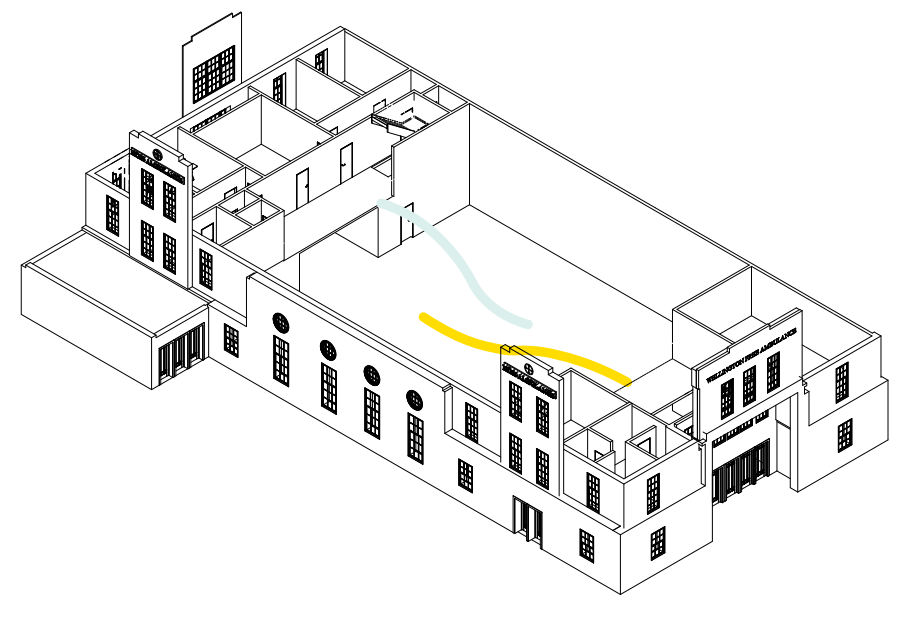

C

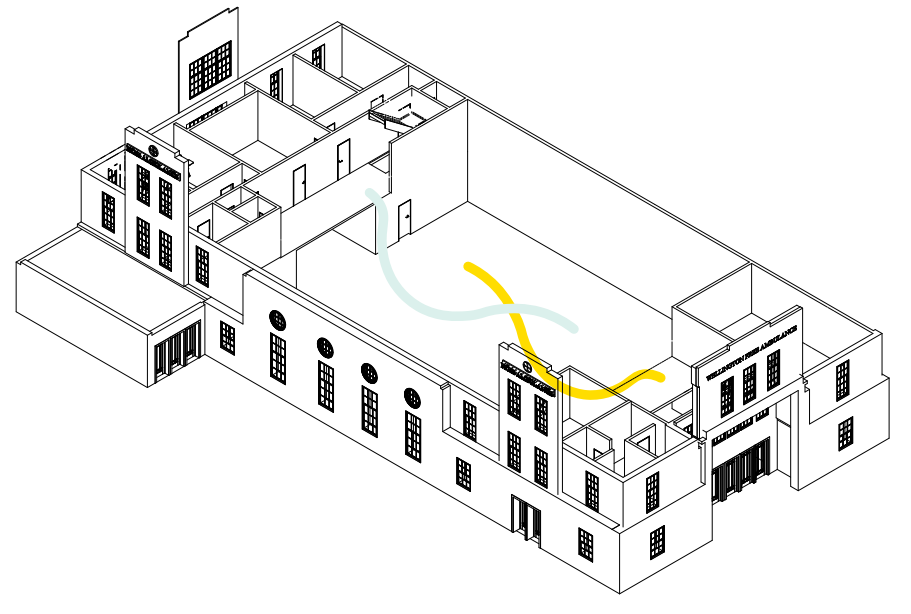

e

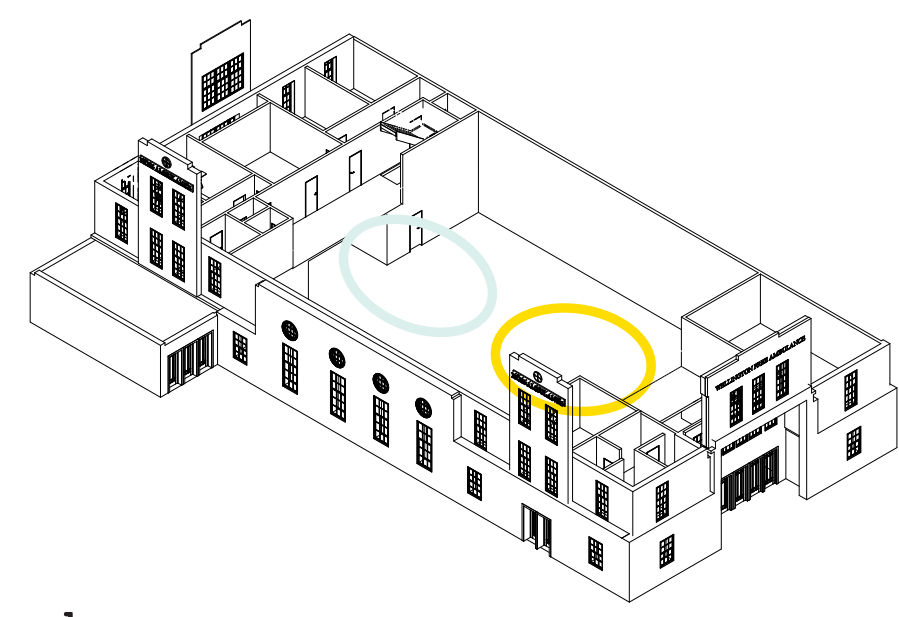

b

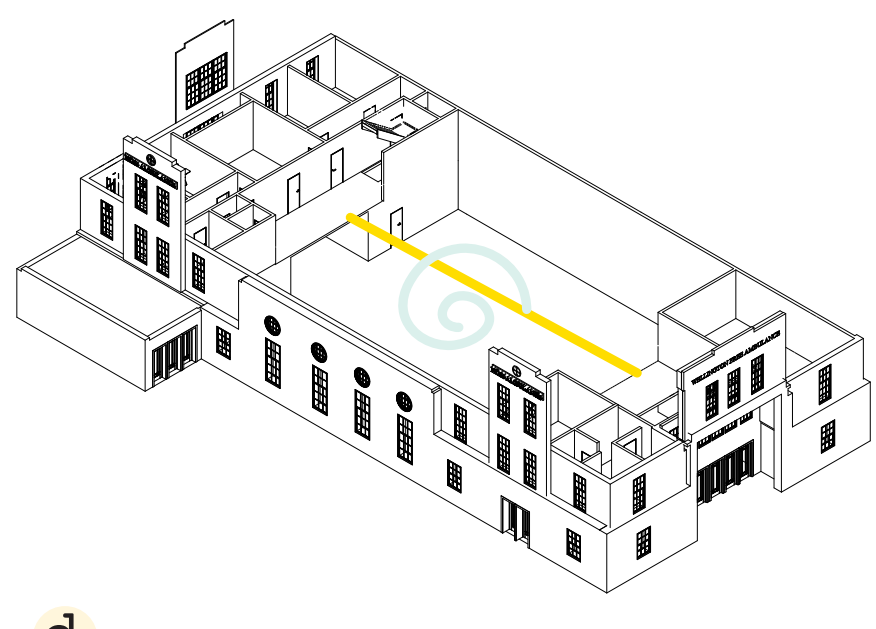

d

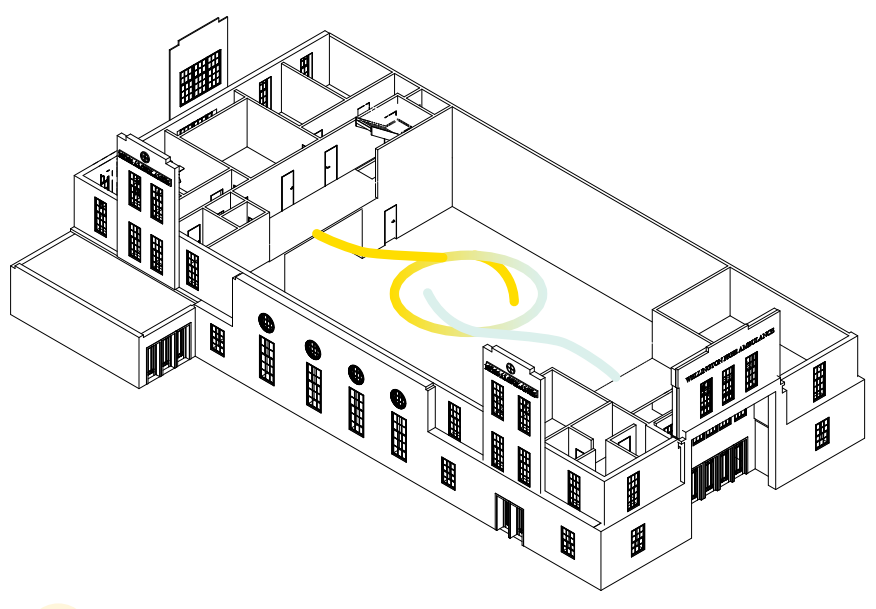

f 


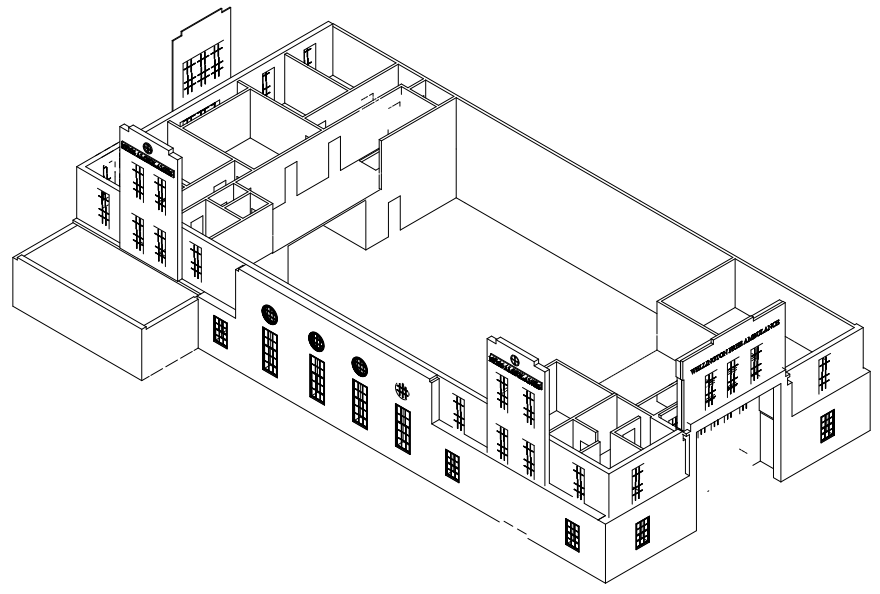



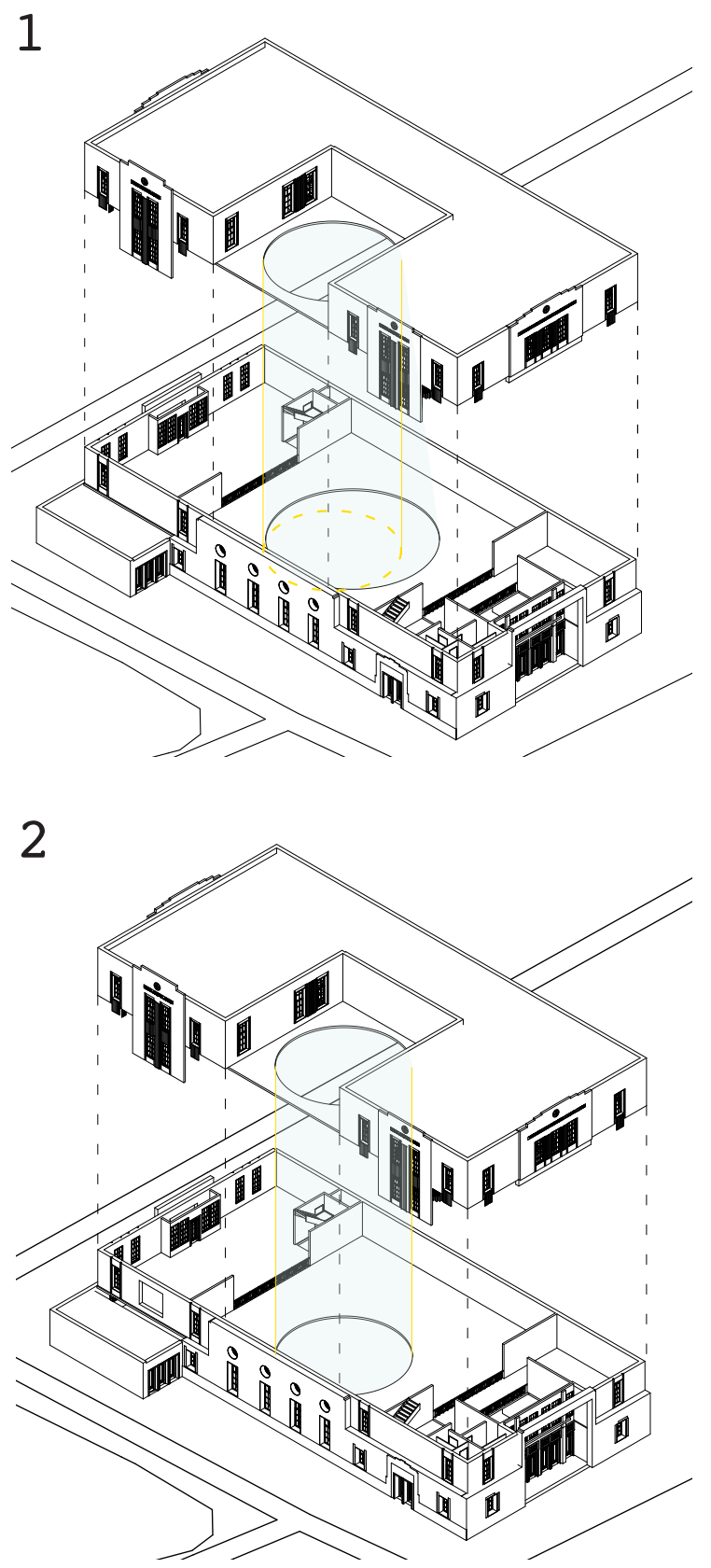

he central circulation form was designed
combining explorations ' $d$ ', ' $f$ ' \& ' $k$ '. The circulation
and skylight also had to have a form relationship between them. Would it be equally positioning but different sizing (Left 1). Equal position and equal sizing (Left 2). Or equal sizing different positioning (Left 3). The circulation took form of a ramp rather then a flight of stairs to allow for inclusive accessibility to the first floor.

The curved form also created a strong contrast between the angular language of the building in order to distinguish the new additions and to add Biophilic influence through natural curved forms. The following step to the right, explored the atmosphere within the space.

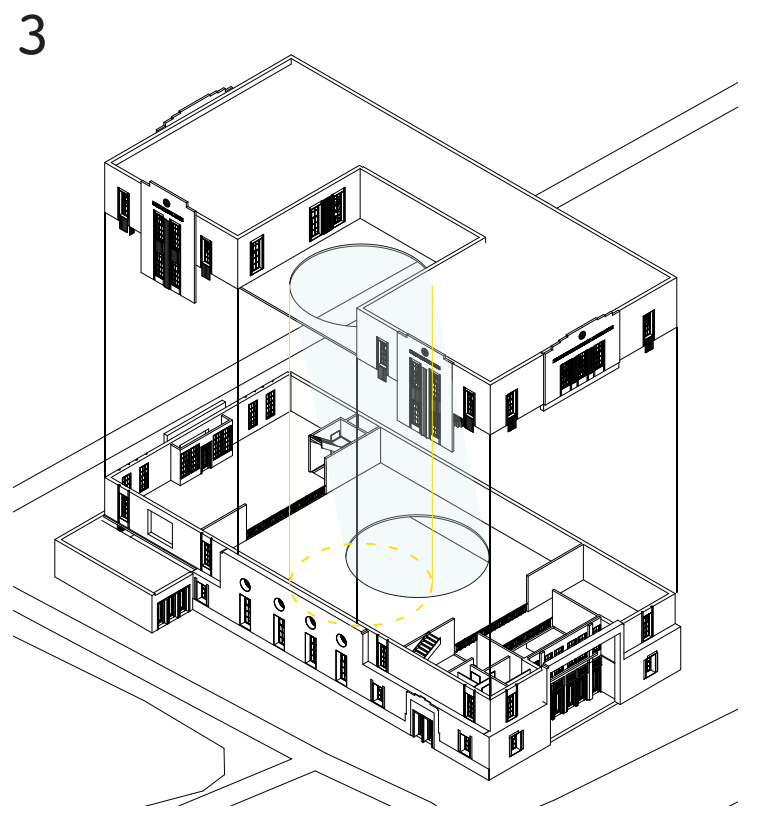

Figure.11.43: Three circulation placements 


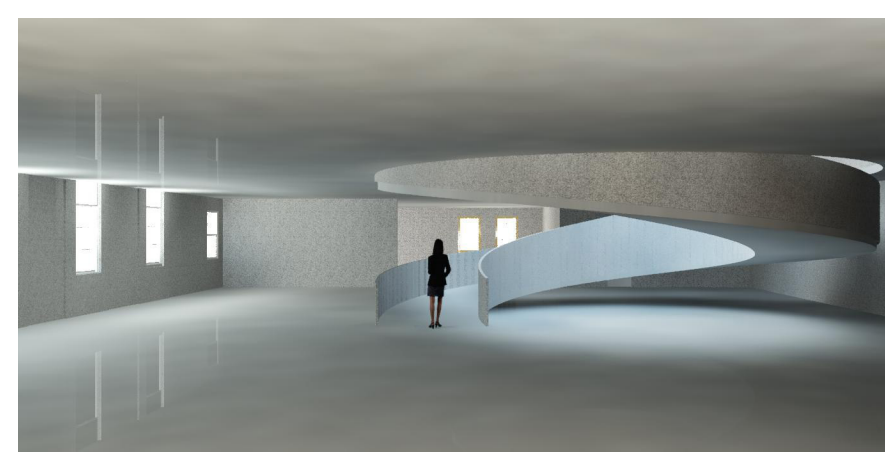

1

New mezzanine cuts off windows and has a claustrophobic feeling.

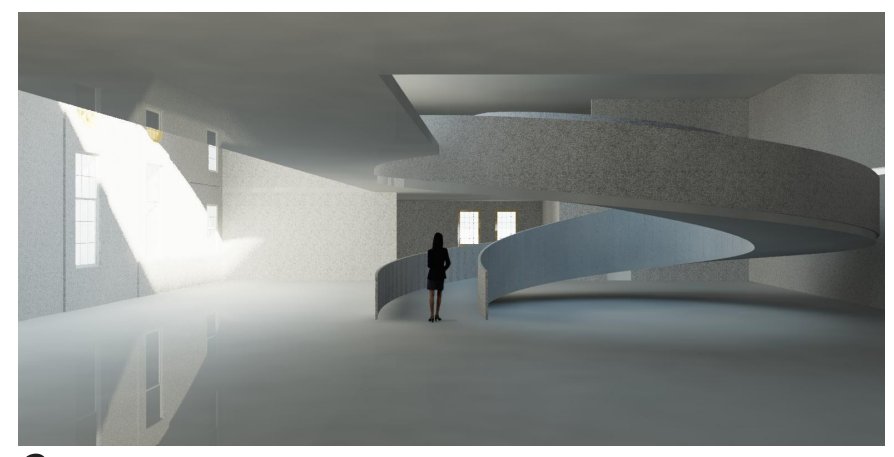

3

Strip mezzanine creates an open feeling but does not utilise space well

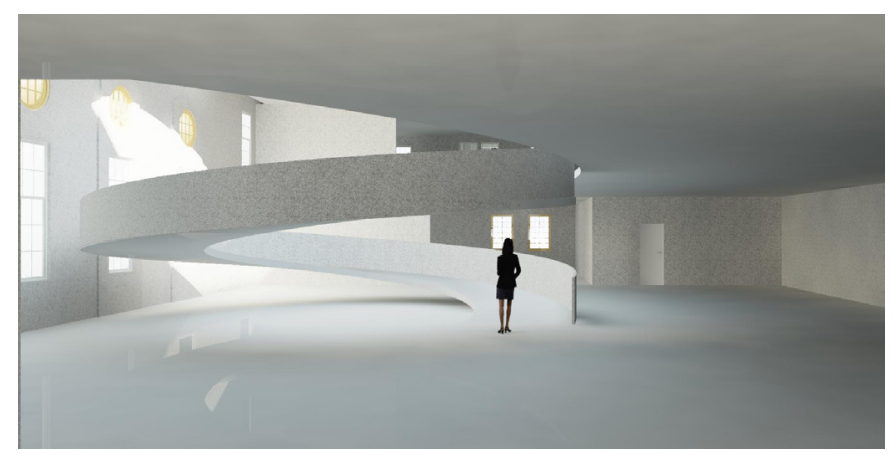

5
Curved mezzanine has better use of space with sympathetic connection.

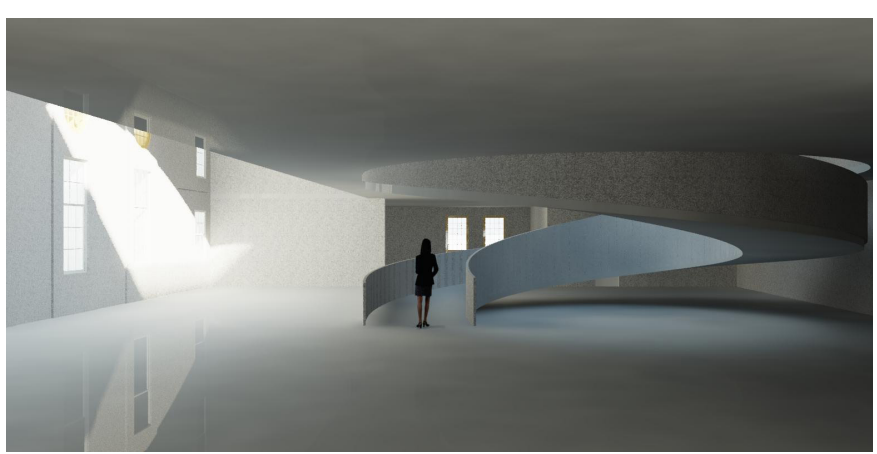

$2 \quad$ Stepping back mezzanine opens up windows but still feels claustrophobic

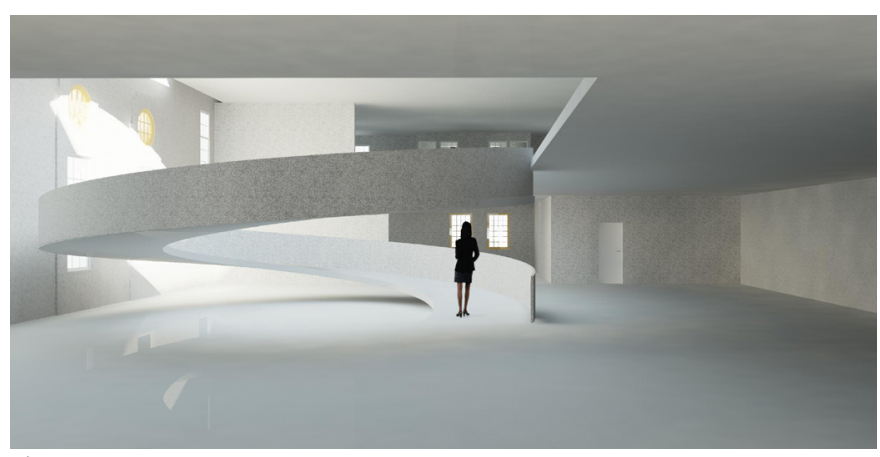

$4 \quad$ Partial mezzanine has no relation to circulation

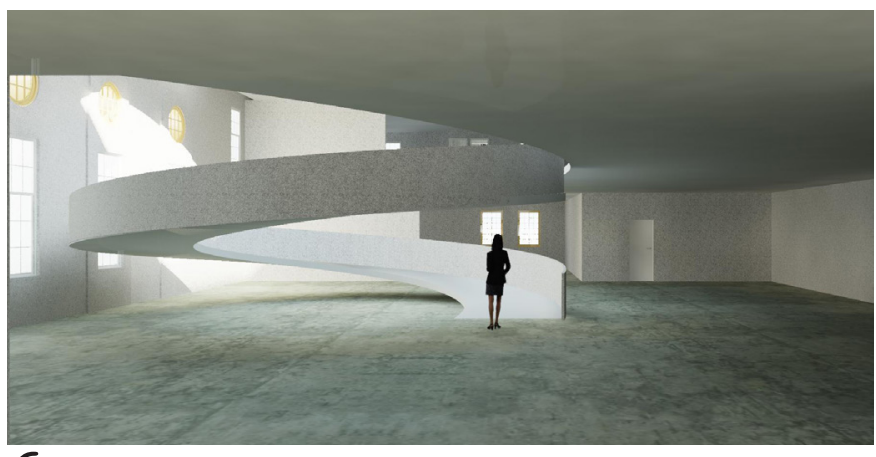

Applying materiality 


\section{Balustrade}

\footnotetext{
The balustrade took influence from the original negative detailing of the buildings facade. One option extracted was maintaining a linear approach or contrasting the predominant lines with the less used scalloped detailing the building also references.
}

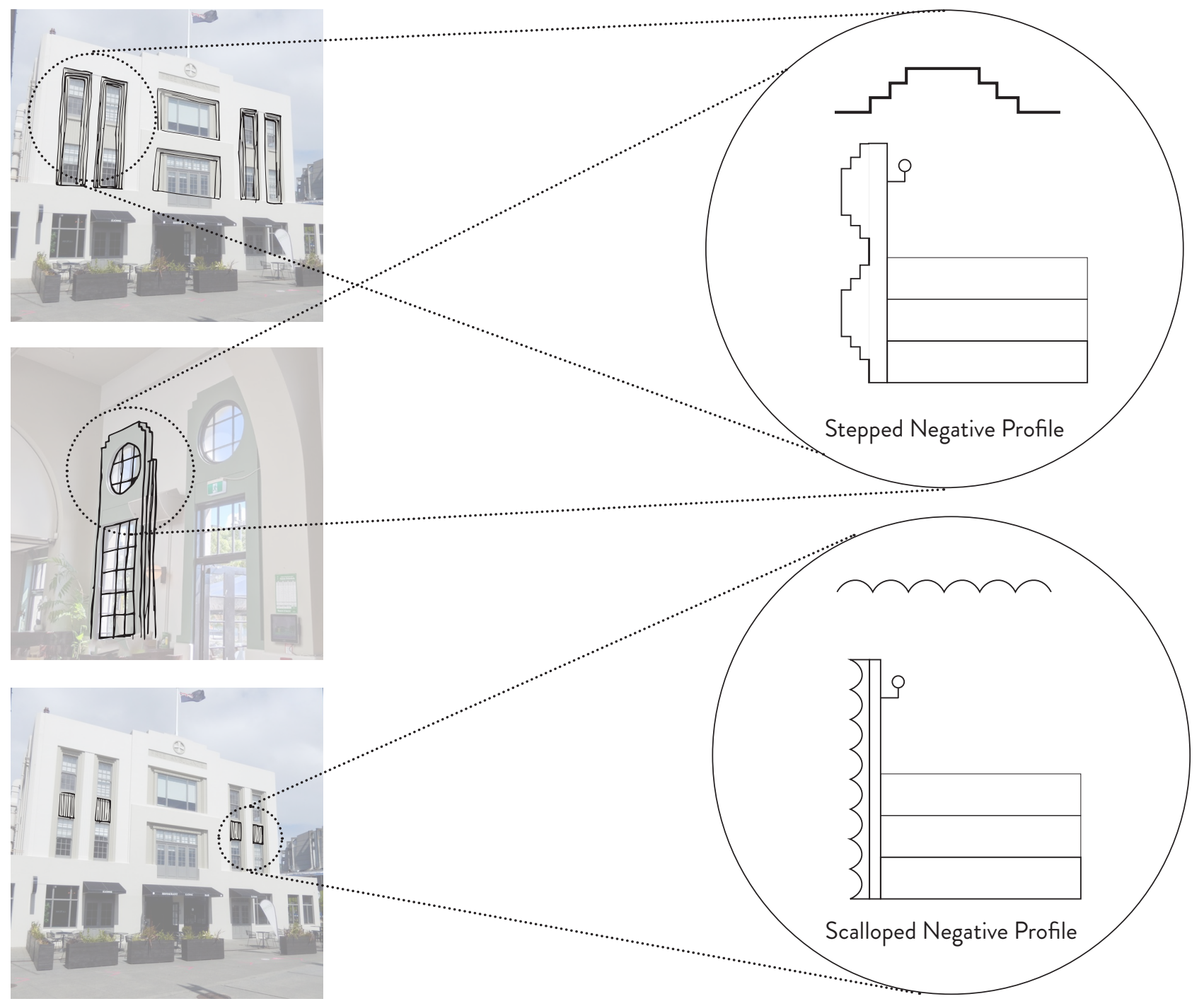

Figure.11.45: Balustrade design from original details 


\section{Plain Balustrade}

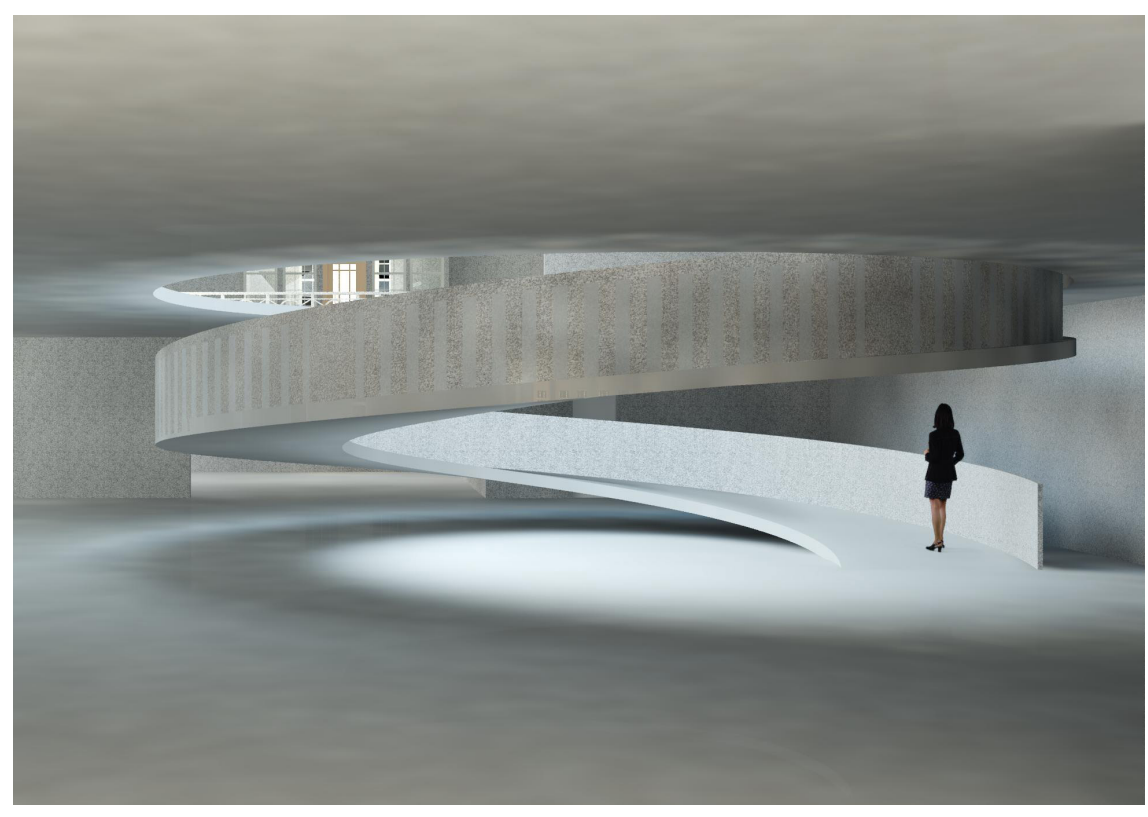

Angular Negative Detailing

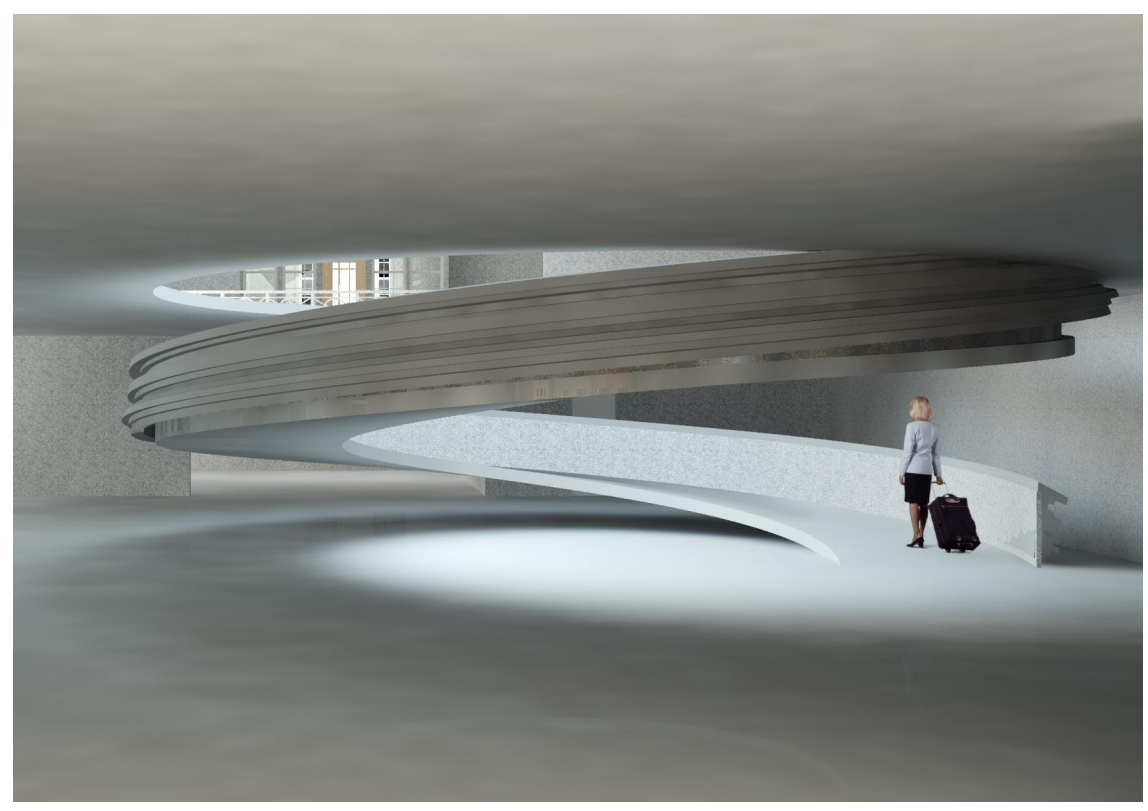

Scalloped Negative Detailing

The scalloped balustrade proved most successful as it compliments the sweeping ramp and contrasts the overall language of the building in keeping with conservation values

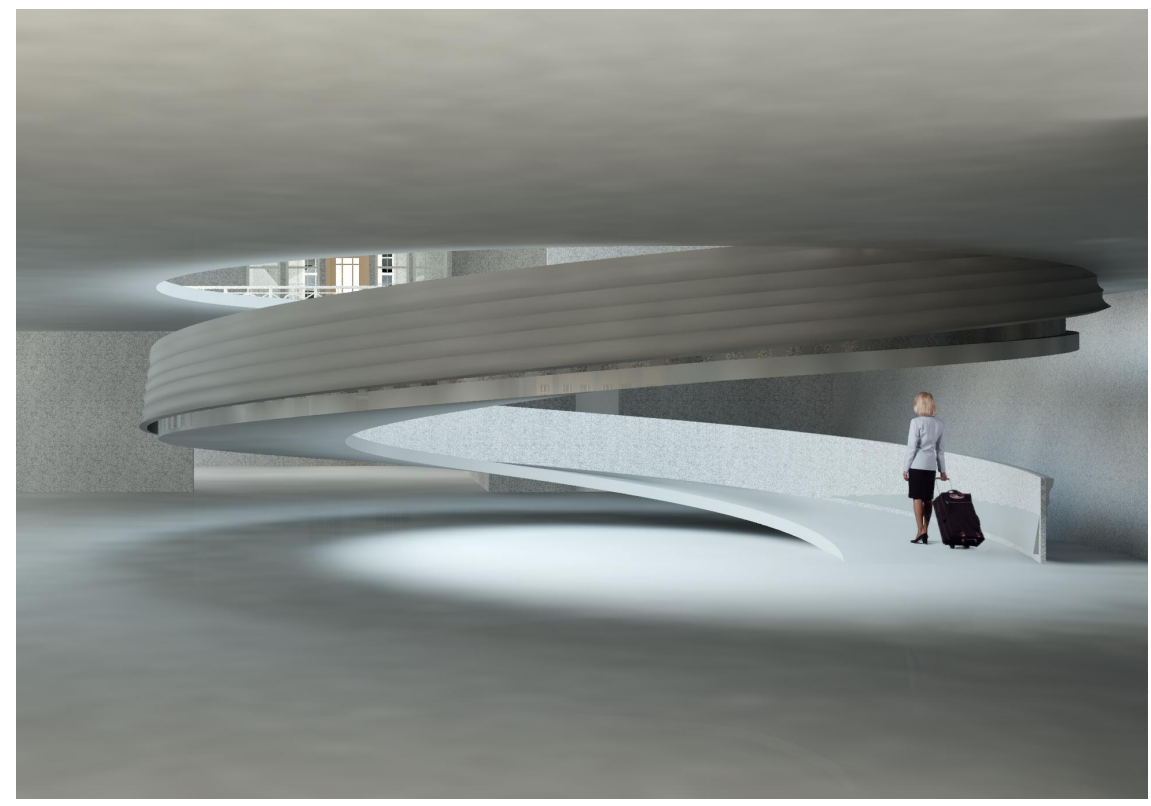




\section{DOME DEVELOPMENT}

t was important for the design to keep a skylight structure in order to keep a light feeling in the main cafe space but also to follow the Biophilic attributes of light and ventilation. The skylight took form of a dome structure in order to relate to the circular ramp bellow. It took influence from the original style of the building and reference Art Deco/Nouveau design. Continuing the scallop shape not just as reference to the style but also as reference to natural forms for Biophilic integration and relation to the ramps scalloped balustrade.

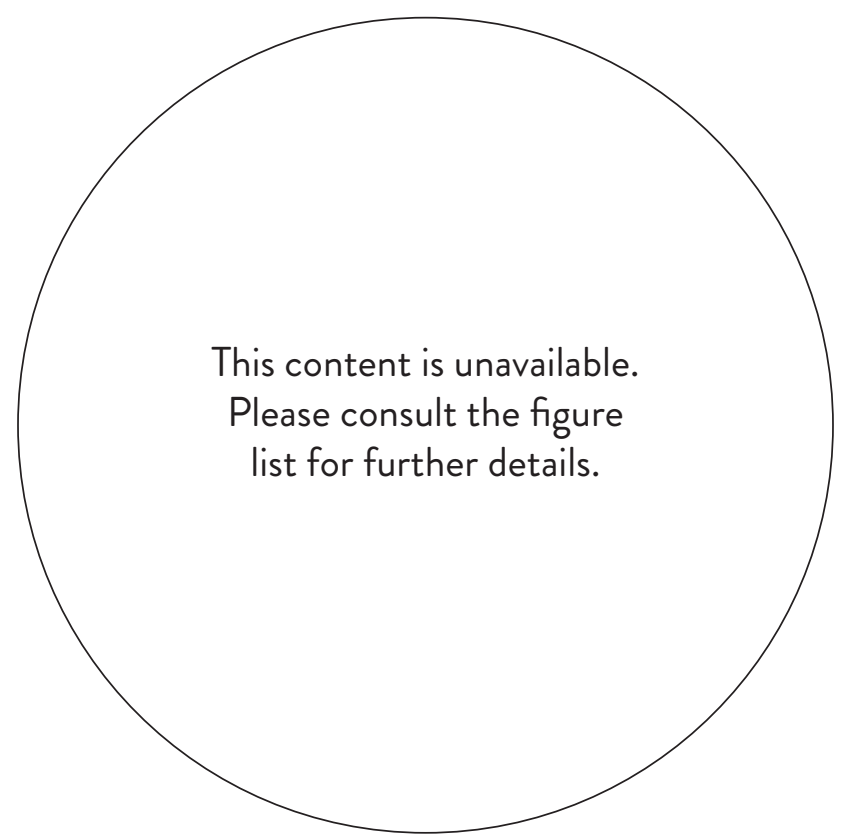

Figure.11.47: Hotel van Eetvelde Dome by Art Nouveau architect Victor Horta 


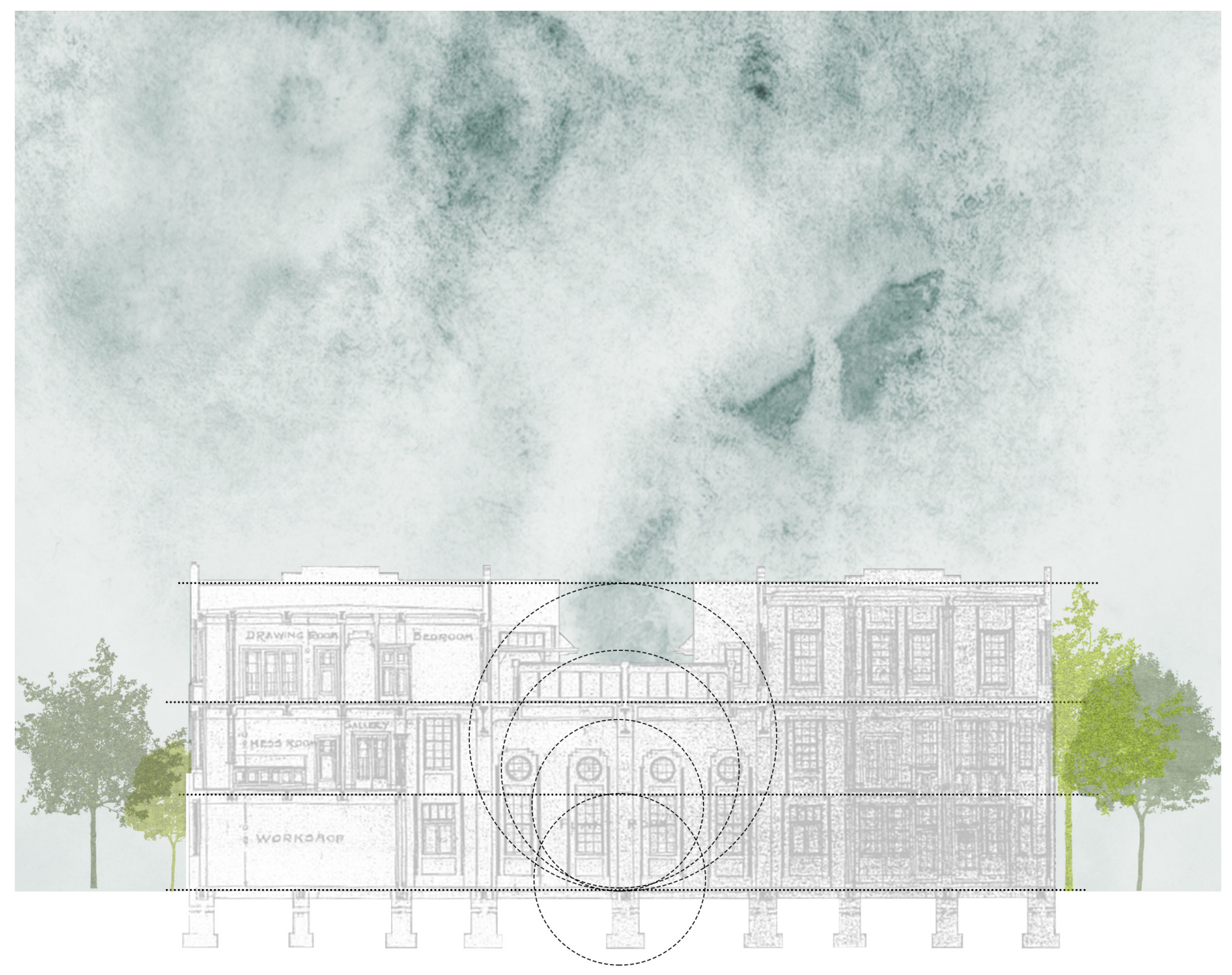

Figure.11.48: Exploration of dome volumes within the space 


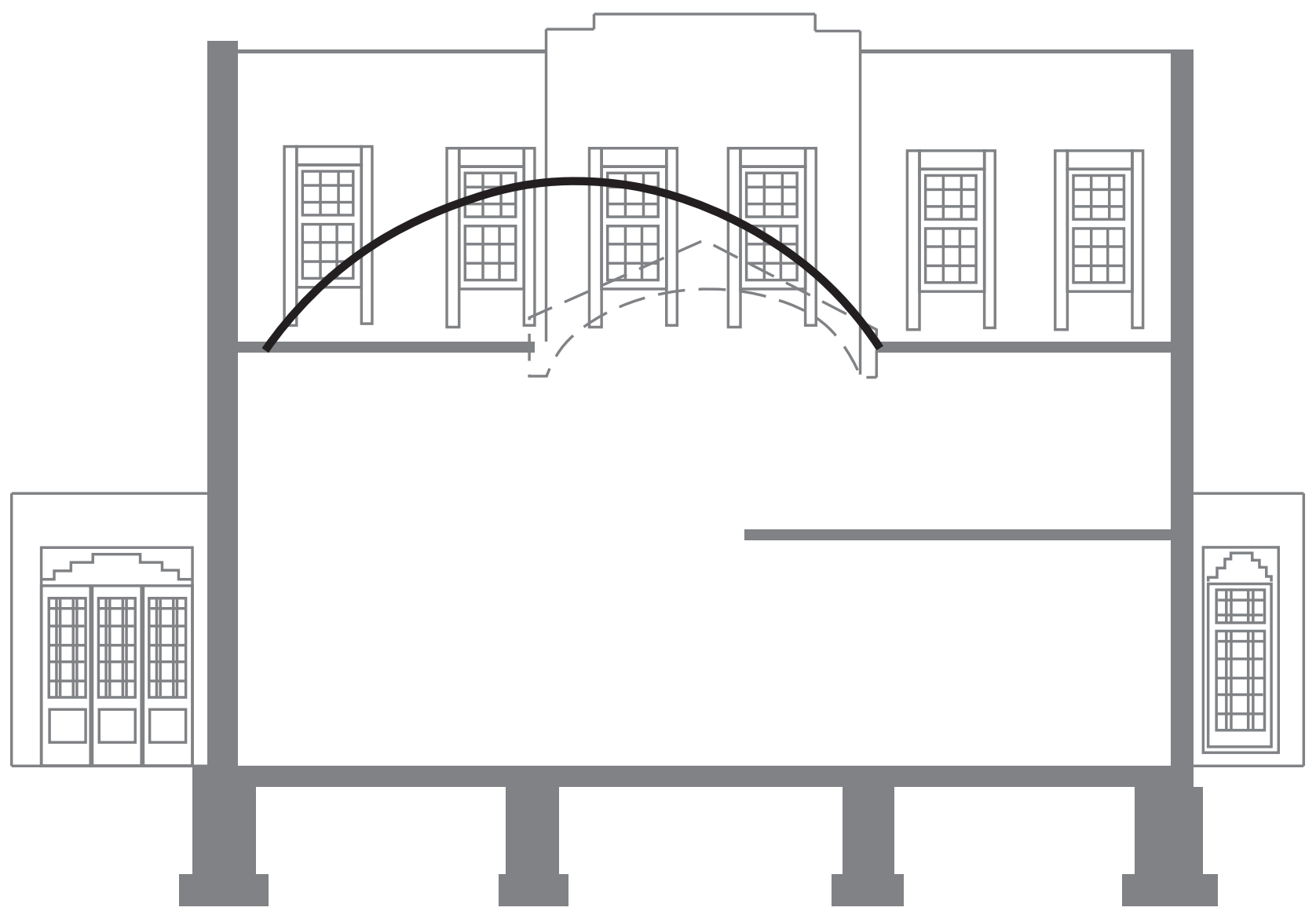

Figure.11.49: Original skylight placement positioning in relation to the new 

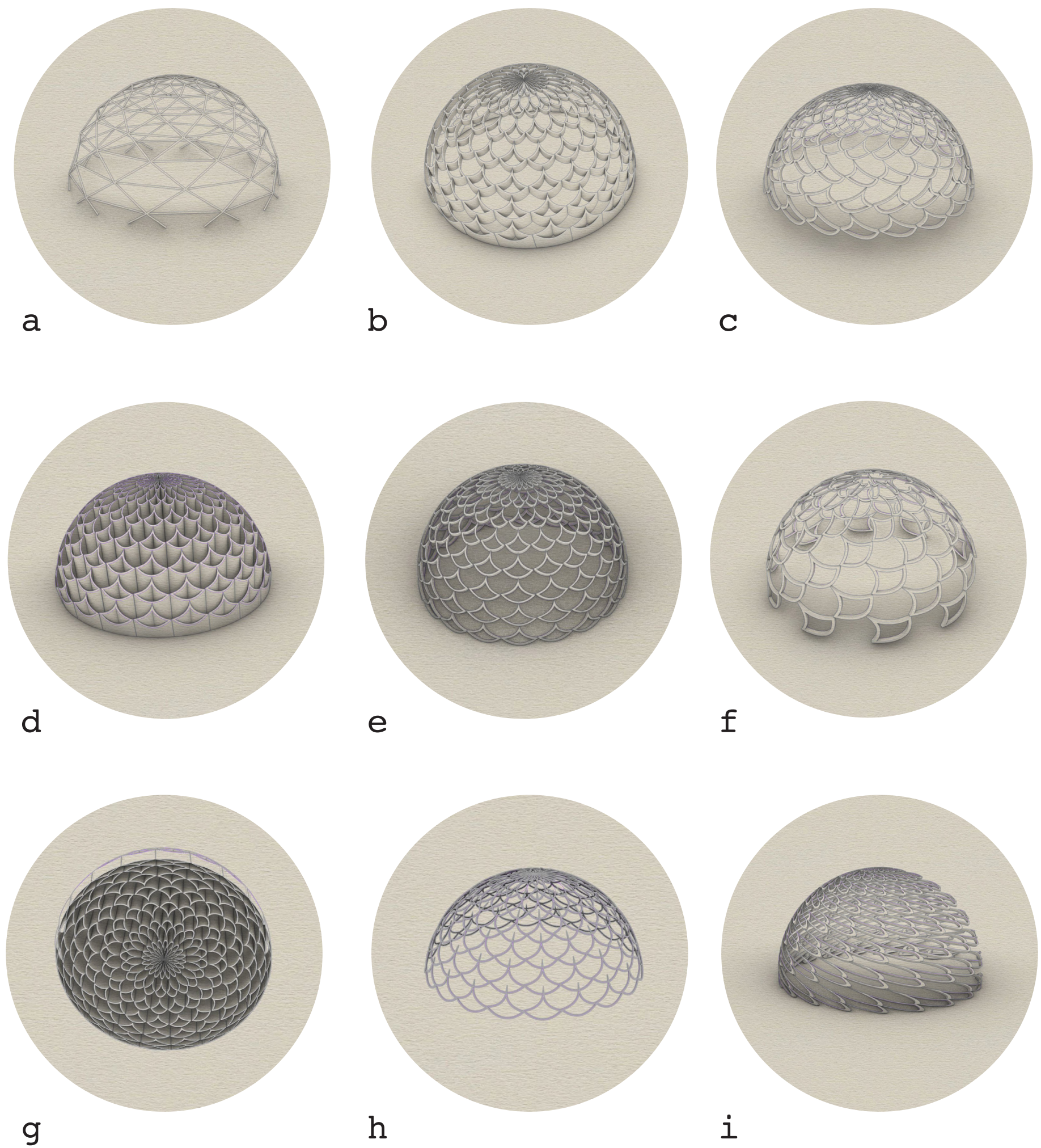

Figure.11.50: Continuing scallop design through dome exploration 


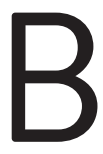
ased on iteration 'e', the following five designs play with proportion and volume. Experimenting with compression and subtraction of the dome 'e'. The sequence of illustrations on the right determined which dome structure worked best with the proportions of the building from a real life perspective of the building.
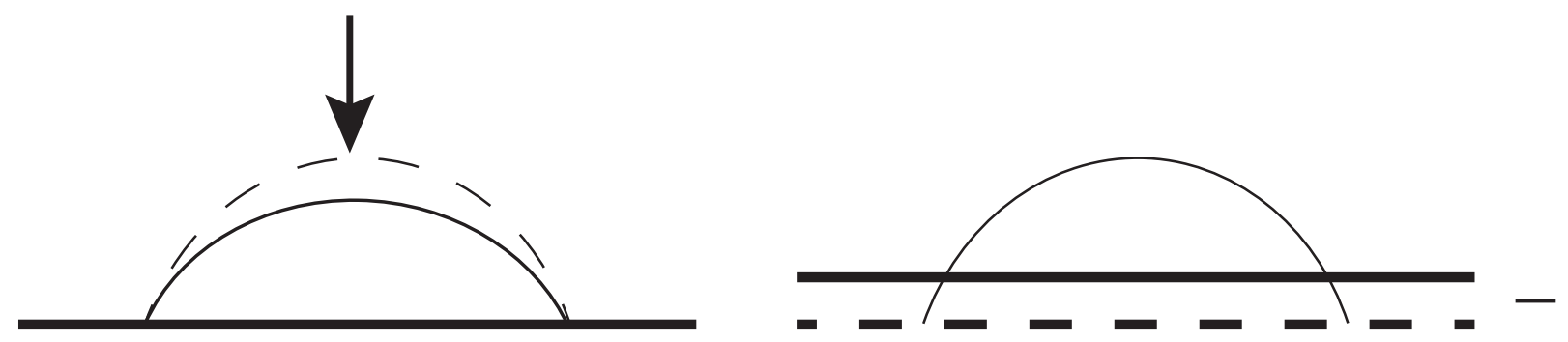

Figure.11.51: Formal change diagram

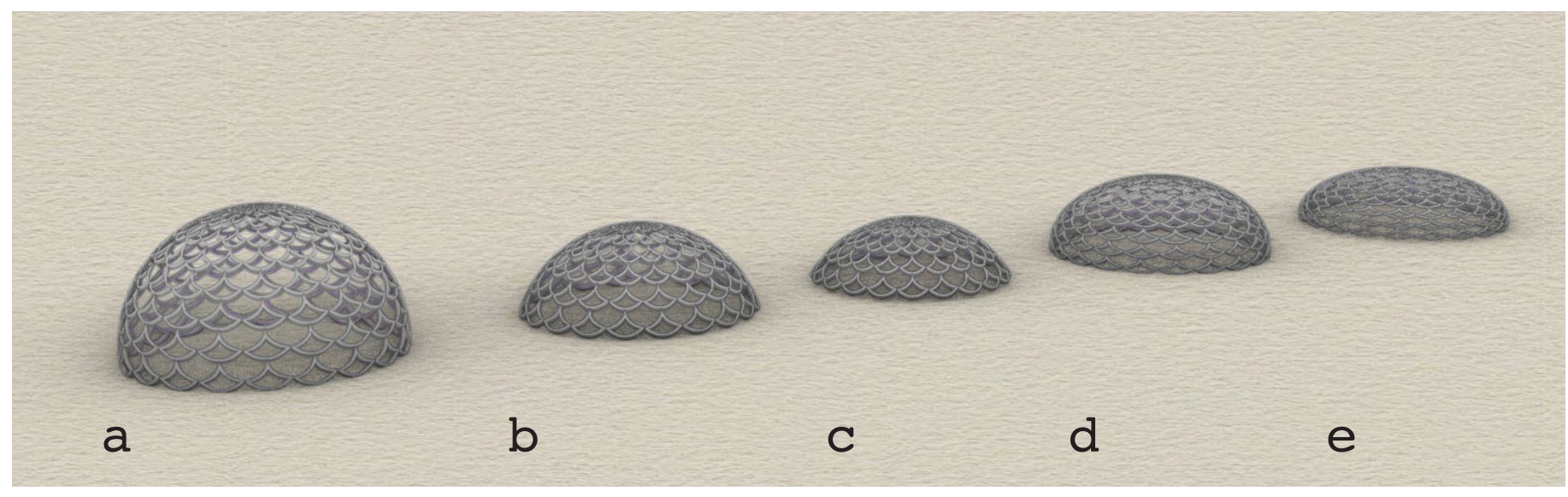

Figure.11.52: Final five iterations 
a

Min.

b

110

品i

C

d

11018

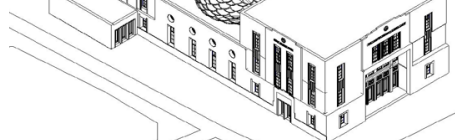

e

1101

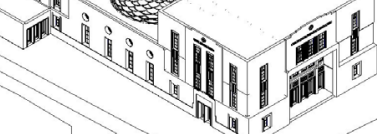
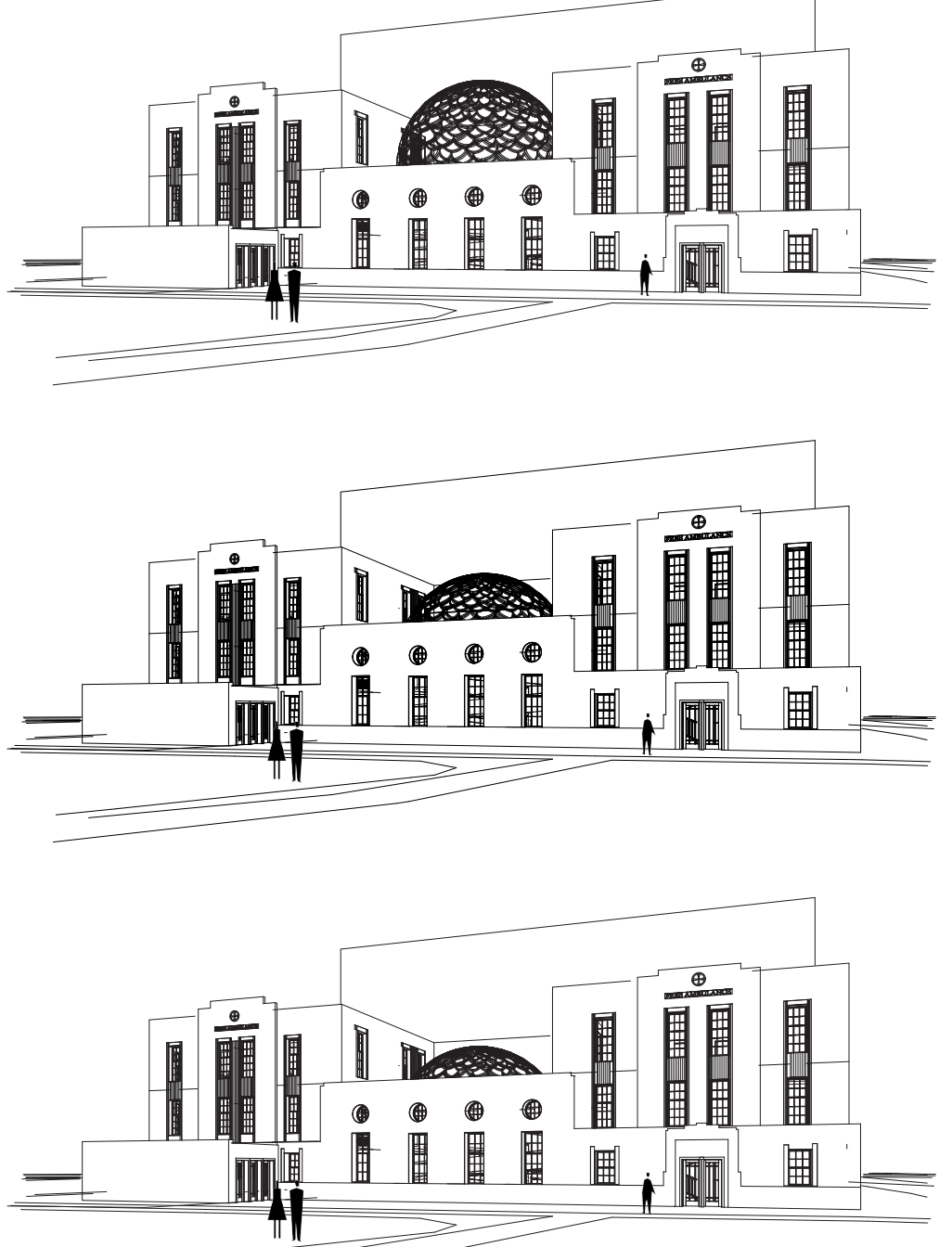

Figure.11.53: Real life views of the final five iterations 


\section{Mullions}

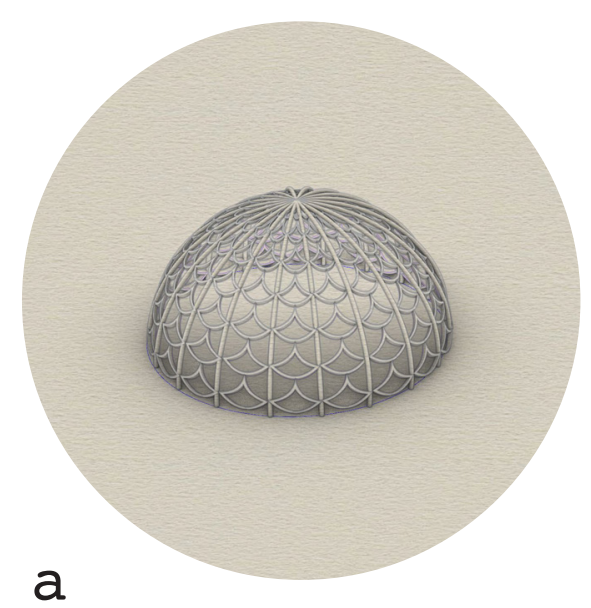

Additional structure and mullions with circular profile

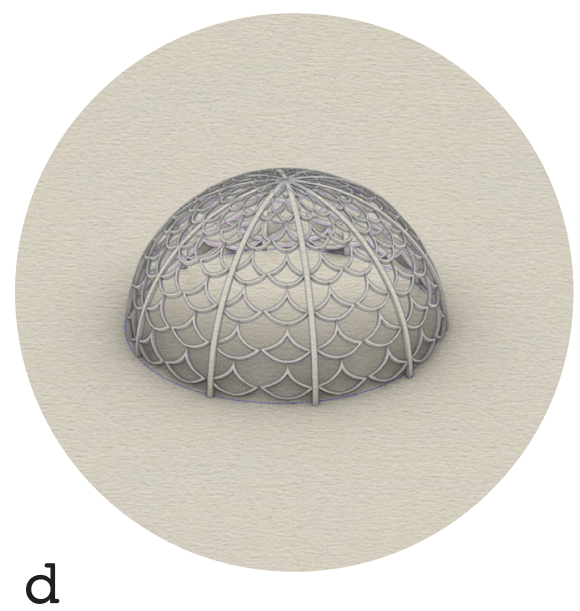

Mullions every second scallop with rectangular profile
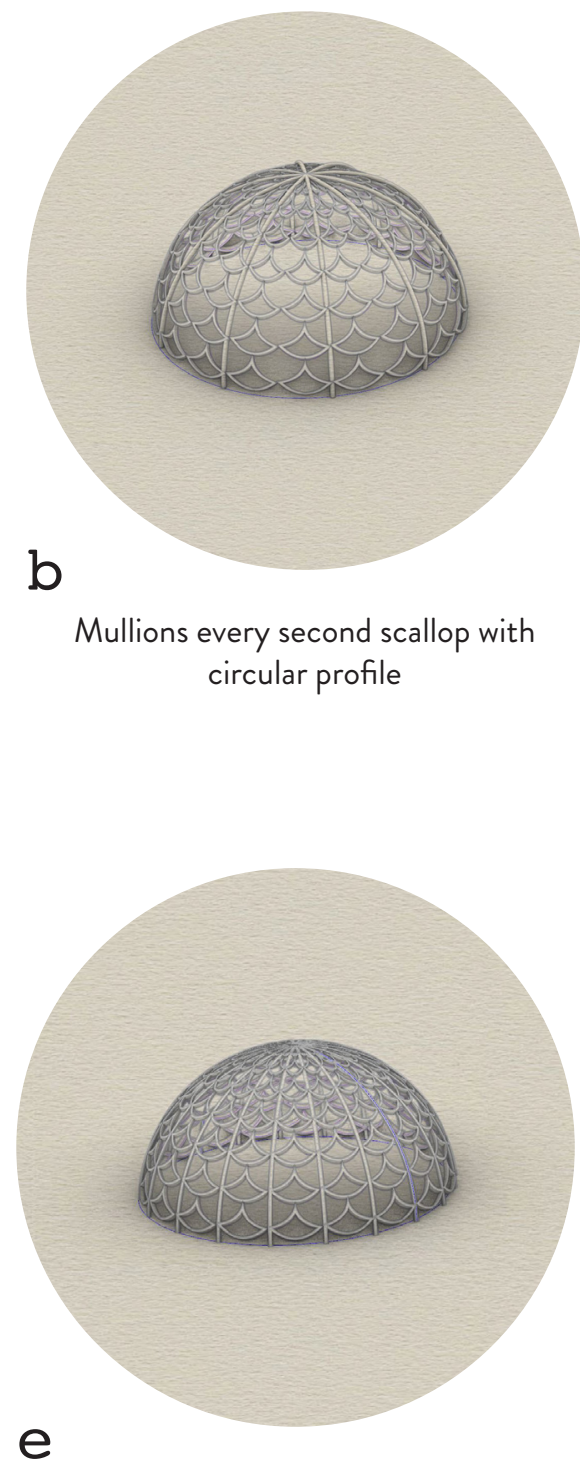

Lessening the hight of the structure

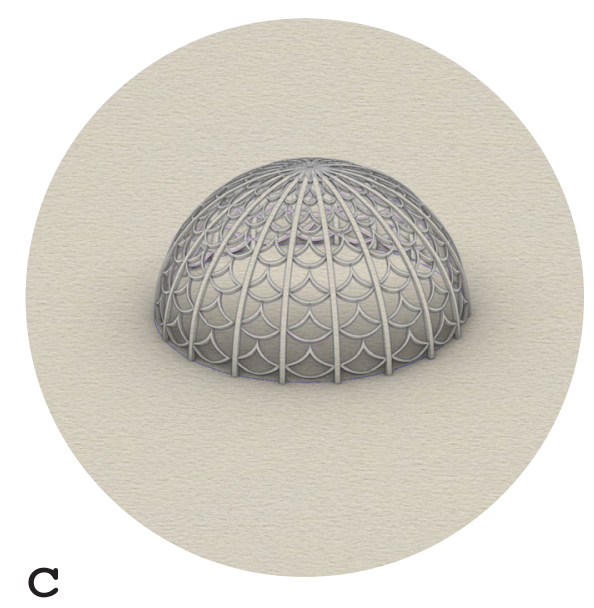

Mullions every scallop with rectangular profile

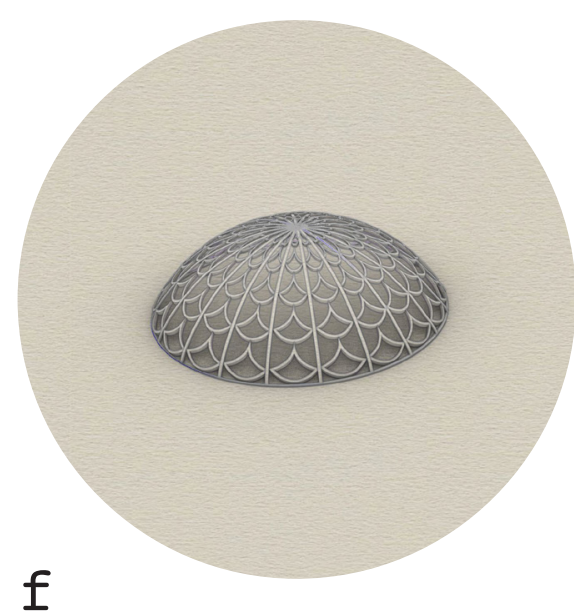

Final iteration

Figure.11.54: Mullion exploration 

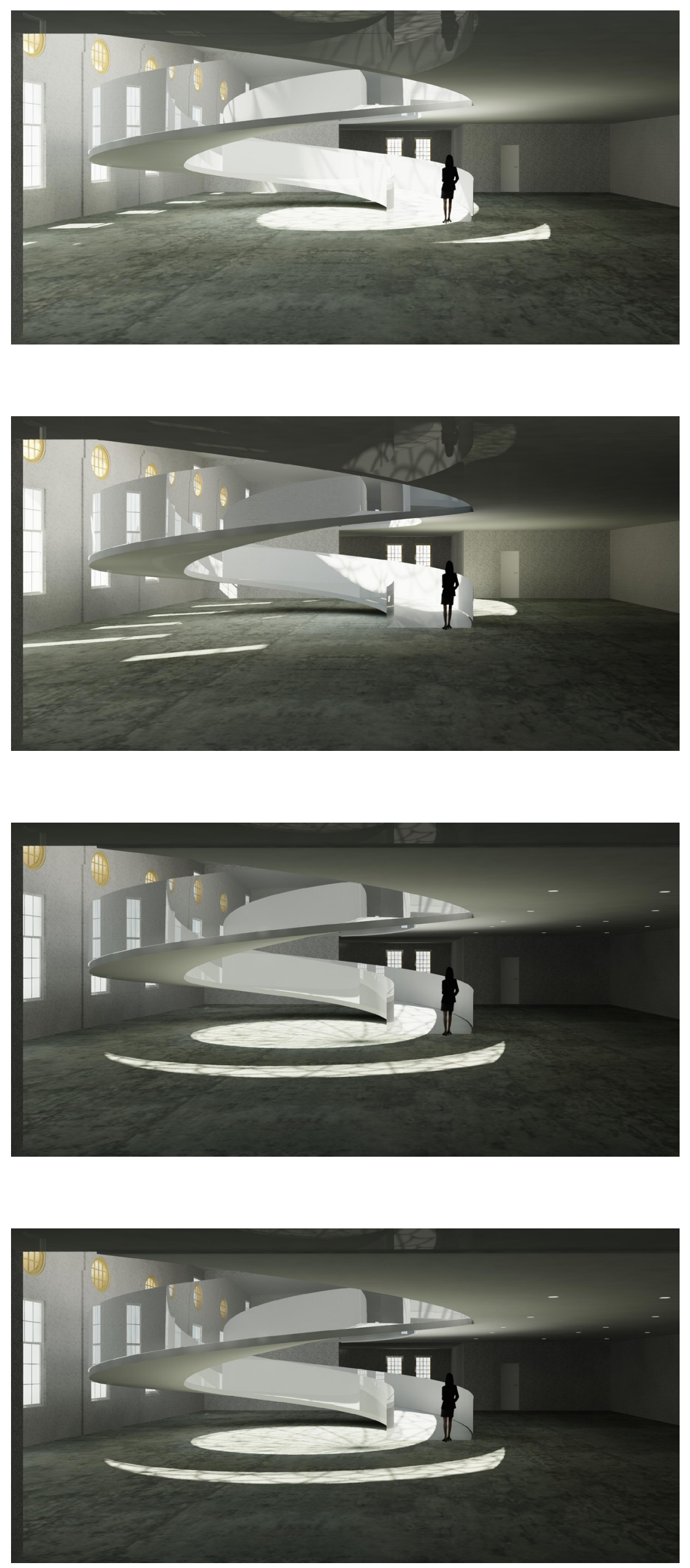

Figure.11.55: Shadows cast by final form throughout the day 


\section{MATERIALS}
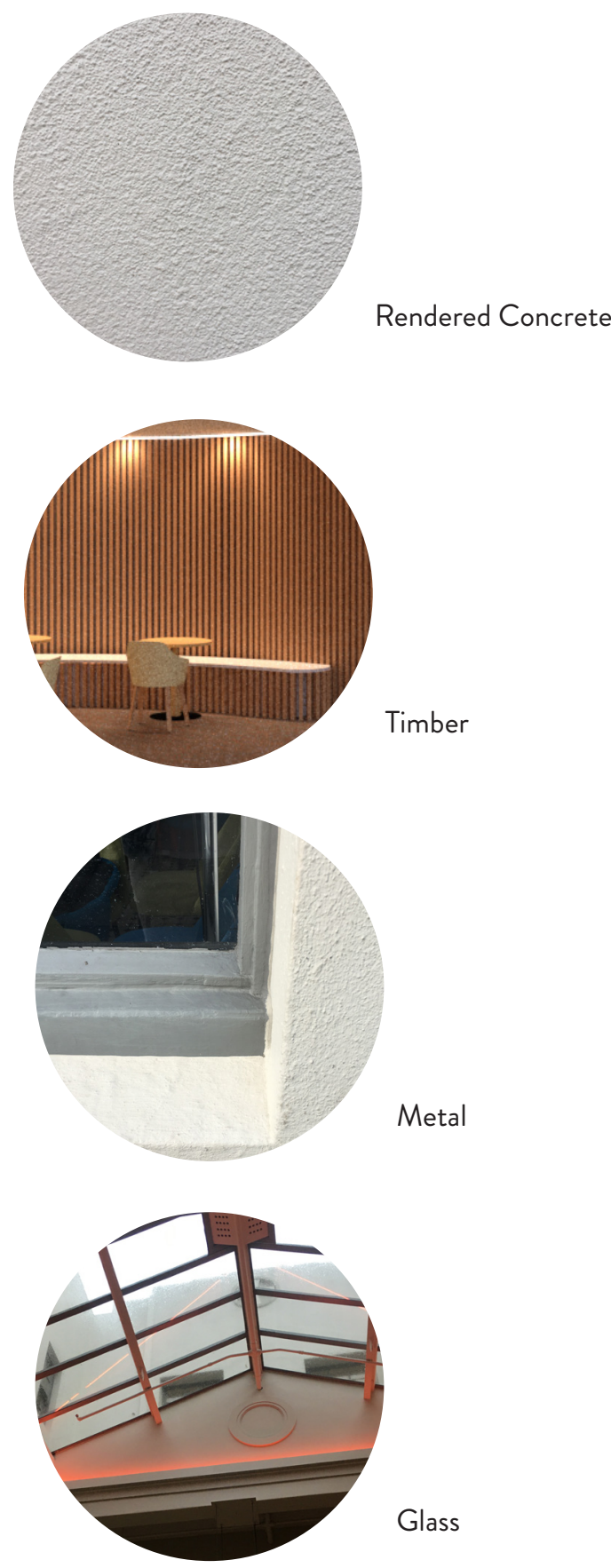

Glass
$\mathrm{T}$ he materials used for this design were either the continuation of the original fabric of the building or are added to incorporate additional concepts The continuation of rendered concrete speaks to the original materiality of the heritage building. The interventions also incorporating natural materials such as timber and greenery to follow Biophilic design attributes.

The glass and metal dome structure also acknowledges the original tent skylight of the building.

Figure.11.56: Materials used 


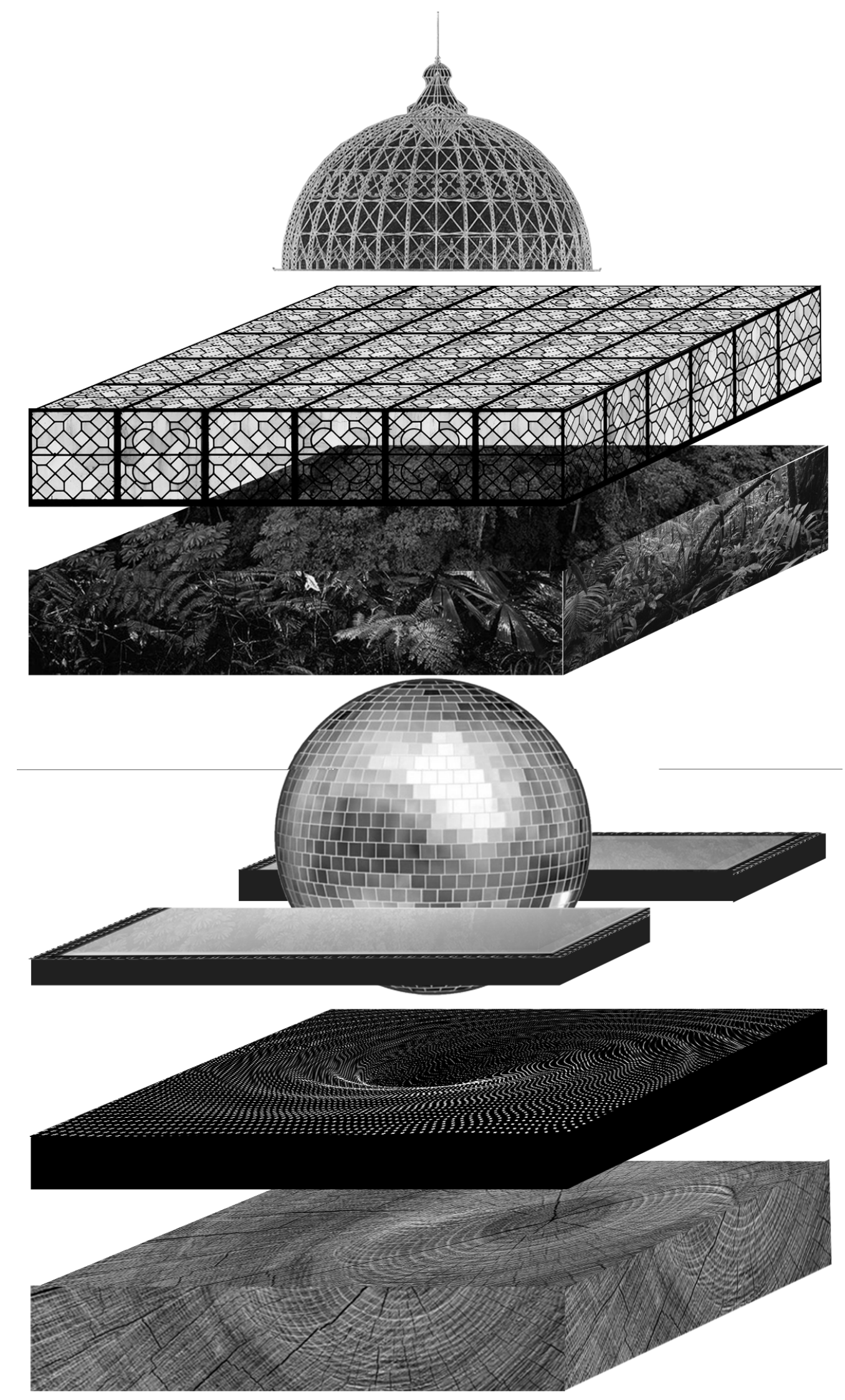

Figure.11.57: Collage of material layering throughout design development 


\section{Cafe Material \& Lighting Exploration}

Primary layout with generic materials

\section{Materials and generic lighting added}

\section{Pending light options}

More lighting options
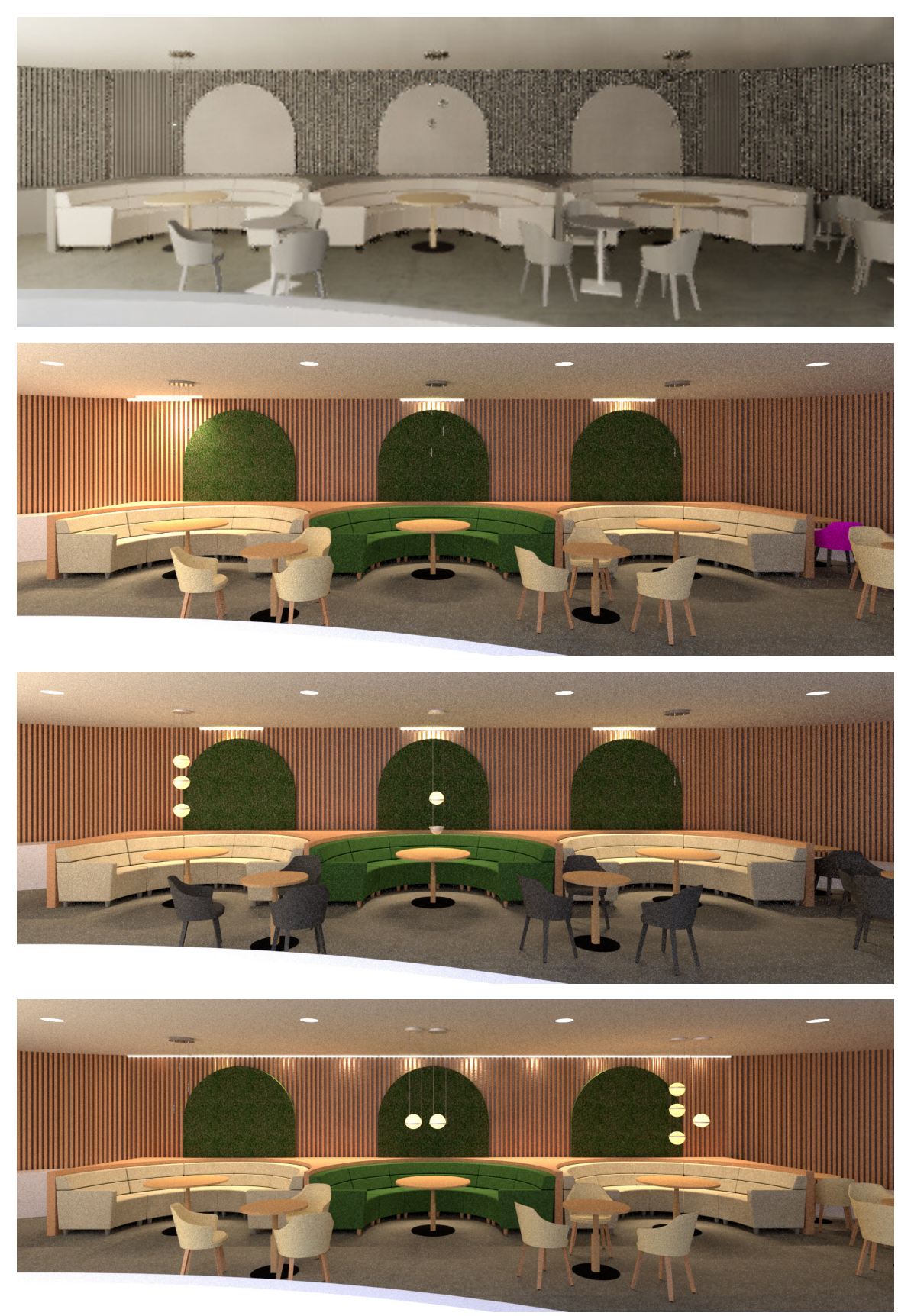
Lighting options continued

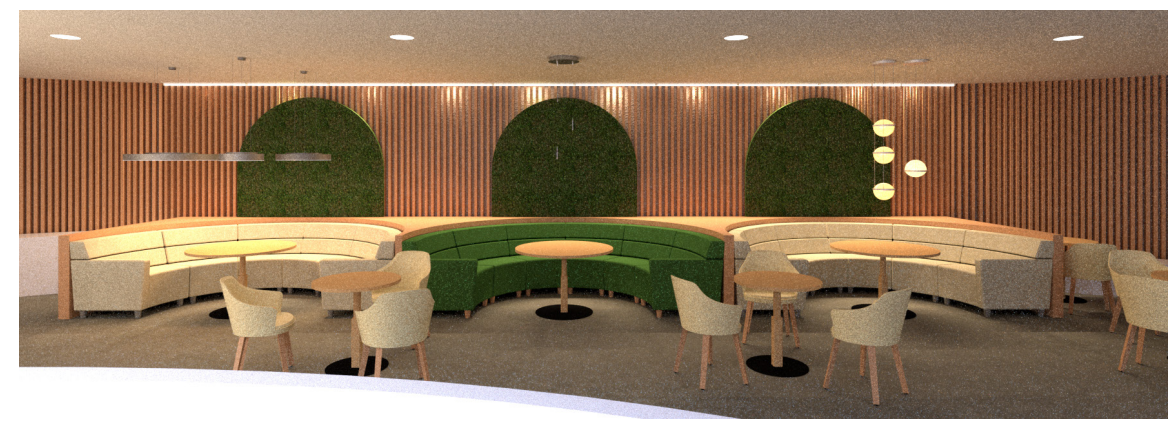

Selected pendants

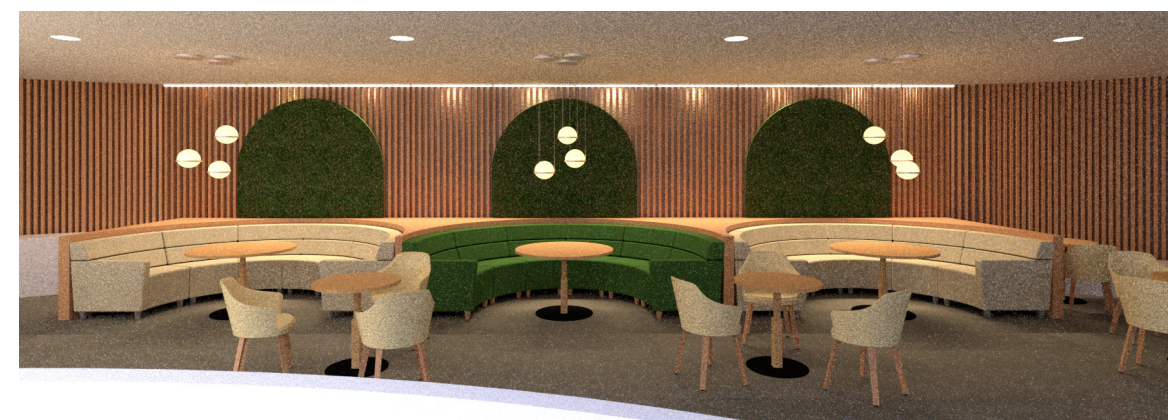

Framed green arch test

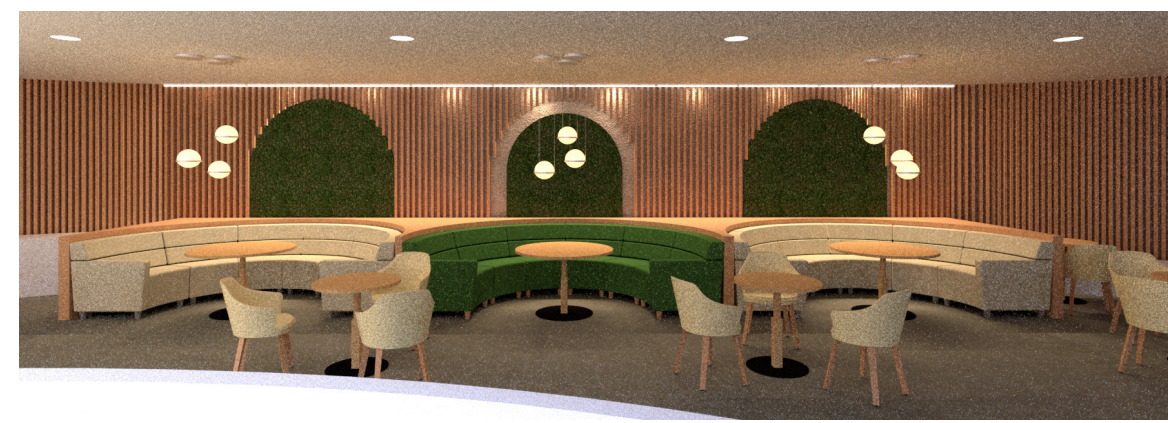

All arches with frame

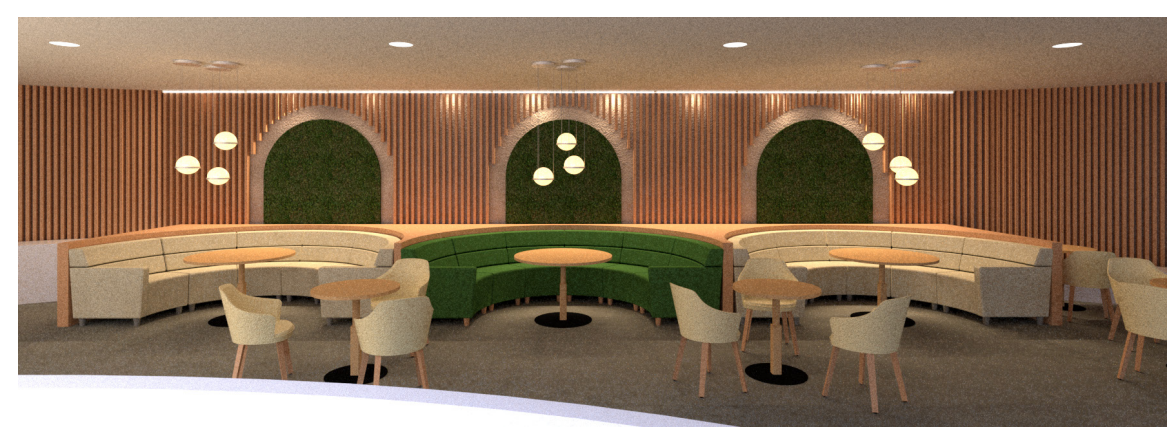




\section{PROMENADE PROCESS}

The idea of the promenade was a recurring theme found throughout the earlier experimental iterations. The idea of the walk way is to enhance that sense of journey and experience when arriving or passing through these places.

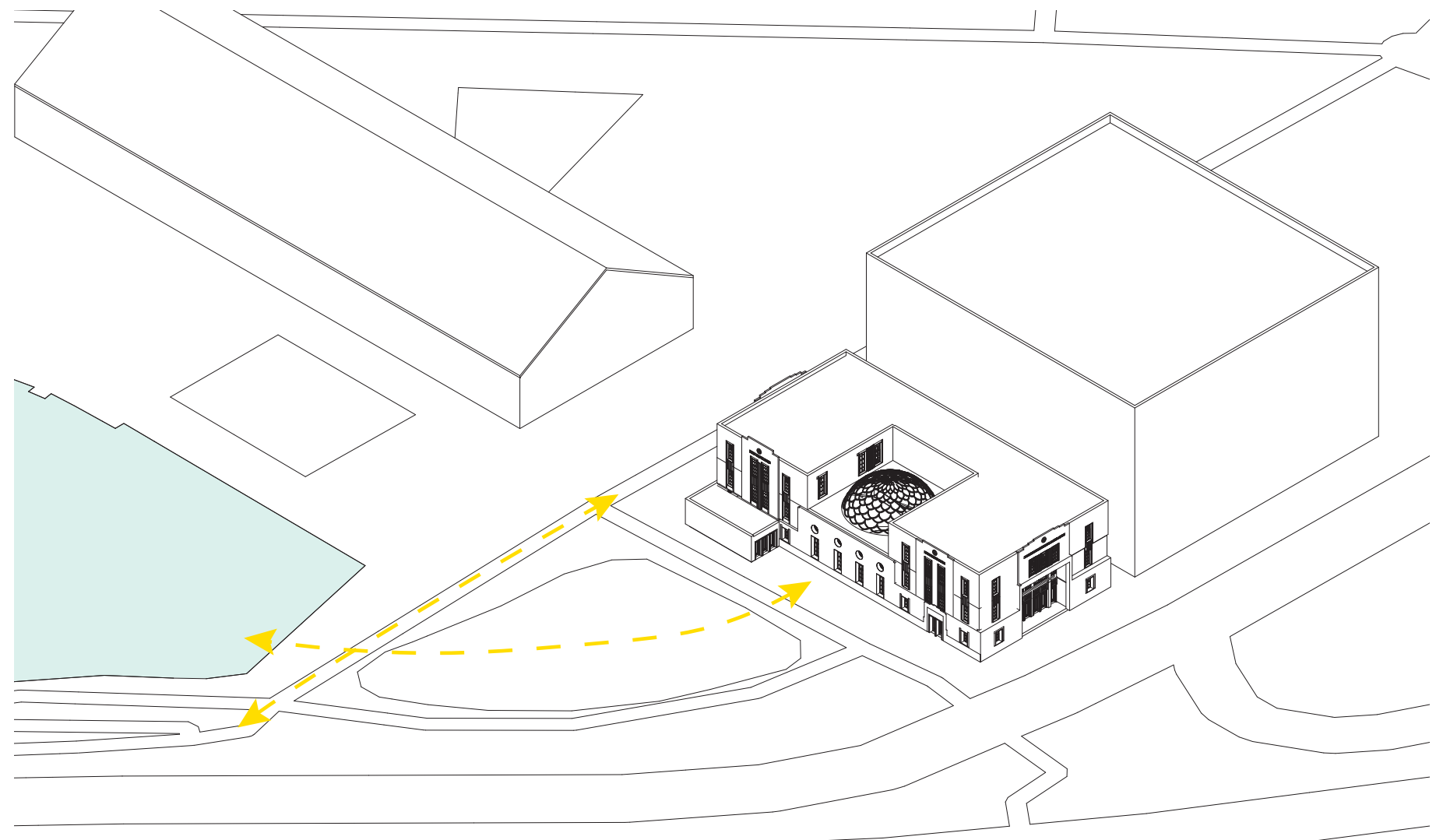

Figure.11.59: Points of connection intended for promenade 


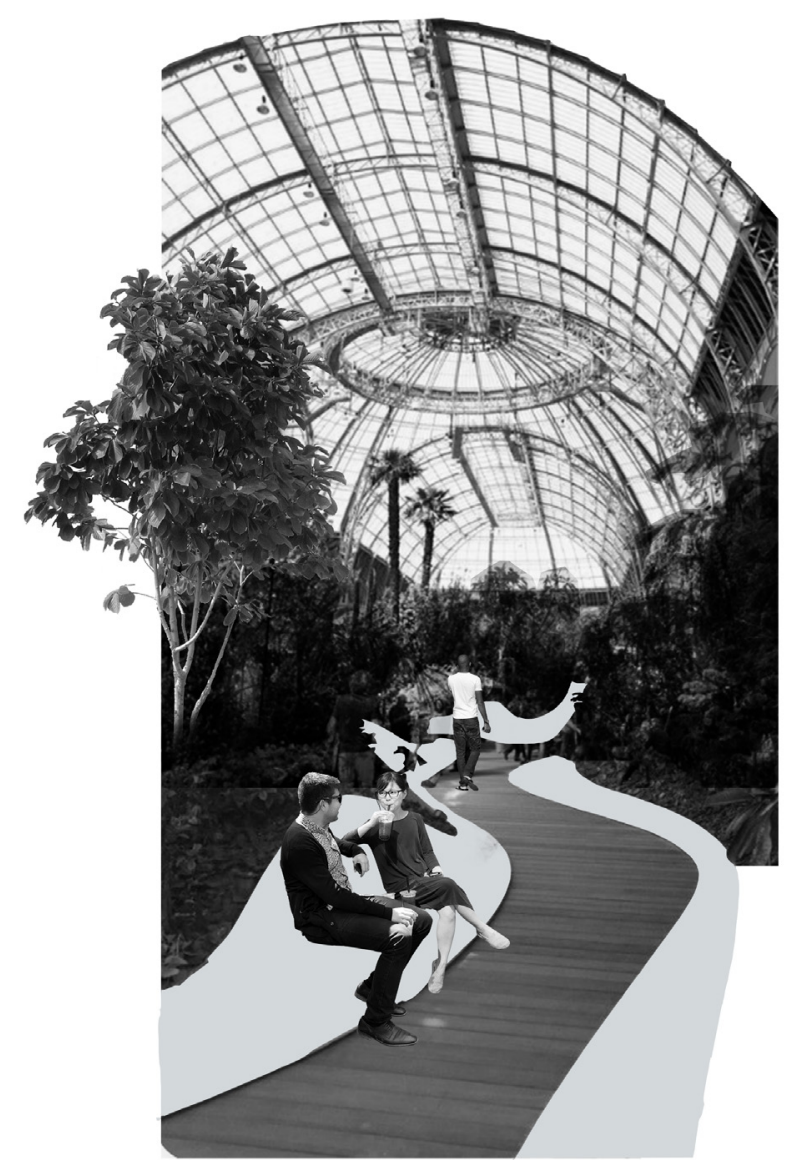

Figure.11.60: Collage experimentation of promenade

\section{PROMENADE}

noun:

a paved public walk, typically one along the seafront.

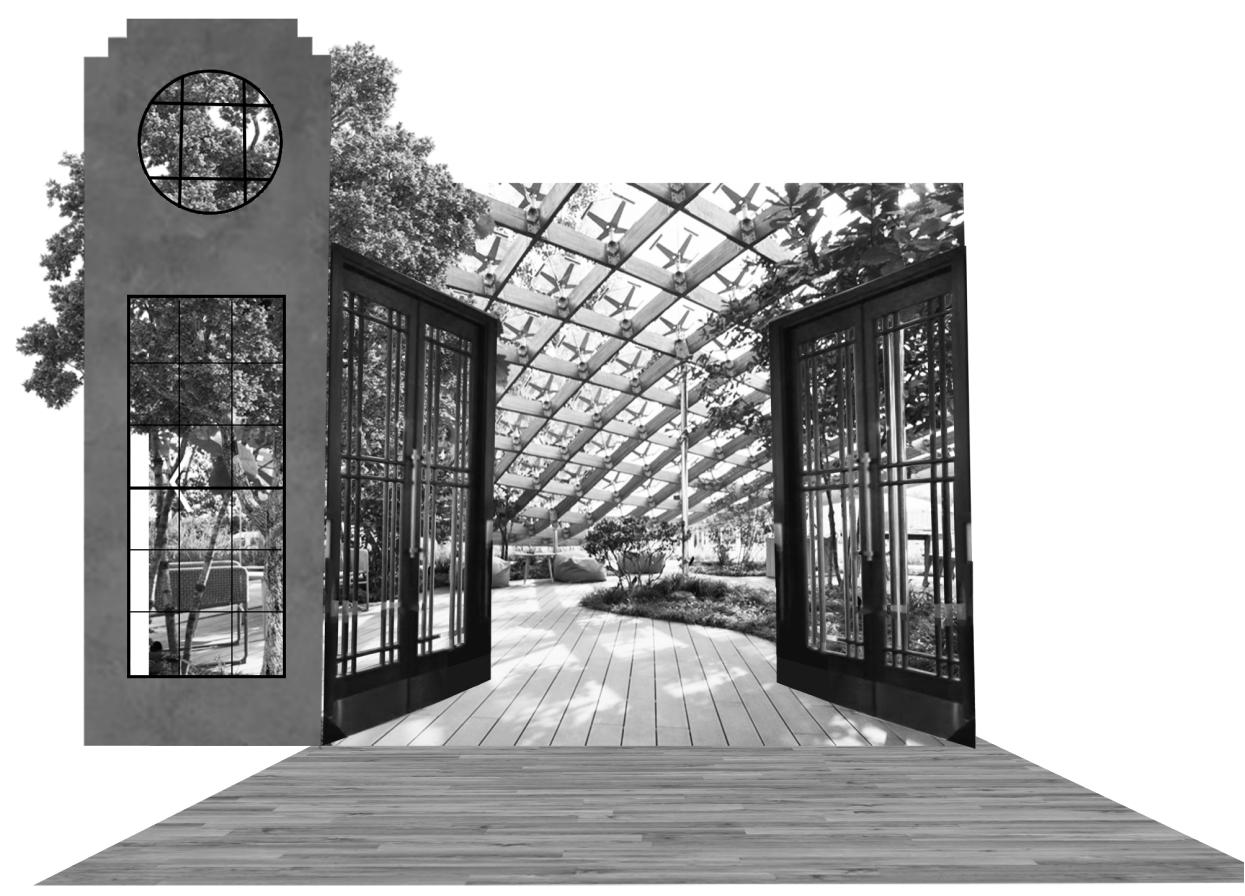

Figure.11.61: Collage experimentation of promenade 


\section{Function}

\footnotetext{
The collage experimentation of the promenade initially looked at being an enclosed space in order to protect from the wind. But upon further consideration more investigation into the intended use was needed in order to fully understand the requirements for the space.
}

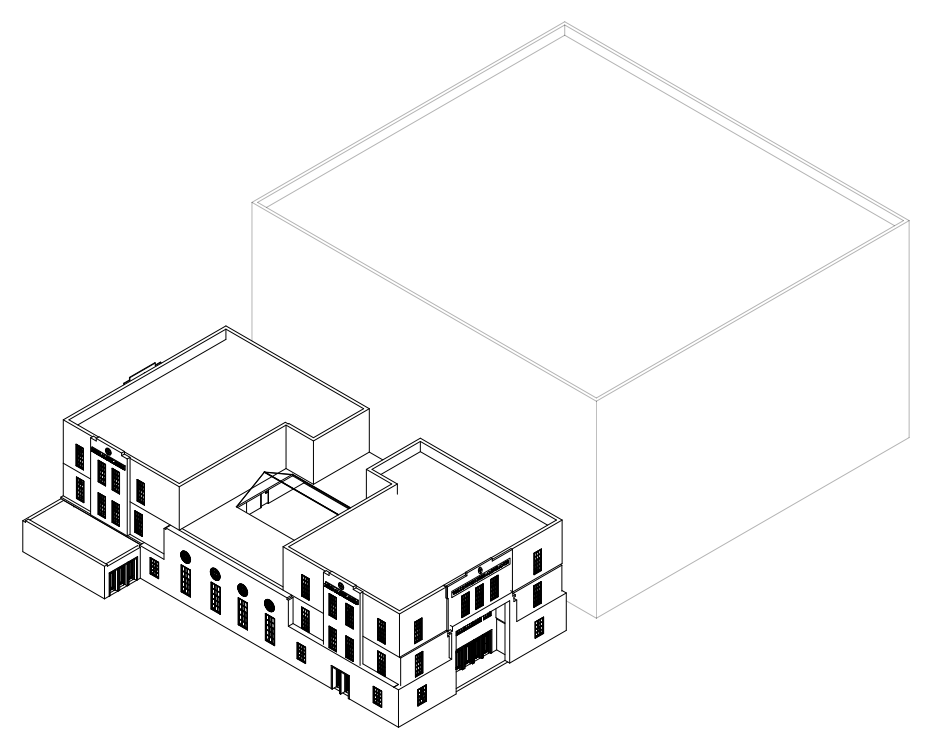

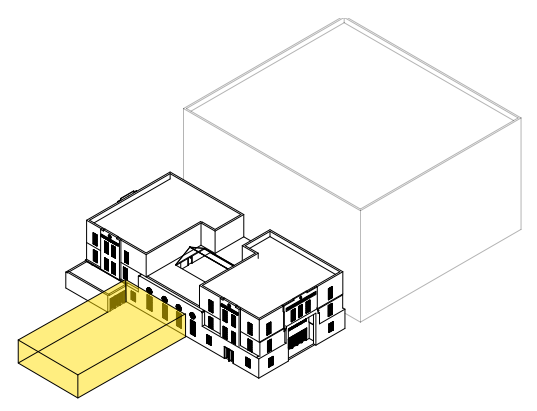

ENCLOSED

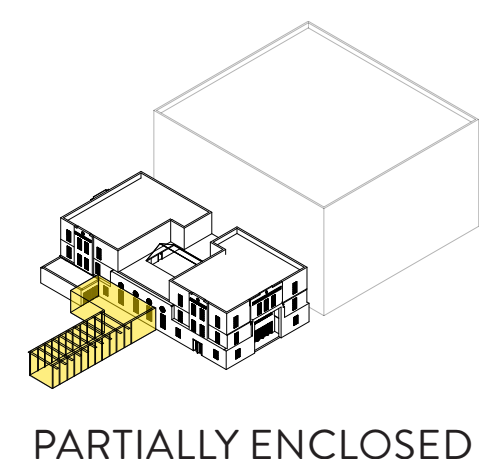

PARTIALLY ENCLOSED

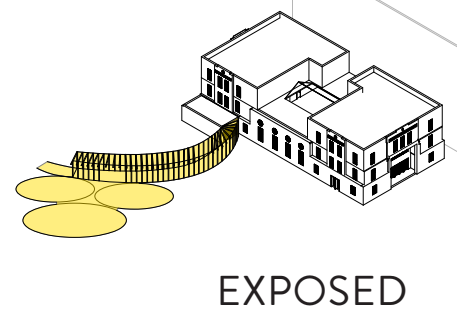

Figure.11.62: Promenade form development 


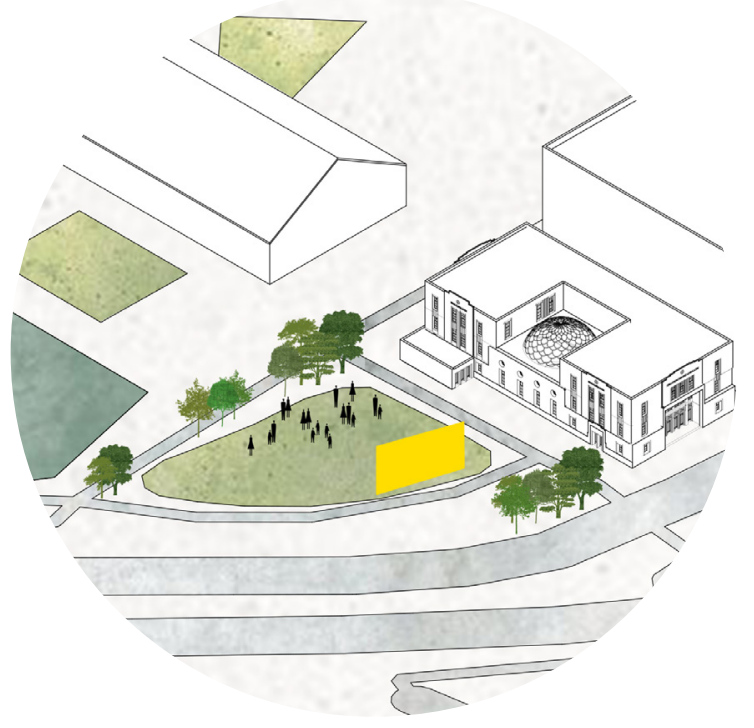

Cinema

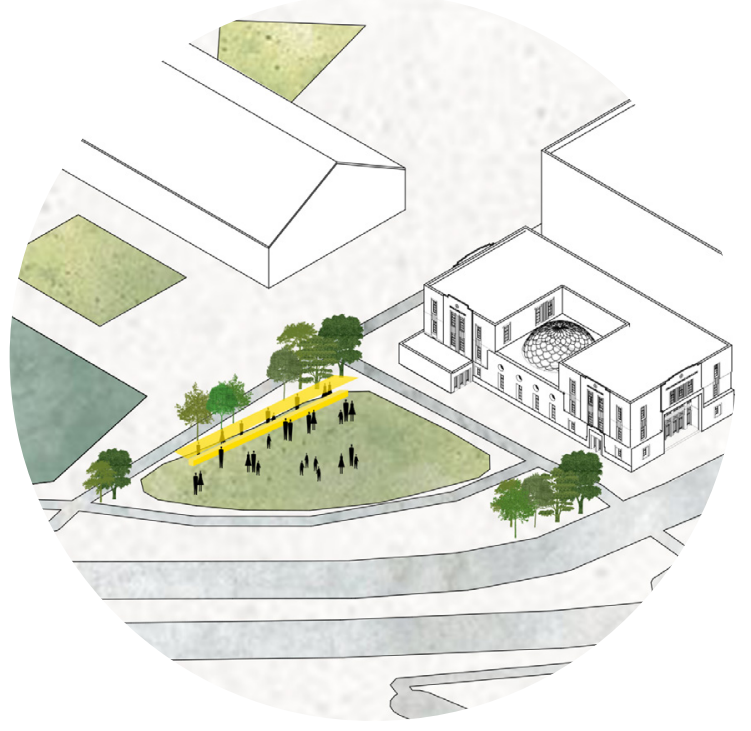

Market

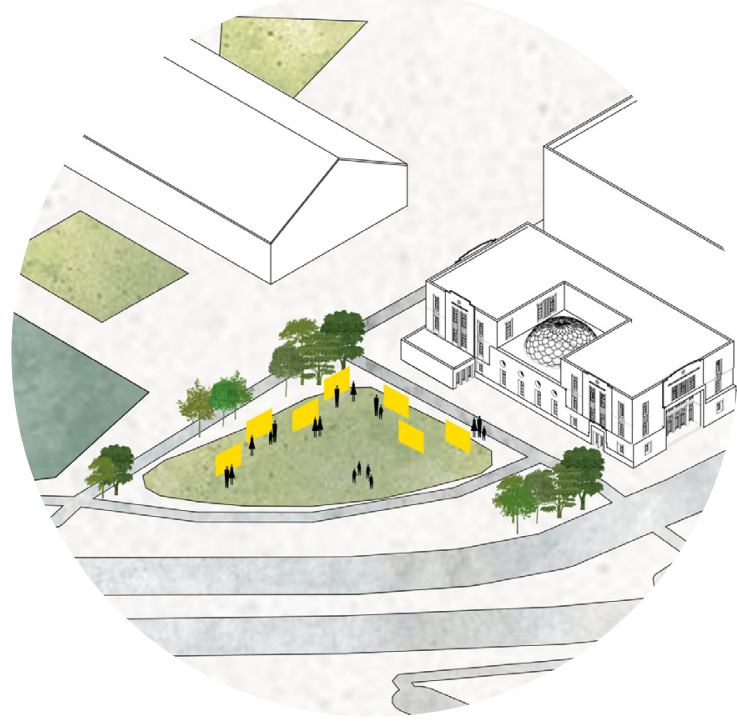

Exhibition

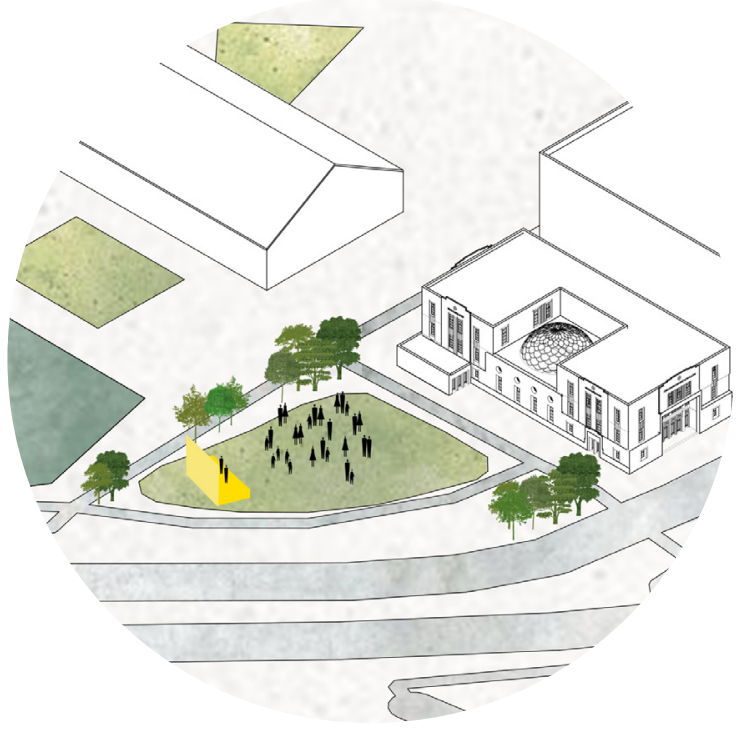

Concert

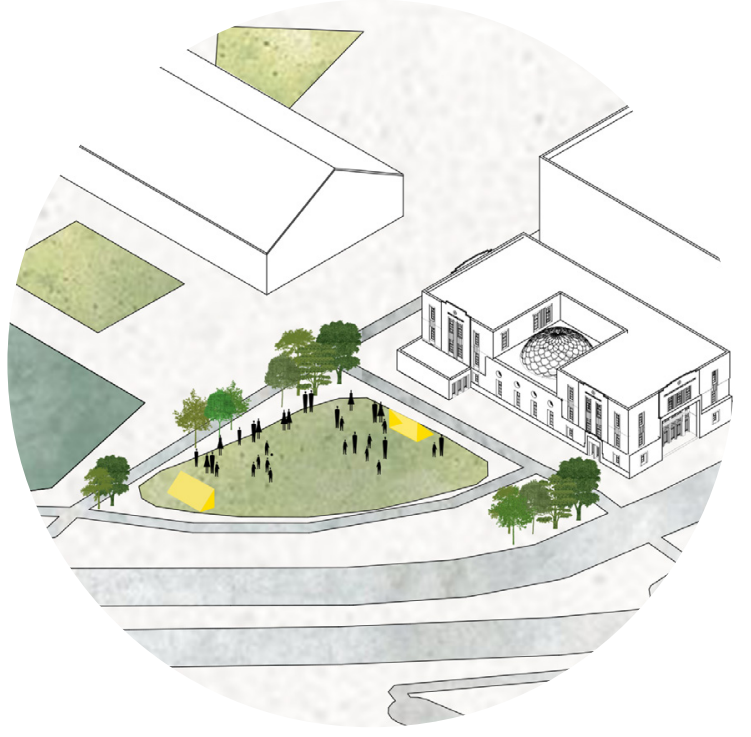

Recreational 


\section{History}

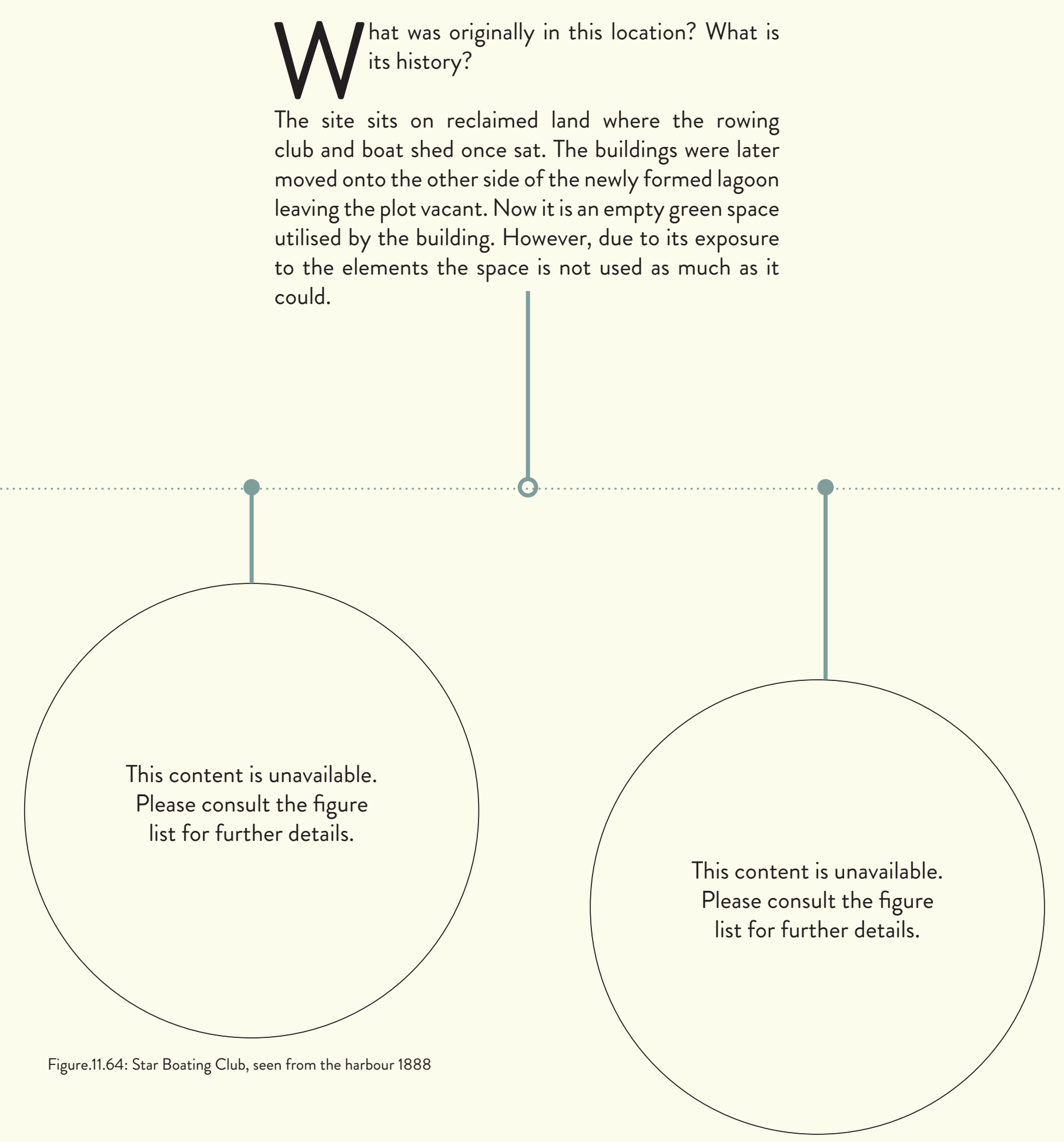

Figure.11.65: Rowing Club Regatta 1890 


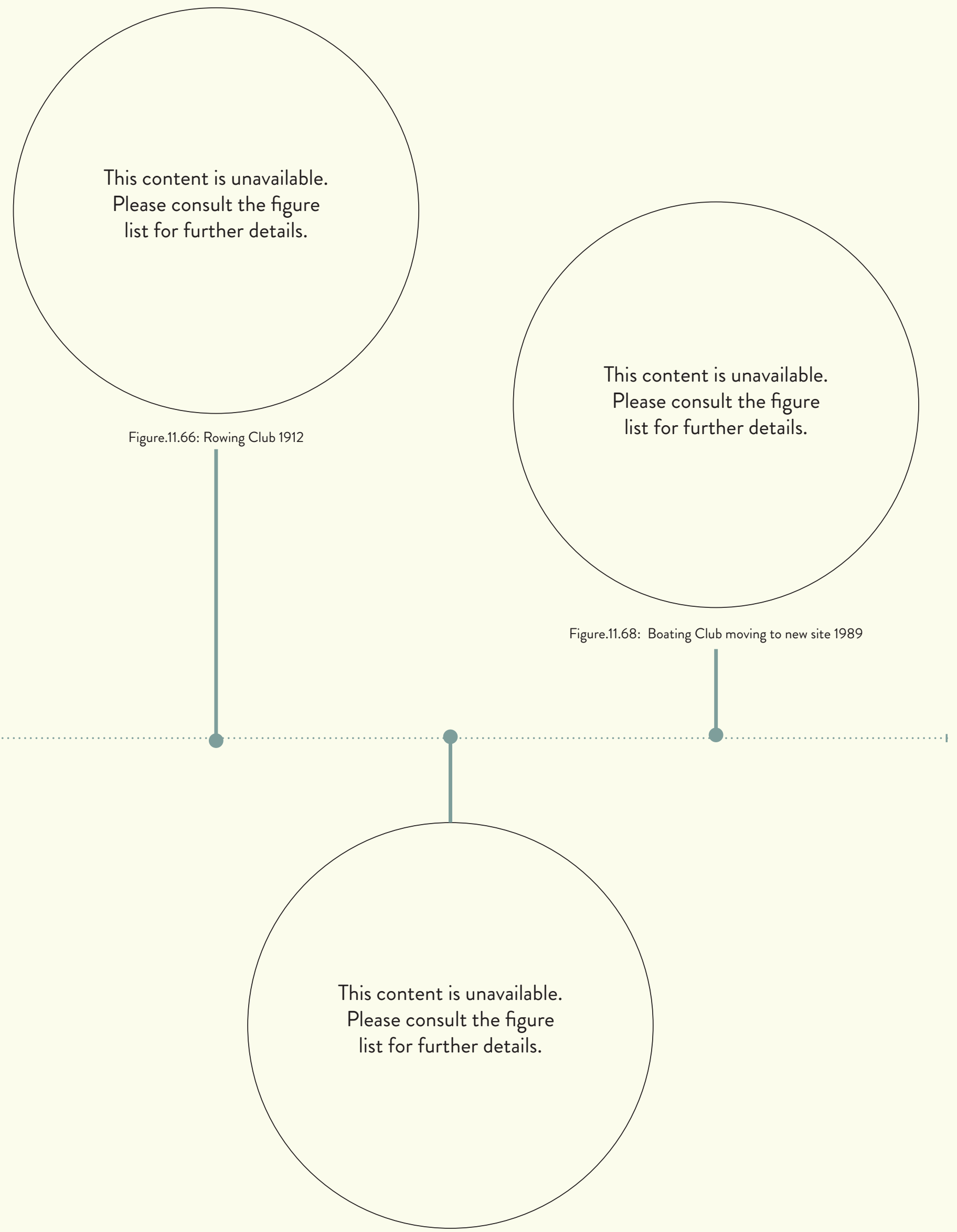

Figure.11.67: Boating Club 1975 


\section{WIND TESTING SITE}

W

hile visiting the site it was obvious that the wind exposure was compromising the usability of the outdoor space. Currently trees have been placed on the south side of the site to help with the strong southerly winds, however the green space continues to only be utilised on fine calm days.

Therefore, it was important to test the type of intervention that would best lessen the effects of the prevailing wind directions. The four main prevailing wind directions were the Northerly, North-Westerly, Southerly and South-Easterly.

This experiment took an indicative approach rather than analytical. The results were looked at from a quantitative perspective, such as looking as to what had larger or smaller impact with the interventions and by rounding up the data to one decimal place.

The set up consisted of a large fan with a grid structure attachment in order to evenly space out the airflow. In front of the fan was a grid of cups to also help distribute the airflow. Then came the 1:500 scale site model with scaled massing to test the intervention possibilities.

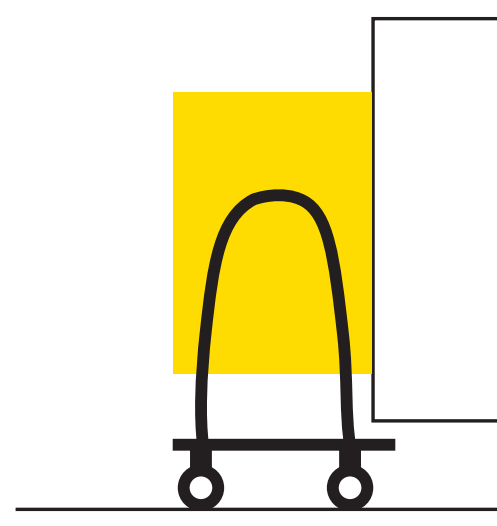

Fan

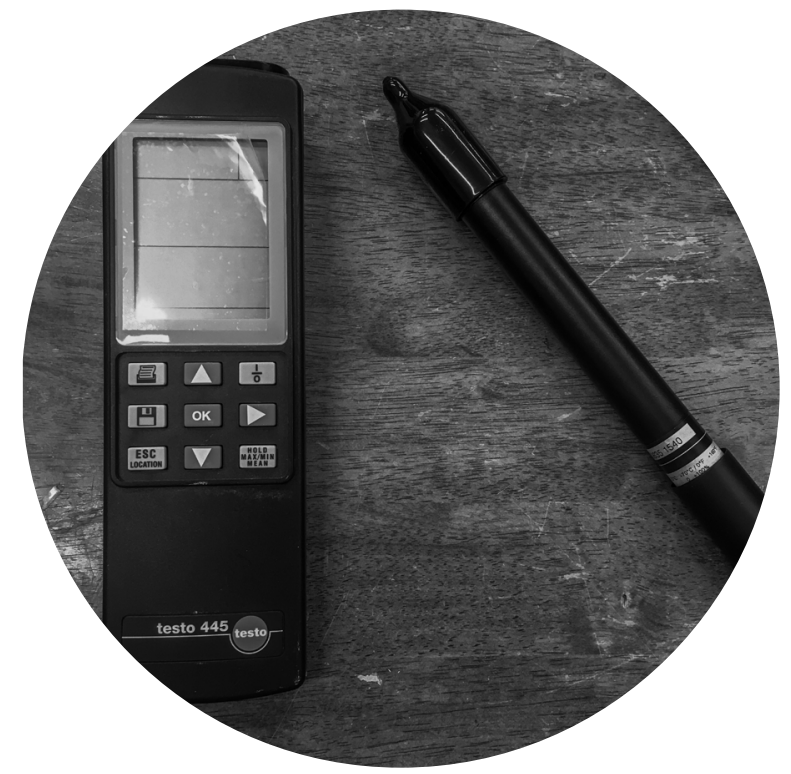

Figure.11.69: Testo 445 anemometer

The omni-directional anemometer used for the experiment was the Testo 445. It measures the maximum air speed regardless of direction. The measuring wand was placed at four different areas of interest around the site and were tested with each wind direction.

Once the preliminary tests were done on the empty site the testing began on different intervention possibilities focusing more on location and scale.

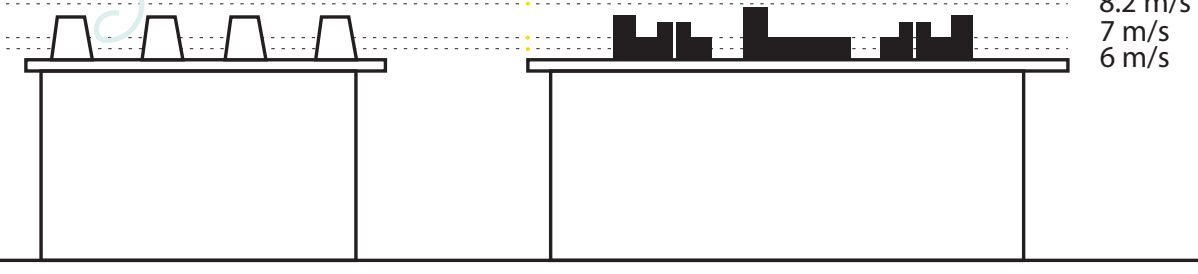




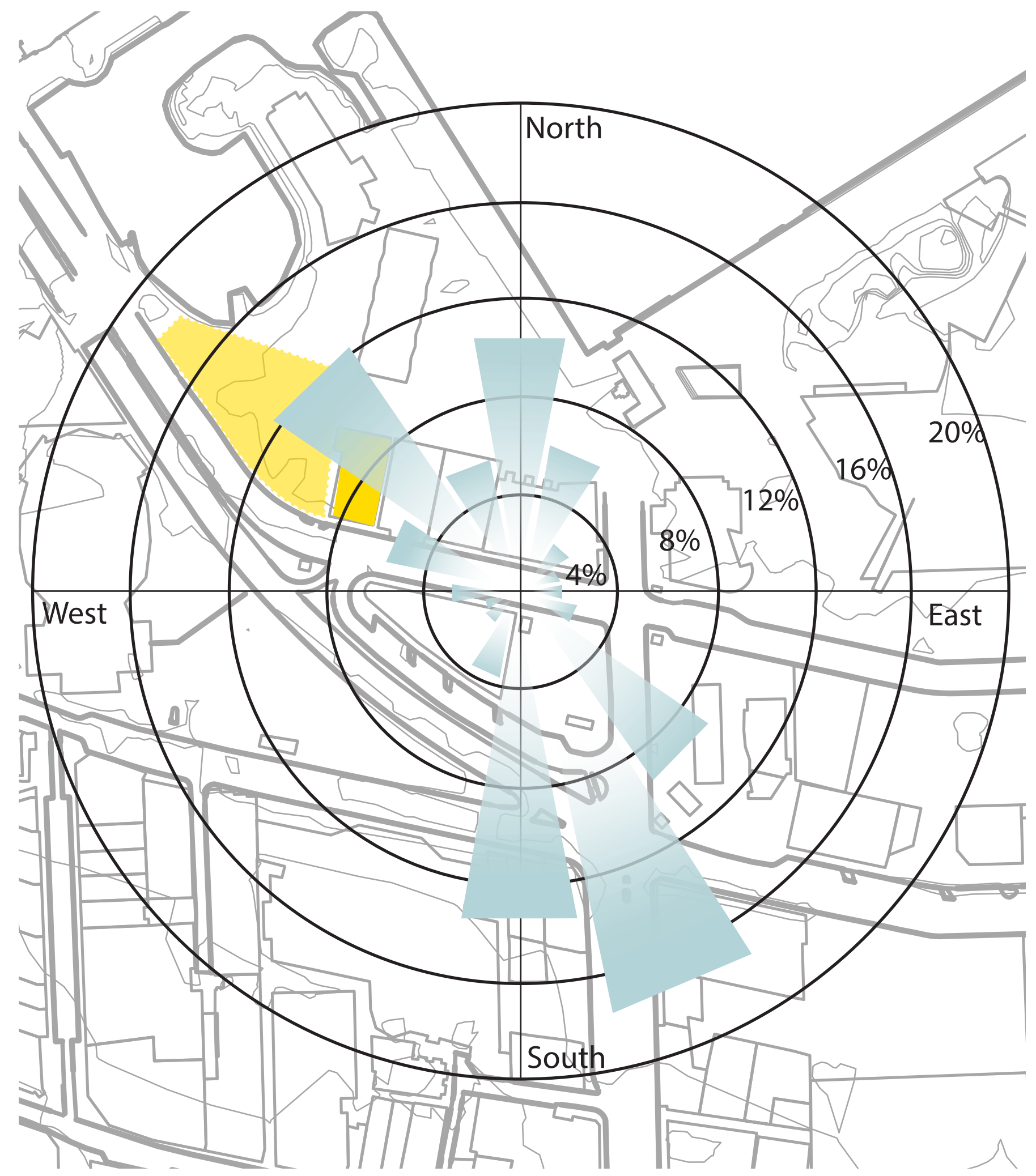

Figure.11.71: Wind rose map around building site 

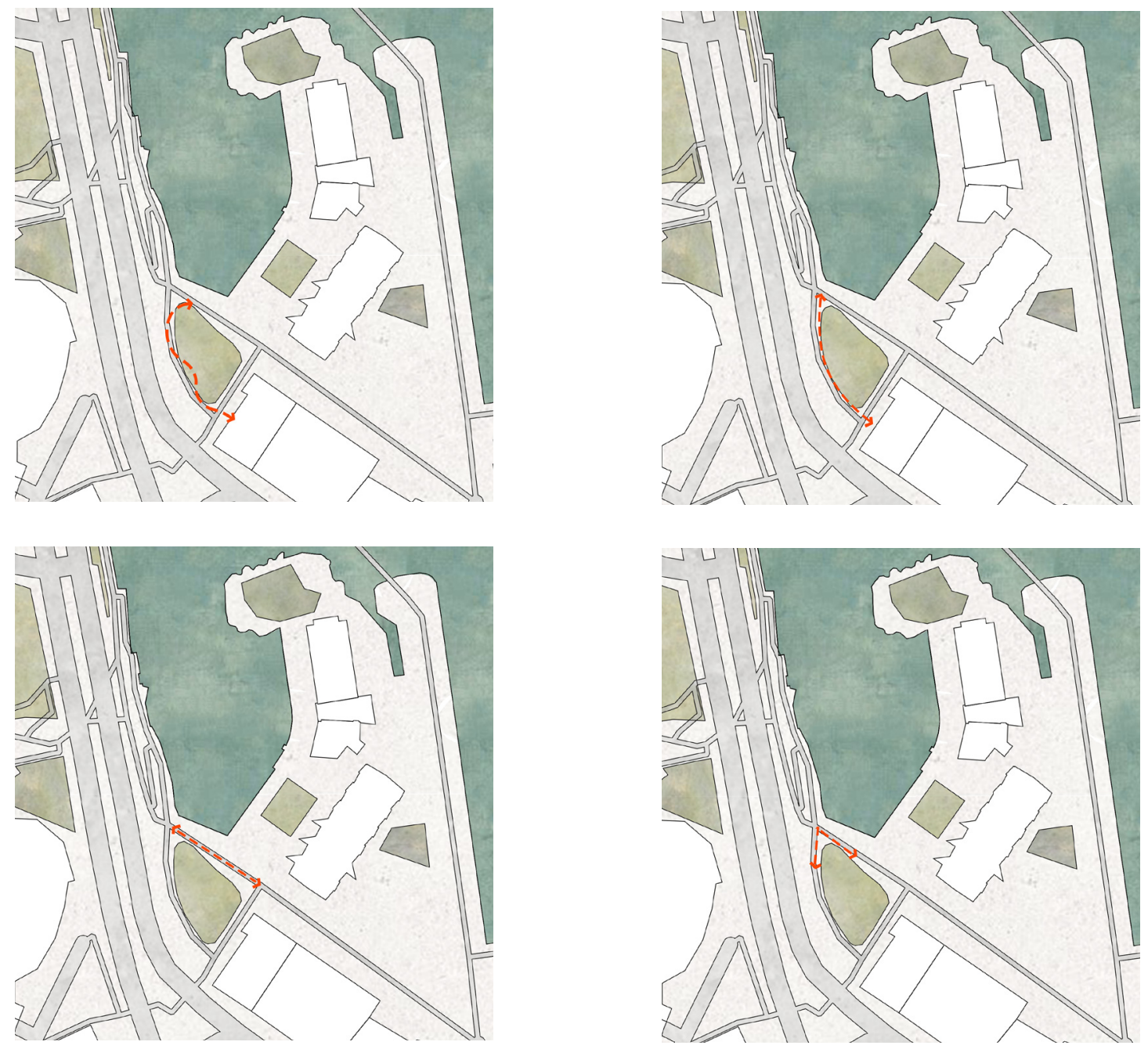

Figure.11.72: Possible intervention locations

Going into the experiment it was envisaged that a natural form would be suitable on its southern end and would require something robust and angular from its northern end. During the experimentation testing was done in four predetermined areas of interest (Figure11.70 marked in yellow) and were tested in the four prevailing wind directions.

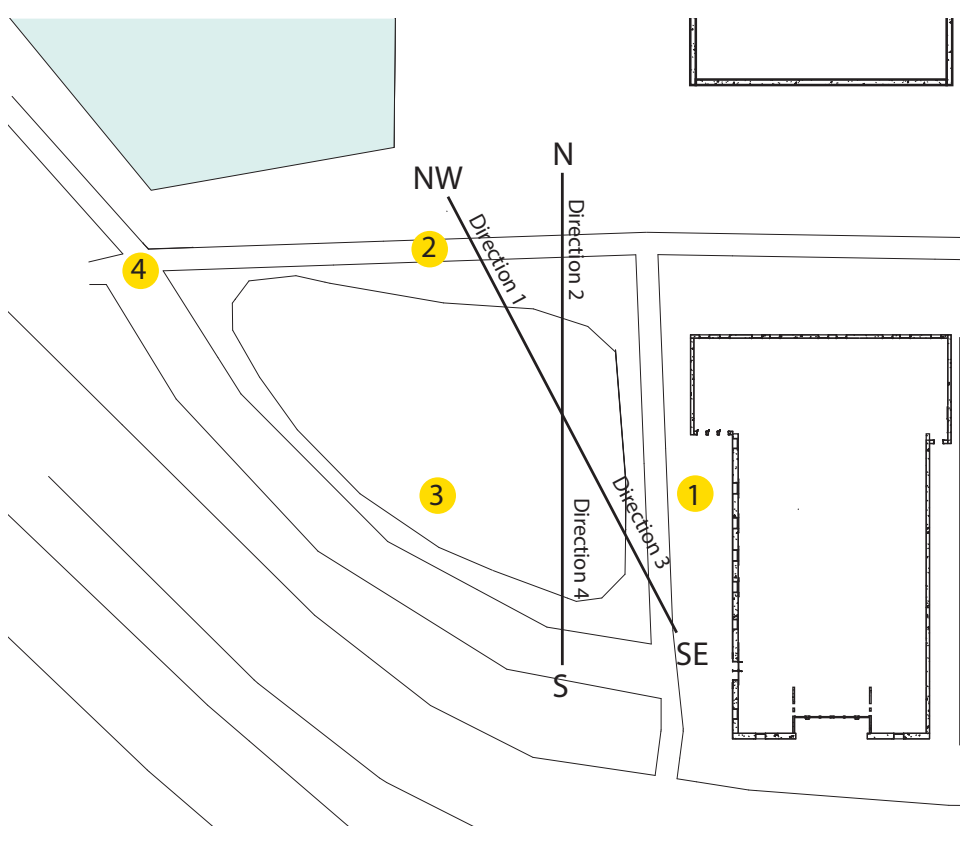

Figure.11.73: Testing spots for experiment 


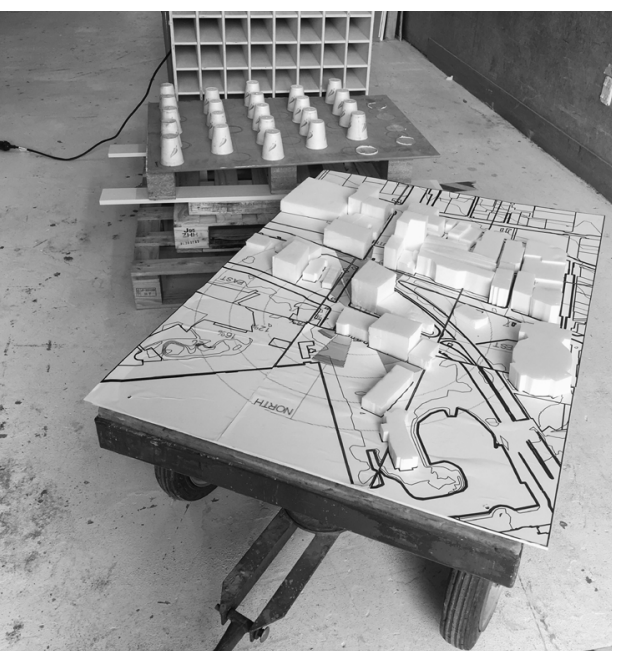

Intervention 1 - 3m Wall along Quay

\begin{tabular}{|c|c|c|c|c|}
\hline & Direction 1 & Direction 2 & Direction 3 & Direction 4 \\
\hline Spot 1 & 2.0 & 2.5 & 1.2 & 0.9 \\
\hline Spot 2 & 4.0 & 3.5 & 2.2 & 1.5 \\
\hline Spot 3 & 2.8 & 4.0 & 1.7 & 1.4 \\
\hline Spot 4 & 3.0 & 4.0 & 2.0 & 2.1 \\
\hline
\end{tabular}

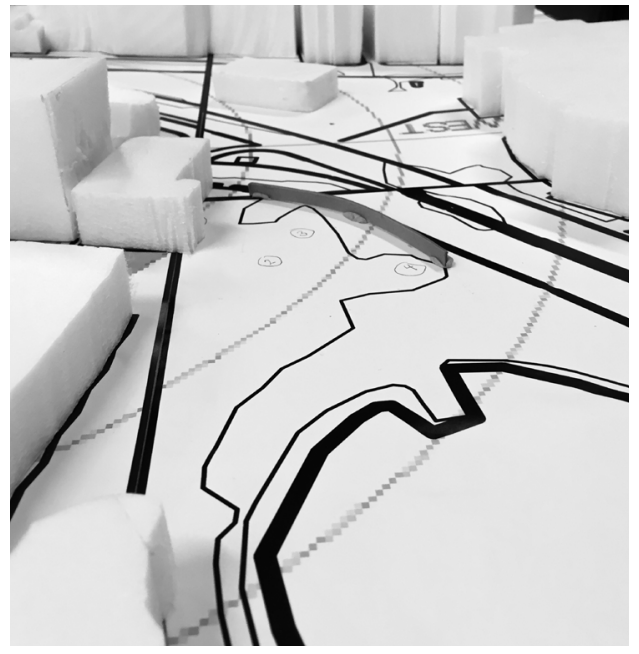

Intervention 2 - 6m Wall along Quay

\begin{tabular}{|c|c|c|c|c|}
\hline & Direction 1 & Direction 2 & Direction 3 & Direction 4 \\
\hline Spot 1 & 2.6 & 3.0 & 1.3 & 1.0 \\
\hline Spot 2 & 3.4 & 5.6 & 1.8 & 1.1 \\
\hline Spot 3 & 2.7 & 4.8 & 2.0 & 1.2 \\
\hline Spot 4 & 3.4 & 5.2 & 2.2 & 1.6 \\
\hline
\end{tabular}

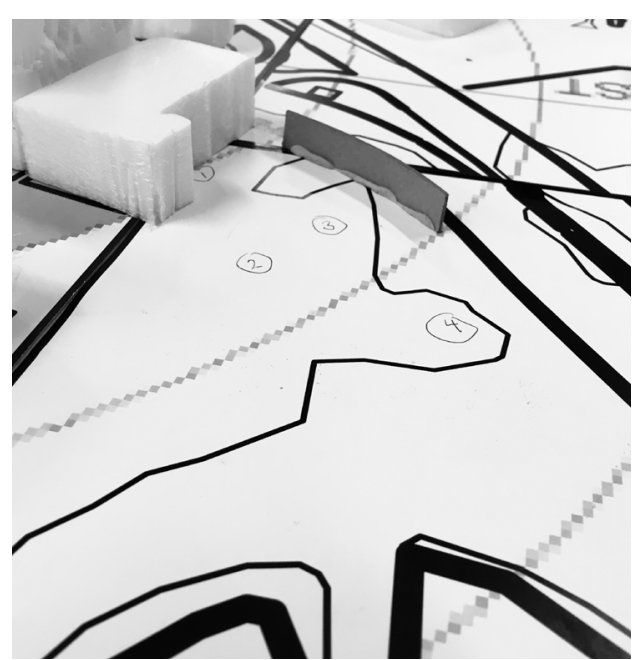

Intervention 3 - Tree wall for Notherly

\begin{tabular}{|c|c|c|c|c|}
\hline & Direction 1 & Direction 2 & Direction 3 & Direction 4 \\
\hline Spot 1 & 1.9 & 1.3 & - & - \\
\hline Spot 2 & 3.1 & 2.2 & - & - \\
\hline Spot 3 & 2.5 & 2.4 & - & - \\
\hline Spot 4 & 3.0 & 3.6 & - & - \\
\hline
\end{tabular}

Figure.11.74: Testing set-up and tables

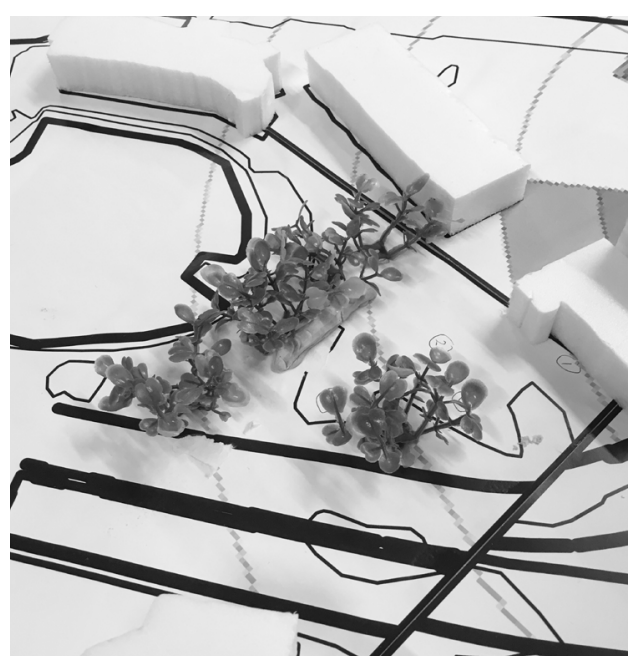




\section{Reflection}

$\mathrm{B}$ ased on these experiments it was proved that the main areas to look at intervening were from the South-Easterly and the Northerly winds.

Looking at the sites' current state you can see that attempts have been made to rectify the issue, with the addition of trees and sand bank along its southern border. It is then the intention to keep these mature trees.

As it is the intention to the connect the building to the neighbouring lagoon it will be important to find a balance of protection from the wind and connection to the water. This is why a more botanical approach was tested for the Northerly direction, following the existing tactics.

The result of the experiment was the need for two strategies. A strategy for the Southerly winds and another one for the Northerly. The southerly being the easier to fix would only need to continue using the established trees and sand bank. However, the northerly requires a more complicated approach as a structural approach would only create another wind tunnel between the Wharewaka Function Centre and the Free Ambulance Building. Therefore, an intervention balancing landscaping contouring and small structures will also help to maintain a connection with the lagoon.

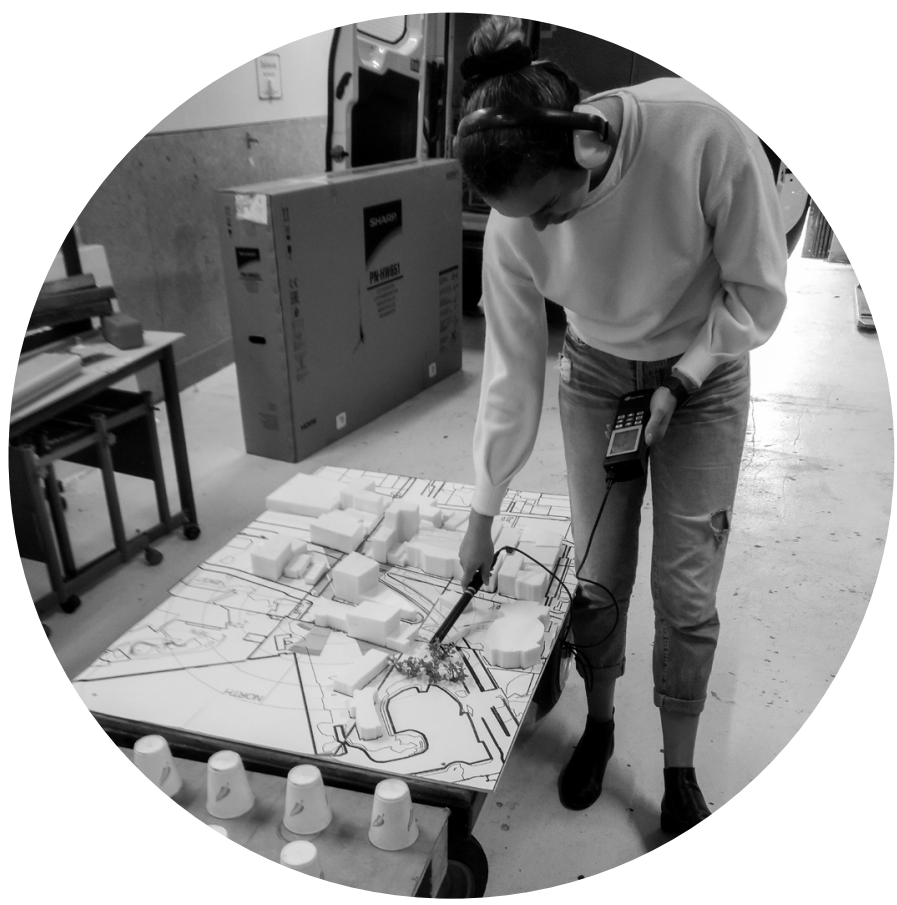

Figure.11.75: Author undertaking experiment

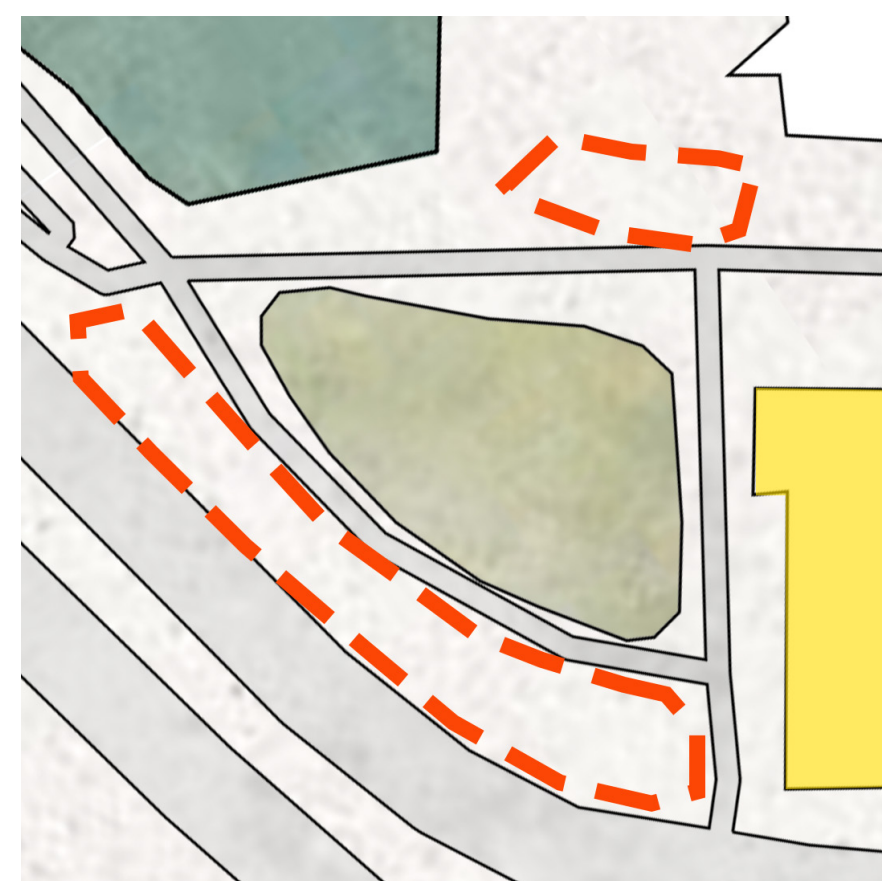

Figure.11.76: Locations of interest 
Structural

S-SE Strategy
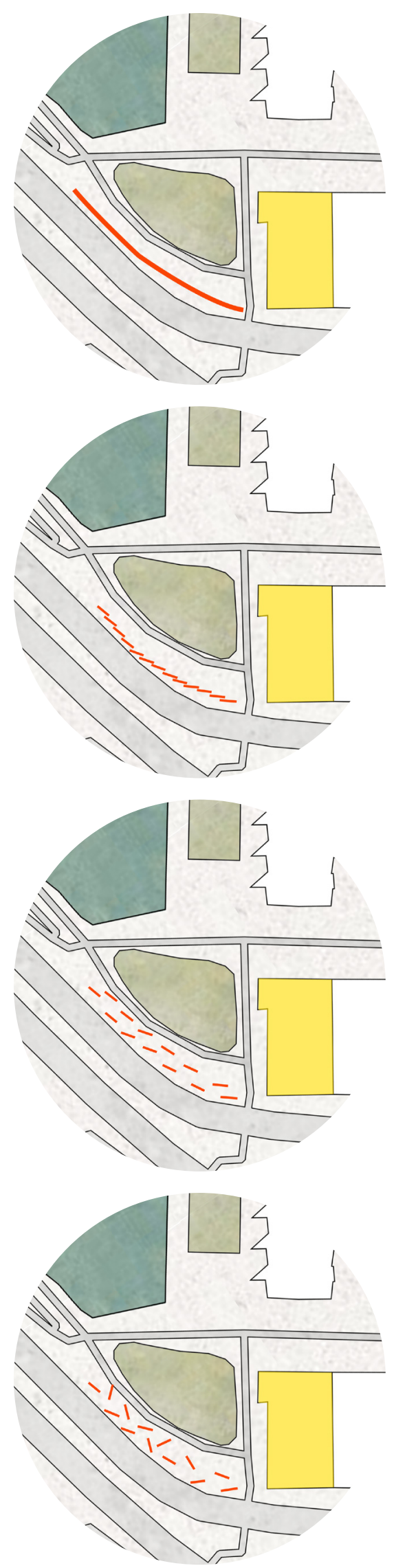

N-NW strategy
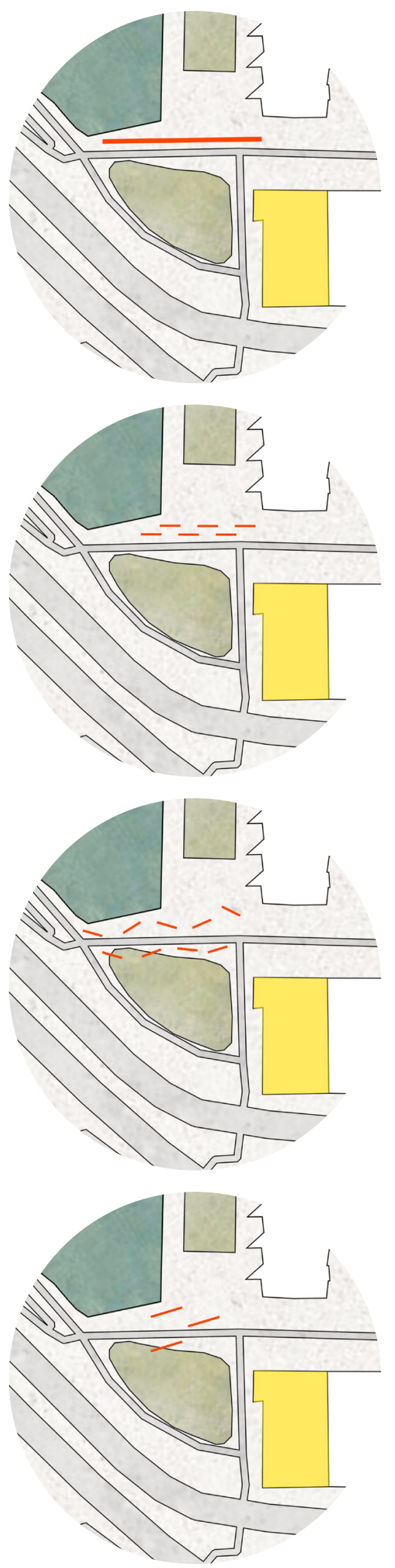

Figure.11.77: Possible interventions 


\section{Wall type experimentation}
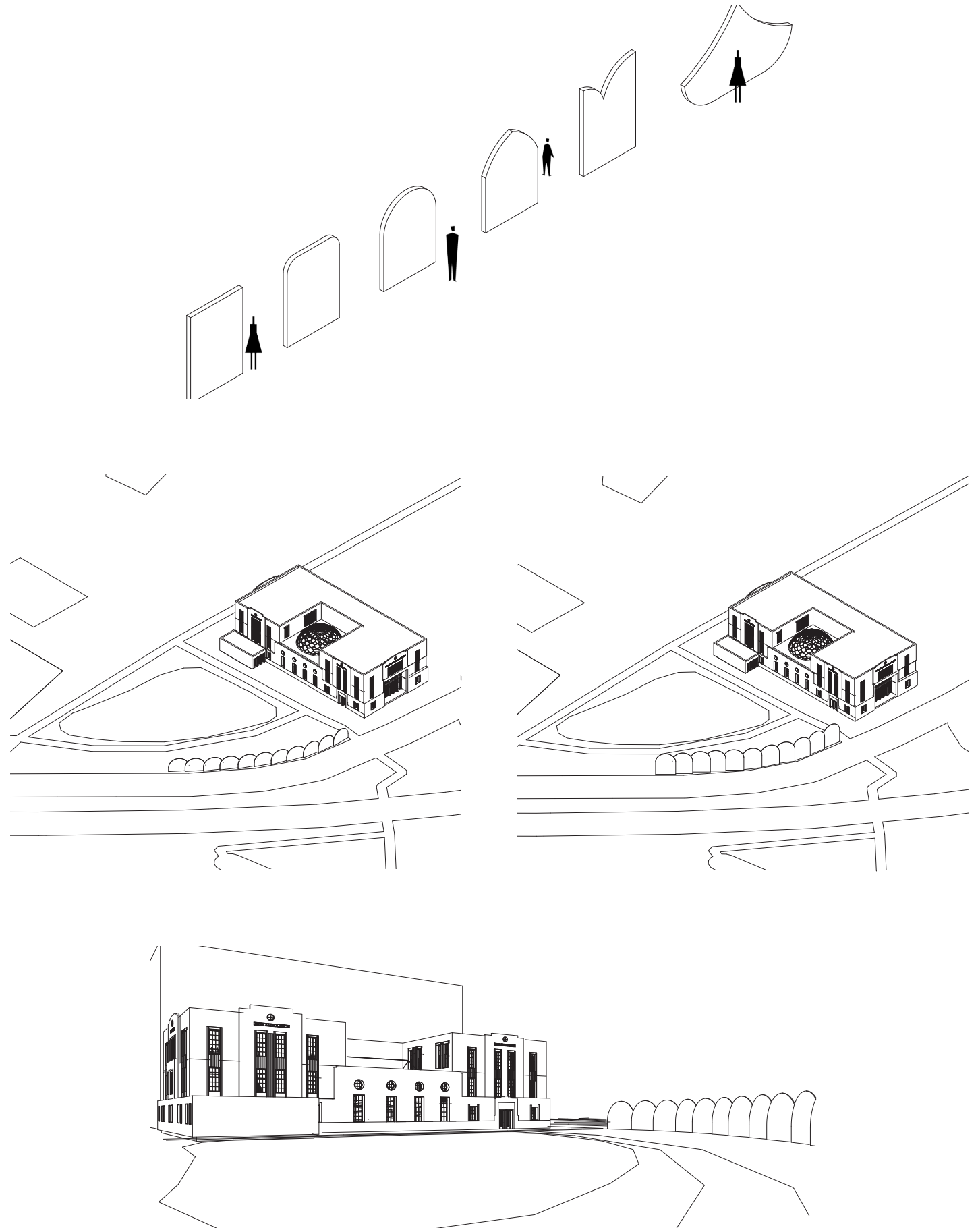

Figure.11.78: Wall iterations 


\section{Green Space}

\footnotetext{
$\mathrm{T}$

he site currently uses a natural approach to wind protection utilising sand mounds and large established trees.

Therefore, this intervention continued to use the matured trees as a natural wall that already exceeded the three meters required by the wind testing. For the northerly approach the landscaping used trees to block some excess wind. This also ensured that the landscaping had enough natural green space.
}

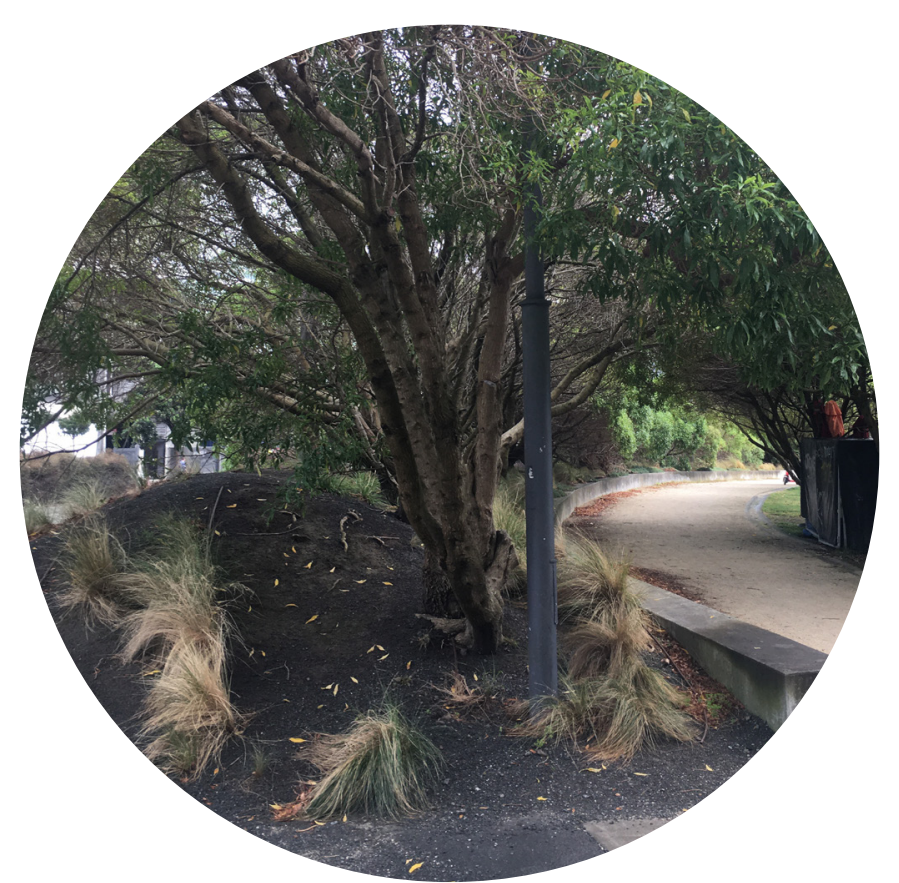

Figure.11.79: Wind breaker currently used on site 


\section{Form Exploration}

The form of the promenade needed to have relationship and connection to the building itself. The intention was to create an adaptable space that could be used for a number of activities that would be required from the users of the former Ambulance Building. This would be done using a mix of viewing platforms, green space and seating areas.
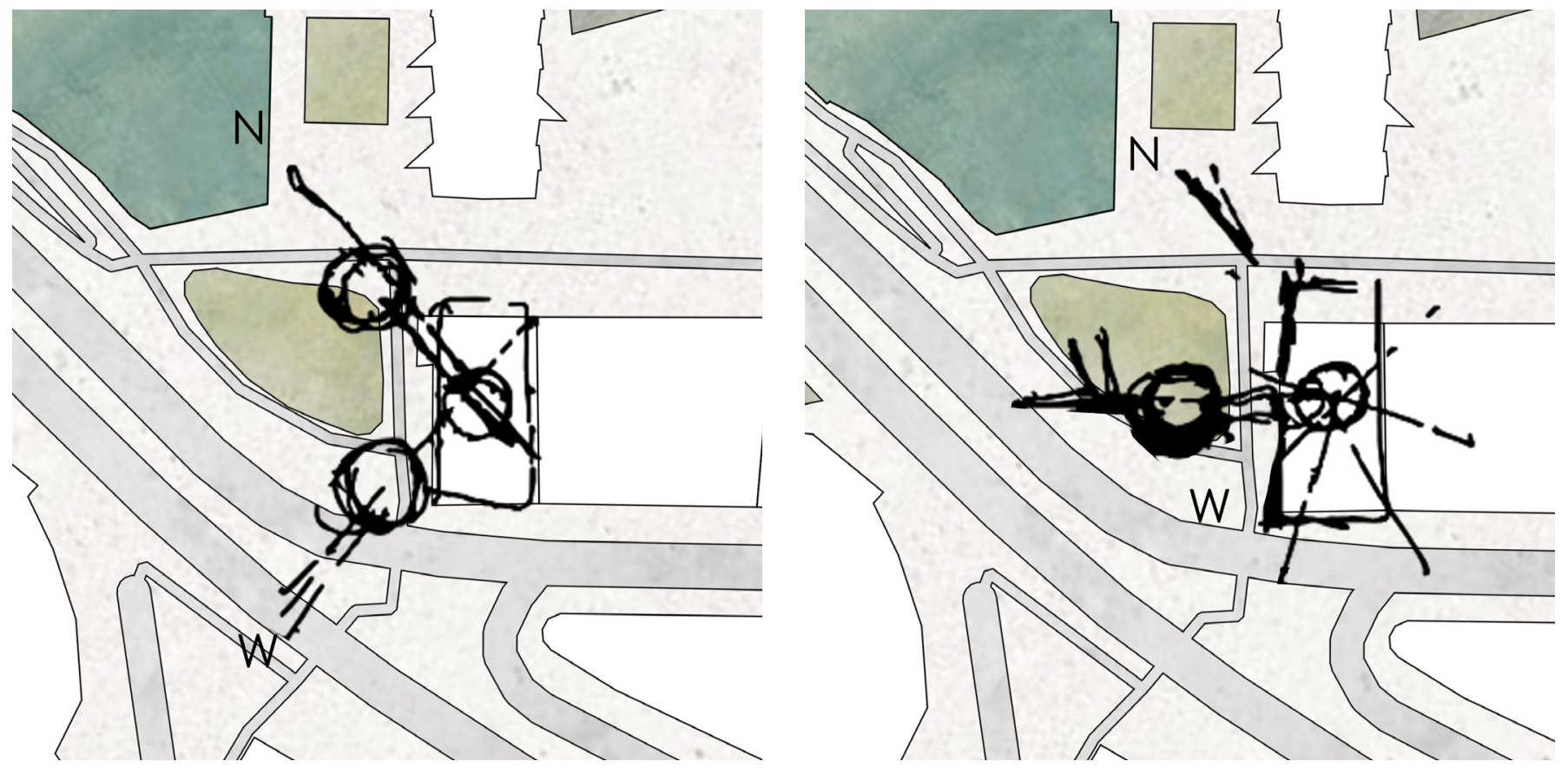

Figure.11.80: Relationship between interior and exterior development 

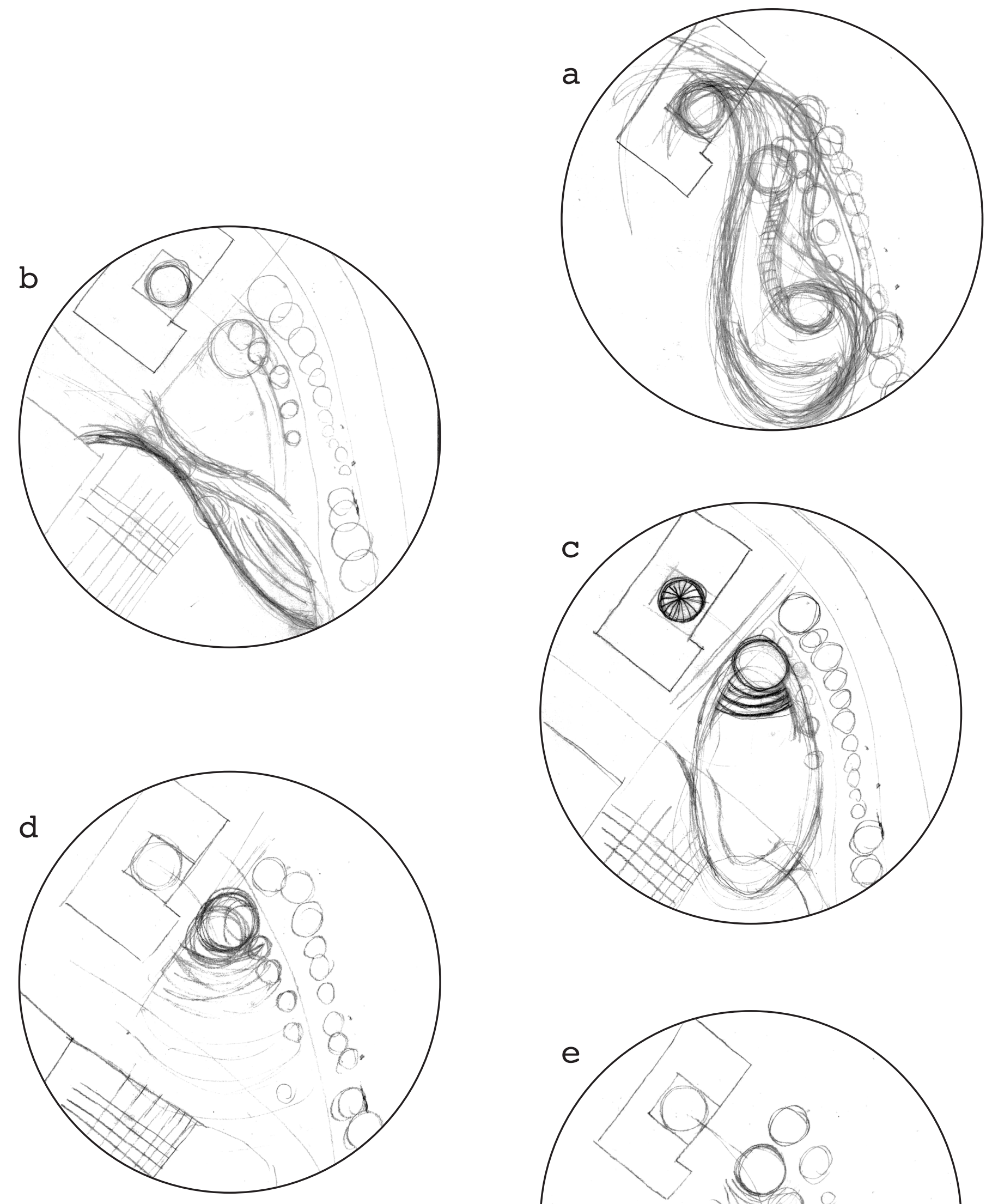

Figure.11.81: Formal exploration of landscaping

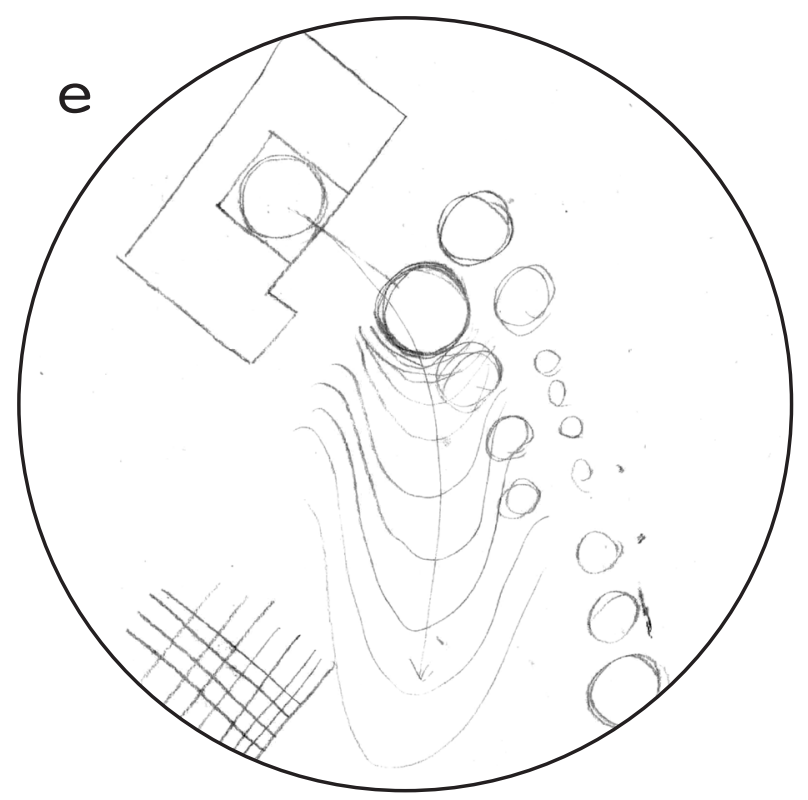




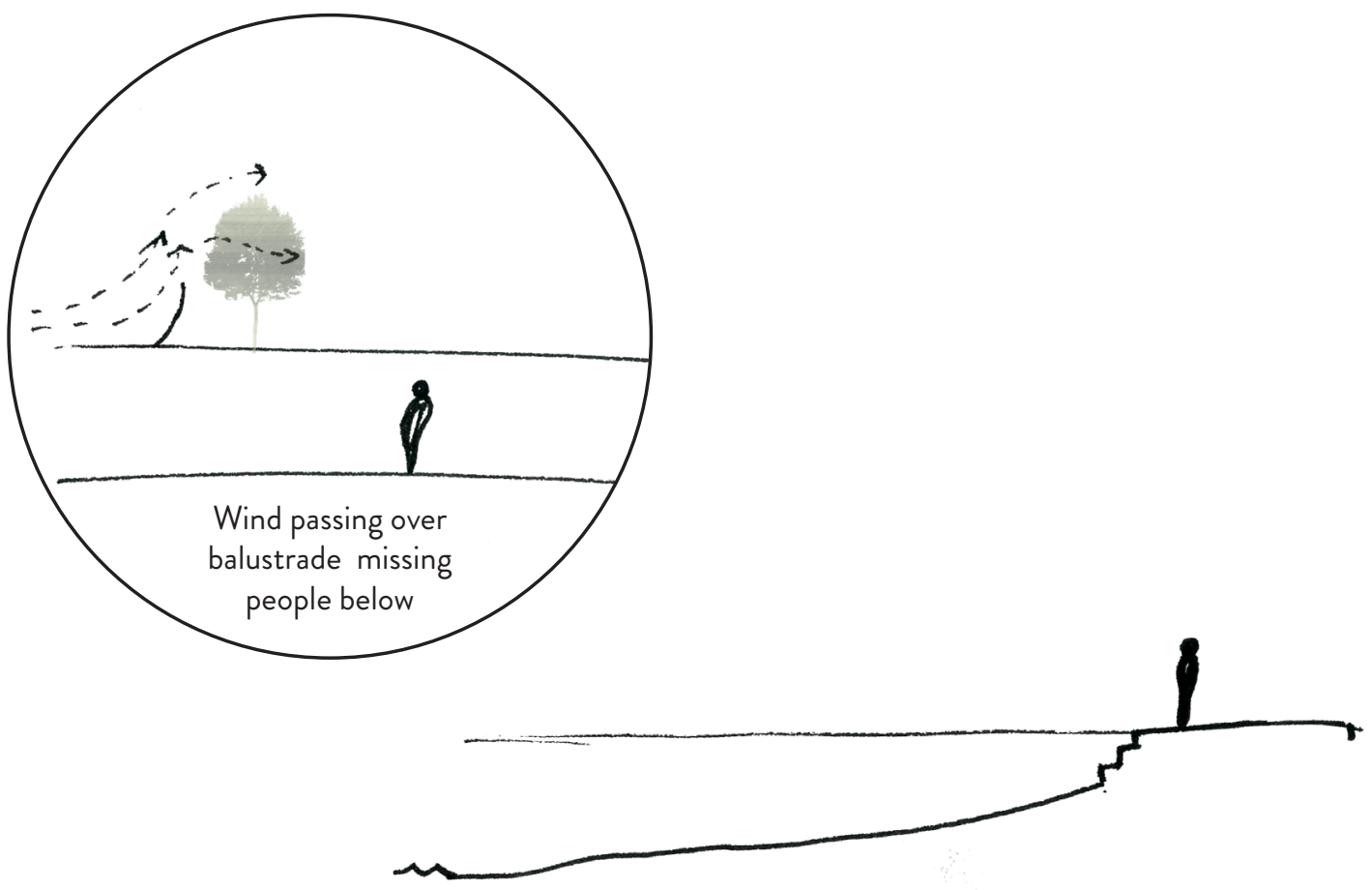

Small steps then slopes down to lagoon

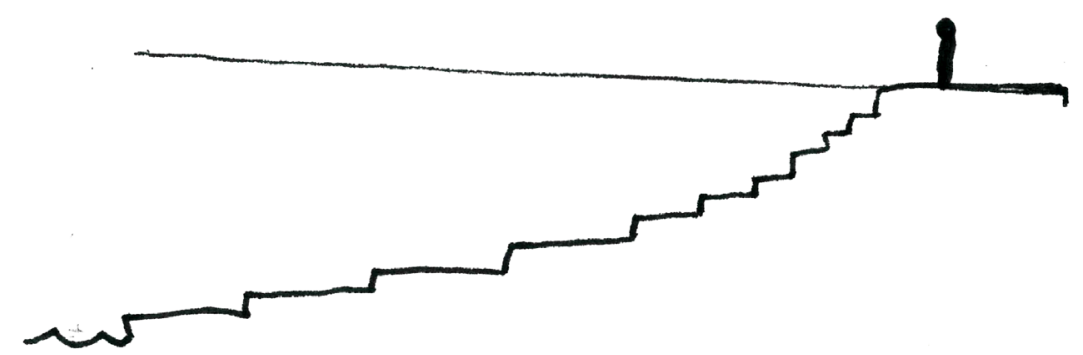

Steps of varying sizes

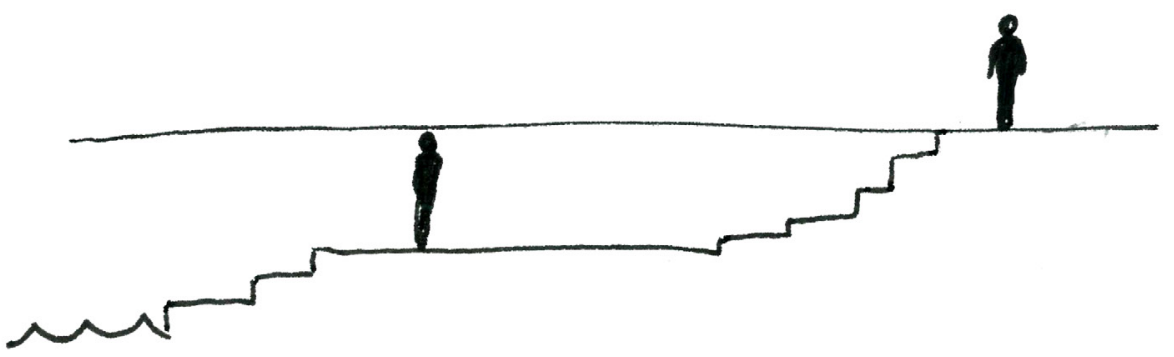

Steps of varying sizes and some flat green space 

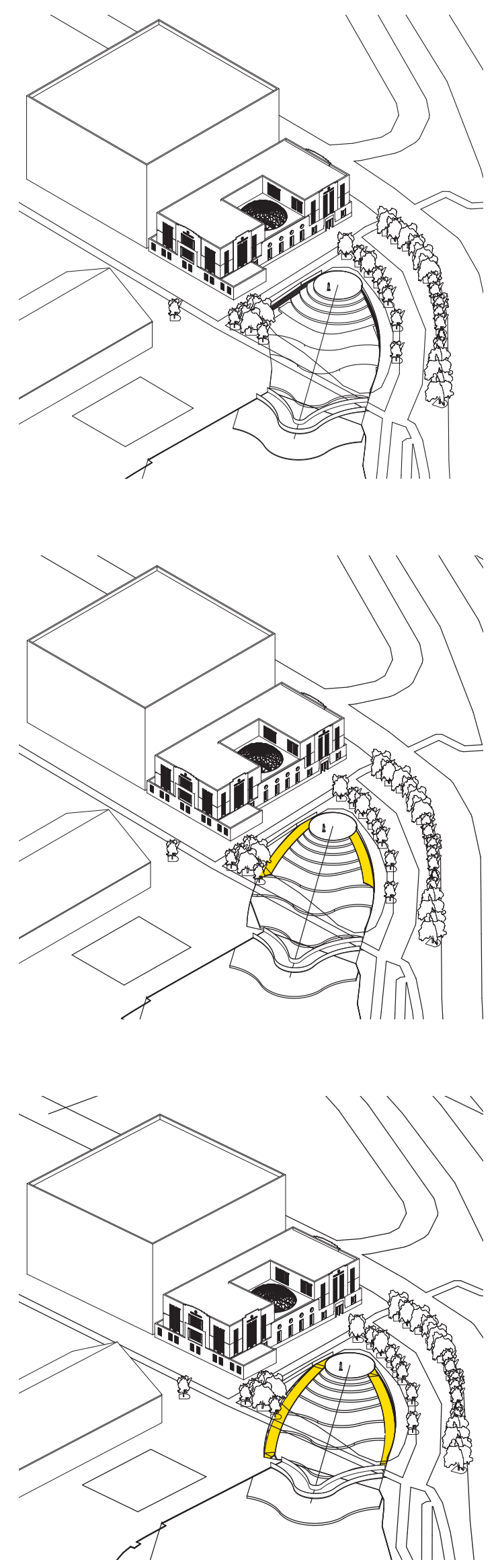

Figure.11.83: Development of ramps and steps 


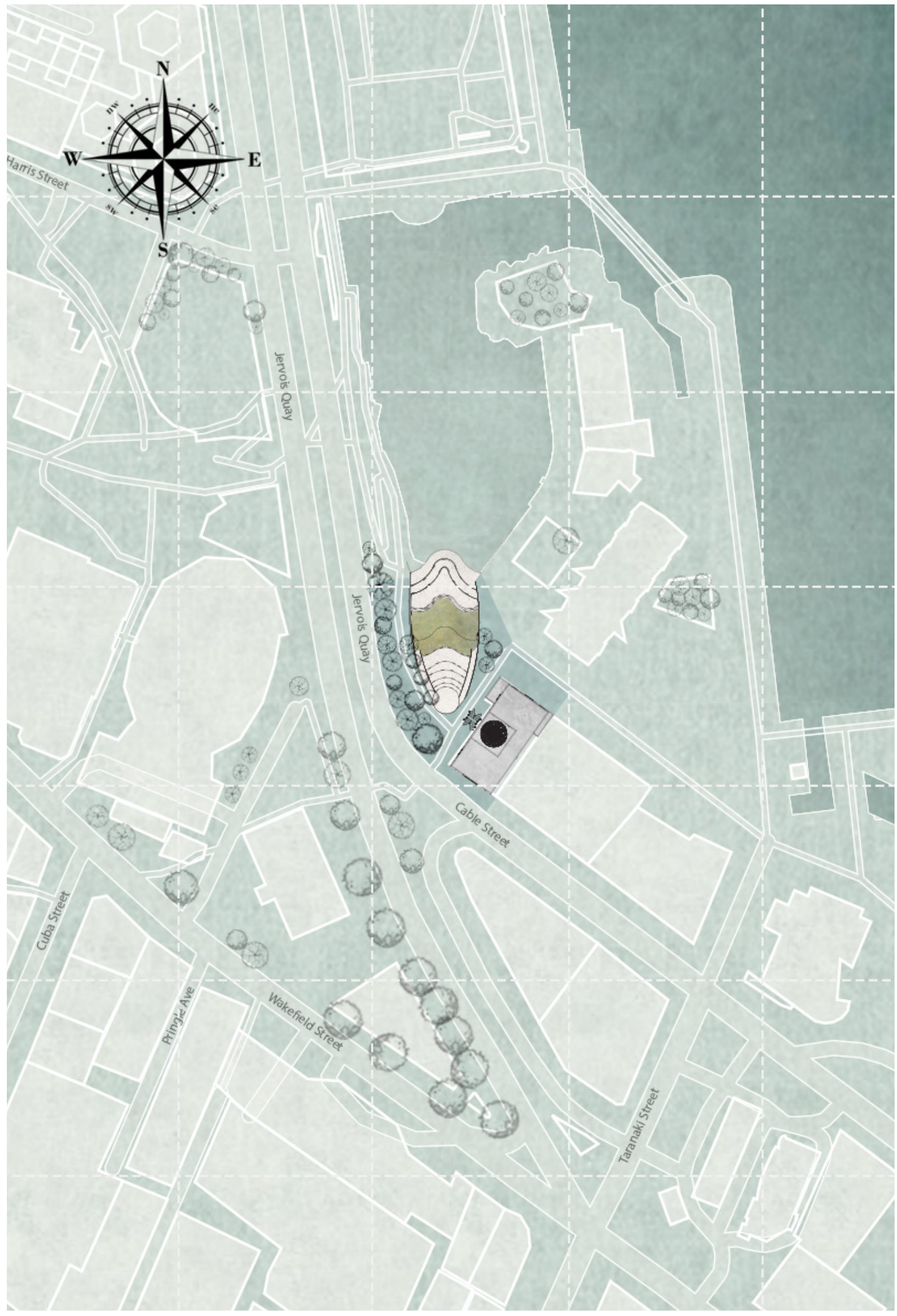


A Cross Cultural Third Place 


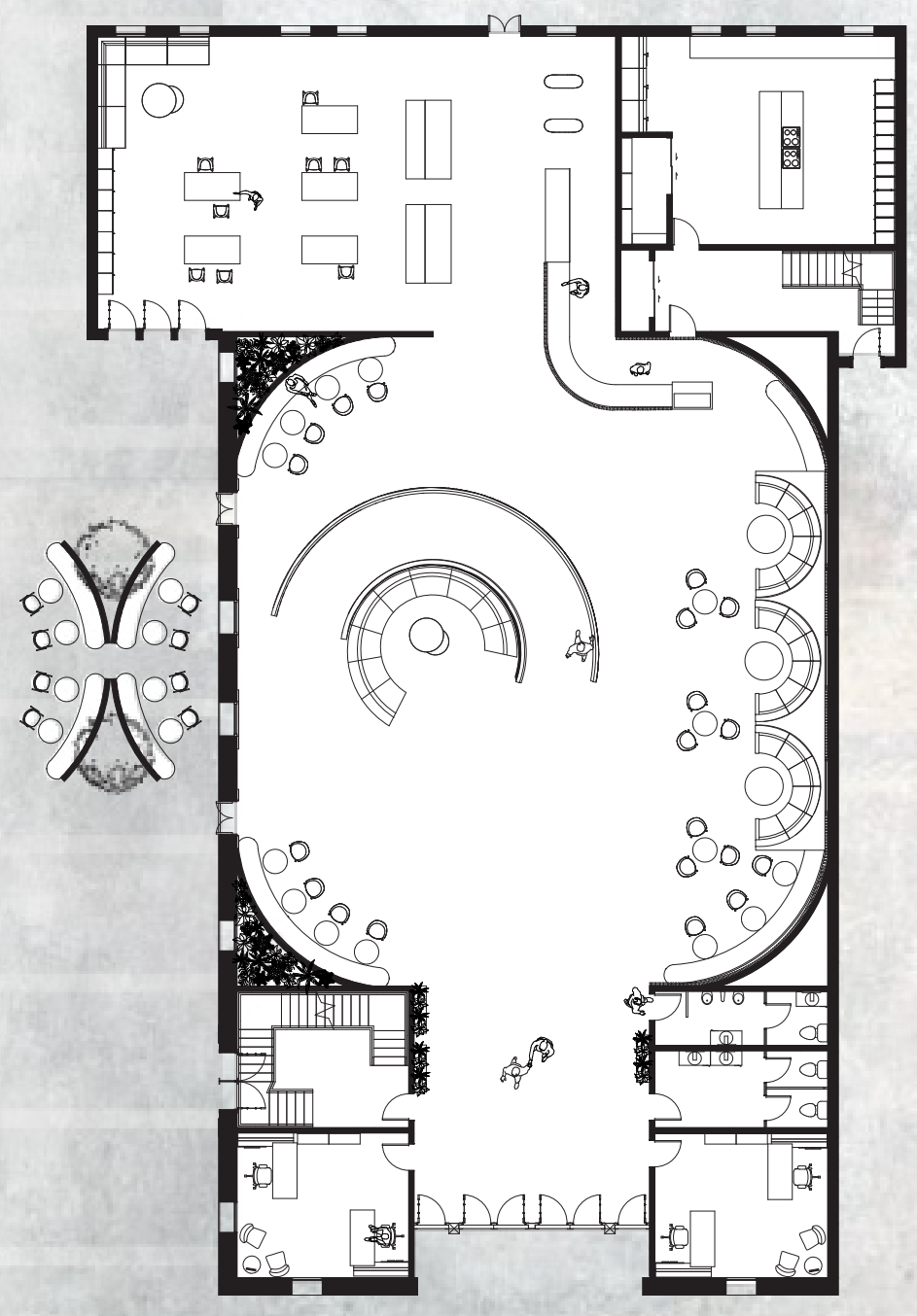

Figure.11.85: Ground Floor 


\section{GROUND FLOOR}

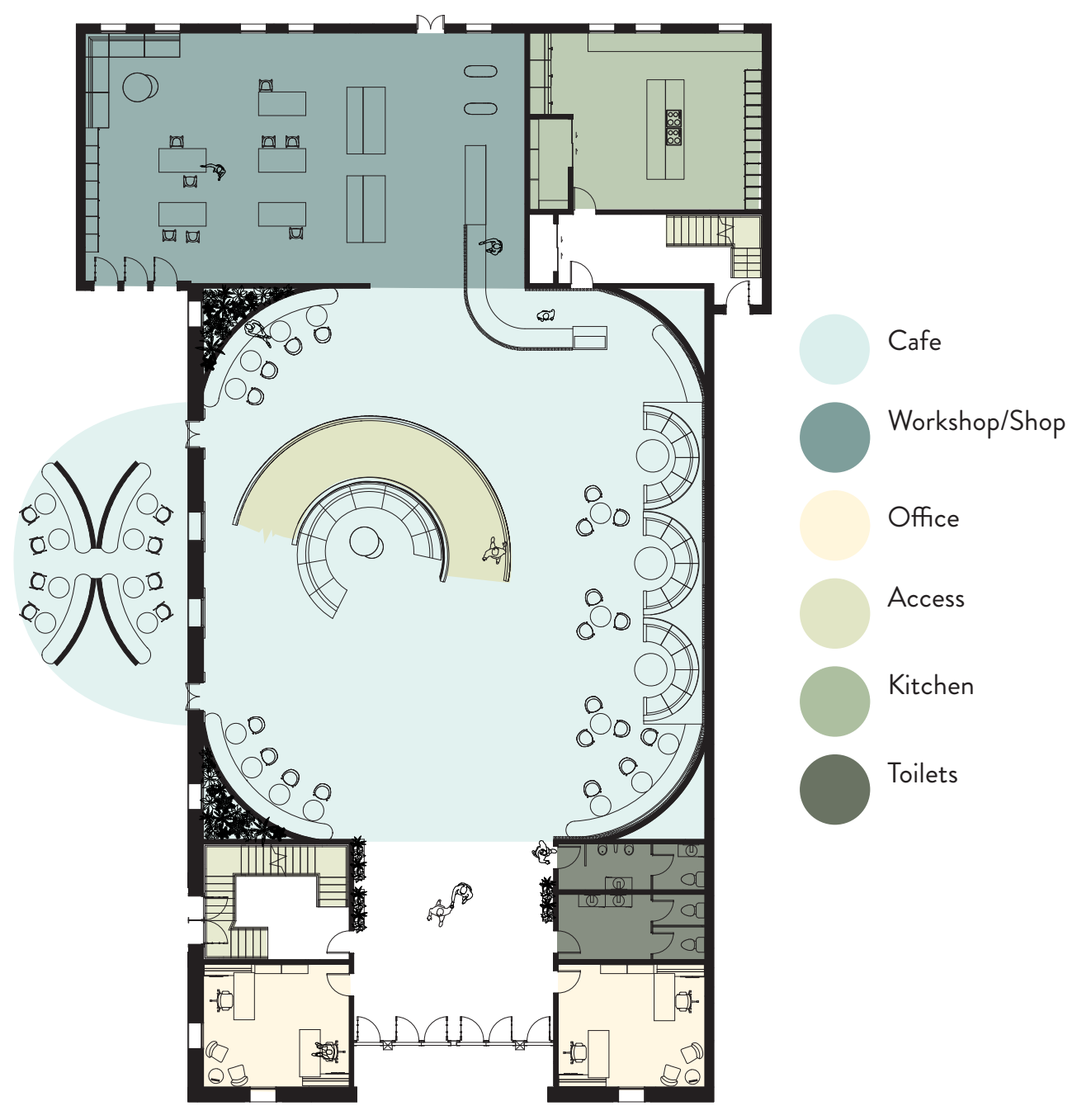




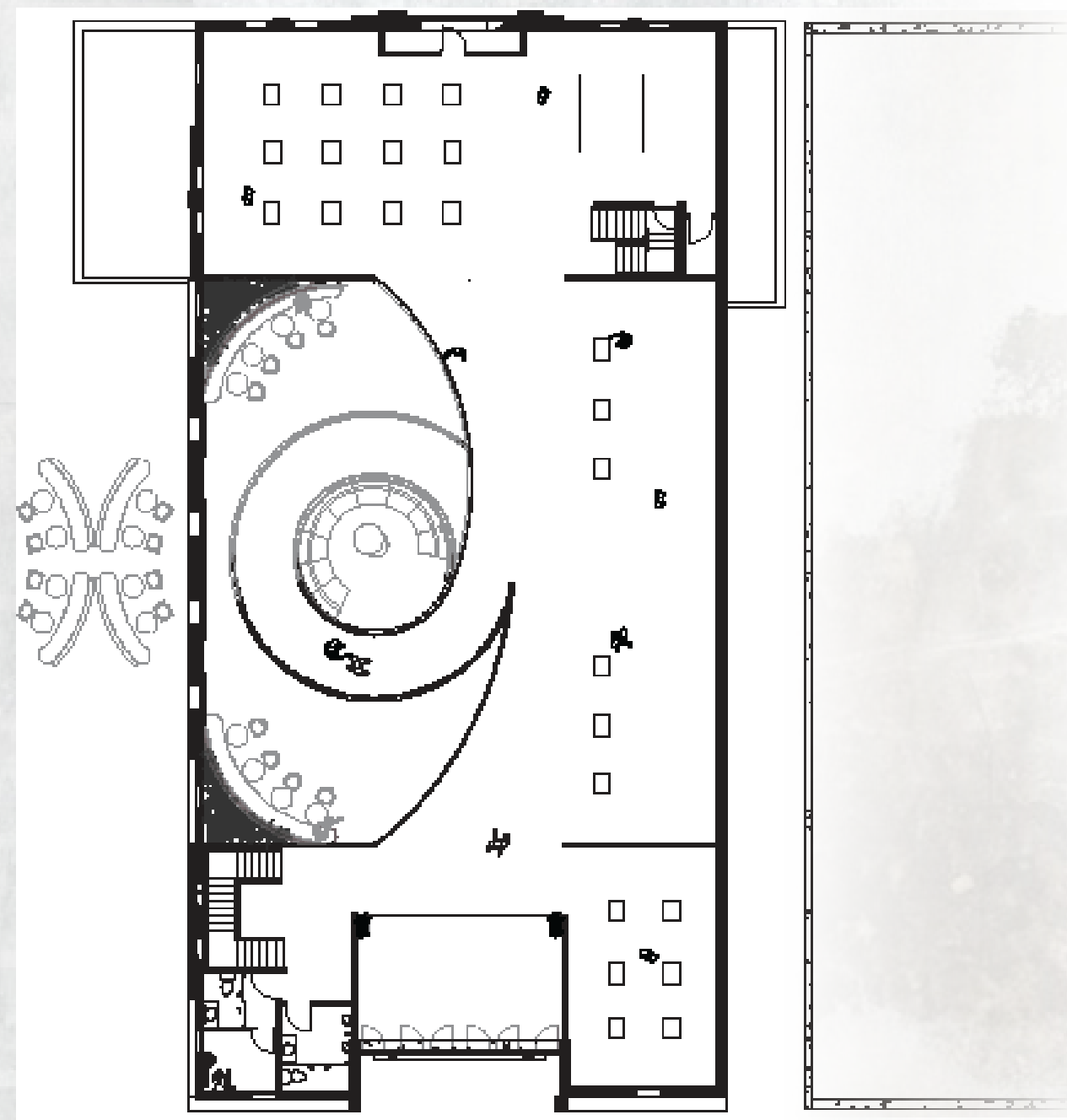




\section{FIRST FLOOR}

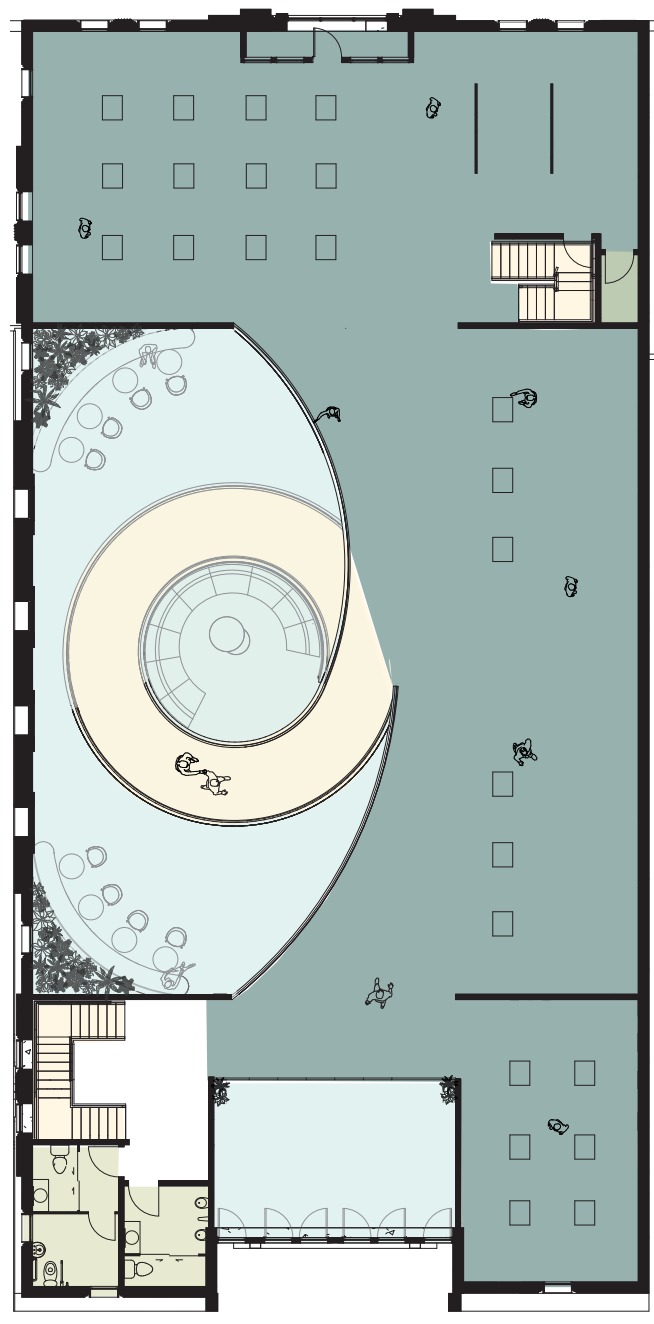



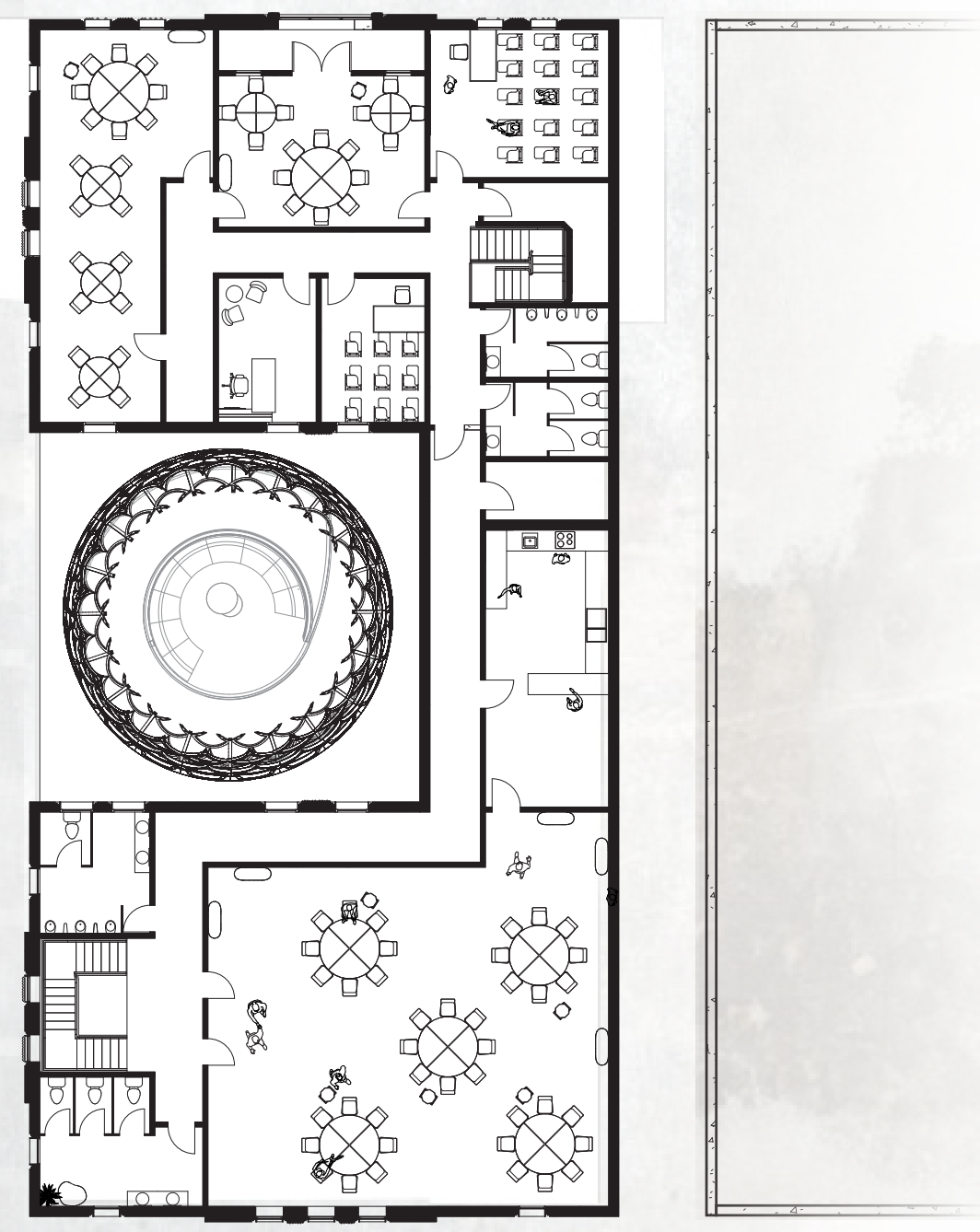

Figure.11.89: Second Floor 


\section{SECOND FLOOR}

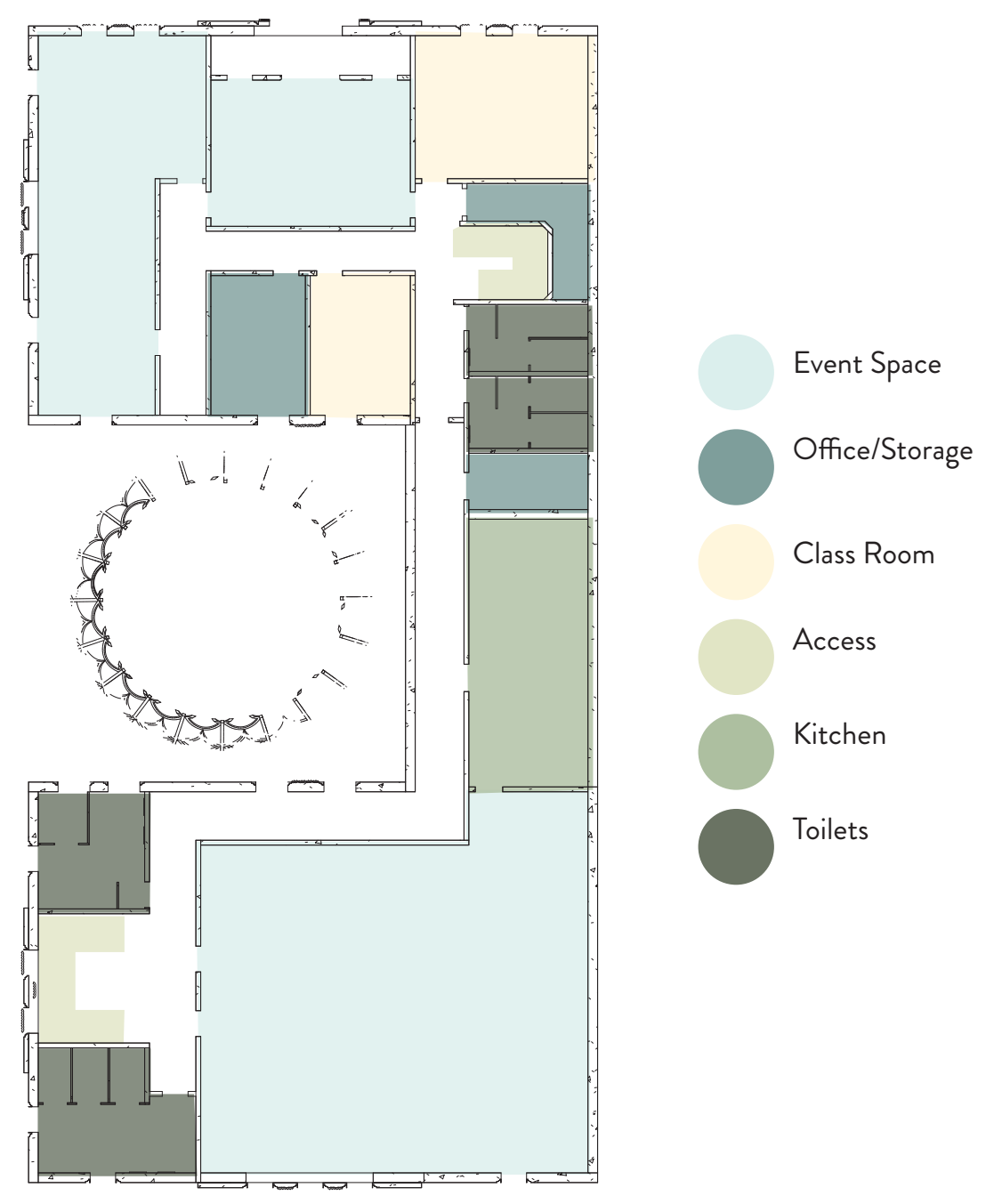




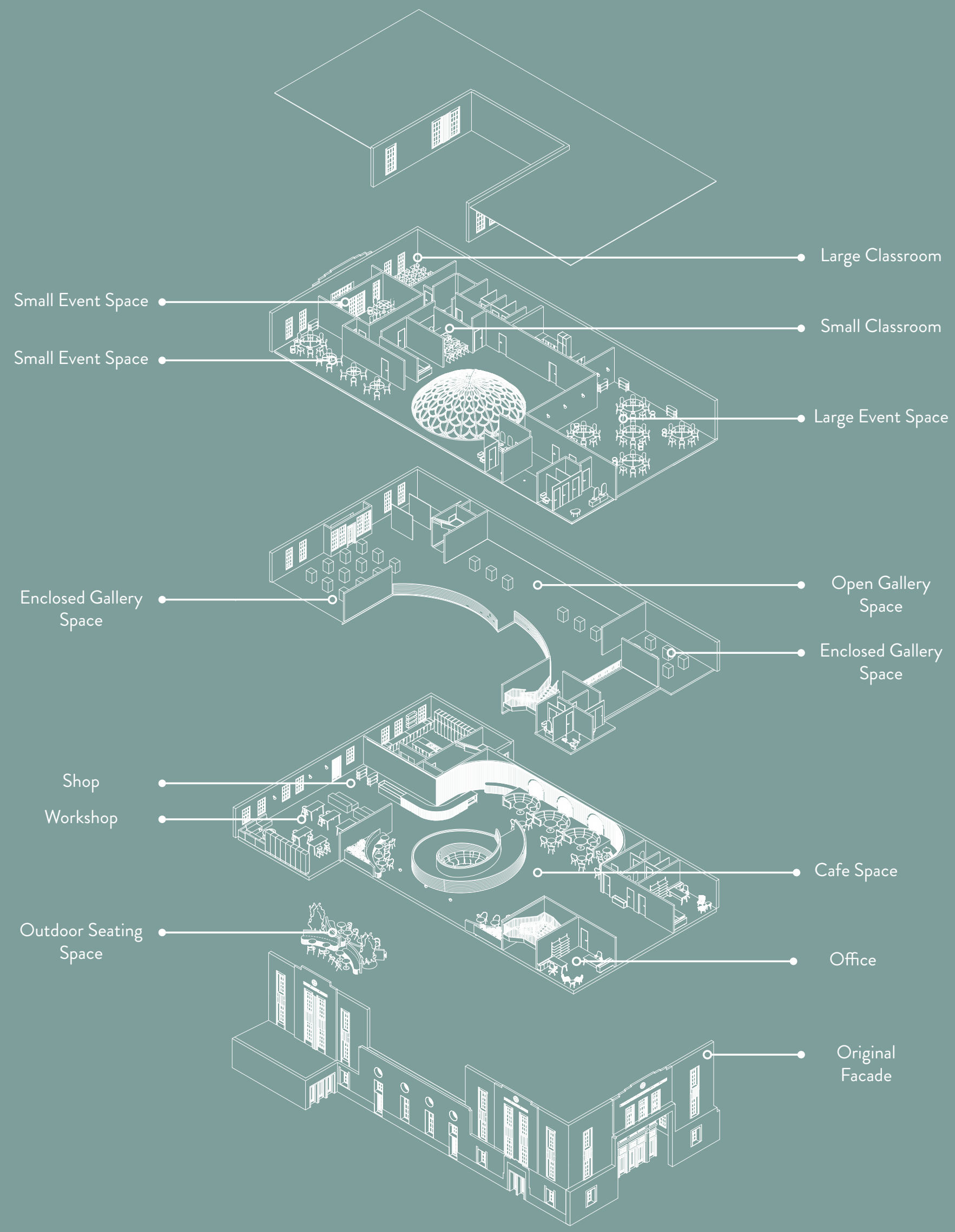

Figure.11.91: Function Axo 


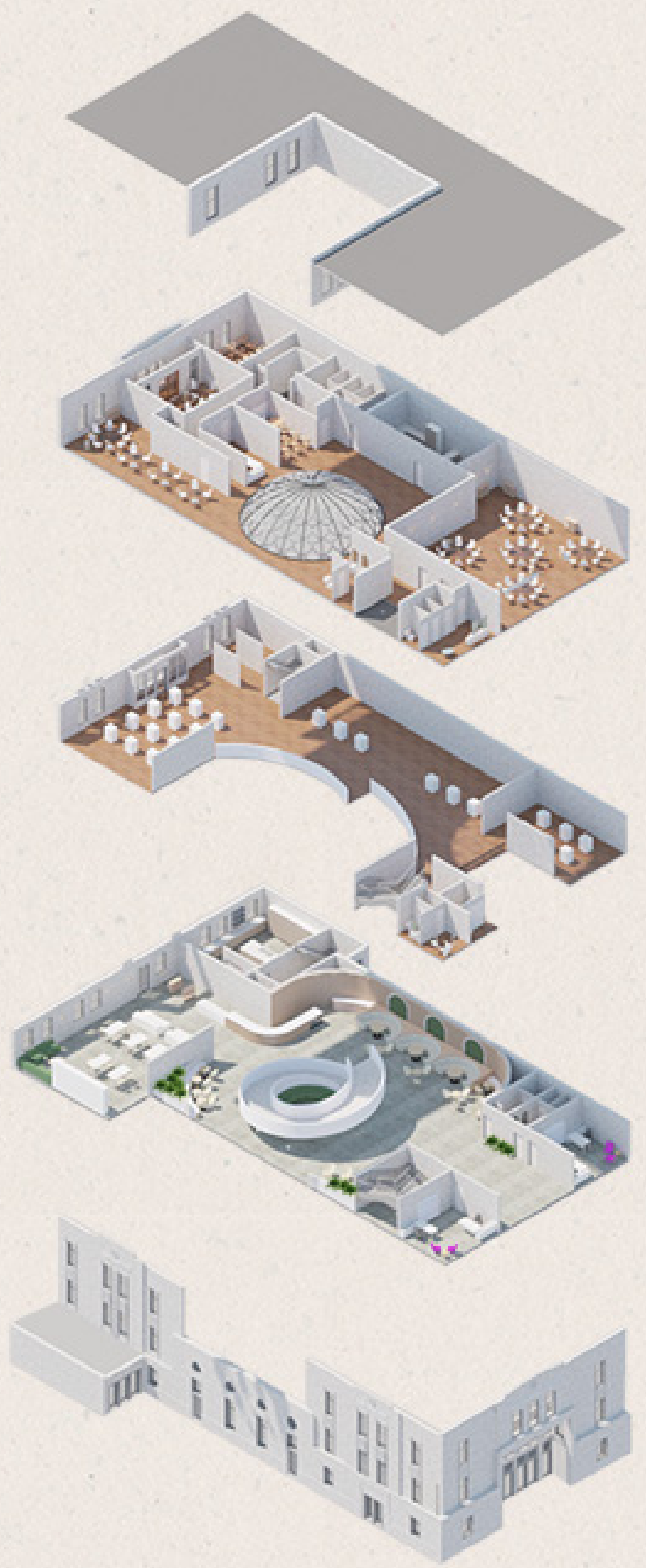

Figure.11.92: Material Axo 


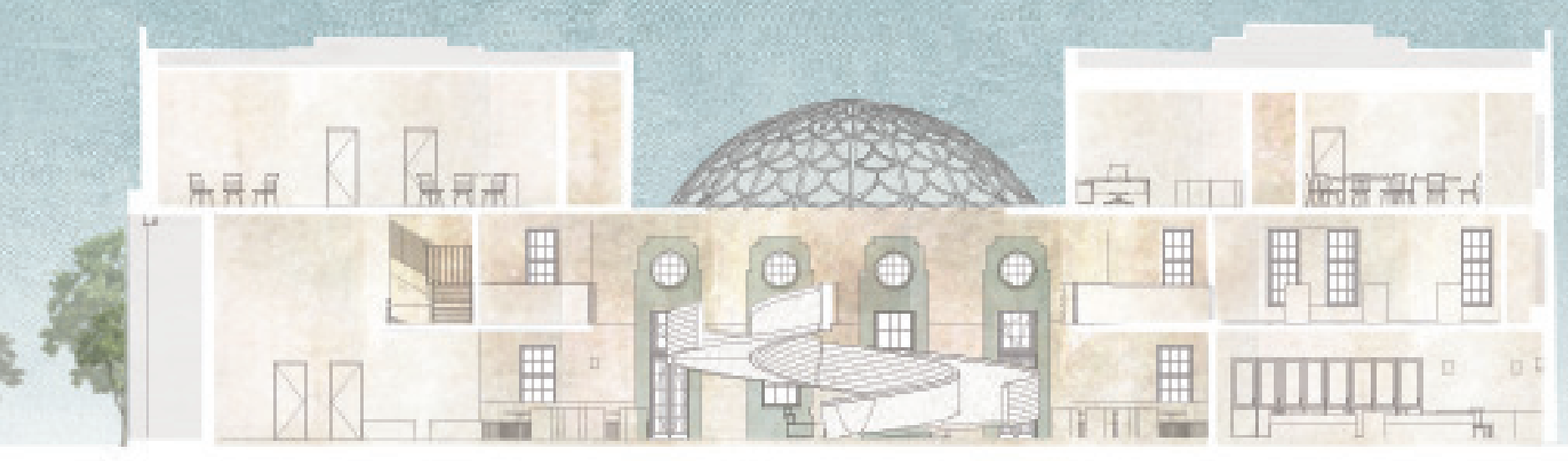





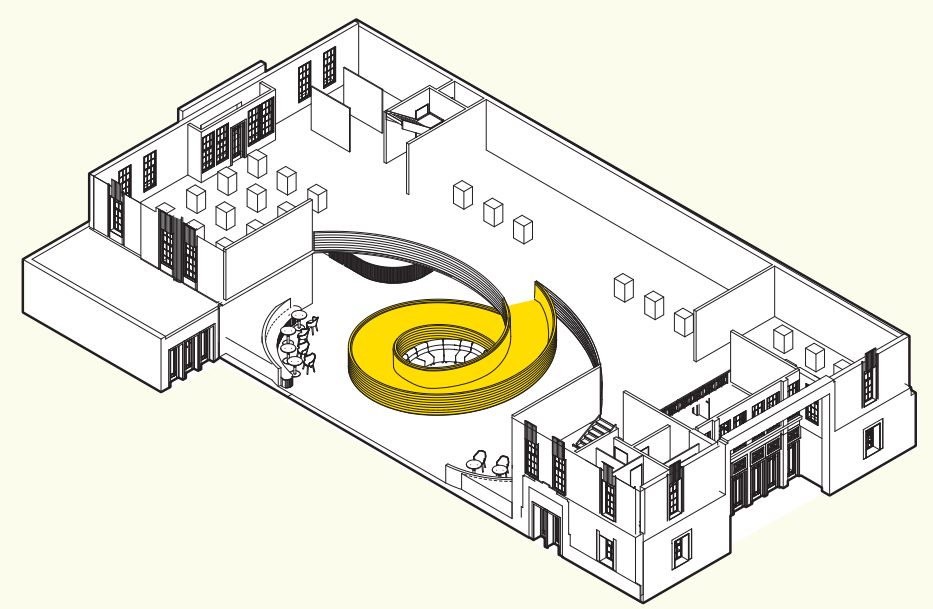

RAMP
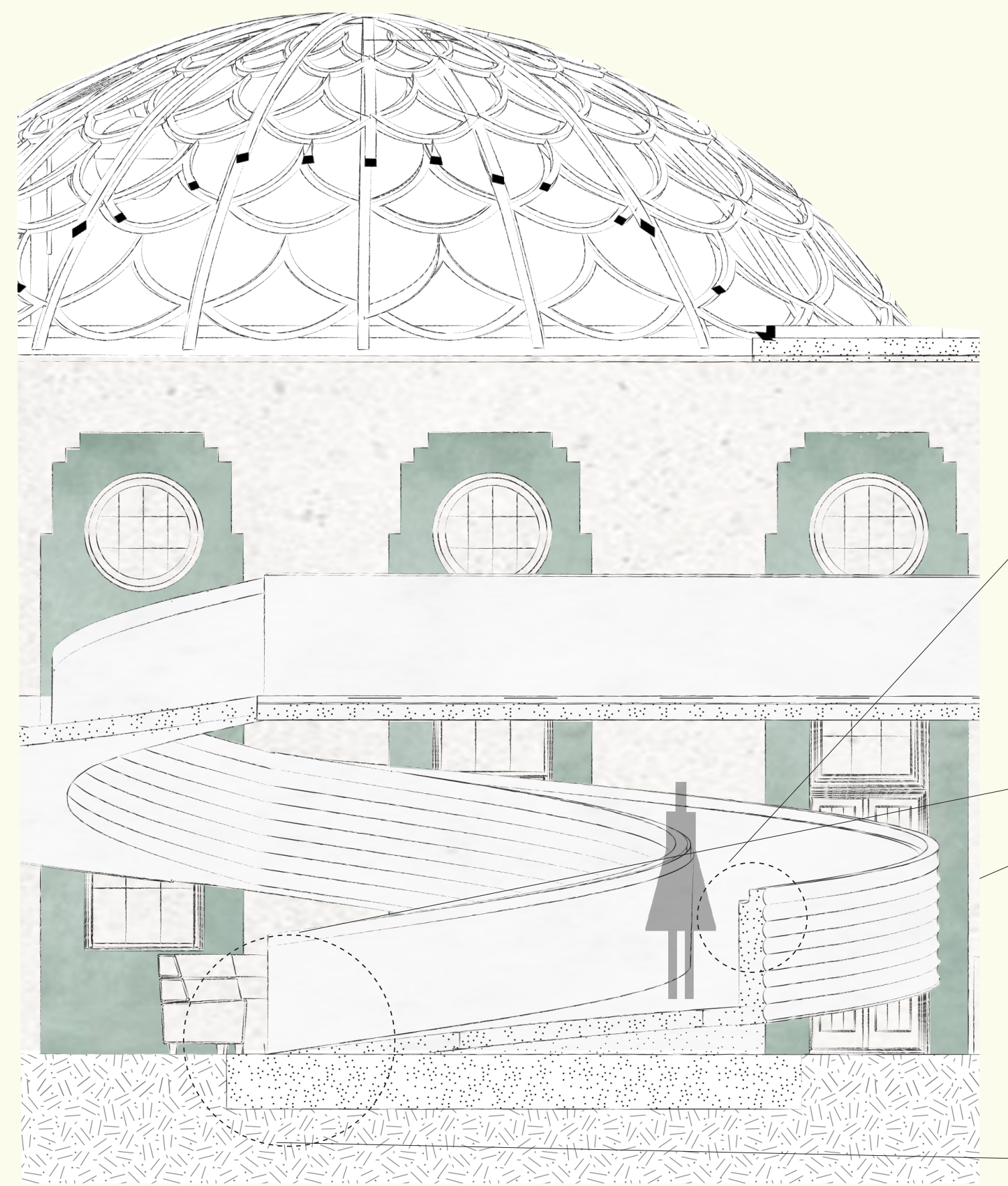

Figure.11.95: Sketch section of ramp 


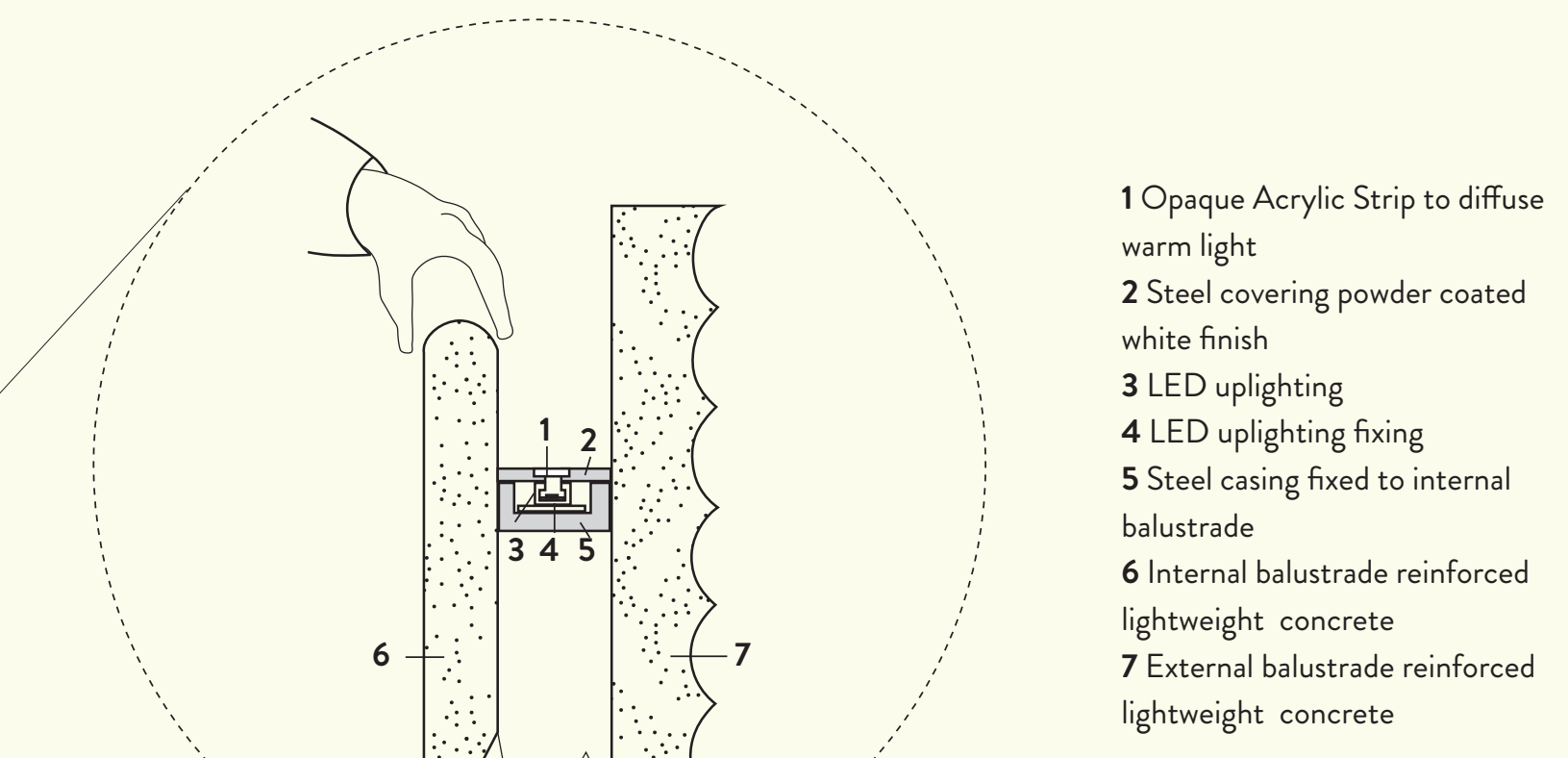

The ramp structure is anchored in order to resist torsion in a seismic event. It is also at a wheelchair friendly gradient to create an inclusive and accessible environment.

Detail 2 


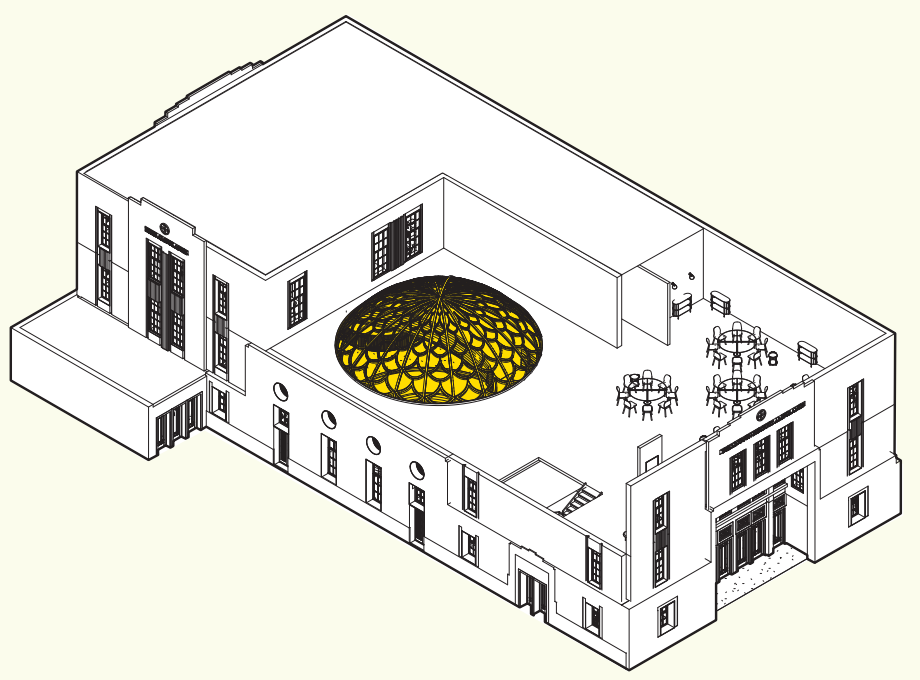

DOME
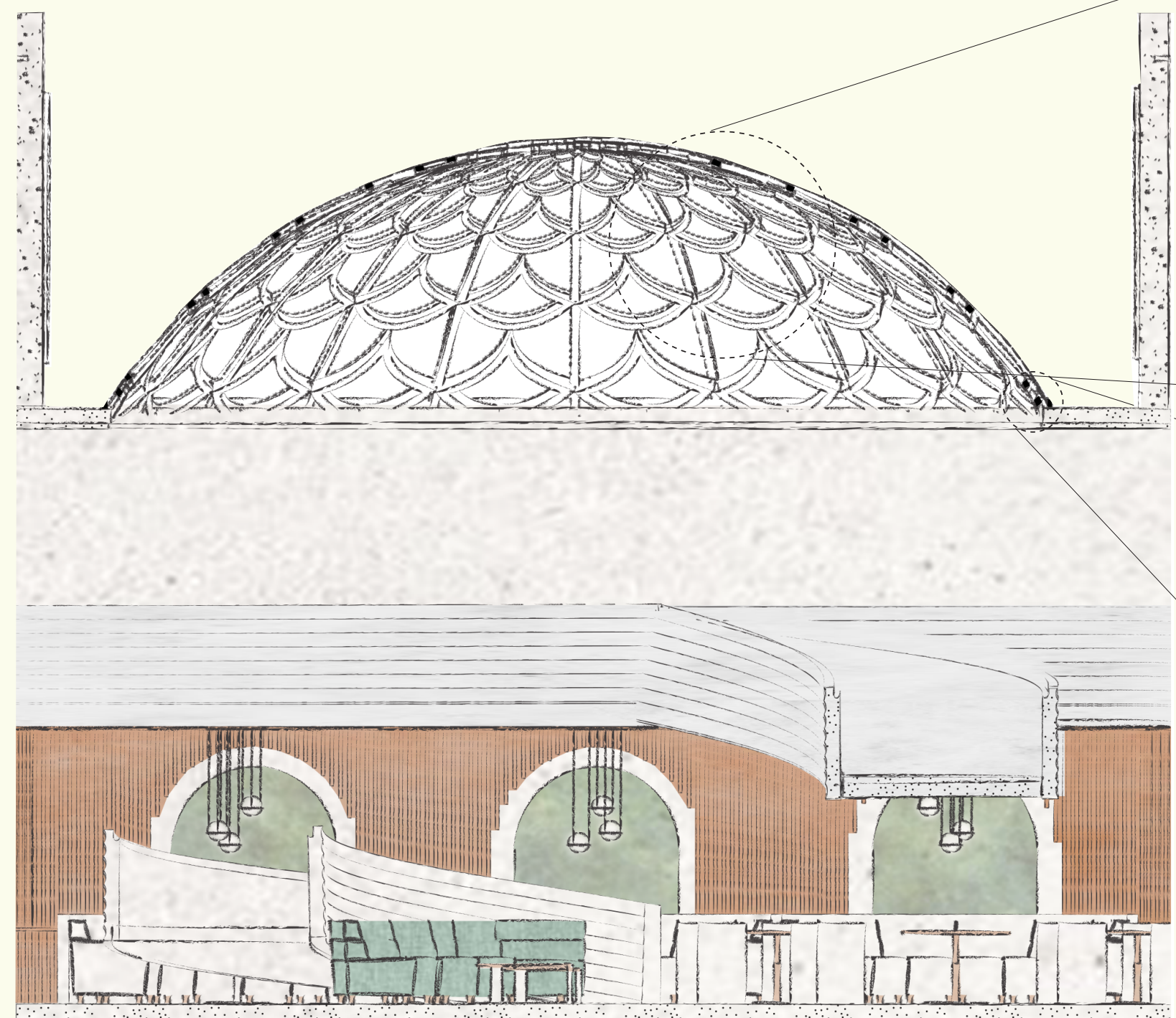

Figure.11.97: Sketch section of dome 
Detail 1

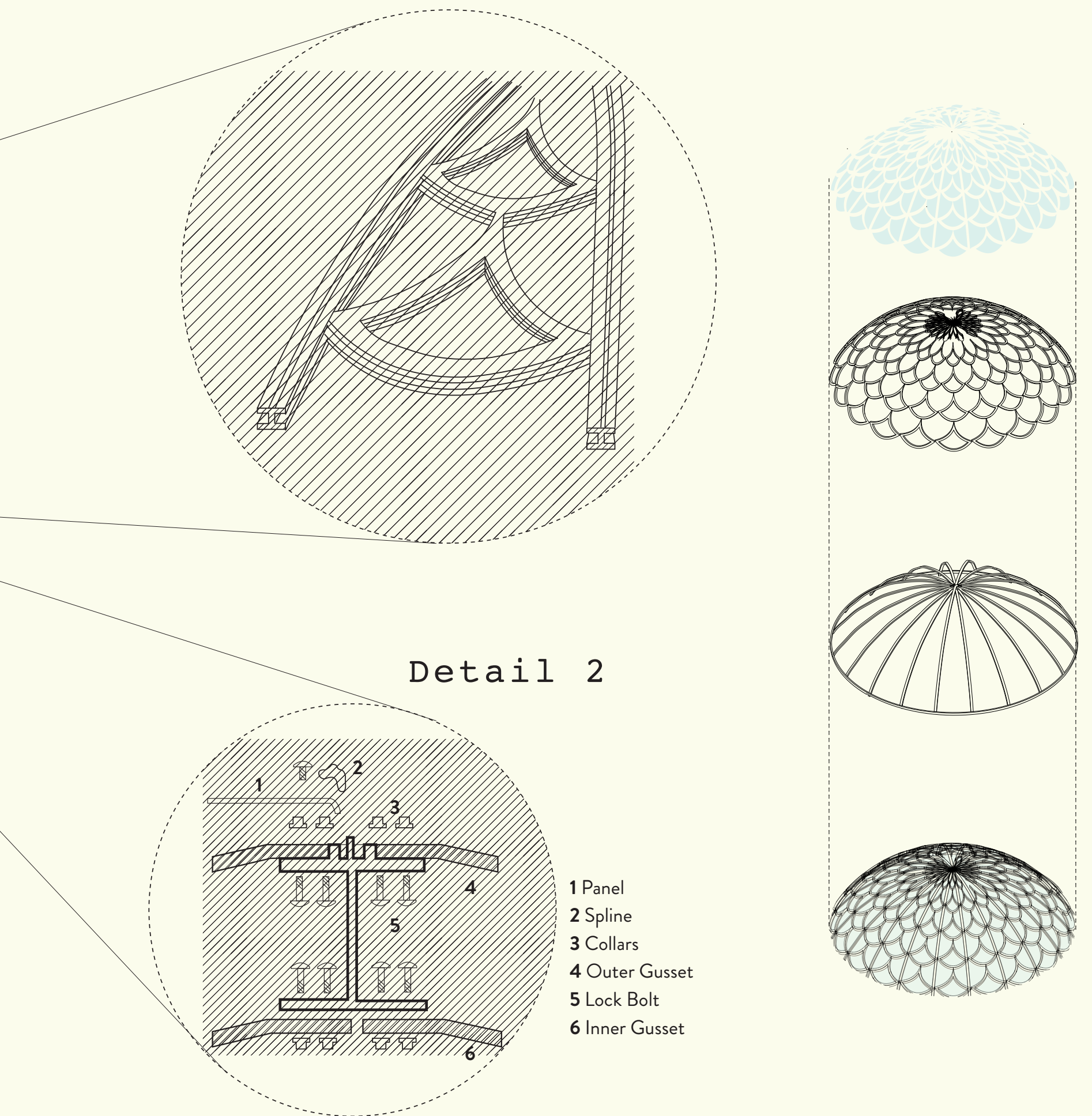

Figure.11.98: Dome details 


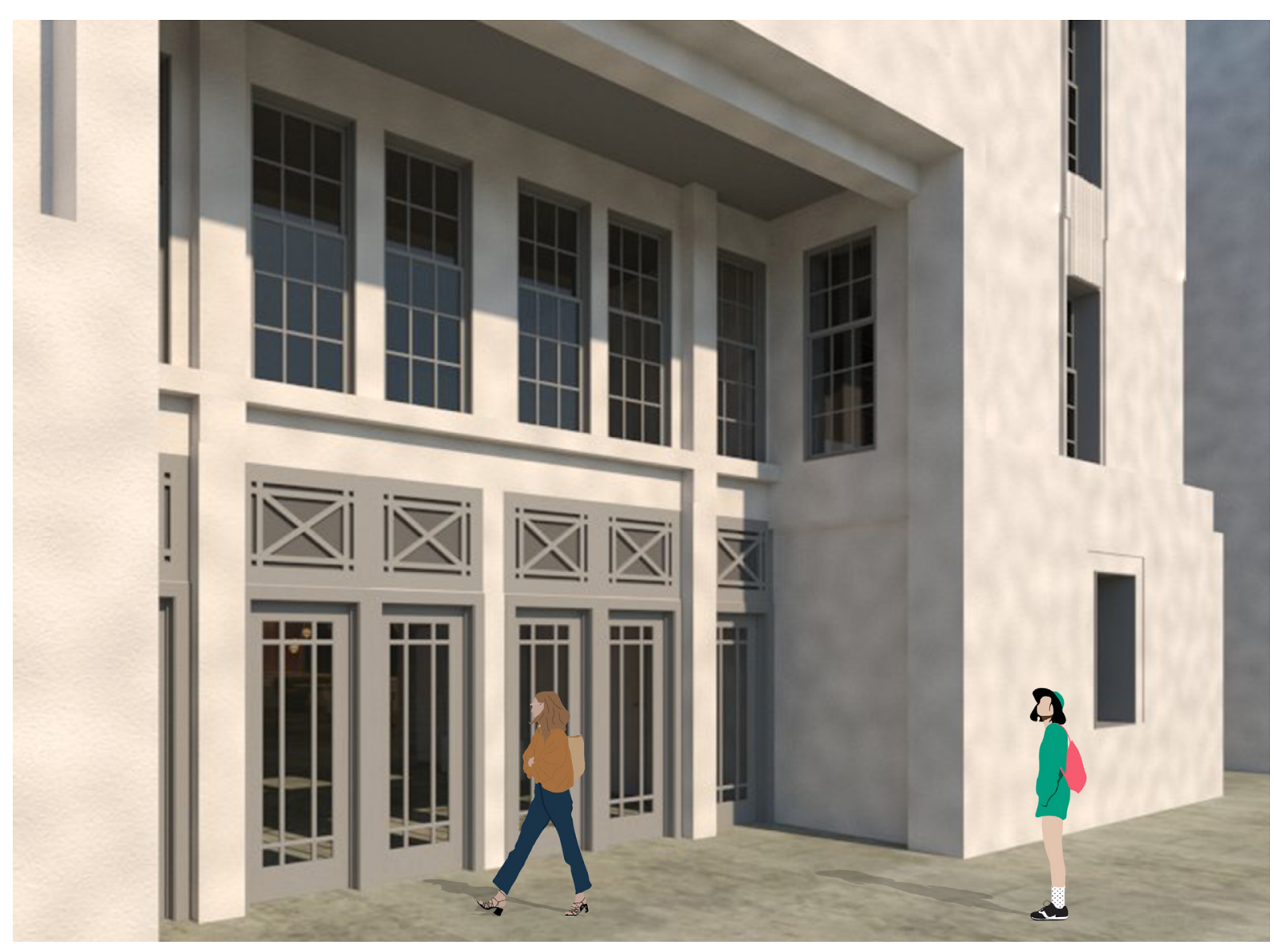

Figure.11.99: Main entrance to the Free Ambulance Building 


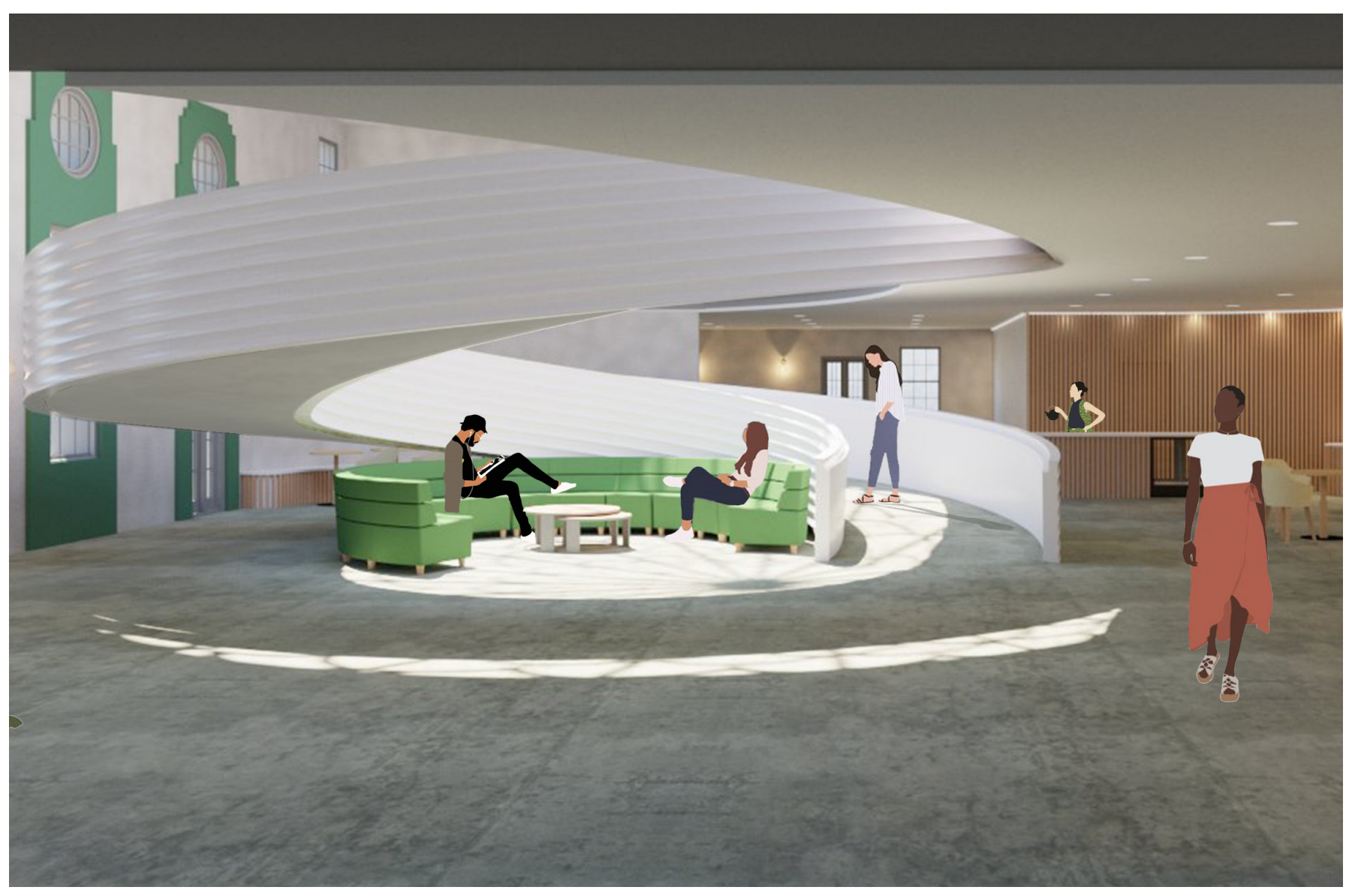

Figure.11.100: Cafe space 


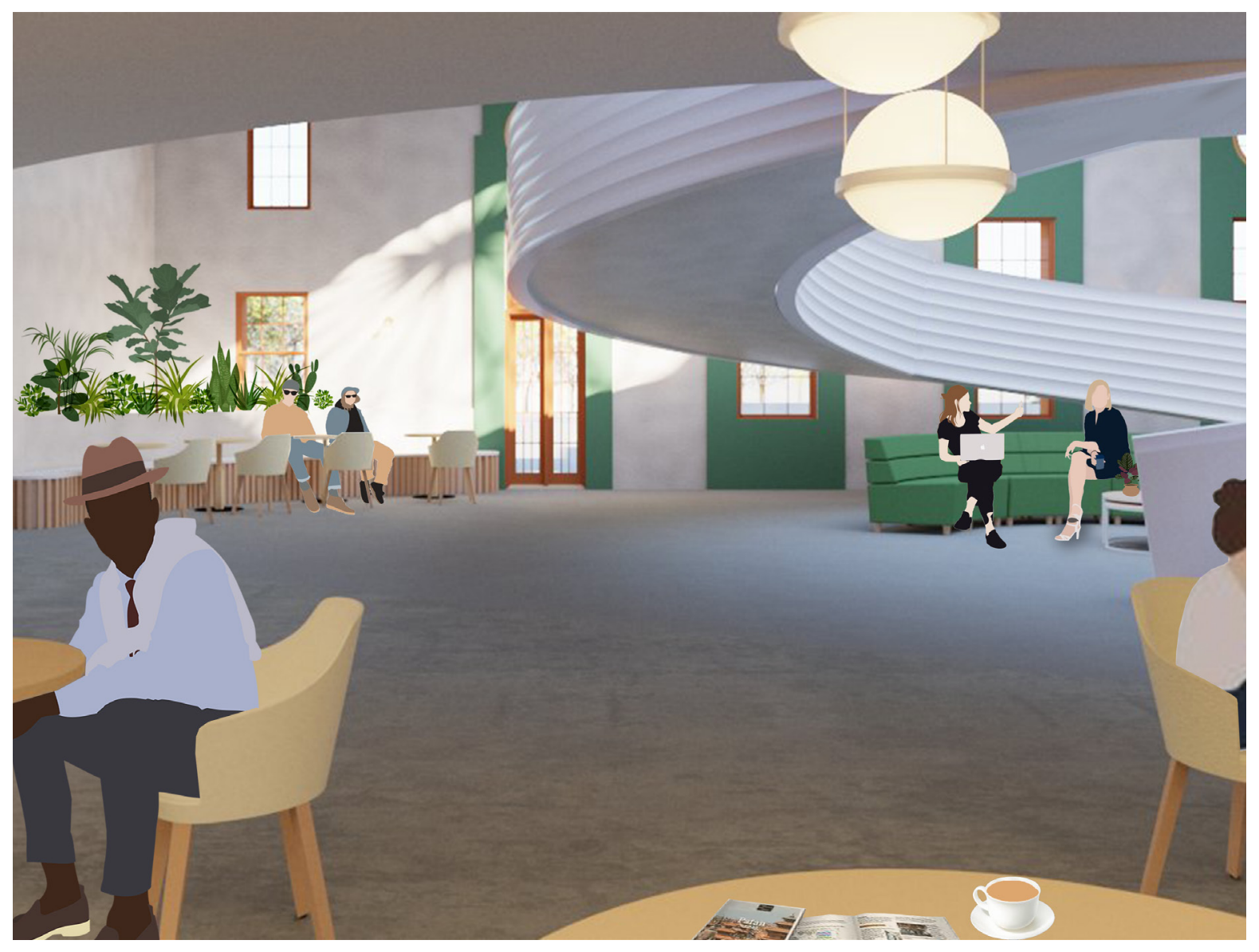

Figure.11.101: View from booth seats 


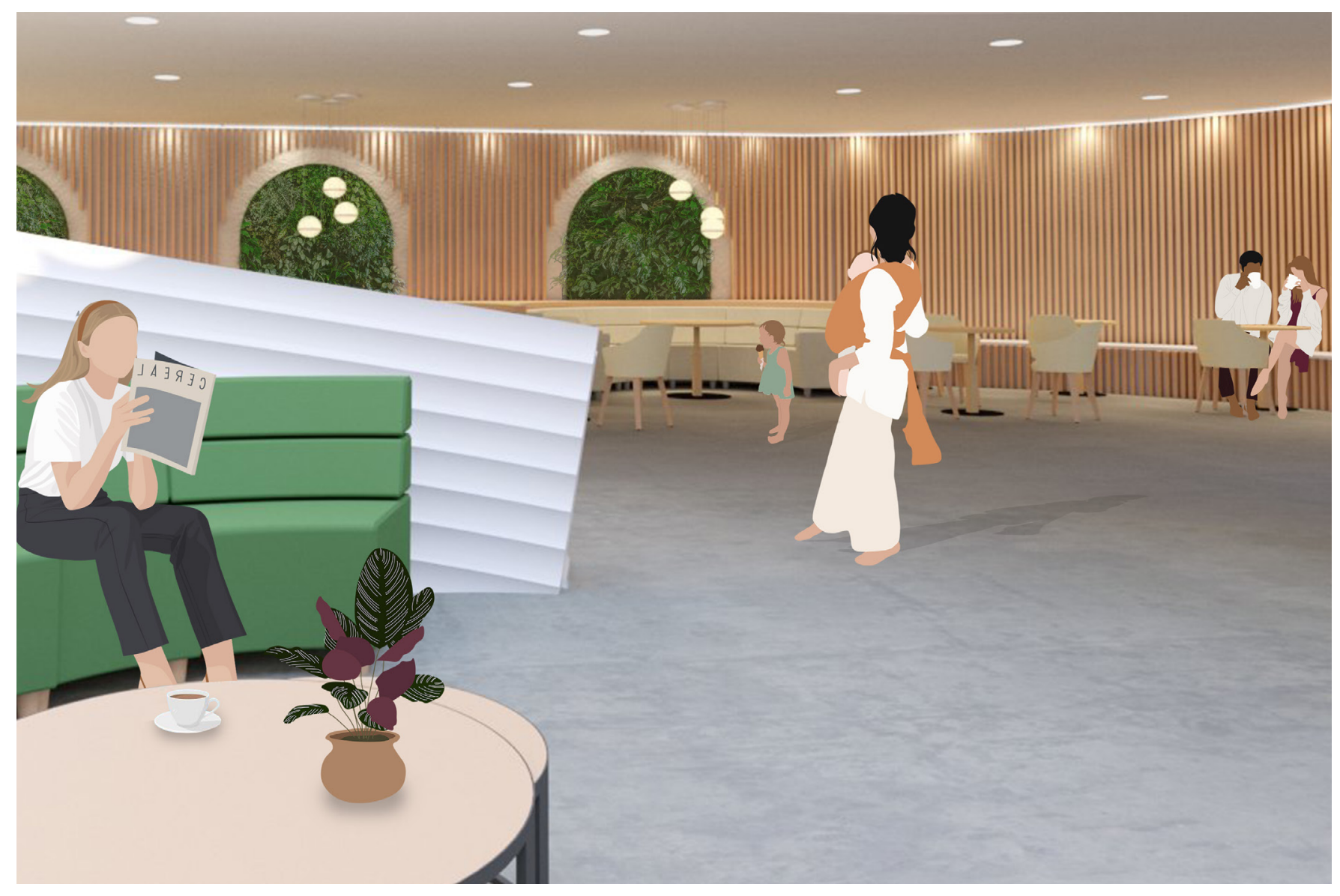

Figure.11.102: View from inside ramp seating 


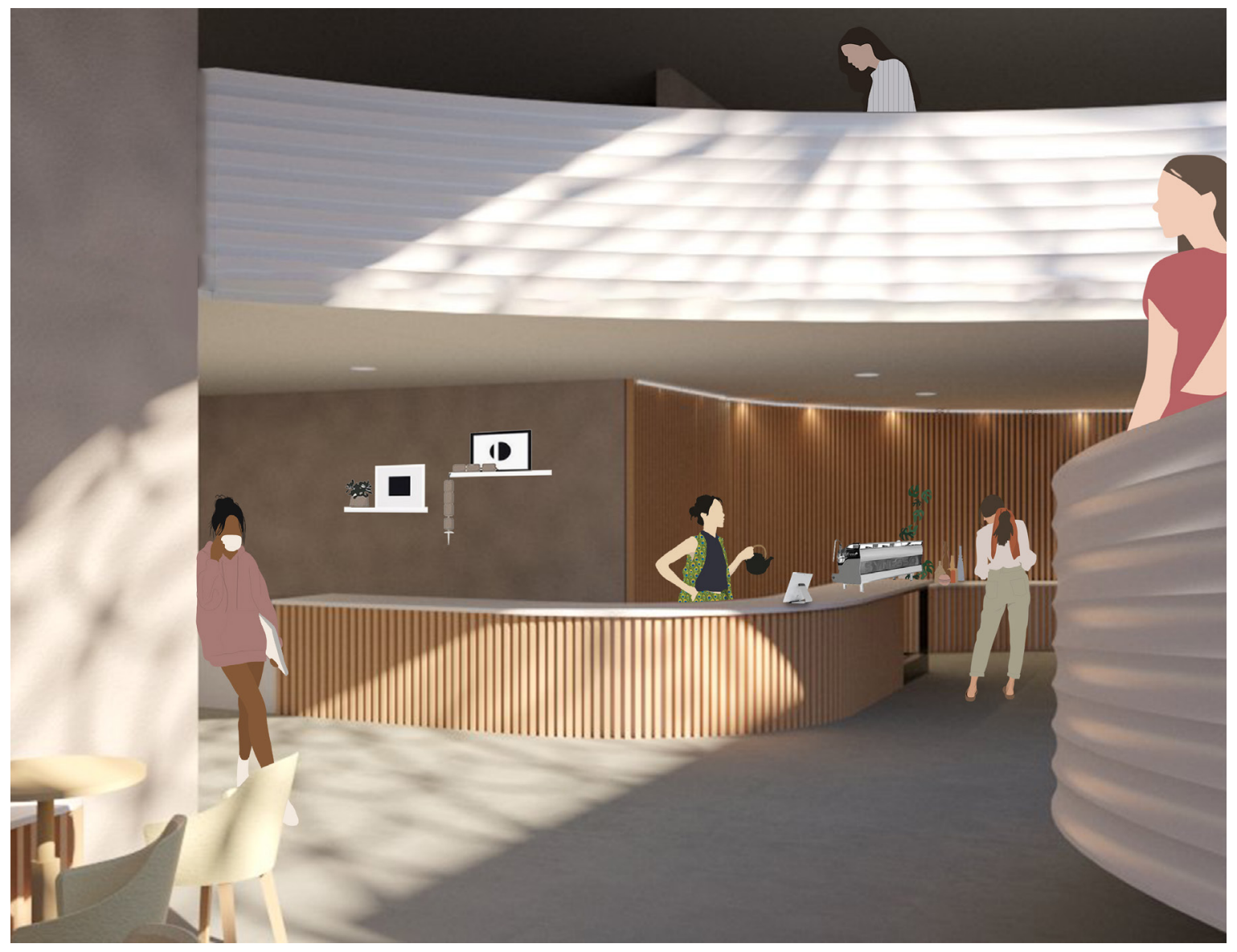

Figure.11.103: Cafe counter 


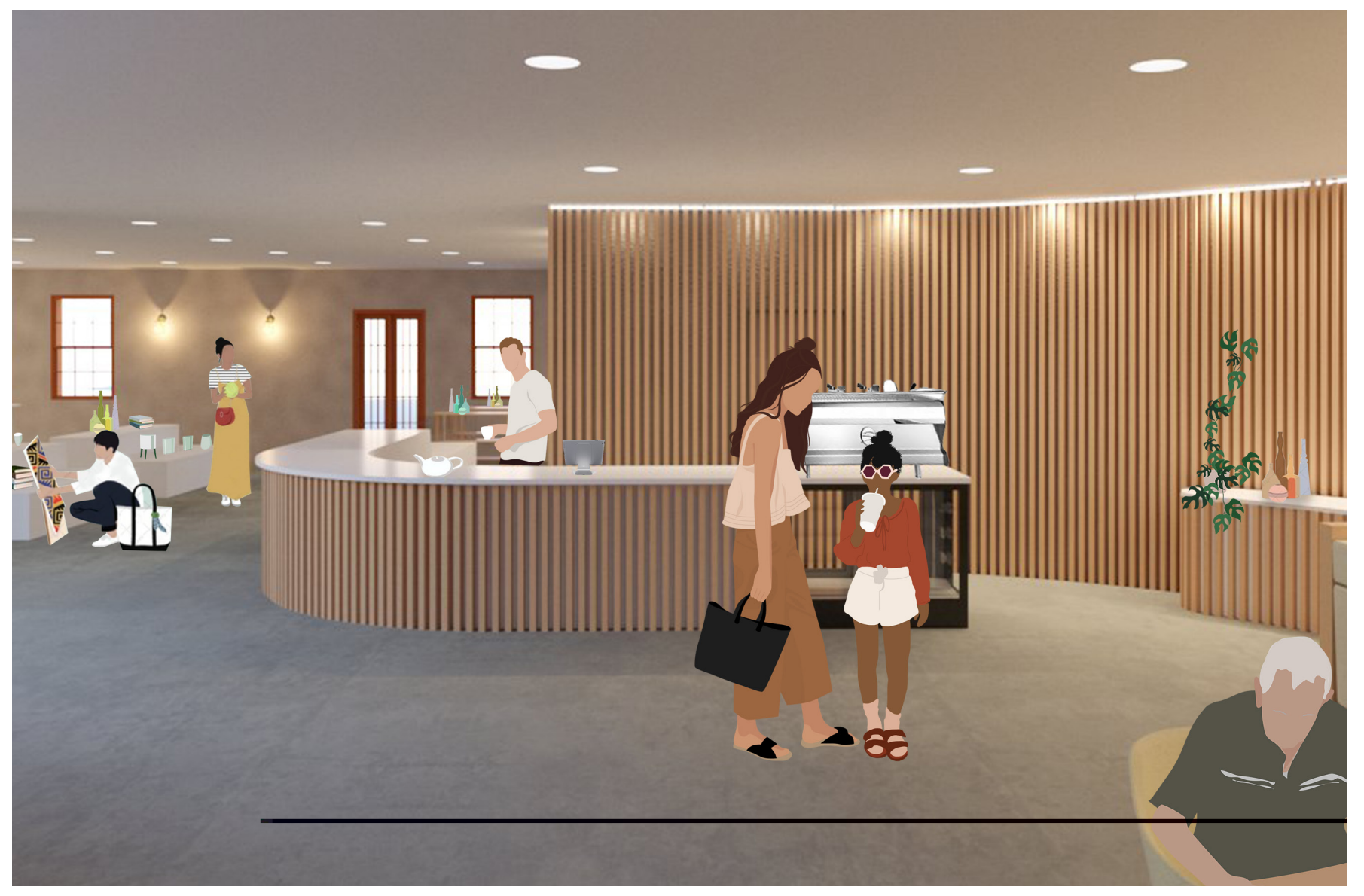

Figure.11.104: Cafe counter and shop 


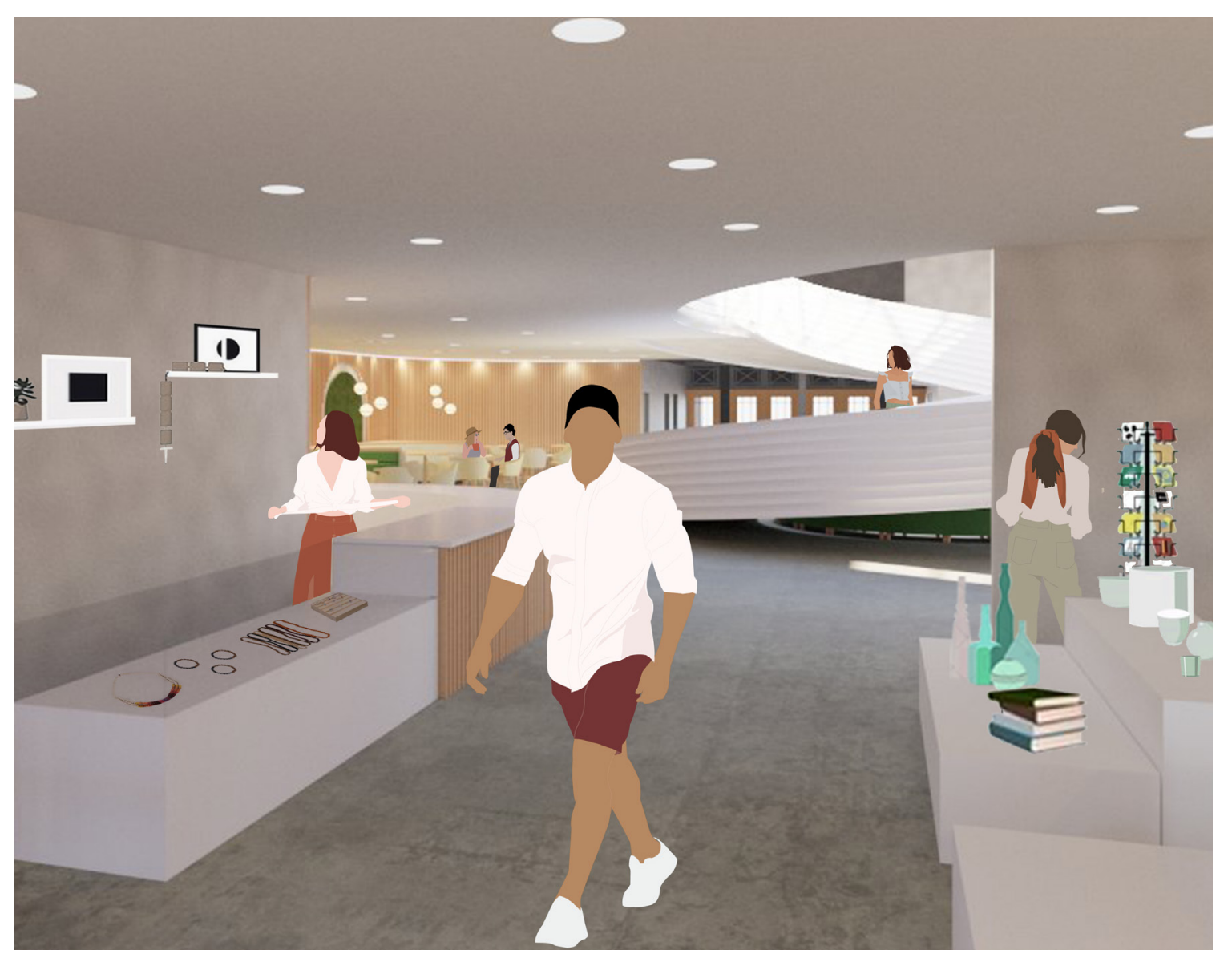

Figure.11.105: Shop and cafe view 


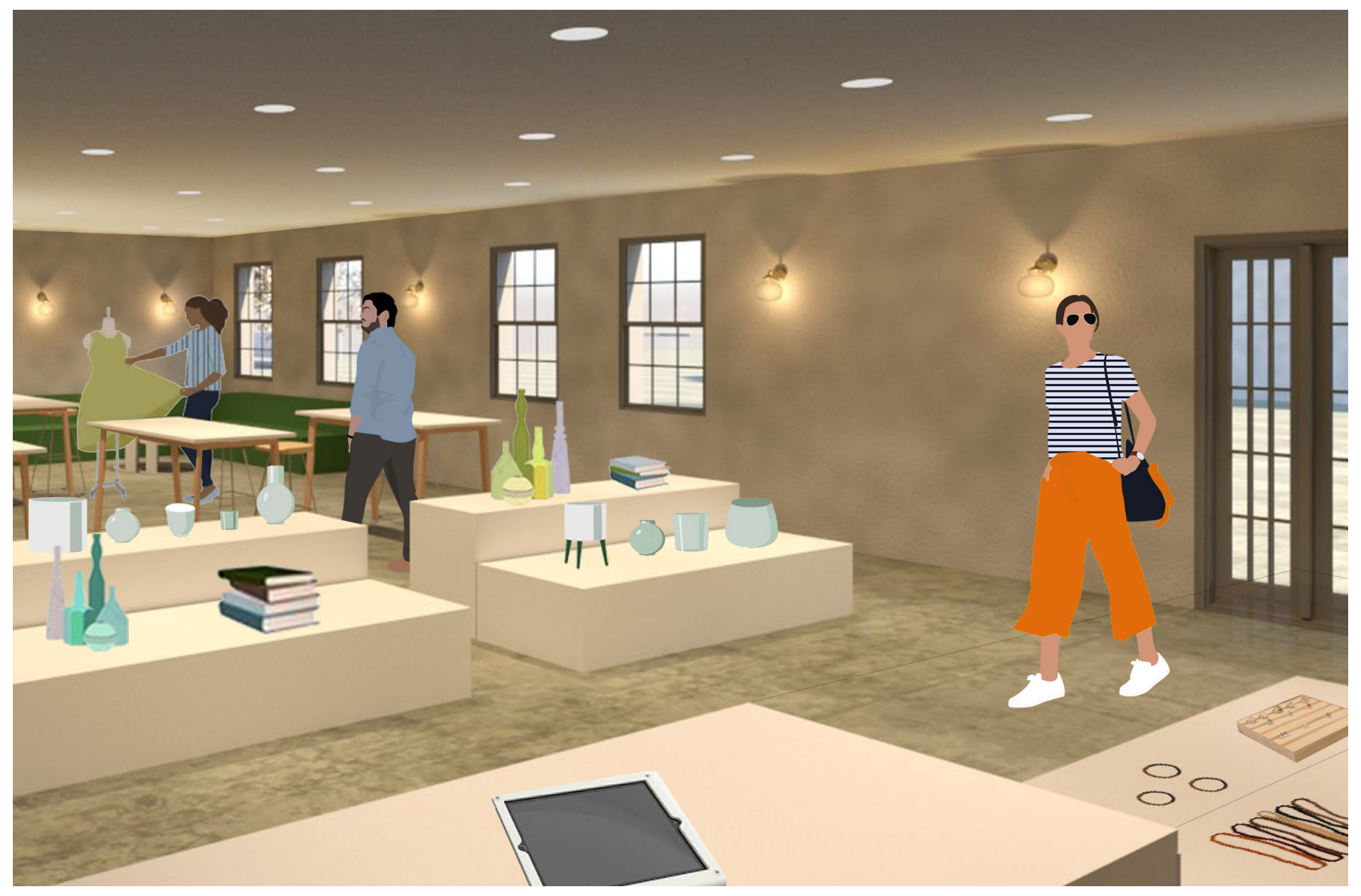

Figure.11.106: Shop and workshop space 


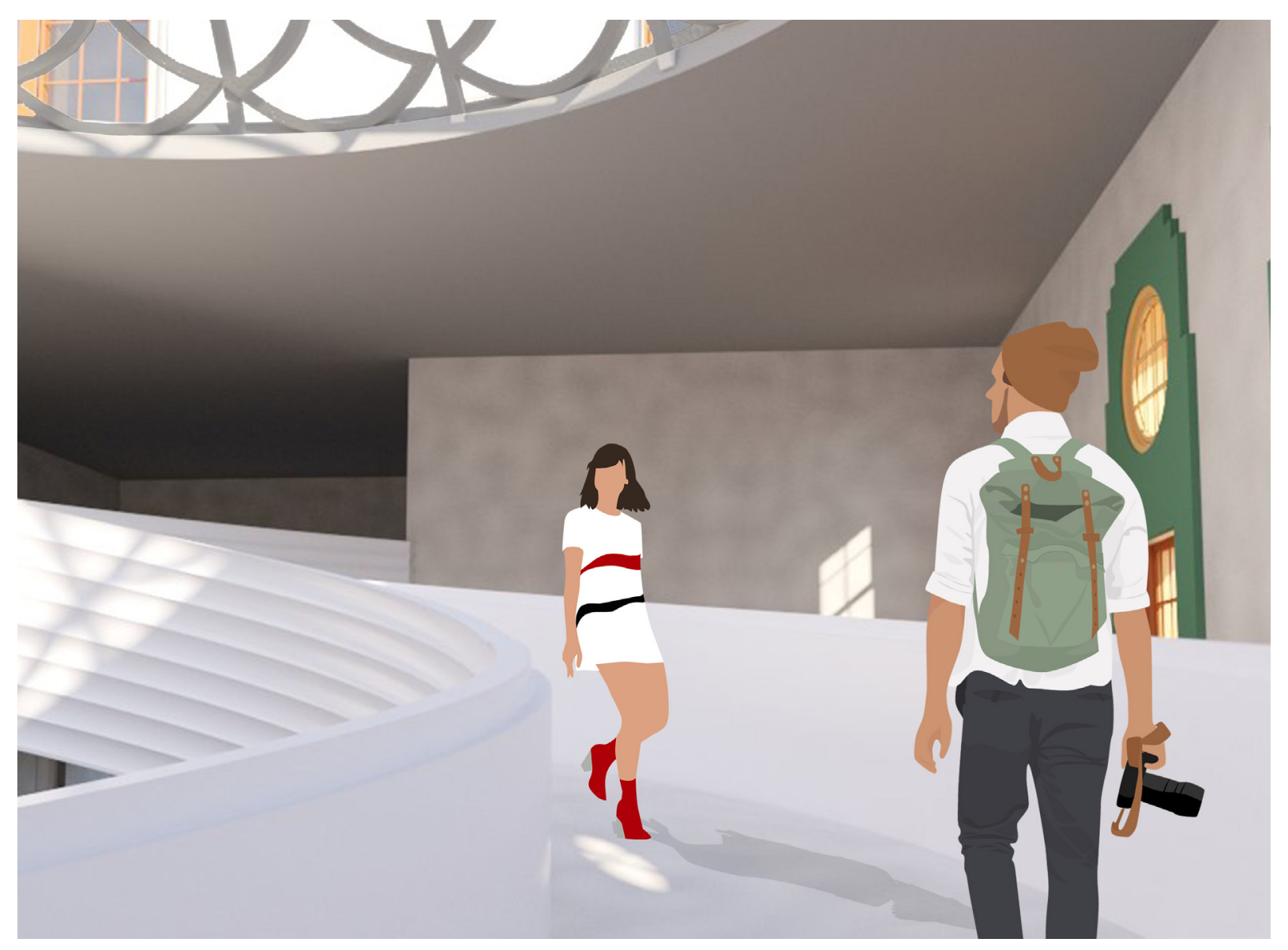

Figure.11.107: Ascending ramp 


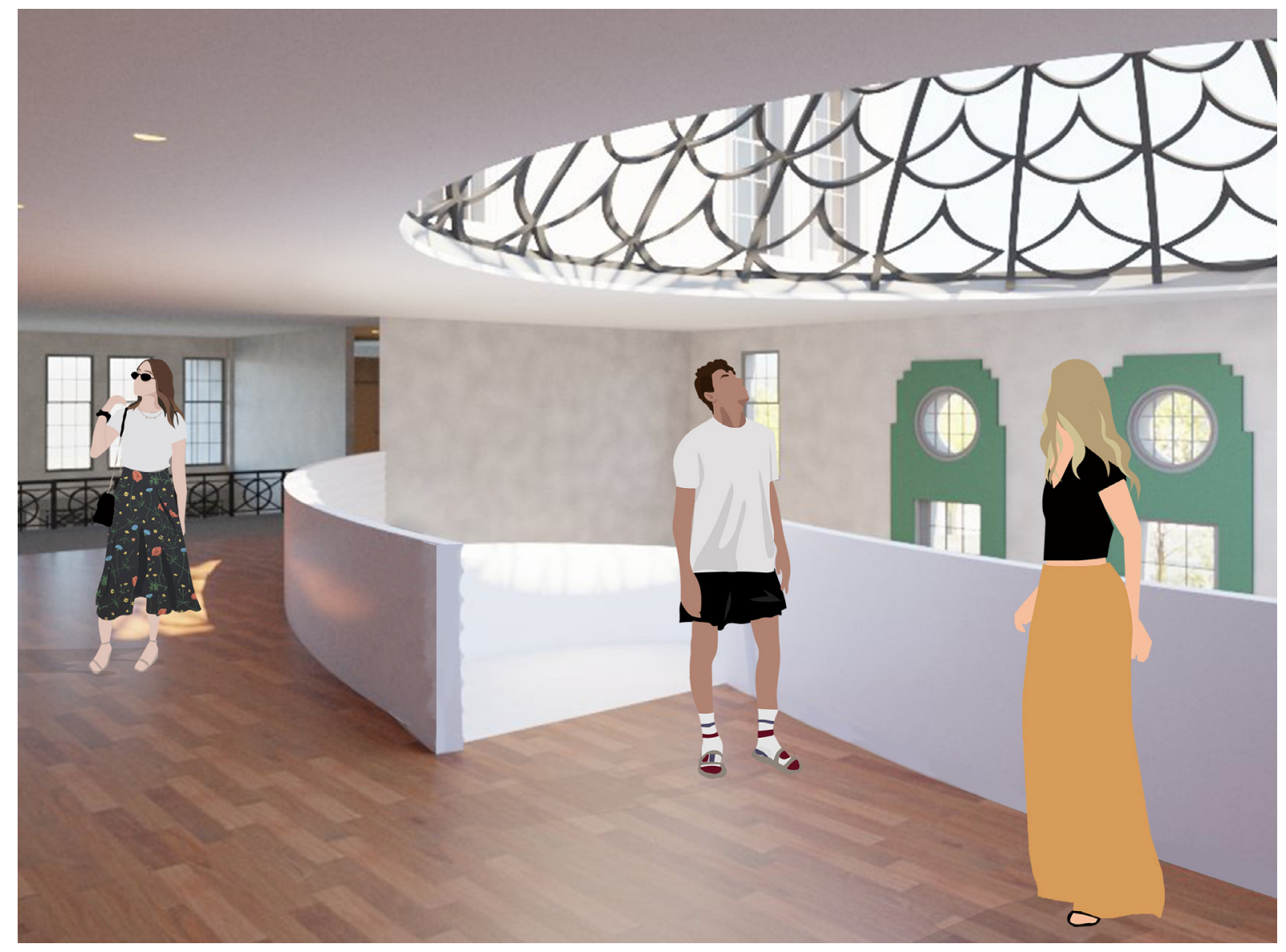

Figure.11.108: Top of ramp and view of dome 


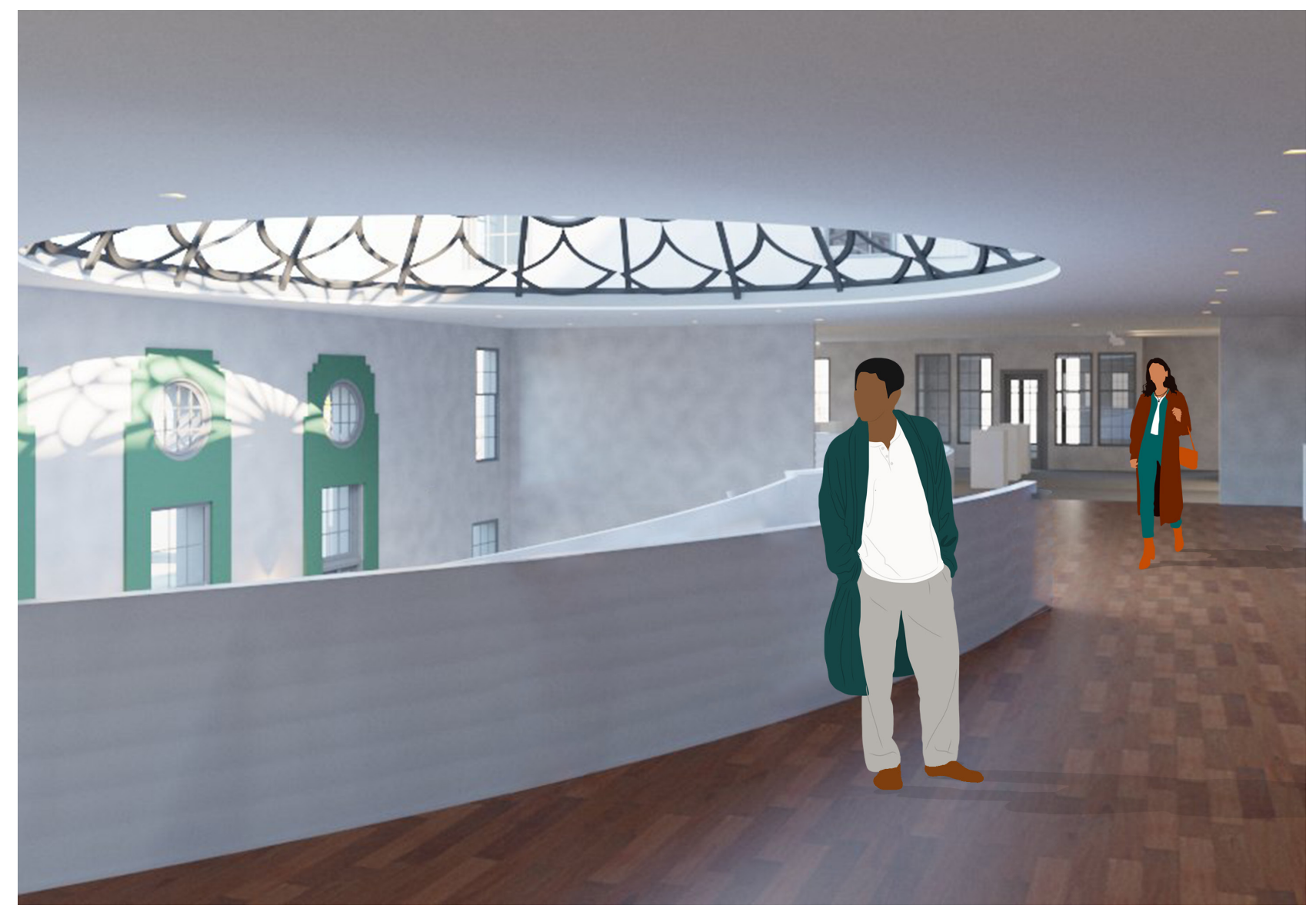

Figure.11.109: View of dome from first floor 


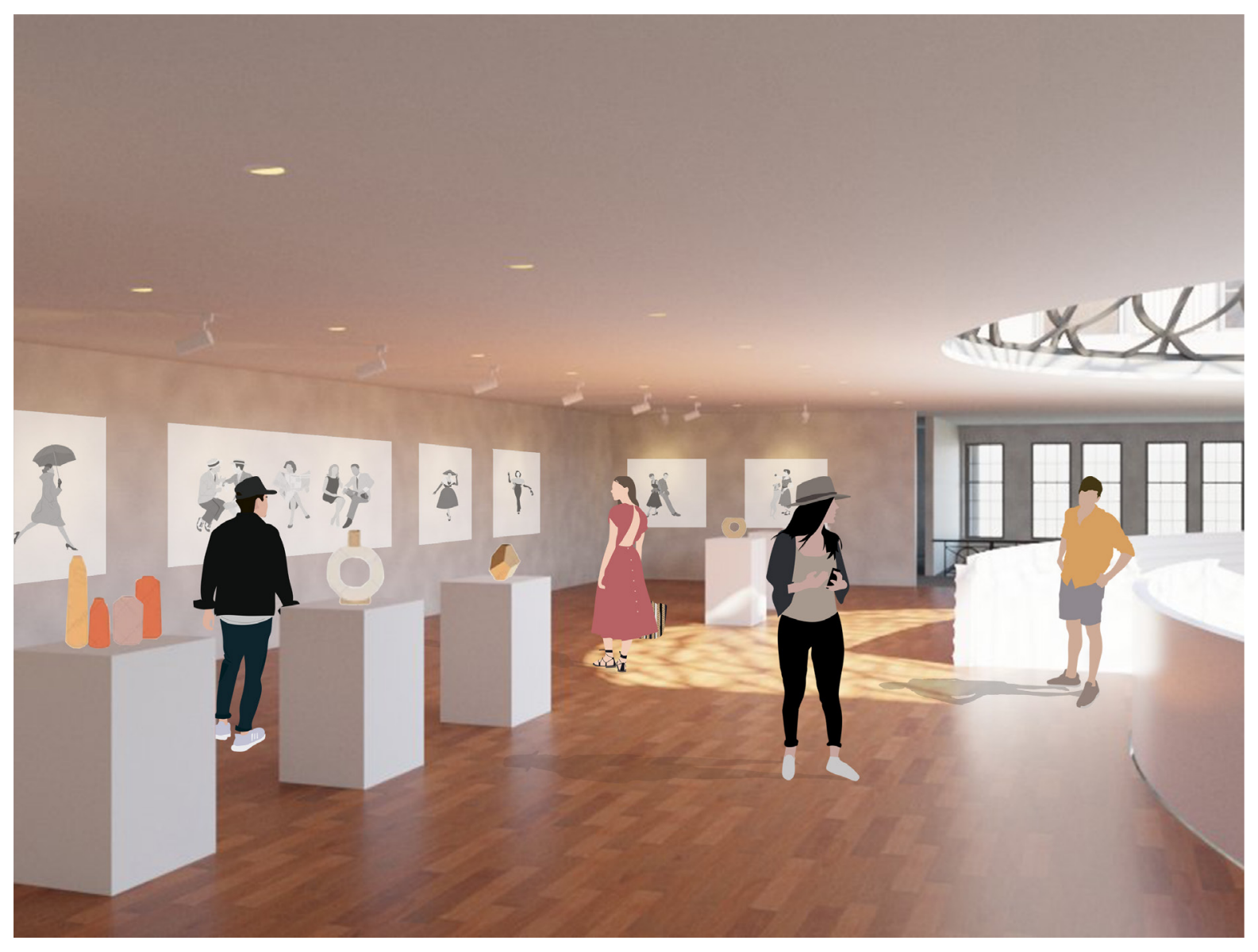

Figure.11.110: Open gallery space 


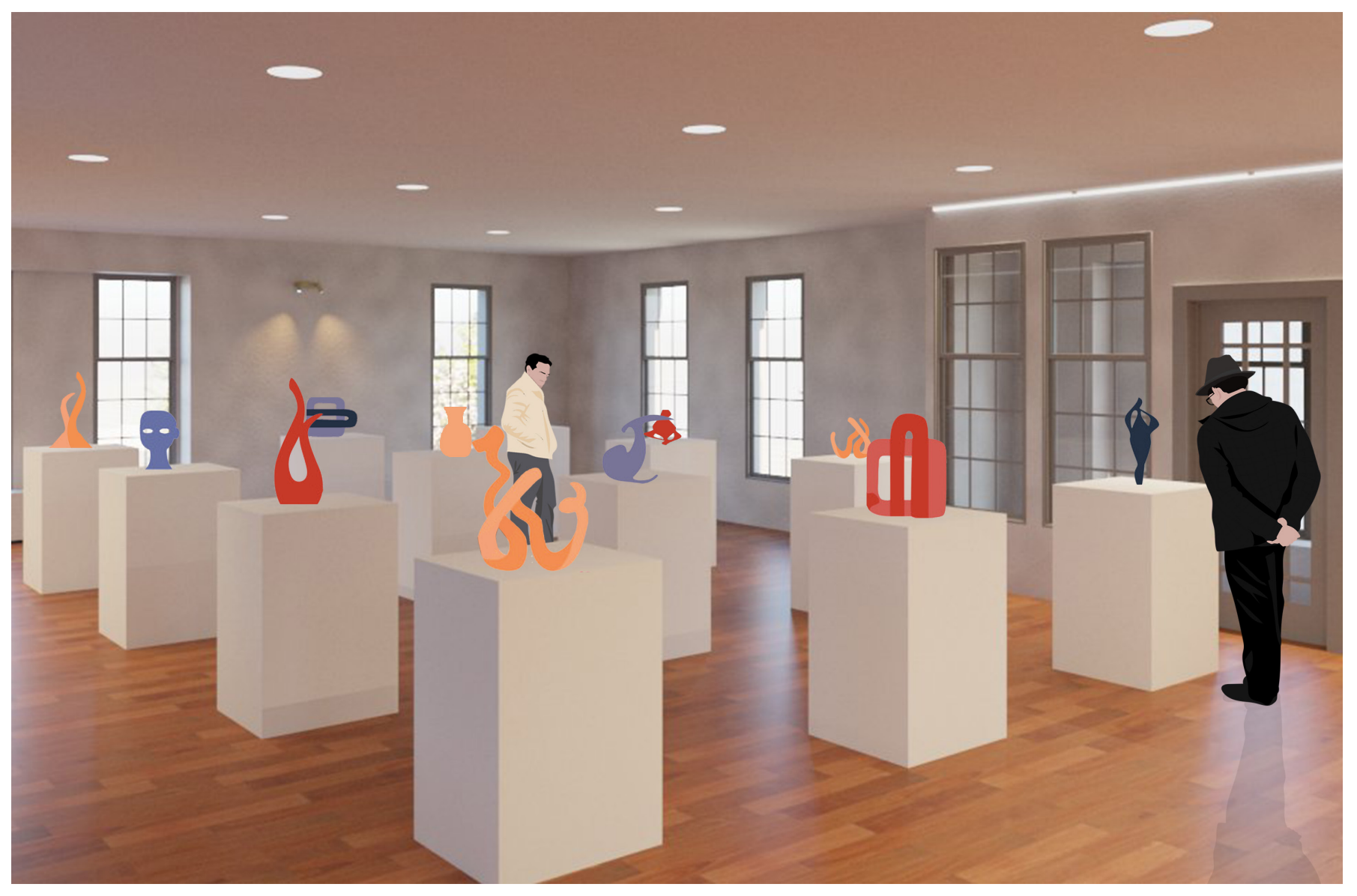

Figure.11.111: Enclosed gallery space 


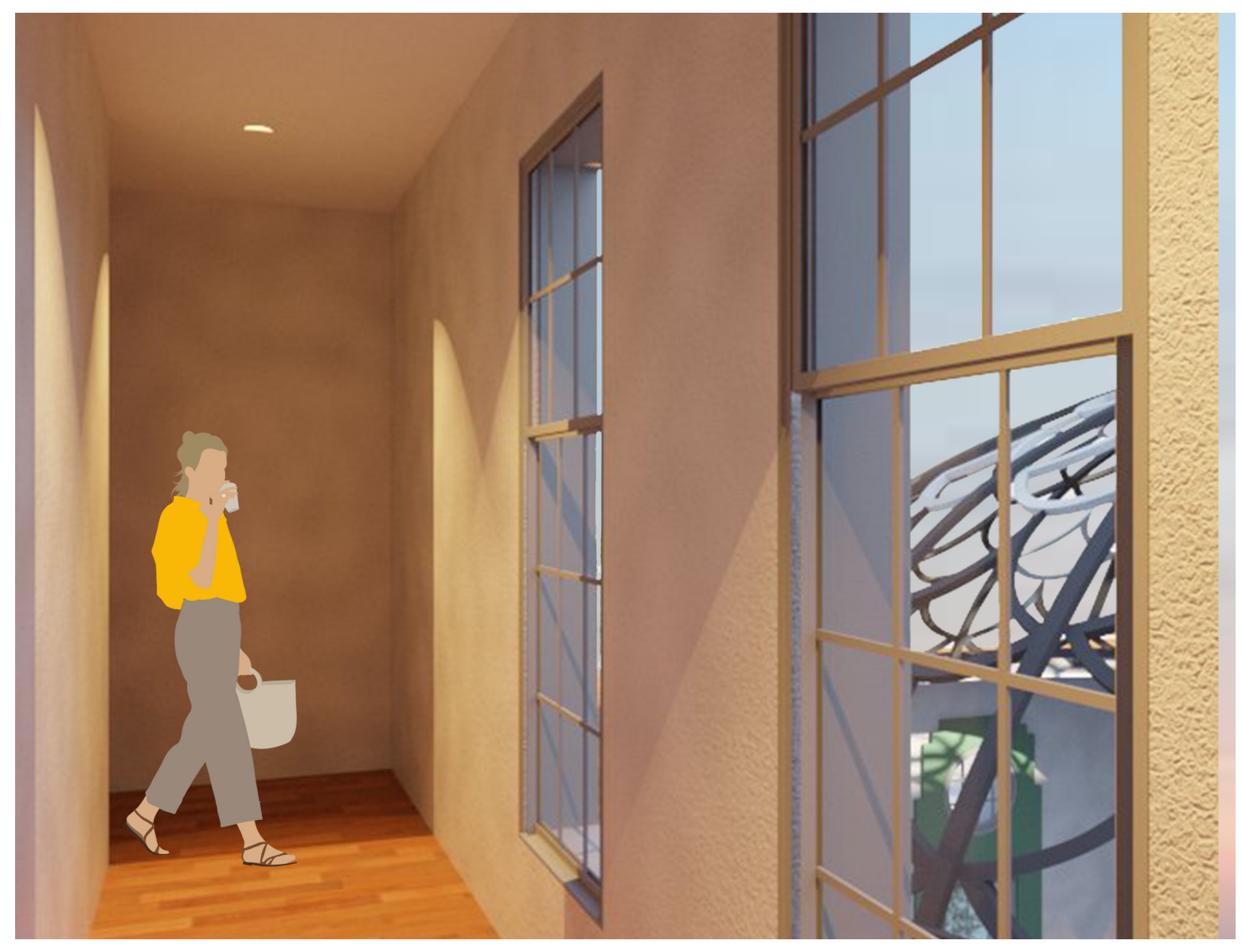

Figure.11.112: Second floor hall and view of dome 


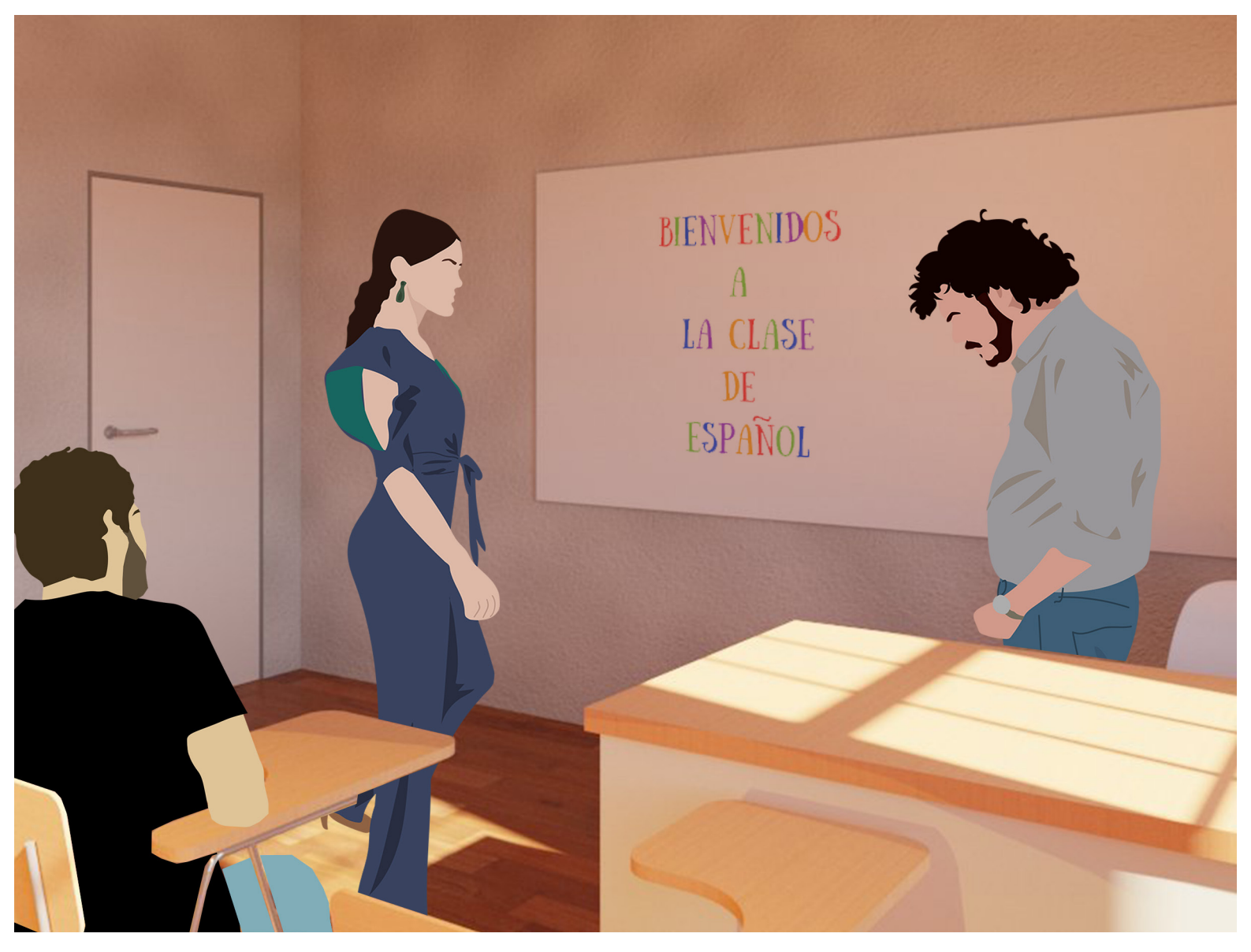

Figure.11.113: Classroom space 


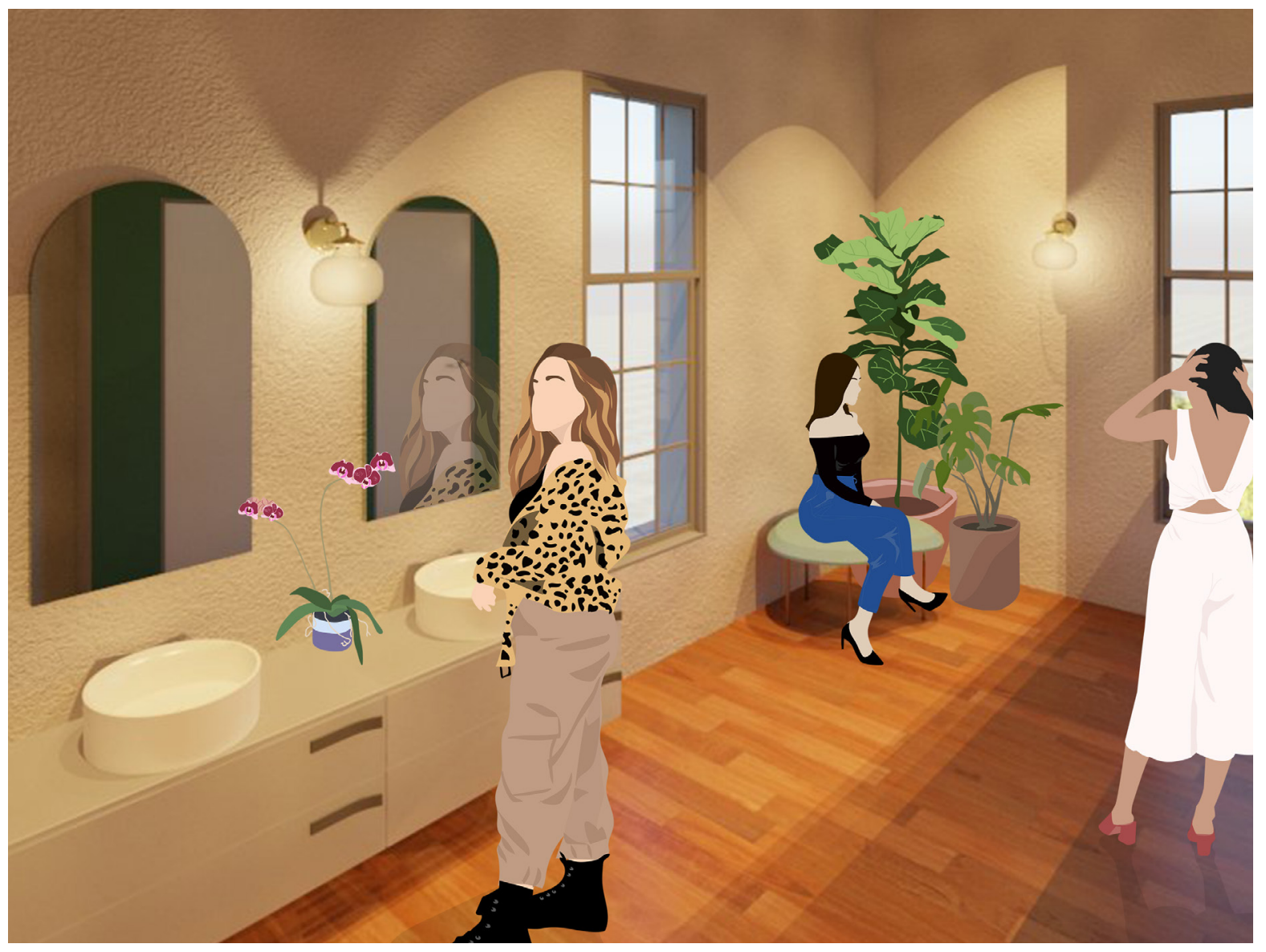

Figure.11.114: Second floor bathrooms 


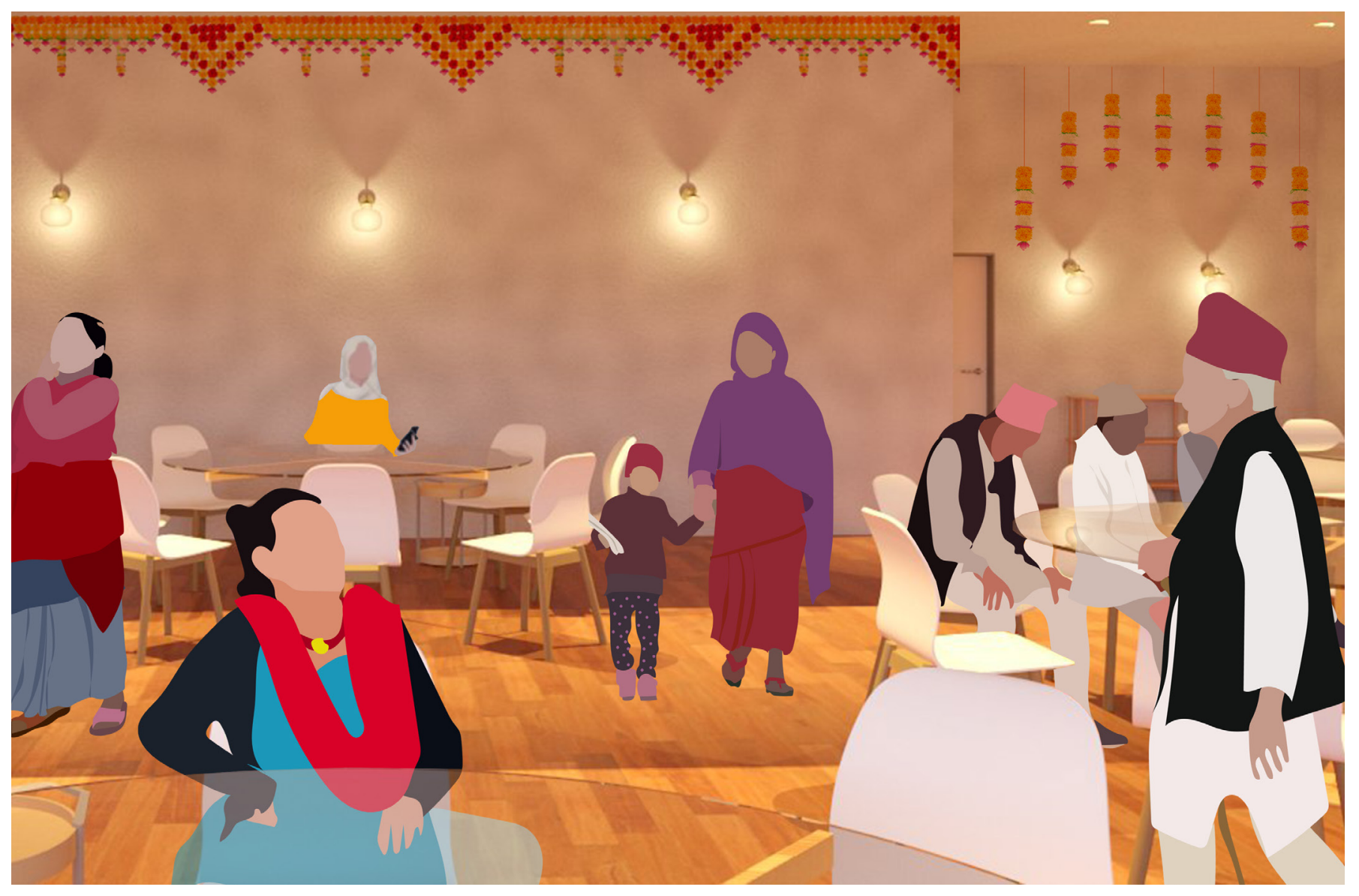

Figure.11.115: Large event space 


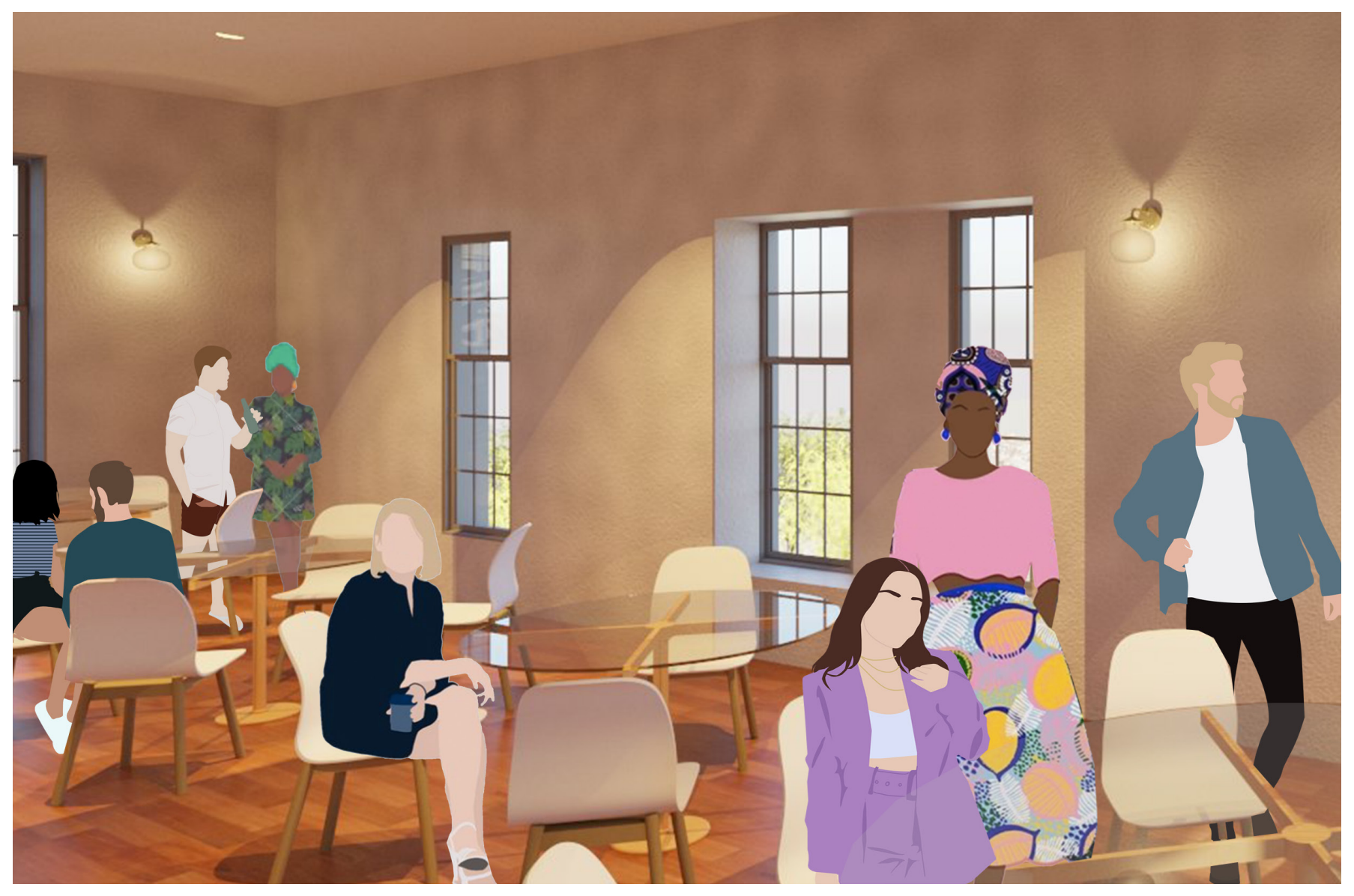

Figure.11.116: Small event space 


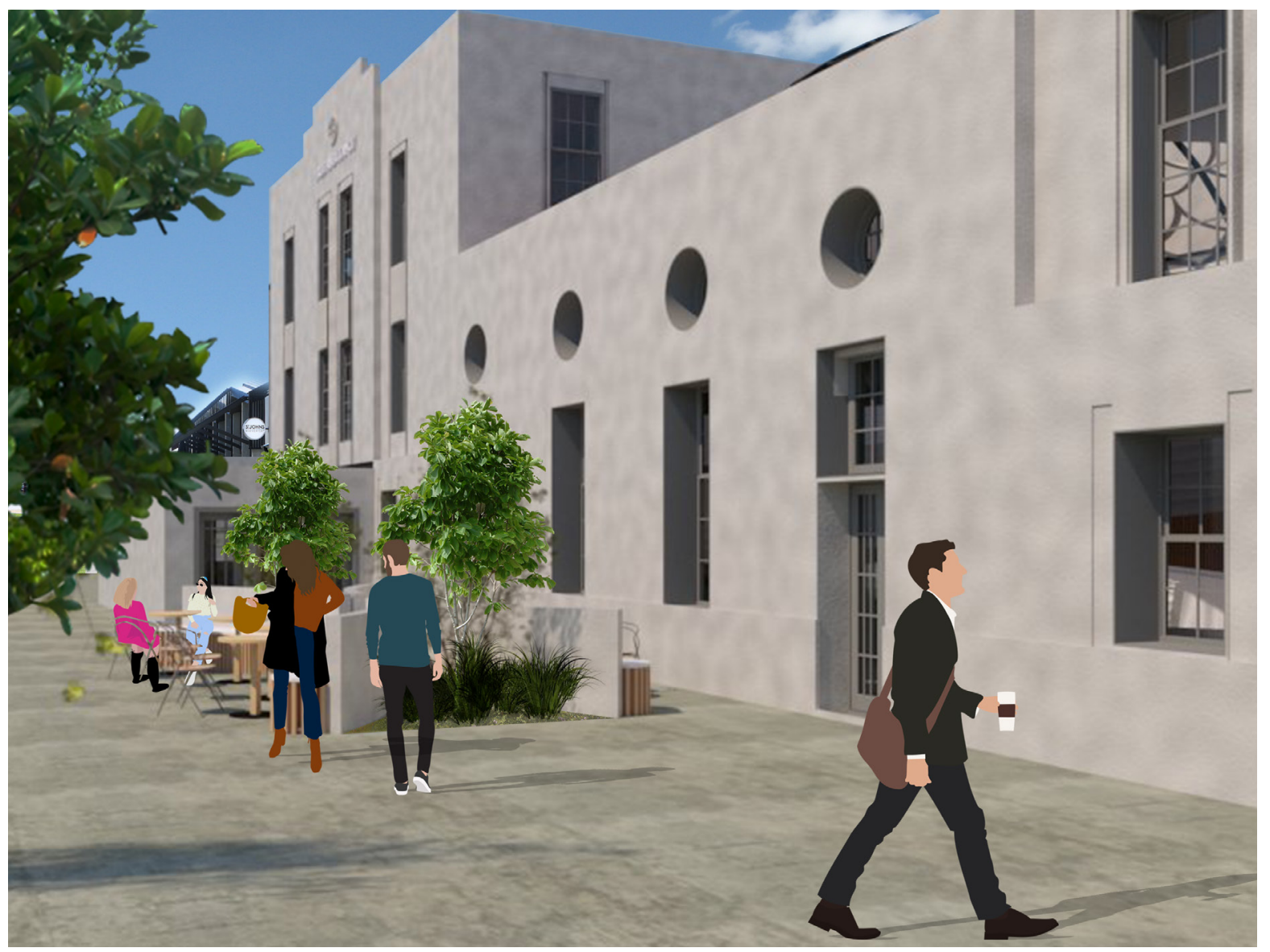

Figure.11.117: Approaching side of Ambulance building 


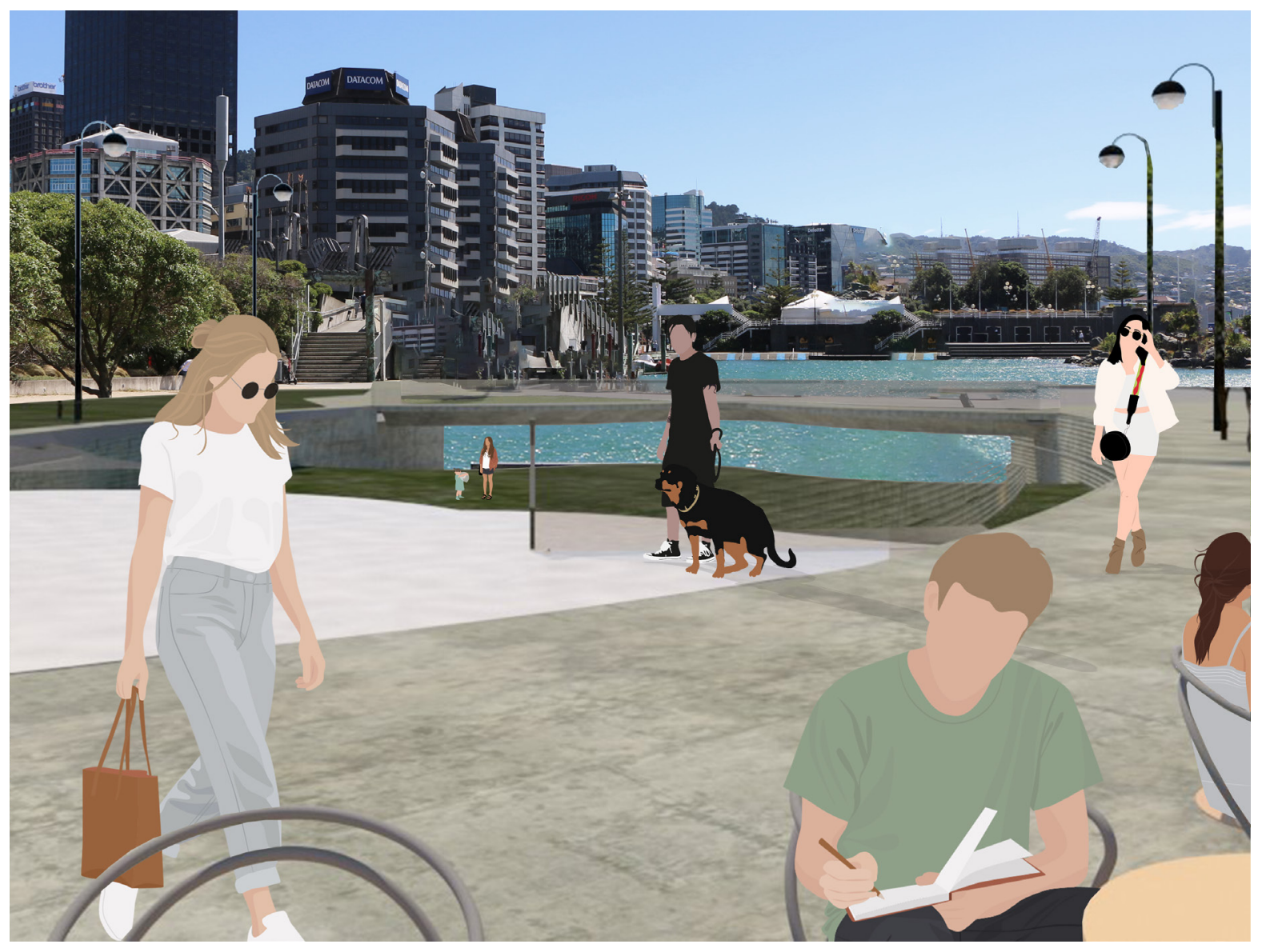

Figure.11.118: View from outdoor seating 


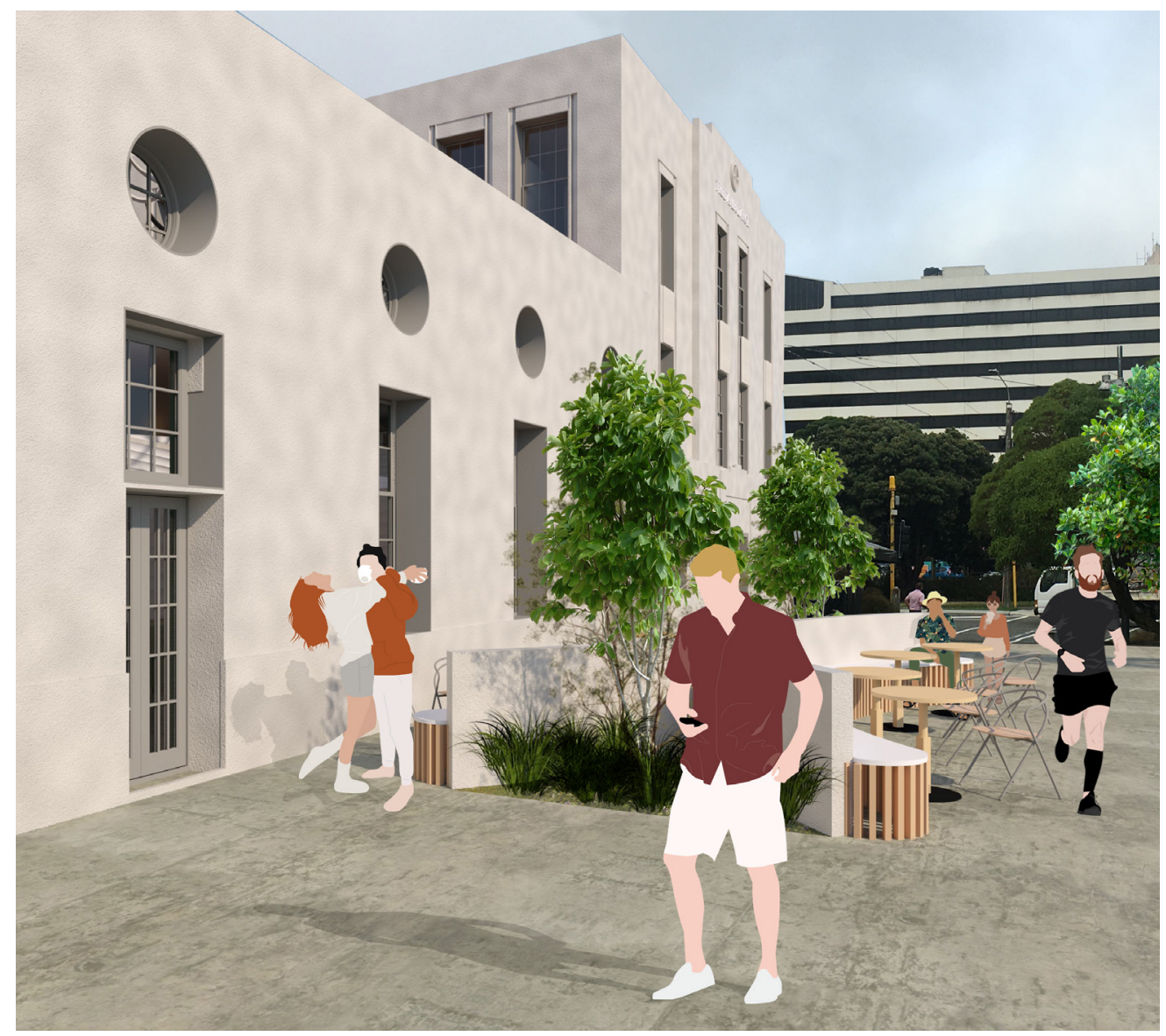

Figure.11.119: Outdoor seating 


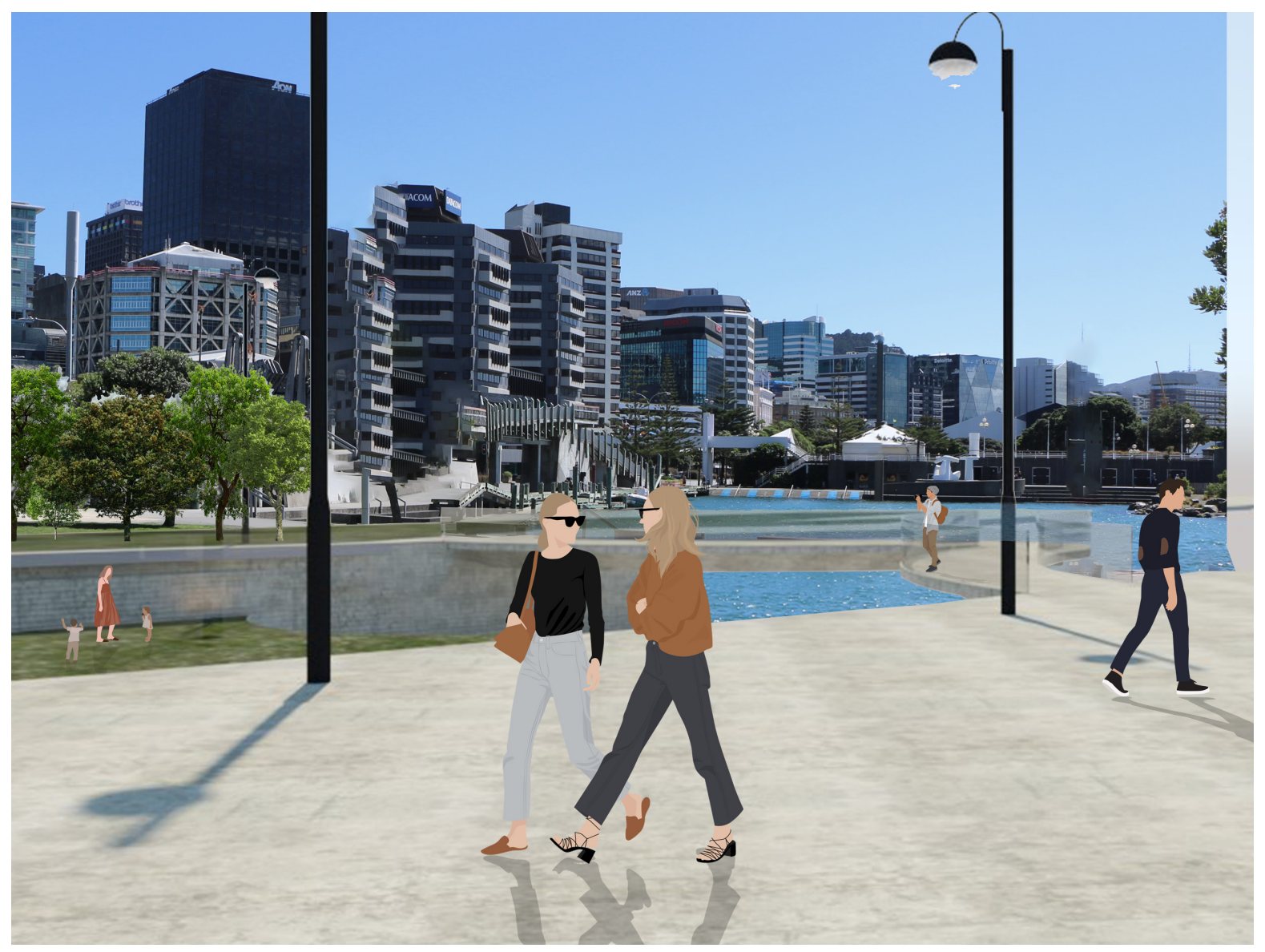

Figure.11.120: View of promenade 


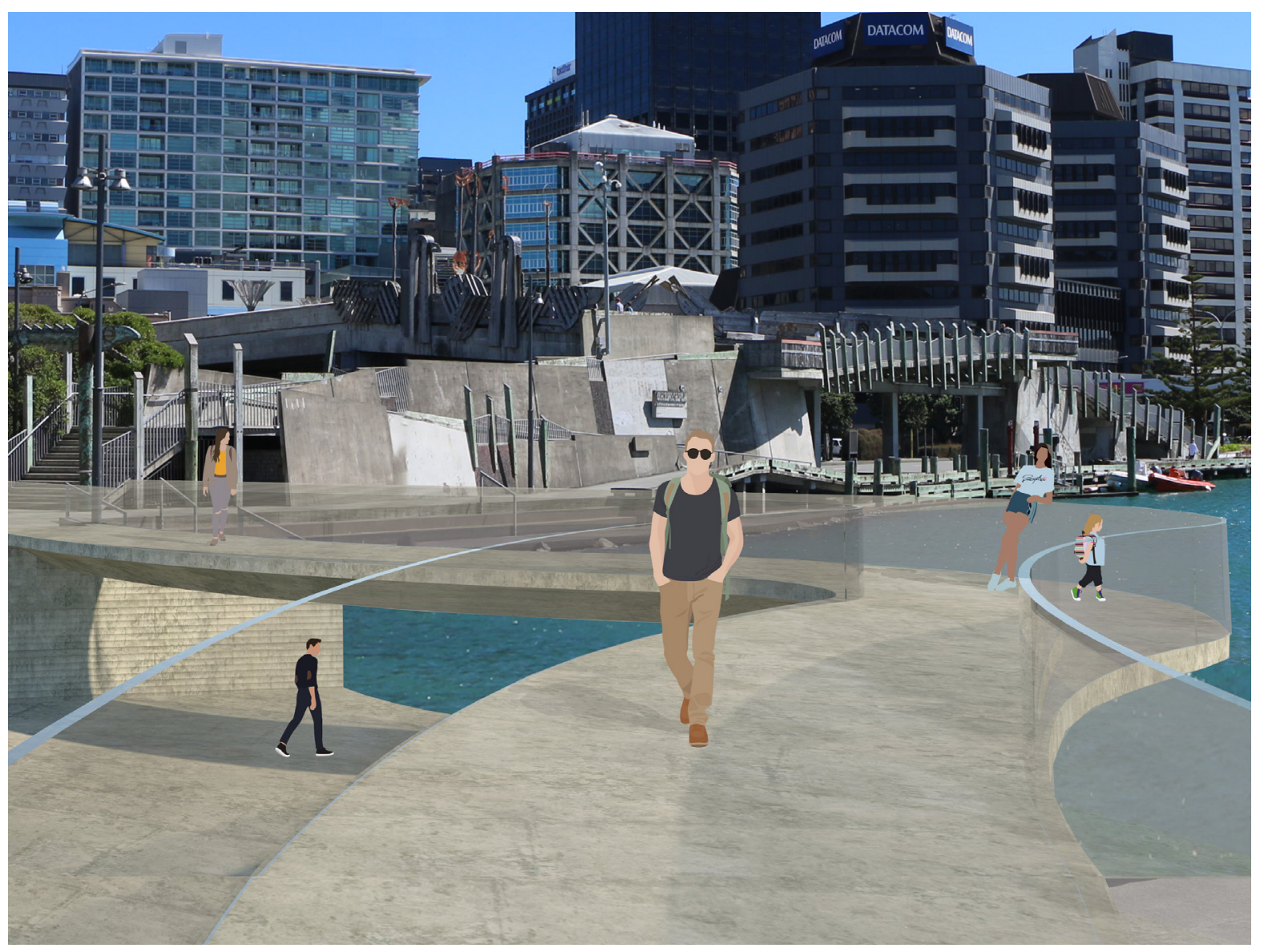

Figure.11.121: Pedestrian bridge 


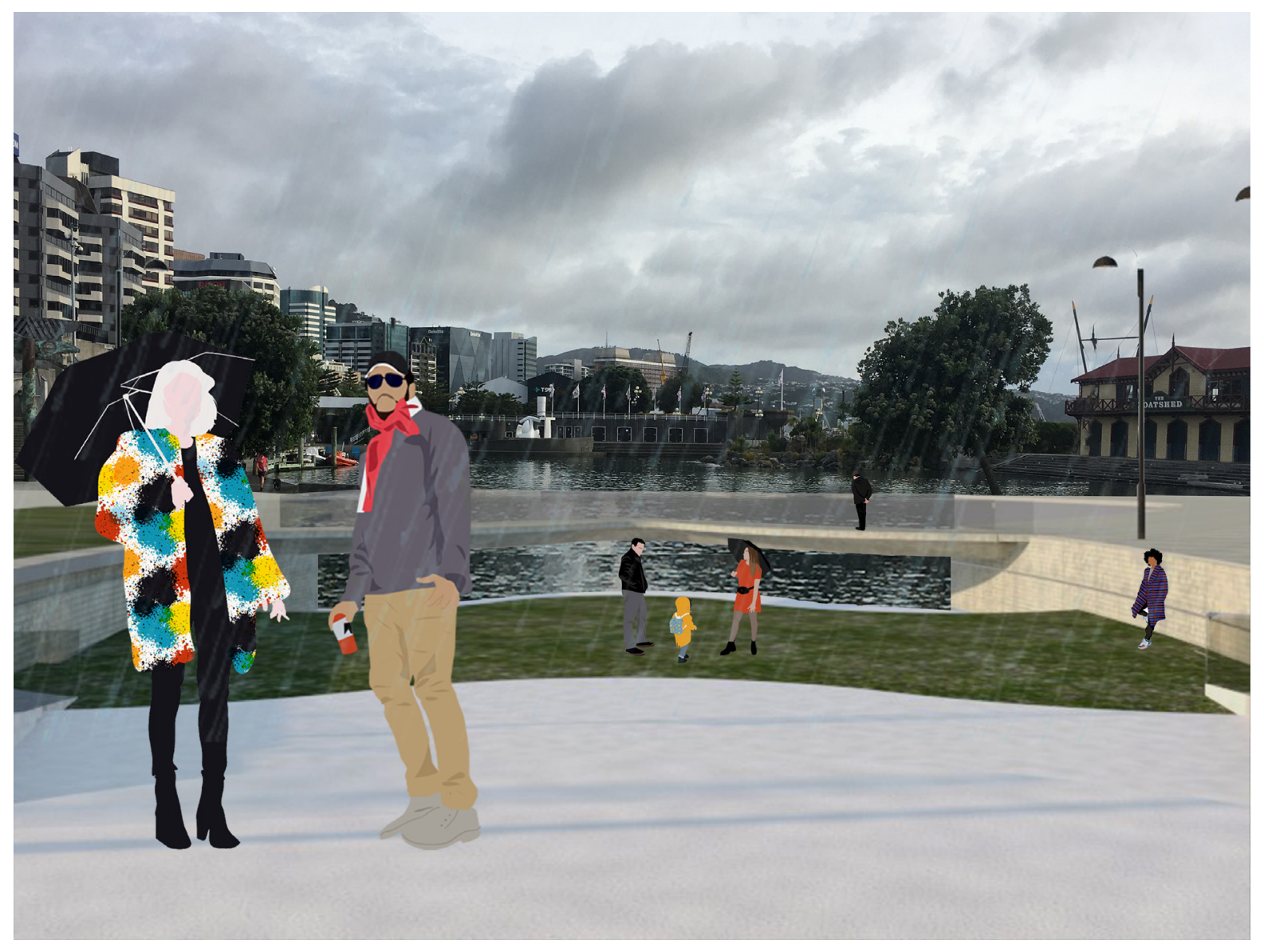

Figure.11.122: View from top of landscaping 


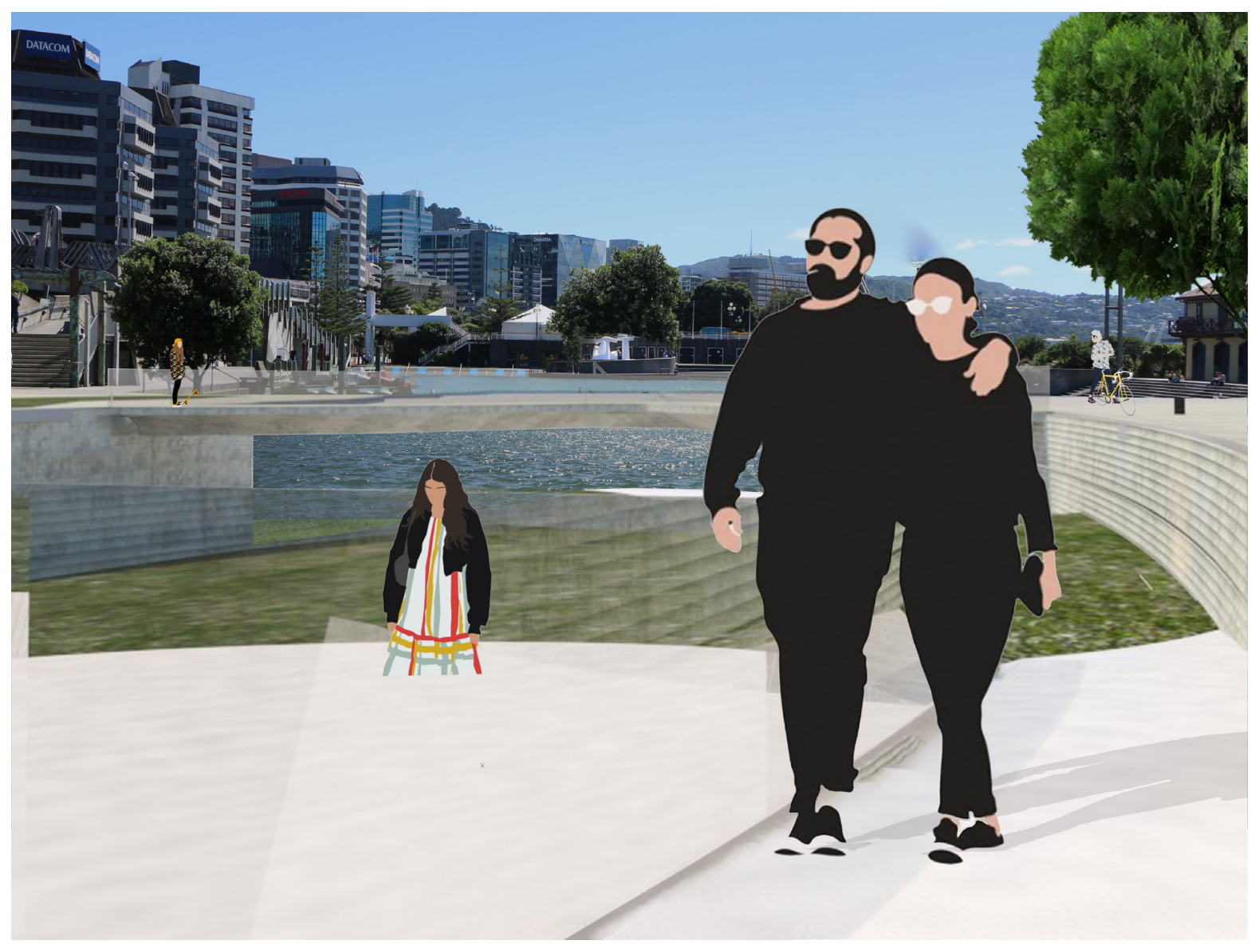

Figure.11.123: Walking down ramp into landscape 


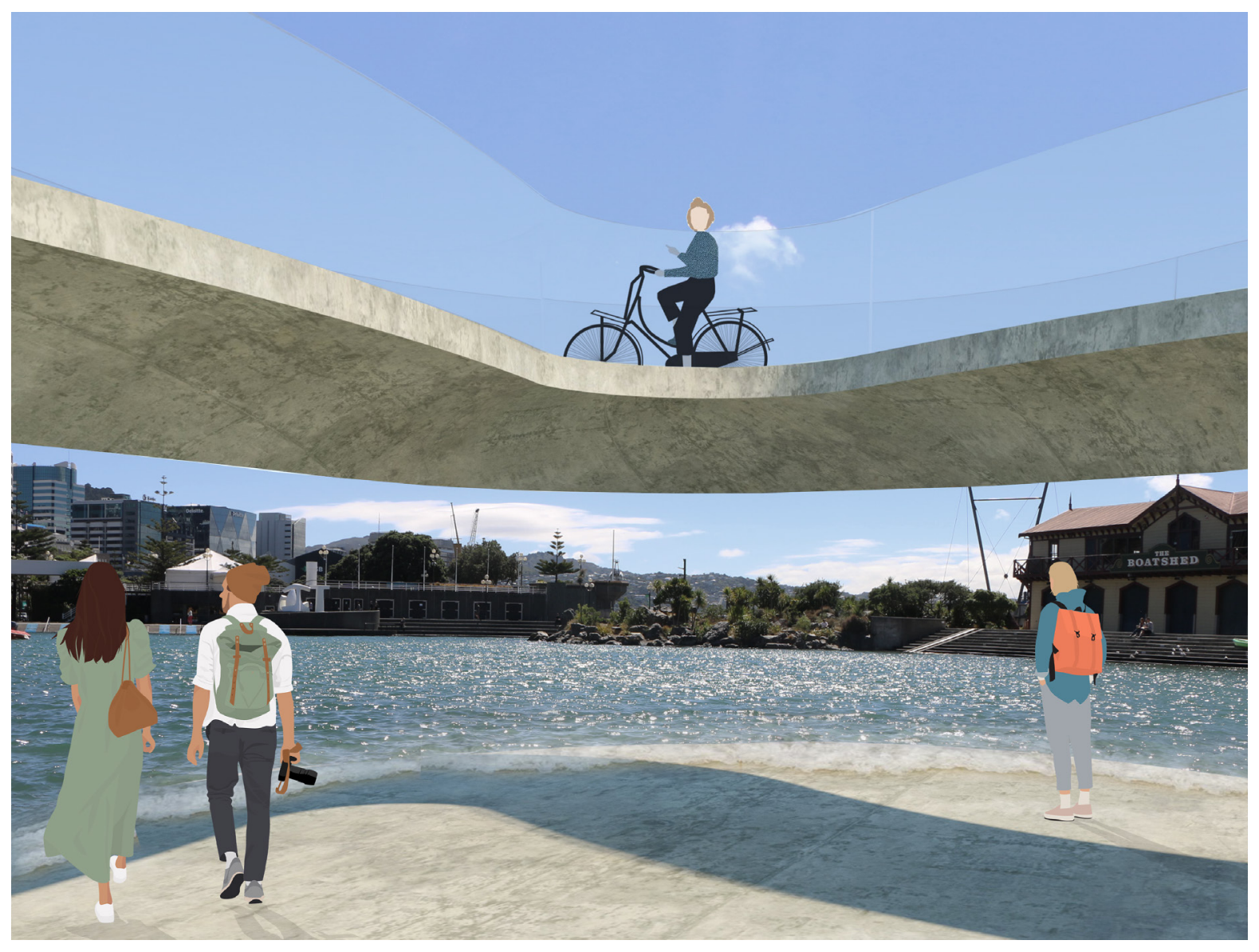

Figure.11.124: Edge of intervention to the lagoon 


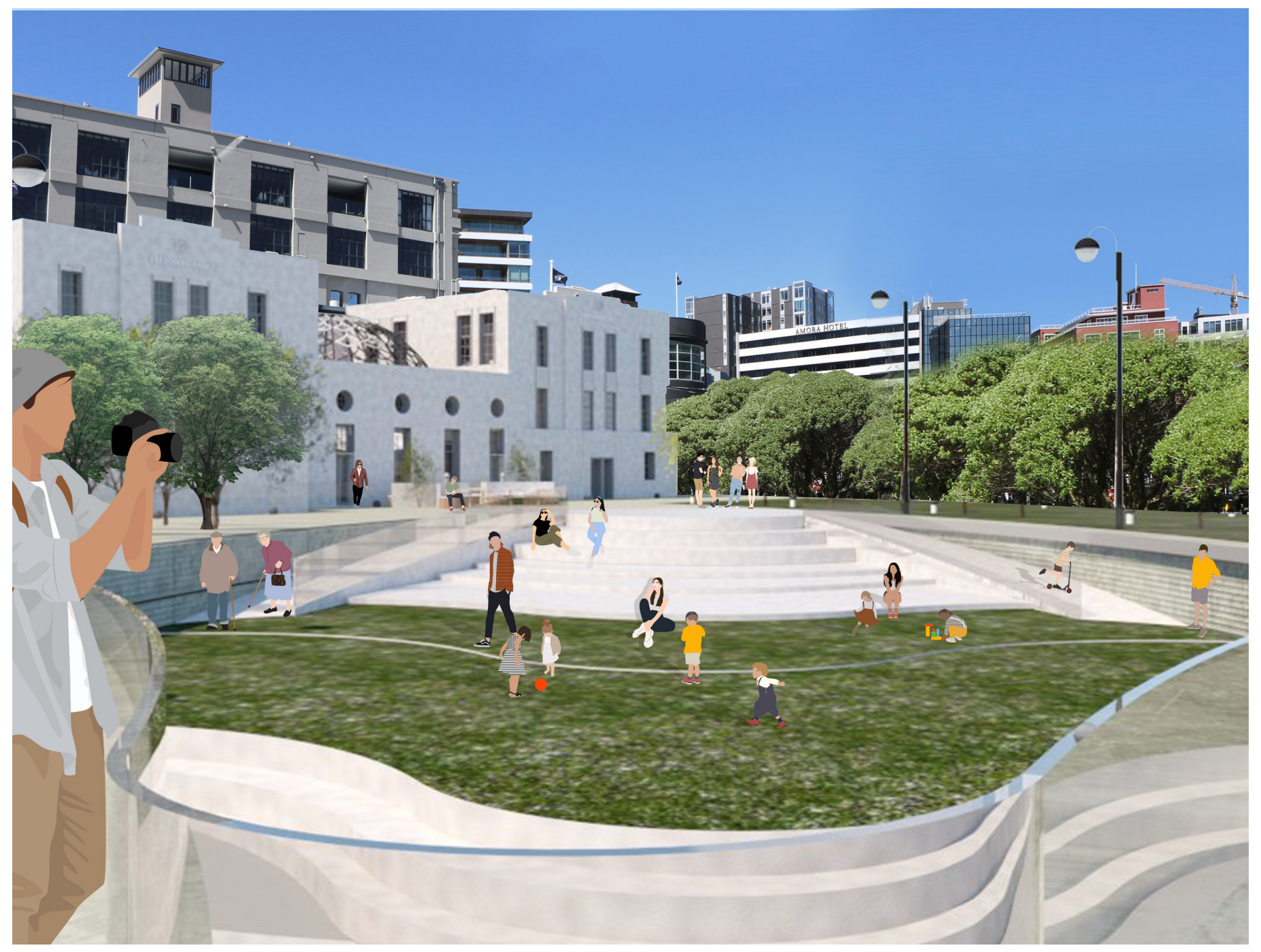

Figure.11.125: View from bridge towards building 


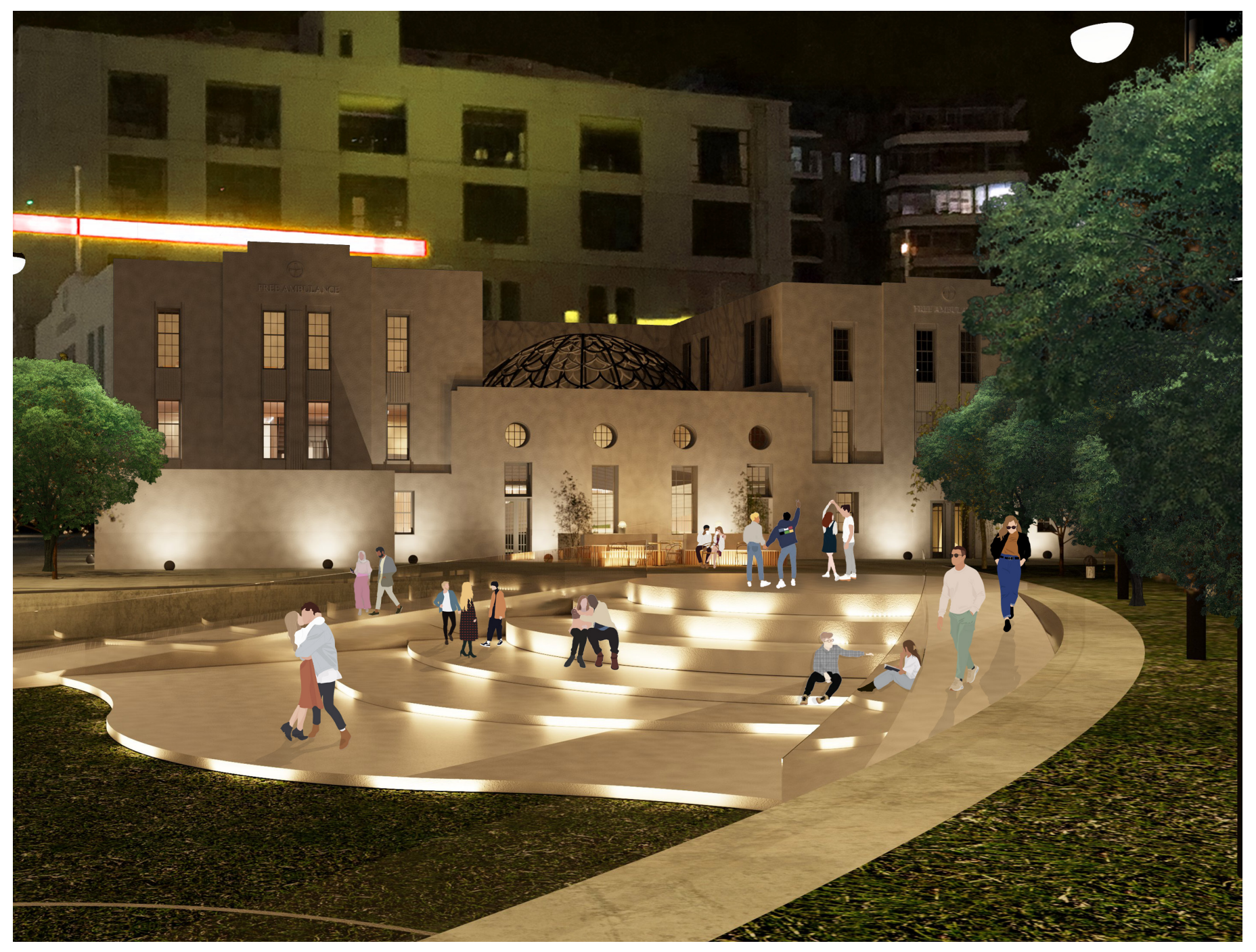

Figure.11.126: Outdoor space at night 


\section{FRAMEWORK CRITIQUE}

This final design was able to complete all aspects of the created framework.

The building itself is in a public area surrounded by substantial foot and vehicle traffic. The building is unique in scale and architectural style for its surroundings and is an important reminder of Wellington's heritage and cultural identity. The building also sits by an area of green space and close to the lagoon's edge.

The intervention not only had to take into consideration the design tactics of the early framework but also its amended consideration such as creating a journey of experience, the principles of Third Place, the essence of the in-between, layering processes and Biophilic design tactics are all being utilised.
The final design also uses narrative elements to express the essence of being transcultural. The central circulation embodying the experience of movement from one place to another and the landscaping morphing out into the adjacent lagoon. The upper levels of the building are reserved for classes and educational purposes as well as multiple events spaces of varying sizes to encourage cultural practices and celebration essential for cultural vibrancy. These spaces as well as the first floors gallery spaces are all open for adaptability and personalisation. The inclusion of natural influence not only complement the Art Deco style but also the Biophilic principle's. This is seen from the natural materials and complimentary colours and the natural light and curved elements.

\section{SITE SELECTION}
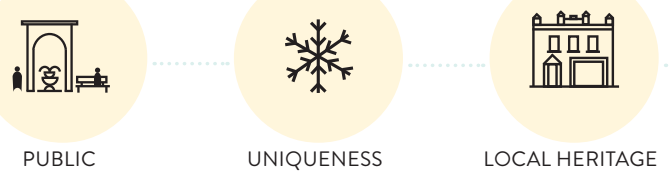

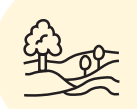

NATURAL LANDSCAPE

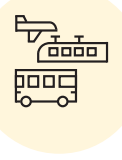

MOBILITY

\section{DESIGN TACTICS}

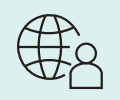

MULTI/TRANSCULTURE

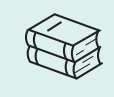

EDUCATIONAL

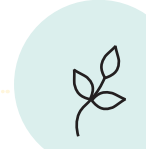

NATURE

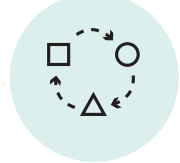

ADAPTABILITY
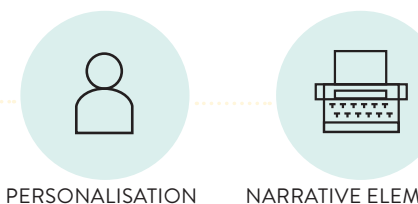

NARRATIVE ELEMENTS

\section{ADDITIONAL CONSIDERATIONS}

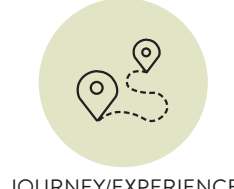

JOURNEY/EXPERIENCE

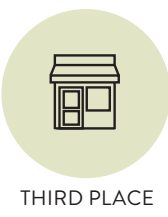

THIRD PLACE

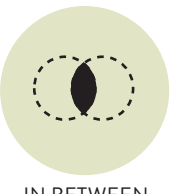

IN BETWEEN

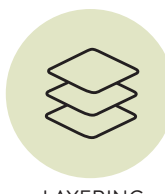

LAYERING

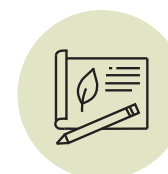

BIOPHILIC DESIGN

Figure.11.127: Framework evaluation 


\section{REFLECTION}

This iteration's attitude towards heritage is strongly within the conservation realm; it respects the original fabric and maintains the buildings integrity while being altered to its new form.

This design also looked at making 'place' in a landscape. The design is a response to the intervention within the building and continuing through into the surrounding area. It acknowledges the heritage of site changing from the sea, then the reclaimed land followed by the boat sheds and the green space.

The experience of going up the central ramp adds another form of performance. The multi-use spaces create several opportunities to bring together this group of people. The domed skylight also references the original skylight while maintaining connection to the new central circulation and sympathetic design elements of the scalloped detailing.

The design of this intervention utilises influences from not only the research gathered for the design framework but also influences from the building itself. The negative detailing for the ramp's balustrade takes influence from the negative detailing from the façade. The repeated curved forms act as a contrast to the angular geometric language of the Art Deco style, while still harmonising with scalloped and arched forms. This allows some distinction between the new and old fabric of the build, as required by heritage conservation practices. The colours and materials used take reference from the pastel softness from the Art Deco period and compliment the natural wood and green tones derived from the Biophilic influence.

Overall, the design has completed all aspects of the amended framework. It has successfully created a cohesive intervention from the interior to the building itself and its surrounding landscape.

Although this design does not directly deal with the expression of the original use of the building, it could be argued that the new function considered with the cultural wellbeing of its users pays a respectful homage of the building's past.

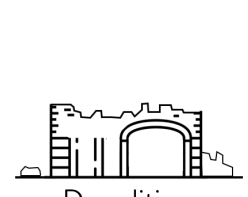

Demolition

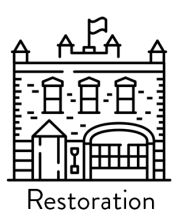

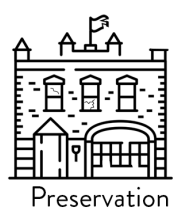

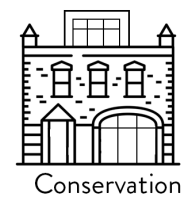





\section{Conclusion}

Conclusion

Future Works

Reference List

Figure List 


\section{CONCLUSION}

$\mathrm{T}$ here has been a significant increase in human migration during the last 100 years due to globalisation (Pollock \& Van Reken, 1999, p. 6). This of course, includes New Zealand, which is now fast becoming a multicultural society (Dalziel et al., 2019 , p. 16). With the increase in movement there are more numbers and varieties of Cross Culture People than ever before. However, little attention has been given to them to help with their grounding and to strengthen their identities and sense of belonging within their new cultural environment.

Given the lack of support offered to CCPs, this design-led research investigates the creation of crosscultural place within heritage architecture.

The primary aim of this research was to find a way to design a place in New Zealand for Cross Cultural People that would promote their sense of identity and belonging to a place. As a result, this design-led exploration developed different iterations and several design techniques. This was done firstly by utilising the local architectural heritage of a place to express how they negotiate their own cultures through architecture and secondly using tactics that they identified to help collectively build identity within that place.

In the first phase, this research looked at Cross Cultural People and what they determined as useful in terms of building a better sense of identity. This was followed by an exploration of the connections between culture, heritage and identity and how and why culture manifests itself in the tangible realm of architecture. Lastly, this initial research looked at the discipline of heritage conservation and what to consider when working with heritage architecture. This was all applied into the formation of a two-part framework that would help select the appropriate heritage building and a variety of design tactics to help in the design process. The framework has been further developed to include aspects such as the 'journey', third place, the in between, layering and biophilic design considerations.

The second phase of this thesis applied the newly formed framework to three iterations in locations with varying degrees of heritage protection. Each iteration looked at individual case studies relating to issues relevant to each design.

The process was careful, slow and well thought out, sensitive and not rushed. All iterations undertook a variety of design techniques such as redrawing and reconstructing the buildings, alongside the research of relevant stories and history.

The final phase and design response utilising the former Ambulance Building on Cable St. was to create an architecturally diverse approach to conservation. It looked at all aspects of the building: its interior, its overall architectural form and its landscaped surroundings.

Through this iterative process, this thesis has revealed methods or strategies to apply on heritage buildings in order to create spaces that help its cross-cultural users build a better sense of identity and belonging. These strategies included cultural vitality and vibrancy tools, conservation methods and Third Place as well as Biophilic design principles. 
In conclusion, the main findings of the developed framework will allow a designer to:

- Create a public and unique Third Place for CCPs

- Utilise local heritage buildings that embody the cultural identity and are supported by the natural landscape.

- $\quad$ Create an adaptable and personal place with narrative elements and Biophilic influence.

- Construct a multicultural place that is educational and evokes experiences of the 'layering and negotiation' of cultures.

The qualities of these places evoke a light, airy and calming atmosphere. However, the aesthetics of the architecture is not the primary focus of this research. The main focus is the harmony between the crosscultural application and heritage conservation.

The places designed within this thesis act as a challenge to the status quo and attempts to provoke standard conservation practices. It enriches heritage conservation management by focusing on the process of making a place within and around heritage.

This thesis uses a tangible form to express and nurture the intangible and unique experiences of Cross Culture People. Not only is the preservation of our local heritage important for the preservation of history and character of a place but also for its citizens; old and new. 


\section{FUTURE WORKS}

W

hile this research has provided a thorough

framework for experimentation, it may require further testing to strengthen the concepts. Several theorists throughout the collected research mention the importance of collaborative input when designing places for a specific group.

While this thesis used Laia Colomer's curated data, further research can be done to gather reactions of CCPs towards each design iterations. This would also help further refine the curated framework.

Future work can also determine whether there would be any deviations in the framework if these places were to be found and developed in different parts of the world.

Overall, the author believes that this design-led research provides a thoughtful contribution towards the multidisciplinary field of heritage studies, touching on the sociological issues of Cross Culture People and the practice of heritage conservation. 


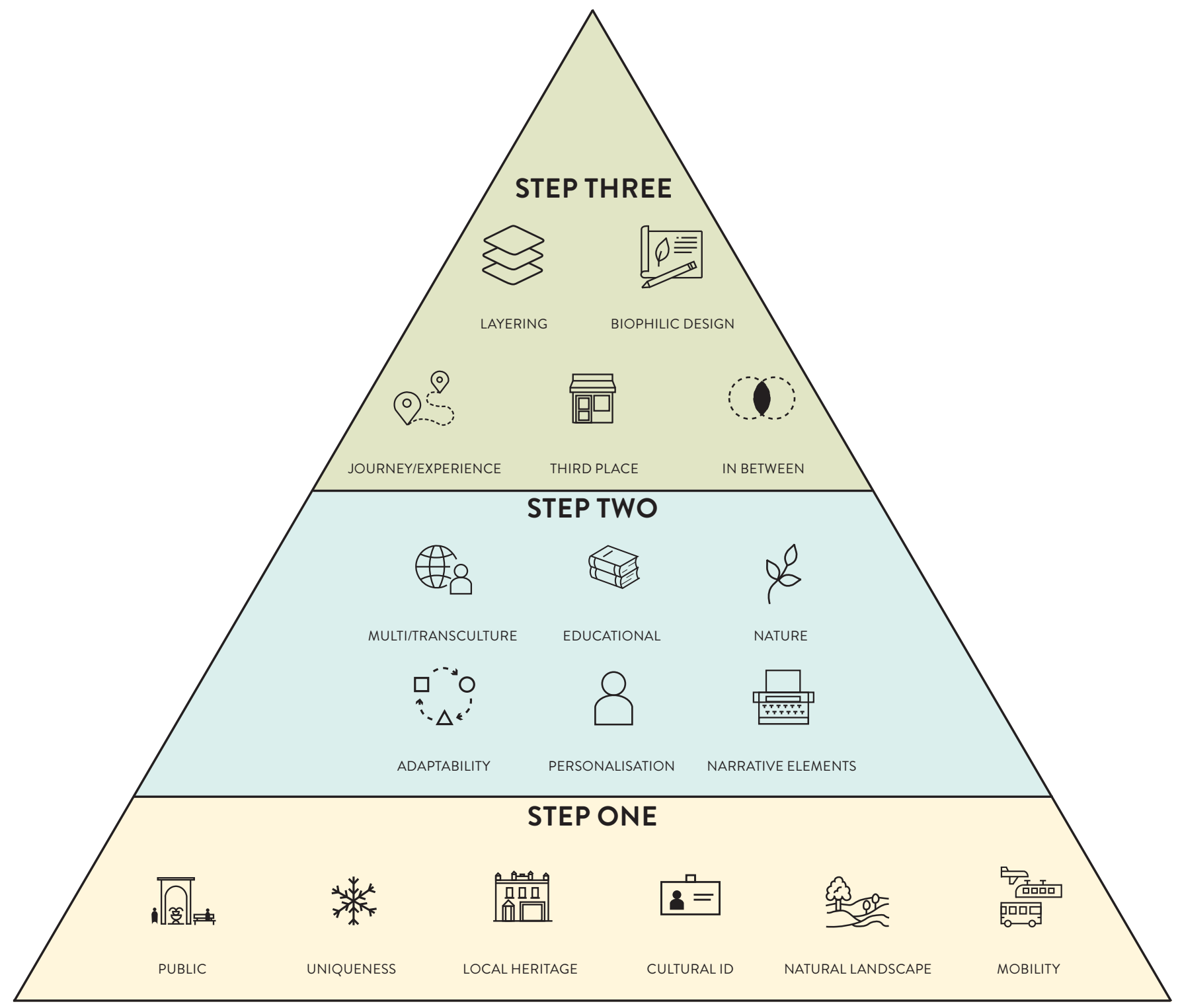

Figure.12.1: Using the design framework 


\section{REFERENCE LIST}

About the List. (n.d.). Heritage New Zealand . Retrieved from https://www.heritage.org.nz/the-list/about-the-list Art Deco| Definition, Characteristics, History, \& Facts. (n.d.). Encyclopedia Britannica. Retrieved from https:// www.britannica.com/art/Art-Deco

Barrett, M. (n.d.). Auckland Art Gallery 'world's best building'. Architecture Now. Retrieved from https:// architecturenow.co.nz/articles/auckland-art-gallery-worlds-best-building/\#img=8

Biophilic Design: A New Scale Emerges. (2018, December). Trim Tab. Retrieved from https://trimtab.livingfuture.org/trim-tab/issue-36/biophilic-design-a-new-scale-emerges/

Bonenberg, W. (2016). Cross-Cultural Design and Its Application in Architecture. In J. Charytonowicz (Ed.), Advances in Human Factors and Sustainable Infrastructure: Proceedings of the AHFE 2016 International Conference on Human Factors and Sustainable Infrastructure, July 27-31, 2016, Walt Disney World®, Florida, USA (Vol. 493). Springer International Publishing. Retrieved from https://doi.org/10.1007/978-3-319-41941-1

Building - A Place for Art. (n.d.). Auckland Art Gallery. Retrieved from https://www.aucklandartgallery.com/ about/building

Théâtre Le Diamant - A Jewel in the Heart of old Quebec. (2018). Coarchitecture. Retrieved from https://www. coarchitecture.com/theatre-le-diamant

Colomer, L. (2017). Heritage on the move. Cross-cultural heritage as a response to globalisation, mobilities and multiple migrations. International Journal of Heritage Studies, 23(10), 913-927. Retrieved from https://doi.org/10 $.1080 / 13527258.2017 .1347890$

Colomer, L., \& Holtorf, C. (2019). What is Cross-Cultural Heritage. In Cultural Heritage, Ethics and Contemporary Migrations. Routledge.

Crossman, T. (2019, February). CCKs: Cross Cultural Kids. Misunderstood. Retrieved from https://misunderstoodbook.com/2019/02/21/ccks-cross-cultural-kids/

Crystal Houses / MVRDV. (2016, April). ArchDaily. Retrieved from http://www.archdaily.com/785923/crystalhouses-mvrdv 
Dalziel, P., Saunders, C., \& Savage, C. (2019). Culture, Wellbeing, and the Living Standards Framework: A Perspective. New Zealand Treasury. Retrieved from https://treasury.govt.nz/publications/dp/dp-19-02

Glendinning, M. (2013). The Conservation Movement: A History of Architectural Preservation. Taylor \& Francis Group. Retrieved from http://ebookcentral.proquest.com/lib/vuw/detail.action?doclD=1114683

Harrison, R. (2012). Heritage: Critical Approaches. Routledge. Retrieved from https://doi. org/10.4324/9780203108857

Hayden, D. (1997). Place Memory and Urban Preservation. In The Power of Place. First MIT Press paperback edition.

Hemi, M. (2015, January 23). Wellington Botanical Gardens: An Origin Story. Museums Wellington. https:// www.museumswellington.org.nz/wellington-botanical-gardens-an-origin-story/

Howarth, D. (2017, March). Iredale Pedersen Hook creates Walumba Elders Centre for flood-hit Australian Aboriginal community. Dezeen. Retrieved from https:/www.dezeen.com/2017/03/27/iredale-pedersen-hookwalumba-elders-centre-flood-hit-australian-aboriginal-community-architizer-awards/

Howarth, D. (2019, February). Freddy Mamani's New Andean Architecture adds colour to Bolivian city. Dezeen. Retrieved from https://www.dezeen.com/2019/02/07/freddy-mamani-new-andean-architecture-bolivia/

ICOMOS New Zealand. (2010). ICOMOS New Zealand Charter for the Conservation of Places of Cultural Heritage Value. Retrieved from https://icomos.org.nz/wp-content/uploads/2020/12/NZ_Charter.pdf

Kellert, S. R., Heerwagen, J., \& Mador, M. (2013). Biophilic Design: The Theory, Science and Practice of Bringing Buildings to Life. John Wiley \& Sons, Incorporated. Retrieved from http://ebookcentral.proquest.com/lib/vuw/ detail.action?docID $=818992$

Lahoud, A. L. (2008). The Role of Cultural (Architecture) Factors in Forging Identity. National Identities, 10(4), 389-398. Retrieved from https://doi.org/10.1080/14608940802518963

Le Diamant-The Building. (n.d.). Le Diamant. Retrieved from https:/www.lediamant.ca/en/explore/building/

Lopate, P., \& The Common. (2011). Above Grade: On the High Line. Places Journal. Retrieved from https:// placesjournal.org/article/above-grade-on-the-high-line/ 
Low, S. M., \& Altman, I. (1992). Place Attachment. (pp. 1-12). Springer US. Retrieved from https://doi. org/10.1007/978-1-4684-8753-4_1

Macdonald, S., \& Tyler, C. W. (2013). Memorylands: Heritage and Identity in Europe Today. Taylor \& Francis Group. Retrieved from http://ebookcentral.proquest.com/lib/vuw/detail.action?doclD=1251047

Mairs, J. (2016, April). Edoardo Tresoldi uses wire mesh to rebuild ancient church. Dezeen. Retrieved from https://www.dezeen.com/2016/04/06/edoardo-tresoldi-wire-mesh-installation-ancient-roman-church-italy/ Memmott, P. (2011). Cultural Change And Tradition In The Indigenous Architecture Of Oceania. Architectural Theory Review, 16(1), 38-54. Retrieved from https://doi.org/10.1080/13264826.2011.560552

Oldenburg, R. (1999). The Great Good Place. Marlowe \& Company.

Oriental Parade Band Rotunda (Former). (n.d.). Heritage New Zealand. Retrieved from https://www.heritage. org.nz/the-list/details/2894

Ott, C. (2019, September 14). Daoíz y Velarde Cultural Center / Rafael de La-Hoz. ArchDaily. Retrieved from https://www.archdaily.com/482244/daoiz-y-velarde-cultural-centre-rafael-de-la-hoz

Pintos, P. (2019, September 7). Palace of Culture / Archiproba. ArchDaily. Retrieved from https://www. archdaily.com/924074/palace-of-culture-archiproba

Pollock, D., \& Van Reken, R. (1999). Third Culture Kids: Growing up among worlds. Nicholas Brealey Publishing.

Proshansky, H. M., Fabian, A. K., \& Kaminoff, R. (1983). Place-identity: Physical world socialization of the self. Journal of Environmental Psychology, 3(1), 57-83. Retrieved from https://doi.org/10.1016/S02724944(83)80021-8

Smith, L. (2006). Uses of Heritage. Routledge. Retrieved from http://web.a.ebscohost.com.helicon.vuw. ac.nz/ehost/ebookviewer/ebook/bmxlYmtfXzE3ODczM19fQU41?sid=4bd8b29c-88c0-4a53-baa174455849663b@sessionmgr4006\&vid=0\&format=EB\&rid=1

Wellington Botanic Garden. (n.d.). Heritage New Zealand. Retrieved from https://www.heritage.org.nz/the-list/ details/7573 
Wellington Botanical Gardens: An Origin Story. (2015, January). Museums Wellington. Retrieved from https:// www.museumswellington.org.nz/wellington-botanical-gardens-an-origin-story/

Wellington City Council. (2002). Combined Management Plan Wellington Botanic Garden Anderson Park Bolton Street Memorial Park. PMC - Wellington City Council Publication \& Design.

Wellington Free Ambulance Building (Former). (n.d.). Heritage New Zealand. Retrieved from https://www. heritage.org.nz/the-list/details/3644

Wellington Heritage-Wellington Free Ambulance Building (Former). (2017, April). Absolutely Positively Wellington City Council. Retrieved from https://wellingtoncityheritage.org.nz/buildings/1-150/47-wellingtonfree-ambulance-building

Wellington Railway Station. (n.d.). Heritage New Zealand. Retrieved from https://www.heritage.org.nz/the-list/ details/1452

Wellington Railway Station. (2017). Absolutely Positively Wellington City Council. Retrieved from http:// wellingtoncityheritage.org.nz/buildings/1-150/44-wellington-railway-station 


\section{FIGURES LIST}

* All figures not listed below are created by the author

Figure.4.2: Polisena, M. (2019). Examples of Mamani's designs [Photographs]. Retrieved from https:// www.dezeen.com/2019/02/07/freddy-mamani-new-andean-architecture-bolivia/\#: :text=Bolivian\%20 architect\%20Freddy\%20Mamani\%20is,as\%20seen\%20in\%20these\%20photographs.

Figure.4.3: Bennetts, P. (2014). Walumba Elders Centre [Photographs]. Retrieved from https://www.archdaily. com/625274/walumba-elders-centre-iredale-pedersen-hook-architects

Figure.7.1: Wilson, Kenneth Adrian (1924-2012). Photographs relating to Wellington. [Ref: 1/2-136011-F]. Alexander Turnbull Library, Wellington, New Zealand. /records/23066344. Retrieved from https://natlib.govt. nz/records/23066344?search\%5Bpath\%5D=items\&search\%5Btext\%5D=kelburn+tea+kiosk

Figure.7.2: Price, William Archer, (1866-1948). Cable car, power house and Kelburn Tea Kiosk, Kelburn, Wellington. Collection of post card negatives. [Ref: 1/2-001613-G]. Alexander Turnbull Library, Wellington, New Zealand. /records/22733242. Retrieved from https://natlib.govt.nz/records/22733242

Figure.7.5-7: Swan, J. S. (1902). Tea Kiosk at Kelburne, Wellington [Drawing Plan]. [Ref: Plans-80-0562]. Alexander Turnbull Library, Wellington, New Zealand./records/23030103. Retrieved from https://natlib.govt. nz/records/23030103? search\%5Bpath\%5D=items\&search\%5Btext\%5D=kelburn+tea+kiosk

Figure.7.8: Swan, J.S. (1904). Tea Kiosk at Kelburne, Wellington [Drawing Plan]. Sheet no 1. [Ref: Plans-80-0560]. Alexander Turnbull Library, Wellington, New Zealand. /records/23178372. Retrieved from https://natlib.govt.nz/records/23178372? search\%5Bpage\%5D=2\&search\%5Bpath\%5D=items\&search\%5Btext $\% 5 \mathrm{D}=$ kelburn+tea+kiosk

Figure.7.9: Daria Scagliola+Stijn Brakkee, Poesia, MVRDV. (2016). Crystal Houses. [Photograph]. Retrieved from https://www.archdaily.com/785923/crystal-houses-mvrdv

Figure.7.10: The Blind Eye Factory. (2016). Edoardo Tresoldi's Wire Mesh Basilica. Retrieved from https://www. dezeen.com/2016/04/06/edoardo-tresoldi-wire-mesh-installation-ancient-roman-church-italy/

Figure.8.1: Robson, E. (1930). Oriental Parade Band Rotunda (Former), Wellington. [Ref: PAColl-5670-01]. Retrieved from https://www.heritage.org.nz/the-list/details/2894

Figure.8.2: Evening Post. (1959). Oriental Bay, Wellington City. [Photograph]. [Ref: EP/1959/4347-F]. Alexander Turnbull Library, Wellington, New Zealand. Retrieved from https://natlib.govt.nz/ records/30649458 
Figure.8.5: Wellington City Council Archives. (1921). Wall screen addition to Band Rotunda, Oriental Bay. [Drawing No. 00237-2430a]. Retrieved from https://archivesonline.wcc.govt.nz/nodes/view/103313

Figure.8.6: Sinclair, J. (1984). Rotunda Elevation [Drawing]. Retrieved from https://www.butterpaper.com/ $\mathrm{cms} /$ news/2422/oriental-bay-rotunda-development

Figure.8.7-8: Wellington City Corporation. (1936). Bathing Pavilion Plans [Drawing No.4]. Retrieved from https://www.butterpaper.com/cms/news/2422/oriental-bay-rotunda-development

Figure.8.9: Avdeev, M. (2019). Palace of Culture. [Photograph]. Retrieved from https://www.archdaily. com/924074/palace-of-culture-archiproba

Figure.8.10: Quiroga, A. (2013). Daoiz y Velarde Cultural Centre. Retrieved from https://www.archdaily. com/482244/daoiz-y-velarde-cultural-centre-rafael-de-la-hoz

Figure.9.1: Smith, Sydney Charles (1924). Lambton Railway Station, Thorndon Quay, Wellington. [Photograph] [Ref: 1/2-047394-G]. Retrieved from https://natlib.govt.nz/records/22827518?search\%5Bpage\%5D=2\&search\%5Bpath\%5D=items\&search\%5Btext\%5D=wellington+railway+station

Figure.9.2: Raine, William Hall, (1937). Wellington Railway Station. [Photograph]. [Ref: 1/2-101166-G]. Retrieved from https://natlib.govt.nz/records/22341254?search\%5Bpath\%5D=items\&search\%5Btex$\mathrm{t} \% 5 \mathrm{D}=$ wellington+railway+station

Figure.9.5-8: Gray Young, Morton \& Young Architects. (1933). Wellington Railway Station. [Drawing No. 1-15]. Retrieved from https://wellingtoncityheritage.org.nz/buildings/1-150/44-wellington-railway-station

Figure.9.9: Diaz, D. \& Groleau, S. (2018). Le Diamant Theatre. [Photograph]. Retrieved from https://www. coarchitecture.com/theatre-le-diamant

Figure.9.9: Leclrec, D. (2018). Salavage of arches \& Walls of second floor of the old YMCA. [Photograph]. Retrieved from https://cetaf.qc.ca/nouvelles-et-evenements/theatre-diamant/

Figure.9.10: Reynolds, P. (2013). Auckland Art Gallery Toi o Tāmaki. [Photograph]. Retrieved from https://www. eventfinda.co.nz/venue/auckland-art-gallery-auckland-central

Figure.9.10: Grainger \& D’Ebro (1884). Free Library \& Art Gallery. [Drawing]. Retrieved from https://www. aucklandartgallery.com/about/building?q=\%2Fabout\%2Fbuilding 
Figure.9.10: Reynolds, P. (2013). Auckland Art Gallery. [Photograph]. Retrieved from https://architecturenow. co.nz/articles/auckland-art-gallery-worlds-best-building/\#img $=6$

Figure.11.5: Smith, Sydney Charles. (1912). Wellington Rowing Club. [Photograph]. [Ref: 1/2-046572-G]. Retrieved from https://natlib.govt.nz/records/23063416

Figure.11.6: Evening Post. (1932). Site for the Wellington Free Ambulance building, Cable Street, Wellington. [Photograph]. [Ref: EP-6864-1/2-G]. Retrieved from https://natlib.govt.nz/records/22769592

Figure.11.7: Evening Post. (1932). Wellington Free Ambulance building, Cable Street, Wellington. [Photograph]. [Ref: EP-6859-1/2-G]. Retrieved from https://natlib.govt.nz/records/23063941

Figure.11.8: Wellington City Libraries (6th Jun 2017). Star Boating Club. In Website Wellington City Libraries. Retrieved 30th Oct 2020 12:13, from https://wellington.recollect.co.nz/nodes/view/1563

Figure.11.9: Wellington City Libraries (17th Aug 2017). Wellington Rowing Club, Jervois Quay. In Website Wellington City Libraries. Retrieved 30th Oct 2020 12:13, from https://wellington.recollect.co.nz/nodes/ view/2457

Figure.11.10: Wellington City Libraries (8th Aug 2019). Wellington Free Ambulance . In Website Wellington City Libraries. Retrieved 30th Oct 2020 12:14, from https://wellington.recollect.co.nz/nodes/view/285

Figure.11.11: Evening Post. (1932). Cable Street, Wellington. [Ref: EP-6865-1/2-G]. Retrieved from https:// natlib.govt.nz/records/22851412

Figure.11.12: Alexander Turnbull Library (1933). Wellington Free Ambulance building at night. [Photograph]. Wellington, New Zealand. Retrieved from https://natlib.govt.nz/records/23228068

Figure.11.13: Goldie, George Neilson Tregilgas. (1939). Cable Street, Wellington. [Ref: PAColl-0128-03]. Retrieved from https://natlib.govt.nz/records/22608875

Figure.11.14: Dominion Post. (1960). New type of Wellington Free Ambulance, probably Wellington Region. [Ref: EP/1960/0426-F]. Retrieved from https://natlib.govt.nz/records/30633906

Figure11.28: Lopate, P., \& The Common. (2011). Above Grade: On the High Line. Places Journal. Retrieved from https://placesjournal.org/article/above-grade-on-the-high-line/ 
Figure.11.47: Hervé, P. (2017). Hotel van Eetvelde Dome by Victor Horta. [Photograph]. Retrieved from http:// balat.kikirpa.be/object/11034134

Figure.11.64: Halse, Frederick James, (1888). Star Boating Club, seen from the harbour looking towards Jervois Quay. [Photograph]. [Ref: 1/2-004072-G]. Retrieved from https://natlib.govt.nz/records/22517934

Figure.11.65: Smith, Sydney Charles (1912). Wellington Rowing Club. [Photograph]. [Ref: 1/2-046573-G]. Retrieved from https://natlib.govt.nz/records/23220442?search\%5Bpath\%5D=items\&search\%5Btext\%5D=Wellington+Rowing+Club

Figure.11.66: Muir and MacKinlay (1890). Rowing Club Regatta. [Photograph]. [Ref: 1/2-003709-F]. Retrieved from https://natlib.govt.nz/records/22745124?search\%5Bi\%5D\%5Bsubject\%5D=Rowing\&search\%5Bpath\%5D=photos

Figure.11.67: Evening Post. (1975). Star Boating Club and Wellington Rowing Club. [Photograph]. [Ref: 1/4022671-F]. Retrieved from https://natlib.govt.nz/records/22777000

Figure.11.68: Dominion Post (1989). Star Boating Club, Wellington. [Photograph]. [Ref:

EP/1989/3286/13-F]. Retrieved from https://natlib.govt.nz/records/22301295 
FIN

Tatiana Astrid Erményi 